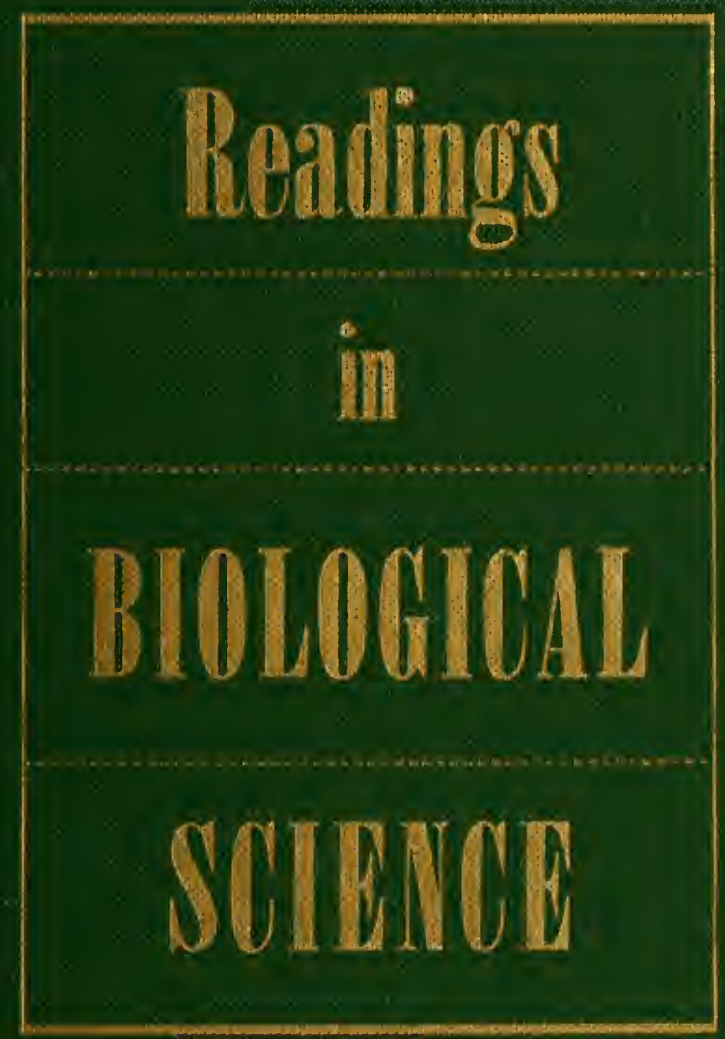


Eutarteng

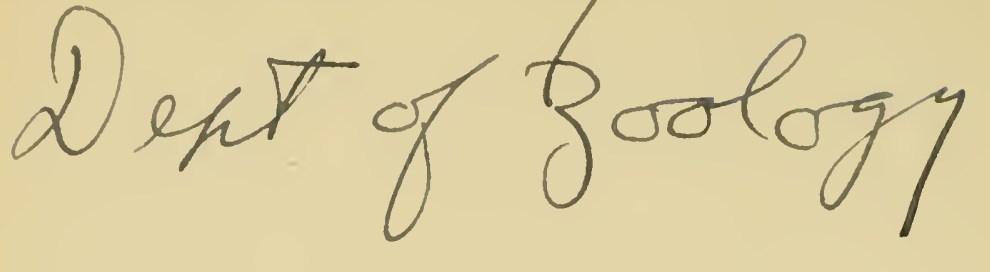



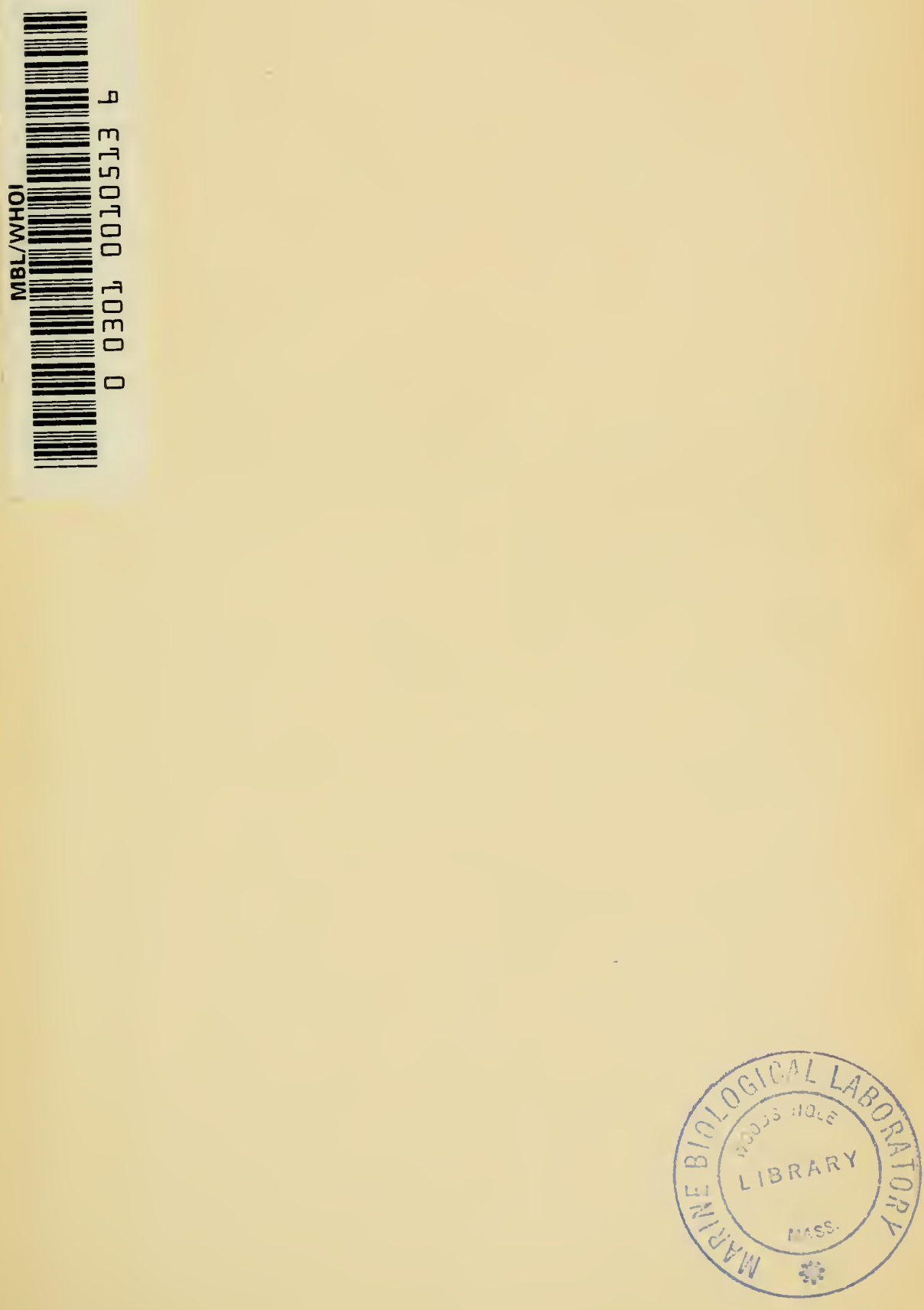



\section{READINGS IN BIOLOGICAL SCIENCE}





\title{
READINGS IN \\ BIOLOGICAL SCIENCE
}

\author{
Edited by
}

\section{IRVING WILLIAM KNOBLOCH, Ph.D.}

Associate Professor of Biological Science

Basic College, Michigan State College

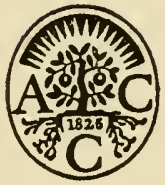

New York and London APPLETON - CENTURY - CROFTS, INC. 
Copyright, 1948, BY APPLETON-CENTURY-CROFTS, INC.

All rights reserved. This book, or parts thereof, must not be reproduced in any form without permission of the publisher.

$43^{8}$ 


\author{
DEDICATED TO \\ MY GOOD COUNSELORS \\ PROFESSOR W. P. ALEXANDER \\ MY WIFE \\ AND \\ MY MOTHER
}





\section{Preface}

Since general education calls for a fulfilment of the aim of teaching students bow to think as well as what to think, it would appear that reading material designed to stimulate and develop the thought processes is important and necessary. Primarily this volume is intended to be read in conjunction with a textbook, and used in this way, it should accomplish much in achieving the goals of a basic biology course. In certain situations, however, instructors may desire to use this book independently as background for a lecture or laboratory course.

The book follows a general plan, but the instructor may not choose to assign the readings in consecutive order. It is organized to start with material on life and the cell and then follow a general scheme of watching the green plant make organic food, of animal nutrition, circulation, and so on. Finally, there are several articles of a philosophical nature which, for the most part, seem to integrate the various divisions of biological study.

It will be evident to the instructor that an attempt has been made to focus on articles that are readable and inspiring rather than those of a classic nature. This idea is in accord with the fast, modern tempo of teaching. When once the student has developed a firm interest in the science, he will wish to examine the classic papers in detail. In reproducing the articles herein presented, a certain amount of abridgment was thought to be desirable to enhance readability.

Many famous biologists have contributed to the development of this book, and the warm thanks of the editor go to them as well as to the various publishers who granted permission to reprint. The source of each article and the author are indicated in a footnote on the first page of each article. Short biographical sketches which give an idea of the caliber of the individual contributors will be found at the end of the book. I am grateful especially to Howard Rather, Dean of the Basic College of Michigan State College for suggestions contained in the introduction and to Dr. Chester A. Lawson, Head of the Department of Biological Science, Michigan State College, for valuable criticisms on the selection of articles destined for inclusion.

I. W. K. 



\section{Introduction}

The college curriculum is experiencing the most extensive face-lifting in its entire career. The early American college was characterized, in one respect, by an odiously rigid set of course requirements, the general idea being that students were entirely devoid of judgment and value-sense. Later this gave way, before the onslaughts of liberals, to a type of curriculum in which the student was hemmed in with few required subjects and overwhelmed with a tempting array of streamlined electives. This change was probably predicated upon the belief, equally erroneous, that students, now that they were in college, were mature adults and had somehow mysteriously gained all the mature attributes of responsible citizenship.

At the present time the pattern is being set for a healthy compromise between these two extreme viewpoints, a compromise which assures the student of the basic, broad, general principles of education and at the same time allows a reasonable amount of free choice of subject-matter. In addition, the general education program cocks a realistic eye at the majority of college students who benefit most by two years of college and who leave school at the end of that time. The program smooths off the rough edges, gathers up the threads, and attempts to assure that a great deal of worth-while integration will have been accomplished both for those who leave and for those who stay.

World War II has shown us the important fact that the human mind is capable of performing astonishing feats when put under pressure. It has demonstrated the value of the scientific mind in producing and harnessing basic research. For example, the atom bomb was not something entirely new but was actually the careful mixing of previously ascertained knowledge with some new material. Many of the ingredients and steps in the bomb's manufacture had been thought out by scientists who had no idea that such knowledge would be used to usher in an atomic age.

This lesson of the power of the trained mind was not lost upon the business man or the industrialist. Evidently the better positions will now be made available to those who can initiate and carry out fundamental research on basic problems in industry and business and also to those who can fulfil the requirements of the modern, alert employee in general. Many college professors and college graduates are being recruited into positions of opportunity where their keen thinking ability is appreciated. 
The old sequence of ridicule, endure and embrace is now being repeated with vehemence.

In many general education programs, and the list is growing by the semester, the improvement of the student's thinking ability is a major goal. Some of the advantages of the new trend are that broader viewpoints are possible, relationships become more evident, dormant interests are aroused, motivation for further inquiry is provided, a personal philosophy of life can be attained and a healthy attitude for the examination of ancient superstitions, provincialisms and intolerances is maintained.

It cannot be too strongly emphasized that the general improvement in the thinking of the great mass of people will determine largely the quality of government that we have. If we allow the dictates of our reveries and our emotions to govern our actions, or if we stop thinking and rely entirely upon recognized authority we shall see a people ridden with race riots, hatreds, crime waves, and docility. These are, among others, the natural fruits of such thinking or lack of it.

Biology, with its great wealth of material and its use of the scientific method has a fundamental rôle to play "in helping students understand the forces that have reshaped our civilization and which now threaten to destroy it. At this of all times it should be clear that understanding the social implications of the sciences is an imperative in general education." 1

1 "Higher Education for American Democracy," Vol. I, A Report of the President's Commission on Higher Education (U.S. Government Printing Office, 1947), p. 52. 


\section{Contents}

PREFACE .

INTRODUCTION

I. Biological Beginnings

Excerpts from "Nature of Man, Humours, Aphorisms and Regimen".

Hippocratcs 2

Excerpts from "De Generatione Animalium" Aristotle 6

Excerpts from "Enquiry into Plants" . Theopbrastus 9

Excerpts from "Natural History" . . . . . Pliny 12

Excerpts from "The First Observations on 'Little Animals'

Protozoa and and Bacteria in Waters"

Antony Van Leeuwenloek 14

The Evidence of the Descent of Man from Some Lower

Form . . . . . . . . Charles Darwin

On the Relations of Man to the Lower Animals

Tbomas H. Huxicy

PAGE

vii

ix

I

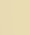

6

2


The Heart and Circulation

A. J. Carlson and V. Jobnson 110

Your Heart

Metropolitan Life Insurance Company and American Heart Association

VI. Nervous and Endocrine Control of the Body . . . . 134

The Background of Human Mentality Ralph Linton 135

The Endocrine Control of the Body . Michael F. Guyer 141

VII. Reproduction . . . . . . . . . . . . . . 154

Reproduction . . . . . . . Emanuel Rádl 155

Sex . . . . . . . . . Michael F. Guyer 159

VIII. Embryology . . . . . . . . . . . . . . 168

Embryology . . . . . . Leslie Brainerd Arey 168

Embryology and Genetics . Thomas Hunt Morgan 172

Old Problems and New in Experimental Embryology.

E. G. Butler 178

IX. Heredity . . . . . . . . . . . . . . . 188

Gregor Mendel and His Work . . . . Hugo lltis 189

Human Heritage . . . . . Carroll Lane Fenton 195

The Study of Human Heredity . Laurence H. Snyder 199

What Will Your Child Look Like? Anram Scheinfeld 206

What Blood Tells. . . . . . . David C. Rife 211

The Inheritance of Disease . . . Paul A. Lewis 215

X. Eugenics . . . . . . . . . . . . . . . 227

Some Bearings of Genetics on Human Affairs .
Otto L. Mohr 228

The Role of Eugenics . . . Edwin Grant Conklin 232

XI. Evolution . . . . . . . . . . . . . 237

The Age of Homo sapiens . . . W. W. Howells 237

Man's Long Story . . . . . . Lewis G. Westgate 243

What We Do Not Know About Race

Wilton Marion Krogman 255

XII. Ecology . . . . . . . . . . . . . . 267

Interdependence of Plants and Animals . . A. S. Pearse 268 
Some Adaptations to the Environment

Bees Raise Questions

Horatio Hackett Newman Henry S. Conard

How Dangerous Is the Jungle

C. Suydam Cutting

XIII. Health and Disfase 297

Enter Louis Pasteur . . . . . . . E. C. Large 298

Pestilences and Moralists . . . Howard W. Haggard 304

Animal Parasites Transmissible to Man

Degenerative Disease Benjarnin Scbriartz 309

Walter Reed and Yellow Fever Karl B. Mickey

322

Grace T. Hallock and C. E. Turner

Mental Disease-A Challenge. Winfred Overholser 340

Mental Diseases

Bernard Jaffe 348

The Significance of Plant Disease in Agriculture

Pollen and Hay Fever . . . . . Margate Kienast 360

XIV. Economic Biology . . . . . . . . . . . 367

Man and Nature . . . . . . . R. T. Young 368

Wonder Plants of Commerce and Industry

A. Hyatt Verrill 372

. Angelo Patri 378

The Vandals

The Conservation of Wildlife
Finishing the Mammals . . . . . . . . . Rosalie Edge 382

The Itinerant Eel . . . . . . Paul Bulla 392

XV. Biological Philosophy . . . . . . . . . . . 398

The Living Machine . . . . . . . R. T. Young 399

Teleological Arguments . . . . Archie J. Babm 407

To What Extent Is a Science of Man Possible?

Frederick Osborn 416

Science Versus Life

A. J. Carlson 423

The Biologist Looks at Man . . Julian S. Huxley $43 \mathrm{I}$

MEET THE AUTHORS

GOOD BROWSING 
relativity and while it may be hard to belicve, our present science will probably look quite amateurish to those men and women who follow us. Many important problems in biology remain to be solved and who can say what transformations their solutions will make in our present-day ideas?

\section{excerpts from Nature of Man, Humours, Apborisms and Regimen *}

\section{H I P P O C R A T E S}

\section{NATURE OF MAN}

He who is accustomed to hear speakers discuss the nature of man beyond its relations to medicine will not find the present account of any interest. For I do not say at all that a man is air, or fire, or water, or earth, or anything else that is not an obvious constituent of a man; such accounts I leave to those who care to give them. Those, however, who give them have not in my opinion correct knowledge. . . .

Now about these men I have said enough, and I will turn to physicians. Some of them say that a man is blood, others that he is bile, a few that he is phlegm. . . The body of man has in itself blood, phlegm, yellow bile and black bile; these make up the nature of his body, and through these he feels pain or enjoys health. Now he enjoys the most perfect health when these elements are duly proportioned to one another in respect of compounding, power, bulk, and when they are perfectly mingled. Pain is felt when one of these elements is in defect or excess, or is isolated in the body without being compounded with all the others. For when an element is isolated and stands by itself, not only must the place where it left become diseased, but the place where it stands in a flood must, because of the excess, cause pain and distress. In fact when more of an element flows out of the body than is necessary to get rid of superfluity, the emptying causes pain.

Now I promised to show that what are according to me the constituents of man remain always the same, according to both convention and nature. These constituents are, I hold, phlegm, blood, black bile, and yellow bile. First I assert that the names of these according to convention are separated, and that none of them has the same name as the others; furthermore, that according to nature their essential forms are separated, phlegm being quite unlike blood, blood being quite unlike bile, bile being quite unlike phlegm. How could they be like one another, when their colours appear not alike

* Reprinted by permission of the publishers from the Loeb Classical Library, Hippocrates, Volume IV, translated by W. H. S. Jones. Cambridge, Mass.: Harvard University Press, 1931. 
to the sight nor does their touch seem alike to the hand? From the following evidence you may know that these elements are not all one, but that each of them has its own power and its own nature. If you were to give a man a medicine which withdraws phlegm, he will vomit you phlegm; if you give him one which withdraws bile, he will vomit you bile. Similarly too black bile is purged away if you give a medicine which withdraws black bile. And if you wound a man's body so as to cause a wound, blood will flow from him. So long as a man lives he manifestly has all these elements always in him.

Phlegm increases in a man in winter; for phlegm, being the coldest constituent of the body, is closest akin to winter. It is in winter that the sputum and nasal discharge of men is fullest of phlegm; at this season mostly swellings become white, and diseases generally phlegmatic. And in spring too phlegm still remains strong in the body while the blood increases. And in summer blood is still strong, and bile rises in the body and extends until autumn. In the summer phlegm is at its weakest. But in autumn, blood becomes least in man, for autumn is dry and begins from this point to chill him. It is black bile which in autumn is greatest and strongest. All these elements are then always comprised in the body of a man, but as the year goes round they become now greater and now less, each in turn and according to its nature.

Now, as these things are so, such diseases as increase in the winter ought to cease in the summer, and such as increase in the summer ought to cease in the winter, with the exception of those which do not depart in a period of days. When diseases arise in the spring, expect their departure in autumn. Such diseases as arise in autumn must have their departure in spring. Whenever a disease passes these limits, you may know that it will last a year.

\section{H U MOUR S}

The fashions of diseases. Some are congenital and may be learned by inquiry, as also may those that are due to the district, for most people are permanent residents there, so that those who know are numerous. Some are the result of the physical constitution, others of regimen, of the constitution of the disease, of the seasons. Countries badly situated with respect to the seasons engender diseases analogous to the seasons.

If the seasons proceed normally and regularly, they produce diseases that come easily to a crisis. If the summer proves bilious, and if the increased bile be left behind, there will also be diseases of the spleen. So when spring too has had a bilious constitution, there occur cases of jaundice in spring also. When summer turns out like to spring, sweats occur in fevers. When the spring turns out wintry, with after-winter storms, the diseases too are wintry, with coughs, pneumonia or angina. For seasons, too, suffer from relapses, and so cause diseases. 
South winds cause deafness, dimness of vision, headaches, heaviness, and are relaxing. A north wind causes coughs, sore throats, constipation, difficult micturition accompanied by shivering, pains in the side and chest. Droughts accompany both south winds and north winds.

It is changes that are chiefly responsible for diseases, especially the greatest changes, the violent alterations both in the seasons and in other things. But seasons which come on gradually are the safest, as are gradual changes of regimen and temperature and gradual changes from one period of life to another.

Sufferers from hemorrhoids are attacked neither by pleurisy, nor by pneumonia, nor by spreading ulcer, nor by boils, nor by swellings, nor perhaps by skin-eruptions and skin-diseases. Blood-spitting may be caused by the season, by pleurisy, or by bile. When swellings by the ear do not suppurate at a crisis, a relapse occurs when the swelling softens; when the relapse follows the normal course of relapses, the swelling rises again and remains, following the same periods as occur when fevers relapse.

\section{A P H O R I S M S}

Old men endure fasting most easily, then men of middle age, youths very badly, and worst of all children, especially those of a liveliness greater than the ordinary.

In summer and in autumn food is most difficult to assimilate, easiest in winter, next easiest in spring.

Do not disturb a patient either during or just after a crisis, and try no experiments, neither with purges nor with other irritants, but leave him alone.

In acute disease use purgatives sparingly and at the onset, and then only after a thorough examination.

When sleep puts an end to delirium, it is a good sign.

Spontaneous weariness indicates disease.

It is easier to replenish with drink than with food.

When on a starvation diet, a patient should not be fatigued.

In the case of acute diseases to predict either death or recovery is not quite safe.

Strong drink dispels hunger.

At the beginning of diseases, if strong medicines seem called for, use them; when they are at their height it is better to let the patient rest.

In every disease it is a good sign when the patient's intellect is sound and he enjoys his food; the opposite is a bad sign.

Those who are constitutionally very fat are more apt to die quickly than those who are thin.

Size of body in youth is noble and not unpleasing; in old age it is inconvenient and less desirable than a smaller stature.

Autumn is bad for consumptives. 
Cold sweats, occurring with high fever, indicate death; with a milder fever they indicatc a protracted disease.

And on whatever part of the body there is sweat, it means that the disease has settled there.

Those who are attacked by tetanus either die in four days or, if they survive these, recover.

Consumption occurs chiefly between the ages of eighteen and thirty-five.

When unnaturally fat women cannot conceive, it is because the fat presses the mouth of the womb, and conception is impossible until they grow thinner.

Kidney troubles, and affections of the bladder, are cured with difficulty when the patient is aged.

If one of the small intestines be severed it does not unite.

It is better to give no treatment in cases of hidden cancer; treatment causes speedy death, but to omit treatment is to prolong life.

Both sleep and sleeplessness, when beyond due measure, constitute disease.

Those diseases that medicines do not cure are cured by the knife. Those that the knife does not cure are cured by fire. Those that fire does not cure must be considered incurable.

R E G I M E N

I maintain that he who aspires to treat correctly of human regimen must first acquire knowledge and discernment of the nature of man in general - knowledge of its primary constituents and discernment of the components by which it is controlled.

Now all animals, including man, are composed of two things, different in power but working together in their use, namely, fire and water. Both together these are sufficient for one another and for everything else, but each by itself suffices neither for itself nor for anything else. Now the power that each of them possesses is this. Fire can move all things always, while water can nourish all things always; but in turn each masters or is mastered to the greatest maximum or the least minimum possible. Neither of them can gain the complete mastery for the following reason. The fire, as it advances to the limit of the water, lacks nourishment, and so turns to where it is likely to be nourished; the water, as it advances to the limit of the fire, finds its motions fail, and so stops at this point. When it stops its force ceases, and hereafter is consumed to nourish the fire which assails it.

Males and females would be formed, so far as possible, in the following manner. Females, inclined more to water, grow from foods, drinks, and pursuits that are cold, moist, and gentle. Males, inclined to fire, grow from foods and regimen that are dry and warm. So if a man would beget a girl, he must use a regimen inclined to water. If he wants a boy, he must live 
according to a regimen inclined to fire. And not only must the man do this, but also the woman. For growth belongs, not only to the man's secretions, but also to that of the woman, for the following reason. Either part alone has not motion enough, owing to the bulk of its moisture and the weakness of its fire, to consume and to solidify the oncoming water. But when it happens that both are emitted together to one place, they conjoin, the fire to the fire and the water likewise. Now if all the fire fall in a dry place, it is set in motion, if it also master the water emitted with it, and therefrom it grows, so that it is not quenched by the onrushing flood, but receives the advancing water and solidifies it on to what is there already. But if it fall into a moist place, immediately from the first it is quenched and dissolves into the lesser rank. On one day in each month it can solidify, and master the advancing parts, and that only if it happen that parts are emitted from both parents together in one place.

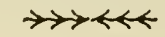

\section{excerpts from De Generatione Animalium*}

\section{(ON THE GENERATION OF ANIMALS)}

A R I S T O T L E

Now some animals come into being from the union of male and female, i. e. all those kinds of animals which possess the two sexes. This is not the case with all of them; though in the sanguinea + with few exceptions the creature, when its growth is complete, is either male or female, and though some bloodless animals have sexes so that they generate offspring of the same kind, yet other bloodless animals generate indeed, but not offspring of the same kind; such are all that come into being not from a union of the sexes, but from decaying earth and excrements. To speak generally, if we take all animals which change their locality, some by swimming, others by flying, others by walking, we find in these the two sexes, not only in the sanguinea but also in some of the bloodless animals; and this applies in the case of the latter sometimes to the whole class, as in the cephalopoda and crustacea, but in the case of insects only to the majority. Of these, all which are produced by union of animals of the same kind generate also after their own kind, but all of which are not produced by animals, but from decaying matter, generate indeed, but produce another kind, and the offspring is neither male nor female; such are some of the insects.

But all those creatures which do not move, as the testacea and animals

"From The Basic Works of Aristotle, edited by Richard McKeon, section translated by Arthur Platt, by permission of Oxford University Press, New York. Copyright 194 I.

† Animals with blood.-Ed. 
that live by clinging to something else, inasmuch as their nature resembles that of plants, have no sex any more than plants have, but as applied to them the word is only used in virtue of a similarity and analogy. For there is a slight distinction of this sort, since even in plants we find in the same kind some trees which bear fruit and others which, while bearing none themselves, yet contribute to the ripening of the fruits of those which do, as in the case of the fig-tree and the caprifig.

The same holds good also in plants, some coming into being from seed and others, as it were, by the spontancous action of Nature, arising either from decomposition of the earth or of some parts in other plants, for some are not formed by themselves separately but are produced upon other trees, as the mistletoe.

Some animals manifestly emit semen, as all the sanguinea, but whether the insects and cephalopoda do so is uncertain. Therefore this is a question to be considered, whether all males do so, or not all; and if not all, why some do and some not; and whether the female also contributes any semen or not; and, if not semen, whether she does not contribute anything else either, or whether she contributes something else which is not semen.

Now it is thought that all animals are generated out of semen, and that the semen comes from the parents. In this investigation and those which follow from it, the first thing to do is to understand what semen is, for then it will be easier to inquire into its operation and the phenomena connected with it. Now the object of semen is to be of such a nature that from it as their origin come into being those things which are naturally formed, not because there is any agent which makes them from it . . but simply because this is the semen.

Now the offspring comes from the semen and it is plainly in one of the two following senses that it does so-either the semen is the material from which it is made, or it is the first efficient cause. Now that which comes from the generating parents is called the seminal fluid, being that which first has in it a principle of generation, in the case of all animals whose nature is to unite; semen is that which has in it the principles from both united parents, as the first mixture which arises from the union of male and female, be it a foetus or an ovum, for these already have in them that which comes from both.

Semen, then, is part of a useful secretion. So we must say the opposite of what the ancients said. For whereas they said that semen is that which comes from all the body, we shall say it is that whose nature is to go to all of it, and what they thought a waste product seems rather to be a secretion.

A further proof that it is not a waste product, but rather a secretion is the fact that the large animals have few young, the small many. For the large must have more waste and less secretion, since the great size of 
the body causes most of the nutriment to be used up, so that the residue or secretion is small.

Again, no place has been set apart by Nature for waste-products but they flow wherever they can find an easy passage in the body, but a place has been set apart for all the natural secretions; thus the lower intestine serves for the excretion of the solid nutriment, the bladder for that of the liquid; for the useful part of the nutriment we have the upper intestine, for the spermatic secretions the uterus and pudenda and breasts, for it is collected and flows together into them. The male stands for the effective and active and the female, considered as female, for the passive and it follows that what the female would contribute to the semen of the male would not be semen but material for the semen to work upon.

So much for the discussion of this question. How is it that the male contributes to generation and how is it that the semen from the male is the cause of the offspring? Does it exist in the body of the embryo as a part of it from the first, mingling with the material which comes from the female? Or does the semen communicate nothing to the material body of the embryo but only the power and movement in it? Now the latter alternative appears to be the right one both a priori and in view of the facts. For, if we consider the question on general grounds, we find that, whenever one thing is made from two of which one is active and the other passive, the active agent does not exist in that which is made, and, still more generally, the same applies when one thing moves and another is moved. It is plain then that it is not necessary that anything at all should come away from the male, and if anything does come away it does not follow that this gives rise to the embryo as being in the embryo, but only as that which imparts the motion and as the form; so the medical art cures the patient.

What occurs in birds and oviparous fishes is the greatest proof that neither does the semen come from all parts of the male nor does he emit anything of such a nature as to exist within that which is generated, as part of the material embryo, but that he only makes a living creature by the power which resides in the semen. For if a hen-bird is in process of producing wind-eggs and is trodden by the cock before the egg has begun to whiten and while it is all still yellow, then they become fertile instead of being wind-eggs. And if while it is still yellow she be trodden by another cock, the whole brood of chicks turn out like the second cock.

The same conclusion is to be drawn from the generation of oviparous fishes. When the female has laid her eggs, the male sprinkles the milt over them, and those eggs are fertilized which it reaches, but not the others; this shows that the male does not contribute anything to the quantity but only to the quality of the embryo.

In all animals that can move about, the sexes are separate, one individual being male and one female, though both are the same in species, as with 
man and horse. But in plants these powers are mingled, female not being separated from male. Wherefore they generate out of themselves, and do not emit semen, but produce an embryo, what is called the seed. For as the egg is an embryo, a certain part of it giving rise to the animal and the rest being nutriment, so also from a part of the seed springs the growing plant, and the rest is nutriment for the shoot and the first root.

It is the nature of those creatures which do not emit semen to remain united a long time until the male element has formed the embryo, as with those insects which copulate. The others remain so only until the male has discharged from the parts of himself, introduced something which will form the embryo in a longer time, as among the sanguinea. For the former remain paired some part of a day, while the semen forms the embryo in several days. And after emitting this they cease their union.

In all this Nature acts like an intelligent workman. For to the essence of plants belongs no other function or business than the production of seed; since, then, this is brought about by the union of male and female, Nature has mixed these and set them together in plants, so that the sexes are not divided in them. But the function of the animal is not only to generate (which is common to all living things) but they all of them participate also in a kind of knowledge, some more and some less, and some very little indeed. For they have sense-perception, and this is a kind of knowledge. Now it is by sense-perception that an animal differs from those organisms which have only life. But since, if it is a living animal, it must also live; therefore, when it is necessary for it to accomplish the function of that which has life, it unites and copulates, becoming like a plant, as we have said before.

\section{$\gg \leftrightarrow \leftrightarrow$ \\ EXCERPts From Enquiry into Plants * \\ THEOP H R A T US \\ DEFINITIONS OF THE VARIOUS CLASSES INTO WHICH \\ PLANTS MAY BE DIVIDED}

Now since our study becomes more illuminating if we distinguish different kinds, it is well to follow this plan where it is possible. The first and most important classes, those which comprise all or nearly all plants, are tree, shrub, under-shrub, herb.

A tree is a thing which springs from the root with a single stem, having knots and several branches, and it cannot easily be uprooted; for instance,

* Reprinted by permission of the publishers from the Loeb Classical Library, Theophrastus: Enquiry into Plants and Minor Works on Odours and Weatber Signs, translated by Sir Arthur Hort, 2 volumes. Cambridge, Mass.: Harvard University Press, 1916. 
olive fig vine. A shrub is a thing which arises from the root with many branches; for instance, bramble Christ's thorn. An under-shrub is a thing which arises from the root with many stems as well as many branches; for instance, savory rue. A herb is a thing which comes up from the root with its leaves and has no main stem, and the seed is borne on the stem; for instance, corn and pot-herbs.

These definitions however must be taken and accepted as applying generally and on the whole. For in the case of some plants it might seem that our definitions overlap; and some under cultivation appear to become different and depart from their essential nature, for instance, mallow when it grows tall and becomes tree-like. For this comes to pass in no long time, not more than six or seven months, so that in length and thickness the plant becomes as great as a spear, and men accordingly use it as a walkingstick, and after a longer period the result of cultivation is proportionately greater. So too is it with the beets; they also increase in stature under cultivation, and still more do chaste-tree Christ's thorn ivy, so that, as is generally admitted, these become trees, and yet they belong to the class of shrubs. On the other hand the myrtle, unless it is pruned, turns into a shrub, and so does filbert: indeed this latter appears to bear better and more abundant fruit if one leaves a good many of its branches untouched, since it is by nature like a shrub. Again neither the apple nor the pomegranate nor the pear would seem to be a tree of a single stem, nor indeed any of the trees which have side stems from the roots, but they acquire the character of a tree when the other stems are removed. However, some trees men even leave with their numerous stems because of their slenderness, for instance, the pomegranate and the apple, and they leave the stems of the olive and the fig cut short.

\section{OF 'MALE' AND'FEMALE' IN TREES}

Taking all trees according to their kinds, we find a number of differences. Common to them all is that by which men distinguish the 'male' and the 'female,' the latter being fruit-bearing, the former barren in some kinds. In those kinds in which both forms are fruit-bearing, the 'female' has fairer and more abundant fruit; however some call these the male trees-for there are those who actually invert the names. This difference is of the same character which distinguishes the cultivated from the wild tree, while other differences distinguish different forms of the same kind.

OF THE MEDICINAL USES OF DIVERS PARTS OF PLANTS

As was said, of some plants the root, fruit and juice are all serviceable, as of all-heal among others; of some the root and the juice, as of scammony cyclamen thapsia and others, such as mandrake; for the leaf of this, they say, used with meal, is useful for wounds, and the root for erysipelas, when scrapped and steeped in vinegar, and also for gout, for sleeplessness, and 
for love potions. It is administered in wine or vinegar; they cut little balls of it, as of radishes, and making a string of them hang them up in the smoke over must.

Of hellebore both root and fruit are useful for the same purposes,-if it is true, as is said, that the people of Anticyra use the fruit as a purge: this fruit contains the well-known drug called sesamodes.

Various parts of all-heal are also useful, and not all for the same purposes; the fruit is used in cases of miscarriage and for disorders of the bladder, while the juice is used in cases of miscarriage and also for sprains and such-like troubles; also for the ears, and to strengthen the voice. The root is used in childbirth, for diseases of women, and for flatulence in beasts of burden.

Of cyclamen the root is used for suppurating boils; also as a pessary for women and, mixed with honey, for dressing wounds; the juice for purgings of the head. They say also that the root is a good charm for inducing rapid delivery and as a love potion.

Of 'wild cucumber' (squirting cucumber) the root is used for white leprosy and for mange in sheep.

Of germander the leaves pounded up in olive-oil are used for fractures and wounds and for spreading sores; the fruit purges bile, and is good also for the eyes; for ulcers in the eye they pound up the leaf in olive-oil before applying it.

OF ROOTS POSSESSING REMIRKABLE TASTE OR SMILL

The differences between roots are shown in their tastes and in their smells: some are pungent, some bitter, some sweet: some again have a pleasant, others a disagreeable smell. The plant called yellow water-lily is sweet: it grows in lakes and marshy places. It has a large leaf which lies on the water: and it is said that it acts as a styptic if it is pounded up and put on the wound: it is also serviceable in the form of a draught for dysentery.

Liquorice is also sweet; some indeed simply call it 'sweet root.' It is useful against asthma or a dry cough and in general for troubles in the chest: also, administered in honey, for wounds: also it has the property of quenching thirst, if one holds it in the mouth.

These then are sweet: other roots are bitter, and some unpleasant to the taste.

Madder has a leaf like ivy, but it is rounder: it grows along the ground like dog's-tooth grass and loves shady spots. It has diuretic properties, wherefore it is used for pains in the loins or hip disease.

The root of polypody is rough and has suckers like the tentacles of the polyp. It purges downward: and, if one wears it as an amulet, they say that one does not get a polypus. 
OF PLANTS POSSESSING PROPERTIES WHICH AFFECT

THE MIENTAL POWERS

As to those that affect the mind, strykhnos is said to upset the mental powers and make one mad; while the root of onotheras (oleander) administercd in wine makes the temper gentler and more cheerful. This plant has a leaf like the almond, but smaller, and the flower is red like a rose. The plant itself forms a large bush; the root is red and large and, if this is dried, it gives off a fragrance like wine.

\section{$\rightarrow \rightarrow \leftrightarrow$ \\ EXCERPts From Natural History *}

\section{P L I N Y}

The birth of triplets is attested by the case of Horatii and Curiatii: above that number is considered portentous, except in Egypt, where drinking the water of the Nile causes fecundity. Recently on the day of the obsequies of his late Majesty Augustus a certain woman of the lower orders named Fausta at Ostia was delivered of two male and two female infants, which unquestionably portended the food shortage that followed. We also find the case of a woman in the Peloponnese who four times produced quintuplets, the greater number of each birth surviving. In Egypt also Trogus alleges cases of seven infants born at a single birth.

Persons are also born of both sexes combined-what we call Hermaphrodites, formerly called androgyni and considered as portents, but now as entertainments. We read of Eutychis who at Realles was carried to her funeral pyre by twenty children and who had given birth thirty times, and Alcippe who gave birth to an elephant.

Transformation of females into males is not an idle story. A girl at Casinum was changed into a boy, under the observation of the parents and at the order of the augurs was conveyed away to a desert island. I myself saw in Africa a person who had turned into a male on the day of marriage to a husband. (It is said that) at the birth of twins neither the mother nor more than one of the two children usually lives, but that if twins are born that are of different sex it is even more unusual for either to be saved: that females are born more quickly than males, just as they grow older more quickly: and that movement in the womb is more frequent in the case of males, and males are usually carried on the right side, females on the left.

All the other animals have a fixed season for copulation and for bear-

* Reprinted by permission of the publishers from the Loeb Classical Library, Pliny: Natural History, Volume II, translated by H. Rackham. Cambridge, Mass.: Harvard University Press, $194^{2}$. 
ing offspring, but human reproduction takes place all the year round and the period of gestation varies-in one case it may exceed six months, in another seven, and it may even exceed ten: a child born before the seventh month is usually still-born. Only those conceived the day before or the day after the full moon, or when there is no moon, are born in the seventh month.

On the tenth day from conception pains in the head, giddiness and dim sight, distaste for food, and vomiting are symptoms of the formation of the embryo. If the child is a male, the mother has a better colour and an easier delivery; there is movement in the womb on the fortieth day. In the case of the other sex, all the symptoms are the opposite: the burden is hard to carry, there is a slight swelling of the legs and groin, but the first movement is on the ninetieth day. But the greatest amount of faintness occurs when the embryo begins to grow hair; and also at the full moon, which period is also specially inimical to infants after birth. The gait in walking and everything that can be mentioned are so important during pregnancy that mothers eating food that is too salt bear children lacking nails, and that not holding the breath makes the delivery more difficult; indeed, to gape during delivery may cause death, just as a sneeze following copulation causes abortion.

It is against nature to be born feet foremost. It is Nature's method for a human being to be born head first, and it is the custom for him to be carried to burial feet first.

It is also well known that sound parents may have deformed children and deformed parents sound children or children with the same deformity, as the case may be; that some marks and moles and even scars reappear in the offspring, in some cases a birthmark on the forearm reappearing in the fourth generation.

Cases of likeness are indeed an extremely wide subject, and one which includes the belief that a great many accidental circumstances are influential-recollections of sights and sounds and actual sense-impressions received at the time of conception. Also a thought flitting across the mind of either parent is supposed to produce likeness or to cause a combination of features, and the reason why there are more differences in man than in all the other animals is that his swiftness of thought and quickness of mind and variety of mental character impress a great diversity of mental patterns, whereas the minds of the other animals are sluggish and are alike for all and sundry, each in their own kind.

Particular individuals may have a certain physical incongruity between them, and persons whose union is infertile may have children when they form other connexions. Also some women have only female or only male children, though usually the sexes come alternately; some women are childless in youth; on some parentage is bestowed once in a lifetime; certain women are always delivered prematurely, and those of this class, if 
ever they succeed in overcoming this tendency by the use of drugs, usually bear a female child.

A woman does not bear children after the age of fifty, and with the majority menstruation ceases at forty. Woman is, however, the only animal that has monthly periods; consequently she alone has what are called moles in the womb. This mole is a shapeless and inanimate mass of flesh that resists the point and the edge of a knife; it moves about and it checks menstruation, as it also checks births: in some cases causing death, in others growing old with the patient, sometimes when the bowels are violently moved being ejected. A similar object is also formed in the stomach of males, called a tumour. . . .

The latter (women who do not menstruate), however, do not have children, since the substance in question (menstrual fluid) is the material for human generation, as the semen from the males acting like rennet collects this substance within it, which thereupon immediately is inspired with life and endowed with body. Hence when this flux occurs with women heavy with child, the offspring is sickly or still-born or sanious, according to Nigidius. (The same writer holds that a woman's milk does not go bad while she is suckling a baby if she has become pregnant again from the same male.) It is stated, however, that the easiest conceptions are when this condition is beginning or ceasing. We have it recorded as a sure sign of fertility in women if when the eyes have been anointed with a drug the saliva contains traces of it.

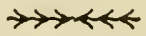

\section{EXCERPTS FROM The First Observations on "Little Animals" Protozoa and Bacteria in Waters*}

\section{A N T ON Y VAN LEEU WENHOEK}

\section{IST OBSERVATION ON RAIN-WATER}

In the year ${ }_{16} 65$, about half-way through September (being busy with studying air, when I had much compressed it by means of water), I discovered living creatures in rain, which had stood but a few days in a new tub, that was painted blue within. This observation provoled me to investigate this water more narrowly; and especially because these little animals were, to my eye, more than ten thousand times smaller than the animacule which Swammerdam has portrayed, and called by the name of Water-flea, or Water-louse, which you can see alive and moving in water with the bare eye.

Of the first sort, that I discovered in the said water, I saw, after divers

"From Antony Van Leeuwenboek and His "Little Animals" by Clifford Dobell. Reprinted by permission of Harcourt, Brace and Company, Inc. 
observations, that the bodies consisted of 5, 6, 7 or 8 very clear globules, but without being able to discern any membrane or skin that held these globules together, or in which they were enclosed. When these animacules bestirred 'emselves, they sometimes stuck out two little horns, which were continually moved, after the fashion of a horse's ears. The part between these little horns was flat, their body else being roundish, save only that it ran somewhat to a point at the hind end; at which pointed end it had a tail, near four times as long as the whole body, and looking as thick, when viewed through my microscope, as a spider's web. At the end of this tail there was a pellet, of the bigness of one of the globules of the body; and this tail I could not perceive to be used by them for their movements in very clear water. These little animals were the most wretched creatures that I have ever seen; for when, with the pellet, they did but hit on any particles or little filaments (of which there were many in water, especially if it hath but stood some days), they stuck entangled in them; and then pulled their body out into an oval, and did struggle, by strongly stretching themselves, to get their tail loose; whereby their whole body then sprang back towards the pellet of the tail, and their tails then coiled up serpent-wise, after the fashion of a copper or iron wire that, having been wound close about a round stick, and then taken off, kept all its windings. This motion, of stretching out and pulling together the tail, continued; and I have seen several hundred animacules, caught fast by one another in a few filaments, lying within the compass of a coarse grain of sand.

I also discovered a second sort of animacules, whose figure was oval; and I imagined that their head was placed at the pointed end. These were a little bit bigger than the animacules first mentioned. Their belly is flat, provided with divers incredibly thin little feet, or little legs, which were moved very nimbly, and which I was able to discover only after sundry great efforts, and wherewith they brought off incredibly quick motions. The upper part of their body was round, and furnished inside with 8,10 or 12 globules: otherwise these animacules were very clear. These little animals would change their body into a perfect round, but mostly when they came to lie high and dry. Their body was also very yielding: for if they so much as brushed against a tiny filament, their body bent in, which bend also presently sprang out again; just as if you stuck your finger into a bladder full of water, and then, on removing the finger, the inpitting went away. Yet the greatest marvel was when I brought any of these animacules on a dry place, for I then saw them change themselves at last into a round. and then the upper part of the body rose up pyramid-like, with a point jutting out in the middle; and after having thus lain moving with their feet for a little while, they burst asunder, and the globules and a watery humour flowed away on all sides, without my being able to discern even the least sign of any skin wherein these globules and the liquid had, to all appearance, been inclosed; and at such time I could discern more globules than 
when they were alive. This bursting asunder I figure to myself to happen thus: imagine, for example, that you have a sheep's bladder filled with shot, peas, and water; then, if you were to dash it apieces on the ground, the shot, peas, and water would scatter themselves all over the place.

Furthermore, I discovered a third sort of little animals, that were about twice as long as broad, and to my eye quite eight times smaller than the animacules first mentioned: and I imagined, although they were so small, that I could yet make out their little legs, or little fins. Their motion was very quick, both roundabout and in a straight line.

The fourth sort of animacules, which I also saw amoving, were so small, that for my part I can't assign any figure to 'em. These little animals were more than a thousand times less than the eye of a full-grown louse (for I judge the diameter of the louse's eye to be more than ten times as long as that of the said creature), and they surpassed in quickness the animacules already spoken of. I have divers times seen them standing still, as 'twere, in one spot, and twirling themselves round with a swiftness such as you see in a whip-top a-spinning before your eye; and then again they had a circular motion, the circumference whereof was no bigger than that of a small sand-grain; and anon they would go straight ahead, or their course would be crooked.

Furthermore I also discovered sundry other sorts of little animals; but these were very big, some as large as the little mites on the rind of cheese, others bigger and very monstrous. But I intend not to specify them; and will only say, that they were for the most part made up of such soft parts, that they burst asunder whenever the water happened to run off them.

THE 2 ND OBSERVATION. RAIN-IVATER

The 26 th of May it rained very hard. The rain abating somewhat, I took a clean glass and got rain-water, that came off a slate roof, fetched me in it, after the glass had first been swilled out two or three times with the rain-water. I then examined it, and therein discovered some few very little animals; and seeing them, I bethought me whether they might not have been bred in the leaden gutters, in any water that might erstwhile have been standing in them.

THE 3 R D OBSERVATION. RAIN- W A TER

On the same date, the rain continuing nearly the whole day, I took a big procelain dish, and put it in my court-yard, in the open air, upon a wooden tub about a foot and a half high: considering that thus no earthy particles would be splashed into the said dish by the falling of the rain at that spot. With the water first caught, I swilled out the dish, and the glass in which I meant to preserve the water, and then flung this water away: then, collecting water anew in the same dish, I kept it; but upon 
examining it, I could discover therein no living creatures, but merely a lot of irregular earthy particles.

The 3 oth of May, after I had, since the 26 th, observed this water every day, twice or thrice daily, I now first discovered some (though very few) exceeding little animacules, which were very clear.

On the 31 st ditto, I discovered more little animals in the water, as well as a few that were a bit bigger; and I imagine that ten hundred thousand of these little animacules are not so big as an ordinary sand-grain. Comparing these animacules with the little mites in cheese (which you can see amoving with the bare eye), I would put the proportion thus: As the size of a small animacule in the water is to that of a mite, so is the size of a honey bee to that of a horse; for the circumference of one of these same little animacules is not so great as the thickness of a hair on a mite.

THE 4 T H OBSERVATION. RA IN - WATER

On June gth, collected rain-water betimes in a dish, as aforesaid, and put it at about 8 o'clock in the morning in a clean wine glass, and exposed it to the air at about the height of the third storey of my house, wondering whether the little animals would appear sooner in water thus standing in the air.

The roth ditto, observing this water, I fancied that I discovered living creatures; but they were so few, and not so plainly discernible, I could not accept this for the truth.

On the I Ith ditto, seeing this water, with the naked eye, stirred in the glass by a stiff gale of wind (which had now blown from the same quarter for 36 hours; the weather being very cold withal, that it did not irk me to wear my winter clothes), I had no thought of finding any living creatures in it; but upon examining it, I saw with wonder quite Iooo living creatures in one drop of water. These animacules were of the smallest sort that I had yet seen.

The 12 th of June, in the morning (the wind being west, with both sunshine and an overcast sky), observing again, I saw the aforesaid animacules in such great numbers in the water which I took from the surface, that now they did not amount to merely one or two thousand in one drop.

The $13^{\text {th }}$ ditto, in the morning, examining the water again, I discovered, beside the aforesaid animacules, a sort of little animals that were fully eight times as big as the first; and whereas the small animacules swam gently among one another, and moved after the fashion of gnats in the air, these larger animacules had a much swifter motion; and as they turned and tumbled all around and about, they would make a quick dart. These animacules were almost round.

On the $14^{\text {th }}$ of June I did perceive the very little animacules in no less number. 
On the 16 th ditto, the animacules seen as before; and the water (which had been, in all, about $1 / 6$ of a pint) being now more than half dried out, I flung it away.

5 TH OBSERVATION . RAIN - WATER

The $9^{\text {th }}$ of June, I put some of the last-collected water, likewise in a clean wine-glass, in my closet; and on examining it, I described no animacules.

The roth of June, observing this foresaid rain-water, which had now stood about 24 hours in my closet, I perceived some few very little living creatures, to which, because of their littleness, no figure can be ascribed; and among others, I discovered a little animal that was a bit bigger, and that I could perceive to be oval.

The 1 ith ditto, observing this water again, I saw the foresaid small animacules, though very few in number.

The 12 th ditto, I saw the very small animacules, as yesterday; and besides these, a small animal that had nearly the figure of a mussel-shell, lying with its hollow side downwards. 'Twas of the length anigh of a louse's eye.

The $13^{\text {th }}$ ditto, I also saw one bigger animacule, like that just spoken of. Moreover I discovered animacules which were somewhat longer than an oval. These were about 6 times as long as the foresaid very small animacules; and their head, which was somewhat long drawn out, they of t-times pulled in, and then looked to be almost round. There were also animacules which appeared perfectly round, their diameter being twice as long as that of smallest animacules of all. These two large sorts were very yielding, so that their body did bend before the least little filament which they chanced to brush against in the water.

The i 6 th ditto, I perceived the oval animacules in yet greater numbers; and they were flat beneath, and round above: and besides these, there were very small animacules that were three times as long as broad, together with divers other sorts which it would take all too long to specify. In the evening of the same day, I discovered little paws on the foresaid oval animacules, which were many in number, in proportion to the animacule. And at this point, I stopped my observations upon this water.

OBSERVATIONS ON WELL-WATER

I have in my yard, standing in the open air, a well, which is about 15foot deep before you come to the water. It standeth at the south, but so encompassed with high walls, that even when the sun is on the sign of Cancer, the coping of the wall is not shown upon. This water cometh out of the ground, which is well-sand, with such force, that whenever I have tried to empty the well there was always about a foot of water still left in. - On a summer's day this water is so cold that 'tis not feasible to keep your 
hand in it for long. Having no thought that there would be living creatures in it (for 'tis very palatable and clear), I examined it in September of last year, and discovered therein a great number of very small animacules, which were very clear, and a bit bigger than the very smallest animacules that l've ever seen. And I imagine (having aforetime weighed a grain of water), that there were commonly more than 500 living creatures in one grain of this water. These animacules were very sedate, moving without any jerks.

In the winter I perceived no little animals, nor did I see any of them this year before the month of July, and then not in such great plenty; but in the month of August, their number was much increased.

\section{OBSERVATIONS ON SEA-WATER}

The 27 th of July, 1676 , I betook myself to the seaside, hard by the village of Schevelinge. Finding myself upon the shore, and observing the sea-water as well as I could, I discovered in it divers little animacules. I gave to a certain person who went into the sea, to bathe himself, a new glass vial and besought him that, when he was in the sea, he would rinse it out twice or thrice and then fill it up with water. This having been carried out according to my orders, I tied the vial up tight with a clean bit of bladder: and on reaching home and examining the water, I perceived therein a little animal that was blackish, having a shape as if 'twere made up of two globules. This little animal had a peculiar motion, after the manner of a very little flea, when seen, by the naked eye, jumping on a white paper; yet 'twas only displaced, at every jump, within the compass of a coarse sandgrain, or thereabouts. It might right well be called a water flea; but 'twas not so big, by a long way, as the eye of that little animal which Swammerdam calls the water-flea.

The 3 ist ditto, having examined this water every day since the 27 th, and perceived no little animals in it; upon this date I did now see a good hundred of 'em where at first I had seen but one; but they were now of another figure, and not only smaller, but also very clear. They were like an oblong oval, only with this difference, that they tapered somewhat more sharply to a point at what I imagined to be the head end. And although these were at least a thousand times smaller than a very small sand-grain, I saw, notwithstanding, that whenever they lay high and dry out of the water they burst asunder, and flowed apart or scattered into three or four very small globules and some watery matter, without my being able to discern any other parts.

The 8th of August, I again discovered a very few of the foresaid animacules; and I now saw a few so exceeding small that, even through my microscope, they well-nigh escaped the sight. And here I stopped my observations. 


\section{THE EVIDENCE OF THE DESCENT OF MAN FROM SOME LOWER FORM *}

\section{H A R L E D A R W I N}

He who wishes to decide whether man is the modified descendant of some pre-existing form, would probably first enquire whether man varies, however slightly, in bodily structure and in mental faculties; and if so, whether the variations are transnitted to his offspring in accordance with the laws which prevail with the lower animals. Again, are the variations the result, as far as our ignorance permits us to judge, of the same general causes, and are they governed by the same general laws, as in the case of other organisms; for instance, by correlation, the inherited effects of use and disuse, etc? Is man subject to similar malconformations, the result of arrested development, of reduplication of parts, \&c., and does he display in any of his anomalies reversion to some former and ancient type of structure? It might also naturally be enquired whether man, like so many other animals, has given rise to varieties and sub-races, differing but slightly from each other, or to races differing so much that they must be classed as doubtful species? How are such races distributed over the world; and how, when crossed, do they react on each other in the first and succeeding generations? And so with many other points.

The enquirer would next come to the important point whether man tends to increase at so rapid a rate, as to lead to occasional severe struggles for existence; and consequently to beneficial variations, whether in body or mind, being preserved, and injurious ones eliminated. Do the races or species of men, whichever term may be applied, encroach on and replace one another, so that some finally become extinct? We shall see that all these questions, as indeed is obvious in respect to most of them, must be answered in the affirmative, in the same manner as with the lower animals. But the several considerations just referred to may be conveniently deferred for a time: and we will first see how far the bodily structure of man shows traces, more or less plain, of his descent from some lower form.

\section{THE BODILY STRUCTURE OF M A N}

It is notorious that man is constructed on the same general type or model as other mammals. All the bones in his skeleton can be compared with corresponding bones in a monkey, bat, or seal. So it is with his muscles, nerves, blood-vessels and internal viscera. The brain, the most important of all the organs, follows the same law, as shewn by Huxley and other anatomists. Bischoff, who is a hostile witness, admits that every chief fissure and fold

\footnotetext{
- From The Descent of Man and Selection in Relation to Sex by Charles Darwin.
} D. Appleton and Co., New York. 1886. 
in the brain of man has its analogy in that of the orang; but he adds that at no period of development do their brains perfectly agree; nor could perfect agreement be expected, for otherwise their mental powers would have been the same.

It may, however, be worth while to specify a few points, not directly or obviously connected with structure, by which this correspondence or relationship is well shewn.

Man is liable to receive from the lower animals, and to communicate to them, certain diseases, as hydrophobia, variola, the glanders, syphilis, cholera, herpes, \&c.; and this fact proves the close similarity of their tissues and blood, both in minute structure and composition, far more plainly than does their comparison under the best microscope, or by the aid of the best chemical analysis. Monkeys are liable to many of the same noncontagious diseases as we are; thus Rengger, who carefully observed for a long time the Cebus Azarae in its native land, found it liable to catarrh, with the usual symptoms, and which, when often recurrent, led to consumption. These monkeys suffered also from apoplexy, inflammation of the bowels, and cataract in the eye. The younger ones when shedding their milk-teeth often died from fever. Medicines produced the same effect on them as on us. Many kinds of monkeys have a strong taste for tea, coffee, and spirituous liquors: they will also, as I have myself seen, smoke tobacco with pleasure. Brehm asserts that the natives of north-eastern Africa catch the wild baboons by exposing vessels with strong beer, by which they are made drunk. He has seen some of these animals, which he kept in confinement, in this state; and he gives a laughable account of their behaviour and strange grimaces. On the following morning they were very cross and dismal; they held their aching heads with both hands, and wore a most pitiable expression: when beer or wine was offered them, they turned away with disgust, but relished the juice of lemons. An American monkey, an Ateles, after getting drunk on brandy, would never touch it again, and thus was wiser than many men. These trifling facts prove how similar the nerves of taste must be in monkeys and man, and how similarly their whole nervous system is affected.

Man is infested with internal parasites, sometimes causing fatal effects; and is plagued by external parasites, all of which belong to the same genera or families as those infesting other mammals, and in the case of scabies to the same species. Man is subject, like other mammals, birds, and even insects, to that mysterious law, which causes certain normal processes, such as gestation, as well as the maturation and duration of various diseases, to follow lunar periods. His wounds are repaired by the same process of healing; and the stumps left after the amputation of his limbs, especially during an early embryonic period, occasionally possess some power of regeneration, as in the lowest animals.

The whole process of that most important function, the reproduction of 
the species, is strikingly the same in all mammals, from the first act of courtship by the male, to the birth and nurturing of the young. Monkeys are born in alnost as helpless a condition as our own infants; and in certain genera the young differ fully as much in appearance from the adults, as do our children from their full-grown parents. It has been urged by some writers, as an important distinction, that with man the young arrive at maturity at a much later age than with any other animal: but if we look to the races of mankind which inhabit tropical countries the difference is not great, for the orang is believed not to be adult till the age of from ten to fifteen years. Man differs from woman in size, bodily strength, hairiness, \&c., as well as in mind, in the same manner as do the two sexes of many mammals. So that the correspondence in general structure, in the minute structure of the tissues, in chemical composition and in constitution, between man and the higher animals, especially the anthropomorphous apes, is extremely close.

\section{EMBRYONIC DEVELOPMENT}

Man is developed from an ovule, about the $125^{\text {th }}$ of an inch in diameter, which differs in no respect from the ovules of other animals. The embryo itself at a very early period can hardly be distinguished from that of other members of the vertebrate kingdom. At this period the arteries run in arch-like branches, as if to carry the blood to branchiae which are not present in the higher vertebrata, though the slits on the sides of the neck still remain, marking their former position. At a somewhat later period, when the extremities are developed, "the feet of lizards and mammals," as the illustrious Von Baer remarks, "the wings and feet of birds, no less than the hands and feet of man, all arise from the same fundamental form." It is, says Prof. Huxley, "quite in the later stages of development that the young human being presents marked differences from the young ape, while the latter departs as much from the dog in its developments, as the man does. Startling as this last assertion may appear to be, it is demonstrably true."

After the foregoing statements made by such high authorities, it would be superfluous on my part to give a number of borrowed details, shewing that the embryo of man closely resembles that of other mammals. It may, however, be added, that the human embryo likewise resembles certain low forms when adult in various points of structure. For instance, the heart at first exists as a simple pulsating vessel; the excreta are voided through a cloacal passage; and the os coccyx projects like a true tail, "extending considerably beyond the rudimentary legs." In the embryos of all air-breathing vertebrates, certain glands, called the corpora Wolffiana, correspond with and act like the kidneys of mature fishes. Even at a later embryonic period, some striking resemblances between man and the lower animals may be observed. Bischoff says that the convolutions of the 
brain in a human foetus at the end of the seventh month reach about the same stage of development as in a baboon when adult. The great toe, as Prof. Owen remarks, "which forms the fulcrum when standing or walking, is "perhaps the most characteristic peculiarity in the human structure;" but in an embryo, about an inch in length, Prof. Wyman found "that the great toe was shorter than the others; and, instead of being parallel to them, projected at an angle from the side of the foot, thus corresponding with the permanent condition of this part in the quadrumana." I will conclude with a quotation from Huxley, who after asking, does man originate in a different way from a dog, bird, frog or fish? says, "the reply is not doubtful for a moment; without question, the mode of origin, and the early stages of the development of man, are identical with those of the animals immediately below him in the scale: without a doubt in these respects, he is far nearer to apes than the apes are to the dog."

\section{R U D I I E N T S}

This subject, though not intrinsically more important than the two last, will for several reasons be treated here more fully. Not one of the higher animals can be named which does not bear some part in a rudimentary condition; and man forms no exception to the rule. Rudimentary organs must be distinguished from those that are nascent; though in some cases the distinction is not easy. The former are either absolutely useless, such as the mammae of male quadrupeds, or the incisor teeth of ruminants which never cut through the gums; or they are of such slight service to their present possessors, that we can hardly suppose that they were developed under the conditions which now exist. Organs in this latter state are not strictly rudimentary, but they are tending in this direction. Nascent organs, on the other hand, though not fully developed, are of high service to their possessors, and are capable of further development. Rudimentary organs are eminently variable; and this is partly intelligible, as they are useless, or nearly useless, and consequently are no longer subjected to natural selection. They often become wholly suppressed. When this occurs, they are nevertheless liable to occasional reappearance through reversion-a circumstance well worthy of attention.

The chief agents in causing organs to become rudimentary seem to have been disuse at that period of life when the organ is chiefly used (and this is generally during maturity), and also inheritance at a corresponding period of life. The term "disuse" does not relate merely to the lessened action of muscles, but includes a diminished flow of blood to a part or organ, from being subjected to fewer alternations of pressure, or from becoming in any way less habitually active. Rudiments, however, may occur in one sex of those parts which are normally present in the other sex; and such rudiments, as we shall hereafter see, have often originated in a way distinct from those here referred to. In some cases, organs have been reduced 
by means of natural selection, from having become injurious to the species under changed habits of life. The process of reduction is probably often aided through the two principles of compensation and economy of growth; but the later stages of reduction, after disuse has done all that can fairly be attributed to it, and when the saving to be effected by the economy of growth would be very small, are difficult to understand. The final and complete suppression of a part, already useless and much reduced in size, in which case neither compensation nor economy can come into play, is perhaps intelligible by the aid of the hypothesis of pangenesis. But as the whole subject of rudimentary organs has been discussed and illustrated in my former works, I need here say no more on this head.

Rudiments of various muscles have been observed in many parts of the human body; and not a few muscles, which are regularly present in some of the lower animals can occasionally be detected in man in a greatly reduced condition. Every one must have noticed the power which many animals, especially horses, possess of moving or twitching their skin; and this is effected by the panniculus carnosus. Remnants of this muscle in an efficient state are found in various parts of our bodies; for instance, the muscle on the forehead, by which the eyebrows are raised.

The extrinsic muscles which serve to move the external ear, and the intrinsic muscles which move the different parts, are in a rudimentary condition in man, and they all belong to the system of the panniculus; they are also variable in development, or at least in function. I have seen one man who could draw the whole ear forwards; other men can draw it upwards; another who could draw it backwards; and from what one of these persons told me, it is probable that most of us, by often touching our ears, and thus directing our attention towards them, could recover some power of movement by repeated trials. The power of erecting and directing the shell of the ears to the various points of the compass, is no doubt of the highest service to many animals, as they thus perceive the direction of danger; but I have never heard on sufficient evidence, of a man who possessed this power, the one which might be of use to him. Some authors, however, suppose that the cartilage of the shell serves to transmit vibrations to the acoustic nerve; but Mr. Toynbee, after collecting all the known evidence on this head, concludes that the external shell is of no distinct use. The ears of the chimpanzee and orang are curiously like those of man, and the proper muscles are likewise but very slightly developed. I am also assured by the keepers in the Zoological Gardens that these animals never move or erect their ears; so that they are in an equally rudimentary condition with those of man, as far as function is concerned. Why these animals, as well as the progenitors of man, should have lost the power of erecting their ears, we cannot say. It may be, though I am not satisfied with this view, that owing to their arboreal habits and great strength they were but little exposed to danger, and so during a lengthened period moved their ears but little, and thus 
gradually lost the power of moving them. This would be a parallel case with that of those large and heavy birds, which from inhabiting oceanic islands, have not been exposed to the attacks of beasts of prey, and have consequently lost the power of using their wings for flight. The inability to move the ears in man and several apes is, however, partly compensated by the freedom with which they can move the head in a horizontal plane, so as to catch sounds from all directions.

The nictitating membrane, or third eyelid, with its accessory muscles and other structures, is especially well developed in birds, and is of much functional importance to them, as it can be rapidly drawn across the whole eye-ball. It is found in some reptiles and amphibians, and in certain fishes, as in sharks. It is fairly well developed in the two lower divisions of the mammalian series, namely, in the monotremata and marsupials, and in some few of the higher mammals, as in the walrus. But in man, the quadrumana, and most other mammals, it exists, as is admitted by all anatomists, as a mere rudiment, called the semilunar fold.

The sense of smell is of the highest importance to the greater number of mammals-to some, as the ruminants, in warning them of danger; to others, as the carnivora, in finding their prey; to others, again, as the wild boar, for both purposes combined. But the sense of smell is of extremely slight service, if any, even to the dark coloured races of men, in whom it is much more highly developed than in the white and civilized races. Nevertheless it does not warn them of danger, nor guide them to their food; nor does it prevent the Esquimaux from sleeping in the most fetid atmosphere, nor many savages from eating half-putrid meat. In Europeans the power differs greatly in different individuals, as I am assured by an eminent naturalist who possesses this sense highly developed, and who has attended to the subject. Those who believe in the principle of gradual evolution, will not readily admit that the sense of smell in its present state was originally acquired by man, as he now exists. He inherits the power in an enfeebled and so far rudimentary condition, from some early progenitor, to whom it was highly serviceable, and by whom it was continually used. In those animals which have this sense highly developed, such as dogs and horses, the recollection of persons and of places is strongly associated with their odour; and we can thus perhaps understand how it is, as Dr. Maudsley has truly remarked, that the sense of smell in man "is singularly effective in recalling vividly the ideas and images of forgotten scenes and places."

Man differs conspicuously from all the other Primates in being almost naked. But a few short straggling hairs are found over the greater part of the body in the man, and fine down on that of the woman. The different races differ much in hairiness; and in the individuals of the same race the hairs are highly variable, not only in abundance, but likewise in position; thus in some Europeans the shoulders are quite naked, whilst in others they bear thick tufts of hair. There can be little doubt that the hairs thus scat- 
tered over the body are the rudiments of the uniform hairy coat of the lower animals. This view is rendered all the more probable, as it is known that fine, short, and pale-coloured hairs on the limbs and other parts of the body, occasionally become developed into "thickset, long and rather coarse dark hairs," when abnormally nourished near old-standing inflamed surfaces.

The fine wool-like hair, or so-called lanugo, with which the human foetus during the sixth month, is thickly covered, offers a more curious case. It is first developed, during the fifth month, on the eycbrows and face, and especially round the mouth, where it is much longer than that on the head. A moustache of this kind was observed by Eschricht on a female foetus; but this is not so surprising a circumstance as it may at first appear, for the two sexes generally resemble each other in all external characters during an early period of growth. The direction and arrangement of the hairs on all parts of the foetal body are the same as in the adult, but are subject to much variability. The whole surface, including even the forehead and ears, is thus thickly clothed; but it is a significant fact that the palms of the hands and the soles of the feet are quite naked, like the inferior surfaces of all four extremities in most of the lower animals. As this can hardly be an accidental coincidence, the woolly covering of the foetus probably represents the first permanent coat of hair in those mammals which are born hairy. Three or four cases have been recorded of persons born with their whole bodies and faces thickly covered with fine long hairs; and this strange condition is strongly inherited, and is correlated with an abnormal condition of the teeth. Prof. Alex. Brandt informs me that he has compared the hair from the face of a man thus characterised, aged thirty-five, with the lanugo of a foetus, and finds it quite similar in texture; therefore, as he remarks, the case may be attributed to an arrest of development in the hair, together with its continued growth.

It appears as if the posterior molar or wisdom-teeth were tending to become rudimentary in the more civilised races of man. These teeth are rather smaller than the other molars, as is likewise the case with the corresponding teeth in the chimpanzee and orang; and they have only two separate fangs. They do not cut through the gums till about the seventeenth year, and I have been assured that they are much more liable to decay, and are earlier lost than the other teeth; but this is denied by some eminent dentists. They are also much more liable to vary, both in structure and in the period of their development, than the other teeth. In the Melanian races, on the other hand, the wisdom-teeth are usually furnished with three separate fangs, and are generally sound; they also differ from the other molars in size, less than in the Caucasian races. Prof. Schaaffhausen accounts for this difference between the races by "the posterior dental portion of the jaw being always shortened" in those that are civilised, and this short- 
ening may, I presume, be attributed to civilised men habitually feeding on soft, cooked food, and thus using their jaws less.

With respect to the alimentary canal, I have met with an account of only a single rudiment, namely the vermiform appendage of the caecum. The caecum is a branch or diverticulum of the intestine, ending in a cul-de-sac, and is extremely long in many of the lower vegetable-feeding mammals. In the marsupial koala it is actually more than thrice as long as the whole body. It is sometimes produced into a long gradually-tapering point, and is sometimes constricted in parts. It appears as if, in consequence of changed diet or habits, the caecum had become much shortened in various animals, the vermiform appendage being left as a rudiment of the shortened part. That this appendage is a rudiment, we may infer from its small size, and from the evidence which Prof. Canestrini has collected of its variability in man. It is occasionally quite absent, or again is largely developed. The passage is sometimes completely closed for half or two-thirds of its length, with the terminal part consisting of a flattened solid expansion. In the orang this appendage is long and convoluted: in man it arises from the end of the short caecum, and is commonly from four to five inches in length, being only about the third of an inch in diameter. Not only is it useless, but it is sometimes the cause of death, of which fact I have lately heard two instances: this is due to small hard bodies, such as seeds, entering the passage, and causing inflammation.

In man, the os coccyx, together with certain other vertebrae hereafter to be described, though functionless as a tail, plainly represent this part in other vertebrate animals. At an early embryonic period it is free, and projects beyond the lower extremities of a human embryo. Even after birth it has been known, in certain rare and anomalous cases, to form a small external rudiment of a tail. The os coccyx is short, usually including only four vertebrae, all anchylosed together: and these are in a rudimentary condition, for they consist, with the exception of the basal one, of the centrum alone. They are furnished with some small muscles; one of which, as I an informed by Prof. Turner, has been expressly described by Theile as a rudimentary repetition of the extensor of the tail, a muscle which is so largely developed in many mammals.

The spinal cord in man extends only as far downwards as the last dorsal or first lumbar vertebra; but a thread-like structure (the filum terminale) runs down the axis of the sacral part of the spinal canal, and even along the back of the coccygeal bones. The upper part of this filament, as Prof. Turner informs me, is undoubtedly homologous with the spinal cord, but the lower part apparently consists merely of the pia mater, or vascular investing membrane. Even in this case the os coccyx may be said to possess a vestige of so important a structure as the spinal cord, though no longer enclosed within a bony canal. 
The reproductive system offers various rudimentary structures; but these differ in one important respect from the foregoing cases. Here we are not concerned with the vestige of a part which does not belong to the species in an efficient state, but with a part efficient in the one sex, and represented in the other by a mere rudiment. Nevertheless, the occurrence of such rudiments is as difficult to explain, on the belief of the separate creation of each species, as in the foregoing cases. Hereafter I shall have to recur to these rudiments, and shall shew that their presence generally depends merely on inheritance, that is, on parts acquired by one sex having been partially transmitted to the other. I will in this place only give some instances of such rudiments. It is well known that in the males of all mammals, including man, rudimentary mammae exist. These in several instances have become well developed, and have yielded a copious supply of milk. Their essential identity in the two sexes is likewise shewn by their occasional sympathetic enlargement in both during an attack of the measles. The vesicula prostatica, which has been observed in many male mammals, is now universally acknowledged to be the homologue of the female uterus, together with the connected passage. It is impossible to read Leuckart's able description of this organ, and his reasoning, without admitting the justness of his conclusion. This is especially clear in the case of those mammals in which the true female uterus bifurcates, for in the males of these the vesicula likewise bifurcates.

The bearing of the three great classes of facts now given is unmistakable. But it would be superfluous fully to recapitulate the line of argument given in detail in my Origin of Species. The homological construction of the whole frame in the members of the same class is intelligible, if we admit their descent from a common progenitor, together with their subsequent adaptation to diversified conditions. On any other view, the similarity of pattern between the hand of a man or monkey, the foot of a horse, the flipper of a seal, the wing of a bat, \&c., is utterly inexplicable. It is no scientific explanation to assert that they have all been formed on the same ideal plan. With respect to development, we can clearly understand, on the principle of variations supervening at a rather late embryonic period, and being inherited at a corresponding period, how it is that the embryos of wonderfully different forms should still retain, more or less perfectly, the structure of their common progenitor. No other explanation has ever been given of the marvellous fact that the embryos of a man, dog, seal, bat, reptile, etc., can at first hardly be distinguished from each other. In order to understand the existence of rudimentary organs, we have only to suppose that a former progenitor possessed the parts in question in a perfect state, and that under changed habits of life they became greatly reduced, either from simple disuse, or through the natural selection of those individuals which were least encumbered with a superfluous part, aided by the other means previously indicated. 
Thus we can understand how it has come to pass that man and all other vertebrate animals have been constructed on the same general model, why they pass through the same early stages of development, and why they retain certain rudiments in common. Consequently we ought frankly to admit their community of descent; to take any other view, is to admit that our own structure, and that of all the animals around us, is a mere snare laid to entrap our judgment. This conclusion is greatly strengthened, if we look to the members of the whole animal series, and consider the evidence derived from their affinities or classification, their geographical distribution and geological succession. It is only our natural prejudice, and that arrogance which made our forefathers declare that they were descended from demi-gods, which leads us to demur to the conclusion. But the time will before long come, when it will be thought wonderful that naturalists, who were well acquainted with the comparative structure and development of man, and other mammals, should have believed that each was the work of a separate act of creation.

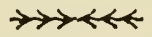

\section{ON THE RELATIONS OF MAN TO THE LOWER ANIMALS *}

\section{THO M A H . H U X L E Y}

The question of questions for mankind-the problem which underlies all others, and is more deeply interesting than any other-is the ascertainment of the place which Man occupies in nature and of his relations to the universe of things. Whence our race has come; what are the limits of our power over nature, and of nature's power over us; to what goal we are tending; are the problems which present themselves anew and with undiminished interest to every man born into the world. Most of us shrinking from the difficulties and dangers which beset the seeker after original answers to these riddles, are contented to ignore them altogether, or to smother the investigating spirit under the featherbed of respected and respectable tradition. But, in every age, one or two restless spirits, blessed with that constructive genius, which can only build on a secure foundation, or cursed with the mere spirit of scepticism, are unable to follow in the well-worn and comfortable trace of their forefathers and contemporaries, and unmindful of thorns and stumbling-blocks, strike out into paths of their own. The sceptics end in the infidelity which asserts the problem to be insoluble, or in the atheism which denies the existence of any orderly progress and governance of things: the men of genius pro-

* From Evidence as to Man's Place in Nature by Thomas H. Huxley. D. Appleton Co., New York. 1871 . 
pound solutions which grow into systems of Theology or of Philosophy, or veiled in musical language which suggests more than it asserts, take the shape of the Poetry of an epoch.

Each such answer to the great question, invariably asserted by the followers of its propounder, if not by himself, to be complete and final, remains in high authority and esteem, it may be for one century, or it may be for twenty: but, as invariably, Time proves each reply to have been a mere approximation to the truth-tolerabie chiefly on account of the ignorance of those by whom it was accepted, and wholly intolerable when tested by the larger knowledge of their successors.

In a well-worn metaphor, a parallel is drawn between the life of man and the metamorphosis of the caterpillar into the butterfly; but the comparison may be more just as well as more novel, if for its former term we take the mental progress of the race. History shows that the human mind, fed by constant accessions of knowledge, periodically grows too large for its theoretical coverings, and bursts them asunder to appear in new habiliments, as the feeding and growing grub, at intervals, casts its too narrow skin and assumes another, itself by temporary. Truly the imago state of Man seems to be terribly distant, but every moult is a step gained, and of such there have been many.

Since the revival of learning, whereby the Western races of Europe were enabled to enter upon that progress towards true knowledge, which was commenced by the philosophers of Greece, but was almost arrested in subsequent long ages of intellectual stagnation, or, at most, gyration, the human larva has been feeding vigorously and moulting in proportion. A skin of some dimension was cast in the 16 th century, and another towards the end of the $18 \mathrm{th}$, while, within the last fifty years, the extraordinary growth of every department of physical science has spread among us mental food of so nutritious and stimulating a character that a new ecdysis seems imminent. But this is a process not unusually accompanied by many throes and some sickness and debility, or, it may be, by graver disturbances; so that every good citizen must feel bound to facilitate the process, and even if he have nothing but a scalpel to work withal, to ease the cracking integument to the best of his ability.

The importance of such an inquiry is indeed intuitively manifest. Brought face to face with these blurred copies of himself, the least thoughtful of men is conscious of a certain shock, due, perhaps, not so much to disgust at the aspect of what looks like an insulting caricature, as to the awakening of a sudden and profound mistrust of time-honoured theories and strongly-rooted prejudices regarding his own position in nature, and his relations to the under-world of life; while that which remains a dim suspicion for the unthinking, becomes a vast argument fraught with the deepest consequences, for all who are acquainted with the recent progress of the anatomical and physiological sciences. 
I now propose briefly to unfold that argument, and to set forth, in a form intelligible to those who possess no special acquaintance with anatomical science, the chief facts upon which all conclusions respecting the nature and the extent of the bonds which connect man with the brute world must be based: I shall then indicate the one immediate conclusion which, in my judgment, is justified by those facts, and I shall finally discuss the bearing of that conclusion upon the hypotheses which have been entertained respecting the Origin of Man.

The facts to which I would first direct the reader's attention, though ignored by many of the professed instructors of the public mind, are easy of demonstration and are universally agreed to by men of science; while their significance is so great, that whoso has duly pondered over them will, I think, find little to startle him in the other revelations of Biology. I refer to those facts which have been made known by the study of Development.

It is a truth of very wide, if not of universal application, that every living creature commences its existence under a form different from, and simpler than, that which it eventually attains.

The oak is a more complex thing than the little rudimentary plant contained in the acorn; the caterpillar is more complex than the egg; the butterfly than the caterpillar; and each of these beings, in passing from its rudimentary to its perfect condition, runs through a series of changes, the sum of which is called its Development. In the higher animals these changes are extremely complicated; but, within the last century, the labours of such men as Von Baer, Rathke, Reichert, Bischof, and Remak, have almost completely unravelled them, so that the successive states of development which are exhibited by a Dog, for example, are now as well known to the embryologist as are the steps of the metamorphosis of the silk-worm moth to the school-boy. It will be useful to consider with attention the nature and the order of the stages of canine development, as an example of the process in the higher animals generally.

The Dog, like all animals, save the very lowest (and further inquiries may not improbably remove the apparent exception), commences its existence as an egg: as a body which is, in every sense, as much an egg as that of a hen, but is devoid of that accumulation of nutritive matter which confers upon the bird's egg its exceptional size and domestic utility; and wants the shell, which would not only be useless to an animal incubated within the body of its parent, but would cut it off from access to the source of that nutriment which the young creature requires, but which the minute egg of the mammal does not contain within itself.

The Dog's egg is, in fact, a little spheroidal bag, formed of a delicate transparent membrane called the vitelline membrane, and about $1 / 130^{\text {th }}$ to 
$1 / 120$ th of an inch in diameter. It contains a mass of viscid nutritive matter - the yelk-within which is inclosed a second much more delicate spheroidal bag, called the germinal vesicle. In this, lastly, lies a more solid rounded body, termed the germinal spot.

The egg or Ovum, is originally formed within a gland, from which, in due season, it becomes detached, and passes into the living chamber fitted for its protection and maintenance during the protracted process of gestation. Here, when subjected to the required conditions, this minute and apparently insignificant particle of living matter, becomes animated by a new and mysterious activity. The germinal vesicle and spot cease to be discernible (their precise fate being one of the yet unsolved problems of embryology), but the yelk becomes circumferentially indented, as if an invisible knife had been drawn round it, and thus appears divided into two hemispheres.

By the repetition of this process in various planes, these hemispheres become subdivided, so that four segments are produced; and these, in like manner, divide and subdivide again, until the whole yelk is converted into a mass of granules, each of which consists of a minute spheroid of yelksubstance, inclosing a central particle, the so-called nucleus. Nature, by this process, has attained much the same result as that at which a human artificer arrives by his operations in a brick field. She takes the rough plastic material of the yelk and breaks it up into well-shaped tolerably even-sized masses-handy for building up into any part of the living edifice.

Next, the mass of organic bricks, or cells as they are technically called, thus formed, acquires an orderly arrangement, becoming converted into a hollow spheroid with double walls. Then, upon one side of this spheroid, appears a thickening, and, by and by, in the centre of the area of thickening, a straight shallow groove marks the central line of the edifice which is to be raised, or, in other words, indicates the position of the middle line of the body of the future dog. The substance bounding the groove on each side next rises up into a fold, the rudiment of the side wall of that long cavity, which will eventually lodge the spinal marrow and the brain; and in the floor of this chamber appears a solid cellular cord, the so-called notochord. One end of the inclosed cavity dilates to form the head, the other remains narrow, and eventually becomes the tail; the side walls of the body are fashioned out of the downward continuation of the walls of the groove; and from them, by and by, grow out little buds which, by degrees, assume the shape of limbs. Watching the fashioning process stage by stage, one is forcibly reminded of the modeller in clay. Every part, every organ, is at first, as it were, pinched up rudely, and sketched out in the rough; then shaped more accurately, and only, at last, receives the touches which stamp its final character.

Thus, at length, the young puppy assumes such a form. In this condi- 
tion it has a disproportionately large head, as dissimilar to that of a dog as the bud-like limbs are unlike his legs.

The remains of the yelk, which have not yet been applied to the nutrition and growth of the young animal, are contained in a sac attached to the rudimentary intestine, and termed the yelk sac, or umbilical vesicle. Two membranous bags, intended to subserve respectively the protection and nutrition of the young creature, have been developed from the skin and from the under and hinder surface of the body, the former, the socalled amnion, is a sac filled with fluid, which invests the whole body of the embryo, and plays the part of a sort of water-bed for it; the other, termed the allantois, grows out, loaded with blood-vessels, from the ventral region, and eventually applying itself to the walls of the cavity, in which the developing organism is contained, enables these vessels to become the channel by which the stream of nutriment, required to supply the wants of the offspring, is furnished to it by the parent.

The structure which is developed by the interlacement of the vessels of the offspring with those of the parent, and by means of which the former is enabled to receive nourishment and to get rid of effete matters, is termed the placenta.

It would be tedious, and it is unnecessary for my present purpose, to trace the process of development further; suffice it to say, that, by a long and gradual series of changes, the rudiment here depicted and described, becomes a puppy, is born, and then, by still slower and less perceptible steps passes into the adult Dog.

There is not much apparent resemblance between a barn-door Fowl and the Dog who protects the farm-yard. Nevertheless the student of development finds, not only that the chick commences its existence as an egg, primarily identical, in all essential respects, with that of the Dog, but that the yelk of this egg undergoes division-that the primitive groove arises, and that the contiguous parts of the germ are fashioned, by precisely similar methods, into a young chick, which, at one stage of its existence, is so like the nascent Dog, that ordinary inspection would hardly distinguish the two.

The history of the development of any other vertebrate animal, Lizard, Snake, Frog, or Fish, tells the same story. There is always, to begin with, an egg having the same essential structure as that of the Dog:-the yelk of that egg always undergoes division, or segmentation as it is often called: the ultimate products of that segmentation constitute the building materials for the body of the young animal; and this is built up round a primitive groove, in the floor of which a notochord is developed. Furthermore, there is a period in which the young of all these animals resemble one another, not merely in outward form, but in all essentials of structure, so closely, that the differences between them are inconsiderable, while, 
in their subsequent course, they diverge more and more widely from one another. And it is a general law, that, the more closely any animals resemble one another in adult structure, the longer and the more intimately do their embryos resemble one another; so that, for example, the embryos of a Snake and of a Lizard remain like one another longer than do those of a Snake and of a Bird; and the embryo of a Dog and of a Cat remain like one another for a far longer period than do those of a Dog and a Bird; or of a Dog and an Opossum; or even than those of a Dog and a Monkey.

Thus the study of development affords a clear test of closeness of structural affinity, and one turns with impatience to inquire what results are yielded by the study of the development of Man. Is he something apart? Does he originate in a totally different way from Dog, Bird, Frog, and Fish, this justifying those who assert him to have no place in nature and no real affinity with the lower world of animal life? Or does he originate in a similar germ, pass through the same slow and gradually progressive modifications, - depend on the same contrivances for protection and nutrition, and finally enter the world by the help of the same mechanism? The reply is not doubtful for a moment, and has not been doubtful any time these thirty years. Without question, the mode of origin and the early stages of the development of man are identical with those of the animals immediately below him in the scale:-without a doubt, in these respects, he is far nearer the Apes, than the Apes are to the Dog.

The Human ovum is about $1 / 125$ of an inch in diameter, and might be described in the same terms as that of the Dog. It leaves the organ in which it is formed in a similar fashion and enters the organic chamber prepared for its reception in the same way, the conditions of its development being in all respects the same. It has not yet been possible (and only by some rare chance can it ever be possible) to study the human ovum in so early a developmental stage as that of yelk division, but there is every reason to conclude that the changes it undergoes are identical with those exhibited by the ova of other vertebrated animals; for the formative materials of which the rudimentary human body is composed, in the earliest conditions in which it has been observed, are the same as those of other animals.

Indeed, it is very long before the body of the young human being can be readily discriminated from that of the young puppy; but, at a tolerably early period, the two become distinguishable by the different form of their adjuncts, the yelk-sac and the allantois. The former, in the Dog, becomes long and spindle-shaped, while in Man it remains spherical: the latter, in the Dog, attains an extremely large size, and the vascular processes which are developed from it and eventually give rise to the formation of the placenta (taking root, as it were, in the parental organism, so as to draw nourishment therefrom, as the root of a tree extracts it from the soil) 
are arranged in an encircling zone, while in Man, the allantois remains comparatively small, and its vascular rootlets are eventually restricted to one disk-like spot. Hence, while the placenta of the Dog is like a girdle, that of Man has the cake-like form, indicated by the name of the organ.

But, exactly in those respects in which the developing Man differs from the Dog, he resembles the Ape, which, like man, has a spheroidal yelk-sac and a discoidal-sometimes partially lobed-placenta.

So that it is only quite in the later stages of development that the young human being presents marked differences from the young ape, while the latter departs as much from the dog in its development as the man does.

Startling as the last assertion may appear to be, it is demonstrably true, and it alone appears to me sufficient to place beyond all doubt the structural unity of man with the rest of the animal world, and more particularly and closely with the apes.

Thus, identical in the physical processes by which he originates-identical in the early stages of his formation-identical in the mode of his nutrition before and after birth, with the animals which lie immediately below him in the scale-Man, if his adult and perfect structure be compared with theirs, exhibits, as might be expected, a marvellous likeness of organization. He resembles them as they resemble one another-he differs from them as they differ from one another. And, though these differences and resemblances cannot be weighed and measured, their value may be readily estimated; the scale or standard of judgment, touching that value, being afforded and expressed by the system of classification of animals now current among zoologists.

It is quite certain that the Ape which most nearly approaches man, in the totality of its organization, is either the Chimpanzee or the Gorilla; and as it makes no practical difference, for the purposes of my present argument, which is selected for comparison, on the one hand, with Man, and on the other hand, with the rest of the Primates, ${ }^{1}$ I shall select the latter (so far as its organization is known) - as a brute now so celebrated in prose and verse, that all must have heard of him, and have formed some conception of his appearance. I shall take up as many of the most important points of difference between man and this remarkable creature, as the space at my disposal will allow me to discuss, and the necessities of the argument demand; and I shall inquire into the value and magnitude of these differences, when placed side by side with those which separate the Gorilla from other animals of the same order.

In the general proportions of the body and limbs there is a remarkable difference between the Gorilla and Man, which at once strikes the eye.

1 We are not at present thoroughly acquainted with the brain of the Gorilla, and therefore, in discussing cerebral characters, I shall take that of the Chimpanzee as my highest term among the Apes. 
The Gorilla's brain-case is smaller, its trunk larger, its lower limbs shorter, its upper limbs longer in proportion than those of Man.

I find that the vertebral column of a full grown Gorilla, in the Museum of the Royal College of Surgeons, measures 27 inches along its anterior curvature, from the upper edge of the atlas, or first vertebra of the neck, to the lower extremity of the sacrum; that the arm, without the hand, is $31 \frac{1}{2}$ inches long; that the leg, without the foot, is $261 / 2$ inches long; that the hand is $93 / 4$ inches long; the foot $11 \frac{1}{4}$ inches long.

In other words, taking the length of the spinal column as 100 , the arm equals 115 , the leg 96 , the hand 36 , and the foot 41 .

In the skeleton of a male Bosjesman, in the same collection, the proportions, by the same measurement, to the spinal column, taken as 100 , are -the $\operatorname{arm} 78$, the leg 110 , the hand 26 , and the foot 32 . In a woman of the same race the arm is 83 , and the leg 120 , the hand and foot remaining the same. In a European skeleton I find the arm to be 80 , the leg 117 , the hand 26 , the foot 35 .

Thus the leg is not so different as it looks at first sight, in its proportions to the spine in the Gorilla and in the Man-being very slightly shorter than the spine in the former, and between $1 / 10$ and $1 / 5$ longer than the spine in the latter. The foot is longer and the hand much longer in the Gorilla; but the great difference is caused by the arms, which are very much longer than the spine in the Gorilla, very much shorter than the spine in the Man.

The question now arises how are the other Apes related to the Gorilla in these respects-taking the length of the spine, measured in the same way, at 100 . In an adult Chimpanzee, the arm is only 96, the leg 9o, the hand 43 , the foot 39-so that the hand and the leg depart more from the human proportion and the arm less, while the foot is about the same as in the Gorilla.

In the Orang, the arms are very much longer than in the Gorilla (122), while the legs are shorter (88); the foot is longer than the hand ( 52 and 48 ), and both are much longer in proportion to the spine.

In the other man-like Apes again, the Gibbons, these proportions are still further altered; the length of the arms being to that of the spinal column as 19 to 11 ; while the legs are also a third longer than the spinal column, so as to be longer than in Man, instead of shorter. The hand is half as long as the spinal column, and the foot, shorter than the hand, is about $5 / 1$ ths of the length of the spinal column.

Thus Hylobates is as much longer in the arms than the Gorilla, as the Gorilla is longer in the arms than Man; while, on the other hand, it is as much longer in the legs than the Man, as the Man is longer in the legs than the Gorilla, so that it contains within itself the extremest deviations from the average length of both pairs of limbs.

The Mandrill presents a middle condition, the arms and legs being nearly equal in length, and both being shorter than the spinal column; while hand 
and foot have nearly the same proportions to one another and to the spine, as in Man.

In the Spider monkey (Ateles) the leg is longer than the spine, and the arm than the leg; and, finally, in that remarkable Lemurine form, the Indri, (Lichanotus) the leg is about as long as the spinal column, while the arm is not more than $11 / 1$ sths of its length; the hand having rather less and the foot rather more, than one third the length of the spinal column.

These examples might be greatly multiplied, but they suffice to show that, in whatever proportion of its limbs the Gorilla differs from Man, the other Apes depart still more widely from the Gorilla and that, consequently, such differences of proportion can have no ordinal value.

But now let us turn to a nobler and more characteristic organ-that by which the human frame seems to be and indeed is, so strongly distinguished from all others, - I mean the skull. The differences between a Gorilla's skull and a Man's are truly immense. In the former, the face, formed largely by the massive jaw-bones, predominates over the brain case, or cranium proper: in the latter, the proportions of the two are reversed. In the Man, the occipital foramen, through which passes the great nervous cord connecting the brain with the nerves of the body, is placed just behind the centre of the base of the skull, which thus becomes evenly balanced in the erect posture; in the Gorilla it lies in the posterior third of that base. In the Man, the surface of the skull is comparatively smooth, and the supraciliary ridges or brow prominences usually project but little-while, in the Gorilla, vast crests are developed upon the skull, and the brow ridges overhang the cavernous orbits, like great penthouses.

Sections of the skulls, however, show that some of the apparent defects of the Gorilla's cranium arise, in fact, not so much from deficiency of brain case as from excessive development of the parts of the face. The cranial cavity is not ill-shaped, and the forehead is not truly flattened or very retreating, its really well-formed curve being simply disguised by the mass of bone which is built up against it.

But the roofs of the orbits rise more obliquely into the cranial cavity, thus diminishing the space for the lower part of the anterior lobes of the brain, and the absolute capacity of the cranium is far less than that of Man. So far as I am aware, no human cranium belonging to an adult man has yet been observed with a less cubical capacity than 62 cubic inches, the smallest cranium observed in any race of men by Morton, measuring $6_{3}$ cubic inches: while, on the other hand, the most capacious Gorilla skull yet measured has a content of not more than $34^{1 / 2}$ cubic inches. Let us assume, for simplicity's sake, that the lowest Man's skull has twice the capacity of the highest Gorilla.

No doubt, this is a very striking difference, but it loses much of its apparent systematic value, when viewed by the light of certain other equally indubitable facts respecting cranial capacities. 
The first of these is, that the difference in the volume of the cranial cavity of different races of mankind is far greater, absolutely, than that between the lowest Man and the highest Ape, while relatively, it is about the same. For the largest human skull measured by Morton contained 114 cubic inches, that is to say, had very nearly double the capacity of the smallest; while its absolute preponderance, of 52 cubic inches-is far greater than that by which the lowest adult male human cranium surpasses the largest of the Gorillas $\left(62-34^{1 / 2}=27 \frac{1}{2}\right)$. Secondly, the adult crania of Gorillas which have as yet been measured differ among themselves by nearly one-third, the maximum capacity being 34.5 cubic inches, the minimum 24 cubic inches; and, thirdly, after making all due allowance for difference of size, the cranial capacities of some of the lower Apes fall nearly as much, relatively, below those of the higher Apes as the latter fall below Man.

Thus, even in the important matter of cranial capacity, Men differ more widely from one another than they do from the Apes; while the lowest Apes differ as much, in proportion, from the highest, as the latter does from Man. The last proposition is still better illustrated by the study of the modifications which other parts of the cranium undergo in the Simian series.

It is the large proportional size of the facial bones and the great projection of the jaws which confers upon the Gorilla's skull its small facial angle and brutal character.

But if we consider the proportional size of the facial bones to the skull proper only, the little Chrysotbrix * differs very widely from the Gorilla, and in the same way as Man does; while the Baboons (Cynocephalus) exaggerate the gross proportions of the muzzle of the great Anthropoid, so that its visage looks mild and human by comparison with theirs. The difference between the Gorilla and the Baboon is even greater than it appears at first sight; for the great facial mass of the former is largely due to a downward development of the jaws; an essentially human character, superadded upon that almost purely forward, essentially brutal, development of the same parts which characterizes the Baboon, and yet more remarkably distinguishes the Lemur.

Similarly the occipital foramen of the Lemurs is situated completely in the posterior face of the skull, or as much further back than that of the Gorilla, as that of the Gorilla is further back than that of Man; while, as if to render patent the futility of the attempt to base any broad classificatory distinction on such a character, the same group of Platyrrhine, or American monkeys, contains the Chrysotbrix, whose occipital foramen is situated far more forward than in any other ape, and nearly approaches the position it holds in Man.

Again, the Orang's skull is as devoid of excessively developed supraciliary prominences as a Man's, though some varieties exhibit great crests

\footnotetext{
- Squirrel monkey.-Ed.
} 
elsewhere and in some of the Cebine apes and in the Chrysotbrix, the cranium is as smooth and rounded as that of Man himself.

What is true of these leading characteristics of the skull, holds good, as may be imagined, of all minor features; so that for every constant difference between the Gorilla's skull and the Man's, a similar constant difference of the same order (that is to say, consisting in excess or defect of the same quality) may be found between the Gorilla's skull and that of some other ape. So that, for the skull, no less than for the skeleton in general, the proposition holds good, that the differences between Man and the Gorilla are of smaller value than those between the Gorilla and some other Apes.

Whatever part of the animal fabric-whatever series of muscles, whatever viscera might be selected for comparison-the result would be the same-the lower Apes and the Gorilla would differ more than the Gorilla and the Man. I cannot attempt in this place to follow out all these comparisons in detail, and indeed it is unnecessary I should do so. But certain real, or supposed, structural distinctions between man and the apes remain, upon which so much stress has been laid, that they require careful consideration, in order that the true value may be assigned to those which are real, and the emptiness of those which are fictitious may be exposed. I refer to the characters of the hand, the foot, and the brain.

Man has been defined as the only animal possessed of two hands terminating his fore limbs, and of two feet ending his hind limbs, while it has been said that all the apes possess four hands; and he has been affirmed to differ fundamentally from all the apes in the characters of his brain, which alone, it has been strangely asserted and reasserted, exhibits the structures known to anatomists as the posterior lobe, the posterior cornu of the lateral ventricle and the hippocampus minor.

That the former proposition should have gained general acceptance is not surprising-indeed, at first sight, appearances are much in its favour: but, as for the second, one can only admire the surpassing courage of its enunciator, seeing that it is an innovation which is not only opposed to generally and justly accepted doctrines, but which is directly negatived by the testimony of all original inquirers, who have specially investigated the matter: and that it neither has been, nor can be, supported by a single anatomical preparation. It would, in fact, be unworthy of serious refutation, except for the general and natural belief that deliberate-and reiterated assertions must have some foundation.

Thus, whatever system of organs be studied, the comparison of their modifications in the ape series leads to one and the same result-that the structural differences which separate Man from the Gorilla and the Chimpanzee are not so great as those which separate the Gorilla from the lower apes.

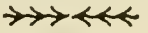




\section{III \\ Life and the Cell}

$\mathrm{H}^{\mathrm{OR}}$ thousands of years mankind was unaware of the intricate detail F existing in the organic world. No doubt, thoughtful scientists sensed, in a very real way, the unexplored universe to be revealed later by the microscope and chaffed at the optical limitations of the human eye.

Our entire concepts regarding the continuity of life, of function, of reproduction and other topics are bound up with and verified by the tremendous wealth of data revealed by the specially-shaped disks of glass in our light microscopes and, lately, by the streams of electrons loosed by the sensational electron microscope.

When Hooke and Leeuwenhoek first saw the cells of cork and the bacterial cell respectively, in the seventeenth century, the great search for the constitution of matter and, indeed, for the mystery of life, had begun in earnest. It was two hundred years later, however, before enough evidence had been collected to warrant the theory that all organisms were composed of cells. Once this theory was accepted, progress seemed to come faster. The nucleus, the chromosomes, the cytoplasm, the other cell bodies were examined and the wonderful stories connected with cell division and later reduction division were pieced together. These studies in turn made possible an understanding of the importance of the chromosomes in carrying factors for inheritance, the assortment of genes, chromosome changes resulting in mutations and other fundamental concepts.

Man has always been interested in his origin and numerous theories have been set forth, some with rather unconvincing assurance. It seems impossible to many that such a highly organized structure as the cell could have evolved from inorganic materials. Man's many futile attempts to duplicate life are a subject of ridicule to the uninitiated. The layman must always realize that the hardest riddles take the longest time to solve and, in terms of biological history, we have scarcely started grappling with the problem. Most scientists feel confident that some generation, in the nottoo-distant future, will have all the necessary factors at hand to answer the riddle of life itself. We also feel confident that once this is solved, several other as-yet unknown problems will arise to perplex them. The true scientists are never perturbed at the thought that their contributions are but bricks in the foundation. Science grows by insistent curiosity and incessant hopefulness. 


\section{"WHENCE COMETH LIFE?" *}

\section{W I L L I S R . H U N T}

Philosophers have for ages attempted to explain life and death and to determine where one leaves off and the other begins. Present-day scientists are continuing to investigate this burning question.

Maybe the turning point is where the protein-building catalyst or enzyme first appears. Although it is non-living itself, it no doubt is the precursor of life, that is, it precedes and gives intimation of the coming of life. Possibly the most primitive living unit may be the gene. Have any of you ever seen a gene? No! It can not be seen even by the ultra microscope, but if we are to account for the hereditary behavior of protoplasm we must postulate invisible genes. Genes, as you remember, are the units or atoms of heredity. Other assumptions are that the viruses or bacteriophages may be the most elementary predator or form of life.

It will not be possible to say just where or how life first appears, but some evidence can now be given that the genes and the viruses are at the boundary or border line of life.

Like life the origin of disease has been subject to many theories and much speculation down through the ages. Primitive peoples believed that evil spirits caused disease. In the Middle Ages invisible particles were thought to be the cause. Bacteria were not even seen until the middle of the seventeenth century, and were only proven to be the cause of disease about sixty years ago.

It has been estimated that there are seven hundred and forty-two living agents causing disease in man. Thirty-one are ascribed to a something, called a virus. There are some forty more viruses causing disease in the lower animals, fowls, insects, fishes and plants. Examples of some virus diseases, to mention a few, are smallpox, rabies, parrot fever, yellow fever, herpes, mumps, measles, infantile paralysis, warts, epidemic influenza and the common cold. Distemper of dogs, foulpox, cowpox, swinepox, jaundice of silkworms and the so-called mosaic diseases of the tobacco, potato and the tomato plants are examples of virus diseases in other groups of organisms.

Just what the nature and properties of these "mysterious purveyors of disease" are has been one of medicine's and bacteriology's greatest problems. Up to recently the following three questions had not been answered: (1) Are viruses animate or inanimate? (2) Are they ultramicroscopic entities related to bacteria? (3) Do they represent inanimate chemical principles like catalysts or enzymes, for example, pepsin, an organic enzyme, which stimulates digestive changes in the stomach?

- Reprinted by permission of the Scientific Montbly, American Association for the Advancement of Science. Copyright 1938. 
We may define a virus as an infective agent below the size limit of microscopic determination which passes through the finest made filters. They are obligate parasites: no saprophytic forms are known. This is not surprising, is it, since symptons are the only nieans of recognizing them? They can not grow and multiply in artificial culture media, but in tissue culture, specific for the virus, the infective agent has been developed. For immunization viruses are propagated by serial injection of animals. Their behavior is very much like that of a living organism.

An open mind is necessary in regard to the nature of viruses. One of the smallest known viruses causes foot and mouth disease. It is only large enough to hold a few dozen protein molecules. Is this consistent with life? Would it be consistent if smaller viruses were discovered? Does not their minute size preclude their being alive? It must be remembered that no virus has a characteristic form or the ability to assimilate lifeless matter. Are not form and assimilation two of the chief attributes of life? These questions can not be answered, for we do not know whether there is a definite boundary line between the living and the non-living.

As a virus is dependent on living cells for its development, does not this suggest that they may be derivatives of those cells, an enzyme or catalyst, for example? Catalysts effect a chemical change. The viruses then may have the peculiar property of stimulating healthy normal cells to reproduce more virus substance. The living characteristics that are possessed by a virus are shown only when the virus is associated with living tissue, namely, metabolic assimilation of heterogeneous substances, adaptation and reproduction.

On the other hand, the principles of proof that a particular species of living organism is the cause of a specific disease is stated in Koch's postulates. First, the causal organism must be found in all cases of the disease; secondarily, it must be grown in successive pure cultures outside the body; thirdly, the cultures must be able to reproduce the disease in susceptible laboratory animals or plants, and lastly, the organism must be recovered from the artificially infected host in pure culture. No doubt if viruses were living they would follow these postulates. They do not satisfy number two, namely, cultivation outside the tissue of the host.

Most of the knowledge about viruses has been gained through the study of tobacco mosaic virus. It is the oldest known. It was first described in 1857 , but its filterability was not discovered until 1892 . It was then discovered that the extracted juice of a tobacco plant affected with mosaic would infect a healthy plant if placed into its tissues or rubbed onto the leaf hairs, even after it had been filtered through a Chamberland filter.

Tobacco mosaic is the most infectious of all virus diseases. Even when dried and ground into a powder, diseased leaves will still have the property of infectability after months of desiccation. The virus may be extracted by ether, chloroform, carbon tetrachloride, toluene or acetone without 
any destruction of its infective properties. An infinitive amount of the virus will increase many times over when inoculated into a normal plant.

The symptoms of a diseased plant are the mottling of the leaves due to alternating patches or spots of light green or yellow, and dark green, but under certain conditions the mottling may be masked.

In 192 I a new concept of the nature of the tobacco mosaic was suggested. The substance of this concept was that it was a product of the host cell, a gene, perhaps, that has revolted from the shackles of coordination, and having the property of reproduction, continued to produce disease only in the living plant cells.

As tobacco mosaic virus is the most outstanding in having properties which are easily worked with, as stated above, and as it is typical and representative of all viruses it has been experimented with extensively. Countless numbers of tobacco plants have been grown and infected artificially. The diseased plants after a certain time were ground up, pressed and the tobacco juice containing the virus extracted. Protoplasm, in general, contains proteins, fats and carbohydrates. Certain enzymes are protein splitters or digesters. Proteolytic pepsin, as noted before, is an organic protein digester. This enzyme was added to some of the plant juices in a test-tube and kept under suitable conditions to see if it would act on the virus. After a certain length of time a small amount of the solution was rubbed on the leaves of some healthy plants. No infection resulted after repeated tests, as the protein causing the disease had been digested. Pepsin is specific in its action; it will not act on fats, carbohydrates, hydrocarbons or salts. Therefore a sound conclusion that the virus is protein in nature can be made.

Certain chemicals such as ammonium sulfate or dilute alcohol will precipitate proteins. They were added to some of the diseased tobacco juice to which pepsin had not been added. A solid precipitate was thrown down. A bit of the supernatant fluid was rubbed on healthy leaves. No infection resulted. A different picture was represented when a neutral liquid, as water, was added to the precipitate and it was dissolved and then rubbed on normal leaves. Diseased plants resulted. These two experiments proved without doubt that the infective agent resided in the protein molecules.

To further prove the nature of the virus, the precipitate was again dissolved in a neutral liquid and ammonium sulfate compound was added. Crystals were formed from the solution. These crystals were refined by ten successive fractionations and recrystallizations. By this technique all impurities as well as all living matter was separated out. Why do we say that living matter was eliminated? Because no protoplasm is known to possess the property of crystallization. Did you ever see a crystalline gonococcus, amoeba or a "crystalline chicken" either in a coop or walking down Fifth Avenue on Easter Sunday or any other day for that matter?

Now if these crystals infect healthy plants far-reaching results can be 
expected in regard to their nature. A few crystals were dissolved in a neutral liquid a hundred million or more times their bulk. Healthy leaves were again inoculated, and all the symptoms of the mosaic virus disease resulted. The conclusion of this experiment was that the crystals were made of many protein molecules, and each molecule of this cluster of crystals is a single virus of the tobacco mosaic disease.

Chemical analysis proves that the virus molecule is very large, a macromolecule. Carbon, nitrogen, hydrogen and chlorine have been found in these molecules, but how many atoms of each and their arrangement is not known. That is, there is no chemical formula for a virus as yet.

In addition to the above chemical methods the ultracentrifuge clarifies the evidence as to the nature of these macro-molecules. The ultracentrifuge gives us a knowledge of the protein itself, degree of purity and the extent of its concentration at each step in its isolation. A pure protein in true solution is made up of molecules of the same size and shape, and it will sediment at a constant rate in an intense uniform centrifugal field. The heavier the molecule the greater the rate of sedimentation. The sedimentary boundaries that arise between protein and solvent are determined by photographing. The molecular weight of the mosaic virus was found to be seventeen million times as heavy as a hydrogen atom. We may now think of this virus as a "macro-molecule" with a structure that must consist of hundreds of thousands of atoms, and may be more.

Is this virus living or non-living? Remember that it can't be cultivated in a test-tube, but bacteria which seem to be their nearest living relatives can assimilate, grow and reproduce in this non-living medium. Yet the only way this virus can grow and reproduce itself is when it is stimulated by contact with the tobacco plant tissues. An infinitesimal particle will infect a normal plant and in a few days the whole tobacco crop will be diseased and producing the original amount of virus a million times over, is not this ability to propagate itself a property of living things?

Maybe this virus lives a Dr. Jekyll and Mr. Hyde sort of life, a dual personality, alive in certain phases of its existence and raising havoc in a tobacco field, and under another set of conditions not alive and harmless as sterile water. It is alive and has the attributes of living things when in the presence of tobacco protoplasm and non-living in other environments.

This crystalline protein causing tobacco mosaic has many points in common with a gene. They are about the same size. They both reproduce under certain specific conditions and can refrain from reproducing for long periods of time without losing this property when favorable conditions exist. Quite a human characteristic! This characteristic can be illustrated by the inactiveness of the genes in an unfertilized egg of a human, thank goodness, or in the resting seed of a daisy or the inactiveness of a virus in dried tobacco leaves or in a spittoon.

Furthermore, the gene and the virus have another similarity in common 
namely, that of unstability. A gene can and does mutate. The virus may suddenly change or mutate to a "masked" form showing no mottling, and this form in turn change into another strain showing a yellow mottling in place of the original light green. The size of the virus molecule increases with these mutations.

The gene to be effective must associate with other genes. It doesn't work alone. A virus must be in contact with living protoplasm to be effective. Is this single gene or virus molecule alive? The evidence points to the answer, "No."

Azotobacter is a heterotrophic genus of nitrogen-fixing bacteria which is able to use free uncombined nitrogen of the atmosphere. It grows in well-aerated arable soils; it is a strict aerobe. Azotobacter is about the size of a yeast plant cell. It obtains its energy from the oxidation of carbohydrates in the soil, and takes in free nitrogen from the air for the synthesis of protoplasm. Is not this a property of living organisms?

Some Russian chemists recently carried out a very interesting experiment. A culture of these bacteria were grown. They were then crushed and their juices filtered off. There were no traces of the cell present. To this filtrate a carbohydrate was added, oxygen and nitrogen gas were bubbled through the liquid. This filtrate then produced ammonia like the culture of living bacteria in the flask of nutrient broth. What was producing the same chemical reaction in the lifeless fluid that was carried out by the living bacteria in their metabolic activities? Enzymes were no doubt responsible in both chemical reactions. More ammonia was produced in the test-tube than in the living culture. May not this be explained by the fact that in vitro the enzymes were not shackled with the extra burden of producing the characteristics of life?

We are still at the starting line of life, and much more work will of necessity have to be done before we can answer all the questions in regard to the nature of genes and viruses. Can't we make the assumption that the organization of matter is just a step in the production of life? Isn't it a matter of complexity of organization from these simple bacteria through the protozoa and metazoa to ourselves? Doesn't matter itself start from protons, neutrons and electrons, combine to form atoms, and atoms to form molecules, and aggregates of molecules to form crystals?

Is not the phenomenon which we call life the chief difference between these organizations? Somewhere and somehow in the general mixup in the formation of carbohydrates, fats and proteins from simpler substances, the catalyst or enzyme makes its appearance. The first catalysts may make amino acids, other catalysts simple proteins from these amines, and then other catalysts more complex proteins. The association of many proteins to form large molecules may be the first genes. These genes arranged themselves in strings to form chromosomes, specialization developed and the attributes of life were exhibited. From the evidence which has been 
given there seem to be two possibilities as to where life first appears, either as macro-molecules in the form of genes or macro-molecules as viruses. Both genes and viruses fit in part into the Mechanistic and the Vitalistic theories of life. But whatever the first form of life was, we may well assume that the enzyme is the precursor of life, and whenever it finds itself in a favorable environment it becomes active and life begins.

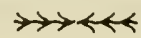

\section{THE LENS TURNED ON LIFE *}

\section{DONALD C ULROSS PEATTIE}

It is Sunday, with a Sabbath meekness on the face of things. Across the roll and dip of the great plain I saw, as I went walking with my blackthorn, the distant woods as blue-black, rainy-looking islands upon the immense watery prairie, and near at hand the young yellow of the willow whips, first brilliance of the year. Now this was a scene a midlander could love, but I went thinking, thinking, wagging that human tail my cane, how all that I saw came to me thus only because of a specified convexity in the cornea of my eye.

The trouble with our human concepts is that we are so pitifully small when it comes to the great, and so unbearably gross when it comes to the small. We occupy a position in the scale of things that is somewhat on the trivial side of total mediocrity. Little wonder if our ideas are mediocre too.

One comes at last to feel that the invention of the microscope by Janssen of Holland in the seventeenth century was the beginning of modern natural history, for the lens added a new dimension to our eyes and enabled us literally to see to the heart of many a problem. The sentence I have just written sounds good enough to pass unchallenged. But it sounds better than it is, for it seems to assert that one man invented the microscope, and it leaves us to infer that, once it was invented, men, peering through it, saw truth at last. In fact, however, having seventeenth-century minds, they did not in the least make of what they saw what we would. Except for a few larger minds, the early microscopists were largely engaged in watching the antics of fleas.

And the revolution in biological thought consequent on the use of the microscope did not take place in the seventeenth century but in the unfinished century, 1850 to our times. It is the modern technical improvements, coupled with the forward march of allied sciences, that have created the merciful triumphs of bacteriology, carried us into a deep perspective of atomic structure and brought light into the dark mystery of protoplasm

"Reprinted from Green Laurels by permission of Simon and Schuster, Inc. Copyright 1936 , by Donald Culross Peattie. 
itself. The seventeenth-century microscopy was necessarily limited by the imperfections of the early instruments, and still more by the state of the allied sciences at the time. But it was, none the less, an era of high adventure in natural history, for the lens, however faulty, gave to all greatly inquisitive minds the first rapturous look at the wonderworld of structure. Without that glimpse, sterility would have fallen upon further inquiry, so that the microscope seems to have come not a moment too soon in the history of natural science.

If I were writing the history of biology, I would tell how the century had been electrified at its opening by Harvey's announcement of the circulation of the blood, and how others applied themselves to the great unfinished business of measuring that mortal tide. When Malpighi turned his lens upon the structure of the lung, he saw for the first time why it is that man draws breath. When Leeuwenhoek peered through his homecontrived microscope, he found the corpuscles of the life stream, that no eye had seen before-and was tickled in his bourgeois soul to set Swammerdam right about them. The heart, the brain, the glands, the nerves, every organ of the human and his fellow vertebrates, became subject to intensive scrutiny. And that scrutiny for the first time revealed the functions of the organs. It is almost impossible for me to believe it, but it is true that not so long ago men did not know that the brain was the seat of thought; some believed that it cooled the blood. No one ever thought more nobly than Plato, but he never guessed what he was thinking with. He had no idea that whatever else thought may be, it is also a physical process, like digestion. So biology was at last founded upon the structure of life itself, and natural history, which is the outdoor view of biology, was tethered at last to physical realities.

Young Jan Jacobz Swammerdam impresses us now as the greatest biologist of his age, and once nıre I am going to slight many accomplishments and tell my story in terms of what Swammerdam learned of the cryptic, multiplex and fantastical insect world.

For the insects constitute an exception to almost everything you can say about the rest of the animal kingdom. You no sooner think that you have established a law, discovered a fundamental plan of animal architecture, or learned a secret of function, than you find some long-faced grasshopper sneering denial at you. The very stuff of which the insects are made is not like ours. They are not built of bones, but encased in chitin. Chitin is the horn of the rhinoceros beetle, the wing of the dragonfly, the sting, the eye, the armor, the hairs, the antennae, the very thread on which the spider escapes you. Nothing will so permanently revise your biological outlook as to discover how different an animal may be from yourself and still in its own environment be a king. The insect, for instance, has what may be called a brain, but how differently constituted. Its sensory receiving organs are scattered, not concentrated into a federal government, so 
that some ants seem to smell with their feet and even in utter blackness so find their way upon a beaten track, whether by smell or touch, that that thought which is memory seems practically to reside in their six wire-like legs. Whereas our sense of balance is located above the Eustachian tubes near the ear, it appears in some insects in a particular joint of the antenna. This sort of topsyturvydom could be developed at length, but it is obvious that the first man who with a clean strong lens and a cool head broke into the hitherto locked world of insect anatomy found himself in an Aladdin's cave of new truths. Of what he saw, Swammerdam made drawings that in three centuries have not, I think, been surpassed.

Throwing health and honor to the winds, Swammerdam achieved a work that was epochal. Singlehanded he discovered half the secrets of the hive. Where Aristotle had seen a king bee as the ruler of the apian community, Swammerdam detected the matriarchy, and proved that the queen is the only effective female of the hive. He unmasked the infinitely effete drones as the true males, and the workers as neuters. He put forth delicate skill, such as the world had never seen, to reveal the anatomy of the eyes and sting and proboscis-that marvelous tongue that dips in the deepest nectaries of the flowers. Of the bee eye nothing escaped him; he saw the many-faceted eyes which are largest in the drone, and the three other eyes that no one else had ever noticed, simple eyes like ours. He alone knew that the compound eye was not a collection of such cameras as our eyes that have pupil and iris, but that it is rather a window, admitting almost all the light that falls on it. As for the sting, he knew that it is curved in the queen, straight in the worker, and wanting in the drone. He experimented with its venom, thrusting the darts into his arm, swallowing the poison, rolling it on the sensitive tip of his tongue. With such a knowledge of bee anatomy as this, science was now for the first time in a position to generalize upon the economy, politics and behavior of the hive. Greatest of the Dutchman's triumphs was his discovery of the metamorphosis of insects. The egg, the caterpillar, the pupa and the butterfly are all, he proved to an astonished Europe, one and the same individual in different growth stages.

I am come now to the last of the three great microscopists of the age, Antony van Leeuwenhoek. Wealthy, but self-made, an expert lens grinder who increased magnification up to two hundred and seventy diameters before he realized that more median lenses give the best results, unwilling to part with the secret of his art, shrewd with a sort of magnified common sense, gossipy, stubborn, ignorant of any language but Dutch and contemptuously proud of it, Leeuwenhoek of Delft was one of the most eccentric personalities of the scientific age, and you may be sure that his English friends in the Royal Society did not miss a wrinkle in his character.

He had, boylike, discovered the sheer rapture of looking at the whole 
world through a lens. Not only were his lenses more sensational than anything that had yet been produced, but the eye at the objective was shrewder, brighter, more restless. There was only one trouble, and that was that the mind behind the lens was not the equal of the crystal or the cornea.

The inveterate Peeping Tom of Delft called his opus Secrets of Nature, and some of the secrets he revealed were the human male's spermatozoa, the bacteria he found in his mouth by scraping his back teeth, the generation of fleas, the eggs of tadpoles, and the true nature of the red corpuscles of the blood. His minor discoveries are almost endless, though he never had the patience to tunnel through until fact met fact in a significant penetration. There was even a moment when he made an absurd pretensionhe declared that he saw in the spermatozoon a whole tiny man, body and limbs and head.

He drove nails in the coffin of the spontaneous generation theory by his discovery that vermin are not bred out of filth but come from eggs laid there by their predecessors. He revolutionized our view of sex, diminishing the importance of the male, when he showed that plant aphids reproduce parthenogenetically, by a sort of virgin birth of endless fatherless generations. He found the true egg of ants, and revealed that what are called and still sold as ant eggs are in reality ant pupae in their chrysalids. One day he discovered the striated nature of muscles, and another he dug out of his rain gutter those fascinating dervish animalculae, the rotifers. He started enough lines of inquiry to found a whole school of biologyand yet he was so jealous of his knowledge that he never took a pupil.

It was in this era, too, that man first worked on the fascinating problem of the irritability and motions of plants, stimulated to it by the arrival from the tropics of a mere botanical curiosity, the sensitive plant. It was an era when men began to suspect and assert-though they risked the rack for it-the animate nature of fossils.

So it may seem to us that the colorful seventeenth century was almost within sight of our own, as it pursued the nature of the cell and attacked the paralyzing myth of spontaneous generation, penetrated close to the heart of sex and unwrapped the mystery that clings around the seed. We have the feeling that the men of that age were coasting along golden shores that were hidden from them in thin mists, and that with a little more perseverance, vision and daring, they would have had a landfall of twentiethcentury discovery. 


\section{HOW LIFE BECOMES COMPLEX *}

\section{S. J . H O L M E S}

Lest the reader be led to expect a discussion of the distractions of living in our modern society, I may explain at the outset that this is a purely biological article. It deals with the complexities of the life processes in plants and, especially, in animals, and how these complexities came about.

Life presents an enormous range in complexity from that of the human body down to the bacteria or organisms even simpler, such as the filterable viruses, if they are organisms at all. An amoeba carries on the same fundamental life processes as a man, with almost no organs. It moves without muscles, transmits stimuli without nerves, digests without stomach or intestine, respires without lungs or gills, and reproduces its kind by pinching itself in two. An amoeba, which is by no means the simplest form of life, is the product of long series of evolutionary changes. It occupies a niche in nature in which it has persisted with little change for millions of years, during which other animals have forged ahead and acquired structural organizations of great complexity and almost endless variety. If we compare the structure of a frog, an insect, a clain, a starfish or an earthworm, we find remarkable differences of form and internal organization but the diverse organs of these animals are devoted to the discharge of the same essential functions. All of them have organs of digestion, absorption, respiration, excretion and reproduction. The varied structures of these animals represent so many different ways of solving essentially the same physiological problems. Why all this bewildering variety of structure and pattern?

Obviously, life as it has become more complex has followed many different paths. For the most part we can not say that one animal solves its problems better than another. The amoeba gets along very well in its way, and so does the starfish, the spider, the squid, the porpoise and all the rest of our animal relatives. They persist and perpetuate their kind, and possibly enjoy life after their fashion, and this is about all a living creature can reasonably expect. As Aristotle observed, the activities of all organisms center about two ends-the preservation of the individual and the perpetuation of its kind. These are the two great problems that face every living creature. Death to the individual or its kind is the penalty for failure to discover the correct solution. Organisms have tried different ways-millions of different ways-of finding an answer to these Sphinx riddles, and the number of right answers that have been hit upon is indicated by the multitudinous diverse types of plant and animal life. A higher type of organization would be of no advantage to a creature in certain situations.

* Reprinted by permission of the Scientific Montbly, American Association for the Advancement of Science. Copyright 1941. 
If an animal or plant occupies a niche to which it is well adapted, it may persist almost unchanged for an indefinite period of time. The lamp shell Lingula has changed very slightly since the Cambrian period. For animals that bury themselves in the sea beach, life some hundreds of millions of years ago was probably much the same as it is to-day. All along the course of organic evolution there are forms that have found their niche and have stayed there, while others that were more adventurous explored new fields and acquired profound changes in adaptation to different kinds of environment.

There are some types of environment that favor an advance of organization, and life, which is ever ready to take advantage of opportunities for its own increase, has developed there into higher forms. Nature apparently strives to fill all kinds of situations with living inhabitants. What she seems to be interested in is having as many children as possible. Whether they are high or low in the scale is a quite secondary matter. Certainly, Nature has been remarkably successful in producing offspring of the most complicated structure along many different lines, and we may now consider some of the ways in which she has achieved this end.

One important influence is an indirect result of mere increase in size. Every student of elementary geometry has learned that as a body increases in size its surface increases as the square of its diameter, while its volume increases as the cube. When a body grows, therefore, its volume increases disproportionately to its surface. This fact has very important consequences for living organisms. In a spherical organism of $1,2,3$ or 4 inches in diameter, for instance, the surface areas would be as 1, 4, 9 and 16, while the volumes would be as $1,8,27$, and 64 . But if the life processes went on at the same rate in these organisms, there would be a more rapid exchange through a given area of surface in the large organisms than in the small ones. As size increases, absorption of nutriment, the elimination of waste and exchange of gases in respiration will have to be carried on so much faster through a given area of surface that further growth would be automatically checked. Perfectly spherical organisms of homogeneous structure, therefore, could not attain a very large size; they never do. Where any considerable size is reached in a plant or animal, it is always attended with structural devices for increasing surface in relation to volume.

A good deal of the complicated anatomy of higher animals is a result of extending surfaces devoted to the fundamental vital processes of absorption, excretion, digestion and respiration. Small animals can obtain sufficient free oxygen by absorbing it through the body-wall. But where size increases, relatively more surface is required for respiratory exchange. Aquatic animals quite generally meet the situation by pushing out the integument to form gills. Among terrestrial animals gills, unless protected by structures by which they are kept moist, are usually replaced by organs that ramify within the body and thus keep respiratory surfaces protected 
from desiccation. Our lungs, for instance, are outgrowths of the anterior part of our digestive tube. The finer subdivisions of the bronchial tubes lead to very thin-walled air cells through which respiratory exchange readily occurs between the air and the blood in the capillaries with which the air cells are richly supplied. If our lungs were ironed out, so to speak, the total area of their surface in intimate association with the blood would be about equal to the wall space of a fair-sized room.

In organs devoted to absorbing food the same principle is abundantly illustrated. Consider the surface of a large tree with its numerous leaves having expanse which may be more than an acre in area. In this expanse of leaves the carbon dioxide of the air is absorbed and, together with water, is built up into carbohydrates under the influence of sunlight. And in the root system with its millions of root hairs there is a great expanse of surface through which water and salts are absorbed from the soil. Organs of excretion, such as our kidneys and their numerous coiled tubules, are devices for bringing a large area of excretory cells into close relationship with the blood. The same statement applies to glands of all sorts, whether devoted to the elaboration of digestive juices or the production of other substances. If we survey our own bodily structure or that of any other complex animal and consider how much of its make-up consists of extensions of surfaces involved in absorption, secretion, excretion and respiration, we will find that we have included no small part of its structural complexity.

But the story by no means ends here. In order to live at all every organism, even the simplest, must perform the basic functions of absorption, assimilation, respiration, excretion, conduction and reproduction. But in order that these basic functions can be discharged in a more highly developed organism, other activities subservient to them have been superadded. Let me illustrate. All organisms must take in nutriment from the outside. In animals the food usually requires to be digested before it can be absorbed and gain access to the living protoplasm. The essential feature of digestion is splitting up food substances by means of enzymes, or ferments until they are rendered capable of solution and diffusion through living membranes. Digestion is a process subsidiary to absorption. The amoeba performs this function in little vacuoles in its protoplasm formed by the secretion of fluid around engulfed particles of food. These vacuoles disappear after their work is accomplished, and the undigested residue of the food is expelled to the outside. They are little stomachs improvised for the occasion. In a hydra we have permanent specialized organs set apart for the function of digestion, but the structures involved are of a very simple and primitive kind. In striking contrast with this is our own digestive machinery with its complicated stomach and intestine and the highly developed glands of liver and pancreas, to say nothing of numerous small glands elaborating their specific kinds of digestive ferments. But where 
so much apparatus is devoted to digestion and absorption, still more apparatus is required in order that the parts can carry on their work. We have muscle fibers in the walls of the alimentary canal which in the esophagus aid in swallowing, and in the stomach bring about the churning motions that facilitate the chemical part of the digestive process, while in the intestine they effect the discharge of food along its course. All these parts are equipped with blood vessels which supply oxygen, remove waste and carry away absorbed food materials to be distributed to other parts of the body. And, again, the movements of the muscular coats of the alimentary canal, the secretions of glands and the regulation of the blood supply are coordinated through the agency of the nervous system and also by special kinds of hormones or internal secretions. These agencies are required to make it possible for the parts more immediately concerned in digestion and absorption to function in an adequate manner.

But in addition to the organs that are directly accessory to the digestive apparatus, animals are equipped with tentacles, teeth and various other organs for the capture of prey. The sharp claws of the cat, the poison glands of the spider and the tentacles of the octopus are all devices to enable their possessor to capture prey upon which the digestive juices of these animals may act. But further complications arise by the development of organs and instincts subsidiary to these activities of capturing and overcoming prey. A striking instance is furnished by the common orb-weaving spiders. Toward evening in summer time one may often witness the marvelous performance of spinning an orb web. The making of the frame of the orb, the placing of the rays, the spinning of the spiral of sticky web and the formation of the central disc, or hub, are carried out with a nicety and precision that have excited the admiration of all observers. The web finished, the spider takes up its position head downward in the center, with its feet on the rays where they readily feel the agitation conveyed by the struggles of an entangled insect. Following the signal, the spider rushes out upon its prey, often employing more web in the endeavor to impede the movements of its victim. Then comes the sudden rush, the burial of the fangs and afterward the leisurely meal. Here we have a complex series of acts in preparation for capturing prey, which in turn is a preparation to the acts of overcoming and feeding upon it, and these activities in turn are more directly subservient to the various acts involved in digesting and absorbing food.

We might take another illustration from the industry of the hive bees, among which there is not only food collecting, but food storing, and, in preparation for food storing, the construction of the beautifully regular six-sided cells of the honeycomb. Or, again, we might cite the grain gathering and storing of the agricultural ants and the peculiar fungus-growing industry of certain species of ants and termites. These activities, indirectly accessory to nutrition, often involve the evolution of highly specialized 
organs for their performance. Among such are the pollen basket on the hind legs of the hive bee, the pollen combs, the wax glands on the underside of the abdomen, and the peculiar wax pincers by which the scales of wax are removed. The whole structure and instinctive behavior of the worker bee have been profoundly modified in relation to the accessory nutritive activities upon which she unselfishly spends so much of her energies. We thus see how, in relation to the primitive function of nutrition, one complication leads on to another, and this again to a third, and so on. The basic vital process of (A) absorption becomes associated with the prelininary and preparatory activities of (B) digestion. These may finally involve elaborate mechanisms for their discharge, but subsidiary to these there are worked in (C) specialized modifications of the muscular and nervous systems, to say nothing of other parts. Subsidiary activities of collecting food, involve often, complicated structures and modes of behavior, and subsidiary to these, again, we have (E) such acts as web spinning and comb making, and many others, each entailing more or less extensive changes of structure and behavior. In this way life becomes more and more complex.

We see much the same sort of thing exemplified in the development of industry. One may manufacture such articles as cigarettes with a very simple layout. A few girls with very simple apparatus could turn out a goodly number of these articles in a day. But if a primitive plant should grow into a large factory, we would find the installation of more complex machinery and no end of accessory activities. There would be janitors, bookkeepers, stenographers, business managers, traveling salesmen, special buyers, pay clerks, advertisers, night watchmen, and perhaps attorneys and plain clothes detectives, all of whom would be engaged in work subsidiary, directly or indirectly, to the fundamental function of the factory. Although the basic function of nutrition may be a more complicated process than making cigarettes, it comes to require in special cases a vast deal of machinery to carry out the subordinate activities and the activities subsidiary to these, and so on to the spinning of the spider's web and the building of the comb of the hive bee.

It would be instructive to consider another illustration of how complications pile up in the evolution of life, and this time I will select the process of reproduction, which is certainly a basic vital function characteristic of all species of living organisms. Its simplest manifestation is in the fission of a very primitive form of life, such as a bacterium. The propagation of all but the simplest of the one-celled organisms commonly involves in some part of the life cycle the intervention of sex. So far as is known, the bacteria, the blue-green algae and some other groups are primarily sexless. Doubtless, life existed on the globe for many millions of years before sex entered upon the scene, but it is a significant fact that it never evolved very far. One might indulge in flights of fancy as to what plants and animals 
might be like if evolution had continued to go on without the development of sex. Certainly, the higher animals, if there were any, would be very different from what they now are structurally, physiologically, emotionally and intellectually. The reader may try to imagine what sort of creatures they would be. His guess would be as good as that of the professional biologist.

We shall not discuss the problem of the biological significance of sex further than to state that its great importance in evolution is attested by the fact that only very primitive organisms were evolved until the advent of sexual reproduction. Then evolution took a spurt upward. The most primitive manifestation of sexual reproduction is the conjugation of two similar simple organisms. Both the nuclei and the surrounding protoplasm of the conjugants fuse to become one flesh, after which often following a resting stage, multiplication by fission goes on as before. At first there is no clear distinction of male and female, but in many one-celled organisms, plants as well as animals, the conjugating individuals are differentiated into a large, relatively immobile female cell and a much smaller, actively swimming male cell. This differentiation parallels the differences between the ovum, or egg cell, and the spermatozoön of the higher animals.

In all the multicellular animals the sex cells are sharply differentiated into eggs and sperm, but in more primitive groups, such as sponges, corals, jelly fish and many worms and molluscs, sexual reproduction is usually accomplished quite simply by discharging the eggs and sperm into the water and leaving their union to chance. In all but the simplest of the multicellular animals the sex cells are produced in specialized organs, often provided with ducts for their transfer to the outside. But sexual reproduction does not involve elaborate behavior or many accessory structures until the development of internal fertilization. This step is one of tremendous importance for further evolution. We see it foreshadowed, as it were, in certain groups of animals in which the fertilization of eggs still occurs outside the body, by the development of instincts that bring about a close association of the sexes during the breeding season. During the period of egg laying in fishes, for instance, the female is closely followed by the male, who frequently rubs against her body and discharges his milt, or sperm, over the eggs as soon as they are extruded. In the breeding season the males of many species develop brighter colors and, sometimes, small bodily protuberances and other structures associated directly or indirectly with the function of mating. These modifications are not, as a rule, extensive. In frogs, toads and some other amphibians a closer association of the sexes is secured by the clasping instinct of the male. As in fishes, the discharge of the eggs from the female prompts the simultaneous discharge of the sperm from her male companion, the eggs being fertilized in the water by the sperm which penetrate their jelly-like covering. That such mating habits probably led to internal fertilization is indicated by the fact 
that among both fishes and amphibians there are species in which the eggs are fertilized within the body of the female, as they are in all the higher classes of vertebrate animals. But, however fertilization of eggs within the body may have been originally accomplished, the process once started has entailed most elaborate developments; it has led to the evolution of diverse structures for the transfer of sperm cells, organs for clasping the female, and the perfection of organs of sight, smell and hearing which enable the males to discover the whereabouts of the other sex. The enormous eyes of the drone honeybee and the elaborately developed antennae which are the olfactory sense organs of male moths are among the many evidences of the influence of the function of mating upon the evolution of organs of sense. When internal fertilization is once evolved, the male is confronted with the problem of distinguishing the female of his own species from all other kinds of living creatures. Here is one of life's hurdles which must be surmounted if the species continues to exist. Consider, for instance, the nuptial flight of the queen bee. When the young queen makes her first flight into the air, a number of the big-eyed drones immediately start in pursuit. Their course is directed not only by sight but by odor, which they detect by their well-developed antennae, which are much more richly supplied with sense organs than those of the queen or worker. Mating takes place in the air and the process is usually fatal to the male. The sperms are stored in a special receptacle in which they may live for years. Apparently, the queen controls the outlet of this organ because eggs laid in drone cells are not fertilized and hence develop into drones, while those which are fertilized develop into queens or workers. In this case internal fertilization involves not only specialization of the reproductive apparatus of both sexes, but the elaboration of organs in the male useful in distinguishing and following the female. The function of mating has, so to speak, put a premium upon the development of activity, acuity of sense, powers of discrimination and special aptitudes of various kinds. It has thus been a potent factor in the evolution of mind, as well as bodily organization. This is indicated especially by the frequently elaborate behavior of many animals preparatory to the act of fertilization. In birds especially, but also in certain insects and spiders, the male performs various antics while courting the female, as Darwin has described in much detail in his writings on sexual selection. Courtship is obviously an activity subsidiary to the union of the sexes and it has led to the development of many structural features and special instincts for display. The brilliant ornamentations of male birds, so wonderfully manifested in the peacock's tail and the plumage of the birds of paradise, is associated with instincts for the effective exhibition of these attractions. A large part of the courtship of male birds involves also the employment of song. Doubtless, few people have ever reflected that the voice owes its origin and at least the early stages of its evolution to its use as an aid to mating. The power of making sounds is possessed in greater 
or less degree by many kinds of insects, but where it is conspicuously manifested, as in crickets, katydids and cicadas, it is employed in courtship. In the vertebrates, although there are a few fishes that make noises of uncertain function, the voice proper first appears in amphibians. The breeding season in the spring is the time in which the croaking of male frogs is most vociferous, and it has been observed that the females go to the localities from which the croaking proceeds. In both the birds and the mammals the voice has acquired other sexual functions, but it still retains its primitive employment as a sex call, a function which has received perhaps its acme of perfection in the song of the nightingale. To a certain extent vocal sounds are made in connection with the battles of the males for the possession of the females, as is exemplified by the nocturnal encounters of tom cats and the challenge uttered by the bull moose as he goes on the war path against possible rivals. But in these cases also the use of the vocal apparatus is closely associated with the function of mating.

With the evolution of parental care the voice comes to be extended beyond its original sexual function and is employed in different ways in fostering and protecting the domestic group. The danger chirr of the mother quail sends her flock under cover; the cluck of the hen keeps her brood closer around her, and her peculiar call indicative of the discovery of food brings the young chicks to share the prize. And the cry of the young mammal causes the mother to rush to the defense of her offspring or to supply its nutrient wants. Crying, by the way, plays a very important biological function which human beings share with their humbler mammalian relatives. It is the part of human language which rests upon a basis of pure instinct. It is a call for help prompted by hunger, distress, fear or perhaps merely the desire for attention, as it may come to be in spoiled babies. On the other hand, the response of the mother to the cry of her infant is doubtless prompted by a strong instinctive impulse even in human beings, as it clearly is in lower mammals.

As social groups came to be evolved, the voice comes to be employed as a means of integrating the activities of the members. Warning cries, grunts of satisfaction in comradeship, cries of distress that bring others to the defense of an animal that is attacked and many other utterances which are instinctively made and instinctively responded to are wide-spread among the higher social and gregarious animals. Finally in man the voice comes to be employed in articulate speech with all that this implies for the further evolution and cultural development of mankind.

We have already commented on our inability to predict what kind of organic world would have been evolved had it not been for the advent of sex. Very probably its highest products would have been voiceless, and since organs of hearing tend to go along with organs for the production of sound, the creatures would have probably also been deaf.

I must point out also another line of development which has grown out 
of activity associated with, and subsidiary to, the function of reproduction. This is the evolution of parental care. Maternal affection does not enter upon the scene until comparatively late in the evolution of animal life. The whole vast groups of worms, molluscs, echinoderms and crustacea do not manifest the least solicitude for the welfare of their offspring. The same statement is true for the great majority of insects, spiders, fishes and amphibians. Among the lower invertebrate animals the discharge of the sex cells into the water fulfills all responsibility for the perpetuation of the species. In the higher invertebrates the simple physiological functions of producing and discharging sex cells are accompanied by accessory activities of various kinds. Many species of insects devote much care to laying eggs in situations that provide food for the future larvae. One might write a whole treatise on the varied and highly specialized modifications of egg laying. The cabbage butterfly is careful to deposit her eggs upon cabbages, mustard or some other member of the natural order of Cruciferae. The mother blowfly chooses meat, if tainted so much the better. The solitary wasp, according to its kind, hunts out a narrowly restricted group of beetles, grasshoppers or insect larvae, stings her victim so as to paralyze but not to kill it, lays an egg upon it, buries it in a hole, carefully fills the hole with dirt, then leaves her progeny to its fate. No maternal affection here. In fact, the mothers do not recognize their offspring as any kin of theirs, if they see them. The whole elaborate and highly specialized performance is gone through blindly and instinctively. There are many kinds of insects which spends much effort in making receptacles for eggs and in storing food for their progeny. Numerous species of solitary bees provision their nests with pollen and honey which the larva feeds upon. Only in a few species do the mother bees remain with the nest and supply food directly to the larvae after they have hatched from the eggs. Care for eggs long antedates care for what comes out of the eggs. But when the association between the parents and their living offspring was once established, a line of evolution was started which has led to the most momentous consequences for the further development of animal life.

I shall pass over the manifestations of care for offspring as it has developed in ants, bees and termites among social insects, and its temporary appearance in a few groups of fishes in which the parents may accompany the young for a short time until the school becomes scattered. In birds one may find various stages from types in which the parents foster and protect the young for a short time and then leave them to shift for themselves, to the domestic behavior of the higher song birds which raise their broods in carefully constructed nests and spend much of their time in keeping the nests clean, brooding their offspring and finding food to fill their hungry mouths. The more care is expended on offspring the more helpless they become, and the more dependent they are upon the ministrations of their parents. Successive generations become more closely tied together. 
In solitary wasps they are completely separated. Neither knows the other. In the robin they are intimately united for a prolonged period. One may often see a nearly full-grown robin soliciting and receiving food from its indulgent parents after it is perfectly able to forage for itself.

Among the mammals, the care of offspring has become part and parcel of the perpetuation of life. In fact, the possession of mammary glands, the unique structural feature to which the class of Mammalia owes its name, would be valueless in the absence of the maternal instinct to foster and nourish the young, and the correlated instinct of the young to obtain its food from the maternal fount. As in birds, parental care increases, as a rule, as we pass from lower to higher forms. In the apes it is exhibited in many ways that appear quite human. We may regard it as the source of social sympathy and affection. It is the earliest form of true altruism. Without it man would probably never have become a "normal animal," as he was said to be by Herbert Spencer.

Parental care, as I have attempted to show (although lack of space forbids producing sufficient evidence for this conclusion), is an outgrowth of accessory reproductive activities which have been superadded to the more primary reproductive functions. If it has afforded the evolutionary basis for altruistic behavior it is because reproduction is fundamentally and essentially an altruistic function. It is concerned not with the individual per se but with others. We can not say that altruism evolved out of egoism. Both are present in the simplest organism that divides by fission. Both are coeval with life itself.

\section{$\nrightarrow \leftrightarrow t$ \\ THE QUEST FOR THE MYSTERY OF LIFE *}

\section{H. GORDON GARBEDIA N}

Why do we fall sick? Why do we grow old? And why do we die? We would have the answers to those great riddles if we could find the answer to the more fundamental problem: Why do we live?

To explain the life process has become the great quest of modern science. That search is already yielding surprising results and unusual benefits to mankind, and if it succeeds in giving us an understanding of the complex phenomena of life it would be the crowning glory of man.

Artificial life created out of non-living stuff in the laboratory is a dream as old as the alchemists' ambition to make gold out of lead. Present-day investigators have obtained results which tend to show that it is possible to make artificial "cells" which contain the spark of life and which are

* Copyright 1933 by H. Gordon Garbedian. Reprinted by permission of Crown Publishers. 
wonderfully suggestive of the possible future realization of the ancient dream of man-made life. These studies have led some biologists to surrender the idea of natural death and to reach instead the daring conclusion that death is "accidental."

Most biologists today prefer the definition given by G. H. Lewes, that "life is a series of definite and successive changes both in structure and in composition, which take place in an individual without destroying its identity."

In his eager desire to find the key that will unlock the mystery of the life process, the scientist has speculated about the awe-inspiring theme of the origin of life. Tracing backward the history of man's evolution, we come to a point beyond which we can go no farther. Through mammals we go back to the age of reptiles; from reptiles to mollusks; from mollusks to seaworms, and from seaworms to slime and single-celled creatures. Beyond that there seems to be a "No Trespassing" sign over a gate which hides from us the greatest mystery of all.

Where did life come from? How did it start? Why has it ascended the evolutionary ladder that it has and where is it going next?

For thousands of years mankind adhered to the notion known as spontaneous generation, according to which living creatures arose spontaneously out of the air or the sea, or out of the mud. There are various schools of thought today which differ sharply in their speculations about life's beginning. There are some scientists who support the theory of Panspermia, according to which life is as old and as fundamental as inanimate matter. Its sperms or spores, according to this view, are supposed to be scattered through the vast universe and to have reached our planet quite accidentally. Lord Kelvin has suggested that they were carried here via those brilliantly illuminated meteorites which constantly bombard our earth from outer space.

The image of Aphrodite rising from the sea has a scientific justification in the view of those biologists who believe that the living has risen on this planet from what we regard as the non-living. These men of science proclaim that it is fairly certain that life originated in the primeval ocean, since the inorganic salts present in the circulating fluids of animals correspond in nature and relative amounts to what we have good reason to believe was the composition of the ocean hundreds of millions of years ago. A new approach to the problem of the origin of life on earth was recently suggested by Dr. Assar Hadding, the noted Swedish geologist, who contends the life began here in warm water puddles after the world's first rains.

Life, according to Dr. Hadding, was impossible until our globe had cooled sufficiently to allow the condensation of water. This first happened, he believes, in the Winter seasons of the two poles. Before that, the surface of the globe must have been covered with loose, hot volcanic ash. 
With the chemical action of water on this ash, he holds, the complicated composition of protoplasm became possible.

The tide of life may have begun flowing in any of these ways. Whatever form animated life may have taken at the start, living beings-plants and animals-did appear when this planet's surface cooled sufficiently to invite organic existence. Life has developed from small and lowly creatures to highly complex creatures. This development culminates in the strangest and most wonderful organization we know of in the universe, the mind of man.

Let us suppose that you are strolling through a park. On a near-by bench sits a man, reading the morning paper under the shade of a giant oak tree which lifts its leafy arms to blue heaven. A flower bed is afire with brilliant hues, while bumble bees murmur among the roses.

Unless you happen to be a biologist, you see little similarity between the man, the tree, the flowers and the bees. But science has revealed that all living organisms within both the plant and animal kingdom-including man-are built of the same chemical stuff. All life is based on an innocent looking jelly-like, semi-fluid substance, called protoplasm after the two Greek words, "protos," meaning "first," and "plasma," meaning "to form" -or, therefore, "to form first." Thomas Huxley, the great British biologist, coined the best definition of protoplasm that we have when he termed it "the physical basis of life."

Protoplasm is contained in the cell, which is the basic unit of all forms of life. The simplest living organisms consist of single celled animals, of which there are about 10,000 species. The common, undistinguished amoeba, a hundredth of an inch in diameter and a great lover of stagnant, muddy waters, belongs to this classification. Other living creatures consist of aggregations of cells, the number varying upon the complexity of the organism. In the human being, millions upon million of these cells, or factories of life, are in combination.

A living cell consists merely of a droplet of protoplasm, surrounded by a wall. The mass within this wall or membrane is called the cytosome. Within this cytosome is a concentrated, mysterious mass called the nucleus.

Nobody knows what the chemical formula for protoplasm is. Very likely it is not a single formula, but a whole series of formulas, each one very complex in itself, with the complexity vastly increased by their interrelations. A correct chemical picture of living protoplasm would probably give us the secret of life.

Carbon is one of its fundamental components. Three types of carbon compounds unite to form protoplasm: the carbohydrates, which are various combinations of carbon, hydrogen and oxygen; fats, a more complicated structure of the same chemical elements; and proteins, the most complicated compounds in protoplasm, which include in addition to carbon, hydrogen and oxygen, combinations of nitrogen, phosphorus, sulphur and 
iron. More than half of the bulk of protoplasm consists of water, while salts including sodium, potassium, calcium, magnesium, iron and manganese, are also present in small quantities.

Constant activity is one of the most important characteristics of protoplasm, as it is in all life. Protoplasm has an energy content which inspires constant interaction between it and the outside environment. Like the engine of your automobile, protoplasm absorbs fuel in the form of food and then burns it to provide the energy necessary for its varied activities. The biologist has named this process metabolism. Protoplasm has as its distinguishing characteristics the powers of growth, reproduction and a keen sensitiveness to environment. The living cells, therefore, feed, breathe, grow and reproduce. During these activities, the carbohydrates, fats and proteins in the cell, through oxidation and other processes, undergo changes by virtue of which their chemical structure is transformed, energy meanwhile being absorbed from them to the cell. To keep the life process going, it is necessary that a new supply of carbohydrates, fats and proteins be continually fed into the living cells and that the waste products produced by the various processes be carried away.

The modern discovery that all life is based on a stuff called protoplasm is one of the greatest in the history of science, and it has led to an eager school of scientists who are striving toward the creation of life in the laboratory. Consequently, scientists have achieved some stirring results which hold the promise that we may be on the threshold of exciting events.

After a person is dead, many parts of the body, it has been proved, remain alive for hours or days. Hair and nails, for example, grow longer after death because the cells from which they grow are still living. In Russia, Dr. S. J. Tchenchulin apparently kept the severed head of a dog alive for more than three hours, while his colleague, Dr. A. Kubliako, kept a human heart functioning for at least thirty hours outside the body that once had owned it.

Professor Woodruff of Yale has further demonstrated that there need be no termination to the continued existence of pure-lived protozoa, or uni-cellular animals. He found no natural death in a culture of Paramecium in 8,500 generations equal to 250 ,ooo years of human life, and the culture was going as well at the end as at the beginning. Morgan of Columbia found that $1 / 250$ th part of a worm will regenerate and be "younger" than the original. These tests pointed to the sensational conclusion that life cells and tissues are potentially immortal, a conclusion which now seems to have received definite confirmation at the hands of Dr. Alexis Carrel, world famous surgeon of the Rockefeller Institute.

Twenty years ago, Dr. Carrel set out to determine just what life power was inherent in the tiny myriad cells known to make up our bodies. $\mathrm{He}$ posed several questions and set out to find answers for them: When man or any other animal died, did he die completely in all parts of the body, or 
did some of the infinitesimal cells go on living for a while on their own initiative? If a cell could be removed from a dead person, could it be made to go on "living" after the rest of the body was dead and buried? Was there eternal life in any part of the human anatomy, and, if there was, would it give us the key to eternal life for the human being as a whole?

The average life of a chicken is only about five years. Dr. Carrel* has in his laboratory, still alive and hearty, some cells taken from the heart of a chicken embryo more than twenty years ago. He has also kept tissue cells from rats, mice, guinea pigs and human bodies growing in his laboratory in favorable culture conditions for many years. Cells taken from brains live only a short time at best, but most of the other cells do very well-as well as the chick's heart.

Dr. Carrel concludes from these results that the human cells are potentially immortal; detached, they might, under the right conditions, go on living and having descendants forever! Combined by nature into bodies, into a system so marvelous and intricate as to produce our brains, they produce also decay and death. The explanation? The best theory that Dr. Carrel can offer is that a single cell in a semi-liquid state is able to discharge its poisons-necessary by-products of life-directly and entirely into this liquid outside itself, while in the body these poisons cannot escape and therefore pile up an inevitable burden of decay and death.

The discovery of biologists that living cells are exempt from oblivion has led many noted scientists to speculate about immortality. Evolutionary biology does not preclude the belief of an endless soul in Nature, in the opinion of some scientists, including Dr. Arthur H. Compton, Nobel Prize winner in physics, who holds: "Biologically speaking, life is essentially immortal. The apple may decay, but the seed grows into a new tree which flowers and begets new seeds. It is because we concentrate our attention upon the tree that we say the end of life is death. Life, whether it be of an apple seed or the germ cells of man, is essentially continuous and eternal.

"The reply is heard, however, 'Though my body may be merely the hull that surrounds the living germ, I want to know what will happen to me when the hull decays.' To this question science has no straightforward answer to give. For when you ask, What will happen to me? you are concerned not with your body, but with your consciousness, mind or soul, which is not material, and regarding which science does not directly concern itself."

* Dr. Carrel is now dead.-Ed.

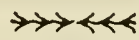




\section{IIII}

\section{The Structure and Function of Higher Plants}

$\mathrm{M}$ AN's primary interest is, understandingly enough, in man. As the world draws closer together, as food problems change from national to international problems, science has turned more and more attention to plant life, for it is upon the carbohydrate and oxygen-producing capacity of the chlorophyll-bearing plant that animal life depends. The layman may well be forgiven his astonishment when he learns that some 80,000 botanists are engaged in solving the riddles of the plant world and thus contributing, directly or indirectly, to human welfare. The botanist stands not only at the core of the food, clothing and shelter problem but frequently is found fighting the front line battles against plant diseases.

Like animals, plants range from single-celled to many-celled structures. Simplest of the plants are the viruses, bacteria, yeasts, and certain algae. They are called simple because they are single-celled and lack root, stem and leaf. One of the interesting things about the bacteria and the simple algae is that they have been found in the oldest rocks and so are extremely old phylogenetically. The fact that many of these simple forms reproduce by binary fission or splitting means that the present individuals are cytoplasmic and in some cases nuclear descendants of the first cells to appear on this earth. This might be termed immortality.

Leaving the single-celled plants, we note more complex arrangementssome are mere aggregations of independent cells stuck together, others show slight differences in form of cells and indicate a type of specialization, a division of labor. Many of the fungi and algae are tremendously complex, as for example the huge puffball and the giant brown algae, the latter growing in the oceans to a length of several hundred feet, with root-like and leaf-like structures. From the one-celled green alga to the billion-celled redwood tree, towering three hundred feet or more, is quite a contrast.

Plant physiology is the science which deals with the functions of plants, their growth, metabolism and kindred subjects. These scientists have been studying for years the formation of sugar, of starches, of rubber, of chicle, of oils in plants. Lately this study has taken a very interesting and vital turn. Botanists are now studying the formation of anti-bacteria, anti-spirochaete, and anti-protozoan substances by plants. Some of these important products are already known to you as penicillin, streptomycin, tyrothrycin and gramicidin. Again plants are furnishing man with life-saving substances 
as they have in the past. We should always be conscious of our debt to the Flemings, the Floreys, and the Waksmans who labor to make life safer and more healthful to their fellow men.

\section{A TOUR OF A TREE *}

\section{H E N S H A W W A R D}

I am standing on a lawn in Carpinteria, near the Coast Highway of Southern California. Above me is a Torrey pine that carries its foliage a hundred feet above the base and spreads it on stout, sprangling arms over a diameter as great as its height. Seen from underneath it is a galaxy of eightinch needles; from a distance it is a delicate cloud of soft gray-green color. Occasionally some one whizzing by in a car remarks, "There's a big tree." For thirty-six years I have known it, watching it grow from sprig to giant, without making any better comment.

This morning I begin to notice what a pine tree is. Its trunk, almost four feet in diameter, is a notable piece of architecture, for it bears the strain of a wide-stretched load, through the hardest gales. Its branches are contrived for spreading tens of thousands of needles to the sun and air, so that they may make sugar to feed new twigs which will spread new needles. $t$ Underground there are thousands of regiments of rootlets that forage for water and mineral food, which must be transported to the sugar factories. All these industrious armies of roots and leaves are engaged in one common purpose-nourishing the seeds in the cones. Such a purpose can not be carried out by haphazard. What generalship directs these myriad forces in orderly cooperation?

If you accompany me on a tour of this tree, viewing the sights that any ordinary microscope shows, you will need no help in making your own speculations about the powers which lie beyond vision.

Squinting through a microscope is hard work; even for a man of long experience it is a tricky task. The only way to go sightseeing comfortably in a tree would be to reduce ourselves to microscopic size, carrying with us a corresponding increase in power of vision. If, for instance, a man nearly six feet tall could reduce himself to one-tenth of his size, his height would be seven inches. In this tree trip he would see a pineneedle as a redtipped stake taller than himself, three-sided, with sharp corners; he could see that two of the sides are concave and decorated with seven rows of glistening white spots, while the third is convex and has twice as many rows of spots. He would feel of the saw-teeth on the corners and would

*From Exploring the Universe by Henshaw Ward. Copyright 1927. Used by special permission of the publishers, The Bobbs-Merrill Company.

$+\mathrm{Mr}$. Ward does not mean to imply that plants function for a purpose here or elsewhere in this article.-Ed. 
wonder about the sticky, brownish stuff that smears part of one side. A needle would be a curiosity which he would of ten tell about.

Hence a tour of a pine tree by a seven-inch person would be ten times as interesting as if he kept his normal height. But even then he would see no more than a pocket lens reveals. Suppose he were reduced to a hundredth of his sizc, so that the needle was nearly seventy feet long and each small saw-tooth became a spine growing from a lump. The whole tree would be nearly two miles high. Then the idea of a "tour" of its roots and branches would not seem a figure of speech.

But even if the sights in a tree appeared a hundred times as large as they now do, a tourist would not see much. The secrets of structure would still be hidden. If we wish to get any proper view of them, we shall have to reduce ourselves to a tenth of the hundredth of our actual height. This ncedle, upon which you have rashly ventured with me, though it hung only ten feet from the ground, is now nearly two miles above ground and is long enough for a two-hundred-and-twenty-yard dash; the top of the tree is seventeen miles above us.

Here you are, two miles above the earth, swinging in the light wind through an arc of five hundred feet. I will make you ten times smaller still, and give you ten times more power of seeing. Now the ground has become a vague, cloudy area twenty miles away; the needle is a mile and a quarter long, and you are sitting on an edge of it that is more rugged than the ridge of the Santa Ynex Mountains.

Perhaps you think we are now prepared for the journey, but I assure you that you will be disappointed if you set out in your present condition. You can not see much. Look down ten feet to the nearest one of the gray mounds that run in a row parallel to the edge where we are perched. It is one of the spots that dot all the surface of the needle. Even in your present smallness you see it as only two feet wide, and you can only make out a mass of pulp and dirt and resin. Nothing is clearly defined. I will make you ten times smaller still. Then, just for the sake of convenient arithmetic, I will reduce you by a factor of 2.I. You are now one three-thousandth of an inch tall. Twenty such creatures as you standing on each other's heads in a column would reach as high as the thickness of the sheet of paper on which you are reading. Do you think I overdo in making you ready to see a tree? You will shortly be complaining that you are too big.

Hold fast to this gummy hillock while I explain the scenery. We are near the base of a needle, one of a cluster of five, and are facing toward the base. Behind us is the tip of the needle, twenty-seven miles away. We are on a resinous mountain ridge that is composed of the water-proof coating of the needle. On our right is the wide, convex side of the needle, which is three hundred fifty yards across; but we see only half of the width because the other side is hidden below the slope. In color it is like a wilted lawn. Its expanse is covered with gray hummocks that heave and gently writhe 
like pulpy craters. On our left is the perpendicular cliff of one of the narrow sides of the needle. It is covered with the same sort of palpitating hummocks and is plastered with brownish lumps of resin in which are stuck white and brown boulders-things that mortals call "dust grains blown by the wind." The ridge on which we sit, between these two sides, looks as if it has been formed out of gray gelatine that had hardened with a translucent, glistening surface in a maze of mounds and hollows. Behind us the ridge slopes up sharply to a height of fifty feet. A hundred yards ahead of us is a queer thing.

As we clamber toward it, bracing our feet in the rough surfaces of the hollows and gripping the knobs on the mounds, we see that we are confronting a cone of gleaming gray. It is embedded in a hill fifty feet high and is pointed toward us, elevated at an angle, like a threatening coastdefense cannon, as if it were set to impale anything that rushed against it. If we clamber to its top and look forward, we see another sharp cone, mounted and pointed toward us in the same way. Back of us along all the miles to the tip, at intervals of from two hundred to six hundred feet, stretches a continuous row of similar cones-three hundred of them. They are the spines that a mortal can feel as a slight roughness when he rubs his thumb down the edge of a needle.

Of course each spine was constructed by a cell. It was formed by protoplasm that was pushed out to a sharp point and hardened there. It was created by an organism that was born with this special power, an organism which was one of the dozen of kinds provided for, to the last nicety of detail, in the swarming multitude of growths in the embryo of a cluster of pine needles. And this endlessly complex multitude was at first all provided for in one small part of a single cell. And that cell had been born from another which, within its single self, contained provision for all the sorts of cells that were to form wood and cones on a whole branch. And all the provisions for the branch were just part of an earlier cell that became a pine-cone. There can not be any chance or miracle about the birth of a single spine. It had to be exactly provided for in the ancestor of a line of cells.

Nor could the individual spines be left to grow as they liked. The number and placement of them had to be governed by some precise apparatus, so that they should grow only on the three edges, that there should be about thirty or forty to the inch, and that all of them should point one way. If we ask why they exist, we shall receive no answer but guesses. Perhaps the young trees were once less likely to be eaten if there were spines to rasp the tongue of some Mesozoic herb-eater. Perhaps-but nobody knows. There they grow, exactly as the seeds of this species have ordained that they should grow for unknown million of years. So stable and enduring is the mechanism of heredity in each of its small details.

Excuse the lecture while you are clinging for dear life to a mountainous 
ridge which swoops through the air thirty miles a second when the wind freshens, and which is so far from the other clusters of needles that you can not see them. We are alone in the wide sea of air-no place for reflecting on an abstraction of biology. Doubtless you wish to get under cover.

Hold fast while we crawl up the slope to one of the white spots that extend in straight rows from base to tip of the needle. It is a hundred feet away. We can reach it if we carefully watch our foothold and grip the sticky knobs that dot the surface.

So-here we are at the border of a pulpy square, forty feet wide, rising five feet above the level of the surface of the leaf. It is heaving like a breathing body. Follow me up the side of it and across it to the dirty looking center. This one of the forty-eight thousand breathing-holes on the needle. (Don't be astonished at that number; it is small because the pine is adapted to a dry life. Some leaves have millions of breathing-holes.) This hole is by no means a safe place, for the passage down through it will close at any time when the leaf grows too dry; we might be caught and suffocated. However, on this foggy morning the chances are good that the hole will remain open. The diameter is more than a yard at the top. As we crane our necks over the edge and peer down, we can see that the passage grows more restricted below, but it looks wide enough for us to wriggle through. Now you begin to realize that you were not made small enough for a comfortable trip through a pine tree. I am going down head first, because there is no fear of dropping into any deep cavern-the space in the needle is close-packed with equipment. You may go feet first if you will feel safer.

For five feet I make a plunge, staying myself with outspread arms and legs; then I squirm five feet more between the soft pulsing walls of the funnel-and drop ten feet, as if I had broken through the ceiling of a room, to a cushiony floor that feels like a rubber mattress filled with water.

Of course this floor is a cell. Every place you can touch in all the height and breadth of a tree is part of a cell. The floor is a breathing, hardworking, intricate individual. In shape it is an irregular oblong, some fifteen feet in width. We are sitting on the end of it-as if on the end of a great sack of water that extends fifty feet in length toward the axis of the needle.

As our eyes become accustomed to the dim light, we realize that we are in a chamber about ten feet in diameter, formed by the ends of a dozen or more cells. These are pressed tightly together-in fact they are practically grown together; for there are ducts communicating between them, and they work as an organized whole. Here and there you can see that between the cells there are passages wide enough for us to creep through, but nowhere wide enough for comfortable walking. You should have allowed me to make you smaller.

If we gaze about a few minutes, taking in one feature after another of this chamber under a breathing-hole, we begin to realize that we are in the 
midst of manifold operations; every square foot of the walls is at work, pulsing, circulating fluids, moving globes and disks about bewilderingly. We feel the vibrations of industry, as if we were in the midst of hardworking machinery where all the noises have been muffled to a low roar. Even the chamber is not mere space between the units of the factory. It is full of activity. You can feel the currents of gas circulating-not in happy-go-lucky drafts, but with orderly purpose. If you had only consented to be made a thousand times smaller than your present lumbering self of one three-thousandth of an inch, you could now see what is happening. As it is, there is no way to show you except by coloring the currents artificially. Hold your hands close over your eyes for a minute while I release the necromantic dyes and let them diffuse themselves throughout the room ... No, not quite yet, another minute, please ... Now you may look.

The red wisps that seep from the cells and come blowing out of the passages between cells, making straight for the funnel above us and passing to the outer air, are oxygen. The bits of gray haze, which float gently from the cells toward the funnel and disappear upward through it, are watervapor. The dark-green strands which steal in toward us from the breathinghole, drifting toward the cells and disappearing into them, are carbon dioxide. As we watch these currents they seem gentle and aimless; there is nothing exciting in their appearance. But if we had super-eyes which could penetrate to all that is taking place, we should know that we are observing the most fundamental mystery in all the course of nature. We are seeing the inorganic world made organic. Be polite for the space of a paragraph while I tell what this means.

A leaf-whether of palm or geranium or cactus or pine-is a factory for converting water and carbon dioxide into organic food. Nowhere else in nature can this miracle be performed. Each of the cells that surround us is an organism which receives a supply of water from the ground and a supply of carbon dioxide from a breathing-hole. Its energy is supplied by the sunlight, from which it extracts certain rays and applies them to the water and the gas. By a process too elaborate and profound for the investigation of chemists it turns the energy of light waves upon these simple molecules, mingling six of each in a massive and unstable molecule of grape sugar $-\mathrm{C}_{6} \mathrm{H}_{12} \mathrm{O}_{6}$. This is easily and quickly converted to starch; it is altered to protein by the addition of elements brought from the ground; it is the basis of all animal life-for no animal could exist but for the food that is manufactured in leaves. The animal kingdom is a parasite upon the industry of the sugar-making disks.

If the cell were a perfectly efficient laboratory, it would build sugar molecules without wasting any water. For water is precious; it must be pursued by millions of industrious rootlets that fight their way through harsh masses of dry soil to wring from it the moisture that it grudges to 
yield. All this hard-won booty must be transported through the roots, up the trunk, along the branches, into the twigs, by leaf ducts, to the thirsty cells. Water is costly, the plant's greatest treasure. Yet it leaks away from the cells, out through their walls, and escapes from the funnels of the breathing-holes. Why should there be such waste? Simply because the needle is an imperfect apparatus. It works well enough to maintain a hardy tree in soil that is not too poor. But it is far from perfect. Here is a text for a long essay on evolution as a process of adjustment. All the adaptations of plants and animals are of that sort-fairly good, sometimes astonishingly good, but never complete. Evolution has been a series of makeshift contrivances.

Still this chamber of gases is by no means so illfitted for its purpose as you might imagine. The cells which open and close the outlet are automatically influenced by the supply of water in the cells; as the supply is depleted, the cells stretch out and make the hole smaller; they will close completely if a hot, dry atmosphere is robbing the leaf of too much water. Furthermore, the chamber keeps the gases well distributed. Carbon dioxide is brought alongside the cell walls, where they can absorb it, oxygen is carried out.

Look through the wall of this cell which forms the right-hand side of the chamber. The wall is thin and almost transparent. Behind it you can see the streams of protoplasm winding up and down and across, engaged in transactions too subtle to be even guessed at. Far along the side you can make out a globe, the nucleus, in which-if only our eyesight were more acute-we could see the chromosomes that lie ready to procreate if the signal comes. The central portion of the cell is full of sap, which is under pressure, keeping the walls taut. Many "organs" of the cell are vaguely visible - the technical' names for which are confessions of ignorance about their function-chondriosomes, Golgibodies, cytoplasmic granules, microsomes. Be at ease. I am not going to discourse on the unknown. I merely wish it understood that you are gazing, not at specks of stuff, but at the "organs" of a life which is far, far beyond comprehension.

Most prominent among the contents of this cell are the green disks, two or three feet in diameter, which float in the protoplasm. These are the places where some red and blue rays of sunlight are set to work for the compounding of water and carbon dioxide into sugar. If you were not so large, you would not be blind to what goes on within the disks. You can see nothing. Science has not yet been able to see anything. We might as well move on.

On to what? When you have clamped this gas-mask over your head and wormed your way two hundred feet toward the axis of the needle (only a third of the distance), you have passed a confusing array of cells of many sorts and of all shapes, jammed together like a medley of elastic factory rooms under hydraulic pressure, flattened here, bulged there, now almost 
spherical, again shaped like a narrow chest. If some botanist were here to lecture as we pass the various factory units, he could tell of cells which combine sugar with substances brought up from the roots, thus forming material from which to build protoplasm; of cells which make resin; of several sorts of cells which form channels for carrying sugar and starch and proteins and water and carbon dioxide. Further information he could not furnish. Which cells govern the repairs of an injured bit of the waterproof coat of a leaf? Whence issue the orders for sending to the stem more sugar, or for receiving more nitrogen and sulphur to increase the stock of proteins? What cells direct the ducts of a given area to furnish more water or to clear away more oxygen? In short, where reside the instincts that direct the cooperation of the two or three million organisms which live between base and tip of one needle? When science can answer, it will have made the first step toward understanding a tree.

We can not linger for any more speculations of this sort, because a long journey lies ahead. Slip into this tunnel which carries a stream of sugar solution to the base of the cluster of needles. What! You are afraid of drowning? But there is no way to move about in a tree except through these ducts that carry water up and dissolved food down. Be courageous. You have now entered into the life of the tree and will find that you can breathe in its sap. Have no fear. Dive in.

The current is swift enough to be rather terrifying, but you will grow accustomed to the speed. It feels like ten miles an hour, and it is that fast if you measure by the sort of standard you used in your human state. Then you had a unit of length called a "mile," which was about nineteen hundred times your height; when you traveled nineteen thousand times your height in sixty minutes you said you were going "ten miles an hour." You are now moving at a rate about nineteen hundred times your height in one hour. The rate will increase somewhat after we reach a large branch. Just what the speed of currents is in this pine I can not learn, but in some fleshy plants the movement of sap is, at times, as fast as five hundred and fifty miles an hour. So we are guessing our present rate very conservatively. As human beings measure distance, we are about two inches from the base of the cluster of needles; as that distance is measured by tree tourists, it is seven miles; hence we shall be forty minutes in reaching the stem.

Perhaps I had best remind you once more, at the risk of repeating too much, that this smooth, round tunnel through which we pass is not an excavation. It is not even a space left vacant by the architects of the needle. No, each section of the tunnel was originally a cell, which removed all of of itself except the sheath, broke down its end walls, and joined itself to the sheaths at either end, thus forming a continuous duct. All space in a tree, everything in a tree, was designed and made by cells.

As we swirl along and you grow accustomed to the fish-like way of breathing, you notice that there are fewer factory cells and that we are 
passing to a region of transportation and storage. Here a duct from another needle comes alongside ours; our tunnel will soon be one of a bundle of tunnels. Gradually, with the utmost nicety, the passages of the five needles are merged into one trunk system. We arrive at the stem.

Here is the junction point for half a dozen bunches of needles. The traffic is as congested and complicated as in a Chicago freight-yard. A hardened botanist may feel assured that all the transfer of water and starch and solids and proteins is managed automatically. Perhaps it is. But if we should try to map the maze of tunnels and the control-points of distribution, we should find that human wit was only dodging the issue when it uses the word "automatic." It would seem just as wise to call the day's work of Chicago automatic. Consider one slight sample-the disposal of some particles of the nitrogen which has been transported all the way from a remote tip of a root. It is very valuable; more of it is required for some needles than for others, and all the needles desire it. Nitrogen has no intelligence for dividing itself into five unequal portions and going where it is needed. A nitrogen compound is very sluggish and must be handled and shipped by sone sort of supervision. What forces apportion it in this labyrinth of busy highways? I am not hinting that there must be intelligence at work; indeed the required skill seems of a higher order than intelligence. I am only protesting that when we say "automatically" we say nothing. The imagination of man has never conceived any term for describing the way in which consignments of sulphur and phosphorus are handled in the node of a twig.

We return down the twig in a sugar stream, and continue on beyond to the branch from which it grows, a hundred-mile trip. You can read of the layers of which the twig is composed-the bark and cork, the cambium and wood and pith-in any text book. You might while away the hours by speculating on how a twig can increase its diameter each season. Three years hence it will be twice as large; its bark must reach twice as far; yet every minute of the time the bark must remain water-tight. For deadly enemies of the tree are always drifting through the air and will invade it if the least spot is left unguarded. Spores of fungi much smaller than the cells would enter the wood and feed upon its stores of food as certainly as bacteria always enter any broken skin of an apple and cause decay. So the bark must always be sealed. How does it increase its circumference without permitting any microscopical gap at any moment?

We enter the branch at a node where three other twigs converge with ours. We are to travel the length of it to where it joins a larger branchsomewhat more than the distance between New York and Chicago. Here the branch is only seven miles in diameter, and at its base is only ten miles in diameter. Somehow this seems impossible architecture. We can conceive a cable of those dimensions, but we can not conceive how the cable could be transformed into a stiff, staunch girder, bent through three ungainly 
angles, that would withstand any storm, though carrying a load of sails, and never be twisted or snapped in two. Human engineers will never devise the struts for such a truss. We marvel when we are smallsized tourists, but we never give a branch a moment's thought when we are sixty-nine inches tall.

If we should stop off midway of the branch, and if we had axes, and if we had enough time and a supply of food, we might cut our way out of this sap tunnel and hack a passage to the spongy heart of the branch. There we should find some open spaces. We could walk all the way to the trunk of the tree. But in order to reach such a passage we should have to chop for nearly a mile. I suppose you would prefer to ride. You may as well go to sleep, for we can hardly reach our destination in less than thirty hours.

When I think of the trunk of this tree, and of how my dull mind has never heeded it, I know that the soul of a savage is more sensitive than mine. It understands better than my cast-iron brain what a tree is. The savage discerns a spirit in it, he worships. I have never thought of anything in it but a wood-pile. The savage perceives a kind of truth that is hidden from all us bridge-playing joy-riders. Even a "vitalist" mystic has had more perception than I. Henceforth I shall try to lift up my eyes to the structures not made with hands. I shall never be able to see the spirit, nor can I ever credit the "vital principle"; for to my prejudiced intellect these seem fancies. But I can at least contemplate the unknown god of cytology and learn to have a humble mind when I see a spire of marvels spreading its magical green shops to the sun.

This trunk bears its leaves to a height of four thousand miles above the earth and spreads them two thousand miles on every side. In its construction there were no cables or cement or steel girders; there were no materials but soft, living cells that formed six-inch walls and pieced the walls together. Out of these tubular sections, whose average length is not more than fifty feet, they devise continuous pipe lines from the most remote root-tip to the highest and farthest needle-ten thousand miles.

On down the trunk we glide. We reach the level of the ground. We continue down for more than a hundred miles, and then can feel that our course is nearly horizontal. Our surroundings are cooler, for we are in a root, traveling out toward a big branch of it.

The current has almost ceased to flow. It is constricted in a narrower passage, and its load of foods is being doled out to hungry cells whose energy must be restored. Have no fear of them. They know what food they need and will not nibble at us. Be alert and don't let yourself get stranded in the smaller and more closely packed cells that now surround us. Keep edging your way along with all your might.

This rootlet is one hundred fifty yards thick at the point where we are, five hundred yards from the very tip. We must force our passage amidst these small, vigorous young cells that crowd before us so stoutly. It is hard 
going. You grow breathless. Well, this is the best that giants can do in such cramped space. We must give up while still three hundred yards from where cells actually come to grips with the soil. We are at the edge of a zone of a rootlet called its "growing point," where cells are being multiplied so fast that the tissue is warmed by their energy; the place is a fountain of new cells which appear to press forward like a determined rabble. But all is orderly. Each of the tens of thousands of individuals knows how to place itself and what to do. If you stayed here a week you would find that the rabble had shaped itself into rows of ducts, and fibers of wood and bark, extending the lines that we have followed through branches and trunk and roots. This growing point is always extending the structure of the root and pressing forward upon the tip, forcing it onward through the soil.

Will you stop here and listen to some prosy words about the operations in the tip, or will you now consent to be made small, so that you may see something for yourself? Science can not reduce your size a great deal more. Just let yourself be minimized to a tenth of your present stature, till you are one thirty-thousandth of an inch tall, like one of the smallest bacteria-that is all that is required.

While you were recovering from the vertigo of the operation I have been carrying you back through the rootlet and out into one of the fine hairs that grow from it. The cells here are actually smaller than those which we saw in the needle, but to you, in your present state, they show a diameter of one hundred twenty-five feet. Finding a passage between them is possible, but difficult. We must take our time, looking for favorable places where we can pry cells apart far enough to make way for our bodies. Gradually, but sliding here and shouldering there, we pass a cell, then a second, finally a seventh. We are at the outpost of a tree.

The outer surface of this outermost cell is wrestling with a bit of loam that is compressed between a huge slab of mica and a boulder of quartz. The loam is in possession of some molecules of water. It grasps them greedily and tries to defend them. The wall of the cell presses close, squeezing between the loam and its protecting slab and boulder, slowly gathering the loam in its embrace, drawing the filmy bits of water by some attraction that physics can not investigate. Slowly, relentlessly, powerfully the cell continues its depredation. The loam is sucked dry. The cell gathers together its booty of moisture, conveys it to the inner side of itself, and pushes it against the outer wall of the next cell. This receives the water and transfers it to a third cell. The water is passed thus from "hand to hand," through the hair, into a fibrous root, and on to a narrow tunnel like the one which conveyed us down from the needle. The water is mingled with other droplets in a stream which flows on, parallel to the sap-duct, on for a hundred miles, on for a thousand miles, on and on till it is delivered to a needle and used in a sugar-making disk. 
The most painstaking study by the cleverest physicists has not revealed certainly how a tree lifts its water from root to leaf. No process of capillary action will account for the lifting of a fuid through such a height.* Sir Jagadis Chunder Bose, after years of careful examination, with the aid of most ingenious and sensitive mechanism, has concluded that water is conducted all the way by the action of individual cells, which pulse rhythmically and exert energy as only living creatures could. The learned world has listened to his theory respectfully. It may be correct, though the "mental picture" which he promises is not one that I can make out. I can not even tell whether the sap in his picture is moving through the interiors of cells or in a passage between cells. If the picture is more lifelike than my untrained eye perceives, we shall learn once more that a tree is not a system of mechanics, but an army of cooperating lives. That is to say, we have made an erudite circle and have arrived at a term which means that we know nothing whatever about the lives or their cooperation. We have arrived at the point where the savage starts his explanation of the spirit in a tree.

As we stand here at the edge of this marauding cell which plunders for the maintenance of a chlorophyll grain sixty-five hundred miles away in a needle, we wonder whence came its piratical instincts. It is a mass of inherited desires and abilities. It was born of an ancestry of cells that reaches back to a time, perhaps a hundred and fifty million years ago, when this genus of tree was first evolved upon the earth. They have left their record in the rocks for geologists to read.

The paleobotanist deciphers this record, and every syllable of his translation is scrutinized by rivals all over Christendom. The result of their combined translations is a proof that this tree, Pinus torreyana, was once a flourishing species, spread far over the earth's surface. For some reason, quite unknown to our best scholarship, the species declined in strength. In area after area it dwindled, shrank, disappeared. Now the only known remnants of the race are small clumps near San Diego and on Santa Rosa Island, and possibly some stray individuals at a few other points. This kind of tree has all but vanished. It will flicker out completely in a few centuries, except as man fosters it. Why did it die?

Here is a flourishing specimen, seeming to have unlimited vitality, growing lustily to a great height. Its vigor seems unabated. Why does its race not succeed in the competition of nature? That is one more secret of our pine tree.

* Capillarity and cohesion of water molecules is now considered a satisfactory theory.-Ed. 


\section{THE FINEST SHOW ON EARTH *}

\section{ED I N B. MATZK E}

If you were given the opportunity of viewing again one single scene from all those that you have enjoyed, that constitute memory's picture book of the past, which would you choose? Would it be one which portrayed the awe-inspiring grandeur of a total eclipse of the sun or possibly one which recorded the glowing, changing colors of an alpine sunset? Or would you turn to a page showing the brilliant patterns of a New England landscape when the days are growing short and your breath rises lazily before you? While a total eclipse and a sunset are passing fancies on the part of nature, lasting for moments or minutes at the most, autumn foliage in eastern North America clothes the hills in brilliant vestments for weeks at a time.

To what are these colors of autumn due? The ordinary cells of plants owe their green to two pigments, called "chlorophyll $a$ " and "chlorophyll $b$. " These can be extracted from the leaf with warm alcohol, and the solution becomes a deep rich green, a green that through long association with us on this earth has become soothing and restful to our eyes; no color seems quite so pleasing as that of chlorophyll, no color is so important, since only plants that contain this can manufacture foods, for themselves and for us. In addition to the two chlorphylls, two other pigments are also present in ordinary leaves; these vary from yellow to reddish orange. One of these, carotene, is common in carrots-a scientific justification, it has been suggested, that "carrots are good for the complexion." The yellow and orange pigments are less complex, chemically, than the green chlorophylls, and they are also more stable. When the weather gets cold in the fall, the green colors, which break down more easily, tend to disappear, and then the yellow and orange, which have been present all along but masked by the others, become visible. These are largely though not entirely responsible for the golden tints of autumn. These four pigments together constitute only a minute fraction of the fresh weight of the leaves-about twenty-six hundredths of one percent-a very small fraction when we consider how important they are, especially the chlorophylls. There is another group of soluble yellow pigments which are not very significant in fall coloration.

Most striking of the colors of autumn are the reds. These are due to an entirely different group of substances, called the anthocyanins, compounds associated with sugars, dissolved in the cells of the leaves. These vary from the brightest scarlet through all the shades of red and magenta to the deep blues and purples found in some leaves and many flowers.

* Reprinted by permission of the Scientific Montbly, American Association for the Advancement of Science. Copyright $194^{2}$. 
Simple experiments show that the color of these substances depends partly upon the amount of acid present. If the center of a head of red cabbage, which is rich in these anthocyanin pigments, is cooked, and to the liquid obtained a little vinegar is added(vinegar is acetic acid), the juice of the cabbage will become bright red; if a little ammonia is poured in, the solution becomes blue to yellowish green. The greater the acidity, the deeper the red color will be.

Various factors are responsible for the development of these red and blue pigments. First there is the genetic makeup of the plant. Maples inherit the ability to manufacture these substances, while hickories do not; the petals of the buttercup are never red, while those of the scarlet sage rival the faces of the most highly embarrassed.

For the most part, light is important in the formation of the anthocyanins. The sunny side of an apple is brighter than the shady side; the "stem end" is more richly colored than the "flower end." Perhaps in days gone by you pasted your initials in opaque paper on green apples, and when the fruits ripened there were the letters in green on a background of red. The more modern version of this, as described by Arthur, is to paste Cellophane on a green apple, put India ink marks on the cellophane, and then expose the apple to a suitable lamp; the skin of the apple shaded by the ink remains green. Photographic negatives have been printed on the skins of apples in shades of red and green, using sunlight as a light source.

It has long been known that red leaves of the Virginia creeper contain more sugars than green leaves on the same plant collected at the same time. In 1899 Overton put the leaves or leafy stems of various plants, such as some species of lily, of holly and of columbine, into sugar solutions, and after some weeks they became red. Injured branches of trees often become bright red, while the rest of the tree is still green, presumably because the sugars manufactured by the leaves are not transported away, and consequently stay where they are made. Abundance of sugars favors the development of the red pigments.

It is common knowledge that brisk weather-without prolonged frost -is conducive to rich coloration, and experimental work supports this general observation. Both with leaves and flowers this is true. A blue bellflower and a red primrose were pale, almost white, when grown under warm greenhouse conditions. Cool weather, though preferably not too frosty, stimulates colors in autumn leaves as well as in healthy youngsters.

Though abundant water favors the growth of plants, it does not result in brilliant coloration. Of course drought is fatal, but a degree of dryness toward the end of the season results in beautiful colors. Experimentally this can be shown by watering sparingly some plants that are "vulnerable," and by watering others lavishly; the former will have the red pigments more strikingly developed.

Although leaves rich in sugars are often brilliantly colored, plants grow- 
ing in soil abundantly supplied with nitrogen are often just green. In general both leaves and flowers of northern plants are brightly colored, due to the strong light and low temperatures. However, in 1902, Wulff, collecting plants far above the arctic circle in Spitzbergen, found that in some areas visited by northern birds and fertilized by their excreta, which are rich in nitrogen, the plants were a healthy green, while the same species, growing in poor soil, were brightly colored. Anthocyanins develop best when the supply of nitrates is limited, even if the other conditions are favorable, suggesting, perhaps, that opulence and loveliness do not necessarily go together.

All these factors are important in the formation of these red-blue pigments, known as the anthocyanins. Normally they do not act separately, but through complex interrelationships, and there are exceptions to all of them. Although light is so important in the formation of these substances, the root of the beet, which develops in the dark, is rich in anthocyanins. But in dealing with living things there are always exceptionslittle touches that make life worth while.

The drab brown colors of the late autumn, those of the sere if not the yellow leaf, result largely from still another group of substances, the tannins, or from compounds related to them. These are the same materials that are derived from the bark of certain trees, especially oak and hemlock, which are used in the tanning or hardening of leather. Tannins are almost universally present in the higher plants, though generally not in quantity sufficient to make their extraction practicable.

When the green pigments break down in the fall, the yellows which have been present all along become visible; simultaneously the reds and blues develop in certain plants so that various combinations and color effects are produced. After all these have disappeared, the brown remains - the brown that is destined to form a part of this good earth.

Most important of all our trees in producing the vivid colors of autumn, particularly in northeastern United States, is the sugar maple. Sometimes this is just yellow, but more often red pigment is developed, especially toward the tips of the branches, where the illumination is most effective. This tree is the one which is tapped in the spring, and from the sap maple syrup and maple sugar are obtained. It forms extensive groves, especially in New England, and is really the king pin in the coloration of the north. There is a brilliance to the red of the sugar maple that is unrivaled in any of our other trees-a brilliance that gives it an animation and almost a touch of light-heartedness that rather belies the temperament of the sturdy people with whom it shares the soil. In swampy areas similar effects are produced by the red maple, though it, too, may be just a bright yellow.

Associated with the sugar maple are the birches, especially the white birch. These are normally yellow in the fall, and it is common to see the gold of the birches and the red of the maples standing in sharp contrast 
to the dark green of the white pines and the hemlocks; such contrasts make the colors appear all the more striking. This is especially true in New England, where the "murmuring pines and the hemlocks" are so wide-spread. The aspen leaves also add their touch of flickering yellow, while the waxy barks of the white birches presage the snows that lie in store.

The rolling hills and ancient mountains of our northeastern states form a perfect setting, so that the trees for miles around may be seen at a glance -as if to make it easy for us to enjoy the sight. The hills and valleys and lakes and streams also offer a variety of conditions-of soil, of moisture and even of temperature, and so are important in producing diversity and intensity of color in plants growing close together, even in plants of the same species.

South of New England the center of the stage is held not by the sugar maple, but by the oaks. The warm reds and reddish browns are furnished mostly by these trees. Each species of oak adds its own touch to the general pattern. By far the most brilliant is the scarlet oak, which amply justifies its name in the fall. Not a striking tree otherwise, the scarlet oak passes unnoticed until it takes on its cloak of autumn, and then it stands out like one whose modest virtues have been unappreciated. There is a whole galaxy of oaks in eastern North America, each of which typically ripens into a color that is largely its own. The white oak, whose staunch timbers have been used so extensively in shipbuilding, often has leaves red above and white underneath. When they blow in the breeze, the tree presents a curiously changing color pattern. Pin oak may assume an orange-brown color; chestnut oak becomes a bright yellow; black-jack oak may be brownish red, but more often is a glossy light brown, suggesting the leather of new riding boots; red oak passes from green to yellow to brown, while black oak soon becomes a dull brown. In spite of all these variations in the oaks, and in spite of the brilliance of their coloration, compared with the sugar maple there is a slight touch of the sombre in their effects.

While the maples and oaks form the theme of this symphony, the variations are provided by many of our other trees. Dogwood, white or pink at blossom time in the spring, is just as pleasing in the fall, with its red leaves and red fruits; and dogwoods are found from Maine to Florida and west to Texas. Along the banks of streams, and in low ground generally, the sour gum and sweet gum are often seen. These may also be red, or they may be clothed in royal purple. Sour gum is one of the first trees to turn in the fall-a harbinger of the great display to come. White ash may be yellow, or it is sometimes reddish or bluish purple. Sassafras, whose roots are sometimes brewed into a tea, especially in the spring, and served (under protest) to children, adds its tone of bright orange to the drier hillsides. Like the dogwood, it is widely distributed in eastern North America. 
While these trees wield a giant brush of red and purple, others, such as the chestnut oak, are responsible for the brilliant yellow. Hickories, cspecially saplings, of ten show the touch of Midas. There are hillsides on which the tulip tree grows that look for all the world like the pot of gold at the end of the rainbow. The tulip tree is one of our oldest trees, geologically speaking. It has literally come down through the ages. In the Blue Ridge country it gets as much as two hundred feet in height and ten feet in diameter. Also adding its light yellow to the autumn landscape, especially in the haunts of man, is the Ginkgo, maidenhair tree of the Orient. With its fan-shaped leaves and exotic type of branching, it seems indeed like a tree of the Far East, especially to an occidental. It is known definitely only in cultivation, having come to us as a temple tree from China and Japan. Once found growing wild clear across the northern hemisphere, it has aptly been called a "living fossil," for it alone survives of an ancient group that has otherwise passed. Seward has suggested that each year, for a short time, its leaves reflect the glory of that golden age when it flourished so abundantly.

Last of the trees to turn is the black cherry. Rather appropriately, it takes on all shades, from yellow to deep red to dark purple-a fitting resumé of events that have transpired, and all the more striking when, in November, the skies are often dark and even the noon-day shadows are long. At this time, too, the steel-gray bark of the trunks of the beech stands in marked contrast to its light brown leaves.

Although trees play the major role in this whole display, shrubs also, contribute, especially the sumachs and the blueberries. Most of the sumachs, like the dwarf and the smooth, become bright red or scarlet. At times though, the staghorn sumach, whose twigs are downy like antlers in spring, takes on all the colors of the rainbow, from violet to red, sometimes in one leaf, and almost in one leaflet. "Infinite shades of color" says the artist; "gradual changes in acidity," says the scientist.

Related to the sumachs is the poison ivy, usually a vine, but shrubby at times. Its leaves are often bright red, in contrast to the ivory white fruits. The latter look like simple symbols of purity, though they are poisonous. Boston ivy shows similar color effects in the leaves, but without a trace of malice.

No other shrubs are so common in eastern North America as the blueberries; some of them are to be found growing in dry soil, while others inhabit swamps and bogs. Almost universally they turn a bright red in the fall; they may augment the colors of the maple, the oak and the sour gums, or they may stand in sharp contrast to the green of the pitch pine, the southern white cedar and the mountain laurel. Due to the oaks, sumachs and blueberries, much of New Jersey looks toward the end of October as though some giant had passed through the countryside with a single large pot of red paint and had applied it lavishly. Barberry, including the 
cultivated form, becomes a bright, slightly rusty red. On Cape Cod and in New Jersey the cranberry plants in the bogs turn a dull, reddish purple after the fruits have been picked; at the same time glasswort splashes its vivid red against the brown of the grasses in the salt marshes along our coast.

In dry, rather sandy soil the grasses, especially the beard grasses, may be seen bowing in unison to let the breeze go by. These also become colored in the fall, forming reddish brown carpets on the hillside. Very slowly do they fade, so that the tints of autumn may still linger at Christmas time; and these grasses often stick up hopefully through the first thin snows. Only long after the winter silence has descended do they fade into a pale yellowish brown.

Not a little is added by the fruits that ripen in the fall. Bittersweet sprawls and twines and shows its orange capsules and scarlet seeds; hollies, growing in swamps as well as in sands, mature their red berry-like fruits; barberry bushes are often laden with red; while hawthorn, after the leaves are gone, shows brilliant red against the blue of the autumn sky.

These are some of the more important contributors to that symphony of color that is played each year on the hillsides of North America. If there is a "hard-frost" or a pronounced "dry-spell," the performance is syncopated, leaving the dark green of the pines and hemlocks and spruces enlivened only by the barks of such trees as the birch, the beech and the red maple.

The brilliant display of autumn is really the result of two sets of factors; one is the wonderful assortment of broadleaved trees in the East, capable of developing these colors; the other is the weather-the clear, bright days and cool, crisp nights that are so characteristic of the fall in our eastern states. "Football weather" is conducive to brilliant foliage, as well as to husky voices on Sunday morning.

On what parts of the earth does this coloration occur? There are only three large areas of temperate broad-leaved forests on this earth-one in eastern North America, one in eastern Asia and one in Europe, including central Europe and the British Isles. In the southern hemisphere such forests are almost lacking, except for a small region in southern South America, mostly in Chile, and very limited areas in Tasmania and New Zealand.

Eastern North America and eastern Asia are strikingly alike in their plant populations. It may seem rather anomalous that floristically there is a greater similarity between eastern North America and eastern Asia than between our own East and our own West. No places on this earth have a richer assortment of valuable broad-leaved trees than eastern North America and eastern Asia. Our West has matchless forests of conifers, like the pines, Douglas fir, redwood, and hosts of others. In fact, many of the lands that are washed by the waters of the Pacific are rich in conifers. 
But the West is relatively poor in broad-leaved trees. Climatically, eastern Asia, including much of Japan, is also similar to eastern North America. Consequently, it is logical to find that these two regions both show brilliant colors.

On the other hand, much of northern Europe has cool, damp, cloudy weather in the fall. This is not so true farther south, so that in the Danube valley beautiful foliage does occur. In parts of the Alps, due mostly to shrubs, the colors are also pronounced.

Continental Europe, furthermore, does not have the wealth of broadleaved trees that occurs in eastern North America, though many of the missing species will grow there if planted. In fact, many of them are found in Europe in fossil form. When the glaciers came down from the north in the last ice age, the plants in North America advanced south before them. Our mountain ranges run north and south, so that this was possible. In Europe, when the ice sheets came down, the flight of the plants was impeded, since the mountain ranges run mostly east and west. Local mountain glaciers advancing probably made the escape still more difficult, and consequently many of the trees perished. The sweet gum, the tulip tree, the hickory and the sassafras, for instance, grew in Europe until the last glaciation. This is known from fossils. Partly because of climate and partly because of the relative paucity of broad-leaved trees, Europe does not have the display that we have here. Eastern Asia largely escaped the last glaciation, while Greenland and Antarctica have not emerged from it to this day.

One topic more might be discussed-namely, the significance of coloration in plants. It is well known and generally accepted that insects are attracted to flowers partly on the basis of their color, though bees, like many men, are red-green color blind. Young leaves unfolding in the spring often show the same tints that are developed in the fall; and it has been suggested that these pigments serve to absorb light and thus raise the leaf temperature. Others claim that the pigments act as a protective screen against certain rays of light that may be deleterious in various ways.

While these last two explanations may possibly be of some significance in autumn coloration, it seems hardly probable that the development of these striking colors in the late fall is very important to the plant. The same trees may get along perfectly well without them, and often do. It appears more likely that the conditions are favorable, the stage is set, and the show goes on, without any deeper significance. Perhaps this is the botanical expression of "art for art's sake." In any event, it is a gracious way of saying good-bye.

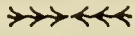




\section{"SUPERNATURAL" PLANTS *}

\section{K A R L C . H A M N E R}

First of all, let us supply the foundation by determining just exactly what a plant hormone is-the importance of which cannot be overemphasized. The name hormone was first applied to substances produced in certain organs of the animal's body and carried by the blood current to other organs where their effects were manifested. Plants, of course, do not have a blood stream, but it has been shown that there are substances produced in certain localities in the plant and transported to other localities where the effects become evident. These have been called plant hormones.

We are all familiar with the fact that plants turn toward the light. One of our favorite songs contains the following lines, "As the sunflower turns toward her god when he sets, the same look which she turned as he rose." This is a recognition of the responses of one plant to light. If you have ever grown seedling plants in your room, you may have noticed their tendency to grow toward the window. These responses to light are brought by a plant hormone.

Many years ago, early plant scientists were interested in finding out why plants grew toward the light. Working with tiny oat seedlings, growing in dark basements, they found that the plants did not bend toward the light if the tip of the plant was removed. If they removed the tip of the plant and illuminated one side of the tip leaving the rest of the plant in complete darkness, they could cause the plant to bend by putting the tip back on. The plant always bent toward the direction from which the tip had been illuminated. They were able to extract from the tips a substance which would cause the plants to bend even though the tip was not present. They identified this substance as a particular chemical compound which they called auxin. Its action on the plant is caused by the fact that it promotes growth in the cells on the side of the plant to which it is applied. When a plant is illuminated on one side this hormone travels down the shaded side of the plant causing greater growth there and thus causing the plant to bend toward the light.

Undoubtedly, the discovery of auxin has considerable practical value and may make quite a difference in our every day living. The chemist not only has identified naturally occurring auxins, but he has also synthesized new compounds which work just as well, or even better, than the ones produced by the plants themselves. These chemical compounds have proven very useful. A solution containing some of these chemicals, or a lanolin paste of them, may be applied to cuttings in order to stimulate a more rapid root formation. Sometimes the rapidity with which roots

\footnotetext{
* Reprinted from one of a series of radio broadcasts entitled Excursions in Science, General Electric Company, 1946.
} 
appear, after the chemical has been applied, is truly remarkable. Solutions of auxins have been sprayed on plants when they were flowering and frequently resulted in the development of seedless fruits.

An even more important practical application has been the use of auxin solutions to "stop drop" of apples. Apple trees are sprayed with these solutions shortly before harvest and the auxin causes the fruits to hang on for a much longer period than they would otherwise, giving the farmer more opportunity to complete his harvest before many of the ripe fruits have fallen.

Recently, there has been a new development and perhaps the most important application of auxin yet discovered. It has been found that certain weeds, when sprayed with a high concentration of auxin, are completely killed. In some cases the solution will selectively kill weeds and leave the desired plants unharmed. The use of one of these auxins, known chemically as 2,4 dichlorphenoxy acetic acid $($ or 2,4 D) may save farmers millions of dollars through the elimination of bind weed on many of our midwestern farms.

So you see, there has been a great practical application of the discovery of this plant hormone-a discovery which was brought about because certain plant scientists many years ago were interested in an understanding of why the tiny seedlings grew toward the light.

Apparently there are several other kinds of plant hormones, although none of these have been identified chemically. Evidence that these hormones exist is based upon experiments in which the plant receives a stimulus in one organ and the effect is produced in some other organ. Evidence of this kind indicates that flowering of some plants may be caused by a hormone.

Let us consider, for example, some of the responses of the ordinary cocklebur plant. The time at which this plant flowers is determined by the length of the day. It does not flower in the middle of the summer when the days are long, and it is stimulated to flower when the days become short in the late summer and early fall. You can keep the plant from flowering at any time of the year by exposing it to artificial light at night. On the other hand, you can cause it to flower in the middle of the summer when the days are long by placing a box over it at five o'clock at night and removing the box at eight the next morning, thus giving the plant a short day treatment. It is not necessary to cover the entire plant. You may place one or two leaves of the plant in complete darkness at five P. м. each day by tying a black bag around these leaves and removing the bag at eight A. M. each morning. Thus, the plant will flower if a few of its leaves are exposed to short day. The leaves receive a stimulus and transmit it through the stem to the buds which exhibit the responses.

But this is not the only evidence that a flowering hormone exists. If a 
cocklebur plant is caused to flower in the middle of the summer by exposing it to short day conditions, other plants may be caused to flower by grafting them to the plant which was originally treated with short day. If one branch of a cocklebur plant is induced to flower by exposing it to short day, all of the branches on the plant will flower whether or not they are exposed to long day or complete darkness. Many types of plants respond in a manner similar to cockleburs. Grafting experiments have shown that the stimulus for flowering may be transmitted from one species of plants to another.

All of this evidence indicates the presence of a hormone for flowering. Of course, one must realize evidence for a flowering hormone is circumstantial. We will not be able to say with certainty that such a hormone exists until the chemist has identified it, synthesized, and produced its effects by injecting it.

Assuming that scientists can find out what this hormone is, the point may be raised of whether or not this discovery will prove important. There is little difficulty in stating its value. It would be hard to speculate as to what we might expect this new hormone to do, but an attempt to draw a parallel with the discovery of auxin could be made. One may wonder what importance would have been attached to the efforts of the early plant scientists who were trying to discover the plant hormone which caused little oat seedlings to bend toward the light. It is quite possible that no one foresaw the applications which would be made of this hormone after its discovery. The plant scientists working on this problem spent much of their time in dark basements where they grew their seedlings, and they were considered useless but probably harmiess, by their neighbors, even by their fellow scientists. Yet we know of the great developments which have come from their discoveries. Thus we can reasonably assume important practical applications of the flowering hormone after its isolation and synthesis.

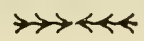




\section{IV}

\section{Nutrition}

THE kinds and amounts of foods that we consume determine to a 1 large extent our individual health and our fitness as a nation. This is brought out forcefully, of course, when a person exhibits signs of some specific deficiency in his diet or when a nation suffers from famine.

There is probably no subject of biological interest which is contaminated with more misinformation than that of foods. Many people seem to be obsessed with the idea that the normal diet contains an inadequate amount of vitamins and that they must perforce supplement their diet with regular and expensive dosages of vitamins. It cannot be too strongly urged that these products be taken only when the family physician recommends them for some specific condition. Another peculiarity of our food problem is that processors remove some of the minerals and vitamins and then add them with a great deal of unnecessary fanfare.

Probably the largest percentage of misleading publicity revolves around the packaged "health foods" for constipation, for ulcers, and for diabetes. Then we have the various soaps and lotions which will, apparently without any aid, bring the bloom of health to "tired" skins and, in the majority of cases, assure one of a "successful love life."

At the present time proper nutrition is one of the world's most pressing problems since hundreds of thousands of people are feeling the effects of the serious dislocation of the food raising and distribution activities of their countries. A nation is never contented on an empty stomach.

\section{FOOD AND FITNESS *}

\section{A. J . C ARLSON}

Our country produces probably the greatest variety and quantity of good foods. Are we making the most of this resource for optimum health? For the last ten years we have been told that one third of the American people are ill fed, that these forty-million American citizens suffer from malnutrition. Is this true? And if it is true, what are the reasons for it, and what can we do about it? In fact, very recently we were told much more.

* Reprinted by permission of the Scientific Montbly, American Association for the Advancement of Science. Copyright 1942. 
At the National Conference on Nutrition for Defense, held in Washington, D.C., a year ago, Dr. Thomas Parran, chief of the U.S. Public Health Service, said: "Studies of family diets by the Department of Agriculture in all income groups of the Nation show that one third of our people are getting food inadequate to maintain good health" and "less than one fourth of us are getting a good diet." If this is true, that makes it, not forty million, but about one hundred million Americans with an inadequate diet, from any and all causes. The question is: Is this true? These alarming claims for national malnutrition appear to be based primarily upon a series of surveys conducted by the Bureau of Home Economics of our Federal Department of Agriculture, assisted in some of the field work and statistical analysis by the Department of Labor. These surveys embraced some 4,000 urban and village families of various levels of income and some 2,00o rural families of varying levels of income, selected from representative regions of our country. The surveys consist in reports from these families as to how much money they spent for food, and what kinds of food were bought, and in the case of rural families, how much and what kind of food they consumed from the crops on their own farms. These field investigators (some of them on WPA) had to take or did take the people's word for all these alleged facts. It is impossible to determine the degree of accuracy or honesty (accuracy as to memory) of whatever member of these families gave the facts or alleged facts to the enumerators.

Nor do the surveys indicate the amount of foods actually eaten or the amount of food wasted. The latter factor is probably not inconsiderable, particularly in the families of the higher income groups. I know of no statistics on this point, but on the whole, my experience indicates that the food waste at the table increases with the economic prosperity of the family.

On the basis of the kind and quantity of the food bought or grown on the farms, the Bureau of Home Economics estimated the diets of these families as excellent, good, fair or poor. We wish to point out that no physical or medical examination was made of the members of these families. Not even such a simple physical fact as the determination of the body weights of the people involved seems to have been undertaken. I can only express my great regret that the value of these statistics must so largely be left up in the air as regards evidence for good or bad nutrition in our country by neglecting such an obvious factor as medical evidence of the health status of these people concerned. Good medical examinations of members of around 6,00o families in our country does not seem a superhuman task. I feel certain that if competent medical men in the U.S. Public Health Service, in the Bureau of Home Economics of the Department of Agriculture or in the Federal Department of Labor were not available, a suitable approach to national and state medical societies would have re- 
sulted in cooperation sufficient to carry out such a medical survey at little or no cost to the government. The surveys as conducted were made at considerable cost to our tax-paying citizens.

Is that the only evidence of national malnutrition? Do our hospital records, our mortality statistics, our medical examination of our young men for the Army and the Navy point to a nationwide malnutrition in America? Mortality statistics, even were they reliable, would only reveal extreme malnutrition. They would not tell us much about early stages of malnutrition. Between three and four thousand people are recorded as dying from pellagra (a disease due to an inadequate diet) each year. There is no recent rise in this category. Of course, there are many more people sick from pellagra than people who die from this disease, possibly as many pellagra patients as 100,000 in our country each year. Advanced scurvy is now almost unknown in the United States. Beriberi is somewhat less rare, especially if we include those cases due primarily to chronic alcoholism and consequent failure to eat enough good food. Rickets is not a killing deficiency disease. We may have anemia from too little iron in the diet; but lack of iron is just one of the many causes of anemia. So national mortality statistics fail to answer our question, but so far as they go, they do not point to a state of well-nigh universal malnutrition in the United States. And the same is true of records of our hospital admission. Of course, you may reply that doctors do not recognize early stages of malnutrition. Well, if physicians don't, are WPA workers and Washington politicians any more competent in this field? According to Colonel Rowntree, M.C., U.S. Army, the first 800,000 Army draftees of 1941 examined were on the average $671 / 2$ inches tall, or of the same stature as our 1917-18 Army draftees, but our 1941 draftees averaged 8 pounds heavier than those of World War I. According to General Hershey rejections of draftees on account of underweight are so far about the same as the rejection for obesity, or each around 4 per cent. So you see even the story of our draftees does not point to a universal and demonstrable malnutrition. According to the Statistical Bulletin of the Metropolitan Life Insurance Company, the average length of life as computed on the basis of mortality of the company's industrial policy holders in 1941 was 63.42 years. This is an all-time high for the sixty years that the company has recorded this information. This does not support the claim that one hundred million Americans suffer from malnutrition. But I am not willing to go all the way in supreme optimism, as does Mr. J. R. Hildebrand (National Geographic Magazine, March, 1942), who asserts that our "machine food age-born of roads, research and refrigeration-has made the United States the best-fed nation in history." We have the food to do it, had we the intelligence.

Well, what happens to us when we do not eat enough good foods? Can we know, without asking a doctor, when we suffer from malnutrition? 
And if we ask the doctor can he tell us when and what? The simplest situation is this: Assuming absence of chronic diseases, if an adult does not eat enough for energy needs he loses weight, if a child does not eat enough for energy needs he soon ceases to grow. Any layman can strip and step on the scales. The physical and mental impairments following prolonged inadequate intake of essential protein, essential fatty acids, essential inorganic salts and vitamins are more insidious. They can not at present be diagnosed even by the physician, unless they are well advanced, and by exclusion of many other factors that may produce similar symptomssuch general symptoms as decreased physical and mental endurance, decreased appetite, etc. The anemias we encounter in the population are usually not due to too little iron in the diet. Nervous disorders and poor intelligence are very rarely due to vitamin deficiencies. The signs and symptoms of such dietary deficiency diseases as scurvy, rickets, pellagra, beriberi, "war" edema (protein deficiency) any up-to-date doctor can detect and eliminate. But no one (doctor or layman) can be sure in regard to the early stages of these dietary deficiencies. We have recently been told by a national committee of physicians, who should know, that one of the first signs of malnutrition is decreased appetite, and that laymen can diagnose their own state of nutrition by the state of their appetite for food. This is too good to be true. If it is true, and it is also true that one hundred million fellow citizens suffer from malnutrition, it is clear that the American appetite for good food is sunk, and that it probably will take something more potent than synthetic vitamin pills to restore it to a level of national safety.

This sounds discouraging, if not alarming, at least to laymen. Must our national safety and well-being in the matter of nutrition be thus left in the fog, pending further medical and nutritional research? Not at all. America is a paradise in the matter of abundance and variety of all the foods requisite for an optimum human diet. And if we are average normal men and women, we still have our primitive urges of hunger and appetite, notwithstanding recent published assertions to the contrary. How do you suppose our ancestors carried on, in the total absence of modern knowledge of food chemistry, vitamin requirements and the alleged necessity of "a pint of milk a day"? I do not think Sioux Indians got much milk from the wild buffalo. The American Indian had neither cows nor goats. And yet he carried on. It is evident that for the greater part of human history man did very well nutritionally by eating enough of all available varieties of natural foods, guided by his hunger and appetite. Nutritional safety lies in omnivorousness, in consuming, so far as possible, foods in their natural states, and, in the case of fruits and vegetables, eating some of them raw. Some of our malnutritions started with the processing, the refining and the "purification" of such foods as the cereal grains, modern milling processes shunting the most valuable part of these natural foods into the 
mouths of chickens, cattle and hogs. The cereal grains hold valuable proteins, vitamins and minerals. Human dietary safety on this front would seem to be: Go back to first principles-putting the whole grain into the flour and the bread. This can be done. We can learn to like it. There is no more "purity" or nutritional virtue in white bread than in white winter butter. I think we could learn to prevent the oxidative rancidity of whole grain flour. And until we have that problem licked, what is the matter with storing the wheat and milling the flour as we need it? I do not see any essential economic principle in storing the flour in place of storing the wheat. In my judgment, the recent addition of a little of the vitamins and minerals now milled out of the grain and singing peans of dietary salvation over this "enriched" flour and bread is not a sound policy either for to-day or to-morrow. Let us get back to first dietary principles on this front also. The whole wheat, rye or rice grain is one of our least expensive protective foods. On the whole we can trust nature as to the genuine nutritive elements in the whole grain-yes, trust nature further than the chemist and his synthetic' vitamins. Recently, Professor Drummond (Journal, American Medical Association, March 7, 1942), the scientific adviser to the British Ministry of Food, voiced this reluctance to put the dietary safety of a nation on synthetic vitamins as a long-range policy. He thinks we must and should provide the natural vitamins in the natural foods. I stand on that platform, until we know a great deal more than we know to-day about foods and human nutrition.

How vital are vitamins? What happens when our breakfast, lunch and supper do not adequately balance with all the known vitamins every day in the year? The vitamins are vital. Even the kangaroo and the crow do not get on without them. They get all the vitamins required in their natural food. So did our ancestors. So could we. On an adequate abundance of natural foods we store vitamins in the body against weeks and months of vitamin scarcity. If we live mainly on such vitamin deficient foods as white bread, polished rice, fat salt port, refined sugars, refined and hydrogenated vegetable oils, refined lard, etc., serious things happen to our health when our body stores of vitamins are depleted or nearly depleted. It should be obvious to all laymen that every meal every day does not need to be vitamin balanced. Our body stores take care of our urgent needs for weeks or months, unless we have already subsisted on the minimum for some time. It is a fact that an adult man in average good health can go without any food whatever for at least forty days, without showing any recognizable vitamin deficiency. At the end of a forty-days' fast the man is considerably emaciated and more readily fatigued, but his appetite for good food is keener than ever. There is to-day entirely too much blarney and ballyhoo about synthetic vitamin pills. Under any and all circumstances these pills are said to give us the abundant life, including intelligence, men- 
tal stamina and moral conduct! The tragedy here is this: Few if any of the people who can afford to buy these pills need them, few if any of those who need them can afford to buy them. The consumer should insist that advertising of food conform to honest and factual education of adults in nutrition, for it is obvious that the consumer pays the freight of all food advertising in the increased cost of the advertised foods.

We are urged to drink milk, and to eat meats, eggs and vegetables for our needs of inorganic salts. Is that a good insurance? Is it enough? Can we get adequate mineral insurance at less cost through other foods? While it appears true that herbivorous mammals have sought "salt licks" for countless ages, and our forebears fought wars for possession of sea salt as their more sophisticated descendants now do battle for crude rubber and mineral oil, it seems obvious that except for the element iodine in restricted areas of the earth the dietary needs of minerals were efficiently met by the common non-purified, non-processed natural foods. So far as I know this would still hold true, except for the cooking of such foods as meats, fruits and vegetables and the habit of discarding the cooking water. To be sure the otherwise excellent natural food, milk, is so deficient in iron that an exclusive or almost exclusive diet of milk for weeks or months brings on an anemia due to the iron deficiency in the diet. How does the American dietary stand as to some of the essential mineral needs such as calcium, phosphorus, iron and iodine? The iodine deficiency in the States whose soil and water were depleted of iodine by the waters from ancient glaciers is now taken care of by putting the iodine back into our table salt. The iodine was there before our ingenious chemists learned to take it out. In so far as purification deteriorates our food, the science of chemistry does not serve man's welfare. Professor C. H. Sherman, of Columbia University, an outstanding expert on nutrition, has long held the view that the American diet is probably too low in calcium and possibly in phosphorus for optimum nutrition. This problem is complicated by the fact that a modicum of vitamin D is involved in the adequate absorption and utilization of calcium and phosphorus, particularly in the growth and maintenance of our bones. Can not the possibility of a dietary danger in this field be met, universally and without cost, by adding a little calcium, phosphorus and iron to our table salt? This should offer no insurmountable difficulties, and there is no evidence that a slight excess above actual needs of these minerals works any injury to our health. We are urged to eat milk for its calcium. Yes, milk is a good source for lime. But milk is a relatively expensive food, and even in our country, with a plethora of foods there is not enough milk to go around, at least as long as we insist on butter and cream for our table and turn so much of the valuable skim milk into channels other than human food. I think we should put a little lime, phosphorus and possibly iron into our table salt as a national insurance 
towards good nutrition. But I wonder how many vitamin B pills we must consume before we nurture sufficient intelligence to take this apparently rational step.

It seems clear that we do not know the extent of malnutrition in our country. But some malnutrition, especially pellagra, obesity, underweight, anemia, does prevail here. Why? The causes for the malnutrition that does prevail are both numerous and complex. Among these are: chronic infections, worry and mental strain, faulty dietary habits, ignorance as to what makes up an adequate diet, personal laziness, poverty, misleading food advertisements, denaturing of such staple and standard foods as flour (wheat, corn) and bread, possibly too great consumption of purified sugars and candy, waste of good foods, especially fruits and fats, etc.

Since man and his health constitute our most important natural resource, we must proceed without delay and with all the brains at our command to find better and more reliable methods to diagnose the signs and symptoms of incipient dietary deficiencies. Such knowledge will give us a clearer understanding of what constitutes an optimum diet for optimum health, so far as health is determined by diet alone. This, it seems to me, is a primary charge on the science of medicine, of biology, the science of chemistry. But we who labor in these fields will proceed faster along these lines, if we are encouraged by an understanding of the urgency and the difficulties in the problem and the cash cost of its solution on the part of all citizens.

Pending this greater scientific understanding as to human food needs for optimum health, these important things can and should be done now: (a) cleanse our present food and nutrition education of all fads, of all selfish commercial and myopic political propaganda; and (b) move our nutrition education from the ivory tower down to comprehension and appreciation of the common man. We have the brains and the cash to do it. Have we the will to carry on this hard task, when a possible superior health for all is the only goal, the only reward? I wonder.

\section{$\rightarrow \leftrightarrow t$ \\ WHY WE EAT WHAT WE EAT * \\ WARREN T. VA U GHA N}

Why do we eat what we eat? Possibly this should be preceded by another question, "Why do we eat at all?" The answer is elementary: we eat because we have to, because we are hungry. Also we eat because we like the taste of things. Many a fat old dowager eats chocolate peppermints, not because she is hungry but because she likes chocolate peppermints.

* Reprinted by permission of the Scientific Montbly, American Association for the Advancement of Science. Copyright $194^{\circ}$. 
As a corollary, we also eat because we are in the habit of eating. In this country we are in the habit of eating three meals a day. The Britisher is not actually a different species of animal that requires four meals daily, but he has found tea and crumpets in the afternoon a pleasant custom and has made it habitual.

The same three premises will be found to apply also to the original question. What we eat depends in part upon necessity, in part on habit and in great measure on taste. Convenience is also a factor. The newborn babe does not suckle at his mother's breast primarily because he or his mother knows that mother's milk contains most nearly the ideal proportions of protein, fat, carbohydrate and minerals. He does so in part because it is the most convenient thing to do. Mother's milk is not an absolutely necessary food. Many children are raised, from birth, on cow's milk, and some who are allergic thereto thrive on substitute food mixtures which contain no milk of any sort.

Down through the ages, from the earliest savages, dietary habits have been conditioned in great measure by the availability and convenience of the various foods, their palatability and by past experience with them on the trail-and-error basis. Experience has taught us concerning their taste, nutritional value and harmlessness.

As we sit in one of the more sumptuous restaurants in a large city and glance over the many pages of the à la carte menu we might wonder to what kind fate we owe our opportunity to order any number of the most delectable concoctions garnered from the farthest corners of the earth. Aladdin could not have done as well, since many of the finest of these foods were unknown to him in his remote time. We no longer stroke the lamp, but with a few strokes of the pencil we are far better off than he was. Today nearly all of the really good foods on earth are available nearly everywhere, convenient as the corner grocery, palatable as man and nature can render them and guaranteed reasonably harmless by food laws and inspection. A good family dinner of today would render a Roman emperor of the banquet era green with envy.

How has this been accomplished? Several years ago an interesting novel started with the collapse of a bridge, the Bridge of San Luis Rey. On the bridge at the moment of the catastrophe there were a number of persons, some of them total strangers. The remainder of the book traced the former life of each of the victims up to the moment of the collapse, thus bringing to light those forces which gradually brought these victims together for their final destruction. As we sit, ready to destroy the delicacies before us, it would be interesting to trace them, likewise, back to their original sources. Space will not permit discussion of too large a number of our victims, but those selected will serve as examples for the experiences of others.

Our story must start with earliest times, when more or less isolated groups of the human race were scattered here and there over the earth, 
and before the words trade and commerce had been invented. Shall we start with the Garden of Eden near the eastern end of the Mediterranean or shall we be more modern and commence on the plateaus of Tibet? Shall we be ultra-modern and assume that those precursors which ultimately became man might, like plants, have started at several places on the earth, provided conditions were right? It makes little difference in the present discussion, although in passing we might point out a fallacy in the story of Eden. Tradition today has it that the apple was the cause of the downfall. Botanists tell us, however, that this fruit had its origin in cooler climates, northern Europe and especially northern Asia. The apricot appears to have been the more likely contender for the honor, since it appears to be indigenous to Asia Minor. One might argue that if the apple story is true, the Garden of Eden was not in Asia Minor but more nearly at the site now more widely accepted as the cradle of the human race. Parenthetically, however, the Bible makes no mention of an apple. It merely alludes to the fruit of the tree of knowledge.

We might use the apple as an example of the method of propagation and distribution of foods. It seems improbable that all varieties of apple came from a single ancestral tree. Today there are thousands of varieties within this genus, Malus. Some are edible, while others are not. It seems probable that, under proper conditions, plants closely resembling each other and now all grouped within the apple genus took their origins independently, in the same way that the wheat of today was derived from the wild grasses of Asia Minor, while Indian corn was developing entirely independently from the teosinte grass of Mexico or from another local ancestral grass.

The crab apple of North America is indigenous to the New World and presumably was developing independently while the finer edible apples were evolving in Eurasia. But the point to be made is that those varieties which came to be used as foods usually took their origins from some unusually fortuitous specimen and have been distributed across the continents from this original source. Today North America is the greatest apple region in the world. We have our indigenous members of the genus, most of which are still wild and scarcely edible, but the cultivated apple of North America was originally imported into this country from Europe and more remotely from its original habitat in the cooler climates of the Old World. To be sure, man has improved the fruit by fertilization, selection and cross-breeding, until there are now hundreds of more delicious varieties descended from the original parent.

But the happy fact is that most of those foods cultivated for use by man may be traced back through historical records to an approximate original source, even though there are inferior domestic varieties which are probably indigenous to particular areas.

It makes a rather thrilling picture to visualize nomadic tribes wandering here and there within rather restricted areas; coming by accident upon an 
unusually delectable specimen of a plant which they have been accustomed to use as food; returning to the same plant whenever feasible, to again enjoy its delicious morsels; and then, as they become less nomadic, taking seeds or cuttings from this particular specimen, to plant in a more convenient place nearer home; nurturing it most carefully, protecting it from the weather and feeding it as it grows, thus establishing the earliest rudiments of husbandry. Into the sequence of the picture, next comes contact, either peaceful or warlike, with other more or less remote tribes; realization that others have likewise developed better specimens of different foods; and the resulting exchanges by barter or by inportation following conquest, this being the first step in the spread of cultivated foods across the earth.

Much of this occurred in prehistoric time. Carbonized apples have been found in the habitations of the prehistoric Swiss lake dwellers. It is true that these may have been the original wild apples rather than cultivated varieties. Apples were known to the ancient Romans and Phoenicians, who raised them in their gardens.

Before the dawn of written history man made a great discovery which enabled him to depart from that nomadism which forced him to change his abode with the seasons, so that he might always be where food was available. The discovery enabled him to remain permanently in one place. This was the cultivation of wheat and the making of flour which could be baked into bread for use when fresh vegetables and game were not available.

The origin of wheat is not definitely known, but it appears to have been developed originally from the wild grasses of Asia Minor or Egypt or around the shores of the Caspian Sea. It was introduced into China about 3000 B. C. and was described as being present in Egypt about 2440 B. C. It was used by the Swiss lake dwellers. Fortunately, other groups had also learned to cultivate grasses indigenous to their own territories for use as food. Rye is supposed to have originated in the Orient. It has been cultivated by man probably as long as has wheat. Both were used in the Bronze Age. However, rye was not cultivated in ancient India, Egypt or Greece. It is today the principal cereal of northern Russia, Scandinavia and northern Germany.

Barley was probably the first crop grain of the human race. It was described in Egypt as early as wheat, and the Egyptians claimed it to be the first of the cereals used by man, introduced by their goddess, Isis. It was a sacred grain to the early Greeks, used in sacrifices and in the cereal festivals. Pliny called it the most ancient cereal. The Cimbri, early progenitors of the Britons, made their bread from barley, which remained the chief food grain of England until as recently as the eighteenth century.

Rice is the most extensively cultivated of the grains and is the principal cereal food for over one third of the entire population of the earth. It appears to have originated in tropical Asia and was introduced into China 
about 3000 B. C. The ancient Romans knew the grain, but it was not introduced into cultivation in Europe until the sixteenth century.

Corn appears to be indigenous to the region of Mexico. It has been in cultivation since prehistoric times and is unknown in the wild state. Columbus first saw corn in Cuba in 1492 . He carried it to Spain, from where it was rapidly distributed to most of the regions of the earth. When the new world was discovered corn was in cultivation from Canada to Brazil and from California to Chili. Some of the Icelandic sagas described as early as 1002 A. D., what may well have been corn on the New England coast. The early explorers following Columbus described the cultivation of corn and lima beans, along with pumpkins, by the Indians in the New England region.

As tribes grew larger and, for economic reasons and purposes of protection, banded together into nations, the distribution of cultivated foods within the nations was facilitated and commerce between them developed. Now, perhaps, we are in the era of the caravan routes across Asia, when trade dealt not only with hides and cloths, precious metals and jewels but also with the less highly perishable of the foods from foreign lands. Chang Chien, Chinese explorer, had established overland trade routes between China and the Roman Empire by 115 B. C. As the routes of travel, by land and by sea, reached farther and farther, the spices eventually made their appearance in the Mediterranean countries. They were not quickly perishable, and they stimulated the palates of the Europeans as nothing had done before. Almost from the day of their appearance, exploration and commerce were guided in great measure by the desire of the white man for spices and more spices. This desire was a potent factor in Columbus' discovery of America, Magellan's circumnavigation of the globe, and the early settlements in America under the British East India Company. Love of spices was the cause for many a war. Attila, the Hun, required three thousand pounds of pepper as a part of the ransom of Rome. Many were the massacres countenanced in the Dutch East Indies in an effort to retain a monopoly on spices.

As the various peoples learned of the uses of their own foods, and their value in commerce, they often made every effort to establish monopolies. On many occasions attempts were made, sometimes successfully, to steal the secrets. An outstanding example occurred, not in horticulture but in sericulture. The Chinese had preserved the secret of silk manufacture for many centuries. In $55^{2}$ A. D. two monks who had lived for some time in China first smuggled silk worms, in a hollow bamboo, to Constantinople, where, under the protection of the Emperor Justinian, they inaugurated the silk industry in Europe.

Coffee was indigenous to Abyssinia, where the natives ate the raw grain as a stimulant. In the fifteenth century the Arabs discovered the value of the bean and started its cultivation in southern Arabia. From the port 
of Mocha, knowledge of it spread to Egypt and Constantinople in the sixteenth century, to Venice and then to England in the seventeenth century. It was then that coffee houses and cafés sprang up in the European centers. Religious zealots denounced coffee as an intoxicating drink. The Arabs kept their secret until the eighteenth century, when coffee was grown successfully in Java. Today Brazil is the world's greatest coffeeproducing country.

Chocolate first became known to the white man when Montezuma, the Aztec Emperor, gave Cortez a drink of the delicious beverage from a golden cup. The Spaniards carried cocoa back to Spain, keeping its source secret for many years, selling it at a high price, as chocolate, to the wealthy classes in Europe.

Cinnamon, native of Ceylon, was known to the ancient Hebrews, Greeks and Romans, but was not cultivated by them. It was carried across Asia Minor by the Arabs, who kept its source secret for nearly one thousand years.

Apricot is native of Armenia, Arabia and the upper portions of Central Asia. The fruit was held in such high esteem that, according to Disraeli, Tradescant joined a crusade against Morocco in 1620 for the sole purpose of stealing apricots for import to Britain. The cultivation of apricots in England dates from that time.

In one way or another, we see, then, that foods relished by one group of persons were gradually disseminated to other parts of the world. At times the route was quite circuitous, as in the case of the Irish potato. This food, native of the mountainous regions of Chili and Peru, was unknown in the hotter climate of Mexico, at the time of the discovery of America. From South America it was carried to southern Europe, whence it made its way to Ireland. It was later introduced into New England by a group of Irish colonists. Here was a New World plant, introduced into a different part of the New World via the Old World. In this way it succeeded in passing the barrier of the tropics, where it does not grow. Its cousin, the tomato, made easier progress northward from South America, since the barrier did not prevent its propagation. Early explorers found the edible varieties in wide use in Mexico, as well as South America, and according to Jefferson it was being grown in Virgina in $178 \mathrm{r}$. It was not, however, until after 1812 that the tomato came into use as a food in this country. The prejudice against it was probably due to two factors. Tomatoes were supposed to be poisonous, possibly because of their relationship to the deadly nightshade. Also, the earlier tomatoes which had not been intensively cultivated were by no means as good as they are today.

The foods which we eat today may be fairly accurately traced back to nearly all parts of the world. To Asia we are indebted for tea, rye, onion, rhubarb, buckwheat, radish, pistachio, licorice, peach, cucumber, almond, grape and the soy bean. Tropical Asia has contributed the citrous fruits, 
rice, cottonseed, egg plant, black pepper, taro (dasheen, cocoyam), mango, mangosteen and endive. The islands of the Pacific and Indian Oceans were the source of coconut, bread-fruit, nutmeg and grapefruit. If there were no Ceylon we should have no cinnamon. Northern Europe and Asia comprised the birthplace of the edible varieties of apple, fennel, currant and gooseberry, while the mustard or cabbage family-turnip, rutabaga, cabbage, cauliflower, mustard, kohl-rabi, broccoli, Brussels sprouts-are indigenous to northern Europe.

From the region of the Caucasus Mountains we have obtained asparagus, quince, pear and plum. Asia Minor and the eastern end of the Mediterranean, where men made such early progress, is fairly well determined as the original home of wheat, barley, shallot, fig, date, English walnut, apricot, olive and artichoke. Garlic, although favored in Italy today, took its source from Tartary.

Southern Europe has contributed parsnip, celery, leek, chestnut, filbert, carrot and lettuce. The last may also have been indigenous to the Orient.

Africa has contributed no great quantity of food, but their quality is good. Spinach is said to have originated in northern Africa, watermelon, cantaloupe, and akee from tropical Africa and coffee from Abyssinia. The original home of the oat has been placed both in Abyssinia and the Danube River basin.

The New World has been no mean contributor. From North America come huckleberries, cranberries, pecans, hickory, pumpkin and possibly the kidney bean. Cocoa, corn, avocado, peanut, allspice, guava, vanilla, sapodilla, papaya, star-apple, cassava, chocho and sweet potato stem from tropical America, while pineapple, lima bean, Irish potato, tomato, maté and the herbaceous peppers found their origin in South America. A few foods were already so widely distributed in a cultivated or semi-cultivated form at the commencement of exploration that their original sources must remain unknown. This applies particularly to banana, plantain, ginger and yam.

Nor is the list complete. Within the last half century we have observed many new importations, particularly in our own country, where climatic conditions are so varied that both tropical foods and those that thrive in the cold northern climates may find suitable conditions for growth. The labors of the Bureau of Plant Importation, so delightfully described by David Fairchild in his memoirs, "The World Was My Garden," have made available within our own boundaries many of the most delectable of foods, especially those fruits indigenous to the tropics, such as mango, mangosteen, sapodilla, guava and akee. As time goes on these will undoubtedly come into more wide-spread use, as have their less perishable tropical cousins, orange, grapef ruit, banana and pineapple.

The foods that we eat today stem from three general sources: (I) those indigenous to America; (2) those imported by the early colonizers from 
the older civilizations, which in turn had collected them from remote places; and (3) the newer tropical foods which are just making their start.

The history of the cultivation of foods parallels the history of the human race. However, it has not been until well within historical time that commerce and exploration have made such wide varieties so generally available. We read of the banquets of King Solomon and the extravagant feasts of Belshazzar, and of the Roman banquets, some of which are reported to have cost the equivalent of a thousand dollars per guest. Let us sit in at some of these meals.

The ancient Hebrews, who learned their cookery from the Egyptians, made quite a ceremony of their feasts. Three successive invitations were sent to each guest. When all were gathered together they sat cross-legged around a low table. The food was mainly a stew, since knives and forks were not available. The cut-up morsels were folded by the guest between slices of bread and eaten. The grease was rubbed from the fingers onto other pieces of bread, which were thrown to the dogs, waiting as anxiously as they do today. Servants were ready with pitchers of water for washing the hands. There were two persons to a dish. The food included flesh, fish, fowl, melted butter, bread, honey and fruit, four or five dishes in all.

The Greeks inaugurated the system of eating in a reclining position, while being sprinkled with perfumes to combat the odor of perspiration. They had two courses. The first was fish and meat, vegetables and entrees. The second, pastry and fruit, was followed by salty cakes, cheeses and the like to promote heavy drinking. This was accompanied by music, songs and slave dances, and garlands were entwined about the heads of the participants "to counteract the action of the wine."

The Romans learned cookery late. In 174 B. C. there were no cooks nor public bakers in Rome. The common people lived on a porridge made of pulse. There were several vegetables. Fish, domesticated animals and wild game helped out. The wealthy learned of the luxuries of the table from the Asiatic wars. They went mad on the subject of gastronomy. The best cooks were the most expensive slaves. The Emperor Vitellius, an enormous eater, sent his legions to every part of the empire to procure new and exotic foods. In a typical Roman feast the first course, merely an appetizer, consisted of conger eels, oysters, mussels, thrushes served on asparagus, fat fowls, shellfish and marrons. The second course had more fish, venison, wild boar and wild fowl. The third, or main, course included the udder of swine, boar's head, fricassees of fish, duck and other fowl, pastries and bread. Cheeses, lampreys, tongues of nightingales, brains of peacocks and flamingoes, mushrooms and the rarest vintage wines were served.

While Petronius' description of Trimalchio's feast is satirical, we may presume that the foods listed were the delicacies of the time. Also, he could not have mentioned any foods that were then unknown. We may 
therefore list some of the favorite foods of the days of Nero, as follows: Mcats. Sausage, beef, kidney, pork, bacon, lamb, lambstones, sweetbread, liver, chitterlings (present-day chitlings).

Seafood. Lobster, pilchard (sardine), mullet, sole, lamprey (an eellike fish), snail.

Fowl. Wheatear, goose, capon, blackbird, pheasant, guinea, stork, thrusl, peacock, gizzard.

Game. Hare, boar, bear.

Fruits. Danıson, pomegranate, fig, date, apple, peach, grape, raisin, quince, olive.

Vegetables. Chickpease, pulse (a legume), scallion (shallot or onion), mustard, beet, lupine (a legume), turnip.

Seasoning. Pepper, vinegar, cumin (a spice of the caraway family).

Nuts. Almond, chestnut.

Sweets. Honey.

Dairy Products. Hen's eggs, goose eggs, cheese.

Confections. Tarts, custards, marchpane, junket, household-bread.

This was the day of the vomitoria, when the gluttonous banqueters stepped aside into special rooms provided for the purpose, emptied their stomachs and returned to start again. Perfumes, music, dancing, dice, gambling and votive offerings to the gods provided the divertissement.

There must have been considerable monotony to the diet. So many of our more delectable fruits and vegetables were lacking. There were no potatoes, tomatoes, chocolate, vanilla, corn, peanuts, pecans, rice or coffee. The list is not complete. They lacked many of the spices which are so popular today. According to story, garum was their favorite sauce. This was made from the entrails of fish allowed to ferment until liquefied, sort of a prehistoric Worcestershire sauce or anchovy paste. This story was told by Horace, who was the cartoonist of the day and inclined to exaggerate. It may not be quite true.

The Britons learned cookery from their Roman conquerors and from Germanic immigrants.

In the Dark Ages, all Europe forgot how to cook. Charlemagne's banquets were barbaric affairs, with never more than four dishes, chiefly spitted meat. With the Crusades the art was reintroduced again from the East. The Medici of Florence were chiefly responsible for the renaissance of cooking. Catherine de Medici introduced it into France, where, from the point of view of the epicure, it has remained paramount ever since.

Such, then, is the story of why we eat what we are eating today. It is the thrilling history of man, responding first to necessity, later urged on by the need for availability and convenience, and subsequently developing the urge for new tastes and for greater palatability of his sustenance. It is the story of patient husbandry through the ages, of disease and death following trial-and-error, of avarice, thievery and war. It is the story of ex- 
ploration and discovery. When, today, we complain that our soup is not properly seasoned, that our melons are not sweet enough, when we complain of the dryness of our grapefruit or of the sogginess of the sweet potato, let us, instead, give thanks to those unsung heros of the past whose exploits have made it possible for us to sit each day at dinners such as were never dreamed of by the epicures and gluttons, kings and emperors of bygone days.

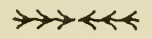

\section{FADS, FANCIES AND FALLACIES IN ADULT DIETS *}

R U S E L L M . W I L D E R

Many years ago, as a student in Heidelberg, I read an essay by a famous physiologist. It dealt with the borders of the realm of science. The domain of scientific knowledge was symbolized by an ancient kingdom. There was a central capital; a limited region roundabout was well ordered and habitable, and surrounding this latter was a dense forest. This forest was haunted by goblins. Some of these were only fantasies, figments of the imagination of the inhabitants of the cultivated part of the land; some in truth were mischievous demons. A number of highways radiated from the capital, but although they were conceived with the military purpose of ultimate extension to the borders, they mostly ended where the forest began, and beyond their endings few men dared to venture.

Consider the effect on this kingdom of science that came from the pioneer efforts of Louis Pasteur. The path he blazed through the forest of ignorance has been widened and straightened by the scientists who followed him, and now has been converted into a highway which is paved and illuminated as far as the frontier. Mankind thus has been protected from most of those diseases caused by parasites. In consequence, the pestilences of the past no longer haunt us, childbed fever has lost its terrors, and the mortality of infants has fallen dramatically. In consequence also, surgeons operate safely, and public health campaigns are ordered with such assurance that most of the so-called infectious diseases in time undoubtedly will be eradicated from the earth. I have in mind such diseases as yellow fever, typhus fever, hookworm disease, tuberculosis and syphilis.

Sometime after Pasteur another path was blazed through the jungle, and this now is being widened, straightened and lighted into a highway. You have heard the story of Eijkmann, in the Dutch East Indies, who observed the weakened legs of chickens fed with polished rice and showed

* Presented before the Minnesota Chapter of the Society of the Sigma Xi, Scientific Research Society of America, February 18, 1938. Reprinted from the Sigma Xi Quarterly with the permission of the Society of Sigma Xi. Copyright 1938. 
that giving the hulls of rice would cure the malady. That was pioneering. Along the trail came Takaki, who eliminated the disease known as "beriberi" from the Japanese navy. In Funk's paper, published in 1911 , entitled "The Etiology of Deficiency Diseases," there appears for the first time the word "vitamin," applied to a substance Funk had extracted from rice hulls, with which polyneuritis in fowls and beriberi in man could be cured. The blazing of the trail was completed, and road-building began. Knowledge which previously had been developed was incorporated in the new nutritional highway, knowledge of calories, of mineral materials, of the relative value in nutrition of different proteins, and already in a space of time shorter than the lives of most of us firm foundations have been constructed and the more dangerous turns of the road have been permanently eradicated.

With this highway safe for travel, the next thing to be done was to tell the people about it, to convince them of its stability, to provide rules of the road which would insure safe driving and prevent "jay-walking." The telling has been undertaken with unlimited enthusiasm, but not always by those best qualified, and too frequently by men whose interest was motivated by the commercial advantages obtainable. Promoting the vitamins, indeed, was done with such a blaring of trumpets that cautious men, including many physicians, who had the real interest of the public health at heart, became fearful that more harm would result than good. Their cautiousness has aroused the resentment of some of the experimentalists in nutrition which is not deserved. Physicians have learned from bitter experience to be critical of new knowledge pertaining to health. Their fingers have been burned too often.

Not more than thirty years ago, when knowledge about parasitic disease had reached a stage of development comparable to what now is known about nutrition, there still were surgeons and other educated people who pooh-poohed the "germ theory." I well recall the extreme disgust with which an orthopedic surgeon, having completed the manipulative care of a fracture in a case also requiring blood letting, would call on his junior associate to perform this part of the treatment and say to us students on the benches: "This job is one for a 'sterile' surgeon." I remember too how shocked we were that an older general surgeon refused to have anything to do with rubber gloves and the then still new ideas about asepsis. Even today the public has much to learn of the dangers which lurk in unpasteurized milk, and of the wherefores of public health measures.

The attitude of the average doctor toward the newer knowledge of nutrition is probably a reflection of the public mind. Like newspapers, they say, doctors give the public what it wants, and health measures are resisted by most people as infringements on personal rights. Doctors generally are called when somebody is sick. "Neither they nor the public think primarily in terms of prevention. They don't seem to realize that 
a large part of the prevention, even of infectious diseases, is dependent upon physical stamina, which in turn is partially dependent upon nutrition. The medical profession, because of this public attitude, is made up of trouble-shooters." I suggest that this is a reasonable criticism, both of the public and of very many, and perhaps a majority, of the members of my profession. Well people have not taken to the idea, said to have been prevalent in China, of paying doctors to keep them well and I think it is true that the average doctor in the private practice of medicine is not conspicuous for social-mindedness. However, there are thousands of exceptions. It must not be forgotten that promotion of most of our health legislation has been effected largely through the efforts of organized medicine.

The task which today confronts those of us who are interested in the public health differs in many respects from that which was accomplished so successfully by our fathers and grandfathers. It was possible to provide by legislation for protection against infectious disease and the number of people that needed to be educated about sanitation were relatively few. In matters pertaining to diet, legislation can help much less and progress must depend on universal education. Unfortunately, most people will never read "Man, Bread and Destiny" or Sherman's monograph on "The Chemistry of Food and Nutrition," or any of the many other authoritative treatises available on the subject of nutrition. Most people, I am sad to say, cannot even distinguish between authority and quackery. Most of them, so long as we retain the present system of economics, will get most of what information they ever receive from commercial advertising, which by its very nature cannot be disinterested.

To meet the problem of mass education in matters of nutrition, the Council on Foods was organized. At first it was called the "Committee on Foods of the Council on Pharmacy and Chemistry of the American Medical Association." The pages of popular magazines and newspapers were filled with advertisements of food products. The growers, producers and distributors of such products had learned the value of the health appeal. Great campaigns were promoted by co-operative organizations in favor of meat, of flour, of vegetables and other natural foods, as well as of packaged and prepared foods, with or without additions of minerals and vitamins. Copywriters were especially alert to dramatize the interest in vitamins, but proteins also received attention, as well as calories "for energy" iodin to "prevent goiter," iron to "combat anemia" and other minerals for other purposes. It seemed that some authoritative body was needed which could pass judgment on food products and food advertising in the same way that the Association's Council on Pharmacy and Chemistry had functioned so effectively in the field of drugs, and that thereby the mass education effected by advertising could be guided so that truthful information would be disseminated. The power of advertising is ter- 
rific. "It speaks and the whole world listens." The money spent annually exceeds a billion dollars, and I am told that the advertising of foods represents a substantial part of it. If this tremendous power could be turned to the socially useful purpose of disseminating truthful information about foods, it might not be impossible to make our people the healthiest and most vigorous men and women the world has ever known. On the other hand, like a sales tax, the cost of food advertising is borne chiefly by those who can least afford it, and to assess them for the disadvantage of receiving misinformation is to add insult to injury.

Manufacturers of food products, distributors, and others interested in the promotion of natural or processed foods for which claims are made in relation to the promotion or maintenance of good health, are asked to present to the Council not only the product but also the advertising material used for advancing sales, and if these conform to certain standards the product is accepted as complying with the rules of the Council. Acceptance is necessary before any food product may be advertised in any of the publications of the American Medical Association. One of these, the Joumal of the American Medical Association, gocs to every physician in the land. The product also will be listed in a book to be published on "Accepted Foods," and the manufacturers are allowed to display, on the package label and in accompanying advertising matter, a seal to indicate that the product and advertising has been accepted-The Seal of Acceptance.

A number of great advertising agencies and many manufacturers early indicated their willingness to cooperate, and now the number of food products which have earned the right to display this seal is impressive. An enormous amount of advertising literature has been reviewed and approved. Much of the labor of the Council may go unrecognized because it consists of the elimination of misleading health claims before they appear in the printed advertising. A great deal of advertising literature, particularly that prepared in the form of educational charts, goes to schools, and the importance of the reviewing and revising that this material receives cannot be overestimated. Many school teachers have learned not to use matter for display which does not carry the Seal. By these means those companies and advertising agencies which are willing to tell the truth about their products, and thereby assist the cause of good nutrition, are given a distinct commercial advantage.

The principal rule for consideration of a food by the Council is that no product will be accepted or retained when the manufacturer or his agent makes false, exaggerated, or misleading statements as to its source, method of collection, preparation, or as to its value for nutritional purposes. Also, if it is the opinion of the Council that the general policies of a given firm are clearly detrimental to the welfare of the public, its products, otherwise unobjectionable, may be rejected. In addition, certain practices of 
unfair advertising are discouraged, especially that of making disparaging statements about the wares of competing firms. . . .

The work of the Council on Foods and that of the councils supported by the American Medical Association for the consideration of drugs and of apparatus for physical therapy necessitates the employment of a staff of thirty-seven secretaries. The salaries of these secretaries, together with the necessary expense for office space and facilities, are assumed by the American Medical Association, whose burden is further increased by the fact that much advertising is lost to its publications because of products which fail to meet the standards set by these Councils, and which consequently are not permitted to advertise in any of its journals. No remuneration of any kind is received by the members of the Councils, and the charge that the Councils ever are influenced in deciding on a product by whether or not it is advertised in these journals is false. No single member of these councils would continue to serve if there were the faintest truth in such an allegation. The idea is preposterous.

In addition to passing on submitted products, the Council reserves the privilege of publishing informative statements about foods of any kind, whether or not these are eligible for consideration or have been submitted. The privilege, as a general rule, is exercised only in the case of firms whose advertising is flagrantly deceptive.* An example cited by the Council was "Ovaltine," manufactured by the Wander Company of Chicago. In the issue of December 12, 1931, of the Journal of the American Medical Association appeared a report by the Council from which I have taken the following excerpts:

The advertising claims made for "Ovaltine" were that it was a "Swiss food discovery" and "a scientific food concentrate containing in highly concentrated form practically every single food element necessary for life" ... "recommended by 20,000 physicians the world over . . . as a building and restorative food for convalescents and invalids, for stomach disorders and feeble digestion, for nervous and run-down conditions, as a means of inducing calm, restful sleep."

It was claimed furthermore, and I can cite only a tenth of these claims, that " 'Ovaltine' actually makes children want to eat more-and increases the nourishment and digestibility of every bite they take."

The product, as advertised, was a concentrated form of malt, milk and eggs flavored with cocoa. The Council (then the Committee) found "Ovaltine" to be "an example of the way in which our recognized foods are exploited like 'patent medicines' to credulous and ignorant people." Here is the emphasis on impaired digestion, sleeplessness and nervousness; here again are the pseudo-scientific claims, here again are the exploitation of a foreign chemist and the mystery associated with the type of advertising that was used to build "Santogen," the glorified cottage cheese, into America's most popular nerve tonic, more than a decade ago.

* The opinions expressed are not necessarily those of the editor or publisher.-Ed. 
This is only one example of dozens of similarly plain-spoken judgments by the Committee, or the later Council. Among the products to be found non-acceptable was Fleischman's yeast, distributed by Standard Brands, Inc., New York.* Numerous reasons were given. I can quote only one paragraph of the decision. It appeared in the issue of the Journal of the American Medical Association for January 24, 1937: "Illustrations of athletes are presented, with the comment that 'their sturdy build shows they are abundantly supplied with the four important health-building vitamins' would seem to imply that nothing else need be considered in the diet. No mention is made of vitamin C, nor is any mention made of calories or protein, or other dietary essentials, or the countless other factors involved in the maintenance of good health in addition to the four vitamins, A, B, D, and G." The objection in this case was to a sin of omission, the omission involving deception. Much else was found in the Fleischman advertising which was non-acceptable. The report continued: "There are now available on the open market a number of fresh and dehydrated yeast preparations which are advertised conservatively with claims based on the actual composition of the product. Fleischman's yeast, in contrast, is sold with grossly exaggerated or unwarranted claims." The adverse decisions of the Council on Ovaltine and Fleischman's yeast, and many other similar rejections, do not imply that the products in question are not wholesome foods. The fault, in most cases of rejection, is in the advertising. Another example cited by the Council was Welch's certified, pure pasteurized grape juice. There are many nutritional advantages in grape juice. It is a pleasant wholesome beverage, a good source of vitamin $\mathrm{C}$ and of certain minerals, a very acceptable product. The Welch Grape Juice Company, however, "leads the reader to believe that its product has specific properties for reducing weight, which is untrue; it cannot "burn up fat' and its sugar chemically plays the same part in metabolism as does any other available carbohydrate. Welch's is anything but 'the big element in the build-up diet of the child, comparable to mother's milk,' as claimed. Its advertising is manifestly an artfully designed piece of deception to enmesh the credulous and those uninformed in nutrition and physiology, a hodgepodge of nutritional and physiologic chicanery, falsities, vagaries, misrepresentations and claptrap, a revival of the nostrum blurbs of the past." These pleasant phrases are quoted from the decision. Perverse advertising of this character brings good advertising into disrepute and does harm to the majority of the food trade. The company, when informed of the opinion, failed to express willingness to accept the changes suggested, and therefore its product was rejected.

This brings up the subject of foods with therapeutic claims. The Council considers them separately, and believing that treatment of existing disease is a subject in which only physicians are competent to act, it

* Fleischman's yeast is now advertised in a much more acceptable manner.-Ed. 
permits such claims only when the advertising is limited to medical journals. The layman is cautioned to beware of so-called "health foods" for which the makers claim curative or health-giving properties. The Council has been explicit in defining the proper use of such terms as bealth, bealthful and wholesome. It permits statements of well-established nutritional or physiologic values of foods, but consider the term bealth food, and claims or statements to the effect that a food gives or assures health, to be misinformative: "An adequate or complete diet and the recognized nutritional essentials established by the science of nutrition are necessary for health, but health depends on many other factors. . . . No one food is essential . . . and there are no bealth foods. The term bealthful . . . as used, commonly means that the food described corrects a possible nutritive deficiency or some abnormal condition in such a manner as actively to promote health. It incorrectly implies that the food possesses unique (or unusual) health-giving properties ... which makes its use in advertising . . . misleading."

Advertising through the mails, although regulated by the rules of the Post Office, is very difficult to control. "Sucker lists" are compiled by professional snoopers who sell them to the purveyors of nostrums for the exploitation of the sick. For instance, persons who have diabetes, as I know from a large experience, soon are found out by these vampires, and from then on are deluged with intimate, solicitous letters advising a trial of this or that "cure," or the use of some so-called "diabetic food." A general decision of the Council on so-called "diabetic foods" reads as follows:

There is authoritative evidence that commercially prepared special diabetic foods are of limited usefulness to the diabetic patient and that the availability of insulin makes them no longer necessary. Artificial substitutes for ordinary foods are not to be favored; it is much better for the diabetic patient to learn how to plan his diet with foods in common use and readily available. The diet should be exactly prescribed in carbohydrate, protein and fat and total calories.

The designation of a food as a diabetic food merely because it is low in carbohydrate is now unwarranted and misleading and gives the erroneous impression either that the food, taken in unrestricted quantities in diabetes, is harmless or that it has remedial action. Except for the necessity of restricting foods to avoid overstepping the food tolerance, there are no special diabetic nutritional requirements. The exploitation of starch-free or low carbohydrate foods containing an excess of protein for use by diabetic patients is unwarranted. Protein may be tolerated almost as poorly, if not quite as poorly, as starch in diabetes.

The Council does not limit its activities to criticism. Where popular prejudice is found to be injurious to the food industry an attempt is made to combat it. Such prejudice also is socially disadvantageous. In some cases it represents the survival of antiquated scientific opinion, but usually it has been built up by the preachments of faddists or by the advertising of competing foods. Specific instances of wholesome foods that have been hurt by such prejudice are oleomargarine and white bread. The Council 
has attempted, by publishing the true facts, to correct the false impressions. Thus several brands of oleomargarine bear its Seal of Acceptance, and much has been done to wear down the opposition to bread. Let me quote from Dr. Fishbein's comment on bread:

Before making a definite statement as to the actual value of white flour bread as contrasted with whole wheat, it should be emphasized again that neither white flour bread nor whole wheat bread constitutes a single article in diet for any intelligent person. As pointed out by McCollum, there are many reasons why the American can eat white flour bread satisfactorily. "White flour," he says, "keeps much better than whole wheat flour, and so can be handled with less commercial hazard. The American public likes white flour bread, and I do not see any reason," he continues, "why this taste should be disturbed. The important thing is to insist upon the consumption of a sufficient amount of what I have termed the protective foods-milk and vegetables of the leafy type-to insure that calcium deficiency, and the vitamin deficiency of white bread, will be made good."

The supporters of whole wheat as against white flour for dietary purposes argue that the human bowel requires a certain amount of roughage in order to exercise its functions satisfactorily. This point must not be considered without reference to the varying conditions that may exist in different individuals. Dr. W. C. Alvarez of the Hooper Foundation for Medical Research has vigorously attacked the unguarded and unqualified recommendation of coarse food substances: "Some men and women can be greatly helped by bran," he says, "and their constipation can be cured if they happen to have the digestion of an ostrich; but if they happen to have congenitally defective or handicapped digestive tracts; if they have ulcers or narrow places, they cannot handle the mass of indigestible material, and they promptly get into trouble." Many other dietary substances such as celery, lettuce, spinach, and raisins provide roughage. Why ask bread to be like Messalina-all things to all men?

The various activities of the Council not only have borne fruit as regards the standards of advertisers of accepted products; the influence also is apparent in the advertisements of products not submitted or even of those that have been rejected. This is true for Ovaltine and Fleischman's Yeast, to which reference was made above; not that the advertising of either of these products would be acceptable now, without considerable revision, but that in both cases improvement has occurred. The same can be said of the advertising of the Kellogg products from Battle Creek and of Cream of Wheat, and numerous other well-known brands of processed foods. Advertisers are appreciating that elevating their standards is as helpful to them as it is to the public.

An authoritative pamphlet entitled "Facts, Fads and Frauds in Nutrition," prepared by Mitchell and Cook and published by the Massachusetts State College, contains the following quotation from Dr. L. Jean Bogert:

The fact is that food fads flourish because people want them. It makes little difference to the food faddist whether the particular dietary cult he follows incorporates a few grains of truth along with the dross or not; he is attracted to this cult because it satisfies some craving to try a novel dietary, to be in fashion, to attract attention by being unusual in diet, or from the desire to do something 
about his health. He may benefit by the simpler diet, more regular living, and especially through the belief that he will be helped, but this proves nothing as to the theories on which the cult is based, and the same results night have been more painlessly attained by other means. The food faddist represents a psychological type and often drifts from one dietary cult to another; as long as we have this type of people in such large numbers, diet fads and cults will persist and will be profitable to their originators.

At the risk of repeating what already may have been told, I must reiterate the general principles of good nutrition; because these are the "rules of the road" of the highway of nutrition. They are:

I. Eat more liberally of what McCollum names "the protective foods," milk, cream, eggs and cheese, green vegetables and the principal fruits. The American diet probably is sufficiently supplied with meat, potatoes and other tubers, dried beans, peas, and nuts. You probably could do with somewhat less flour and much less sugar.

2. Go in for variety in purchasing food. Not everything is known about what is essential. The principal food factors have been isolated, but there are others not yet identified. Safety lies in diversification of the diet, and danger attends restriction. No one food is a perfect food.

3. Watch your weight. Obesity shortens life expectancy and favors the development of diabetes and other so-called degenerative diseases. If the body weight lies above the standards set by the actuarial tables of the life insurance companies, limit the intake of fats, starches and sugar, but not that of milk or other protecttive foods.

4. Don't expect too much, even of a perfect diet. Other things than food can cause ill-health. The rules of the road are designed for community health, and may need modification to meet the requirements of certain individuals.

Truthful food advertising provides people with the information they need to understand nutrition, and better nutrition unquestionably will benefit our people immensely. On the other hand, incorrect or fraudulent advertising works immeasurable harm. Therefore, I would like to add one more rule to the "rules of the road." It is to follow the highway markers placed on the package labels and advertising matter of those products which have been accepted by the Council on Foods-The Seal of Acceptance. When purchasing foods give preference to brands that bear this label. Thereby you will protect your family; also you will help to convert food advertising into a socially beneficent institution carrying truly educational information about foods and nutrition to the consciousness of those less able than you are to protect themselves from prejudice, fads, fancies and fallacies.

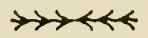




\section{$\mathbb{V}$}

\section{Circulation}

T seems but yesterday when men spoke with bated breath of the "great 1 killers" such as the black death, typhoid fever, diphtheria, and tuberculosis. At the present time we are hearing more and more about heart disease and its leadership in the decimation of mankind. Many believe that a large part of the increase in disorders of the circulatory system is due to the increased nervous strain of modern living and the inability of the system to repair itself fast enough. Whatever the reason, medical men are alarmed at the trend.

As the late Dr. Alexis Carrel pointed out-man is delicate. Every year, in the United States, there are about 100,000,00o illnesses, serious or slight. In the hospitals, 700,00o beds are occupied every day of the year. The care of these patients requires the efforts of 145,000 doctors, 280,000 nurses, 60,000 dentists, and 150,000 pharmacists. It also necessitates 7,000 hospitals, 8,000 clinics, and 60,000 pharmacies. The public spends annually $\$ 715,000,000$ on medicines. Medical care, under all its forms, costs about $\$ 3,500,000$, ooo yearly.

As the viruses, bacteria and other infectious agents are gradually but inexorably brought under control, the degenerative diseases are allowed to show their full potentiality and this is one of the reasons why the afflictions of the heart have inched their way upward into a position of leadership. Medical science now has another very real and difficult problem to solve.

\section{THE HEART AND CIRCULATION *}

\section{A. J. CARLSON A N V. JOH N O N}

Grossly, blood appears to be a homogeneous, red, viscous fluid. But microscopically, one can see that it is composed of discrete particles suspended in a watery fluid. The particles, called the formed elements, consist of the red blood cells, the white blood cells, and the platelets. These may be separated from the fluid portion, or plasma, simply by allowing blood, treated to prevent clotting, to stand in a tube. The formed ele-

* Reprinted from Machinery of the Body, revised edition, by A. J. Carlson and V. Johnson by permission of the University of Chicago Press. Copyright 194I. 
ments are slightly heavier (sp. gr., 1.09o) than plasma (sp. gr., 1.030), and they slowly sink by gravity. This difference in specific gravity is insufficient to cause settling of the-formed elements from plasma in the circulation where blood is kept in continual agitation.

The formed elements make up about $40-50$ per cent. of the volume of whole blood; and plasma, 50-60 per cent. These figures vary somewhat, even in health, with temporary physiological changes in the water content of the blood. If one sweats profusely, the cells are temporarily more concentrated, and the volume percentage of the plasma is reduced. If considerable water is drunk, for a short time there will be a larger proportion of plasma. In any case, the fluctuations are slight and temporary, and the relative proportions of cells and fluid remain fairly constant.

Approximately 90 per cent. of the plasma consists of water, in which many substances are dissolved or suspended. Obviously, at one time the plasma contains every product which tissue cells use and obtain from the outside and also all substances produced by cells which are transported to other organs to be used, in turn, by them, or excreted from the body. In addition, other materials are found, all of which contribute in some way or other to the maintenance of the relative constancy of the internal environment of cells.

In view of the importance of the circulating fluid, it is not surprising to find that elaborate mechanisms have been evolved which guard against its loss should a blood vessel chance to be ruptured. One of nature's devices in invertebrates has been to produce spasms or strong contractions of ruptured vessels, which serve to pinch off the opening. In vertebrates the same end is served by the coagulation or clotting of blood, which everyone has observed in his own blood escaping from a ruptured vessel. When blood is drawn from a vein into a beaker, it retains its fluidity only a short time. It is converted into a semisolid gelatinous mass, or clot, in some four to eight minutes. If clotted blood is examined under the microscope, threadlike or needle-like processes are seen to appear. As they increase in length and number, they form an entangled interlacing network called fibrin. Between the meshes the formed elements (red and white blood cells) and some of the fluid become entrapped in the solidifying mass. As it solidifies, the clot also shrinks, squeezing out from its interstices a straw-colored fluid known as serum, which collects above the clot and retains its fluid consistency indefinitely.

Two distinct factors seem capable of initiating the clotting process: contact of the blood with injured tissues or damaged cells or contact of blood with "foreign" surfaces possessing certain physical properties different from those of the smooth lining of the blood vessels, with which the blood is normally in contact.

Contact with injured cells- If blood is drawn into a vessel whose inner surfaces are properly prepared, taking care that fluid from tissues neces- 
sarily injured in the experiment at no time comes into contact with the blood, clotting fails to occur, or is greatly delayed. This fluid blood, even after hours, can then be made to clot within a few minutes by adding juices compressed from almost any tissue. Something present in cells generally, liberated when they are injured, is able to initiate the clotting process.

Contact with foreign surfaces: platelet disintegration-If blood is drawn carefully, so as to avoid contact with injured tissues, it will clot in the normal time if the container is glass. But, if the glass beaker is lined with paraffine, clotting will be delayed. The essential difference here seems to be the physical nature of the glass or paraffine surface to which the blood is exposed. Just what this difference is, is not clear, except that watery solutions "wet" a clean glass surface but drain from a paraffine or waxy surface, leaving it quite dry. In general, surfaces which are "wet" by water, on which a thin film of water tends to remain after most of the water is drained off, behave like glass as regards clotting. Surfaces which are not "wet" by water, in general, retard clotting.

Clotting can even be induced in the blood vessels when the blood is exposed to the proper surfaces. If a pin is stuck through a vein, a thin clot forms on the pin as the blood flows by. Or, if particulate matter of a suitable kind is injected, each particle soon comes to be covered with a thin clot.

Just why this happens is not clear. But, if the process is carefully observed under the microscope, it will be seen that certain of the formed elements of the blood-the blood platelets-collect upon surfaces like glass and quickly disintegrate. At a paraffined surface this occurs only slowly. The platelets seem to be involved in these surface relationships, and their disintegration apparently initiates clotting. This can be verified in other ways. If blood is drawn into an ice-cold vessel, and is immediately cooled sufficiently, clotting does not take place, and examination reveals that the platelets have remained intact. As soon as the blood is again warmed, the platelets quickly disintegrate, and clotting occurs. Why platelets respond in this way to temperature changes is not known, but the important consideration here is that the clotting seems to be dependent upon platelet disintegration. Various chemicals are also known which delay the breakdown of platelets. They all retard clotting.

\section{THE RED BLOOD CORPUSCLES}

The red blood cells, or erythrocytes, are the most numerous of the formed elements, each cubic millimeter of human blood containing four and a half to five millions. Human erythrocytes are biconcave disks, a little less than $0.008 \mathrm{~mm}$. or about $1 / 3,200$ inch in diameter. They are normally of such uniformity in size that histologists frequently use them as handy units of measurement, including a red cell in a drawing to indicate the size of the cells in any tissue, relative to this nearly uniform red-cell size. 
They appear to be perfectly homogeneous, although there are indications that some internal structural differentiation of parts exists.

The striking visual characteristic of mammalian red cells is the absence of a nucleus. This at once raises the question, "Are these cells really alive?" Evidence has been presented that the life of any cell is in some way bound up with the nucleus. Certainly, these red cells are alive during the early stages of formation before they pass into the circulating blood. For at this stage they possess perfectly normal nuclei. At this developmental stage they must be considered alive. And, indeed, even the mature red cells of vertebrates other than mammals are nucleated. But in man and other mammals the nucleus is lost before the cell becomes a functioning unit. It may, therefore be more accurate to refer to these structures not as cells but as corpuscles- "little bodies." Perhaps the relatively short period of time during which red cells course through the blood stream-about ten to thirty days, on the average-is in some way related to this absence of a nucleus.

\section{H E M O G L B I N}

The most interesting chemical entity in the cell is hemoglobin, which is a protein (globin) in combination with an iron-containing pigment (hematin). It constitutes $95 \%$ of the solids of these cells. Each $100 \mathrm{cc}$. of blood contains a total of about $15 \mathrm{gm}$. of hemoglobin. The main functions of the red corpuscles are carried out by means of this substance, which incidentally, also confers upon blood its red color. This pigment has the capacity for combining spontaneously with oxygen when free oxygen is present in relative abundance in the environment. The union is a loose one, so that, when the surroundings contain little or no free oxygen, the oxygen breaks apart from the molecule and, by physical diffusion, passes into the oxygen-poor regions.

\section{A N E MI I}

Anemia is an abnormality in which the red cells of the blood are reduced in number, or are deficient in hemoglobin, or both. Instead of a normal count of about five million cells, the anemic individual may have but four or three or even less than one million cells per cubic millimeter of blood, depending upon the severity of the anemia. Anemia is an abnormal state in which there is a breakdown of the formation-destruction balance which normally maintains the physiological constant of about five million.

The harm done to the organism in any anemia depends upon the chief function of the red cells, namely, that of transportation of oxygen. If there is a deficiency either of red cells or of hemoglobin, the quantity of oxygen supplied to the tissues generally is reduced, cell oxidations are hampered, energy liberation inadequate, and normal cellular function 
impaired. Muscles fatigue quickly, and, if the anemia is severe, they function scarcely at all, and the patient is bedridden, able to carry on only the minimal energy-liberating reactions requisite for bare maintenance of life. When even this is no longer possible, cellular death and death of the organism occur.

Of special interest is the condition known as "pernicious anemia." It derives its name from the fact that prior to 1927 this condition was as uniformly fatal as inoperable cancer. The blood count decreases for a time, there might be then a remission with a return of the count toward normal, and then a relapse more severe than the first attack. In each new attack the count goes lower, culminating in death after two to five years. Formerly, nothing could be done to stop this inevitably fatal course.

Soine years ago a group of investigators at the University of Rochester under the direction of Dr. Whipple became interested in experimental anemias produced in animals by repeated extensive hemorrhage. They observed the effects of various foods upon recovery from the anemia. They tried many foods quite empirically and at random, guided by no preconceived notions or hypotheses. Of all the articles they fed, they found that liver had the most striking effect. Of all the dogs made anemic in the manner described, those fed liver recovered more rapidly than the others.

Now, of course, this experimental anemia was not pernicious anemia. The latter condition in man displays features which are quite distinct from most other anemias. The appearance of the red blood cells is abnormal, and serious changes in the alimentary tract and central nervous system occur. The dogs showed none of this.

Yet here was a case in which red-cell production was in some way enhanced by the ingestion of a specific food, namely, liver. Why not try it, at least, upon patients with pernicious anemia? And so in 1927 two Harvard University physicians, Minot and Murphy, fed large quantities of liver to their patients daily. A striking recovery was effected. In the intervening years many investigators have confirmed these findings. A few days after beginning of liver feeding, the blood count commences to rise and in a few weeks approximates or even reaches the normal, and the subject is comparatively well. Note that liver does not cure the condition. When the liver intake is stopped, the anemia promptly returns and unless liver feeding is reinstituted, death is sure to follow.

\section{THE WH T E BLOOD CELLS}

The white blood cells are less numerous than the red cells, a cubic millimeter containing about 7,000 of them. They are semi-transparent and are difficult to see unless they are stained. This applies to most of the cells of the body except the red cells, which are naturally colored. The white cells are devoid of hemoglobin and differ from the red cells in other 
structural features as well. They are always nucleated, even in the mature form circulating in the blood.

Though fewer in number, the white cells are no less important than the red cells. When they are markedly reduced in numbers, as occurs in certain diseases, the individual becomes quite susceptible to infections, especially around the mouth and throat. Very great reduction in numbers (e. g. to 500 or 1,000 ) is fatal.

The best known function of the white cells or leucocytes is in the protection of the body against infectious disease. These cells, though usually spherical in the blood stream, possess the capacity for changing their shape and moving about in the tissues, ameba-like. Furthermore, they display the primitive capacity for engulfing particles by phagocytosis and for destruction and digestion of such particles as are of an organic nature. However, it is only in emergency situations that these activities come into play-that of invasion of the body by infectious organisms, or in other cases of tissue destruction.

In the immediate vicinity of infections by certain kinds of bacteria a remarkable series of reactions occur. When bacteria lodge in the deeper layers of the skin, they commence to destroy the tissues of the skin partly by means of toxic products which they liberate in their metabolism. Changes soon take place in the adjacent blood vessels. They dilate widely, leading a great quantity of blood into the infected region, producing the familiar reddening, and, because blood is warmer than skin, a characteristic, localized warmth. Quantities of fluid enter the tissue from the blood vessels, causing a swelling.

In all this the blood leucocytes display a typical behavior. They seem to adhere to the blood-vessel wall in the injured area, and, by ameboid movement, they migrate through the vessel wall in great numbers. Free from the circulating blood, they migrate toward the bacteria and phagocytize them. Fragments of local cells killed by the bacteria are also engulfed by the leucocytes. The ingested bacteria are usually killed and digested, but in the course of this process numbers of the leucocytes themselves may be destroyed by bacterial poisons. As they disintegrate, the leucocytes liberate their digestive enzymes, which, in turn, act upon other nearby dead cells and cell fragments. The net result is the local accumulation of blood and tissue fluids, digestive enzymes, dead tissue cells, living and dead leucocytes and bacteria, and cell fragments in all stages of disintegration. The whole conglomerate, thick, semifluid mass is called "pus," A rather large collection of pus is called an "abscess."

Fluctuations in the White Count-In the level of the white-cell content of the blood we encounter another example of a physiological constant. Physiological constancy is relative. There are fluctuations, and the normal is more of ten correctly expressed as a range, with certain upper and lower limits, than as a fixed, dead level. The normal range is larger for the 
white cells than for the reds. Counts anywhere from about 5,000-9,000 per cu. $\mathrm{mm}$. are found in normal adult individuals and are said, therefore, to lie within the range of the normal. Even in this same person fluctuations of this magnitude may occur from time to time. Attempts to correlate these changes with other normal physiological activities have not always been very successful. It has been said by some, for example, that during digestion or muscular exercise or exposure to cold there is a temporary increase in numbers. Other investigators have been unable to confirm these findings. To establish relationships of this sort would be most important, for it might yield suggestions as to the possible functions of the white cells in the normal individual.

There is no question about the increases in the white count which attend certain infections. In pneumonia, appendicitis, tonsillitis, and many other infectious diseases, the white count is elevated to $12,000,15,000$, 25,000 , or perhaps even to 50,000 . This we call a "leucocytosis." With the aid of the white count, therefore, it is possible for physicians to detect the presence of infections in internal structures like the appendix, which are hidden from view. Within limits, the degree of the leucocytosis parallels the severity of the infection, so that counts taken at frequent intervals often give evidence as to whether the infectious process is increasing in severity or is subsiding.

THE BLOOD PLATELET S

The third and last kind of formed elements are the blood platelets. They are roughly disk-shaped, far smaller than red cells, and show none of the special internal structural differentiation characteristic of cells. Their origin is obscure, although it is suggested that they too arise partly in the red bone marrow because bone-marrow injury of ten markedly reduces their numbers. Recent observations indicate that they are also formed by phagocytic cells in the lungs. A platelet count is difficult to make because of the rapidity with which these bodies disintegrate in abnormal surroundings. Such counts as have been made indicate that the normal variations cover a wide range. Though averaging about 250,000 per $\mathrm{cu} . \mathrm{mm}$., counts anywhere from 200,000 to 600,000 have been considered normal.

\section{CIRCULATION OF THE BLOOD}

The heart is a muscular organ lying within the thorax, inclosed in a sac of fibrous connective tissue (the pericardium). In mammals it is completely divided by a partition into two parts, the so-called "left heart" and "right heart." Leading from the left heart is a large vessel, the aorta, which arches upward, backward, and then downward, extending to the lower abdominal cavity. All along its course it gives off arteries, which branch more and more profusely into smaller and smaller vessels, the capillaries, whose walls are but one cell in thickness, whose internal cali- 
ber is about that of a red-cell diameter, and which are diffusely distributed to organs and tissues everywhere.

The capillaries then unite to form tiny veins which, in turn, join to form larger and larger veins. The veins of the lower portions of the body empty into the inferior vena cava, and the veins of the head and neck are tributaries of the superior vena cava. These two large venous channels empty into the right heart, completing what is known as the systemic circulation.

From the right heart springs the pulmonary artery, which soon divides into two, one for each lung. Each pulmonary artery divides into smaller and smaller arteries and finally into the lung or pulmonary capillaries, which penetrate all parts of the organ. These, again, collect into larger and larger veins, finally forming the pulmonary veins, which empty into the left heart. This makes up the pulmonary circulation. (The left and the right heart are each divided into two chambers.)

The atria or auricles (the receiving chambers, one on each side of the heart) have distinctly thinner walls than the ventricles (the pumping chambers, one on each side of the heart). The thicker walls of the ventricles are responsible for almost all the pumping action of the heart. The walls of the left ventricle are much thicker than those of the right. This we relate to the greater work done by the left ventricle. It pumps blood through the entire systemic circuit, while the right ventricle has the easier task of pumping blood only through the lungs, a much shorter distance.

On each side of the heart is a valve system, between auricle and ventricle, which permits blood to flow only from the auricle to the ventricle, and which is closed automatically by blood starting to move in the reverse direction. These are the right and left auriculoventricular valves. Guarding each exit from the ventricles are also valves of a somewhat different construction, called the semilunar valves, from the fact that each is made of three half-moon shaped leaflets. The long margin of each leaflet is attacked to the vessel wall, the short margin being free. The aortic semilunar valves are located at the beginning of the aorta. They permit blood to flow from the left ventricle into the aorta, but they are closed by any reflux of blood in the reverse direction. The pulmonary semilunar valves lie at the beginning of the pulmonary artery and prevent backflow of blood from the pulmonary artery into the right ventricle. There are no true anatomical valves at the orifices of the left and right auricles, where the veins empty into the heart.

The automatic rhythmicity of the heart has received much attention. The heart is not entirely peculiar in this respect, for rhythmic responses are the rule in many organs and systems. The intermittent nature of the breathing movements is a good example, involving rhythmic contractions and relaxations of the muscles of breathing. But this is different from the 
cyclic action of heart muscle in the following respect. If the nerves of the muscles of breathing are severed, the movements cease at once. Their contractions are entirely dependent upon rhythmic activation through their external or extrinsic nerves. The beating of the heart, on the other hand, continues even after all its nerves are cut. The rhythmicity and automaticity are inherent in the heart itself. In fact, if the organ is completely removed from the body, it will continue to beat for some time. Nor is the integrity of the organ itself required for this automaticity. A bit of the heart muscle, cut off from the organ, may continue to contract rhythmically. Even in tissue culture, microscopic pieces of cardiac tissue sometimes continue to pulsate.

During each cardiac cycle, characteristic sounds are produced by the heart. They can be heard by placing the ear against the chest over the heart, or by leading the sounds to the ears through the tubes of an instrument called a stethoscope, the receiving end of which is placed over the heart. In each cycle two distinct sounds are heard, termed the "first" and "second" heart sounds. The first is low pitched, the second is sharper, louder, higher pitched, and of short duration. The only way to appreciate what these sounds are like is to listen to them. They roughly resemble the sounds of the syllables "lubb-dup."

The second sound is known to be due to vibrations set up by the sudden closure of the semilunar valves very soon after the beginning of ventricular diastole. Experimental injury to these valves modifies the sound, corresponding to faulty function. If they are slit open, for example, so that they do not close tightly in diastole, and blood therefore leaks back into the ventricles, the second sound is of a rather soft hissing character, called a "murmur." Instead of the normal "lubb-dup," there is heard "lubbshhh."

This finding is of significance not only in indicating the cause of the second sound but also in detecting the existence of defective valves. If the valves are damaged by syphilis, for instance, the presence of the injury may be detected by the abnormality of the second sound.

The first heart sound is of more complex origin. It is partly due to vibrations set up by closure of the auriculo-ventricular valves at the beginning of ventricular systole; for, if these valves are damaged experimentally, or by disease, the sound is somewhat modified. However, the sound persists even though, for the moment, the flow of blood through the heart is stopped experimentally. During such time, of course, all valve action ceases. The second sound is eliminated, but the first persists in modified form. It is thought that for the most part this sound is caused by vibrations set up by the contractions of the muscle fibers. Even skeletal muscle fibers produce such vibrations, giving rise to sounds which can be heard by placing a stethoscope on any contracting muscle.

Throughout the vascular system all the vessels are hollow tubes of dif- 
ferent diameters, ranging from the large aorta, an inch in diameter in man, to the microscopic capillaries barely large enough to admit a red blood cell. Variations in the thickness of the walls roughly parallel the variations in internal caliber, the wall of the aorta in man being about one-eighth inch in thickness, the capillary walls being of microscopic size. The actual internal structure as well as the thickness of the vessel walls are significantly different in different parts of the vascular tree. These structural differences are of considerable importance to the physiologist, who finds an intimate interrelationship here between structure and function.

Much of the wall of the aorta and larger arteries consists of smooth muscle. The spindle-shaped cells are arranged circularly around the vessel. Contractions or relaxations of these fibers are capable of changing the caliber of the vessels.

The outermost coat of the arteries is made up largely of connective tissue, which also invades the muscular layer to a certain extent. In the connective-tissue layer proper there are a great many elastic fibers, which give the vessel its elasticity and distensibility, so important in the circulation. The connective-tissue layer renders the wall tough and resistant, so that, though it "gives" somewhat under high internal pressures, it resists rupture even by very high pressures.

The arteries and veins are lined with thin, flat, epithelial cells which always present a smooth surface to the moving blood.

The extremely fine final terminal branches of the arteries just before the capillary bed is reached are termed arterioles, or "little arteries." They possess all the layers found in the larger arteries, although each coat is much thinner.

The veins are structurally like the arteries except that their walls are thinner. Because there is less muscle than in arteries or arterioles, there is considerably less possibility of active change in the caliber of the veins. They are rather easily collapsed, as can be demonstrated on the superficial veins of the skin.

Connecting the arterioles with the veins is the capillary bed. As we pass from arterioles to capillaries, two significant anatomical changes are apparent. The walls now become exceedingly thin. The capillary vessels have lost all the coats of the arteries except one-the thin, flat, innermost cell layer. There are almost no connective tissue and no true muscle (excluding Rouget cells). For the most part the wall consists simply of a tubular extension of the continuous smooth lining of the arteries.

Also, the branching of the vascular tree is here more profuse than at any other part of the system. One arteriole breaks up into a number of capillaries whose individual diameters are only a little smaller than those of the tiniest arterioles.

Mention has been made of the fact that the veins are more easily collapsible by externally applied pressure than are the arteries. This is not due 
so much to the thinner walls of the veins as to the low pressure of the blood within. If we measure the average pressure of the blood in successive regions of the vascular tree, we find that there is a continuous decrease from the heart through the arterial and capillary and venous regions. In the aorta close to the heart the average pressure is always highest. It is lower in the arterioles and capillaries and still lower in the veins. The lowest pressure is in the veins closest to the right auricle. At this point the pressure is about at atmospheric pressure or (in mammals) even lower. The rate at which blood escapes from a hole in a vessel demonstrates these differences very well; it spurts rapidly from an artery and flows much more slowly from capillaries or veins. Even large vessels in the neck near the heart may bleed very little through a small hole.

The heart is capable of adjusting its output to the rate of activity of the body. When more blood is required, mechanisms are automatically set into operation which increase the rate and strength of the heart beat and hasten the rate of the circulation. But note that this mechanism alone would increase the rate of blood flow to all the organs simultaneously. It allows for no differentially greater flow to one organ or system than to another. If the heart pumps more blood, all organs share in the general increased blood flow. Not only can the output of the heart change, but also there are mechanisms which change the distribution of the blood to the various organs differentially, in accordance with their varying rates of metabolic activity.

Disorders of the blood vessels are fairly common and their effects are to be understood on the basis of the disarrangements of blood-vessel physiology which they entail. Some blood-vessel defects have already been referred to in connection with intra-vascular clotting of blood. Plugging of an infected blood vessel with a thrombus often serves the useful end of decreasing the bursting of the damaged vessel, but it also may produce serious damage or death. Plugging of vessels to parts of the brain or to the heart may be suddenly fatal.

The effects of occlusion depend, first, on the importance of the organ whose vessel is occluded and, second, on whether or not other vessels also carry blood to that organ, as is generally the case.

Allied in their effects to those of complete obliteration of vessels are conditions which abnormally narrow the caliber of vessels. This may be in the nature of a more or less localized blood-vessel spasm, or a thickening and hardening of the walls of the arterioles and arteries. Again, the effects depend upon what blood vessels are involved. Hardening (and narrowing) of the arteries of the brain may so interfere with proper nutrition of that organ as to cause serious mental derangements. Involvement of the kidney vessels may so damage those organs as to make impossible the proper elimination of wastes.

Hardening of the arteries is essentially a disease of the old. It seems in 
part to be a specific manifestation of the unexplained but rather general loss of elasticity of many tissues in old age. This effect upon the skin of the aged is known to all. But many aspects of hardening of the arteries are puzzling. The narrowed caliber of the vessels and the change in structure of the walls have not as yet been satisfactorily accounted for.

Usually associated with hardening of the arteries is a chronic elevation of the arterial blood pressure. The systolic pressure may rise to 250 or $300 \mathrm{~mm}$. Hg. By some, this is looked upon as a compensatory adjustment, by which blood is forced through the narrowed vessels, and a more or less adequate circulation is maintained. The seriousness of high blood pressure (hypertension) lies partly in the danger that some blood vessel may rupture. Rarely does this occur in large vessels, with dangerous extensive hemorrhage. More often it involves vessels of such size that the loss of blood per se is not important. But if this bleeding occurs in a vital, and particularly a friable, structure like the brain, serious damage may result. Many brain cells may be torn and damaged by the blood escaping under high pressure. Everyone knows of individuals who have suffered such a "cerebral accident," which often causes paralysis, and is commonly known as a "stroke." The rationale of having people with high blood pressure lead as quiet a life as possible is obvious when we recall that muscular exercise and excitement elevate the arterial blood pressure. This, of course, would increase the danger of rupturing a vessel.

\section{Y M P H A D L Y M P VES S L S}

The lymphatic system is a circulatory system having rather intimate anatomical and physiological interrelationships with the blood-circulatory system, similar to it in certain respects and quite different in others. Lymph vessels, like blood vessels, are distributed to all parts of the body. We may liken the system anatomically to the capillaries-plus-veins portion of the blood-circulatory system. The lymphatic system possesses no counterpart of the arteries and, consequently, does not have a true continuous closed circulation. The fluid of the vessels, called "lymph," enters the system in the lymph capillaries, which resemble other capillaries except that they appear to be closed at their terminal ends. The lymph flows from the capillaries of all parts of the body into larger and larger vessels resembling veins in that they possess valves and are thin walled. In fact, the lymph vessels have even thinner walls than the veins. Larger and larger vessels finally converge to the left-shoulder region in the thorax, where the lymph empties into a large vein of the blood-circulatory system.

But where does the lymph come from? From where does it pass into the closed lymph system? Lymph, in general, originates as tissue fluidthe fluid which surrounds all cells. This, in turn, has reached the cells from the capillaries of the blood-circulatory system. Thus fluid may reach the cells by only one route-the arteries, arterioles, and finally capil- 
laries, through whose walls it passes by diffusion and filtration. But there are two possible return routes. The fluid (lymph) either may re-enter the capillaries and be carried onward in the venous stream or may enter the lymph capillaries. The exact mechanism is not known. At any rate, once in a lymph capillary, the fluid slowly moves on in a devious course through larger and larger vessels, empties into the large vein mentioned, and so eventually returns to the heart.

From this it is apparent that in composition the lymph must resemble blood. It consists of those constituents of blood which are able to penetrate the capillary wall, plus elements that may be added to it by the tissues. It contains no red corpuscles and has much less protein than blood plasma. Otherwise it closely resembles blood plasma in composition.

At rather frequent intervals along the course of a lymph vessel are structures called lymph nodes. These are made up essentially of a network of connective tissue, in the meshwork of which are located two special kinds of cells. These are (a) cells which mature into one kind of white blood cell-the lymphocytes-and (b) phagocytic cells which possess the same capacity as ameba for engulfing particles. As the lymph flows through the vessels, its course is interrupted by the nodes, through which it must pass, trickling through the packed lymphoid cells and phagocytes. The lymph nodes, as we may judge, play a large part in determining the peculiar functions of the lymphatic system.

What are these functions? In the first place, the lymph system helps return tissue fluids to the blood circulation. In these fluids are some of the waste products of metabolism on the way to excretion. But why cannot this return be carried out adequately by the capillaries and veins of the blood-circulatory system? Why have the two routes of return? With our present information we cannot answer these questions entirely satisfactorily. It seems to be true, however, that solid particles seem to be able to get into the lymphatic capillaries much easier than into the blood capillaries. Then, as the fluid trickles through the lymph nodes, some of these solid particles are filtered out and thereby prevented from entering the blood stream. In the lymph nodes near the lungs of city dwellers, for example, so many particles of dust and soot are filtered out that in the course of a normal lifetime the nodes become very dark or even black in appearance.

Bacteria in the lymphatics may be filtered out and phagocytized in the lymph nodes.

Sugars and amino acids are absorbed chiefly into the blood capillaries directly. But the fats that we ingest, digest, and absorb pass mainly into the lymphatics. Of course, even the fat soon gets into the blood stream via the lymphatics.

Another function of the lymphatics is the manufacture of lymphocytes. They course along with the lymph and, with it, enter the blood stream. 


\section{YOUR HEART *}

It is true-that there is an actual increase in heart disease, but this increase does not apply to all the people. Americans as a whole are living much longer than they used to live, because comparatively few lives are now cut short by the infectious diseases of childhood and youth. As a result there are many more older people in the population than there used to be, and it is in the older ages that the heart is most likely to get in trouble. The increase in heart disease that we hear so much about is primarily a problem of late middle and old age. In youth and early middle age there is much less heart trouble than there used to be.

It is not true-that nothing can be done about heart disease. The heart may bear much and not break. It has tremendous reserves of power. The verdict of heart trouble in most cases does not mean death overnight. Thousands of persons with damaged hearts are living comfortable, happy, useful lives right now because they are cooperating with their doctors in giving their hearts a chance. Many of them may live as long as they could reasonably expect to live without heart trouble. Some of them even have a chance of complete recovery.

\section{H E A R T F C T S}

Your heart is only as big as your fist, but most of its bulk is muscle. It has just one job-to pump out into the arteries the blood returned to it by the veins. All the millions of cells in the body depend upon the rapidly circulating blood stream for the necessities of life and the removal of wastes. The brain in particular must have a continuous supply of fresh oxygen. Since the brain runs the body, death comes within seconds-at most a very few minutes-after the heart stops beating.

The amount of blood in your body is comparatively small-it makes up only about 8 per cent. of your body weight. But to keep that blood in circulation through miles of blood vessels during an ordinary day of work, play, and rest, the healthy heart pumps from 9 to 10 tons of blood at an average daily rate of 70 strokes per minute. The normal pumping action of the healthy heart is a continuous series of regular contractions and relaxations-beat-rest, beat-rest, beat-rest, and so on for about $2 \frac{1}{2}$ billion times if the pumping continues for 70 years.

When you are "taking it easy," your heart takes it easy. It then rests nearly twice as much as it works. But during periods of exceptional physical exertion or emotional stress it may beat twice as fast as usual and pump out twice as much blood. The faster the heart beats, the harder it works and the less time it has to rest. On this important fact is based

- Reprinted from Your Heart by permission of the Metropolitan Life Insurance Company and the American Heart Association, 1946. 
much of the medical advice we are given regarding the protection of the middle-aged healthy heart and the care of the sick heart.

\section{COMMON TYPES OF HEART DISEASE}

Heart disease is a convenient term used to cover a multitude of different diseases, most of which are quite unrelated except as they all involve the heart or blood vessels.

The most common types of heart disease are those associated with infections, especially rheumatic fever and syphilis; or with high blood pressure; or with disease of the coronary arteries. Other less common but inportant types are caused by defects present in the heart or blood vessels at birth (congenital defects), or by overactivity or underactivity of the thyroid gland.

\section{The Young Heart}

\section{HEART DISEASE ASSOCIATED IVITH INFECTIONS}

Generally speaking, it is possible for the heart to become involved in practically any infectious disease if the germs causing it or their poisons are carried to the heart in the blood stream, or if the heart becomes exhausted in the fight put up by the body against the disease. In these days, however, very few cases of heart disease are caused by infections other than rheumatic fever and syphilis. One important reason for this is that many communicable diseases are now being prevented by immunization, or are being treated successfully with serums or drugs before they have a chance to infect or weaken the heart.

Heart disease caused by an infection goes by the name of the part of the heart affected, plus the ending itis, which means "inflammation of." Hence we have myocarditis, inflammation of the myocardium, or heart muscle; pericarditis, inflammation of the pericardium, the bag of membrane enclosing the heart; aortitis, inflammation of the aorta, the great blood vessel leading out of the lower left chamber of the heart; and endocarditis, inflammation of the endocardium, the membrane which lines the hollow heart muscle. Since the endocardium covers the valves of the heart as well as its inner walls, endocarditis frequently leaves scars which may cause narrowing (stenosis) of one or more valves or may interfere with their proper closing.

Rheumatic Heart Disease. Rheumatic heart disease begins nearly always in childhood between the ages of 6 and 12 as the result of one or more attacks of rheumatic fever. Many cases of rheumatic heart disease in adults may be traced to a partly forgotten or mild attack of rheumatic fever or chorea (St. Vitus's dance) in childhood.

The cause of rheumatic fever, which plays such havoc with young hearts, is not clear. The solution to the whole puzzle is now one of the chief objectives of medical research. Just as a lighted match starts a fire in 
kindling already laid in a stove or fireplace, so an attack of a disease caused by germs of the streptococcus family-for example, tonsillitis, scarlet fever, or streptococcal cold-often lights up rheumatic fever in a child or young adult who is susceptible to it. What makes an individual susceptible seems in most cases to be an inherited tendency to rheumatic fever, which may be increased by poor diet, inadequate protection from cold and damp, and crowded living conditions that give germs a chance to spread easily from throat to throat. Unfortunately, one attack of rheumatic fever makes a child more susceptible, rather than immune, to further attacks, and repeated attacks are more likely to damage the heart.

The earliest symptoms of rheumatic fever may be slight fever, nosebleeds, loss of appetite, failure to gain weight, and pain (often vague and fleeting) in joints and muscles. The uncontrollable twitching or jerking of the face, arms, or legs, commonly known as St. Vitus's dance, is sometimes a sign of rheumatic fever. This disease may attack all parts of the heart and, in some cases, clear up with little or no trace. But commonly it leaves scars in the endocardium which interfere more or less with the working of one or more of the valves of the heart. By following the advice of the physician with regard to work and play, individuals with rheumatic heart disease, whose hearts have not been too severely scarred, may lead productive and normal or near-normal lives.

Prompt and continuing medical care during attacks of rheumatic fever is essential, and good nursing care is of prime importance. The child must be kept in bed during the active stage in order to give the heart the rest it requires to make as good a recovery as possible. The doctor is the one to say when the child may ger up and how active he may be as he returns to normal living.

The best, but not absolutely certain, protection against recurrences is periodic medical supervision, with emphasis on the proper balance between rest and activity, good nutrition, and protection from respiratory infections. The use of sulfa drugs under medical supervision to ward off the streptococcus infections which so often light up rheumatic fever is giving promising results in preventing recurrences in susceptible children.

Sypbilis of the Circulatory System. Syphilis continues to be a common cause of infectious disease of the heart and blood vessels. This disease does more damage to the aorta than to other arteries or to the heart itself. Probably the germs (spirochetes) of syphilis invade the heart and aorta soon after they first enter the body, but as a rule actual disease of these organs does not appear for many years. Fortunately syphilis of the heart and arteries is now a preventable disease, since the spirochetes can be destroyed before they damage the aorta or heart if treatment is begun in the first, or chancre, stage.

Bacterial Endocarditis. This serious infection of the endocardium, or heart lining, is caused in most cases by an invasion of bacteria of the coccus 
family. These bacteria are much more likely to gain a foothold if rheumatic heart disease or a congenital defect or some other abnormal condition already exists. The rare acute form is caused by any one of several different kinds of bacteria which may enter the blood stream and attack the heart in the course of an illness elsewhere in the body-for example, pneumonia or meningitis. In the more common subacute form, Streptococcus viridans (the green streptococcus) is usually responsible. This germ hides and multiplies in blood-clot nests in the endocardium. With the sulfa drugs and penicillin at the physician's disposal, the outlook for the control of bacterial endocarditis is much more hopeful than it was a very few years ago.

\section{The Middle-Aged Heart}

\section{HEART DISEASE ASSOCIATED IVITH HIGH BIOOD PRESSURE}

High blood pressure, or hypertension, is the most common cause of heart disease in middle age. What hypertension is and why it causes heart disease are known. But what causes hypertension itself is still a puzzling question. Many cases of hypertension are associated with disease of the kidneys (renal hypertension) or with a disease or functional disturbance of the nervous system or endocrine glands. The majority of cases of hypertension, however, are labeled "Cause Unknown."

High blood pressure which develops without any discoverable cause is called essential hypertension. It seems to run in some families, many members of which through several generations have had essential hypertension or troubles associated with it. Also it appears to be most common among people who are overweight.

What "Blood Pressure" Is. Everyone has blood pressure. It is simply the pressure of the blood against the walls of the arteries which are always completely filled with blood. Everyone's blood pressure goes up and down. It is highest during systole, the period when the heart pumps a fresh load of blood into the elastic-walled arteries which stretch to accommodate it, and lowest during diastole, the period when the heart pauses between beats to fill with blood. High blood pressure is commonly taken to mean high systolic pressure. However, the diastolic pressure is fundamentally the more important of the two, because it represents the basic pressure exerted on the arterial walls independently of the additional pressure due to the contraction of the heart. The physician also attaches great importance to the relationship between the systolic and diastolic pressures. The difference between the two is called the pulse pressure.

The second factor which makes everyone's blood pressure normally an up-and-down affair is the way the arterioles behave during emotional stress. These tiny blood vessels are the smallest branches of the arteries. They are controlled by nerves which automatically make them constrict 
(tighten up) or dilate (open wider). They tighten up when you are all keyed up with joy, fear, anger, worry, or working under tension. When they constrict, less blood can get into them from the arteries, and so the pressure of blood in the arteries goes up. When the excitement is over they dilate (open wider), and the pressure goes down.

Hypertension, or bigh blood pressure, means simply that tbrough some nervous or toxic influence the arterioles tbroughout the body-and there are miles of them-are kept more or less constantly in a constricted, or tightened-up, state.

Hypotension, or low blood pressure, means that the blood pressure remains more or less constantly within or below the lower limits of normal pressure. Unlike high blood pressure, it does not cause heart disease. Indeed, low blood pressure seldom causes real illness of any kind, and definite diseases in which it occurs are very rare. Individuals who are physically below par, especially if they are underweight, may have hypotension. However, the blood pressure of many healthy individuals tends to be lower than the average for their age. If your doctor concludes that you are one of these "low-normal" individuals, you may consider yourself fortunate because you may expect to live longer than other people.

How High Blood Pressure Affects the Heart and Arteries. The effect of hypertension on the heart is what you might expect if you screwed down the nozzle of a hose connected with a water pump. Just as the pump would have to work harder against increased resistance in the hose to keep water spraying out of the nozzle in the same volume as before, so the heart must work harder against increased resistance in the arteries to keep blood flowing through the constricted arterioles at nearly the normal rate. To take care of this extra work the heart muscle is forced to enlarge. And often. but not always, the walls of the arteries become scarred and thickened-a process called sclerosis, or hardening, of the arteries (arteriosclerosis).

A strong heart and wear-resistant arteries may be able to cope with high blood pressure for years without much trouble. In some cases there may be no symptoms at all; in others, there may be headaches, dizziness, general aches and pains, and possible shortness of breath. These symptoms also appear in other common conditions. Instead of wondering whether you have high blood pressure the sensible thing to do is to see your doctor.

Sometimes high blood pressure clears up of itself before it has a chance to damage the heart and blood vessels, or it may be lowered to a safe level by drugs or diet or surgery if it is discovered in time. Even malignant hypertension, a severe form of high blood pressure which often progresses very rapidly, has recently been treated with good results in some cases.

Persistent bigh blood pressure, however, nearly always results in enlargement of the heart muscle-the first step in the development of hypertensive heart disease. The progress of hypertensive heart disease to the 
point of heart failure can often be delayed for many years, even into old age, by following the doctor's advice and leading a life of moderation in all things-in work and play, in eating, in smoking, in emotional reactions.

The Aging Heart

\section{CORONARY HEART DISEASE}

Heart disease caused by disease of the coronary arteries, which have the job of supplying the heart muscle itself with blood, is most common after age 50. Thickening of the coronary arteries (coronary arteriosclerosis), usually associated with hypertension, is the chief cause of coronary disease. Its harmful effect on the heart is explained by the reduction of the blood supply of the heart muscle (the myocardium) which occurs when the coronary arteries are narrowed or blocked. However, the reserve strength of the heart muscle and its blood supply are both so great that they are not easily exhausted. Many people are able to live quite comfortably with coronary heart disease if they are careful not to place too great a strain on their hearts. With the object not only of prolonging their lives but also of enabling them to be useful and happy, the physician helps them to strike a balance between too many and too few restrictions. The main thing to strive for is equanimity. Some people with a comparatively small amount of heart damage and disability make themselves worse through sheer nervousness.

Angina Pectoris. The inability of the coronary arteries to perform their duty properly is made plain by a symptom so important that it is often regarded as a disease in itself. This symptom is called angina pectoris. Angina pectoris is a painful, strangling, oppressive sensation under the breastbone, frequently radiating down the arms, which is brought on by exertion and lasts for only a few minutes. It is not like any ordinary pain in the chest, and a person who has had it once seldom needs to be persuaded to see a doctor.

Coronary Thrombosis. The most serious "accident"which may occur in coronary disease is the sudden closing (occlusion) of a coronary artery by a blood clot (thrombus). It causes severe crushing pain in the chest, accompanied by weakness, pallor, and sweating, which persists in spite of rest. Sometimes the pain is mistaken for acute indigestion. A doctor should be summoned at once, because this is a real heart emergency. However, the great majority of persons survive the first attack of coronary thrombosis, and most of the survivors live for many years. After the damage done to the heart muscle has had opportunity to heal through a long rest in bed, the heart has an excellent chance to recover sufficiently to allow normal or near-normal activities. 


\section{SIG N AND SYMPTOMS}

It is important to realize that the heart may be innocent of causing many of the feelings of discomfort which are frequently blamed on it. The cavity of the chest and the upper part of the abdomen, which is separated from the chest by only a thin sheet of muscle, are packed tightly with organs. Any extra pressure, such as gas in the stomach or small intestine, for example, may give rise to pain in the chest with which the heart has nothing whatever to do. On the other hand, any discomfort in the chest which is directly related to exertion or excitement should be a signal to consult a physician.

The heart itself may at times act queerly without having anything organically wrong with it. Common but annoying experiences of this kind are skipped beats, palpitation (consciousness of the heart beat), and very rapid beating of the heart. Noticeable misbehavior of the heart beat, or any other annoying symptoms which may make you think you have heart trouble, should always be investigated by a physician. If the physician, after a careful examination, says that nothing is wrong with your heart, believe bim. Many people make themselves miserable by continuing to think that they have heart disease, even after one or more physicians have told them that their hearts are sound.

There are a few symptoms which should always be investigated, because they indicate the need of medical attention whether they are due to heart trouble or not. One of these is shortness of breath when at rest or on exertion which has not previously caused breathlessness. Shortness of breath associated with moderate exertion is an early symptom of a weakened heart muscle. It is caused most commonly by the congestion of blood in the lungs which occurs when the left side of the heart fails to pump on all the blood it receives from the right side via the lungs. Sudden acute attacks of breathlessness may come on while in bed at night. When asthmatic breathing complicates this form of breathlessness, the condition is called cardiac asthma.

Swelling of the feet and ankles is another early sign of possible heart weakness. When the circulation is slowed up because the heart fails to pump with its customary vigor, fluid may gather in the tissues and cause swelling, which is usually first noticed in the feet and ankles.

\section{THE HEART-BLOOD VESSEL EXAMINATION}

The ideal way to forestall the onset of heart trouble is to see your doctor for a check-up every year and to consult him between times at the appearance of one or more of the symptoms which may or may not indicate heart trouble or hypertension.

If you tell the doctor you are worried about your heart or your blood 
pressure, the first thing he will do is to ask you to describe your symptoms. Symptoms are indications of trouble, like pain, which only you can feel. As they give the doctor important information about you, it is essential that you describe them honestly and carefully. The doctor will then proceed to look for signs of trouble-things which he hinself can detect with the help of various instruments and tests.

\section{CHECKING UP ON YOUR BLOOD PRESSURE}

In taking your blood pressure your physician will measure the amount of pressure exerted by the blood against the main artery of your arm at the peak of the heart beat (systole) and at the pause between beats (diastole). The apparatus the doctor uses is familiar to almost everyone because blood pressure is now measured in the course of practically every medical examination, although this procedure came into general use only a generation ago.

If necessary, the doctor will also examine the interior of your eyes with an instrument called an ophthalmoscope, which enables him to see the minute blood vessels at the back of the eye. Since these blood vessels are sinilar to those in other less accessible regions of the body, the ability to observe them directly gives the doctor an idea of how good your blood vessels are. From an analysis of your urine (urinalysis), and perhaps by other tests of kidney function, your doctor will gain valuable information about the condition of your kidneys. This knowledge is important because high blood pressure or hypertensive heart disease is sometimes associated with kidney disease.

\section{CHECKING UP ON YOUR HEART}

Usually the physician first feels (palpates) and taps (percusses) the cardiac region of the chest to determine the position, size, and shape of your heart. In addition, he may ask you to stand behind the screen of a fluoroscope while he studies the shadow of your heart cast by $\mathrm{X}$-rays on the screen. To have a permanent record for further study and future comparison, he may also have an X-ray picture taken.

By listening to the sounds made by your heart in action through a stethoscope, which magnifies them, the doctor is able to detect "murmurs" or other deviations from normal. Heart murmurs are gentle, blowing sounds which may or may not indicate that something is wrong with the heart. A great many murmurs have little or no importance. Others may indicate that damage has been done to the valves or heart muscle as a result of rheumatic heart disease or some other condition.

The physician may also wish to have an electrocardiogram made. This is a written record of the electrical activity which sweeps down and over your heart at each heart beat. The sensitive apparatus that does the writing at the dictation of the heart is called an electrocardiograph. The physician 
can tell whether the wave patterns recorded in an electrocardiogram are normal or abnormal, and so gain additional evidence about the condition and action of your heart muscle.

In addition to these methods of examining the heart, there are many others which your doctor will use if he thinks it necesary. For example, the extent and speed with which the red cells of the blood settle down when a sample of blood is allowed to stand in a column (sedimentation test) is a valuable means of uncovering rheumatic and other infections. Determining the way the heart behaves in various forms of physical exercise may be used in testing the heart's function. In short, there are now so many ways of taking the guesswork out of the heart examination that it is no wonder that our doctors today are able to make more accurate diagnoses than could doctors in the old days.

\section{I V I G G W T H HEART DISEA S E}

If the doctor finds that you have any form of heart trouble after making his examination, he will tell you because he must depend upon your cooperation. He has at his command many potent drugs and new surgical techniques, but he cannot live your life for you. And in the long run it is the way you live, more than the medicines you take, that determines how long and how happily you will live with an impaired heart.

The object of the way of living which doctors usually recommend for persons with heart trouble is the lifting of all removable burdens-for example, those imposed by fatigue, obesity, infections, and emotional upsets.

\section{EXERCISE AND REST}

The speeding up of the heart's action which accompanies sudden or violent or prolonged physical exertion can easily be accommodated by healthy young hearts, but it puts an extra and unnecessary strain on damaged or middle-aged hearts. The amount of exercise which a person with heart disease or high blood pressure may take will be carefully prescribed by the physician, and the patient must use judgment and discretion in carrying out the doctor's advice according to his ability to perform without getting tired or out of breath.

Things to remember are:

I. Don't run or walk fast to catch anything-train, bus, streetcar, plane, or any other vehicle. As the saying goes, "It is better to miss it and live than catch it and die."

2. Don't walk against a high wind, as this throws an extra strain on the heart.

3. Don't do any more climbing than is necessary-if you must go upstairs or up hill, do it slowly with frequent rests.

4. Slow up-use moderation-in everything you do. Get out of bed slowly -never junp out. Cut down the speed at which you work, or work for shorter hours if possible. The doctor may advise a change of occupation if your present work is too fatiguing. 
5. Go to bed early. Take a nap or at least lie down during the afternoon. When you are asleep or resting, your heart gets extra rest.

\section{EATING}

Eating big meals taxes the heart, since its work is increased during digestion. Also, overeating is the most common cause of obesity, and carrying around an extra load of fats puts extra strain on the beart.

When a person is sick in bed with heart trouble, the physician usually restricts the amount of food and fluid allowed. In all cases, moderation in eating is usually advised both to keep weight down and to lighten the work of the heart. Five or six light meals a day are sometimes better for the heart than three large, heavy meals. In some cases the doctor may prescribe a special diet. There is no one special diet which will apply in all cases. Specific dietary instructions must be provided by the physician to fit the need of each individual.

\section{SMOKING}

So far as we know now, smoking tobacco does not cause actual heart disease, but excessive smoking may cause disagreeable disturbances of the heart beat, even in healthy people, and aggravate the symptoms in certain types of heart disease. Recent experiments have shown that smoking tobacco makes the arterioles tighten up, just as they do under emotional stress, and constriction of the arterioles raises the blood pressure. Hence smoking may have a harmful effect in arteriosclerosis and heart disease associated with arteriosclerosis and high blood pressure. A person with heart trouble or hypertension may feel better if he avoids the use of tobacco, and in some cases the physician may forbid smoking.

\section{AVOIDING INFECTIONS}

A person whose heart is already handicapped must take care to avoid the added burden and possible risk of further damage imposed by infections, such as colds, sore throats, pneumonia, and infections of the sinuses and teeth. Anyone with heart trouble who develops an acute infection should go to bed and call his doctor. On recovery he will require a longer convalescence and a more gradual return to work than would a person with a normal heart.

\section{KEEPING IN TOUCH WITH THE DOCTOR}

A person with heart trouble must keep in close touch with his doctor. His diet, weight, activity, rest-in short, his way of life-are more important than drugs and require constant medical supervision. Although some forms of heart disease are benefited by medicines, the drugs employed are extremely powerful, and their effect on a particular patient must be checked frequently. 


\section{PHILOSOPHY OF LIFE}

Cultivating a serene, optimistic outlook on life helps a great deal in relieving an impaired heart of unnecessary strain. This may be difficult for people who have always been high-strung-quick on the emotional trigger - prone to work too hard or worry too much. Yet the people who are willing to slow up their previous living pace-to go ahead with less speed, less haste, less worry, less fear; who accept the situation and adjust to it cheerfully, coaxing their hearts along without letting their impairment become an obsession-these are the people who have the best chance of a full, happy, and prolonged existence despite heart trouble.

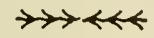




\section{VY}

\section{Nervous and Endocrine Control of the Body}

$T^{H E}$ great development of the cerebrum in man is responsible, in a 1 large way, for man's preeminence over the lower forms of life. For example, the periodic triumphs of the insects over man are not planned by the insects. On the other hand, man's reasoning is enabling him to control the insects.

It is, indeed, a long jump from the withdrawing from contact of its pseudopodium by the simple, one-celled Ameba, a type of nervous response, to the creative genius of an artist or the working out of a formula by a physicist. Evolution means change and the nervous system has evolved according to the same laws as other parts of man. Sometimes evolution has taken peculiar turns. Witness the now-extinct dinosaur who had two brains, one in his head and the other in his sacral region so that he could make both head and tail of it.

Concerning the brain, there are many types of untruths extant. One is the false study known as phrenology by means of which one is supposed to tell certain qualities of the brain by fingering the bumps on the cranium. Some people believe too that the size of the brain is an indication of the quality while others hold that the more convolutions one's cerebrum has, the greater is one's thinking ability. Of course, these ideas are no longer valid.

The study of the ductless glands and their products is now one of the most active fields in animal physiology. Malfunction of these important structures is now known to cause certain types of diabetes, goitre, sterility and so on. Some of these products or hormones have been isolated and purified sufficiently so that cures for certain conditions are possible. Hopes run high at the present time for the use of hormones in a more sustained attack upon human diseases and even upon abnormal behaviour. 


\section{THE BACKGROUND OF HUMAN MENTALITY *}

\section{R A L P H L I N T O N}

Human behavior is vastly different from the behavior of the other mammals, even that of our cousins the apes. Nevertheless, just as the physical differences between men and apes diminish in importance and cease to be a bar to relationship when they are studied against the background of mammalian variation, the differences in behavior diminish in importance when they are seen in their proper perspective. There is a gap to be sure, and this gap will never be bridged by fossil evidence of the sort which is gradually bringing the structure of men and apes into a continuous evolutionary series. Behavior does not fossilize, and the actual links disappeared when the half-men of the late Pliocene and early Pleistocene became extinct. However, human and animal behavior can be shown to have so much in common that the gap ceases to be of great importance.

The outstanding quality of living as opposed to dead matter is that living matter responds to stimuli in ways which increase its chances of survival. The living being apprehends its environment and acts to adapt itself to it. This irritability of protoplasm, its capacity to receive and transmit stimuli and to react to them purposefully, is the foundation of behavior. It is equally characteristic of the amoeba, that speck of jelly which lies at the root of the animal family tree, and of man, who has perched himself on its highest branch.

In unicellular organisms such as the amoeba all parts of the individual are sensitive to all sorts of stimuli and the whole individual responds to them. In slightly more complex organisms, where a number of cells have banded together for their mutual advantage, there is a specialization in function. The surface cells receive and transmit stimuli while the interior cells respond to bring about the changes necessary for the survival of the organisın. In still more complex organisms, including our own, there is a further specialization in function. All such organisms begin as mere aggregations of cells which become differentiated into a surface layer, highly sensitive to stimuli, and a less sensitive interior. As the individual develops, part of this surface layer remains on the outside and develops into the skin and the various sense organs. Another part is folded in and buried among the less sensitive cells. This becomes the nervous system. The buried part of the original sensitive surface layer specializes in the transmission of stimuli just as the exposed part specializes in their reception.

In animals organized on the radial principle, such as jellyfish and allied forms, the nerves form a continuous net. In those organized along axial

"From The Study of. Man by Ralph Linton, D. Appleton-Century Company, Inc. Copyright 1936. 
lines, which includes all long, bilaterally symmetrical beings from worms to men, there is an axial nervous system. This means that there is a main trunk of nerves running down the center line of the animal with branches leading off from it to the various organs. From our point of view, these organs may be divided into two classes, the receptors, such as eyes, nose, and ears, which are in touch with the outside world and receive stimuli from it, and the effectors, such as the muscles, which act to bring about changes adapting the individual to his immediate surroundings. The function of the nerves is to carry stimuli from the receptors to the effectors much as a telephone line carries messages from one person to another.

The link-up of receptor, conductor, and effector is known as the reflex arc and is the mechanical basis of behavior in all organisms advanced enough to have nervous systems. In those which have axial nervous systems, the structure of the conductor part of this circuit is highly complicated. The nerves which link receptor and effector are composed of a series of specialized cells, neurons, whose ends approach but do not actually join each other. The gaps between the neurons are called synapses and play a vital part in all the more complicated forms of behavior. Neurons are so organized that they will carry impulses in only one direction. The impulse started by a stimulus impinging on one of the receptors passes along the connecting neuron at the rate of about 400 feet a second until it comes to a synapse, which it jumps, passing on into another neuron, and so on until it reaches the effector. At the synapses there is a resistance of some sort which affects the impulse. It may be slowed down or even blocked at the point. It may also be deflected to any one of several neurons, if their ends lie close enough, or split so that it continues to travel down, several of them simultaneously to different effectors. However, the resistance to impulses offered by the synapses diminishes with use. The oftener a synapse has been jumped, the easier it is for the next impulse to jump it. This wearing of paths through the synapses is the neurological basis of learning and habit formation.

In the more complex organisms, such as our own, there is a constant reception of varied and often conflicting stimuli. The impulses arising from these stimuli have to be sorted out and directed to ensure the sort of reaction which will be most profitable to the whole body. The conductors of the various reflex arcs are therefore routed through various reflex centers, which serve somewhat the functions of a telephone central. In these centers the ends of many neurons are brought close together so that the incoming impulses can be sorted out, switched from one line to another or distributed. Just how the reflex centers distinguish between impulses, inhibit some, and direct others is still a profound secret, but they do this in frogs and philosophers alike. The mechanics of the reflex arcs and reflex centers are the same in all animals having axial nervous systems.

The main trunk of an axial nervous system (in vertebrates, the spinal 
cord) is itself a reflex center. All impulses are routed through it on their way from receptor to effector. However, within this trunk there are specialized areas which have superior powers of discrimination. These might be compared to district, as opposed to local, telephone centrals. In axially organized animals one of these superior reflex centers is always located at the forward end of the main nerve trunk, in the head, where it is in close touch with the specialized sense organs also located there. In vertebrates this forward reflex center, the brain, dominates the other reflex centers. To continue the telephone simile, the brain is a sort of supercentral which leaves routine business to the district centrals in the spinal cord and elsewhere but which has forwarded to it all calls which are of uncertain significance or which seem to require special action.

The dominance of the brain over the other reflex centers was much less marked in the early vertebrates than in the later ones. In some of the dinosaurs, for example, the brain was actually smaller than the reflex center at the rear end of the body. One of the most important features of vertebrate evolution has been the increase in brain size relative both to the size of the body and to the size of the other reflex centers. Coupled with this there has been a steady increase in complexity of brain structure and in specialization of function within the brain.

In the lower vertebrates the brain functions mainly in the direct reception of stimuli from the sense organs and in making automatic adjustments to these stimuli. At the amphibian level a new division of the brain appears, the cerebrum. This specializes in more complex and selective reactions. As we come up the evolutionary scale, the cerebrum increases in size in relation to the other parts of the brain and more and more takes over the function of directing the individual. In primates and especially in man it quite overshadows the rest of the brain and takes care of the organism's activities, with the exception of a few simple necessary ones such as breathing, swallowing, and changing the size of the pupil of the eye.

The cerebrum is made up of an enormous number of neurons set in a bed of connective tissue. There are at least $10,000,000,000$ of these in the brain of a normal human being. Each neuron is separated from its neighbors by synapses. The paths of impulses through this maze of neurons and synapses are not organized at birth but are established by the process of path-wearing already described. Every time an impulse passes through the cerebrum on its way from receptor to effector a large number of neurons and synapses are involved and there is a change of some sort in the cerebral structure. These changes are the structural basis of memory and habit in the individual. The cerebrum is a specialized organ for learning and also for those higher forms of selection and integration of stimuli which we call thought.

The nervous system is the foundation of behavior, and, as far as we can 
determine by any means now at our disposal, there is nothing distinctive in the human nervous system. In this just as in every other part of their physical structure men fit squarely into the general mammalian patterns. Even the human brain is almost identical with the anthropoid brain. We must grant that the structural and mechanical elements underlying behavior are the same in men and in animals. Let us see whether the uses to which this equipment is put differ in the two cases.

All behavior consists of reflexes, combinations of stimulus and reactions made possible by the structural and mechanical features just described. Reflexes are of two types, unconditioned and conditioned. In unconditioned reflexes the path of the impulse from receptor to effector is already established when the individual is hatched or born. The link-up of the elements within the reflex arc is hereditary, like any other part of the individual's physical structure. In conditioned reflexes the path of the impulse from receptor to effector is not determined at birth. The link-up of the elements within the reflex arc comes as a result of selection and routing of impulses within the reflex centers coupled with the gradual wearing of paths through the synapses. The unconditioned reflex is the foundation of automatic or instinctive behavior, the conditioned reflex is the foundation of learned behavior. All animals with nervous systems have reflexes of both types, but the relation which the reflexes of each type bear to the total behavior of the individual varies tremendously with the kind of animal. For example, insects owe most of their behavior to unconditioned reflexes, while men owe most of theirs to conditioned reflexes.

It used to be believed that animal behavior was controlled by instinct, human behavior by a mysterious and purely human quality called thought. No psychologist holds this view to-day. What we call thought is really an integral part of behavior, for there can be no mental activity without muscular activity of some sort. The muscular activity may be reduced to the point where it can be detected only by the most delicate instruments, but it is there just the same. Thinking is as much a matter of reflex arcs as is the winking of the eye. It is based on a combination of unconditioned and conditioned reflexes and on the selection and routing of stimuli.

In a comparative study of the mental activities of men and animals, the investigator is handicapped at the outset by the fact that with animals there can be no recourse to the introspective method. If any student could be a white rat or a chimpanzee for a half an hour he could give us a clearer picture of what goes on inside animals' minds than we are likely to get in twenty years of experimental work. As it is, we can only deduce the mental processes of animals from their behavior. If we approach the human mental processes from the same angle, the results are almost identical.

Let us take first of all the matter of learning, I. E., of establishing conditioned reflexes. In experiments at the University of Wisconsin the ability for learning mazes in white rats and in sophomores was tested and com- 
pared. The results revealed no important differences in the learning processes of the two groups, while in speed of learning the rats had somewhat the best of it. Of course maze-learning presents a problem of a very simple sort, with a solution dependent on trial and error and the establishment of habits through repetition. There is no need to establish complicated reactions.

Perhaps the most interesting experiments in animal learning which have been made to date are those being carried on at the time of this writing by Dr. Wolfe at the Institute of Human Relations at Yale University. Dr. Wolfe has been experimenting with young chimpanzees, using slotmachines which have been dubbed "chimpomats." By the insertion of poker chips, the chimpanzees get food. The chimpanzees have learned not only to insert chips, but to distinguish between chips of different sizes and colors, using each type of chip in the proper machine and inserting two chips where two were required. They learned the process first by imitating their human instructor and then by imitating one another. They have established associations between the chips and food which are so strong that they will work as hard to get the chips as to get the food itself. When chips are scattered among them in their living quarters, where there are no "chimpomats," they will select those which are of value and keep them until they are taken to the room where the "chimpomats" are. The stronger will also take chips from the weaker in very human fashion.

It is safe to say, that is, there are differences in the learning processes of men and animals; these differences are quantitative rather than qualitative. Men may learn more or learn more readily, but they learn in the same way. It is in the solving of problems, where the individual has had no opportunity for learning, that the mental superiority of human beings is most evident, so let us see whether there are any fundamental differences in the human and animal thinking processes.

It has been held that the superior performance of men in solving new problems is due to their having imagination and reason, qualities which animals lack. Recent experiments make this appear improbable. Imagination is the ability to picture in the mind situations which are not present. Reason is the ability to solve problems without going through a physical process of trial and error. Reason would be impossible without imagination, for in reasoning the situation has to be comprehended and the results of certain actions have to be foreseen. The trials are made and the errors eliminated in the mind. If we study human and animal behavior from the same objective standpoint, it secms certain that if we allow these qualities to men we must allow them to animals as well.

When the young chimpanzees pick up the chips scattered in a room where there are no "chimpomats," selecting those which are usable in the machines and discarding those which are not, they show imagination. They must have some sort of mental image of the machines and of the 
use to which the chips can be put. Moreover, from their behavior in the fact of situations new to them we must allow them at least the rudiments of reasoning power. One of the best-known experiments used to determine this consists in putting a banana in the middle of a pipe, where the ape cannot reach it from either end. After trying direct methods and convincing himself that they are useless, the ape will take a stick and push the banana along the pipe, then go around to the other end and get it. Between the first direct attempts and the use of the stick there will usually be a period of physical quiescence during which the animal is mentally sizing up the situation. During this period mental images of the banana in various non-existent positions must be formed and various methods of getting it into one of these positions pictured, tested against past experience, and discarded, for when the ape begins operations once more he usually seems to have a clear idea of what he is going to do. Moreover, once the problem has been solved, the solution is remembered and the same thing will be done immediately when he is again confronted by the same situation. Apes can even go a step further and fit two sticks together to get a poking tool of the necessary length. In one instance a female chimpanzee confronted by the pipe-and-banana problem and given a pair of sticks which could be fitted together tried them singly and then gave up and began to play with them. When they fitted together by accident, she showed signs of considerable excitement, took them apart and fitted them once more, then used them to get the banana. Even after getting it, her interest in the sticks continued, and she kept joining and separating them until she had mastered the principle. It is difficult to see how the mental processes underlying such behavior differ from those of a man who makes a discovery and realizes its possible application. Apes will also cooperate in projects for getting food, showing by their actions that they are able to comprehend both the basic situation and what the other apes who are working with them are trying to do.

In all fields where exact tests can be applied, chimpanzees seem to have the same mental powers as human children three to four years of age. There is a strong presumption, therefore, that the differences in animal and human mentality are purely quantitative. The ape stops at a certain point in the development of the mind, while the human goes on. However, as the ape cannot tell us what is going on inside his head, the best that we can do at present is to render the Scottish verdict of "not proven." Even if there are qualitative differences in human and ape thinking, so many of the thought processes appear to be the same that no scientist would doubt that human thinking is a direct outgrowth of animal thinking. Human intelligence, like the brain which produces it, is the result of certain recognizable tendencies in mammalian evolution.

No one can deny that there are profound quantitative differences in human and ape thinking. The facts are too obvious to require exposition. 
At the same time, even the quantitative differences must not be overestimated. The complexity of normal human activities as compared with those of animals does not give us a just basis for measurement. In both men and animals most behavior is a matter of habit. Having learned to do a thing, we can thenceforth do it without having to think about it. Our thinking ability is only brought into play when we are confronted by new situations. The civilized man can do more things than the savage because he has had an opportunity to learn to do more things. All the tests which have been applied to the two to date seem to show that their innate mental ability is approximately the same. In the same way, men have better opportunities for learning than apes and this puts them far ahead. The superior mental equipment of men is responsible for the existence of this wealth of things to be learned, but the wealth has been produced by many brains working over many generations. It could not have been created by any one mind. The son of a civilized man, if he grew up in complete isolation, would be nearer to an ape in his behavior than to his own father.

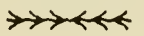

\section{THE ENDOCRINE CONTROL OF THE BODY *}

\section{I C H A E L F . G U Y E R}

Human behavior is not confined to a mentor in a bony capsule at the upper end of the spinal column; the whole body participates. The extent to which this is true can be fully appreciated only after acquaintance with the remarkable part played by certain internal secretions-bormones as they are called technically-in our physical and mental well-being. So spectacular and obvious are some of the effects of these that public interest has been aroused, with the result that there has been a rather wild exploitation of this field in the press under such captions as, "The Chemistry of the Soul," "The Glands of Destiny," "Rejuvenation through Monkey Glands," and equally sensational titles. If one accepts at face value the twittery eloquence of the professional word slingers who write under such headings, then this is surely the date of the endocrine glands! We used to dream of romance, with each yearning soul finding its unerring way to its predestined mate; we now talk of propinquity and hormones. We used to preach thrift; of late we have been practicing New Dealism which feeds us by destroying our food and protects us from penury by squandering our savings (in this connection there is a suspicion of hypertrophy of some endocrine gland which has to do with bone deposition in the head region). We used to hear of sin; we next found psychoanalysis with its slogan of unsatisfied self-expression; but now the devil turns out

* Reprinted from Speaking of Man, by Michael F. Guyer with the permission of Harper and Brothers. Copyright 1942, by Michael F. Guyer. 
to be only good hormones gone wrong. The mooning, lovelorn Romeo of the Mid-Victorian age has become the saxophone addict of today who brays his way into the favor of his ladylove. The languishing Lydias of yesteryear with their scented elegance and euphemistic indirection have given place to the leaping Lenas of today with their cigaretted breath and cocktailed assurance. To what else can such a revolution be due if not to some reversal of the endocrine glands? In these times, indeed, when children run their parents, freshmen instruct their professors, and wives support their husbands, reversal seems the order of the day, and on what else can we blame it in this scientific age if not on the latest biological discovery?

The facts regarding hormonal effects are so striking in themselves as not to require such epic heightening. In no field of biologic research are more brilliant discoveries being made than in that of the so-called "internal secretions," nor do any recent scientific disclosures hold out greater promise of increasing human welfare and happiness than do these. Since the secretions in question do not pass out from their place of origin through ducts as do ordinary glandular products, but are absorbed directly into the blood or lymph and circulated throughout the body, the glands which produce them are called the ductless or endocrine glands.

Hormones are second in importance only to the nervous system in keeping the parts of the body in harmonious operation. They can stimulate or inhibit the activity of some organ or tissue in a part of the body far distant from the source of the secretion itself, and what we are, physically, intellectually, and emotionally depends in no small measure upon them. Many physical and even mental abnormalities are being traced to hereditary or acquired imbalance of the endocrine glands.

In man and other vertebrates the known endocrine organs are special areas in the pancreas called the "islets of Langerhans," the thyroid gland, the parathyroids, the pituitary body, the adrenals, the sex glands, and certain secretory structures in the walls of the upper intestine. Other organs such as the thymus, pineal body, liver and stomach have been suspected of endocrine functions although the evidence is as yet inconclusive. Hormones have within the past few years also been demonstrated in several kinds of invertebrates, and hormone-like substances have even been identified in plant tissues.

The pancreas is a gland concerned primarily with the elaboration of a digestive fluid which is discharged through the pancreatic duct into the upper intestine. Scattered throughout its substance, however, among the lobules which secrete the ordinary pancreatic juice, are small independent areas of a very different looking tissue known as the islets of Langerhans. These cells secrete a substance known as insulin which passes directly into the blood stream and serves, probably in co-operation with the secretion of the adrenal glands, to control the metabolism of sugar in the body. 
If these islets are incapacitated in some way an insufficiency of insulin occurs and a condition known as diabetes (diabetes mellitus) results. A characteristic symptom of this form of diabetes is increase of sugar in the urine. Sugar is the most available source of energy in the body and a simple sugar known as glucose is always present normally in the blood to the extent of 0.1 to 0.15 of I per cent. It is easily oxidized, hence most of our body heat comes from the burning of this sugar. When the sugar metabolism of the body becomes so defective that sugar is constantly wasted, through the urine, the condition is therefore a serious one. Insulin is now widely used in the treatment of diabetes and is restoring the general health and prolonging the lives of many persons. Its discovery has meant for diabetics a change from a life expectancy of two or three years to one of twenty or more. Sir Henry Dale has depicted the helplessness of the physician of only a few years ago when confronted by this then dreaded disease, in the following words: "As a student in the medical wards, I remember hearing a great physician, faced with a case of diabetes, express the view that it would have been better for the patient if his condition had not been discovered."

It is interesting to note in this connection also that secretion of the pancreatic digestive fluid itself does not proceed until the pancreas is stimulated by a hormone known as secretin. Secretin in turn is produced in the walls of the small intestine as a result of the entrance of the acid contents of the stomach following gastric digestion.

The human thyroid gland consists of two lobes attached to the sides of the lower larynx, connected by a narrow band across the mid-line. That of an average-sized, normal man weighs from 20 to 25 grams. It is slightly larger per unit of body weight in women, and still relatively larger in children. Its secretion plays a very important part in maintaining a proper balance of the nutritional and growth processes. The active principle, known as thyroxin, has been isolated in the form of an organic iodine compound containing no less than 60 per cent. of iodine. It is now prepared synthetically by chemists.

Thyroxin operates apparently by regulating oxidation rate. Overabundance of its secretion (byperthyroidism) speeds up the heartbeat, causes higher temperature by raising the metabolic rate of body cells some 30 per cent or more, increases perspiration and, in general, overstimulates the body activities. Hyperthyroid persons are usually highly nervous, overactive and emotionally unstable. A condition known as exophthalmic or toxic goiter, characterized by bulging eyes, excitability and thinness sometimes results. Surgical removal of part of the gland may effect a cure. On the other hand, any condition of sustained emotional stress is likely to induce thyroid overactivity. Thyroid insufficiency (bypotbyroidism) causes the chemical processes of the body to proceed sluggishly; glandular, muscular and mental vigor are impaired; heat production is reduced, some- 
times by as much as 40 per cent, and in adults there is often loss of hair. The skin, especially of the face and hands, may thicken and become puffy giving rise to a condition known as myxederna. Inadequate development or atropliy of the thyroid in the young child produces a condition known as cretinism characterized by retardation in mental, physical and sexual development. The tongue and abdomen of the cretin tend to protrude and the legs are usually bowed. Permanent dwarfism is established. Such children, if treated in time with thyroxin or dried thyroid gland of ten show remarkable improvement, both in body and mind.

Simple goiter usually reveals itself through pathological enlargement of the thyroid gland. That iodine deficiency is an important and possibly the sole cause is indicated by the fact that many remarkable cures have been effected in early stages through the administration of iodine in some form, and by the fact that this type of goiter can be largely prevented through the use of food which contains traces of iodine, or by the occasional addition of small quantities of iodine salts, commonly sodium or potassium iodide, to ordinary food. That this is an important matter, is evident from the fact that in the so-called "goiter belts" some 25 per cent. of the men and some 50 to 60 per cent. of the women show at least traces of thyroid enlargement. Goiter is very common in the Great Lakes region of our own country and is usually found in glaciated regions where the iodine content of soil and water is low compared with that of coastal plains. The Andean plateau in South America, the Alps, Pyrenees and Carpathian mountain regions of Europe, and the Himalayan plateau in Asia are all characterized by a high incidence of goiter.

The well-known experiments of Dr. Marine in Akron, Ohio, seem to have been the beginning of our present-day widespread administration of iodized salt to school children. He found that of 2,190 children treated with iodine, only 5 had goiter at the end of the experimental period, whereas of 2,305 similar children not given iodine 495 displayed goiter. After eleven years of the systematic use of iodized salt on the part of school children in Detroit under the supervision of the pediatric section of the Michigan State Medical Society, the incidence of enlarged thyroid had been cut from 35 per cent. to less than one per cent. Similar results have been achieved in other states. Cleveland, Ohio, seemed to be an outstanding exception at one time, inasmuch as, following the use of salt, the drop in thyroid enlargement was only from 31 per cent. to 18.5 per cent. When the city health department investigated the matter, however, it was found that two of the local manufacturers of the iodized salt being used were providing a salt that contained only one-third of the amount of iodine stated on the label, and that, furthermore, a large chain store was selling a brand that contained no iodine at all. In one canton of Switzerland where 50 per cent. of newborn babies had thyroid enlargement, after the use of iodized salt was made compulsory for pregnant mothers, not a 
single case of congenital goiter was found during three years of observation. It is an interesting fact that, I, 500 years before Christ, the Chinese used iodized salt in the form of burnt seaweed or burnt sponge for the treatment of goiter.

Frog or salamander tadpoles fed on thyroid are forced into precocious maturity. Frog tadpoles quickly develop legs, absorb their tails, and transform into miniature frogs, sometimes no larger than a fly. On the other hand, a young tadpole deprived of its thyroid glands is unable to become a frog though it continues to live, and may grow far beyond the normal size of a tadpole. If at any time such a tadpole is fed thyroid, however, it promptly undergoes metamorphosis.

It is perhaps a significant fact, according to Hoskins and Sleeper, that more than ro per cent. of the victims of the psychosis commonly called dementia praecox-a malady that fills one-fifth of all occupied hospital beds in the country-show some degree of thyroid deficiency, and generally improve after administration of thyroxin.

To discover if too much or too little thyroxin is present in an individual, a test called the "basal metabolism test" is employed. A normal resting person who has had no food for twelve hours produces a remarkably constant amount of energy in a given time as shown by the even carbon dioxide output which results from internal oxidation. In persons suffering from goiter or from lack of thyroid activity, the severity of the condition can be estimated by determining how far the rate of internal oxidation deviates from that of a normal individual.

The parathyroids in man usually exist as four minute glands weighing in all not over two grains, although additional accessory parathyroid tissue is not uncommon. Each is about the size of a small pea. They are closely attached to the thyroid. Their secretion shares with Vitamin D, control of the calcium and phosphorus content of the blood, and since calcium is of prime importance in many physiological processes from clotting of blood and muscular tone to formation of bones and teeth, and phosphorus is likewise indispensable, the proper functioning of these glands is allimportant to the organism. Parathyroid deficiency is characterized by overexcitability of the whole nervous system, and often by epileptic-like seizures; fractured bones are delayed in healing, and in the young, growth of the skeleton is retarded. Complete removal brings about a condition known as "tetany," characterized by painful spasmodic contractions of the muscles of the extremities. The calcium content of the blood is greatly diminished. The respiratory tract, the temperature of the body and the heart are also affected. Injection of a soluble calcium salt will relieve the attack of tetany and, for a time, restore the individual to normal. Death results in a few days after the removal of the glands if the condition remains untreated.

The pituitary gland is a small body of double origin, attached by a 
stalk to the base of the brain. In man it is about the size of a hazelnut and weighs approximately 0.6 to 0.8 grams. It lies in a bony pit in the floor of the skull. The forward part, called the anterior lobe, arises from the rear of the embryonic mouth cavity; the posterior part, or posterior lobe, originates as a down-growth chiefly from the brain.

Although of small size the pituitary body liberates a number of hormones which not only affect the body in general but also influence most, if not all, of the other endocrine glands. The secretions of some of these, in turn, influence the pituitary gland. Because of its manifold secretions and widespread influence it has been called "the master gland" of the body -also, "the conductor of the endocrine orchestra." Following its removal, atrophy of the thyroid, adrenals and sex glands occurs. Underdevelopment of the pituitary gland is usually associated with sexual infantilism; the germ glands, or gonads as they are termed technically, never produce gametes (ova or spermatozoa), and their endocrine activities do not appear. The result is that the accessory reproductive structures and the secondary sex characters of the male or female never reach the adult state. If, in experimental animals, the pituitary gland is removed during early pregnancy, abortion results. This can be prevented, however, by daily injections of pituitary extracts, as can the other changes which follow removal of the gland. Thus it is evident that all the phenomena controlled by the sex hormones are dependent indirectly upon the normal functioning of the pituitary body.

Two potent products have been obtained from posterior lobe substance. One of these acts powerfully on uterine muscular contractions and is sometimes used to hasten childbirth. The second substance affects the smooth muscle of the arterioles; also, the volume of urine secreted. It has been of use medicinally in control of diabetes insipidus. This form of diabetes, which is unrelated to the commoner diabetes mellitus, is characterized by profuse secretion of dilute urine and excessive thirst.

The anterior lobe secretes at least six specific hormones; a growth hormone; one which stimulates the thyroid; one which induces lactation; and three, called "gonadotropic hormones," which incite various gonad activities. The first recognized and perhaps the best known is the one that promotes general body growth, particularly growth of the skeleton. Overactivity of this lobe leads to gigantism, underactivity, to dwarfism and persistence of the infantile condition. Giant rats have been produced by daily injection of anterior-lobe substance into the body cavity of either normal animals or those with excised pituitary. Autopsies on various human giants have revealed tumorous and enlarged pituitary glands. If the excessive secretion begins in youth while the growth zones of the long bones are still unossified, lengthening of the bones, particularly of the arms and legs occurs, and a form of gigantism is the outcome; but if such 
overactivity does not appear until maturity a different type of enlargement takes place in certain bones, notably those of the hands and feet, and the cheekbones, jawbone and the bony ridges over the eyes, so that condition of deformity known as acromegaly results. On the other hand, the well-proportioned, intelligent midget is commonly the subject of anterior pituitary insufficiency. Such pituitary dwarfism in man can be successfully treated with anterior lobe extract provided it is administered before the closure of the growth zones of the long bones which follows the advent of the adult sex hormones. This type of dwarfism is apparently unrelated to that caused by thyroid deficiency, since thyroxin will not correct it.

Repeated transplants of anterior lobe substance induce precocious sexual maturity and ovarian growth. Young mice which ordinarily become sexually mature at the age of about thirty-five days, following such treatment may become fully mature by the end of twenty-one days. Biologists at the University of Wisconsin have made practical use of this gonadstimulating property of anterior lobe material by using it to speed up spawning in various fish. They were able thus to spawn rainbow trout two months in advance of the normal time and so gain a longer growth period of the young fry before transplantation from hatchery to stream. What was more important, however, they showed that highly prized game fish which have hitherto proved refractory to artificial spawning, such as bass and muskellunge, can be made to spawn freely by such injections. It thus becomes practicable to grow the young of such fish in hatcheries for a time for later use in replenishment of fished-out waters.

The adrenal glands, as the name implies, are associated with the kidneys. Each gland is a double structure, consisting of a core or medullary portion which is derived from the adjacent sympathetic nervous system, and an enveloping cortical portion originating from the lining of the body cavity. The secretions from the two parts differ in physiological action.

The secretion from the medullary portion called adrenalin, has not only been isolated in a pure state but has also been synthesized in the laboratory and is widely used as a drug.

Adrenalin is used medicinally to relieve bronchial spasms in asthma, and in conjunction with local anesthetics, for constricting blood vessels and thus preventing rapid diffusion of the injected substance. It is also occasionally used in attacks of hives or of hay fever. Introduced directly into the heart tissue in certain cases of collapse, it will sometimes initiate renewed contraction in a heart that has ceased to beat. It is also employed to induce temporary elevation of blood pressure following collapse of the circulatory system during surgical operations.

Professor Cannon and his associates concluded from their experiments that under stress of such emotional states as pain, suffocation, fear or rage, 
the adrenals are stimulated to an increased output of adrenalin. This, in turn, supplies the body with muscular power to resist or carry out any of the actions that may take place under these emotions for the welfare or preservation of the individual. The sugar of the blood-the most favorable source of muscular energy-increases in quantity; if digestion is in progress its activities are suspended and the blood is shifted to the organs immediately necessary for muscular exertion-the lungs, heart and central nervous system; the blood becomes more coagulable; heart action becomes more vigorous; muscular fatigue is counteracted by the extra hormone; in brief, such fundamental readjustments are instituted as are favorable to great feats of strength or endurance, whether these be fighting or running away.

The hormone activities of the gonads have long been known. Ovaries and testes alike, besides forming germ cells, also produce internal secretions which influence the individual profoundly, both physically and mentally. The male gonads or testes have so-called "interstitial tissue" distributed throughout, between the sperm-producing tubules, and it is from such interstitial glandular cells that the male sex hormone, testosterone, is supposedly derived. Castration of male domestic animals is a common practice and the modifications of the distinctively masculine features that result are strikingly apparent. Also, larger, fatter and more docile animals are thereby secured. Even human beings have frequently been so treated, and it is only within relatively recent times that the castration of boys to provide high-pitched voices for cathedral choirs has been abandoned. Once the secondary sex characters have appeared, however, they are unaffected by later castration.

Much experimentation has been in progress with the lower animals in recent years and many significant facts regarding the sex hormones have been discovered. It has been found, for example, that the suppression of the secondary sex characters and accessory reproductive structures can be prevented in the young developing male castrate if repeated injections of testicular extracts or the male sex hormone, testosterone, are given. Testosterone has not only been isolated in pure form but can be artificially synthesized by the biochemist. In such mammals as the rat or guinea pig, if the ovaries of a female are transplanted into a male which has been previously unsexed, the latter under stimulus of the ovarian secretions assumes a behavior like that of the female. Its hair and skeleton come to resemble more those of the female than of the male, and its rudimentary milk glands become enlarged to functional size. If the ovary of a Mallard duck is completely removed, at the succeeding moult she takes on the very different plumage of the male. Likewise, if the ovaries are removed from very young hens they develop to a greater or lesser degree the more ornate plumage, the spurs, wattles, comb and larger size of the cock. The development of these characteristics will be still further increased if extract 
of the male gonad is injected, or if the gland itself is transplanted to such castrates.

A condition which reveals-the importance of sex hormones in sex differentiation was discovered by Professor Lillie in his study of the "freemartin," a sterile female calf born as a twin to a male calf. In cattle, when of twin embryos one is male, the other female, the blood vessels in the fetal membranes of the two may fuse in such a way that their blood intermingles. The male gonads develop ahead of those of the female with the result that the male sex hormone is the first to pass into the joined circulatory systems. It interferes with the growth of the ovary in the female causing sterility and modifying more or less profoundly various of her secondary sexual characters so that they tend to assume the male condition. Yarious other biologists have shown in several kinds of lower vertebrates that when male and female embryonic or larval forms are grafted together, the sex hormones of one may alter profoundly the sexual system of the other.

In the female of the backboned animals, including man, the rhythmical occurrence of ovulation is correlated with rhythmical changes in the secretions of the ovary. In mammals the hormones so far identified with the ovary have been derived from two sources; namely, the follicular fluid which surrounds the egg before it is shed from the ovary, and a yellowish mass of cells called the corpus luteum which come to fill the ruptured follicle after the egg has been discharged. The two hormones differ decidedly in function although there appears to be a reciprocal or supplementary relationship between them. The corpus luteum increases in size for a time and then undergoes retrogressive changes and is finally absorbed. The duration of this growth period depends upon whether or not the discharged ovum has been fertilized and is developing in the uterus. If such development is in progress the corpus luteum increases in size and becomes what is known as the corpus luteum of pregnancy. Its persistence depends upon the length of the gestation period of the animal concerned. If an embryo is not developing in the uterus, the corpus luteum disappears shortly and a new follicle gradually accumulates liquid, projects from the ovarian surface and at the proper interval discharges another ovum. Thus the cycle of ovulation is repeated rhythmically unless interrupted by pregnancy. Hormones from the anterior lobe of the pituitary body also have a part in stimulating the ovary to ovulation.

The corpus luteum hormone seems to have as one of its functions the preparation of the uterine wall for implantation of the fertilized ovum, for if the corpora lutea are destroyed implantation does not occur. However, the uterine wall must first be sensitized by the follicular hormone before the corpus luteum extract is effective. On the other hand, once implantation has taken place, injection of follicular hormone will cause abortion. A product has been isolated from the corpora lutea which relaxes 
the pubis symphysis before parturition and thus facilitates bearing the young. The same or similar relaxative hormone has also been recovered from the placenta, or nutritive disk by which the fetus is attached, and from the blood and urine of pregnant animals. The hormone from the corpora lutea which inhibits ovulation during pregnancy also stimulates the development of the mammary glands. Thus normal pregnancy is dependent upon many balanced endocrine factors ranging all the way from the periodic preparation for it to the insurance of a food supply in the form of milk at its conclusion. A hormone which appears very early in pregnancy makes it possible to diagnose human pregnancy with a high degree of accuracy within the first month.

The great importance of endocrine glands in controlling the later development of vertebrates, particularly the role they may play in determining the conformations of various parts of the body, opens up the broad question of internal secretions as factors in human development. There can be no doubt that many physical and even mental abnormalities in man are traceable to deficiencies of the endocrine glands or to upsets of their normal interrelations. Atrophy or hypertrophy of such a gland may produce profound effects in the furthermost reaches of the body. Height, broad or slender form, length of arms and legs, shape of face, quality of voice, distribution of hair or of fat on body, and even emotions are in greater or less measure conditioned by the relative functionings of the various endocrine glands during earlier development and later life. And there is no reason to doubt that the amount and quality of the secretions in various family strains are as much the expression of hereditary factors as many other individual characteristics. The hereditary aspects of these glands, however, are likely to be overlooked, because they are also subject to environmental modifications, and because we are accustomed to think of them in terms of their immediate activities instead of their genetical constitutions.

Certain types of human defectives, such as cretins and so-called Mongoloids, even when of different races, often show marked resemblances. The abnormalities in the case of cretins are ascribed to hormonal imbalance-particularly to thyroid deficiency in the affected individual-and those of the Mongoloids are suspected of being the result of endocrine disturbances in the mother, or due to fetal nutritive insufficiency.

Either thyroid or pituitary deficiency is an important factor in dwarfing, but it should not be overlooked that inheritance may have been the determining cause for the changed condition of the gland in the first place. That such developmental anomalies cannot always be attributed to improper functioning of an endocrine gland of the affected individual itself, however, is shown by the fact that some such defects appear far back in the early fetus before its endocrine glands are functional. Nor can the abnormality be attributed in all cases to endocrine defects of the mother, 
since pedigree tabulations are known which clearly show that the condition can be transmitted from the paternal side.

As to just where to draw lines among hormones, vitamins and other chemical substances of the body which likewise produce pronounced physiological effects when present in almost unbelievably small amounts, no one can yet say. The vitamins are of dietary origin. Absence of any one of them from our food results in its own particular type of disorder. The chemical structure of a number of both the vitamins and the hormones is now known and that of others is in fair way of solution. It is a significant fact that calciferol, the active principle of Vitamin D which is sometimes called the sunshine vitamin, belongs in the same chemical group (the sterols) with the male and the female sex hormones. An even more surprising fact is that the cancer-producing constituent of coal tar has a type of chemical structure that also suggests the nucleus of the sterols. Nor is this relationship of the sex hormones and the cancer incitant merely a fanciful one, for when the latter is injected in properly graduated dosage into rats, reactions characteristic of female sex hormones are initiated.

Then, too, there are the recently discovered neurohumors-chemical mediators between nerve endings and the organs to which their impulses are transmitted. Some endocrinologists would recognize these as true hormones. If so, the distinction which we commonly make between endocrine and nervous regulation of the body becomes decidedly obscured. The rate and force of the heartbeat, for example, is controlled by two different nerves. Impulses from the vagus nerve render the beat weaker and slower, those from the cardiac-sympathetic nerve, stronger and faster. It has been discovered that the vagus produces its effect by the release of a minute amount of acetylcholine; the sympathetic operates by discharge of a substance very like adrenalin, called sympatbin, of which there are apparently two types, E. and I. The evidence is increasing, indeed, that transmission of all impulses from nerve fibers to receptive cells, whether glandular, muscular or even other nerve cells, is of this same chemical type.

And now what of romance, of drama? Has it all vanished into the neutral drab of everyday scientific fact? Why, as someone pointed out, even the dramatic tragedy which thrilled us in our childhood that Jack Spratt could eat no fat, his wife could eat no lean, is doubtless reducible to a mere difference in endocrine complex. Possibly Jack was a cadaverous hyperthyroid and his buxom wife a slightly hypothyroid individual. And probably old King Cole was a merry old soul merely because of wellbalanced endocrines. At least it is certain he would not have been merry, had they been much out of balance! The broad fat tenor or the long thin bass, is possibly but the puppet perpetrated by his hormones. Thus always is the scientist taking the joy out of life by destroying our most cherished 
illusions! Perhaps it is not inappropriate to point out in this connection, however, that a beautiful painting is none the less beautiful to one who happens to know the chemistry of pigments.

The emotional side of man is peculiarly sensitive to the ebb and flow of the endocrines. Ugliness and beauty, melancholy and happiness, and even to some extent goodness and badness, are reflections of hormonal harmonies or disharmonies. The biologist can but pause and wonder at the changes in behavior which sometimes follow even a slight shift in endocrine balance. Parathyroid deficiency, for example, with its ensuing depletion of calcium and phosphorus in the blood, commonly means change in an individual's whole attitude toward life so that he becomes irritable, dissatisfied and disagreeable - a pest in home, school, or among companions. Children afflicted with convulsive seizures, mental depression, spells of irrational speech and terrifying dreams, or even those who manifest screaming, fighting, maniacal attacks, have been brought back to normal, rational behavior by means of parathyroid extract. The four parathyroid glands of man-little larger than four grains of wheat-constitute, indeed, a slumbering volcano of misbehavior since, once their output is restricted by injury, removal, or disease, a well-nigh demoniacal possession may follow. In man, complete removal is followed by death.

Even old age seems to be the result of a slow alteration of the internal chemical complex of the body following a gradual change of the endocrine balance. Every individual, in fact, is really a different chemical medium at different ages. Several features of old age, such as lowered metabolic rate, feelings of chilliness, dryness of skin and scantiness of hair, picture distinctly thyroid deficiency. Concomitantly the thyroids of the aged show evidences of atrophy including partial replacement by inert fibrous tissue. Whether or not we shall eventually be able to counteract the senilityinducing factors remains to be seen. This much is certain: death is not an inherent attribute of living matter. There is no natural death among the protozoa. The rolling, flowing amoeba which the indifferent freshman eyes nonchalantly through his microscope, is venerable almost beyond belief, for it is a bit of immortal living matter that began existence in the heyday of life's creation. Moreover, although the natural lifetime of a fowl is only six or seven years, tissue removed from the heart of a chick embryo has been kept alive and growing in artificial cultures for over thirty years.

Then, possibly, if one but lets his fancy roam, there may be more romantic behavioristic applications of our rapidly accumulating store of biochemical knowledge. May we not even come to the pass where our parsons, instead of trying to scare us out of hell, or hell out of us, will merely line us up once a week for the proper dose of hormones or antihormones as each case may require, and thus leave their sermon time free for the contemplation of more pleasant things than the corrective terrors of the damned? May not the timid lover be hormonized by his physician into 
the courage of his convictions? On the other hand, where we now have beauty parlors for hair curling and nail coloring, may we not in the future have hormonal parlors where even the least colorful maiden may, for ten dollars, receive a shot in the arm guaranteed to induce sufficient "oomph" to overcome the matrimonial disinclinations of even the most reluctant male? And there is the husband who is always falling in love with every pretty face and who hath a roving eye. Perhaps the solution for the future wife will be merely to take him to the proper endocrinal studio for a hypoderm of anti-philanderine, and thus have him tuned down a few octaves to the standard pitch of ordinary husbandly docility. Who knows, perhaps even the mate-changing habits of our movie stars might be attuned to the plodding pace of the great majority of our convinced, if not convicted, monogamists, who drift along with one spouse, and with neither prospects nor desires for the hazards of another! 


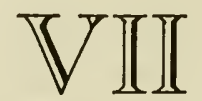

Reproduction

$\mathbf{R}_{\text {EPRoduction is ordinarily thought of as an extremely complex phe- }}$ Rnomenon coupled as it is, sometimes, with spermatogenesis, oogenesis, reduction division, copulation and fertilization. It becomes less complex in appearance, at any rate, when we review the process in simple plants and animals. Sexual reproduction in Paramecium, for example becomes simply the side by side conjugation of two specimens with the subsequent exchange of nuclear material.

When we examine some of the numerous instances of reproduction in which no sex is involved, a type known as asexual reproduction, the matter appears very elementary. In bacteria the cell simply divides into two equal parts and each half then proceeds to grow into an adult bacterium. In yeast tiny protuberances called buds appear on the parent cell, grow larger and eventually detach themselves or break off.

One aspect of this subject which needs amplification is that reproduction is the process by which immortality is attained. At first this may sound fantastic but if one considers that tiny bits of living matter passed on to the offspring from the parents in the form of eggs and sperms are lineal descendents from similar structures passed on to them from their parents and so on back to the dawn of man's emergence from pre-man, the thought soon loses its aspect of improbability.

When we list the characteristics of life we frequently mention reproduction as one of the main features distinguishing it from the inorganic. Stones do not beget stones nor does a piece of iron ore divide into two pieces of ore, except by fracture. The dividing line is not as sharp as formerly thought. Protein molecules as found in a piece of dried beef are still protein molecules but they do not reproduce themselves. The essential part of chromosomes, the genes, are now thought by many to be large complex protein molecules and yet these do duplicate themselves every time a chromosome divides lengthwise in cell division. The difference here seems to be that a living system is necessary in conjunction with the molecules. That brings us back, of course, to the nature of life and the student will observe that we have described a neat little circle and are now back to the same relative position where we were when we started this discussion. Someday the answer will be forthcoming; someday all the proper types of bricks will be assembled, the bricks repre- 
senting research achievements, and someone can then build up the true picture for us to see.

\title{
REPRODUCTION *
}

\author{
E M A N U L R Á D L
}

\section{MODES OF REPRODUCT $10 \mathrm{~N}$}

One of the most important and characteristic features which differentiates the living from the non-living, is the power of reproduction. No organism is formed by the action of material forces, but each one is produced by a living predecessor. From the time of Aristotle, however, there have always been some who have maintained this assumption to be incorrect, and that there are certain circumstances under which spontaneous generation may take place. Moreover, the method by which life arises from life, a phenomenon without analogy in inorganic nature, presents a problem which is just as obscure in the lowest types of life as in mankind.

Life renews itself in two ways: the first sexually, when two individuals are essential for the production of the offspring; the second asexually, when one individual alone can produce another.

In asexual reproduction a smaller or larger portion of the body separates itself from the mother organism, and by growth and differentiation develops into a new individual. This individual exists side by side with the mother organism, which, in the meantime, has replaced the part cut off. If the organism divides into two roughly equal halves we speak of "fission"; "budding" takes place, on the other hand, when the newly developed organism separates from the body of the old one as a comparatively small branch. Finally, if it is produced from a single cell, which is usually formed in a special organ of the mother body set apart for its production, we speak of reproduction by "spores."

In sexual reproduction there are always two, if not independent individuals, then at least physiologically (sexually) different organs, whose products unite: the male, which forms spermatozoa, and the female, in which the ova are formed. In exceptional cases one of the sexes (the male) can be suppressed. We then speak of parthenogenesis, when unfertilized females lay eggs capable of development. Among the higher animals, especially among mammals, parthenogenesis does not occur, although the eggs of birds and mammals often begin to segment without being fertilized. At a time when Darwin was still considering his theory, Hofmeister discovered that even the so-called sexless Cryptogams reproduce themselves

* Reprinted from The History of Biological Theories by Emanuel Rádl, translated by E. J. Hatfield, with the permission of The Clarendon Press, Oxford, r930. 
sexually, but that here the sexual and asexual methods of reproduction alternate in a peculiar way. The green mosses form eggs and sperms, but the fertilized egg does not develop into another moss plant. It forms a capsule on a brown stalk, in which asexual spores are formed. These fall to the ground and eventually germinate to form a new sexual plant. Thus the little moss plant has two life periods: in the first it lives as a green plant, which forms sexual organs; in the second as a brown capsule, which forms asexual spores.

The ferns, horsetails, and lycopods all go through these two phases, though in them the sexual individuals are small and inconspicuous, while the asexual, on the other hand, are large, being (in the case of ferns) the actual fern plants, which bear asexual spores. Among flowering plants, the first, or sexual phase, is very much reduced. While the algae reproduce themselves now sexually, now asexually, the higher plants, from the mosses upwards, follow an ordered alternation of the two methods of reproduction; the higher the plant, the more developed is its asexual phase, and the more reduced the sexual phase becomes. The meaning of this alternation is by no means clear.

More recently the analysis of the behavior of the chromosomes during fertilization has shown that there are specific sex-determining chromosomes; further, that the inheritance of sex follows the same Mendelian rules as does the inheritance of any other bodily character. This does nothing, however, to help in the understanding of the whole phenomenon of sex.

\section{THEORIES A BOUT THE NATURE OF SEX}

The philosophy of sex, to which man has always devoted much thought, has passed to-day into the chromosome theory. Much of Aristotle's philosophical system originated in the recognition of the difference between the two sexes; this gave him his ideas about matter and form. In the female are embodied the passive principles, in the male the active, creative, formative principles. Even Harvey allowed himself to be influenced by these ideas, and he compared the female uterus with the brain; as the latter possesses the power to form images of external objects, so the uteruswhose ideas are the eggs-forms them in the image of the fertilizing male. In the speculations of the evolutionists of the eighteenth century the broader aspects of sex were absolutely neglected. The result of the discovery of eggs and spermatozoa was that the true nature of the problem was obscured. They imagined that they could answer all questions on the subject by examining those structures. The theory that the complete man lies already enclosed within the ovum or the spermatozoön suggested that one sex, either the male or the female, represented a superfluous, purposeless creation of mother nature.

The German romantic philosophers looked with wonder upon the 
phenomena of sex. Their most fundamental idea, that of polarity, was often inseparable from the idea of the contrast between the sexes. Even Schopenhauer devoted a special chapter to observations on the metaphysics of sexual love. Led by the poets, and by Goethe-the man of the world,- these philosophers were able to appreciate the fateful power of the differences between the sexes. Since Darwin's time, however, biologists have not considered the subject of any paramount importance. It is true that Darwin based his theory of sexual selection on the differences between the male and female of the same species. This theory, however, lacks most of the beauty which characterizes living nature. He only saw in these differences secondary adaptations to the external conditions of life. Since then this subject has lost much of its significance. Blind to the processes of actual life, and carried away by their observations of microscopic structure, biologists have tended to look upon the problem of sex, under which, according to some philosophers, all the problems of the world lie hidden, as merely a problem of chemistry and of cell structure. From the fact that the spermatozoön and the ovum are both cells, it was inferred that there is no essential difference between them. By considering the sexual cells from which they originate, instead of the adult individuals, in all the fullness of their life and struggle, they concluded that there is no essential difference between man and woman; the differences which actually exist between them are, according to these theorists, merely special adaptations for the purpose of facilitating the union of the spermatozoön with the ovum.

All the contrivances connected with sex are variations upon one and the same theme; firstly, they enable the sex cells to come together, and secondly, they insure that the egg shall be nourished and kept in safety. We call the one set of contrivances "male," and the other "female." All these relationships are of a secondary nature, and have nothing to do with the real essence of fertilization; this is the union of two cells, and is therefore purely a cell phenomenon. In these views we agree with Weismann, Rich, Hertwig, Strasburger, and Mallpas, who have expressed similar opinions (O. Hertwig, Allgemeine Biologie, 1902).

On this view one question alone remains: what is the meaning of the process of fertilization itself? In the simplest forms of life, as, for instance, the bacteria, there were originally no sexual differences. These developed gradually, and began in the fusion of two otherwise similar cells. To facilitate conjugation one cell gradually assumed a passive role, and the task of accumulating food; the other became more active, hence smaller, and sought out the former. Thus began the differentiation between ovum and spermatozoön. When, later, multicellular organisms developed, the process of reproduction was taken over by a few cells, and for the purpose of facilitating conjugation the two sexes became differentiated in various directions.

This is the way in which Strasburger, Maupas, and Weismann ac- 
counted for the development of sexual differences. The latter also thought that these differences in sex play an important part in bringing about variation. The offspring inherits some characteristics from its father, others from its mother, and hence embodies a new combination of characters. Others have given such obvious explanations of all the facts connected with sexual life that there seems to be nothing which is beyond the comprehension of these scientists! Do we ask what is the basis of sex-love? Jaeger puts forward the hypothesis that it consists in a similarity between the exhalations of the male and the female, and in a chemical attraction set up by these exhalations. Pfeffer has actually succeeded in obtaining a proof of this hypothesis in the case of certain plants. Mantegazza also gave a very similar explanation. Others, like Nägeli, have considered that the attraction is electrical in nature.

But why do two cells strive to unite? why the electricity and the chemical attraction? The reason is not a very abstruse one! According to some scientists cell conjugation developed from a kind of cannibalism. One cell devoured its neighbour, became strong, passed on the capacity for devouring its neighbour to its successors, and so conjugation began. Jacques Loeb suggests (1906) that fertilization has the following significance: the spermatozoön brings into the ovum certain chemical substances which hasten segmentation; this can, however, be brought about without the help of the spermatozoön, merely by the influence of certain chemicals. A little potassium chloride or cooking salt is a substitute for the male element, as has been shown at any rate in Echinidae worms, starfish, and other animals. A mechanical stimulus (as has been demonstrated on the frog) may act in the same way.

Boveri (1902), on his side, compared the egg to a watch which has not been wound up; fertilization simply winds the spring, and this makes segmentation possible. According to him the essential factor is the centrosome, which enters the ovum with the spermatozoön. For Herbert Spencer also the object of fertilization was no mystery; life is like a constantly moving wave; the beginning of life resembles the heaving surface of the water; it becomes calmer and calmer as development proceeds; in the ovum such a peace prevails that a new impulse must come to it from outside; the fertilizing spermatozoön is like a stone thrown into a pond; life is set in motion again, and the power for a new period of development is given. ${ }^{1}$

When we contemplate the activities and struggles of the Universe, it would seem as if the antithesis between male and female plays the most important part in the whole drama. The most beautiful and the most vile in practical life, in philosophy, and in literature, is developed under the

${ }^{1}$ A systematic account of the problems of sex is given by P. Geddes and J. Thompson in The Evolution of Sex, 1899; L. Dante, La Sexualité, 1899 . H. His gives the history of the subject in "Die Theorien der geschlechtlichen Zeugung," Arcbiv. für Anthropologie, iv, 1870 and 1872 (incomplete). 
spell of antithesis. It is the inevitable inspiration of the poet. In every religion we find in its metaphysical foundations some solution of the question of the relation between man and woman.

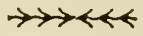

SEX *

M I C H A E F . G U Y E R

Most biologists would agree that the fundamental behavior patterns of the animal world, whether of mice or men, are determined largely by the two elemental urges of hunger and sex. To these, fear might be added as a close third. If one is to understand the human individual or human society, therefore, he must make his interpretations with the consciousness of these inclinations always in mind. To be sure, they may appear in many secondary forms: that of sex particularly may take on a thousand disguises. Nevertheless these universal drives are always in evidence to the discerning eye.

One has but to pick up his daily newspaper to realize what share of attention sexual affairs and their irradiations command in our enlightened land. Many newspapers probably give an erroneous impression about our sexiness because they thrive on sensationalism. This fact in itself, however, carries with it the conviction that they have a reading clientele avid for their alleged revelations. By their constant harping on the theme of sex and by playing up sexual delinquencies, real or fancied, on every occasion, they have made us oversensitive to the subject and probably kept our minds on it to an unwholesome degree. Through description and innuendo certain newspapers have become veritable aphrodisiacs which keep many of our more suggestible citizens at a fever pitch of amatory expectancy. They give the impression that most of our people think of little else, and this is far from true.

Most amusing of all, perhaps, is what seems to be the belief of the present generation, particularly the rising section of it, that they have discovered sex-that it came into being coincident with bobbed hair, bare knees and their adolescent ballyhoo. The whole matter is highly comical when one realizes that as a matter of fact old Father Stonehatchet or even an Eocene monkey could give them the laugh on their naïveté. However this may be, in these piping days of swing and jollity, of saxophones and sexophiles, it is the fashion for our young folks to appear sophisticated and daring. Particularly smile-provoking are the supposedly spicy and "hard-boiled" contributions which so often appear in our college or high school magazines. Occasionally, it is true, one finds sexually minded individuals who

* Reprinted from Speaking of Man, by Michael F. Guyer with the permission of Harper and Brothers, Copyright 1942, by Michael F. Guyer. 
can't look at a monkey paperweight without wondering whether it's a he or she, and who, if they heard the name used, would suspect the sextant of being an instrument invented by some Nevada judge to measure sex appeal, but such persons are decidedly in the minority.

Of course our young folks are sexy, as their parents, and their parents' parents were before them, clear back to the primeval protoplasm of creation's dawn, and also, of course, most of them have the same average intelligence, capacity for necessary inhibition and common sense that their parents had, and they will act, therefore, in much the same way, including worrying over the rising generation. They may be a bit intoxicated at present but surely will come the morning after when they will sober down to the headache and the hard office chair.

Our young sophisticates profess to laugh at what they consider the sentimentality of the past generation, but oh, who of us have not by some misfortune been compelled to listen to their favorite songs which palpitate over the radio! Those about some black or other hued "mamma," about dancing with tear-stained eyes and love-anguished hearts, about their "blues," their sighs and their various other emotional gripings, about the little lovenests for two-oo-oo-oo, ad nauseam, until to the Mid-Victorian "sentimentalist" it all becomes excruciatingly funny when not too boresome.

Not sentimental? Come to any one of the campuses of our larger coeducational institutions and gaze at the throngs of ambulant adolescents, with here and there and everywhere, soulful males and sighful females strolling hand-in-hand from class to class; any observer can see the humor of the situation even though the performers do not. True, such displays are staged mainly by traditionless youths from our larger cities, but individuals of this type have swarmed into our colleges in such numbers in recent years as almost wholly to eclipse the former college clientele from homes of refinement where good taste, delicacy of feeling and a sense of propriety were not scorned as reprehensible repressions.

And then, take what our young sophisticates call music-jazz or swing -a series of constipated, strangling sounds emitted in a skip-stop rhythm which goes over and over and over the same inane little theme, made harsh by occasional clanging discords-apparently a sort of sauce piquante to the ears of modern youth. Where a solo effect is introduced it is usually given to that orchestral bastard of reed and brass, the saxophone, whose every tone reveals its illegitimate origin.

What most people fail to realize is that sex is so universal in nature, and therefore so commonplace as to be nothing unique, startling or all-absorbing. One finds sex shadowed forth in the first dim gropings of the lowliest living matter. The amours of the protozoa may not seem to promise much as portraiture of modern sex appeal, but sex in the making is there, nevertheless. One can trace its course upward through worm, fish, fowl and 
beast. Undeniably, when properly regarded and controlled, it constitutes the mainspring of action in many of the most vital, romantic and sacred relations of human kind. Yet it is only part of life in this universe of so many interesting things and experiences, and therefore is something that should be kept in its proper place. Those modern advocates of "being natural" or "getting back to nature" as they vociferously proclaim their doctrine, may well note that through the whole realm of animal life, from the lowliest to the highest almost without exception, actual sex function is paramount during only a brief period of the animal's career and therefore plays but a secondary role in its total existence.

Without sex the world of plant and animal life would certainly seem very strange. There would be no flowers. In the animal world there would be little difference in appearance among the individuals of a species since there would be no necessity for discriminating male from female. Ornamentation and the displays of courtship often incident to mating would be nil. The power of making sounds, even, might not have developed since. it is most commonly used as an aid to mating. The songs of birds, the stridulations of such insects as katydids, crickets or cicadas, the spring trilling of creatures like male frogs, the various calls of different mammals have probably all arisen primarily as sex calls which insure the bringing together of male and female at mating time, even though later such sounds have often taken on other functions. The bellowing of bulls or the caterwauling of tomcats are vocal challenges more indirectly associated with mating, while the familiar clucking and warning signals of hens and various other female forms is an extension to the protection of young. Vocalizations of various kinds of ten come eventually to serve for the welfare of flocks, herds, or other social groups. And in man, of course, voice has advanced into articulate speech and all the advantages associated with language.

Sex is determined ordinarily by a chromosomal mechanism in the germ cells. In man, for example, with his 48 chromosomes ( 24 pairs; one of each kind from each parent) there is a special pair of chromosomes, called the $\mathrm{XY}$ pair, which, unlike the others, do not match. The Y member of this pair is smaller than the $\mathrm{X}$ member. In one of the last divisions of the maturing germ cells the various corresponding pairs of chromosomes line up side by side (synapsis) in such a way that in the ensuing cell division each of the two newly formed cells receives one or the other member of a pair but not both. Thus $\mathrm{X}$ would go into one of the new cells. $\mathrm{Y}$ into the opposite one. In this way each definitive germ cell while receiving only half ( 24 in man) of the original number of chromosomes, gets one of each pair; that is, one of each kind. This is called the reduction division. The original number ( 48 in man) is restored at the time of fertilization: 24 being contributed by the spermatozoon and 24 by the ovum. Whether a given chromosome of the reduced set is of maternal or paternal origin 
is merely a matter of chance. In other words, the reduced number of chromosomes in any germ cell is a random assortment of the original chromosones of maternal and paternal origin. The only necessity is that each final germ cell (gamete) have one of each kind of chromosome, since each kind carries special hereditary determiners and has its own particular role to play in the development of the new individual. Thus, for instance, if we arbitrarily represent the chromosomes of a given individual by $\mathrm{ABC}$ $a b c$, and regard $A, B$ and $C$ as of paternal and a,b, and $c$ as of maternal origin, then in synapsis only $A$ and a can pair together, B and b, and C and c; but each pair operates independently of the other so that in the ensuing reduction division either member of a pair may get into a cell with either member of the other pairs. That is, the line-up for division at a given reduction might be any of the following: $A B C, A B c, A b c, A b C$. $a b c$ abC aBC aBc This would yield the following eight kinds of gametes, $\mathrm{ABC}$, abc, $\mathrm{ABc}$, $\mathrm{abC}, \mathrm{Abc}, \mathrm{aBC}, \mathrm{AbC}, \mathrm{aBc}$, each kind of chromosome required to cover the entire field of characters necessary to a complete organism. Since ova and sperm would be equally likely to have these eight types of gametes, the possible number of combinations for such germ cells would be $8 \times 8$, or 64.

Computed on this basis, in man with his 24 pairs of chromosomes the number of different combinations producible would be $282,429,536,48 \mathrm{I}$. The fear of standardization in mankind expressed by some of our literary folk, does not, therefore, seem very alarming. Sex makes anything like complete standardization virtually impossible.

As noted, the $\mathrm{X}$ and $\mathrm{Y}$ chromosomes of man constitute a pair originally, but after the reduction division half of the total number of sperm cells will contain an X, the other half, a Y. Females of species such as man, however, are characterized by the possession of two X's and no Y. This means that after the reduction division every ovum will carry an X. It is evident, therefore, that there are equal chances of producing an $\mathrm{XX}$ type or an $\mathrm{XY}$ type of fertilized ovum. The XX type develop into females, the XY type into males. Thus sex is automatically launched on its course at the very inception of development. Since there is no Y element in many species of animal, $\mathrm{X}$ substance seems in some way, to be the determining factor.

Sex chromosomes are not only agents of the sex-determining mechanism; they also carry the determiners of certain hereditary characteristics. Such traits display what is termed sex-linked inheritance. The form of color blindness characterized by inability to distinguish red from green is such a sex-linked trait. In the color-blind man the single $\mathrm{X}$ carries the gene of this defect. Mated to a woman with both $\mathrm{X}$ chromosomes normal (XX), their daughters although getting the paternal defective $X$, also get a normal $\mathrm{X}$ from the mother, and this normal $\mathrm{X}$ is sufficient to insure normality of vision in all daughters (XX), or in other words, the character is what is 
known as a sex-linked recessive. The sons of such a color-blind father will all be of normal color vision (XY) since their single $\mathrm{X}$ chromosome comes from the mother. Furthermore, they are incapable of transmitting the defect. When the daughters marry, however, since each carries one defective $X, 50$ per cent. of their ova will carry this $\mathrm{X}$ and 50 per cent. will carry a normal X. Married to a man of normal color vision (XY) such women are equally likely to have color-blind sons (XY) or sons with normal color vision (XY), since the chances are equal for a Y-bearing spermatozoön to meet either type of ovum. The daughters, on the other hand, will all be of normal color vision, but 50 per cent. of them will, like the mother, be carriers of the defect. If such a carrier (XX), however marries a color-blind man (XY), the expectation is that half of the daughters will be color-blind, $(\mathrm{X} \overline{\mathrm{X}})$ and half will be carriers $(\mathrm{XX})$. Also, 50 per cent. of the sons of such a mating will be color-blind (XY), the others, of normal color vision (XY). More than twenty sex-linked traits are known in man. Among these may be mentioned hemophilia (excessive bleeding), various eye defects, certain skin abnormalities such as absence of sweat glands, and several neural and mental anomalies. In the hereditary nervous disorders, the sex-linked factor not infrequently supplements an additional factor borne on one of the ordinary chromosomes.

Evidence of the opposite sex in normal man is seen in the possession of nipples, a minute uterus masculinus and other rudimentary structures. Since each sex possess the potentialities of the other, either may, under adverse conditions, become intersexual. Cases of intersexuality in some degree are occasionally encountered in both man and domesticated animals. Generally it is a case of an undeveloped male in which, apparently because of the absence of normal testicular hormone, both male and female organs develop to a certain point so that a neutral type results.

While there is nothing novel about sex and while it will work out much the same generation after generation in a given stock of people, there is little doubt that many of our young folk of today know more of the true facts of sex and have fewer absurd notions and sentimental balderdash about it than did their more recent forebears. They are not going to look on sex as something which, even at its best, is shameful, as something which should be tolerated merely because of its indispensability for the continuance of human existence. The chastity couch which intrigued the puritanical conscience represents a vegetarian form of love that will find no response in their marital dietary. As a result they will probably live happier, saner, more wholesome lives than did these apostles of fleshly mortification. If they make mistakes they will pay the inevitable penalties of lowered ideals, blunted capacity and blighted lives, and not infrequently, of loathsome disease and death. The latter, disease and death, is perhaps the only penalty that will appeal to the less delicately minded of them, but even 
they can surely convince themselves of the facts by a visit to almost any clinic in the land, mental, surgical or medical.

Very often of late, our colleges and universities have come in for a scoring at the hands of some excitable individual who, having taken pen in hand and sex in mind, with the aid of a little fact and much fiction, paints a lurid picture of his inner convictions. In his mind, coeducation has become wholly coo-education, and he lays himself out in a heart-rending account of how terrible the struggles of the male student are along the thorny path of learning with a bare-kneed "babe," all waved and scented, as his traveling companion. How much the wish is father to the thought in such ebullitions it's difficult to say, but such writers forget that the present generation boys have grown up with the bare-kneed sisters, mothers, cousins, and aunts, to say nothing of grandmothers, and that as a result, to them, unlike their palpitating mentors, bare knees are no longer "a treat."

Virtue is a matter of purity of heart rather than of the conventional outlook of a particular age or people on the externals of life. As regards dress, to put it bluntly, girls of the present time are probably less alluring and therefore less dangerous to the weaklings among men than in earlier days because there is little mystery left about them. The human mind is so constituted that it is fascinated by mystery. The half-revealing, halfconcealing garments of former days were unquestionably more provocative to the imagination, and in matters of sex it is imaginative stimulus that makes behavior run riot rather than the bold facts of anatomy. Our modern woman's dress certainly leaves little or nothing for the imagination to play around, and from the standpoint of morals it is probably better so. Since chance revelation of the feminine form has ceased to be an excitant to the masculine eye the whole situation makes for a more wholesome attitude between the sexes.

For some years the problem seems to have revolved around the question of to skirt or not to skirt-the amount of leg to expose. In earlier days, as revealed in English poetry at least, it was apparently the breasts that received most attention. Thus, we find such amorous clerics as the bachelor poet Herrick rhapsodizing about this or that or the other detail of his "Julia's breasts," and even such masters as the great Shakespeare himself enthusing over:

Her breasts, like ivory globes circled with blue,

A pair of maiden worlds unconquered.

Whatever may have been the beauteous type of the poet's dream-and perhaps it was mainly a dream-in the give and take of everyday living it is probably more wholesome for man to think of these necessary mammalian accessories in terms of their nutritive rather than their ornamental functions. Here, too, with the passing of mystery, indecorous fancies vanish. 
Young women may well be on guard against the flashily dressed, boastful, or swaggering type of man, because he is usually a vain, self-centered, unreliable, or overcompensating individual, who possesses few qualities that would make him a devoted husband or father. Habits firmly established are seldom changed much by marriage, hence to expect a man's emotional attitudes to be reversed by such a ceremony is to flout experience. If he is not an industrious, intelligent, considerate type before marriage, there is no nagic that will make him such when wedded.

To the inexperienced young man perhaps the most dangerous girl is a baby-faced, rather pretty, physically alluring, up-and-coming type, of relatively low mentality. With our lax educational standards she not infrequently finds her way into the high school, or even through it and into college, but she rarely lasts out the freshman or sophomore year. Like the decerebrated frog of the physiological laboratory, her food-catching, swallowing, and sexual reflexes, are normal, but she has little or nothing above her ear level to make her promising material for a wife or mother. Frequently such an individual is not only lacking in judgment and good taste when it comes to the serious or finer matters of life, but sometimes she is also wanting in the proper inhibitions which are indispensable to right living.

But this does not mean, of course, that the little wiles of young folk, which are usually harmless, are to be condemned. After all girls are girls and boys are boys, and down deep in his heart every Jack wants his Jill and every Jill her Jack. And nature has so built us that the fulfillment of these wishes-often unadmitted to ourselves-begins the forward march long before we recognize that it's in motion toward its matrimonial goal. When a girl reaches a certain age it is just as natural for her to begin practicing her little coquetry toward boys as it was for her to play with her dolls earlier, or play "grownup," and what not. How else would she find the right matrimonial pal in this serious though glorious game of life? And so back of the playful coquetry of the little Dorothys and Geraldines who challenge and intrigue a boy's attention-often (not always) unknown to themselves-there is a deadly earnestness. And girls, from the sheer necessities of the case, are past masters of such arts when compared with boys, since the outcome-home, safety, provision for self and children, love-are of so much greater fundamental importance to them. Nature says to them, "a mate must be had and you must attract," and the game is on.

Blame them for it? Heavens no! Bless them! Otherwise mankind would go blundering through life missing most of its fineness; much of its worthwhileness and practically all of its spice. Why quarrel with the way nature insists on having things done? Who in his right senses would do away with that judicious mixture of the sexes which gives so much tang to human affairs? 
Thoughtful women often ask why it is that men are so prone to select the merely pretty woman rather than the woman of proved worth; why some little doll-faced snip of a girl can so often mislead or make a fool of an otherwise sensible man. Why, indeed? It has been suggested that a pretty woman is usually a physically healthy woman and that there is an unconscious biological tendency toward choosing a healthy mate. This may be a factor.

Aesthetic sense, a feeling for the beautiful, is an important factor which draws men to pretty women, although here again one can't escape the factor of male rivalry. It is undeniable that each race or tribe of people has its own ideas of what constitutes manly or womanly beauty, and the standards of one race are often regarded by another as ridiculous or incomprehensible. For instance, an African chief of a tribe in which the women perforate the lips and stretch them out for two or three inches by the insertion of solid disks or rings until they resemble the beak of a duck, was much surprised at the stupidity of an explorer's question as to why this was done. He replied for "beauty."

It is an undeniable fact that to the more impulsive, unthinking type of man, mere prettiness is in itself a strong lure. Yet most sensible men, even when under the spell of beauty, know how to discount it if it is not accompanied by character, good sense and a self-respecting spirit. And one sees many a man, after playing around with the free and easy, paintedbeauty kind of girl, turn to the plainer, more demure, more unselfish type, when it comes to taking a wife. Apparently he realizes that the happiness and sanctity of a home is likely to be more secure in such hands.

After all, physical beauty is not the only-indeed, not the main factorin that elusive quality called charm, and it is really charm that irresistibly attracts a man to a woman. What is charm? Who knows? Everyone recognizes its existence and its power but no one can wholly analyze it. It involves to a considerable degree, graciousness, tact and kindness; cheerfulness, or vivacity is an indispensable ingredient; evidence of pleasure in the company of the masculine companion, tempered with appropriate reserve, must not be missing; and through it all runs, unobtrusively, perhaps even unconsciously, the play of sex, or better perhaps, that irradiation of sex which takes the form of a mild and inoffensive coquetry-what men call being feminine. To describe charm is like trying to give directions after the fashion of the cook who tells one to take a cup of this, a bit of that, and a pinch of something else. Charm, nevertheless, is a very real quality and is the chief ingredient of the emotional complex which constitutes the sentimental appeal of a woman to a man.

One gathers fragments of wisdom concerning sex and marriage as he journeys through this world of divorce courts and scandals-yes to a minor extent-but mainly, of that great army of "good sports" who know how to give and take fairly in the intimate and complex relationship of 
wedlock. The biologist can only conclude that unquestionably the healthiest, happiest mode of life for either normal man or woman is found in marriage, that no career which frustrates the experiences of family life can compensate for it. It is for this outcome that nature has prepared mankind from almost the very beginning of life on the earth. To insure the most satisfactory outcome, the mutual affection of the participants should be a matter of growth based upon repeated association. There is usually a period before courtship, in which one is in position to learn much about the desirability or undesirability of a particular individual as a marriage mate. Only an ill-balanced person is likely to rush blindly into matrimony. Where properly consummated the man-woman relationships of life make for a unity of interest and ripening of emotional satisfactions as do no other experiences, and the spirit of mutual self-sacrifice and love thus engendered flowers into altruism and universal good will. And finally, as the fires of life burn lower and lower, the fires of love drop down to flames of gentler tempo, so that the happily mated pair are content to let them purr along in a pleasant glow of mutual admiration and devotion. 


\section{VIIII \\ Embryology}

$W^{E}$ have come a long way from the viewpoint that the egg and the sperm contain the offspring in miniature. Our modern microscopes have shown the absurdity of this notion. The essential parts of the gametes are the chromosomes with their genes. The latter are chemical substances which in some as yet mysterious way are concerned with the development of all the characteristics of the adult.

Embryology is concerned with the development of the fertilized egg into a nature embryo or possibly farther. Cell division is mitosis and the development of daughter cells into one kind of tissue or another is differentiation. The fact that two daughter cells, presumably with the same genes will develop into dissimilar tissues is startling and poses a problem which has not as yet been solved. That these cells, tissues, and organs differentiate in the right place and develop their proper function at the right time is an even greater cause for wonderment.

There are many theories to account for these mysteries but it must be remembered that a theory does not become a law simply by constant repetition. The mysteries of the cell require much work before we can gain a glimpse of the truth.

An attractive theory for which proof seems to be lacking is that the genes in the nuclei of daughter cells are not similar to each other but that some mechanism is operative which changes the chemical structure of genes to suit the future use to which the cell is to be put. This does not imply the operation of an outside force but may be something hereditary within the genes themselves or it may be environmental in nature.

\section{EMBRYOLOGY *}

\section{E S L I E B R A I N E R D A R E Y}

Originally 'embryology' was a term restricted to the events of prenatal development. Only gradually was it realized that developmental processes continue long after birth. One branch of embryology traces the

- Reprinted from Developmental Anatomy by Leslie Brainerd Arey with the permission of W. B. Saunders Company and the author. Copyright 1940 by the W. B. Saunders Company. 
formative history of animals from germ cell to adult. It paints the progressive panorama of change that cells, tissues, organs, and the body as a whole undergo in attaining their final stages. Another division attempts to explain on the basis of experiment the way in which development works.

Although the most striking changes in the development of man and mammals occur while the young (first called an embryo and later a fetus) is still inside its mother's womb, yet development by no means ceases at birth. Birth is a mere incident in the whole developmental program. The human newborn is utterly dependent for food and care; many years of infancy and childhood must elapse before it becomes self-maintaining in human society. Only at about the age of twenty-five are the last of the progressive changes complete, whereupon an individual becomes truly adult.

All vertebrate animals are organized upon a common anatomical plan. Similarly, their fundamental mode of development is essentially identical. While the comparative viewpoint is indispensable for gaining a broad understanding of embryology, it has been of special importance in supplying missing pages of the human developmental story. The extent of this reliance on related forms will be appreciated when it is stated that the youngest human embryos known are already embedded in the uterus and possess their three primary germ layers.

A general concept of how man and other animals develop from a single cell by orderly and logical processes should share in the cultural background of every educated mind. From the theoretical side embryology is the key that helps unlock the secrets of heredity, the determination of sex and organic evolution. The body does not just happen to be arranged as it is. Each end-result in structure is preceded by a definite, developmental course of events. Embryology is able to interpret such rudimentary structures, variations, anomalies and 'monstrous' conditions, as well as to throw light on the origin of certain tumors and other pathological changes in the tissues. Furthermore, obstetrics is basically merely applied embryology.

In the middle of the seventeenth century, it was generally believed either that fully formed animals exist in miniature in the egg, needing only the stimulus of the spermatozoön to initiate development, or that similarly preformed bodies, male and female, constitute the spermatozoa and merely enlarge within the ovum. To be consistent this doctrine of preformation had to admit that all future generations were likewise encased, one inside the sex cells of the other, like so many Chinese boxes. Serious computations were even made as to the probable number of progeny thus present in the ovary of Mother Eve, at the exhaustion of which the human race would end. The modern teaching, known as epigenesis, was proved correct when von Baer discovered the mammalian ovum in 1827 and later demonstrated the three primary germ layers from which all embryos and their constituent parts develop. 
A multicellular embryo begins life as a fertilized egg. The fertilized egg straightway becomes a ball of cells, which soon organizes into three sheets known as the primary germ layers. From these the tissues, organs and body rapidly emerge. At the end of the developmental period the adult body may be many billions of times bulkier and heavier than the original egg.

It seems like a long span from the egg to the trillions of cells that comprise the completed body of man, yet this prodigious final number can be attained quite readily by repeated cell division. So rapid is the doubling process that some 45 generations of mitoses are sufficient.

The first important move toward organization in a young embryo establishes three superimposed, cellular plates, the primary germ layers. From their positions they are termed the ectoderm (outer skin), mesoderm (middle skin) and entoderm (inner skin). Since the ectoderm covers the body it is primarily protective in function, but it also gives origin to the nervous system and sense organs through which sensations are received from the outer world. The entoderm, on the other hand, lines the primitive digestive canal and is from the first nutritive; later it also becomes respiratory. The mesoderm, lying between the other two layers and later splitting into two sheets, naturally performs the functions of circulation, muscular movement, excretion and reproduction; it also gives rise to the skeletal structures which support the body. The germ layers are however, not so absolutely specific in their potentialities as was once thought.

HUMAN SEX CELLS

Although always relatively large, the exact size of a mature ovum is correlated with the amount of stored food substance and not with the size of the animal producing it. The smallest eggs are those of the mouse and the deer (about $0.07 \mathrm{~mm}$.); the largest have a diameter measurable in inches (birds; sharks). Most ova are nearly spherical in form and all possess the usual cell components. There is little difference in the size of the eggs formed by the various placental mammals; mouse, man and whale are nearly equal in this respect. The mammalian egg is small in comparison with many ova; yet when set beside ordinary cells it is truly big, since it is just visible to the naked eye as a tiny speck. The diameter of normal, fresh specimens of human ova is now known to be about $0.135 \mathrm{~mm}$. Nevertheless, all the eggs necessary to replace the present population of North America could be placed in a cubical vessel three inches square.

At one time human sperm cells were regarded as parasites, and under this misapprehension the name spermatozoa or 'semen animals,' was given them. Although its length is nearly one-half the diameter of a human ovum, the relative volume is only as $1: 85,000$. All the spermatozoa required to produce the next generation of North America could be contained in a spherical vessel having the diameter of an ordinary pinhead. 


\section{OVULATION A ND SEMINATION}

The discharge of the ovum from its follicle (in the ovary) comprises ovulation. In primates, ovulation is periodic, at intervals of about four weeks. The human female begins to ovulate at puberty (about the fourteenth year) and ends with the menopause (about the forty-seventh year). Generally only one follicle and ovum mature each month, the ovaries alternating with irregular and unpredictable sequence. Thus from the many thousands of potential ova provided, only about 200 ripen in each ovary during the thirty-odd years of sexual activity.

Sometimes two or more follicles mature and expel their eggs simultaneously; this phenomenon is responsible for the common type of multiple births. The reason why only one follicle at a time ordinarily reaches maturity is because of the nice balance maintained between the amount of follicle-ripening hormone (prolan A) and the response of the ovary to it. Hormone oversecretion brings about multiple ovulation, while undersecretion is responsible for ovulatory failure. How long the human egg retains its ability to receive a sperm and then start developing cannot be stated with certainty. It is now generally believed that the fertilizable period is not more than a day.

For many years ovulation and menstruation were supposed to take place synchronously. But when actual data was collected, it became apparent that this assumption is untrue. In reality the time of ovulation is about midway between two menstrual periods.

The purpose of coitus is to introduce spermatic fluid into the vagina. Spermatozoa gradually attain their full functional state, retain it for a limited period, and if not discharged, then slowly decline in vigor until death and resorption supervene. At the climax of coitus, ejaculation occurs; involuntary muscular contractions forcibly eject the older spermatozoa, along with the secretions of several accessory glands which discharge at the same moment. The combined fluid mass is the seminal fluid, or semen. The volume of the ejaculate is about 4 c.c. and in it swim some 300,000 ,ooo spermatozoa. An acid environment, such as the vagina where the seminal fluid is first deposited, is deleterious or fatal to spermatozoa; a neutral medium, as furnished by the uterus and tubes, is more favorable.

The outstanding functional feature of spermatozoa is their lashing flagellate swimming which resembles that of a tadpole. Forward progress of the human spermatozoön is at the rate of about $\mathrm{r} .5 \mathrm{~mm}$. a minute which, in relation to their respective lengths, compares well with average swimming ability for man.

These innate activities, however play but little part in the transport of sperm through the female genital tract. Passage from vagina to uterus is the result of muscular movements of the cervix. The journey through the uterus is similarly accomplished, in some animals at least, by muscular 
propulsion. The total period required by human spermatozoa in reaching their destination is unknown, but it cannot be more than a few hours at the most. There is no good reason for believing that the duration of fertilizing capacity of the sperms extends beyond a day or two.

The penetration of the ovum by the spermatozoön and the resulting fusion of their respective nuclei, constitutes the process of fertilization. In practically all animals fertilization also supplies the stimulus that starts the ovum dividing. The meeting and union of the human cells is believed usually to take place in the upper third of the uterine tube.

\section{T W INS AND T W IN I NG}

The frequency of multiple births varies considerably among different countries and races. Twins occur among American whites once in every 88 births, triplets have a frequency of $1:(88)^{2}$ and quadruplets appear in the ratio of $\mathrm{I}:(88)^{3}$. Six appears to be the maximum number of simultaneous births that is well authenticated for man.

At the outset a distinction must be drawn between true twins and a false type that masquerades under the same name. The coincident production of two or more individuals is most commonly due to the independent ripening and development of an equal number of independent eggs. In these instances ordinary, or fraternal twins are said to be produced. These offspring may be all of the same sex, or mixed as to sex, and such false twins have only the same degree of family resemblance as occurs in brothers or sisters of different ages. Properly speaking, they are not twins at all but, as in lower animals, merely members of a litter. Quite different are the identical, or duplicate twins. This group includes those true twins characterized by always being of the same sex and so strikingly similar in physical, mental and pathological traits that only rarely is their diagnosis difficult. This identity is enforced by their derivation from a single egg, whereby each member acquires precisely the same chromosomal heritage and hence the same genetic constitution.

Very rarely identical twins are conjoined as a 'double monster.' All grades of union are known but conjoined twins of equal size have the best chance for survival.

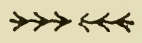

\section{EMBRYOLOGY AND GENETICS *}

\section{THOMAS HUNT MORGA N}

The stratified rocks of the earth's surface reveal the most recent part of the long history of the evolution of the animals and plants living at the

- Reprinted from Thomas Hunt Morgan, Embryology and Genetics. Copyright 1934 by Columbia University Press. 
present time. While it took millions of years to bring about these changes, the development of each individual from an apparently simple egg to the visibly complex form of the adult is now only a matter of days, or even hours. The comparison may be misleading, however, since there have probably been long periods when little or no change took place in the species, and the next advance, appearing in a single individual, may actually have occurred in infinitesimal time, from gene to gene, involving only a sudden alteration in one of the units of heredity.

The identification of the egg cells with the single-celled ancestors from which the higher forms have evolved calls for qualification. The converse statement may be nearer the truth, namely, that the egg of today is as different from the original unicellular ancestor as the adult today is different from that ancestral adult. Both statements call for reservations, for everything turns on what is meant by likeness and difference. In the egg there are all the potentialities for quickly developing the characteristics of the adult form, and in this sense the egg differs immensely from the original one-celled ancestor. The difference lies in the units of heredity in the two cases: only in their visible form are the protozoön and the egg somewhat alike. Since we know nothing about the constitutional differences between the hereditary elements in the original protozoön and those of the egg of today, it is futile to attempt to make any serious comparisons between the relative complexity of the two. Only superficially are they alike in their visible structures.

In another respect, however, we may make comparisons. The ancestral type needed to pass through fewer visible changes from egg to adult. In the unicellular forms, the protozoa, that multiply by self-division, each daughter cell has little more to do than to enlarge to the original size, and in the lower metazoa the stages, after division of the egg, are very few compared with those of higher forms. But even then the comparison may be misleading, for in the higher forms it is the visible changes that are considered, and we think of them most often as changes in form or structure, while the physiological processes in the unicellular and multicellular types are probably much more alike. In the higher forms these processes are separated into organ systems, but they may be much the same as in the protozoa. Descriptive embryology concerned itself entirely with changes in form, and very little with the physiology of development. Only recently has the latter received serious attention, although there have always been a few students interested in the physiology, especially in the later stages, of the vertebrate embryo.

For many years-let us say between 1850 and 1900-embryologists were engrossed with the idea that development of higher forms recapitulated the entire historical path over which their evolution had passed. This became known as the recapitulation theory. An immense amount of purely descriptive embryological work was carried out under the in- 
fluence of this theory, and today the embryology of all types of animals is known, often in the most minute detail. In small transparent eggs the developmental stages may be followed under the microscope; and, even in eggs that are more opaque, technical methods have been devised that reveal the changes taking place beneath the surface. The perfection of these methods-staining, imbedding in paraffin, cutting into thin slices, mounting these in balsam on glass slides, and reconstructing the whole in wax-occupied for a long time the attention of a great number of professional enbryologists, to the exclusion of considerations dealing with the physical and chemical events that lie behind these visible stages of development. The historical appeal was irresistible, especially if one believed that what he was seeing and describing was the history of "creation"-or, as it was called, evolution. There was soon established an immense body of information concerning the development of all the main animal forms. Accurate observation was called for, of the same order as that of all pictorial art. Beautiful illustrations of the development from egg to embryo appeared in a host of monographs. The better the artist, the more brilliant his performance. The anatomy of development became as well known as the older anatomy of adult structures that had likewise called for close observation and an artistic sense of representation in color and perspective.

During the final years of the last century and down to the present time a new interest appeared, called experimental embryology, and sometimes developmental mechanics. The reaction that had set in against the old interpretation of the developmental stages as a recapitulation of the ancestry was in part responsible for this change of interest. New ways of finding out something of what is going on behind the scene, the discovery of potentialities in the egg never before suspected, the application of methods to bring about unnatural changes in the development, the emphasis on the role of the environment in normal development, all conspired to awaken new interest.

Into the new fields of exploration many of the young embryologists entered with renewed enthusiasm. A great deal was revealed and many more problems, very different in kind from those that had fascinated the preceding generation, appeared. Here it seemed was the possibility of further advance in an understanding of the developmental processes; and the idea that embryology could be placed on an experimental basis was especially attractive to those who were familiar with the great advances that the experimental method in chemistry and physics had brought about. The embryologist found himself dealing with problems so different that it did not seem possible to apply at once the laws of chemistry and physics. He dealt with such complex materials as proteins, colloids, and with such complex problems as surface forces, permeability, etc., that the physical scientists themselves had not yet brought into line with the rest 
of their work. In fact, nearly all of the experimental work, so called, in embryology remained still on the biological level. It made known many conditions in the development of the egg that had never before been suspected, but the appeal to physics and chemistry of the so-called developmental mechanics was more often by analogy than by demonstration, and even "chemical embryology" has been largely a description of the kind of chemical compounds found in the egg and embryo. It is true that the transformation of some of these compounds into the other substances or into the finished product is an essential part of the embryological problem, but the embryologist is very largely concerned with the kinds of reactions that lead to the particular changes in form of the embryo, as well as with the origin of substances from other materials.

The extraordinary fact that an egg with little visible organization develops into a complicated adult, with a vast amount of organization, had aroused the interest of the philosophers from Aristotle to Whitehead, and in a broad way they realized the mystery of something happening that had no parallel in other fields of scientific interest. These thinkers were mainly impressed with the kind of organization expressed in form as the most important feature of development, and today this still remains as the most outstanding feature of development. That these changes in form might depend on chemical changes in the embryo was either taken for granted or ignored.

The most discussed "principle" of philosophy goes under the name of entelechy. The entelechy, supposedly the same idea under that name in Aristotle's teachings, was postulated as a principle, guiding the development toward a directed end-something beyond and independent of the chemical and physical properties of the materials of the egg; something that without affecting the energy changes directed or regulated such changes, much as human intelligence might control the running or construction of a machine. The acceptance of such a principle would seem to make it hardly worth while to use the experimental method to study development, since it would be directed and regulated by the entelechy. In fact, the more recent doctrine of "the organism as a whole" is not very different from the doctrine of entelechy, except in so far as other ways, by which the whole might be coördinated in an ultra or supermaterialistic way, might be imagined.

Therefore, unless it be granted that the principles involved in development are of a different order from physical principles in the broadest and most recent usage of this term, it would seem better to table these metaphysical questions, and to try to discover, despite the amount of time and labor involved, how far a knowledge of the chemical and physical changes taking place in the egg will carry us toward an understanding of the developmental processes. It may, of course, be found that an understanding of the kind of system present in the egg, sometimes still called the 
organization of the egg, will require relatively new principles peculiar to colloid systems, balanced salt solutions, semipermeable membranes, phase boundaries, etc.; but if these "principles" are still found to follow physical and chemical laws, whether the old ones or new ones, for large-scale phenomena with which embryology appears to be concerned, the study of embryology would still come to range itself under a broader conception of natural processes, including in its scope both living and dead material. If, on the other hand, it should turn out that an understanding of living materials calls for something quite new to the physical sciences, it will then be time to examine the nature or un-nature of this something. Meanwhile it seems clear that the next step should be a determined effort to learn all that we can about the kind of system or configuration that constitutes the egg. This statement does not mean that we should resort entirely to the kind of analyses which chemists and physicists have invented for the study of their kinds of materials, but that we should not neglect any possible means of penetrating further by experimental methods, on the biological level, into the behavior of such systems.

It is unsafe to say that the physico-chemical problems are different from the biological problem until we know more about the latter. For it must be obvious to every student of embryology that we have only begun to get information as to the "organization" of the egg on the biological level, and know as yet very little about the chemistry and physics of development. Should it turn out that neither the classical mechanics, nor the new physics suffice, the ground will at least be prepared for the discovery of some new kinds of principles that apply to living things. But until it has been shown that what we call the property or properties of living things are entirely out of line with what is known as non-living systems, it may be short-sighted to resort to obviously metaphysical principles, or even to temporize with them. It is this alternative that separates those whom the philosophers insist on calling mechanists, and those whom the biologists call metaphysicians. There is no need to attempt a compromise by saying that each has his own realm, because the scientist regards mysticism as an outmoded way of attempting to offer a finalistic solution of the problems he studies.

Most modern biologists are not, however, so much impressed by the idea that there is a principle of life as they are by the great variety of phenomena shown by living things. It seems to them premature as well as pretentious to discuss some imaginary ideal property of life when there is abundant evidence pointing to the conclusion that there are many properties of living things of many different kinds, each crying out for solution before attempting to synthesize them into life. Of course one may pick out one or more of these, such as consciousness, or purpose, or free will, and make it the sine qua non of living things, but it should not pass unnoticed that the selection is usually one of the most obscure phenomena of 
living things. Formative forces, polarity, symmetry, and purposeful regulations are examples of this in the embryological realm.

The story of genetics has become so interwoven with that of experimental embryology that the two can now to some extent be told as a single story. It is true there are still wanting many important points of contact, but enough is known to make it possible to attempt to weave them together into a single narrative. Although each has developed in large part independently of the other, nevertheless today their interdependence is so obvious that the geneticist takes for granted the main outlines of the facts of embryology, and the embryologist is coming to realize his dependence on the evidence from genetics. For example, cell division and the behavior of the chromosomes at maturation of the eggs and sperm have supplied the working scheme for the theory of heredity. The changes that take place during the maturation of eggs and sperm are contributions from embryology. Conversely, genetic analysis has made it possible to go behind these visible changes into the very constitution of the chromosomes themselves. The common meeting point of embryology and genetics is found in the relation between the hereditary units in the chromosomes, the genes, and the protoplasm of the cell where the influence of the genes comes to visible expression. Concerning the manner of functioning of the genes during development, I have contrasted, in the following pages whenever an opportunity arises, two possible views, and suggested a third. The implication in most genetic interpretation is that all the genes are acting all the time in the same way. This would leave unexplained why some cells of the embryo develop in one way, some in another, if the genes are the only agents in the results. An alternative view would be to assume that different batteries of genes come into action as development proceeds. The former view, namely, that all the genes are acting all the time in the same way, leaves the embryological problem where it has always been supposed to be, viz., in the protoplasm. The alternative view might appear to give a formal explanation of development, but is inconsistent with results obtained by changing the sequence of the cleavage planes by compression. Roux and Weismann attempted to explain development in somewhat this way, by assuming that the determinants in the chromosomes are qualitatively sorted out during development. There was at the time no evidence in favor of this view, and there is now much that is opposed to it. The idea that different sets of genes come into action at different times is exposed to serious criticism, unless some reason can be given for the time relation of their unfolding.

The following suggestion may meet these objections. It is known that the protoplasm of different parts of the egg is somewhat different, and that the differences become more conspicuous as the cleavage proceeds, owing to the movements of materials that then take place. From the protoplasm are derived the materials for the growth of the chromatin and for 
the substances manufactured by the genes. The initial differences in the protoplasmic regions may be supposed to affect the activity of the genes. The genes will then in turn affect the protoplasm, which will start a new series of reciprocal reactions. In this way we can picture to ourselves the gradual elaboration and differentiation of the various regions of the embryo.

\section{$\gg \leftrightarrow 4$ \\ OLD PROBLEMS AND NEW IN \\ EXPERIMENTAL EMBRYOLOGY * \\ E. G. BU T L E R}

Ever since man possessed the ability for correlated mental activity he has undoubtedly speculated on the phenomenon of embryonic development. The manner in which a living organism comes into being, takes on definite organized form, undergoes the establishment of vital functions, and, finally, assumes the characteristics of a complex adult body, seldom fails to elicit the interest of intelligent human beings.

Although the study of embryology is rooted deep in antiquity, references in pre-Grecian literature to developing organisms are, unfortunately, somewhat fragmentary. During the rise of Greek culture, however, nearly all philosophers devoted some attention to problems of development and several wrote extensively on the subject. With Hippocrates, observation began to take precedence over speculation, and he and his associates left records indicating considerable time devoted to the study of embryos in a variety of animals. Finally, toward the end of the fourth century, B. c., Aristotle wrote the first book dealing solely with embryonic development, "De Generatione Animalium."

The son of a physician, Aristotle was reared on the works of the Hippocratic school and was early trained in methods of dissection. It is doubtful if any of Aristotle's scientific work excelled that which he did on embryology. His methods and tools were inadequate, his observations often too few, and many of his conclusions far from correct, nevertheless, he arrived at an insight into animal development far exceeding that of any predecessor. He seems to have appreciated that embryonic development is not a mere unfolding and growth of structures already established, and he resorted, not infrequently, to physical or mechanical comparisons. Referring to the developing parts of an embryo, he wrote, "It is possible, then, that A should move B, and B move C; that, in fact, the case should be the same as with automatic machines shown as curiosities. For the parts

* Based upon an address presented at the annual dinner meeting of the Princeton Chapter, of Sigma Xi, May I9II, and adapted here by permission of the author and of the Society of the Sigma Xi. 
of such machines while at rest have a sort of potentiality of motion in them, and when any external force puts the first of them in motion, immediately the next is moved in actuality." " This cannot be called a refined physicochemical analysis of development in the modern sense, but it marked a beginning in the right direction. Aristotle also compared the growth of an embryo to the effect which rennet has on milk and, likewise, to the growth of the yeast. To paraphrase a remark by Charles Darwin, many later embryologists have been "mere schoolboys to old Aristotle."

Aristotle's work influenced embryological thought for at least twenty centuries, and, with the passage of time, the study of embryology had its ups and downs. During the middle ages an enormous amount of speculation regarding development teetered, often precariously, on an exceedingly meagre amount of observation. At times embryology and theology joined hands, and we find in embryological endeavors search for a nobler concept of life. Embryology and art were sometimes associated, as in the case of Leonardo da Vinci, who not only left in interesting drawings evidence of careful dissections of the pregnant uterus, but also records of quantitative studies on growth. On the basis of surprisingly accurate measurements he compared embryonic growth with post-natal growth, including a study of relative sizes of organs during development.

Passing rapidly over the years, let us pause for a few moments in the seventeenth century, a period to which modern embryology is particularly in debt. Then lived and worked, to mention a few names only, Leeuwenhoek, inventor of the microscope; Malpighi, with notions of preformation within egg and embryo; Sir Thomas Browne, of singularly enquiring mind; Walter Needham, physician and experimenter; deGraaf, whose name is perpetuated in the Graafian follicle of the mammalian ovary; and William Harvey, keen observer and lucid writer.

William Harvey's book, Exercitationes de Generatione Animalium, was published in $165 \mathrm{I}$. It must have been in the nature of what would now be called a scientific "best seller." After publication of the first edition in London in 1651 , three editions, all in Latin, came out during the same year bearing the imprint of Amsterdam publishers. The first English translation appeared in 1653 . The frontispiece of Harvey's book is an engraving of Jove, holding a sphere which represents an egg. From the sphere are being liberated all the animals under heaven, and on it is written, "Ex ovo omnia." Although the epigram does not appear in such form in the text, this dictum, all life from eggs, is the continuing thesis of Harvey's book and was one of his great contributions to embryological knowledge.

A man of the ability and versatility of William Harvey, cannot be passed by hastily. As an observer and experimenter of the first order, he wrote, ". . . there be one onely roade to Science, namely, that by which

${ }^{1}$ From the translation of Aristotle's De Generatione Animalium by Arthur Platt, Oxford Press, igro. 
we proceed from things more known, to things known less; and from that which is more manifest, to that which is more obscure; . . . " 2 Problems of growth and differentiation puzzled Harvey, and will puzzle us in some detail in a few moments. However, he handled these problems generally in a manner much better than his predecessors or contemporaries. Some have held that he sought to endow developing embryos with an imminent spirit of special sort, but as W. K. Brooks pointed out years ago, when Harvey referred to a "vital principle," he probably meant to say that the embryo was alive, with no thought of implying supernatural agencies. Parts of embryos, Harvey wrote, "are at once similar and dissimilar, and from a small similar is a great organ made." ${ }^{3}$ This might be taken as a text by modern students of embryology, who discuss embryonic localization and determination, and construct for us maps of the egg to show the presumptive fate of each part.

Embryonic development in higher animals involves an orderly sequence of events, including production of sex cells, the ovum or egg in the female, the spermatozoön in the male; fertilization, which is the union of an egg and a spermatozoön; and, following fertilization, all of those processes concerned with growth and differentiation of the new individual. As I have mentioned, eggs from various types of animals have long been a subject of study. Spermatozoa were first seen by a man named Dr. Ham and reported to the Royal Society in 1677 . Knowing little about the structure of the egg and the spermatozoön, and less about the nature and significance of fertilization, it is not surprising that many early embryologists were led by their inaccurate observations down the easy path to the theory of preformation. It was the simplest way-to make the deduction that all structures of the adult body were present in miniature, in other words, preformed, either in the egg or in the spermatozoön. And, as one would anticipate, two conflicting schools of thought arose. One school, called the ovists, insisting that all adult structures were preformed in the egg; the other school, called the spermists, insisting that all structures were preformed in the spermatozoön. For the adherents to either school, embryonic development meant an unfolding of structures already present.

I never tire of reading the description of a spermatozoön written in 1699 by one of the zealous spermists, Dalenpatius. It is beautifully phrased and thoroughly inaccurate. Speaking of human spermatozoa he wrote: "They move with wonderful rapidity and by the strokes of their tails produce little waves in the substance in which they swim. But who would believe that in these a human body was hidden? Yet we have seen such with our own eyes. For while we were observing them attentively, a large one threw off its surrounding membrane and appeared naked, showing

${ }^{2}$ From the 1653 translation of Harvey's De Generatione Animalium, printed by James Young for Octavian Pulleyn, London. (Copy in the New York Academy of Medicine.)

${ }^{3}$ lbid. 
distinctly two legs, thighs, breasts and arms. . . . it was a delightful and incredible sight." " (Emphasis should be, of course, on the word, incredible.) Here we have a bold description of preformation as envisaged by an ardent spermist. Other observers thought they saw microscopic horses in the semen of the horse, similar animalcules, but with larger ears, in the semen of the donkey, and minute roosters in the semen of the rooster.

The ovists were no less backward than the spermists in putting forward their claims for the egg. "Emboitment," the notion that, like box within box, all future structures were already present within the egg, presented no particular obstacle for a dyed-in-the-wool preformationist of the ovist school. As one (Haller) wrote: "It follows that the ovary of an ancestress will contain not only her daughter, but also her grand-daughter, her greatgranddaughter, and her great-great-granddaughter; and if it is once proved that an ovary can contain many generations, there is no absurdity in saying that it contains them all."

Naturally, the preformationists did not flourish unchallenged. Opposing theories grew up under the general title of epigenesis. In its extreme form epigenesis was the exact opposite of preformation. The theory of epigenesis held that the egg, for example, was a simple homogeneous structure. According to this view, there was not only no preformation, but, on the contrary, no differentiation at all within the egg or spermatozoön. Adherents of the most extreme views of epigenesis were under the necessity, therefore, of explaining how heterogeneity could come from homogeneity, how an undifferentiated egg could give rise to the complicated differentiated structures of embryo and adult. And, as so frequently happens, when obstacles such as these are encountered, recourse was often made to some type of vital force, a vis essentialis or a nisus formativus, which it was easy to think, shaped the course of embryological events.

Embryologists have long recognized that neither the extreme view of preformation nor epigenesis were correct. Yet, there were elements of truth in each. The spermatozoön and the egg, each is far from being a homogeneous structure. Each is a highly differentiated cell, with complicated internal organization. Still, the differentiation of the spermatozoön, the egg and the developing embryo are in no sense simply the presence in a miniature of adult structures. Development of the fertilized egg is a far more complicated process than any early embryologist ever dreamed. And, only in relatively recent years has the embryologist been able to glimpse some of the underlying mechanisms involved.

Descriptive embryology has long been concerned in following the origin of adult structures back to their earliest appearances in egg and embryo. Thus we have been able to recognize "anlagen" or primordia of

4 Dalenpatius as quoted by Vallisneri. From Lewis and Stohr, Text-Book of Histology, Blakiston, 19r3. (English translation by Lewis from Berger's German translation of Vallisneri.) 
organs. It has been possible to make maps of certain eggs and in many cases to point out, with great accuracy, the exact material that will give rise to certain organs. We know, for example, just what materials will go into the making of the brain, what material will form the digestive canal, the muscles, bones, and so on.

Embryonic development is, in the main, a continuous procedure, once fertilization has occurred. Two outstanding processes are always in evidence; cell multiplication and cell differentiation. Thus, starting with the fertilized egg, the new organism grows in size and its parts become differentiated and specialized. The fertilized egg, which is a single cell, by continued division forms first an aggregate of many cells. Then the manycelled aggregate begins to undergo differentiation into special layers of cells, in particular, an outer layer, called the ectoderm, an inner layer or entoderm, and a middle layer, or mesoderm. Each of these three layers has a definite significance, or fate, in normal development, and, as stated above, maps showing the presumptive fate of different regions can be made. For example, the ectoderm in one region gives rise to the brain, whereas in other regions it goes into the formation of the epidermis of the skin. The heart, blood vessels, and all bone and muscle come from the mesoderm, and so on.

With an extensive knowledge of normal embryology, investigators naturally began to try experiments with the developing egg and embryo, and hence has grown up the field of experimental embryology. Experiments can best be performed on eggs and embryos which develop outside the body of the mother. Among the most favorable and most commonly used are embryos of the amphibia, such as the frogs and newts. Eggs of these animals are shed by the female into the water, where fertilization takes place, and the embryo develops in its aqueous environment, shielded only by certain protective membranes. Hence, we have a readily available supply of embryos. By removal of the outer protective membranes, the experimenter can easily secure naked embryos, and, by the use of suitable small instruments and appropriate microscopes, can perform many operations in these embryos, such as extirpating pieces of an embryo, and transplanting cells from one location to another.

What would happen, for example, if in an early stage of development a group of cells, which normally would form a part of the brain, was removed and cells transplanted in their place which normally would form epidermis of the skin? In other words, suppose that presumptive brain cells be replaced by presumptive epidermal cells. This and many similar experiments, have been performed during recent years by experimental embryologists in this country and abroad. From these experiments we learn that cells which normally would form the epidermis of the skin in the belly region of the embryo, if transplanted to the proper site at the proper time, will develop into nerve cells of the brain. Conversely, cells 
which normally would become brain cells, if they are transplanted to the belly region of the embryo, are "demoted," so to speak, and become merely belly epidermis. Furthermore, it can be shown that, if placed in the proper location, belly epidermis instead of becoming brain, may become muscle tissue, or even a part of the kidney.

Such experiments command our attention. They show that, although cells in early developmental stages may normally have a very definite presumptive fate, this fate can be changed when the position of the cells in question is changed. Hence, we can be certain, that in the young amphibian embryo determination of parts has not, at least in all cases, been irrevocably established. The fate of a certain group of cells can be altered by changing their location in the embryo. Accordingly, it appears that in some manner the immediate surroundings of cells are of basic importance in determining their significance in development.

It should be stated, however, that the alteration in the fate of embryonic cells can be brought about only in young stages of development. Quite early in embryonic development a time is reached at which the fate of the embryonic cells becomes irrevocably determined. When this times comes, epidermis from the belly region, if transplanted to the brain region then "refuses" to be influenced by the new surroundings and "insists" on developing into skin epidermis. Hence, when such cells are transplanted, we will have formed a little abnormal knot of epidermis cluttering up the brain region. Or, conversely, if presumptive brain tissue be transplanted to the body wall in the belly region, a bit of abnormal nervous tissue will later be found trying to develop on the belly wall. Such results have been obtained many times in amphibian embryos, and the experiments are relatively easy to perform.

The question arises as to what forces are responsible for setting up this irrevocable determination of regions in the young embryo at a certain stage in development? This question is too large and too involved to take up in detail in a discussion such as the present one. But, permit me to give a few hints with regard to what is going on.

In one special region of a developing amphibian egg-a region which biologists will recognize as the dorsal lip of the blastopore-is situated what Professor Spemann has called the "center of organization." An extensive series of experiments have shown that this center of organization is responsible, to a great extent, for the organization of cells forming some of the main axial organs of the body, such as the brain, the spinal cord, and the predecessor of the spinal column, which is called the notochord. Once this center of organization has become active, then regions under its influence become irrevocably determined.

I shall give you just one example, of the manner in which the center of organization appears to operate. If cells are taken from this center and transplanted so that they can influence presumptive skin epidermis in the ventral 
body wall, leaving the local epidermis in place in its normal location, then brain and other axial organs will develop from this epidermis. In other words, the center of organization can assert itself, and can induce belly epidermis, in its normal location, to form brain tissue. In fact, the center of organization, when transplanted to a foreign site, can induce the formation of a whole new body axis, actually a little twin embryo attached to one side of the primary embryo.

Further research has shown that, rather than a single organizing center, a series of such centers become operative as embryonic development progresses. The center just referred to, usually known as the primary organizer, is concerned with the establishment during normal development of the main axial organs, such as brain, spinal cord, and associated structures. Other organization centers, the secondary organizers, have been demonstrated which are concerned with development of parts of the eye, the ear, mouth structures, and so on. And there are, in all probability, many more secondary centers of organization which we know little or nothing about at the present time.

It will be well to emphasize the particularly fundamental feature of development that has been revealed by the methods of approach and the new operative techniques just described. That fundamental feature of development I shall call cellular interaction. Cells in a developing embryo realize their own special roles in development as they are acted upon, and, in turn, act upon other cells and groups of cells.

Further evidence of interaction among cells has also been obtained from a somewhat different type of research. My own interests in cellular interaction, together with those of several of my students, have centered for a number of years around the phenomenon of regeneration. The word regeneration, in the biological sense, refers to the replacement by cellular multiplication and differentiation of structures lost by accident, or otherwise removed from the body of an organism. It is well known that nearly all animals possess the capacity for regeneration to a greater or lesser degree. In higher vertebrates, such as man, the capacity for regeneration is restricted, for the most part, to the formation of new tissue as it takes place during wound healing. Certain lower vertebrates, however, notably the ampibia, possess a high degree of regeneration capacity. Entire organs, such as a limb or a tail, can be completely regenerated. In a sense, therefore, the ability to regenerate lost parts represents the retention of the cells of an organism of embryonic capacities for growth and differentiation. Thus, in the phenomenon of regeneration we have opportunity for study and analysis of cellular interaction, as it underlies growth and differentiation.

If young animals are used, such as young salamanders, regeneration proceeds with surprising rapidity. For example, if I take a young salamander and amputate a fore limb across the upper arm, a new limb will grow 
out from the cut stump within a period of three or four weeks. Such a regenerated limb will be complete in every detail, including upper arm, forearm, hand, and fingers. During this process of regeneration new skeletal elements, new muscles, new blood vessels, and so on are formed. The regenerated limb is as perfect, structurally and functionally, as the original one.

If the processes underlying the regeneration of structure, such as limb, were really understood we would be a long way toward understanding many of the fundamental processes of embryonic development. We know that, after removal of a limb, a group of cells gradually appears at the point of amputation. These cells in many respects represent a type of embryonic cell. From this aggregate of cells, called a regeneration blastema, is formed nearly all new structures of the regenerated limb. But what governs the growth and differentiation of the blastema cells into new structures? What determines that certain cells in the aggregate will give rise to skeleton, others to muscle, and so on?

In an attempt partially to analyze the situation, one of my students, Dr. Thornton, removed all of the skeletal elements from the limb stump at the time of amputation. The method adopted was briefly as follows. Using a young salamander, he amputated a fore limb through the middle of the upper arm. Then the humerus was carefully exarticulated from its socket at the shoulder joint and completely removed. Such a procedure left the upper arm as a collapsed limb stump, made up of muscles, connective tissue, blood vessels, and nerves, but entirely devoid of the skeleton. What type of limb will regenerate from such a deficient upper arm?

The results from these experiments showed that such animals regenerated normal limbs. As the regeneration blastema formed, it was observed that some of the cells developed into a new humerus, regardless of the fact that none of the old humerus was present to take part in the process. Here, then, is new evidence for the assertion, that the direction in which cells differentiate depends somehow on their situation and surroundings. There is evidence, that under one set of circumstances certain cells may go into the formation of muscle, whereas under other conditions it is possible that the same type of cells will form skeleton. In an active field of limb regeneration, therefore, it is clear that what happens to individual cells depends on the relation of the cells to each other and to the field as a whole, as well as on their inherent potencies.

Recently we have been able to secure still further information regarding the manner in which cellular interaction is involved in regeneration. Professor O. E. Schotte of Amherst and I have undertaken an investigation of the alterations which occur in an amphibian limb rendered nerveless and then amputated.

It has long been known that the presence of nerves is essential for regeneration of an amphibian limb. By devising a suitable operative tech- 
nique, it has been possible to render and to maintain the limb of a small salamander totally nerveless and thus completely to prohibit regeneration. One of the results of these experiments has been that, when a limb fails to regenerate, because of the lack of innervation, antagonistic processes set in which lead to regression. The situation can best be presented by describing a single experiment.

A limb, rendered nerveless by previous operation, was amputated near the wrist. Under these conditions no regeneration ensued, but on the contrary, all of the skeletal elements, muscles, and other tissues of the wrist went into regression and gradually disappeared. Then the regressive processes spread to the lower arm, and it, in turn, disappeared. Finally, the tissues of the upper arm underwent the same changes. The processes involved in these alterations are the opposite of growth and differentiation. They are regression and dedifferentiation and represent, in a sense, embryonic processes in reverse. It is as though a limb could say: "If I can't regenerate, I insist on going into regression."

To complete the account of this experiment, it must also be stated that, if nerves are permitted to grow back into a limb at any time during the process of regression, then the tables are turned, and growth and differentiation begin at once in the limb tissues. There seems to be a balance between growth and differentiation on the one hand, and regression and dedifferentiation on the other, and it appears that the nerves of the limb in some manner control this balance.

I have now presented evidence from two different sources; first, from the manner in which organs are established in early embryonic development; second, from the manner in which tissues can be regenerated. These two types of evidence have been chosen to illustrate the primary point, namely, the cellular interaction is always in evidence and apparently of paramount importance in the organization, differentiation, and growth of structures.

In conclusion, it should be emphasized that, regardless of how far modern biologists have traveled beyond seventeenth century workers in improving their acquaintance with problems of organization and growth, a woeful lack of real understanding of the processes still remains. It is evident, I believe, to all experimental embryologists that, underlying the organization which they study in embryonic and regenerating tissues, is a physico-chemical background. It is important to keep in mind at all times that there is a physiological chemistry of the developing embryo, as well as of the adult body. When we develop conceptions of cellular interaction during embryonic development, we are dealing, I am convinced, with problems of inter- and intra-cellular chemistry. And it seems certain that investigations of cellular chemistry, as related to growth and differentiation, offer a tremendous field for future work. It is a field, however, in which successful investigation will continue to require the devis- 
ing of new and ingenious techniques. As Professor Spemann once remarked, "we still stand in the presence of riddles, but not without hope of solving them. And riddles with the hope of solution-what more can a man of science desire?"

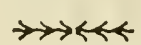




\section{$\mathbb{I X}$ \\ Heredity}

$\mathbf{T}^{\mathrm{T}}$ is truly a long step from tall and dwarf peas to human inheritance but 1 the gap is being bridged slowly and painstakingly. Almost every student is interested in the genetics of hair color, of right or left handedness, of color blindness, of hair blazes (white areas in otherwise colored hair), of disease, of twinning, of intelligence and of musical ability, among other things. A comparatively few years ago the knowledge of human inheritance was fragmentary, inconclusive and scattered. At the present time it is none of these things although it should be borne in mind that many years must elapse before we know as much about this field as we know now about the fruit fly, the favorite of animal geneticists. Dr. Gates has recently brought together most of our knowledge regarding human inheritance into a two volume work and while this is a notable contribution, it reflects the opinion that we know only a mere fraction of the knowable.

With plants and the lower animals we are able to breed, cross-breed, make chromosome preparations and use other intimate techniques, all of which are impossible or difficult when using human material. Much can be learned regarding the inheritance of human traits however by studying pedigrees for some generations, particularly those where abnormalities are in evidence or where the parents are of different racial groups.

Almost every layman has one or more misconceptions regarding heredity. Some of the more common errors are, (1) blood will tell, or, he is of blue blood (2) listening to good music or good literature will create a taste for these things in the unborn child (3) peculiar markings on the skin of the child are caused by the sight of some animal or other object which frightened the mother (4) the blood of the mother passes into and through the child in the uterus (5) syphilis and gonorrhea are inherited (6) two pure white people can have a black child (7) two blue-eyed parents can never have a brown-eyed child (8) that environment is not important in the development of a person's heredity and (9) that a child always resembles the more strong-willed of the two parents. 


\section{GREGOR MENDEL AND HIS WORK *}

\section{H U G O I L T I S}

It is 120 years since, in a small village on the northern border of what was called Austria at that time, a boy was born in a farmer's house who was destined to influence human thoughts and science. Germans, Czechs and Poles had settled side by side in this part of the country, quarreling sometimes, but mixing their blood continually. During the Middle Ages the Mongolic Tatars invaded Europe just there. Thus, the place had been a melting pot of nations and races, and, like America, had brought up finally a splendid alloy. The father's name was Anton Mendel; the boy was christened Johann. He grew up like other farmers' boys; he liked to help his father with his fruit trees and bees and retained from these early experiences his fondness for gardening and bee-keeping until his last years. Since his parents, although not poor compared with the neighbors, had no liquid resources, the young and gifted boy had to fight his way through high school and junior college (Gymnasium). Finally he came to the conclusion, as he wrote in his autobiography, "That it has become impossible for him to continue such strenuous exertions. It was incumbent on him to enter a profession in which he would be spared perpetual anxiety about a means of livelihood. His private circumstances determined his choice of profession." So he entered as a novice the rich and beautiful monastery of the Augustinians of Bruenn in 1843 and assumed the monastic name of Gregor. Here he found the necessary means, leisure and good company. Here during the period from 1843 to 1865 he grew to become the great investigator whose name is known to every schoolboy to-day.

On a clear cold evening in February, 1865, several men were walking through the streets of Bruenn towards the modern school, a big building still new. One of these men, stocky and rather corpulent, friendly of countenance, with a high forehead and piercing blue eyes, wearing a tall hat, a long black coat and trousers tucked in top boots, was carrying a manuscript under his arm. This was Pater Gregor Mendel, a professor at the modern school, and with his friends he was going to a meeting of the Society of Natural Science where he was to read a paper on "Experiments in Plant Hybridization." In the schoolroom, where the meeting was to be held, about forty persons had gathered, many of them able or even outstanding scientists. For about one hour Mendel read from his manuscript an account of the results of his experiments in hybridization of the edible pea, which had occupied him during the preceding eight years.

Mendel's predecessors failed in their experiments on heredity because they directed their attention to the behavior of the type of the species

* Reprinted by permission of the Scientific Montbly, American Association for the Advancement of Science. Copyright $194^{2}$. 
or races as a whole, instead of contenting themselves with one or two clearcut characters. The new thing about Mendel's method was that he had confined himself to studying the effects of hybridization upon single particular characters, and that he didn't take, as his predecessors had done, only a summary view upon a whole generation of hybrids, but examined each individual plant separately.

The experiments, the laws derived from these experiments, and the splendid explanation given to them by Mendel are to-day not only the base of the modern science of genetics, but belong to the fundamentals of biology taught to millions of students in all parts of the world.

Mendel had been since 1843 one of the brethren of the beautiful and wealthy monastery of the Augustinians of Bruenn, at that time in Austria, later in Czechoslovakia. His profession left him sufficient time, and the large garden of the monastery provided space enough, for his plant hybridizations. During the eight years from 1856 to 1864 , he observed with a rare patience and perseverance more than 10,000 specimens.

In hybridization the pollen from the male plant is dusted on the pistils of the female plant through which it fertilizes the ovules.* Both the pollen and the ovules in the pistils carry hereditary characters which may be alike in the two parents or partly or entirely different. The peas used by Mendel for hybridization differed in the simplest case only by one character or, better still, by a pair of characters; for instance, by the color of the flowers, which was red on one parental plant and white on the other; or by the shape of the seeds, which were smooth in one case and wrinkled in the other; or by the color of the cotyledons, which were yellow in one pea and green in the other, etc. Mendel's experiments show in all cases the result that all individuals of the first generation of hybrids, the $F_{1}$ generation as it is called to-day, are uniform in appearance, and that moreover only one of the two parental characters, the stronger or the dominant one, is shown. That means, for instance, that the red color of the flowers, the smooth shape of the seeds or the yellow color of the cotyledons is in evidence while the other, or recessive, character seems to have disappeared. From the behavior of the hybrids of the $F_{1}$ generation, Mendel derived the first of the experimental laws, the so-called "Law of Uniformity," which is that all individuals of the first hybrid generation are equal or uniform. The special kind of inheritance shown by the prevalence of the dominant characters in the first hybrid generation is called alternative inheritance or the pea type of inheritance. In other instances, however, the hybrids show a mixture of the parental characteristics. Thus, crossing between a red-flowered and a whiteflowered four o'clock (Mirabilis) gives a pink-flowered $\mathrm{F}_{1}$ generation. This type of inheritance is called the intermediate, or Mirabilis, type of inheritance.

* What is meant here is that the eggs in the ovules are fertilized by the sperms in the pollen grains.-Ed. 
Now, Mendel self-fertilized the hybrids of the first generation, dusting the pistils of the flowers with their own pollen and obtained thus the second, or $\mathrm{F}_{2}$ generation of hybrids. In this generation the recessive characters, which had seemingly disappeared, but, which were really only covered in the $F_{1}$ generation, reappeared again and in a characteristic and constant proportion. Among the $F_{2}$ hybrids he found three red-flowered plants and onc white-flowered plant, or three smooth-seeded and one-wrinkled-seeded plant, or three plants with yellow cotyledons and one with green ones. In general, the hybrids of the $F_{2}$ generation showed a ratio of three dominant to one recessive plants. Mendel derived from the behavior of the $\mathrm{F}_{2}$ generation his second experimental law, the so-called "Law of Segregation." Of course, the characteristic ratio of three dominant to one recessive may be expected only if the numbers of individuals are large, the Mendelian laws being socalled statistical laws or laws valid for large numbers only.

The third important experimental law Mendel discovered by crossing two plants which distinguished themselves not only by one but by two or more pairs of hereditary characters. He crossed, for instance, a pea plant with smooth and yellow seeds with another having green and wrinkled seeds. The first, or $F_{1}$, generation of hybrids was of course uniform, showing both smooth and yellow seeds, the dominant characters. $F_{1}$ hybrids were then self-fertilized and the second hybrid, or $F_{2}$, generation was yielded in large numbers, showing all possible combinations of the parental characters in characteristic ratios and that there were nine smooth yellow to three smooth green to three wrinkled yellow to one wrinkled green. From these so-called polyhybrid crossings, Mendel derived the third and last of his experimental laws, the "Law of Independent Assortment."

These experiments and observations Mendel reviewed in his lecture. Mendel's hearers, who were personally attached to the lecturer as well as appreciating him for his original observations in various fields of natural science, listened with respect but also with astonishment to his account of the invariable numerical ratios among the hybrids, unheard of in those days. Mendel concluded his first lecture and announced a second one at the next month's meeting and promised he would give them the theory he had elaborated in order to explain the behavior of the hybrids.

There was a goodly audience, once more, at the next month's meeting. It must be admitted, however, that the attention of most of the hearers was inclined to wander when the lecturer became engaged in a rather difficult algebraical deduction. And probably not a soul among the audience really understood what Mendel was driving at. His main idea was that the living individual might be regarded as composed of distinct hereditary characters, which are transmitted by distinct invisible hereditary factors-to-day we call them genes. In the hybrid the different parental genes are combined. But when the sex cells of the hybrids are formed the two parental genes separate again, remaining quite unchanged and pure, each sex cell contain- 
ing only one of the two genes of one pair. We call this fundamental theoretical law the "Law of the Purity of the Gametes." Through combination of the different kinds of sex cells, which are produced by the hybrid, the law of segregation and the law of independent assortment can be easily explained.

Just as the chemist thinks of the most complicated compound as being built from a relatively small number of invariable atoms, so Mendel regarded the species as a mosaic of genes, the atoms of living organisms. It was no more nor less than an atomistic theory of the organic world which was developed before the astonished audience. The minutes of the meeting inform us that there were neither questions nor discussions. The audience dispersed and ceased to think about the matter-Mendel was disappointed but not discouraged. In all his modesty he knew that by his discoveries a new way into the unknown realm of science had been opened. "My time will come," he said to his friend Niessl.

Mendel's paper was published in the proceedings of the society for i 866 . Mendel sent the separate prints to Carl Naegeli in Munich, one of the outstanding biologists of those days, who occupied himself with experiments on plant hybridization. A correspondence developed and letters and views were exchanged between the two men. But even Naegeli didn't appreciate the importance of Mendel's discovery. In not one of his books or papers dealing with heredity did he even mention Mendel's name. So, the man and the work were forgotten.

When Mendel died in 1884 , hundreds of mourners, his pupils, who remembered their beloved teacher, and the poor, to whom he had been always kind, attended the funeral. But although hundreds realized that they had lost a good friend, and other hundreds attended the funeral of a high dignitary, not a single one of those present recognized that a great scientist and investigator had passed away.

The story of the rediscovery and the sudden resurrection of Mendel's work is a thrilling one. By a peculiar, but by no means an accidental, coincidence three investigators in three different places in Europe, DeVries in Amsterdam, Correns in Germany, Tschermak in Vienna, came almost at the same time across Mendel's paper and recognized at once its great importance.

Now the time has arrived for understanding, now "his time had come" and to an extent far beyond anything of which Mendel had dreamed. The little essay, published in the great volume of the Bruenn Society, has given stimulus to all branches of biology. The progress of research since the beginning of the century has built for Mendel a monument more durable and more imposing than any monument of marble, because not only has "Mendelism" become the name of a whole vast province of investigation, but all living creatures which follow "Mendelian" laws in the hereditary transmission of their characters are said to "Mendelize." 
As illustrations, I will explain the practical consequences of Mendelian research by two examples only. The Swede, Nilsson-Ehle, was one of the first investigators who tried to use Mendelistic methods to improve agricultural plants. In the cold climate of Sweden some wheat varieties, like the English square-hood wheat, were yielding well but were frozen easily. Other varieties, like the Swedish country wheat, were winter-hard but brought only a poor harvest. Nilsson-Ehle knew that in accordance with the Mendelian law of independent assortment, the breeder is able to combine the desired characters of two different parents, like the chemist who combines the atoms to form various molecules or compounds. He crossed the late-ripening, well-yielding, square-hood wheat with the early-ripening, winter-hard, but poor-yielding Swedish country wheat. The resulting $F_{1}$ generation, however, was very discouraging. It was uniform, in accordance with Mendel's first law, all individuals being late-ripe and pooryielding, thus combining the two undesirable dominant characters. In preMendelian times the breeder would have been discouraged and probably would have discontinued his efforts. Not so Nilsson-Ehle, who knew that the $F_{1}$ generation is hybrid, showing only the dominant traits, and that the independent assortment of all characters will appear only in the $F_{2}$ generation. Self-fertilizing the $F_{1}$ plants he obtained an $F_{2}$ generation showing the ratio of nine late-ripe poor-yielding to three late-ripe well-yielding, to three early-ripe poor-yielding, to one early-ripe, well-yielding wheat plants. The desired combination of the two recessive characters, early-ripe, wellyielding, appeared only in the smallest ratio, one in sixteen-but because recessives are always true-breeding, or as it is called "homozygous," NilssonEhle had only to isolate these plants and to destroy all others in order to obtain a new true breeding early-ripe and well-yielding variety which after a few years gave a crop large enough to be sold. Thus, by the work of the Mendelist, Nilsson-Ehle, culture of wheat was made possible even in the northern parts of Sweden and large amounts heretofore spent for imported wheat could be saved.

Another instance shows the importance of Mendelism for the understanding of human inheritance. Very soon after the rediscovery of Mendel's paper it became evident that the laws found by Mendel with his peas are valid also for animals and for human beings. Of course, the study of the laws of human heredity is limited and rendered more difficult by several obstacles. We can't make experiments with human beings. The laws of Mendel are statistical laws based upon large numbers of offspring, while the number of children in human families is generally small. But in spite of these difficulties it was found very soon that human characters are inherited in the same manner as the characters of the pea. We know, for instance, that the dark color of the iris of the eye is dominant, the light blue color recessive. I remember a tragi-comic accident connected with this fact. At one of my lecture tours in a small town in Czechoslovakia, I spoke about the heredity 
of eye color in men and concluded that, while two dark-eyed parents may be hybrids in regard to cye color and thus may have children both with dark and blue eyes, the character blue-eyed, being recessive, is always pure. Hence two blue-eyed parents will have only blue-eyed children. A few months later I learned that a divorce had taken place in that small town. I was surprised and resolved to be very careful even with scientifically proved statements in the future.

Even more important is the Mendelian analysis of hereditary diseases. If we learn that the predisposition to a certain disease is inherited through a dominant gene, as diabetes, for instance, then we know that all persons carrying the gene will be sick. In this case all carriers can be easily recognized. In the case of recessive diseases, feeblemindedness, ${ }^{*}$ for instance, we know that the recessive gene may be covered by the dominant gene for health and that the person, seemingly healthy, may carry the disease and transmit it to his children.

With every year the influence of Mendel's modest work became more widespread. The theoretical explanation given by Mendel was based upon the hypothesis of a mechanism for the distribution and combination of the genes. To-day we know that exactly such a mechanism, as was seen by the prophetic eye of Mendel, exists in the chromosome apparatus of the nucleus of the cells. The development of research on chromosomes, from the observations of the chromosomes and their distribution by mitosis to the discovery of the reduction of the number of chromosomes in building the sex cells and finally to the audacious attempt to locate the single genes within the chromosomes, is all a story, exciting as a novel and at the same time one of the most grandiose chapters in the history of science. A tiny animal, the fruit fly, Drosopbila, was found to be the best object for genetical research. The parallelism between the behavior of the chromosomes and the mechanism of Mendelian inheritance was studied by hundreds of scientists, who were trying to determine even the location of the different genes within the different chromosomes and who started to devise so-called chromosome maps.

Correns, Baur and Goldschmidt in Germany; Bateson and his school in England; Devries in Holland; Nilsson-Ehle in Sweden, are the outstanding geneticists of the first decade after 1900 . But soon the picture changed. The Carnegie Institution for Genetic Research in Long Island, under the leadership of Davenport and later under Blakeslee, became one of the world's centers of genetic research. In 1910, T. H. Morgan, then at Columbia University, later at the California Institute of Technology, started his investigations with the fruit fly, Drosopbila, and founded the largest and most active school of geneticists. The U.S. Department of Agriculture with its network of experimental stations connected with more than a hundred agri-

- Not all feeblemindedness is inherited. Some cases are due to accidents or falls, some to disease. - Ed, 
cultural colleges became the most admirable organization for breeding of better crops and farm animals based upon the principles of Mendelism. The ideas developed by Mendel have found a new home here in the new world.

From 1905 to 1910 , I tried by lectures and by articles to renew the memory of Mendel in my home country and to explain the importance of Mendelism to the people. This was not always an easy task. Once I happened to be standing beside two old citizens of Bruenn, who were chatting before a picture of Mendel in a book-seller's window. "Who is that chap, Mendel, they are always talking about now?" asked one of them. "Don't you know?" replied the second, "it's the fellow who left the town of Bruenn an inheritance!" In the brain of the worthy man the term "heredity" had no meaning, but he understood well enough the sense of an inheritance or bequest.

\section{$\gg \rightarrow \leftrightarrow$ \\ HUMAN HERITAGE * \\ CARROLL LA NE FENTON}

Man has been inheriting for a million years, but his study of the process dates back a scant half century. At various times during the former period he has lost color from skin, eyes, and hair, has reduced the thickness of his jaw, enlarged the capacity of his skull, and improved his brain. The half century of study, however, has been largely devoted to clearing away ancient treasures of misconception. Much of this still remains to be done before human beings will admit the results of their own genes and chromosomes.

\section{SIM PLE CHARACTERS MAY SEEM COM PLEX}

Our most obvious inheritance is sex, controlled by two $\mathrm{X}$ chromosomes in women but an $\mathrm{X}$ and a $\mathrm{Y}$ in man. Much simpler, however, is tanning, a character developed when sunshine causes cells of the skin to pile up grains of brown pigment just beneath the surface. Though such grains are not inherited, the power to make them is controlled by one dominant gene in each of two paired chromosomes. The opposite is a recessive gene that seems to do nothing; fair-skinned whites who get two of these sunburn endlessly since their cells cannot make protective pigment.

If a fair-skinned recessive marries a person who is pure for tanning, their children will get one gene of each kind, as any hybrid must. These children are sure to tan, for one dominant gene can control the skin cells about as well as two.

It is not clear how many characters exist which involve one pair of genes. They undoubtedly include certain types of nearsightedness and clubfoot,

* From: Our Living World by Carroll Lane Fenton, copyright 1943 by Carroll Lane Fenton, reprinted by permission of Doubleday \& Company, Inc. 
and at least one kind of dwarf appears as a simple Mendelian recessive. Short fingers are produced by a dominant gene which also makes the whole body short and stocky. Those of us who lack these defects are "pure" for the normal recessive gene, which lets bones, especially those of the fingers, develop to full length.

There seems no doubt that human albinism, like that of guinea pigs, is a recessive character that appears only when a fertilized egg receives two appropriate genes. One gene has no effect, for it is hidden by normal coloring of skin, eyes, and hair. Since albinos frequently do not marry, this recessive character affects only about one person in ten thousand, or a total of about thirteen thousand people in the entire United States. On the other hand, a white patch of hair above the forehead is caused by one or two dominant genes whose action seems to be regulated by age, and perhaps by other factors. As a result, the character sometimes appears in small children, but may be delayed until those who possess it are twenty or thirty years old.

HAIR COLOR INVOLVES SEVERAL GENES

Since World War I we have heard a great deal about the Nordics, a tall and supposedly superior race whose narrow heads are covered with yellowish or straw-colored hair, which may be so pale as to look almost white. Studies of heredity show that these blond hues depend upon one pair of recessive genes which seemingly appeared as mutants and replaced darker genes among folk who wandered into northern Europe some five thousand years ago. These genes combined with other recessives controlling great height, fair skin that does not tan, and blue eyes.

After becoming racially distinct the Nordics spread far and wide through western Europe, interbreeding with other peoples whom they met or conquered. Nordics grew darker and darker as they intermarried until their racial traits survived only in shape of skull and other obscure characters. But their genes for hair color did not vanish. Today the heredity of European races is as mixed in this respect as it is in most other characters.

GENES MAY CO-OPERATE

Skin color, which differs from the power to make sun-tan pigment, is complicated. When whites and pure negroes cross, their children are mulattoes of intermediate type. This suggests partial dominance, but the children of mulattoes are too varied for any $1: 2: 1$ ratio. Indeed, they show almost every conceivable gradation between the pale skin of one grandparent and the "black" one of the other.

These gradations have long puzzled scientists, especially of the United States, where racial color is the subject of strong prejudice. After collecting an enormous number of records these investigators conclude that both whites and negroes have four pairs of contrasting genes that control 
skin color and behave with all the independence of those determining hue, sleekness, and shagginess of coat in guinea pigs. Each "negro" gene contributes a substantial quota of dark brown pigment, while each "white" one produces a small amount of the same or a closely related substance. When the two races cross, these genes combine equally in fertilized eggs, so that mulattoes (the $F_{1}$ generation) are intermediate in color. Among offspring of the mulatto generation, however, there are bound to be all sorts of combinations. Though the majority will have some black and some white genes, a few will receive only one type and a few the other.

Such sorting explains why, after generations of racial crossing, there still are some six hundred and fifty thousand pure negroes in the United States-people without a trace of white color genes. It also lays an old sob story, the one of a white girl who married a man who seemed to be white, only to find that her first baby was "as black as coal." Since all black genes are dominant, a person who seems white almost certainly is so; many persons whose color genes are as pure as those of their distant white ancestors emerge every year from matings between part-negro parents. Second, no person who is light enough to pass for a white can carry enough genes for negroid color to make his children coal black or even a healthy brown. Each gene produces its quota of pigment, and all blacks are dominant.

Multiple series of genes controlling one character are very important in man. Several pairs control human height, those for shortness being dominant. As a result, two tall parents are likely to have tall children, though some youngsters may violate this rule by receiving all genes for shortness from both father and mother. Short parents, however, are likely to have hidden genes for tallness which combine in their children.

\section{SOME CHARACTERS ARE LINKED WITH SEX}

Baldness is variously blamed upon disease, worry, hats, mental work, and failure to anoint one's scalp with the latest brand of hair tonic. Instead it is hereditary. Disease can only hurry it a little, while no tonic on earth can prevent it if the right genes are present in a member of the proper sex.

There actually are three types of baldness, each a distinct character with its own determiners. They are inherited like other genes, but their power to act is controlled by secretions of the sex glands. In males these secretions enable the genes to dominate. Ovarian secretions give the genes so little chance to act that they almost seem to be recessives.

Common color blindness, which makes red and green look gray, is a sex-linked character, linked to the $\mathrm{X}$ chromosome. A man who has received one gene for this trait is color-blind, since his $\mathrm{Y}$ chromosome cannot contribute the normal dominant. A woman, however, cannot become colorblind unless she inherits the proper recessive genes from both her father and her mother. Since this does not happen very often, few women show 
the defect. Yet many women carry the recessive gene and so transmit color blindness to at least half their sons.

Four sex-linked characters are known in man at least, and others may be discovered. The most serious is haemophilia, or bleeding, a recessive trait which somehow keeps the blood from clotting and so from sealing wounds. A male bleeder who marries a perfectly normal wife cannot give the defect to his children, nor can his sons pass it on. But his daughters, though healthy throughout their own lives, will give one gene for bleeding to half their sons.

The majority of man's characters are determined by genes in forty-six other chromosomes, most of which are longer than the $\mathrm{X}$, while all are longer than the Y. Since chromosomes are chains of genes or gene capsules, it becomes obvious that the bulk of human heredity depends on sorting, pairing, and dominance that takes place without reference to sex.

\section{SOME DISEASES ARE HEREDITAR Y}

Most of us have been taught that disease is not inherited, since germs cannot be transmitted by way of sperms and eggs. The latter statement seems to be true, but the former is not. Mankind suffers from many diseases caused by defects or faulty operation of human tissues and organs, and of these an increasing number are known to be hereditary.

Bleeding of the kidneys is a dominant character, as are albumin in the urine and a type of diabetes which causes excessive urination, with equally excessive thirst. A form of anemia in which red blood cells become sickle-shaped is a dominant character. Pernicious anemia also is inherited in some families, though in others it seems to develop without any help from genes.

Most familiar of all hereditary ailments are those grouped as allergy. They include hay fever, asthma, hives, eczema, ivy poisoning, indigestion, sick headaches, and other disorders, all caused by abnormal sensitivity to foods, pollens, dust, smoke, medicines-even to heat and cold. One authority says that asthma is a dominant trait, while another thinks it recessive. Hay fever has been called a dominant that sometimes skips generations, but it also has been diagnosed as a straight dominant. One author believes that each sort of allergy is the product of multiple dominant genes. This would explain much variation, but the genes also seem to be controlled by age and other factors. Thus a child was allergic to milk at birth, but his mother developed sensitivity to wheat at the age of seventytwo.

\section{MENTAL DEFECTS ARE INHERITED}

Mental qualities are even more problematic than those involved in disease. Thanks to tedious but careful collection of data, we know that at least two kinds of feeble-mindedness are hereditary. Thus one group of 
families in which both parents were defective produced 470 feeble-minded children but only 6 who were normal. When only one parent was defective the proportion was 193. to 144. Other matings, as well as gradations from idiots to morons, seems to show that the common type of feeblemindedness is controlled by a small set of multiple genes which also are recessive.

Some mild types of epilepsy are allergic, being caused by such foods as wheat; others are results of accidents or infections, and so cannot be inherited. But at least one tenth of all epilepsy is a distinct hereditary character, apparently being determined by multiple genes. Insanity, too, is a hodgepodge; a variety of mental ailments that may or may not be related. Some types are caused by accidents or genes, others by worry or extreme unhappiness.

\section{MENTAL INHERITANCE IS NOT SIMPLE}

Family superiority is not traced to a single ancestor. One good parent may produce a sporadic genius, but it takes two superior parents in generation after generation to keep a whole family notably above par. Conversely one bad ancestor is not enough to explain a defective family that lasts and proliferates for generation after generation. We have no means of knowing how much superior ability is helped by wealth and family training; how effectively genius as well as mere normalcy can be swamped by lack of money, broken homes or other demoralizing conditions.

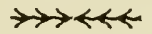

\section{THE STUDY OF HUMAN HEREDITY *}

\section{A U R E N C E H . S N Y D E R}

One of the most interesting biological developments of the past decade has been the increasing realization of the importance of a knowledge of human heredity in everyday life. Of course a certain respect has been paid to heredity for a long time. The considerations given matters of birth, family background and race testify to this fact. It is only recently, however, that we have had any exact knowledge of the transmission of factors for diverse characteristics from generation to generation in human beings.

When the laws of heredity were discovered, tested and finally understood in experimental plants and animals, it was inevitable that the attention of the geneticist should be drawn to the study of similar phenomena in man. Gradually a body of knowledge on the genetics of man has been built up, and, as always happens when sufficient basic facts are accumulated, a series of practical applications has appeared.

* Reprinted by permission of the Scientific Montbly, American Association for the Advancement of Science. Copyright $194^{\circ}$. 
The first of these practical applications involves the physician, who may find a knowledge of human heredity of value in diagnosis, especially early diagnosis. Instances are on record in the medical literature involving telangiectasis, polycythemia vera, spina bifida, orthoglycemic glycosuria, multiple exostoses and others, where the proper diagnosis was not made until the genetic background was taken into account.

A second practical application of a knowledge of human heredity consists in the outlining of preventive measures as a result of the examination of the family history of the patient. Tests for pre-clinical and laboratory signs of a disease which has a genetic basis may be made in the relatives of affected individuals, and proper preventive measures instituted where indicated, before the condition becomes acute. This is being done by many physicians in cases of pernicious anemia and its antecedent achlorhydria, in certain types of cancer, in hemolytic icterus, in hypertension, in diabetes and in other cases where a genetic background is known.

A third practical application involves the lawyer. In recent years the heredity of sereral substances (antigens) found in human red blood cells has been carefully worked out. On the basis of this knowledge a man falsely accused in a paternity case may be cleared of the charge in certain instances.

As a fourth practical application of a knowledge of human heredity, such knowledge may furnish the basis for advice on prospective marriages. It is a common experience for the geneticist to be asked, "What are the chances that this trait which is in my family background will appear in my children:" Sometimes it is a trait which the individual may be desirous of having in his children, such as musical ability, intelligence or red hair. At other times it may be an unwanted trait such as feeblemindedness, dementia praecox or deaf-mutism. When such questions are asked, the geneticist must call on his knowledge of the trait concerned, the possible genetic basis, the variability caused by different environments, and from this composite picture reach some answer. Frequently the answer must be vague and unsatisfactory because there is not enough exact knowledge concerning the parts played by heredity and by enrironment in the production of the trait. Sometimes, however, where such knowledge is at hand, valuable information may be given.

In a recent case a hemophilic patient with a typical family history of the disease stated that his three daughters had not been told the nature of his affliction, nor were they to be told, since he was ashamed of the hereditary blemish, as he considered it. Yet if these daughters marry, half their sons will be expected to have hemophilia, a condition which proves fatal in childhood in the majority of instances. Advance knowledge of the chances of hemophilia in these families would at the very least make it possible for the mothers of sons to have everything in readiness for an emergency transfusion at any time. 
In another case, a girl blind from aniridia was amazed to learn. upon consulting a geneticist, that half of her children of both sexes would be expected to have the abnormality.

Fifth, a knowledge of human heredity may furnish the basis for advice on prospective pregnancies. A young man recenty came to us for advice on a family history of psoriasis, a skin disease. His father and grandfather had the disease, as did several brothers and sisters and some nieces and nephews. The young man's wife was then pregnant. After becoming pregnant she had learned of and seen the shin affliction of her husband's relatives. which in the case of the girls and women. prevented the wearing of sleereless or low-necked gowns. The young wife became obsessed with the idea that her child would have psoriasis. It preyed on her mind to such an extent that she was in danger of a nervous breakdown. Close examination of the family history revealed that in this family the psoriasis nerer appeared in a child unless one of the parents showed it. Only certain members of each family showed it, although all came in contact with it. It was apparendy beharing as a dominant character. Since the young man in question was entirely free from the disease. it was possible to assure his wife that there was no danger of the child's inheriting the condition.

Sirth. a genetic knowledge can provide the necessary information for setting up eugenic and euthenic programs for the protection of society. a problem in which every citizen should be able to take an intelligent part. based upon experimental data, not on opinions, prejudices or the exaggeration of the uncertainties.

Serenth and last, there is every indication that with the discovery of more test factors of the sort exemplifed by the blood agglutinogens. the taste deffciencies and others which can be determined in early childhood. we shall eventually be able to predict in children the probability of the occurrence of latent genetic diseases and abnormalities which may prove to be closely linked in inheritance with such test factors.

The various hinds of hereditary behavior now known are so complicated that their uncerstanding requires a certain amount of study. This means that no one is justived in stating on his own responsibility that a given trait in man is or is not conditioned by hereditary factors unless: (1) He is thoroughly familiar with the known kinds of herediary behavior. (:) He is familiar with the character under discussion in all its varying manifestations. (3) He has carefully investigated the character in a scientific manner from a genetic standpoint. This often involves the cooperation of geneticists. physicians, dentists and psychologists.

As in other sciences any hypothesis of heredity, besides accounting for the facts at hand. must stand the acid test of predictive value.

In order to apply a knowledge of heredity to practical problems in human beings, certain fundamental conclusions must be granted. Among 
the conclusions taken for granted in the application of genetics to man are the following:

(1) The biological basis for the dozen or more major kinds of hereditary behavior has been adequately established by experimentation in animals and plants.

(2) Man fulfills the biologic requirements for being subject to the same laws of heredity as other organisms. (Among these requirements are sexual reproduction, a chromosome mechanism in which the chromosome number is reduced to half in the sperms and eggs, physiologic processes similar to those of other organisms, etc.)

(3) Hereditary factors are associated with the chromosomes. The evidence for this now amounts to what is practically a complete proof.

(4) Mental traits have their basis in physico-chemical structure, and are susceptible to the same laws of heredity as other characters.

(5) Heredity and environment are cooperative in the production of any finished character. One or the other influence may in certain circumstances appear negligible, but the dual nature may always be demonstrated.

Let us turn for a few moments to the principles involved in the analysis of human pedigrees.

The transmission of diverse hereditary factors from one generation to the next involves a series of phenomena resulting finally in the visible expression of characters in observable ratios. Most of the events in this series develop in direct consequence of the laws of probability, the probabilities being exactly determinable, thus making genetics more readily amenable to mathenatical analysis at the present time than any other biological science. The included phenomena are as follows:

(1) The segregation of factors into germ cells. Segregation involves the separation of the two members of a pair of factors when germ cells are formed so that one member of the pair goes to one of the resulting cells, the other member to the other. Thus half the germ cells will normally contain one factor of the pair, half the other. If the two members of the pair of factors are different, so that the individual is said to be heterozygous for that pair, the germ cells will be of two sorts, in equal numbers, in regard to that pair of factors. Thus the probability that any given germ cell of a heterozygous individual will contain a particular factor is one half. However, abnormal segregation is known, in which certain factors do not separate from each other, thus changing in these instances the probability of a given germ cell containing a particular factor.

(2) The assortment of factors during segregation. If an individual is heterozygous for two or more pairs of factors, the factors segregate at random if they are located on different pairs of chromosomes. Thus, in regard to two pairs of factors, four kinds of germ cells will be produced in equal numbers; in regard to three pairs of factors, eight kinds in equal numbers, and so on. The chance of a given cell containing any two particular factors is therefore one fourth, any three particular factors, one eighth, and so on. However, if the factors are located on the same pair of 
chromosomes (in which case they are said to be linked) these probabilities are altered, roughly in proportion to the relative distance between the two pairs of factors on the chromosomes. This distance determines how often the factors may assort at all, the assortment approaching a random one as the relative distance increases.

(3) The type of mating. When a population consists of various sorts of individuals, there will be, of course, various sorts of mating possible. The kinds and proportions of germ cells available for fertilization in any particular mating will depend upon the genetic composition of the individuals involved in the mating. Mass matings in a population may be at random or may be assortative (that is, certain types of mating tending to occur to the exclusion of others). The probabilities for various kinds of offspring depends among other things on the type of mating.

(4) The frequencies, in the population, of the genes concerned. The two members of a pair of factors may be equally distributed in a population, or one may be common and the other rare. The relative proportions can be determined by the use of certain mathematical technics, and are of importance wherever mass matings are concerned. Moreover, the frequencies of the two members of a pair of factors may have reached an equilibrium in the population, or they may not yet have done so. This too may be deduced by special methods. Gene frequencies and equilibria become of especial importance in the modern analysis of human pedigrees, and will be further discussed later in this paper.

(5) The union of the germ cells. Fertilizations normally occur at random, that is, any sperm has an opportunity equal to that of any other sperm of fertilizing a particular egg; conversely, an egg has a probability equal to that of any other available egg of being fertilized by a particular sperm. Here again, however, exceptions occur, and cases of selective fertilization are known. In such cases the probabilities are of course shifted.

(6) The interaction of factors, during development, with each other and with the enviromment, resulting in observable characters (pbenotypes). The characters finally produced and the proportions in which they are produced will depend upon this and the preceding five phenomena. These phenomena, serially taking place from generation to generation in specific environments, give rise to the phenotypic expressions of characters in definite ratios, from the analysis of which the laws of heredity have been deduced.

The type of inheritance involved in any particular case, the number of pairs of factors concerned, the mode of interaction and other relevant conclusions have long been determined from the study of the phenotypic ratios derived from specific types of mating. The classical genetic analyses of animals and plants have necessitated the scrutiny of at least three generations (parents, $F_{1}$ and $F_{2}$ ). Often additional generations (back-crosses, $F_{3}$, etc.) have been required. As long as such planned matings were readily 
made, there was no necessity of searching for other types of analysis. With the growing interest in the study of human inheritance, however, it was increasingly realized that the classic methods could not serve in this field. It became imperative to devise technics which would obviate the necessity of knowing the precise genotypes of the parents, and which would eliminate the need for the study of $F_{2}$ generations, back-crosses, etc.

Once the need was felt, the technics were not long in appearing. In general, such technics are based primarily on derivations of the frequencies of the genes in the population, the derivations being made from the frequencies of observable phenotypes. On the basis of such gene frequencies, the results of various mass matings may be predicted. The many methods now available have originated in scattered laboratories. Contributions to this field have been made in England by Fisher, Haldane, Hogben, Penrose and others; in Germany by Bernstein, Lenz, Wellish and others; and in America by Burks, Wiener, Wright, Cotterman, Rife, Snyder and others. In the course of the development of methods for analyzing human inheritance the number of generations required for the analysis has been reduced first to two, and finally to but one, while the requisite knowledge of the precise genotypes of parents has been gradually reduced and finally eliminated entirely.

It must not be thought that methods which lessen the required number of generations available for study or which minimize precise genotypic knowledge concerning parents are more desirable or more efficient than the classic methods. It is merely that they must serve, as efficiently as possible, in a field in which test matings of precisely known genotypes are not available.

It will be readily seen that no single method can answer all the questions about the genetic bases of human characteristics. Various technics are concerned in solving the problems as to the number of pairs of factors involved, whether these factors are acting as dominant, recessive, blending, sex-linked, sex-influenced, lethal or multiple factors, whether or not epistatic relationships are present, and whether the factors are linked or independent. In predicting the proportions of different types of offspring to be expected from various mass matings involving specific phenotypes, complications arise in that a single phenotype often includes several different genotypes. In linkage studies a heterozygous genotype may include both coupling and repulsion phases. Hence it is necessary to provide suitable statistical corrections and allowances, since in human data such complications can hardly be avoided.

One of the points most frequently overlooked in the study of human heredity is the matter of equilibrium in gene frequencies. It should now be a commonplace that equilibrium in regard to the genotypes resulting from a pair of autosomal factors exists when the homozygotes for one allele, 
the heterozygotes and the homozygotes for the other allele are in the relative proportions $p^{2}, 2 p q$ and $q^{2}$, respectively, where $p$ and $q$ are the frequencies of the two alleles so that $p+q=1$ and $p$ or $q$ may have any correlative value from o to $\mathrm{I}$. Moreover, if anything occurs to displace the equilibrium, a new equilibrium is reached after a single generation of random mating. For sex-linked genes, epistatic interactions and other complicated cases, equilibrium may be reached more slowly.

Self-evident as these propositions would appear to be, misunderstandings of them and of their implications are all too frequent in discussions of human heredity. It is often said, for example, that a dominant character increases in the general population at the expense of its recessive counterpart until it stands in the ratio of $3: 1$. This statement has no basis in fact. A recent text states that "albinism is due to a recessive factor, which explains why it is so rare" (italics mine). Another book, a treatise on handedness, proclaims that "left-handedness occurs in 25 per cent. of the population, which indicates that it is a Mendelian recessive" (italics mine). Each of these statements shows a complete lack of understanding of the principles of equilibrium.

A recessive character may be common or rare in a population, depending upon the relative abundance or scarcity of the hereditary factor determining the character. Split hand, or "lobster claw," in which the hand has only two large fingers, is due to a dominant factor, the normal complement of five fingers being due to its recessive allele, yet the recessive character is the common condition. Recessive characters may occur in various populations in any frequency whatsoever from o to 100 per cent.

A recent prize-winning essay of the Eugenics Research Association contains this remarkable pronouncement: "We are indeed lucky that the mental disorders or psychoses are not dominant traits, or we would all be insane by now, according to the laws of heredity." In a recent manuscript on fingerprints which I was requested to read and criticize appeared the following paragraph:

"Here we have a pattern (arches) which when crossed with another of the same classification, produces its own kind, plus loops and whorls. This reaction seemed to fit the requirements of a character heterozygous in the parents and segregating in the $1: 2: 1$ ratio. A check on the frequency of arches in the general population quickly invalidated such a supposition, however, for it was found that only about 5 per cent. of all patterns are arches. Support for such an idea would require 25 per cent. loops, 50 per cent. arches and 25 per cent. whorls. Some other explanation was therefore necessary." Here again we have examples of complete misunderstanding of gene frequencies and equilibria.

I have belabored this point because the lack of attention paid to these important considerations has greatly retarded the progress of the study of 
human genetics. The necessity for a thorough understanding of the unique problems involved in the genetics of man must be appreciated before further progress can be made.

Among the problems facing the student of heredity in man, are the following: to test the linkage relations of known human genes and to construct maps of the human chromosomes by the use of the newly elaborated paired-sib technic; to search actively for new genes in man; to further elaborate the gene-frequency technics and other statistical methods for the analysis of hereditary human factors; to determine the phenotypic frequency of various traits in the population-in other words to take a census of human traits; to establish and maintain twin clinics in qualified hospitals; to study intensively the genetic and environmental influences interacting in the production of "mental" characters; to obtain relevant facts about the genetic and environmental backgrounds of socially significant traits of all sorts; and finally to create an awareness of the importance of the genetic viewpoint among physicians, social workers and the general public.

It is the hope of the student of human genetics that such a cooperative line of research may eventually give rise to a social edifice, the foundation of which is made up of substantiated facts about the development, both from a genetic and an environment standpoint, of human characteristics, and the superstructure of which is a tower of eugenic strength which can be defended against any attack. To this end we bespeak the cooperation of biologists, physicians, anthropologists, psychologists, sociologists, legislators and social workers, and we ask the continued faith and support of the public.

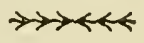

\section{WHAT WILL YOUR CHILD LOOK LIKE *}

\section{A M R A S S CHEIN F E L D}

Given certain facts about you and your mate, we can make some fairly accurate predictions as to what your children would look like.

Were we able to breed people as the geneticists breeds flies, we could make many more predictions, with greater accuracy. By constant breeding and inbreeding, geneticists have established strains of Drosopbila, ranged in rows of bottles in their laboratories, whose genes they know almost as well as the chemist knows the make-up of his various compounds. In fact, with almost the same precision that the chemists mix compounds, the geneticist can "mix," by mating, two flies of any strains and predict the types of offspring that will result.

We cannot, of course, ever expect to do anything like that with human

"From You and Heredity. Copyright 1939, by Amram Scheinfeld. Published by J. B. Lippincott Co. 
beings. Pure strains of humans cannot be produced, like flies, by long inbreeding of parents with children, brothers with sisters, etc. And where flies have 300 offspring at a time and three generations to a month, human couples do not average more than four offspring to a marriage, and only three or four generations to a century.

So, genetically, in most respects we humans are unknown quantities. With regard to your own genes, you can only make guesses, but in this you will be helped considerably not merely by the characteristics which you yourself reveal, but by those which appear in your parents, grandparents, brothers, sisters, and other close relatives. If you are dark-eyed, the chances of your carrying a "hidden" blue-eye gene increase according to the number of your relatives who have blue eyes, and their closeness to you. Going further, if you marry a blue-eyed person and have a blueeyed child then you know definitely that you carry a blue-eye gene. On the other hand, if two, three, four children in a row are all dark-eyed, the presumption grows that you haven't a blue-eye gene.

Likewise, where both parents are dark-eyed, the appearance of a blueeyed baby is proof conclusive that both carry "hidden" blue-eye genes. But if all the children are dark-eyed, it still might mean that only one of the parents has no blue-eye gene.

These qualifications hold for every case where persons have some characteristic due to a dominant gene (dark hair, curly or kinky hair, thick lips, etc.) and wish to know what chance they have of carrying a "hidden" gene which might produce a different trait in their child.

But before we try to make any predictions these facts should be clear:

All forecasts as to the types of children people will have are based on averages determined by the laws of chance.

Wherever dominant and recessive genes are involved, it is like tossing up coins with heads and tails. Toss up coins long enough, and the number of heads and tails will come out even. So if you are carrying one dominant and one recessive gene for any characteristic, were it possible for you to have an unlimited number of children, you'd find that exactly half would get the dominant and half the recessive gene.

With two parents involved, the results will be like those obtained in "matching" coins. This, of course, conforms to Mendel's laws.

When we think in terms of the characteristic produced, the result in "mixed" matings will be that the dominant characteristic (dark eyes, dark hair, etc.) will show up three out of four times, the recessive only one in four, as it requires a matching of the recessive genes.

Of course, where one parent carries two dominant genes, all the children will show the dominant trait. Where one parent carries a dominant and a recessive, and the other parent two recessives, half the children will show the dominant trait, half the recessive.

But here is something else to bear in mind: 
Wherever it is a question of a child's getting one gene or another, or having such and such a characteristic, the odds for every child are exactly the same.

Some gamblers might dispute this, but if you toss up a coin one time and it comes up heads, that does not mean that the next time there is any better chance of its coming up tails. There is the same fifty-fifty chance on each toss-up. Even, if through an unusual "run," there would be ten heads in succession, on the eleventh toss there would still be an exactly even chance of either "heads" or "tails." (This applies to dice, roulette, or any other game of chance. Many a gentleman has lost a fortune trying to disprove it.)

So, let us say, if the odds are even for your having a blue-eyed child, and your first one is brown-eyed, that does not mean that the odds are any better that the next one will be blue-eyed. Even if four or five children in a row are born with brown eyes, there is still that same fifty-fifty chance, no more or no less, that the next child will have either brown or blue eyes.

But perhaps we need not have gone into all this. In the "boy or girl?" question we say that there is a 106 to 100 chance that the child will be a boy. And yet, authorities like Eddie Cantor will tell you that the fact of their having had two, three, or four girls in a row in no way bettered the odds that the next one would not be a girl!

In "boy or girl?" however, it is a simple question of one or the other. But in the case of features or form-in fact, of any detail in the bodythere are innumerable variations to contend with. If you and your mate conform to the average, you will find that the forecasts here presented are fairly dependable. Always, however, allow for exceptions and-whatever happens, do not blame us (or the geneticists on whose studies these tables are based) if the baby does not turn out the way the forecast indicated.

And now to Sir Oracle!

\section{HOW TO USE THESE "CHILD FORECAST" TABLES}

First: If this is to be your first child, find out as much as possible about what genes you and your mate may be carrying by studying other members of your families. * Make allowances for all characteristics influenced by environment.

Second: If you have already had one or more children, also study each child for additional clues as to your genes.

Third: Remember that no matter how many children you have had, or what they look like, the odds that your child will receive a given characteristic are exactly the same as if it had been the first.

Fourtb: In consulting the tables, look for your own characteristic in either of the "parents" columns. (They each apply equally to father or mother.) If you and your mate are of different types, look first for the type most pronounced - the darkest coloring, the most extreme hair form, etc.

" "Family" refers not only to parents, brothers, and sisters, but also to grandparents and other close relatives. 
Fiftb: Remember that these "forecasts" are based on averages in large numbers of matings. With just one child, that child might be the exception.

Sixth: Wherever age is a factor, make due allowances for its future effects or changes that may be expected to take place.

EYE-COLOR FORECAST

\begin{tabular}{|c|c|c|}
\hline $\begin{array}{l}\text { If eyes of one parent } \\
\text { are: }\end{array}$ & If eyes of other parent are: & Child's eyes will be: \\
\hline $\begin{array}{l}\text { BRown (or BLACK) } \\
\text { Type I. If all this } \\
\text { parent's family were } \\
\text { dark-eyed } \\
\text { Type 2. Where some } \\
\text { in this parent's } \\
\text { family have lighter } \\
\text { colored eyes (gray, } \\
\text { green, blue) }\end{array}$ & $\begin{array}{l}\mathrm{x} \text { NO MATTER WHAT COLOR } \\
\mathrm{x} \text { BROWN, Type } 2 \\
\mathrm{x} \text { GRAY, GREEN, BLUE }\end{array}$ & $\begin{array}{l}\text { Almost certainly dark } \\
\text { Probably brown, but possibly } \\
\text { some other color } \\
\text { Even chance brown or lighter } \\
\text { color (usually like that of } \\
\text { lighter-eyed parent) }\end{array}$ \\
\hline GRAY or GREEN & X GRAY, GREEN, BLUE & $\begin{array}{l}\text { Probably gray or green but } \\
\text { possibly blue, rarely brown }\end{array}$ \\
\hline BLUE & $\mathrm{X}$ BLUE & $\begin{array}{l}\text { Almost certainly blue. } \\
\text { (Rarely a darker shade, the } \\
\text { possibilities being less if } \\
\text { parent's eyes are light-blue) }\end{array}$ \\
\hline ALBINo (Colorless) & $\begin{array}{l}\mathrm{x} \text { NORMAL-eyed parent of } \\
\text { any eye-color }\end{array}$ & $\begin{array}{l}\text { Normal, leaning to shade of } \\
\text { normal parent's eyes, unless } \\
\text { this parent carries hidden } \\
\text { "albino" gene, when } 1 \text { in } 2 \\
\text { chance of child being albino } \\
\text { Definitely albino }\end{array}$ \\
\hline
\end{tabular}

\section{EYE-SHAPE FORECAST}

wIDTH: Where just one parent has wide eyes, child will be quite likely to have them.

SLANT: If one parent has slant eyes (but not of Chinese type) child will not be likely to have them unless slant eyes also appear in the family of the other parent. If, however, the parent's eyes are of the Chinese, or Mongolian type, there is great likelihood that child will have them.

LASHES: Where just one parent has long lashes, child may be expected to have them.

\section{STATURE FORECAST}

Both parents tall. The child on maturity will almost certainly be tall, or taller than average.

Both parents short. The child will probably be inclined to shortness, but may possibly be taller than the parents, and even very tall.

One parent tall, one short. The child will incline toward shorter parent.

\section{BUILD}

If both parents are slender, the child will be more likely to be like them than if both parents are fleshy. But build is a highly variable characteristic dependent on so many conditions and genes that it can hardly be predicted. 
HAIR-COLOR FORECAST

\begin{tabular}{|c|c|c|}
\hline $\begin{array}{l}\text { If one parent's hair } \\
\text { color is: }\end{array}$ & Other parent's hair color: & Child's hair color will be: \\
\hline $\begin{array}{l}\text { DARK (BROWN or BLACK) } \\
\text { Type 1. Where all in } \\
\text { this parent's family had } \\
\text { dark hair } \\
\text { Type 2. Where there } \\
\text { are lighter shades } \\
\text { among others in } \\
\text { this parent's family }\end{array}$ & $\begin{array}{l}x \text { No matter what } \\
x \text { RED DARK, Type } 2 \\
x \text { BLONDE }\end{array}$ & $\begin{array}{l}\text { Almost certainly dark } \\
\text { Probably dark, possibly lighter } \\
\text { About equal chance (a) dark } \\
\text { or (b) red-brown or red, with } \\
\text { (c) slight possibility of blonde } \\
\text { Probably dark but possibly } \\
\text { blond, rarely red }\end{array}$ \\
\hline RED & $\begin{array}{l}X \text { RED } \\
X \text { BLOND }\end{array}$ & $\begin{array}{l}\text { Most probably red, and occa- } \\
\text { sionally light-brown or blond } \\
\text { Even chances (a) red or (b) } \\
\text { light-brown or blond }\end{array}$ \\
\hline $\begin{array}{l}\text { BLOND } \\
\text { Type I. If medium } \\
\text { shade }\end{array}$ & $\mathrm{X}$ BLOND & $\begin{array}{l}\text { Fairly certain blond, with } \\
\text { rarely brown. (Red possibly if } \\
\text { this shade is present in either } \\
\text { parent's family) }\end{array}$ \\
\hline $\begin{array}{l}\text { Type 2. If flaxen or } \\
\text { white }\end{array}$ & x BLoND-flaxen or white & $\begin{array}{l}\text { Certainly blond, but with shade } \\
\text { of darker parent apt to prevail }\end{array}$ \\
\hline
\end{tabular}

\section{HAIR-FORM FORECAST}

\begin{tabular}{|c|c|c|}
\hline If one parent's hair is: & Other parent's hair: & Child's hair will be: \\
\hline $\begin{array}{l}\text { CURLY } \\
\text { Type I. If all in this } \\
\text { parent's family are } \\
\text { curly-haired } \\
\text { Type 2. If some wavy } \\
\text { or straight in this } \\
\text { parent's family }\end{array}$ & $\begin{array}{l}\mathrm{x} \text { Any form, except kinky } \\
\text { or wooly } \\
\left\{\begin{array}{l}\mathrm{x} \text { cURLY, Type } 2 \\
\mathrm{x} \text { WAVY } \\
\mathrm{x} \text { STRAIGHT }\end{array}\right.\end{array}$ & $\begin{array}{l}\text { Almost certainly curly } \\
\text { Probably curly, possibly } \\
\text { wavy or straight } \\
\text { Even chance (a) curly or } \\
\text { (b) possibly wavy or straight } \\
\text { Probably curly or wavy, possi- } \\
\text { bly straight }\end{array}$ \\
\hline $\begin{array}{l}\text { WAVY } \\
\text { Type 1. If no straight- } \\
\text { haired persons in this } \\
\text { parent's family } \\
\text { Type 2. If there are } \\
\text { some with straight hair } \\
\text { in this parent's family }\end{array}$ & $\begin{array}{l}\mathrm{X} \text { WAVY Or STRAIGHT } \\
\mathrm{X} \text { STRAIGHT }\end{array}$ & $\begin{array}{l}\text { Almost certainly wavy, rarely } \\
\text { straight } \\
\text { Even chance wavy or straight. } \\
\text { (Rarely anything else). }\end{array}$ \\
\hline STRAIGHT & $\mathrm{x}$ STRAIGHT & Almost certainly straight \\
\hline $\begin{array}{l}\text { K1NkY } \\
\text { Type I. Where all in } \\
\text { this parent's family are } \\
\text { kinky-haired }\end{array}$ & $\begin{array}{l}\mathrm{x} \text { No matter what hair } \\
\text { form }\end{array}$ & Almost certainly kinky \\
\hline
\end{tabular}




\begin{tabular}{|c|c|c|}
\hline $\begin{array}{l}\text { If one parent's hair is: } \\
\text { (contt.) }\end{array}$ & $\begin{array}{l}\text { Other parent's hair: } \\
\text { (cont.) }\end{array}$ & $\begin{array}{l}\text { Child's hair will be: } \\
\text { (cont.) }\end{array}$ \\
\hline $\begin{array}{l}\text { Type 2. Where other } \\
\text { hair forms appear in } \\
\text { this parent's family }\end{array}$ & $\begin{array}{l}\text { X CURLY Or WAVY } \\
\text { X STRAIGHT }\end{array}$ & $\begin{array}{l}\text { Even chance (a) kinky or (b) } \\
\text { curly or wavy; rarely straight } \\
\text { Almost like above, greater pos- } \\
\text { sibility of being straight }\end{array}$ \\
\hline
\end{tabular}

wooly: While fairly frequent among Negroes, it is rare among Whites. Where, however, it appears in even one parent half the children will have wooly hair.

\section{FORECAST OF FACIAL DETAILS}

NOSE

(Nose-shape is not inherited as a unit. Different characteristics of the nose may be inherited separately, one detail sometimes from one parent, another from the other parent. Environmental factors also have great influence.)

Generally: Where both parents have about the same type of nose, a child on maturity will have a similar type.

But: If just one parent has a broad nose, a long nose, or a prominent nose, and the other parent a moderate nose, the child's nose will very likely be of the most extreme type (on maturity).

Where any nose peculiarity has appeared for several generations in either parent's family there is an even chance that the child will inherit it.

\section{EARS}

Large. If just one parent has large ears, the child will very likely have similar ears.

Affixed lobes. Where only one parent has affixed lobes or absence of lobes, and the condition does not appear in the other parent's family, there is little likelihood that the child will have such ears.

\section{MOUTH}

Lips. If just one parent has thick lips, the child will probably have them.

If just one parent has a heavy or protruding underlip (Hapsburg type) the child has an even chance of inheriting it.

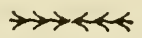

\section{WHAT BLOOD TELLS *}

\section{A V I D C . R I F E}

A few years ago, in a large city hospital, the nurses mixed the identification tags of two new born babies. Both sets of parents, the Smiths and the Browns, claimed one of the babies while no one wanted the other. Various tests were made in order to determine which baby belonged to the Smiths and which to the Browns. Foot prints were compared, as well as head shape and general appearance, but they gave no conclusive evidence. Finally. someone suggested a comparison of the blood groups of the babies with those of the parents.

- Reprinted from The Dice of Destiny by David C. Rife with the permission of Long's College Book Co. Copyright 1945. 
It was found that one baby belonged to group $\mathrm{O}$ and the other to group A. Both of the Smiths were of group O, while one of the Browns was O and the other A. This proved conclusively that the baby of group A belonged to the Browns, as two $\mathrm{O}$ parents can produce only children of group $\mathrm{O}$.

Your blood group depends upon the presence or absence of two substances in your blood stream, known as antigens. The four blood groups, $\mathrm{AB}, \mathrm{A}, \mathrm{B}$, and $\mathrm{O}$ depend upon the presence of both, or of either alone, or of neither of these antigens. The antigens are known as A and B. People of group $\mathrm{O}$ possess neither antigen, those of groups $\mathrm{A}$ and $\mathrm{B}$ possess the corresponding antigens, while those of group $\mathrm{AB}$ possess both antigens.

An individual's blood group is determined by heredity. It is established within the individual months before birth, and cannot be altered by any known environmental circumstance. Age, disease, and climate do not change one's blood group. Even transfusion from one of another group does not permanently alter one's group.

Three different genes are responsible for the four blood groups. One, which we shall represent by $\mathrm{A}$, results in the formation of antigen $\mathrm{A}$. Another, which we shall represent by B, results in the formation of antigen $B$. The third gene, which we shall represent by $O$, produces no antigen.

Two of these genes, possibly $\mathrm{A}$ and $\mathrm{B}$, mutated from the original one, which would have been $\mathrm{O}$. As all three genes are of the same origin only two of them can be present within any individual. In other words, they occur in pairs, as do the genes determining whether or not one can taste P.T.C. (a certain chemical.) Their behavior is a little less simple, however, because three instead of two different kinds of genes are involved. The blood groups are determined by three alleles, $\mathrm{A}, \mathrm{B}$, and $\mathrm{O}$ whereas only two are involved in the determination of whether or not you can taste P.T.C.

Genes $\mathrm{A}$ and $\mathrm{B}$ are each dominant to gene $\mathrm{O}$. But $\mathrm{A}$ and $\mathrm{B}$ show no dominance to each other. People of group $\mathrm{AB}$ are heterozygous for genes $\mathrm{A}$ and $\mathrm{B}$, and each antigen is present to as marked degrees as in those possessing only one of the antigens. People of groups A and B may be either homozygous, or heterozygous for $\mathrm{O}$. As $\mathrm{O}$ is recessive, people of blood group $\mathrm{O}$ are always homozygous.

Knowledge of the mode of inheritance of the blood groups is now widely recognized as of great practical importance in cases of disputed parentage, as well as in other types of identification, such as the baby nixup we have cited. If we know the blood group of the mother and child, we can tell to what group or groups the father had to belong. This is, of course, negative evidence in that it tells only to what groups the father had to belong, and clears a man who does not belong to those groups. If the accused man happens to belong to one of the possible groups of the father, we have no evidence one way or the other as to his guilt. 
Blood is always typed, if possible, before a transfusion. People of group $O$ have two substances in their blood stream known as antibodies a and $b$. These react with antigens $\mathrm{A}$ - and $\mathrm{B}$ in such a manner as to cause clumping of the red blood cells. Such a reaction is called agglutination. If a person of group $\mathrm{O}$ should receive blood from any one of the other three blood groups, antigen-antibody reactions would result in agglutination of the red cells taken in. Likewise those of group A cannot donate to those of group B and those of group B cannot donate to those of group A. Those of group $A B$ cannot donate to those of any other group. Stored plasma can be given to those of any group as the red cells, which contain the antigens, have been removed.

Different races show significant variations in the percentages of the four blood groups (see table below). North American whites show approximately the same percentages as do northern Europeans. Generally speaking, Asiatics show higher percentages of $B$ and less of $A$ than do Europeans. Most American Indians appear to have very low frequencies of both antigens. These variations are of great interest to physical anthropologists, as they serve to suggest common origins and migrations in the evolution of human populations.

Distribution of the Blood Groups Among Various Racial Groups. (After Weiner)

\begin{tabular}{|c|c|c|c|c|}
\hline Racial Group & $\begin{array}{l}0 \\
\%\end{array}$ & $\begin{array}{l}\mathrm{A} \\
\%\end{array}$ & $\begin{array}{l}\text { B } \\
\%\end{array}$ & $\begin{array}{r}\mathrm{AB} \\
\%\end{array}$ \\
\hline 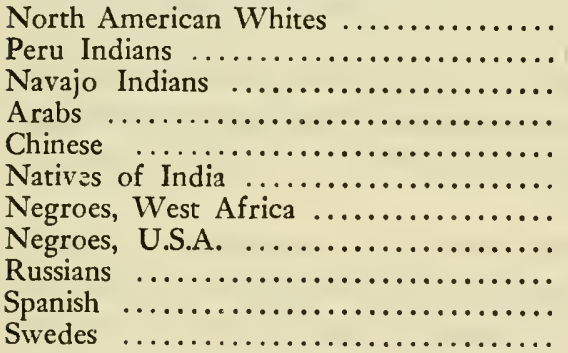 & $\begin{array}{r}45.0 \\
100.0 \\
70.8 \\
34.1 \\
30.0 \\
33.7 \\
52.3 \\
47.0 \\
32.0 \\
43.6 \\
37.9\end{array}$ & $\begin{array}{r}41.0 \\
0.0 \\
28.6 \\
30.8 \\
25.0 \\
24.6 \\
21.5 \\
28.0 \\
38.5 \\
51.2 \\
46.7\end{array}$ & $\begin{array}{r}10.0 \\
0.0 \\
0.3 \\
28.9 \\
35.0 \\
32.5 \\
23.0 \\
20.0 \\
23.0 \\
3.9 \\
10.3\end{array}$ & $\begin{array}{r}4.0 \\
0.0 \\
0.1 \\
6.2 \\
10.0 \\
9.2 \\
3.2 \\
5.0 \\
6.5 \\
1.1 \\
5.1\end{array}$ \\
\hline
\end{tabular}

The anthropoid apes have four blood groups, corresponding to those in man. This suggests that the blood group mutations may have occurred among the common ancestors of such apes and man. Different blood antigens have been shown to be present in many mammals. In domesticated rabbits, strangely enough, there are four blood groups whose hereditary behavior corresponds exactly to the blood groups in man and apes. Recent work shows a tremendous variation in cattle in regard to blood antigens and their inheritance.

Two other blood antigens, known as $M$ and $N$, occur in man quite independently of the blood group antigens. The antibodies for the $M$ and $\mathrm{N}$ antigens do not occur in man, but are prepared from the blood of 
rabbits. The $\mathrm{M}$ and $\mathrm{N}$ blood types are of no consequence in transfusions.

They are used in the same manner as the blood group antigens in cases of disputed parentage. Only two genes are involved in the $M$ and $N$ types. One results in the formation of antigen $M$ and the other in the formation of antigen $\mathrm{N}$. Like the blood group antigens, $M$ and $\mathrm{N}$ show no dominance with respect to each other. Unlike the blood groups, however, everyone possesses two genes for the production of antigens. No individuals have ever been found corresponding to blood group $\mathrm{O}$, that is, lacking both $\mathrm{M}$ and $\mathrm{N}$ antigens. People are of three genotypes; homozygous for antigen $M$, homozygous for antigen $\mathrm{N}$, and heterozygous for antigens $M$ and $\mathrm{N}$. There is only one genotype for each of the three phenotypes. The table below illustrates how both the blood groups and the $\mathrm{M}$ and $\mathrm{N}$ types may be of value in cases of disputed parentage.

Examples of How the Blood Groups and Types may be Used in the Determination of Paternity

\begin{tabular}{|c|c|c|c|c|c|}
\hline \multicolumn{2}{|c|}{ MOTHER } & \multicolumn{2}{|c|}{ CHILD } & \multicolumn{2}{|c|}{ FATHER MUST BE } \\
\hline Group & Type & Group & Type & Group & Type \\
\hline $\mathrm{O}$ & $M$ & $\mathrm{O}$ & $M$ & $\mathrm{O}, \mathrm{A}, \mathrm{B}$ & $M, M N$ \\
\hline $\mathrm{O}$ & $M$ & A & $M N$ & $\mathrm{~A}, \mathrm{AB}$ & $\mathrm{N}, \mathrm{MN}$ \\
\hline $\mathrm{O}$ & $\mathrm{N}$ & B & $M N$ & $\mathrm{~B}, \mathrm{AB}$ & $M, M N$ \\
\hline A & $M N$ & A & $M$ & $\longrightarrow$ & $M, M N$ \\
\hline B & $M N$ & A & $M N$ & $\mathrm{~A}, \mathrm{AB}$ & 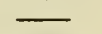 \\
\hline$A B$ & $M N$ & A & $M N$ & 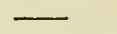 & - \\
\hline
\end{tabular}

Lines in columns 5 and 6 signify that the father could belong to any group or type.

As the $\mathrm{M}$ and $\mathrm{N}$ types are independent of the blood groups, it is possible by testing for both blood reactions to greatly increase the efficiency of tests for disputed paternity. Twelve combinations of blood groups and types are possible within individuals.

Significant racial variations are manifested in the occurrence of the $M$ and $\mathrm{N}$ types although they are less marked than in the blood groups (see table below). The knowledge and techniques of the $M$ and $\mathrm{N}$ types are more recent than for the blood groups, and the available data are correspondingly less extensive.

No other hereditary traits in man have as yet been discovered which are as universally satisfactory to work with as are the blood groups and types. They are established before birth and remain constant throughout life. The tests for them are objective and clearcut, much more so than for P.T.C. Moreover they show considerable variability and none of the genes involved are rare.

Boyd recently tested the blood groups of over one hundred Egyptian mummies. His findings indicate that the distribution of the blood groups among the ancient Egyptians five thousand years ago was apparently about the same as among modern Egyptians. 
Distributions of the $M$ and $N$ Blood Trpes in Various Racial Groups (AFTER WEINER)

\begin{tabular}{|c|c|c|c|}
\hline Racial Group & $M$ & $\mathbf{N}$ & $M N$ \\
\hline 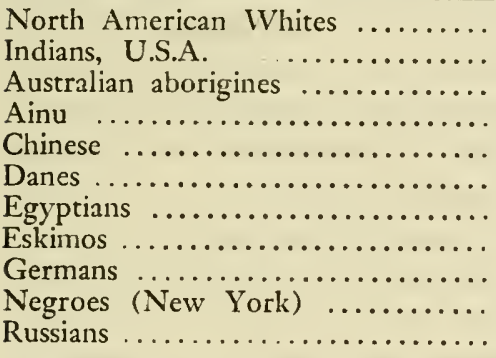 & $\begin{array}{l}29.0 \% \\
60.0 \\
3.0 \\
17.8 \\
33.2 \\
29.1 \\
28.3 \\
66.2 \\
30.2 \\
28.4 \\
32.2\end{array}$ & $\begin{array}{l}21.0 \% \\
4.9 \\
67.4 \\
31.94 \\
18.2 \\
21.4 \\
23.1 \\
2.9 \\
19.7 \\
21.0 \\
21.2\end{array}$ & $\begin{array}{l}50.0 \% \\
35.1 \\
29.6 \\
50.2 \\
48.6 \\
49.5 \\
48.6 \\
31.0 \\
50.1 \\
49.6 \\
46.6\end{array}$ \\
\hline
\end{tabular}

In recent years several other blood antigens have been discovered. All of these appear to be inherited as simple dominants. Of especial interest is the $\mathrm{Rh}$ antigen, which has recently been found to be of considerable importance. If a developing embryo develops the Rh antigen, and the mother lacks the antigen, she may develop the corresponding antibody. This may diffuse through the placenta into the blood stream of the embryo, sometimes with fatal results. In such an event the father must have been either homozygous or heterozygous for the Rh factor. Approximately $85 \%$ of North American whites possess the $\mathrm{Rh}$ antigen. Considerably higher percentages are found among Indians, Chinese and American Negroes.

Knowledge of the inheritance of the blood antigens is not only of value in cases of disputed parentage, but has also thrown considerable light on racial variations and origins. And there is every indication that in the future blood will tell more and more.

\section{$\nrightarrow \leftrightarrow \leftrightarrow$ \\ THE INHERITANCE OF DISEASE *}

\section{P A U L A. L E W IS †}

Considered in a broad and untechnical sense, an individual's inheritance means all those attributes both actual and potential received at or before birth from the parents. This usage has of late years been given up by scientific men in favor of a more circumscribed one, namely, that the inheritance consists of those attributes actual and potential acquired at the moment of conception due to the intrinsic properties of the germ cells.

* Reprinted from Human Biology and Racial Welfare, edited by Edmund V. Cowdry with the permission of Paul B. Hoeber, Inc. Copyright 1930, by Paul B. Hoeber, Inc.

t Died of yellow fever at Bahia, Brazil, on June 30, 1929, while investigating the cause of the disease.-Ed. 
This distinction is of real importance to a clear understanding of the relations between inheritance and disease. The biblical dictum that the sins of the fathers are visited on their offspring for generations has been considered in recent times to be particularly applicable to one contagious disease, syphilis. Children suffering severely from this disease are frequently brought into the world at or before the normal birth period. It is now considered a certainty that in these cases the child is infected at some point in its fetal life definitely subsequent to its conception. In any event, it is infected with an extraneous microörganism carried by one or both parents. On the other hand, it is known, by animal experiment at least, that the offspring of an immune mother are apt to show more than the usual resistance to certain diseases for some time after birth. This, it is recognized, is due to the transfer of protective substances in a passive way from the mother either through the membranes separating the fetal from the maternal circulation in utero or in the milk during the first days of life. Under the older definition, these instances would be considered to be cases of inherited disease or inherited immunity respectively, but are not so regarded under the more rigid definition of inheritance.

Even the circumscribed definition of inheritance as here given may not be wholly accurate. There is much reason to believe that injury to the parents by long-continued exposure to certain poisons such as alcohol or lead may affect the offspring unfavorably and it is also probable on the basis of animal experiments that exposure of the parents to roentgen rays may, under certain conditions, result in altered if not abnormal descendants. In so far as these influences may be manifest through action on the male parent it can only be by some affection of the germ cell itself and it would probably be impossible to frame an entirely adequate definition of inheritance in which these preconceptual influences are justly accounted for. These may for purposes of definition be recognized and passed over.

The outstanding achievement of genetic study has been to show that as a broad biological principle the most diverse general characters can be analyzed into an infinity, almost, of combinations of less inclusive specific unit characters which are inherited independently in principle. Actually they are inherited either separately or in small and apparently "chance constituted" linkage groups. There is every reason to suppose that the mechanism of human inheritance completely conforms to this "Mendelian" scheme. That it does so has been demonstrated for a considerable number of characteristics.

"Disease" is a general concept sufficiently defined for many purposes as any condition of body or mind which departs from "perfect health." A precise definition which shall be more critical than this and cover all the manifestations of morbid processes is extremely difficult to formulate. It is well to recognize this clearly at this point because there is a very general assumption or belief that people are quite definitely divided into 
two classes, those who are born healthy and of sound constitution, and those who come into the world otherwise. All such conceptions, it should be clearly seen, are in fact untrue. A healthy person is one who has no gross anatomical or physiological defects and enough normal general health to get on with.

In fact the great progress made by medicine as an art and a science from the dawn of civilization down to today is based on the steadily developed recognition of the infinite complexity and relative nature of the phenomena included in the general term "disease." And especially the remarkable progress of the last two centuries is due to the extension of this general principle into the study of particular diseases. Even the most simple (apparently) of abnormal conditions is found on closer scrutiny to be of the utmost complexity. A common boil is spoken of in scientific terms as a simple inflammation and even moderately informed lay people know it as the result of some "germ" getting into an insignificant scratch. In reality the processes are complex far beyond our present understanding. Essentially the same process in the lungs gives rise to the acute and often fatal disease, pneumonia. But when pneumonia is examined, even in the light of our present imperfect knowledge, attention being paid to the particular germ giving rise to the infection, and the qualities and distribution of the reaction material in the lungs, it is easy to discriminate more than ten essentially independent kinds of extensive and severe inflammations of the lungs, which would be properly designated by the practicing physician as pneumonia.

It will readily be understood, therefore, that when an attempt is made to deal with the points of contact and mutual influence of two such allinclusive and infinitely complex assemblies of phenomena as those of inheritance and of disease, it cannot profitably be done solely with reference to general principles. Nor would it be useful in this place to attempt a very detailed account of what is known. The plan adopted is to try to give an outline of principles where these are discernible and to illustrate them with such concrete examples as may be most informing to the general reader.

\section{N F ECTIOUS DISEASES}

As previously pointed out there is in the rigid sense no such thing as the positive inheritance of an infectious disease. This lies in the nature of the case since the impelling incident in such a disease is the entry of an agency: germ, bacterium or protozoan, from the environment. None the less, the inheritance is of very vital significance and within certain limits absolutely controls the prevalence of these diseases. This is true when we approach the question from a wide biological viewpoint, regarding species lines. It then becomes in truth a matter of common knowledge. It is probably quite correct to state that each distinct species of animal or plant has 
certain diseases which are peculiar to it, and neither naturally nor artificially transmissible to any other species. Influenza and malaria are fair examples of such diseases of human beings. Asiatic cholera is another. Many cases may be cited in which species lines are not rigidly respected and are yet very influential. Smallpox is such a human disease. It may spread to milch cattle under suitable conditions, but in them produces a modified type of disease similar to the naturally occurring cowpox. Rabies is widely disseminated among the domestic animals, is very frequently transmitted to man but is not known as a disease of birds.

The questions at issue really become debatable when we consider the relation of the racial, familial or individual inheritances within the species. It is now clear that here the lines are much less rigid. There are very certain instances, particularly among plants, where families or strains within the race are quite immune to a particular disease from which the race as a whole suffers most severely. The rust-resistant varieties of wheat and asparagus are familiar cases. Similar cases can be made out among animals. There is no certain instance of an infectious disease affecting one or more race of the human species and leaving another untouched. There are a number of instances when it seems that certain races are less susceptible than others to particular diseases but even here it is impossible in the present state of knowledge to be sure of the significance of the cases. Racial habits as to diet, for example, and the continued state of contact with the disease are apparently influential factors about which there is as yet insufficient information.

When we turn from the race to the individual, vision apparently becomes clearer, for there can be no doubt that with reference to most infectious diseases there are wide individual variations in resistance.

But if we go back for a moment to an earlier period we find a fixed and universal opinion that certain infectious diseases follow family lines to a considerable extent. This is not true of measles or smallpox. It seems conspicuously true of tuberculosis. Most of us can doubtless call to mind families in which severe illnesses and deaths from tuberculosis have been common, and other families in which they have been rare. Large groups of family histories have been collected and submitted to the best available mathematical analysis and these have also given evidence of some difference in the inheritance. But it is also known that under conditions of universal exposure as in crowded cities, practically all individuals have some tuberculosis at some time or other. The disease is one which often lasts in individual cases for years or even through a long lifetime. There is obviously unusual opportunity for infection to follow a family in which it is established. In the face of such considerations on the contrary side, it cannot be maintained that such studies of human family histories as have been made absolutely decide the matter. They do give evidence, however, that familial differences in resistance exist. 
The studies of human material from the pathological standpoint show, as has been said, that most individuals become infected with tuberculosis at one time or another and it may therefore be concluded that neither in kind nor degree are the inherited factors capable of preventing infection. They must, therefore, be exerted on the progress of the disease after the body is invaded by Bacillus tuberculosis.* The direct evidence at present available from human sources does not carry us beyond this point.

In the guinea pig it is found that there are inherited factors which influence the quantity of antibodies (antitoxic substances) which are produced in response to a given stiniulus. There are other inherited factors which influence the severity and precise quality of the ulceration which the tubercle bacillus and some other irritating agents produce in the skin, and in the character of the tuberculous inflammation in the lymphatic vessels and glands. There is also an indication of another group of separately inherited factors affecting the nature of the reaction to dietary deficiencies.

Granted that there are inheritable factors influencing the character of tuberculosis in the individual, any clue as to their dominant or recessive quality is a matter of great interest. Unfortunately the human material lacks the precision of detail necessary for an answer to such a question. The guinea-pig material suggests that where all of the characters favorable to resistance are combined in a family it presents a dominant combination. The first generation crossbreds are as resistant as the most resistant family. In the actual observations they somewhat surpass this mark, indicating the operation of those forces which make for heterosis or hybrid vigor. Where crosses are made between families of less than the maximum resistance the result varies. Some crosses produce offspring as resistant as the better family, another produces an intermediate resistance. In general, dominance of resistance prevails but it is imperfect.

With the coincident and tremendous improvement in hygienic conditions and nutritional well-being in Europe and especially in America, tuberculosis and the minor infections referred to have a greatly diminished prevalence.

A generation ago the general conception of the fundamental nature of inheritance was that it was a blending or fusing of the parental characteristics, stronger characters being diluted by weaker. The cases which such a blend did not explain were regarded as unaccountable exceptions. Then the work of Mendel was revived and it was seen that when inherited qualities were sufficiently analyzed into their component parts the blended was rather the exceptional occurrence. But instances of blending inheritance could not be gotten over or disregarded and it seemed to some students that there must be two principal forms of inheritance. These views have been quite completely harmonized by further study. In the

"Now known as Mycobacterium tuberculosis.-Ed. 
obvious Mendelian case a particular character, which to familiar scrutiny is simple and definite, is controlled by the presence or absence of a single inheritable unit known as the gene. Color in animals, eye color in man, tallness or dwarfness in the garden pea are such characters and their study clearly defined the Mendelian principle in inheritance. Skin color in man if albinism is contrasted with the presence of any pigment is similarly controlled.

But skin color among the pigmented of the human species, tallness or shortness in the human race (excepting particular types of dwarfism), the weight or ear length in rabbits and innumerable other conditions are at first sight not so controlled. The result of a cross between individuals of widely different character is usually a "blended" or intermediate state in the offispring. While it was difficult at first, as has been said, to fit these cases to the Mendelian hypothesis it is now apparent that blended inheritance means that the character as expressed in the individual is the resultant of the combined and overlapping functional expression of the action of two or more genes. It now is the consensus of opinion among students of heredity that this is the true significance of blended inheritance. Mendelian principles are as strictly applicable as in the more obvious instances but more than one, often many, unit characters are involved in the make-up of the observable quality. This is evidently the condition underlying the inherited factors in resistance to tuberculosis.

\section{CANCER AND OTHER MALIGNANT TUMORS}

In general the state of our knowledge of the factors underlying the occurrence of malignant tumors is not dissimlar to that with regard to tuberculosis. The evidence from human sources is of about the same order but less significant on the whole. Tumors have been alleged to frequent occasionally certain families while others remain quite untouched. In the mass there is the sporadic, occasional appearance of a tumor case in most family histories. Cancer is not believed by most authorities to be an infectious disease although the fact that it can apparently be initiated in man and animals by chronic irritation with various substances, even by various parasites, creates many resemblances between tumors and infections. If the tumors classified as sarcomata are included there are cases in which the utmost consideration of detail fails to reveal any precise reason why they should not be accepted as infections; and yet because of that fact that these appearances suggesting infection are the exception rather than the rule, most scientists hold in reserve the thought that even in these cases it is more than possible that some other explanation will be found, that eventually it will appear that all the true malignant tumors (including most forms now classed as such) will be found to originate in causes resident within the body.

Tumors bear a certain resemblance to infection in that those which orig- 
inate in animals are of ten transferable to other animals of the same species by a succession of transplantations of the tumor tissue, or in some instances by extracts of this tissue containing no intact body cells. The conditions governing the transplantation are such as to make the influence of inheritance very apparent. These tumors are never transferable outside the species of animal in which they originate. For instance, mouse tumors can only be propagated in mice. Within the species they are transferable with great difficulty when at all, from one race to another.

This variation in resistance has been the subject of thorough genetic experimentation and analysis in certain instances. When the Japanese waltzing mouse and the common tame mouse were compared it was found that their differences with respect to tumor transplantability across the race line must be under the influence of at least twelve separately inherited unit characters. The reasoning applied to the case of tuberculosis in the preceding paragraphs holds here. We should expect the familial evidence for inheritability in the human race to appear only very occasionally. Even less is known about the fundamental nature of the inherited characters in tumors than in tuberculosis.

There is also a great deal of evidence that the incidence of spontaneous malignant tumors in animals is quite dependent on the inheritance.

\section{DISEASES BASED ON ABNORMAL SENSITIZATION}

A number of disease conditions, all troublesome and some very serious, asthma, hay fever, and various "idiosyncrasies" against particular articles of food or particular drugs have been found to have certain features in common. They are alike in that they are all unusual reactions to particular substances found in the environment which do not affect most people in any harmful way. Of those suffering from the condition some react only to a single substance, others are affected by many substances. The diseases are so common as to be familiar to most people and place need not be given here to any detailed description of them. The simplest, and in many ways most characteristic, is urticaria, or hives. Most people suffer at one time or another from this trouble. Some people always have it as a consequence of eating a particular food, e. g. strawberries, eggs. The skin becomes blotched and irregular wheals are raised above the general level of the skin surface by reason of the fact that the skin in these areas is swollen. The swelling is due to fluid in these areas having left the blood vessels and stagnated in the tissue spaces. In asthma the same general process occurs but the area affected by the swelling is the smaller air tubes in the lungs and these are partly closed, making breathing difficult. In hay fever it is the mucous membranes of the eyes and nose which are affected.

Inquiry has disclosed a well-marked familial influence in these conditions. They are in some measure inherited. The inheritance seems to be based on recessive characters in the Mendelian sense. There is a certain 
difficulty in this interpretation, however, in that not all the offspring of matings with both parents diseased are afflicted. This is susceptible of alternative explanations. It may be that the inheritance is dependent on multiple factors in which case the line between dominant and recessive is not necessarily clean cut. Some characters may be dominant, others recessive and the actual behavior of the individual is the result of a kind of balance.

Another possible explanation is that the disease itself is not inherited but only the liability to contract it. That is to say, an individual potentially sensitive by reason of inheritance may escape the influence of the environmental factor and never reveal his latent tendencies.

\section{DISORDERS AND DEFECTS OF THE CENTRAL}

\section{NERVOUS SYSTEM}

Popular interest in inheritance, alike of normal and abnormal qualities, naturally reaches its highest when the nervous system is considered. From the medical point of view we are here dealing with the diseases referable to a single organ. Gross defects of development occur and are likely to be lethal before their general effects on function can become manifest. Finer defects in structure may well be common but may escape recognition. The brain and spinal cord are affected in the course of infectious diseases which are to be considered as general infections, and also are the seat of infections primary in or affecting, chiefly themselves, e. g. poliomyelitis, encephalitis lethargica, and cerebrospinal meningitis. With reference to these what has been said with regard to the inheritance of immunity or susceptibility to infectious disease generally doubtless has some application in principle but we have no specific knowledge of inherited influences in the particular cases. The functional disorders of the nervous system are manifest in almost infinite variety and the study of them has gradually become a very intricate specialty. From our present point of view only certain outstanding selections can be considered for purposes of illuştration.

Feeblemindedness has a peculiar interest. The condition (one, it may be supposed, of limited development) rests in some instances on an inherited basis as made evident by careful and competent scientific investigation. Is feeblemindedness a disease? Obviously it may be so regarded in the social sense, since on a purely practical basis a highly developed society is forced to maintain large institutions for the care of such of its offspring as are unable to maintain the pace. From the pathological standpoint it is hardly to be looked upon as a disease except in the most extreme or particular instances. But when one begins to discriminate on a quantitative basis all the standards must be arbitrarily chosen. The question clearly becomes an academic one when purely practical standards are disregarded. 
The same may be said of many types of insanity. The discrimination between sane and insane in general is possible on a legalistic and practical basis, however difficult decision in particular cases may be. A perfectly sharp borderline in the scientific sense can hardly be drawn.

But insanity presents another aspect, in that there are certain disorders of the nervous system characterized by definite symptomatic behavior which clearly define them without reference to their severity or, in other words, whether the sufferer is incapacitated or not. The most widely illustrative perhaps is the disease known as essential epilepsy. Those most slightly affected may not only be not incapacitated but may be mentally quite normal or unusually brilliant people. Those most severely affected are or frequently become unquestionably insane. In its mildest forms or in its most severe, the symptomatology is characteristic. The difficulties of recognition in the mild cases are due to the fact that the slight symptoms long pass unnoticed. This disease is inherited in many cases, and apparently usually as a Mendelian recessive. There are indications of sex linkage in some instances and it sometimes appears as a dominant. Multiple factors are probably involved. Other forms of insanity equally well characterized are recognized and some are probably inheritable.

\section{O N G E V I T Y}

It has been increasingly recognized of late that the length of life of the individual is a measurable biological phenomenon, the analysis of which might uncover very interesting facts. It is, of course, a common impression that length of life is determined in considerable measure by inheritance. Some families are thought to be notably long lived. That the condition is counter-balanced by equally well-marked short lived families is possible but this is in the nature of the case less easy to be sure about. When an individual lives a long time we think naturally of his constitution as a responsible factor and when his ancestry and immediate relatives also survive, the constitutional factor becomes more and more apparent. But when an individual dies young, the disease of which he died or the accident of fate which carried him off is the impressive feature. Suffice to say that observations on selected families of animals, fruit flies and guinea pigs particularly, have shown that length of life whether short or long is a definite family characteristic and have given us some clues regarding its hereditary transmission.

Hypothetically if the human race were comprised exclusively of those we know as long lived such diseases as tuberculosis and typhoid fever would be unknown or would be recognized as disorders, disturbing but not especially dangerous to life. Whereas if the population were exclusively of the short lived, cancer, arteriosclerosis and many other diseases would be practically unknown. 


\section{ASSEMBLAGE OF CHARACTERS AND.QUALITIES}

Throughout this presentation it has been evident that the essential characters on which the inheritance of disease depends are separately transmissible units of an almost endless variety. In some few instances one such unit may completely control a disease condition. But in most cases not only is the disease itself only partly influenced by the inheritance but even that part is controlled by a number of separately inheritable unit characters. Our present knowledge fails completely in so far that in no single instance does it furnish a perfect insight into the fundamental nature of even one of these inheritable units. The task for the future is obviously enormous if we are to gain a usable understanding of the inheritance of disease on the basis of rational knowledge. We require to know for the different disease conditions the precise part played by the inheritance in toto; the number of unit characters involved for each case, and their structural or functional nature. It may well be, however, that the obstacles which intervene between our present understanding and a much more perfect and useful one are lessened by some favoring circumstances which may be sketched.

While it is considered fundamental that unit character is distinct in inheritance, certain definite instances are known where diverse characters are usually inherited together. This is termed linkage. Thus in hemophilia (which is manifest by failure of the blood to clot, so that those affected are "bleeders,") the disease condition is linked with the factors determining the sex. It is also true that a single unit character is sometimes known to be concerned with a variety of structures or functions although the author is unable to point out an example of this nature with reference to any disease condition.

From the point of view of pathology, also, there are rather clearly outlined associations between certain structural peculiarities and disease conditions, excluding cases previously outlined where the disease is directly dependent on a particular fault of structure. There are also recognizable tendencies for individuals and families to suffer from or be relatively immune to groups of diseases. Thus the tall, thin, flat-chested type of man is believed to be more liable to acquire tuberculosis. People who suffer from rheumatism and gout are believed to be less liable than the average to acquire tuberculosis. Most of these relationships are, as at present recognized, of the uncertain order resting on the impressions of successive generations of physicians. Yet recent approaches to the subject on the basis of careful measurements, accurately recorded case histories and adequate statistical analysis lend credence to the belief that there is a real and traceable set of associations here which it will be worth while to develop by further studies. Up to now the interest had chiefly centered on recognizing certain 
anatomical types of people and trying to correlate with these the diseases from which they have suffered. The recent work of Draper who approached the question by taking typical cases of certain diseases and studying the physical conformation seems to promise more definite results. Of similar import and carrying even greater suggestion of future interest are observations indicating that the blood grouping, a functional inheritable manifestation developed under definite conditions between the blood cells and the blood serum, is associated in the inheritance with the natural immunity to diphtheria toxin or with the capacity to be immunized against this poison.

Our general culture, our freedom from certain infectious diseases may alike be immediately and largely a matter of social inheritance. Our liability to those diseases, defects, and discomforts which are controlled by the physical inheritance must always be based directly on the qualities of the germ plasm transmitted from father and mother to their children and so to their grandchildren.

We can perhaps sterilize certain obvious defectives and so minimize the economic burden imposed by the maintenance of institutions for their care. But we cannot so durably solve the problems imposed by the fact that disabling defects, diseases and tendencies to the development of disease are inherited. The faulty germ plasm considering the multitude of distorted conditions is too widespread for this. The ancients when they wished to completely subjugate a conquered enemy people "decimated" the population. This seems to be the ultimate which cold-blooded immediate destructive human purpose can achieve. It is doubtful if we shall ever be persistent enough to interfere radically with the propagation of Io per cent. of the defectives even in cases where there is complete agreement as to the need for such measures.

Recognizing the wide distribution, the completely individualistic character of the faults in the germ plasm, it seems that most rapid progress can be made through the development of the individual understanding and conscience. The appeal to family pride has been a most potent force in the past, and one which it may be feared the present unduly loses sight of.

Family pride is likewise regarded as undemocratic. But in terms of generations we can pass to our descendants as we choose a democracy of the unfit or one of the highest personal and social accomplishment. To the development of this end the study of the detailed manner in which diseases or the influences controlling disease incidence are transmitted in inheritance is likely to prove an increasingly useful and stimulating force. At present and doubtless in the end the practical guide to individual judgment would appear to lie in the stem of longevity. A short lived strain may be fundamentally healthy, a long lived one must be at least superior. When this complex of physical attributes is balanced with the knowledge of the 
presence or absence of certain particular diseases in the strain and the whole weighed with a rating for success with the business of life, the basis for the intelligently prideful propagation of the family may be well laid.

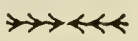




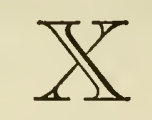

\section{Eugenics}

$\mathrm{E}$ UGENICS is the science which has for its aim the improvement of the human race. The cabbage has been developed from the scraggly cliff cabbage of Europe, the carrot has been selected and reselected from a worthless plant known as Queen Ann's Lace, high-powered hens have appeared by the efforts of man from a tough jungle fowl of low egg production and the improvements in dairy and beef cattle are familiar to all. Man is, of course, making great efforts to improve himself mentally and culturally but the great and important problem dealing with the control of certain mental illnesses, and other hereditary defects has not been attacked with nearly the same vigor.

There are probably over five million feebleminded individuals in the United States and, in addition, several million having other inherited defects such as Huntington's chorea, insanity, and epilepsy. Of course, not all feeblemindedness and epilepsy are inherited. Over twenty states have laws permitting the sterilization of people with these defects thus preventing them from passing the defects along to the offspring. California is probably the only state which makes any attempt to enforce these laws adequately. Sterilization is not a panacea and will not eradicate these defects from the fopulation but it will reduce the number greatly and also the cost of caring for the children of these people.

Segregation of all the feebleminded is just about prohibitive from the cost standpoint. California segregates defectives as much as possible and the idea is to sterilize them before release. In this way they may marry and become a part of normal society but cannot procreate any defective children.

An interesting possibility is that through our present knowledge of tissue culture the sperm-producing tissue of great men can be kept alive for an indefinite time and a family may then decide to have a child in the family sired by a superior person, by artificial insemination of course. This plan would be only a novelty unless such superior germ plasm was used in superior females to produce a group of superior children, in a favorable environment. 


\title{
SOME BEARINGS OF GENETICS ON
}

\author{
HUMAN AFFAIRS *
}

\section{O T T O L. MOH R}

INTERMARRIAGE AND CROSS-BREEDING

A series of fundamental problems has, thanks to our modern knowledge of heredity, come into an entirely new light. This applies, for instance, to the old question of inbreeding. There is a widespread popular belief that intermarriage, e.g., marriage between first cousins, is to be advised against, since occasionally unfavorable results are seen. On the other hand there is ample evidence, also in human material, that intermarriage has no harmful effects at all. As historical examples of very close inbreeding in man, the brother-sister marriages among the Ptolemaic family of old Egypt as well as among the Incas of Peru and the Aztecs of Mexico may be mentioned.

The question is of foremost importance, and an enormous amount of experimental work has been devoted to its solution. The results of these investigations may be summarized thus: inbreeding as such has no harmful effects at all. On the contrary, the astounding progress within animal breeding has been mainly based upon close inbreeding among the offspring of a limited number of prominent sires. In this way we are able to "recapture" as many valuable genes as possible of those carried by the prominent sire in question. Valuable genes, this is the nub of the problem. If an undesirable recessive gene happens to be present within the family strain beforehand, then inbreeding will favor the occurrence of individuals that receive the undesirable gene in double dose, in which case the corresponding harmful character will come to light. The unfortunate results sometimes seen in consanguineous marriages are in other words not due to inbreeding as such, but to the presence of undesirable recessive genes in heterozygous condition in the antecedents of the family. Conversely, if the hereditary factors in the family are good, then even close inbreeding will give valuable offspring.

\section{THE B L UE B LOO D}

Some people are proud when they are able to trace their pedigree back to the portrait of a remote ancestor. From a genetic point of view such "pedigrees" are rather comic. Disregarding possible cases of intermarriage, we have already 64 ancestors in the sixth generation. What does it matter to know one of these, when the rest, the 63 unknown ones, are genetically equally important? If we go the other way, trying to con-

* Reprinted from Heredity and Disease by Dr. Otto L. Mohr by permission of W. W. Norton and Co., Inc., New York. Copyright 1934, by the publishers. 
struct family trees comprising all our ancestors, we do not get far back until we meet persons who, both in personal and social respects, would be regarded as rather undesirable relatives by the present bearers of the family name. Such an investigation is not apt to pronote our respect for the so-called "blue-blood."

On the whole, persistent misconceptions are wide-spread in the fields with which we are dealing. Some of them even have nothing to do with heredity. This applies for instance to the belief in telegony, after-effect, which even Darwin shared. Dog-breeders have been particularly prone to this belief. It is thought that a bitch that by accident has been mated with a male dog of another breed is spoiled, useless for future pure breeding. Now when we know the mechanism of fertilization it needs no explanation that this belief is entirely absurd. Mating, and the fact that a litter of mixed breed has stayed temporarily in the uterus of the bitch has of course not the slightest influence on the germ cells present in her ovary and the genes which they contain.

\section{MATERNAL I M PRESSION S}

More serious in its consequences is the old deep-rooted belief in "maternal impressions" which has caused much unfounded self-reproach among conscientious mothers. Everybody has probably met with the popular conviction that if a pregnant woman happens to see the head of a hare, there is imminent danger of the coming child developing harelip, or even cleft-palate. Birth-marks are traced to burns acquired by the mother, in corresponding locations, and temperamental deviations in a child are attributed to the mother's distress or loss of temper during pregnancy. Conversely, I know of a case in which the husband systematically took his newly married wife to fine concerts in order that the expected child might be musical in contrast to the parents. No wonder that he was badly disappointed at the results of the treatment.

One might expect that it would be comparatively easy to persuade people that external influences of this sort do not penetrate deeply enough to produce changes in the child, which, as an independent individual, happens to spend the first nine months of life as a parasite within the mother's body. But as a matter of fact, according to my experience, it is exceedingly difficult to persuade the parents that the fate of the child in these respects is irrevocably determined already at fertilization, when the two germ cells meet.

\section{S T E R I L I Z A T I O N}

In the United States, up to 1933 , about 16,000 persons had been sterilized because they were for different reasons considered unfit for propagation. But an American committee estimated that no less than i 5 million persons ought to be sterilized up to 1980 , starting with roo,000 a year and increas- 
ing the number up to 400,000 annually. Lenz in Germany regards ro per cent. in each generation as a by no means too high percentage of sterilization. But he even regards "ausgesprochene Hässlichkeit," translated ugliness, as a proper indication for this procedure!

The effect of sterilization is at best very, very slow. To take a single actual example (after Hogben): One of the best known recessive pathological traits in man is ordinary albinism, lack of pigmentation of skin and eyes. This anomaly has an incidence of less than $1 / 100$ per cent. If sterilization of all albinotic individuals was carried out in every generation, it would require a period about equivalent to the Christian era to reduce its incidence to one-half of its present dimensions, a simple consequence of the fact that the heterozygous carriers continue to transmit the gerie.

These examples are not quoted as arguments against sterilization proper. Its application is advisable not only in the relatively few cases in which by this method we may prevent dominant defects from being transmitted to the offspring, but also because irresponsible defectives like imbeciles or schizophrenic individuals are entirely unfit to serve as parents and educators of children, even though we cannot predict that their children will be similarly affected. It should also be remembered that in several cases, as for instance in schizophrenia, the fecundity of the affected is by itself so reduced that, as Nissen's statistics from Norway show, we must assume repeated mutations of the causative genes in order to account for the fact that schizophrenia has not been eliminated by nature's own virtual sterilization of the affected. On the whole, those who are affected with really serious hereditary abnormalities do not propagate at a rate that is sufficient to keep up their number.

\section{B I R T C ONTROL}

It is frequently stated that the widespread application of contraceptive methods will lead to "race suicide" by lowering in a selective way the productivity of the best germinal material. The advocates of this view simply take it for granted that the best germinal material is represented by the "good families," the upper social strata, among which birth control, as is well known, has been most generally applied.

If this view is correct the upper classes would, so to speak, have attained their favored position by natural right, by virtue of their superior genotypical quality, a conception that has been illustrated by the following metaphor: The population is compared to a container filled with milk, a fluid in which larger and smaller fat drops are dispersed. After a while these drops of fat will float to the surface, and the largest, fattest drops of fat will form the upper layer of the cream, the crème de la crème of the French.

From a biological point of view this metaphor is entirely misleading. Let us assume that a particular individual, due to his superior genotypical 
equipment, has been able to fight his way from the proletariat to the propertied class. Here he marries. There is nothing to guarantee that his wife will be on an equally high levvel genotypically. Moreover, when his germ cells ripen, segregation, the very principle of Mendelian inheritance, insures that this valuable combination of genes is again dissolved, and his genes will enter new combinations in his children. These children may very well be quite ordinary as regards their genotypical quality.

But, thanks to better nourishment, better opportunities and training, it is much easier for individuals born in an economically independent class environment, even though genetically mediocre, to remain on the social level of their parents, than it is for an individual of superior genotype to overcome the handicap involved in an unfavorable environment with limited opportunities.

If this is true, this argument against birth control loses its weight. At any rate, an appeal to the intelligent and responsible circles to effectively increase their number of children is futile. The only way open in order to counteract an assumed selective birth rate is accordingly to spread the same information among the poor because every child ought to develop in a good environment. And this goal cannot be attained if we give natural fertility its free course.

THE ATTITUDE OF THE PHYSICIAN IN QUESTIONS OF HEREDITY AN D DISEASE

The individual medical practitioner is most frequently consulted as to the possible consequences of marriage in cases where one or even both partners belong to a family in which the pathological hereditary traits occur. He may, by aid of one of the now existing text-books on the known pathological hereditary traits in man, give valuable advice in quite a few cases. But his judgment should always be given with the reservation involved in the fact that genetics primarily deals with probabilities.

A frequent question is whether a normal person belonging to a family in which a recessive pathological trait occurs may be expected to beget affected children if he marries an unrelated individual. This must of course be answered in the negative. As regards serious dominant abnormalities we have presented quite a few cases where affected heterozygous carriers should be advised against propagation, even though the chance of begetting an unaffected child is $\mathrm{r}: \mathrm{I}$. If such an individual nevertheless takes the chance and begets a normal child, then further propagation should be prevented.

Intermarriage in families where dominant pathological traits occur is generally inadvisable. In families where serious recessive pathological traits are met with, such as extreme eye abnormalities and hereditary types of deafness, the risk involved in an intermarriage of two normal, but possibly heterozygous family members should be made clear to the consultants. 
If they prefer to take the chance, which is at worst $3: 1$ in favor of begetting a normal child, I advise against further propagation if the first child is normal.

As regards serious sex-linked anomalies, as for instance haemophilia, I think affected men should be strongly advised against propagation, since their normal daughters are sure to transnit haemophilia to half their sons.

\section{HEREDITY AN D EN VIRONMENT}

It cannot be denied that the establishment of the fundamental fact that the genes are virtually unchangeable by external agencies is somewhat disillusioning. All the valuable acquirements which conscientious parents may accumulate in the course of life are genetically a dead investment. Conversely, however, the same fact involves considerable consolation. Neither are our evil acquirements visited upon our children genotypically. Irrespective of the parent's dissipated manner of life the children may nevertheless in genetic respect get a good start, this start only depending upon the genes which the parental germ cells contained.

It is quite another matter, however, that the evil acquirements of the parents create a bad environment for the children. It is here that their fatal consequences are to be sought. Alcoholism creates a bad environment, a bad milieu, for the children in almost every respect. Grave infections in the parents may lead to contamination of the children. The same holds true for moral dissipation.

We finish as we started by emphasizing that each individual is a product of two sets of influences, the genes on one hand, the environment on the other. Valuable genes may in a bad environment be hampered in their manifestation. Conversely, a good environment may in many cases counteract and eventually suppress the influence of undesirable genes, and effectively accentuate the manifestation of the valuable genes.

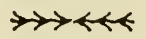

\section{THE ROLE OF EUGENICS *}

\section{E D W I N G R A N T C O K L I N}

Millions of human beings are born so defective in organization that they cannot survive and leave offspring, and although we niay attempt by every means in our power to preserve them we cannot do it. Other millions not so seriously defective we do manage to preserve, with the result that modern society is burdened with multitudes of feeble-minded, epileptic, insane, deaf, blind, and deformed, some of whom at least transmit these defects to their children. It is because of the weakening of natural selection

* Reprinted from Man, Real and Ideal by Edwin Grant Conklin, by permission of Charles Scribner's Sons, Copyright 1943. 
that the human race contains so many defectives. Galton ${ }^{1}$ said, "Our human stock is far more weakly through congenital imperfection than any other species of animals, whether wild or domestic."

Unquestionably this greater imperfection of modern man is the result of nullifying the law of natural selection, so far as that is possible, and of failing to replace it by intelligent human selection. Throughout the course of past evolution, the perfecting principle by means of which animals and plants have been prevented from deterioration, and have been adapted to changing environments, has been the continual elimination of the less fit and the perpetuation of the more fit, that is, the Darwinian principle of natural selection. But by means of his intelligence and inventiveness, modern man has often succeeded in preventing the elimination of the unfit, and by the most extraordinary efforts has preserved the lives of the diseased, defective, delinquent, and insane, and has permitted them to breed as freely as they can, with the result that, whenever any of these defects are hereditary, they are passed on to future generations. Thus arise families and stocks characterized by hereditary feeble-mindedness, epilepsy, dementia, deaf-mutism, some types of blindness, haemophilia, muscular atrophy, and numerous other defects of practically every organ-system of the body.

To eliminate such defective stocks by their ruthless destruction, as occurs in nature and as was practiced in ancient Sparta, would violate our social sentiments of mercy, compassion, and charity. But the preservation of the lives of the unfit does not necessarily require that they should be permitted to leave offspring and thus to perpetuate hereditary defects. It is right and proper that society should care for those of unfortunate inheritance and thus set aside the hard rule of the elimination of the unfit, but it should replace the ruthless process of natural selection by the humane method of intelligent human selection of those who are permitted to procreate their kind. This is the program of eugenics, and although we hear less about this now than we did a few years ago, there is much evidence that it is making progress, not merely in legislation providing for the segregation or sterilization of defectives, but much more in the general and serious concern of prospective parents that their children shall be "well born." The increasing burden of caring for defectives will surely lead to increasing efforts to protect society from this burden, and to more rational customs of preventing the propagation of hereditary defects, and thus to more scientific methods of population control.

This is a program which is already in force in many enlightened societies. Persons showing the most serious hereditary defects are in many states prevented from passing these on to offspring by segregation of the sexes in public institutions, or more rarely by sterilization. But those enthusiasts who think that a new and better race can be produced in this way do not

${ }^{1}$ Francis Galton, Essays in Eugenics, 1909. 
consult reality or reckon with statistics. No breeder of domestic animals or cultivated plants would ever expect to improve his stock by such feeble methods. They are necessary to prevent further deterioration but they offer little or no hope of great improvement.

The difficulty, or rather the impossibility, of any more radical program of eugenics than is involved in the gradual reduction of the fecundity of the worst human types and the encouragement of greater fecundity in the best types makes it extremely improbable that any great or rapid improvement in the inherited nature of the human race can be produced by eugenics. It is relatively easy for the breeder of animals or plants to choose the types which he wishes to propagate and to make new combinations of desirable traits, but the case is far different in man where in the main restrictions on reproductions must be self-imposed, where there is little uniformity of opinion among different peoples and in different times as to what is the best human type, and where social and moral customs are at variance with the best methods of the breeder.

Alexander Graham Bell, ${ }^{2}$ inventor of the telephone, was a skillful breeder of sheep and was also greatly interested in human eugenics. $\mathrm{He}$ had found that he could by selective breeding produce a breed of sheep in which twins were produced at almost every birth, and then by further selection, ewes with four functional teats, instead of two, were produced. But he pointed out the differences in the technique of sheep-breeding as compared with the social conditions governing human reproduction, by supposing that the sheep breeders were compelled to observe the customs which prevail in the most advanced human society, namely (I) all must be allowed to breed and none must be sterilized, (2) weaklings and deformed individuals must receive special care and must be permitted to propagate, (3) polygamous and consanguineous unions must not be permitted, (4) every individual must be allowed to choose its own mate and for life. Under such conditions, he says, no improvement in a flock would be possible, and as long as these social conditions prevail among men no hereditary improvement in the human stock will be possible. But already the first and second of these social customs are being abolished or changed in the most enlightened societies, either by sterilization, segregation of the sexes in public institutions, or by the less drastic method of the social taboo. It does not seem probable that in a free society the third and fourth of these social customs will be abolished, even for the purpose of breeding a race of supermen. Methods of negative eugenics, that is, the prevention of the breeding of defective stock, offer no hope of race improvement, but only prevention of further deterioration.

A much more potent means of race improvement, indeed the only means of improving inherited traits, is by the positive method of breeding

2 A. G. Bell, How to Improve the Human Race, Jour. Heredity, 5, I-7, 1914. 
from the best stock. So far as the human species is concerned this is a counsel of perfection, but at least a gain would be registered if the fashion could be established in society that leaders in thought and action would be expected to have large families, and that, when they do not, it would be generally recognized that they carry some secret hereditary defect. That such a social consciousness or fashion can be established is shown in many countries of the East, where the continuance of the family is held to be the highest social and even religious obligation, but where too little attention is paid to hereditary quality.

A radical system of both negative and positive eugenics was introduced by the Nazi regime in Germany in the 1930's. It was based on the best technique of animal breeders and with little regard to social traditions or moral considerations. In so far as it provided for the legal sterilization of the most defective human beings it was not unlike methods proposed, but rarely enforced, in other countries, but in the field of positive eugenics it showed all the faults and dangers of prejudice, intolerance and ignorance that might be expected in a dictatorship. There is no reason to think that the ideals of such dictators, as to what constitutes the best human types, are progressive, wise, or just. There are too many unknown factors as to what may be needed in the near or distant future, even if their ideals were the very highest possible at present. Furthermore good and bad hereditary traits are so mixed in all men and the possible permutations of these in offspring are so numerous that their transmission is wholly incalculable. Add to this the well-known fact that slight and incalculable changes in environment and training have profound influences on development, and we see that no one is wise enough to foretell what the physical, intellectual, or social worth of his own children may be. Who would have been able to predict from their hereditary antecedents and their early environment and training the development of such men of genius as Beethoven, Schubert, Keats, Faraday, Franklin, Lincoln? And when we add to all these impossibilities of predicting who will be the fittest to inherit the earth, the prejudices of family and class, or race pride and arrogance among those who would attempt to control the breeding of men, we may be thankful that nature has so successfully concealed her methods of producing genius.

Long ago Darwin ${ }^{3}$ expressed to Galton his doubts as to the feasibility of any satisfactory method of selecting the best human stocks, and Huxley ${ }^{4}$ pointed out the difficulties and dangers of permitting any individual or class of individuals to decide which human families are the most fit. $\mathrm{He}$ wrote:

${ }^{3}$ Charles Darwin, More Letters, Vol. "2," p. 43. Appleton, New York, 1903.

${ }^{4}$ T. H. Huxley, "Evolution and Ethics, Prolegomena." Collected Essays, Vol. 9, p. 39, Appleton and Co., New York, 1898. 
I sometimes wonder whether people, who talk so freely about extirpating the unfit, ever dispassionately consider their own history. Surely one must be very fit indeed, not to know of an occasion, or perhaps two, in one's life when it would have been only too easy to qualify for a place among the unfit.

In the present temper of the world the human species would not be improved by the wholesale sterilization of those persons, nations, and races that conquerors and tyrants may proscribe-even if such a thing were possible. When class, national, and racial hatreds are rampant, there is no possibility that a scientific program of eugenics can be wisely enforced. Instead of intelligent mate selection and ethical education aimed at producing the best physical, mental, and moral qualities, we see at present in certain countries a return to the law of the jungle, with natural selection operating on the lowest plane of physical strength, cunning, cruelty. This is "Nature red in tooth and claw," for those distinctively human and civilized qualities of reason and altruism. It is a return to conditions of savagery and barbarism which prevailed in the early history of human society, survivals of which still persist. In the modern world, competition has led to the seizing of the best parts of the earth by the most aggressive and powerful types, such as Arctic areas, desert wastes, tropical jungles, and barren mountains: or, within a single society, to slums, ghettoes, and marginal lands. It has led to the enslavement or exploitation of certain races, tribes, or classes by others, in accordance with what has been called

\section{Nature's simple plan}

That those should take who have the power And those should keep who can.

Whether all mankind can ever become really civilized is a serious question. Certainly it will not be accomplished by breeding perfect brutes, nor, on the other hand, by eugenical sterilization. Of course science recognizes the importance of good environment as well as of good heredity. All that heredity contributes are genes, factors, potentialities. These potentialities become realities only in the process of development and development is controlled not only by genes, but also by all the environmental conditions under which genes function. Thus environment, no less than heredity, enters into the results of development. This is especially evident in the later development of human beings, when example, instructions, habits, the desire of approval and fellowship are potent factors in shaping character. New-fangled eugenics will never replace old-fashioned education, but each should supplement the other.

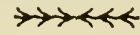




\section{1}

\section{Evolution}

7 HE question of man's origin is as old as man's reason. Our main method 1 of attack seems to be an ever-intensifying search for ancient men and missing links. Comparatively speaking only a handful of men are engaged in the search. Whereas many skeletons of early man have been turned up in various parts of the world we still do not have a clear picture of man's ancestors.

Speaking broadly, the old controversy regarding the fact of evolution is dying down. However the method of evolution is still a subject of much debate. Whatever the name of the theory, the mechanism seems to be gradually centering about the hereditary units, the chromosomes. The genes themselves are apparently subject to change or mutation thereby producing new effects. Chromosomes may become changed in number in individuals through failures in the reduction cycle or through hybridization or crossing.

The layman is often heard asking the question "is evolution going on today and if so where?" As Darwin correctly pointed out, evolution is a slow process and it is as difficult to observe as the gradual descent of the glaciers in the ice age was to the animals of that time. However, plant and animal geneticists have started interesting lines of research here and have found that they can hasten the natural process considerably by species crossing, genera crossing, $x$-rays and other methods. Actually several score of new species of plants and animals have been "created" in this way, many of them perfectly fertile. This is rather a new avenue of approach and the future is very bright indeed for an increase in our knowledge of evolution.

\section{THE AGE OF HOMO SAPIENS * W. W. H O W E L L S}

It is customary to speak of the time since the beginning of the Ice Age, or the last million years, as the Age of Man, because its geological deposits are embellished with the stony fruits of human handiwork as well as with

* Reprinted by permission of the Scientific Montbly, American Association for the Advancement of Science. Copyright 1941. 
the fossilized fragments of man's own frame. But this is otherwise a loose term. What kind of a "man" is meant?

As an erect animal newly distinct from an ape, with a growing propensity to reinforce his hands with rocks and sticks, man is probably older than this, by far. De Terra, it is true, believes that the advent of the ice itself, shifting climatic zones southward in Asia and causing a dispersal of the once flourishing ape family into new and varying environments, was the indirect stimulus to the emergence of man from the anthropoids, so that this event, he thinks, must have happened within the Pleistocene period itself. But many students, Hooton being the most articulate, feel that man must have been evolving for several million years at the end of the preceding Tertiary age, using tools of stone which can not even be recognized to-day before getting to the stage of physique and culture which we see in the earliest known remains. Man's age, in other words, is doubtless several times as great as the "Age of Man."

On the other hand, we ourselves, in our present form, constitute one particular and definite species of man, the species Homo sapiens, which must have arisen later on within this total limit of time. He is an advanced type and is distinct from various other known human forms. However, almost all these forms seem to be well above, and therefore later than, the earliest imaginable stage of true humanity, and all may be thought of as lines, gradually separating, which descended from the original human stem. Homo sapiens appeared somewhere as such a line but how old he is, as a species, we do not know. Curiosity as to his age is not simply the mark of a fond antiquarianism, for information on the pace of recent human development would give us a better perspective for the possibilities of future change in mankind. How old, then, is Homo sapiens?

We really can not say, taking the remains alone. If we dutifully repeat only what paleontology has revealed so far, it would seem as though Homo sapiens were very recent. (Actually, we know somewhat more about the age of our nearest neighbor in time, the species of Neanderthal Man.) There is, however, some imperfect evidence that indicates Homo sapiens as being fairly ancient, and there are various abstract considerations and deductions which bear this belief out.

Put purely in terms of skeletal evidence, this is what we know. 1. There is archeological proof of human existence apparently throughout the Pleistocene, running back a million years, to use a figure, or 1,000 millenniums. 2. There are remains of the species Homo sapiens, and Homo sapiens only, going back some 30 millenniums (more or less, actual dates not being certain) to the Cro Magnons, who appeared at the beginning of the Upper Paleolithic, the last portion of the Old Stone Age. 3. In the previous $95^{\circ}$ or more millenniums (the disproportionately long Lower Paleolithic, comprising $19 / 20$ ths of the whole Pleistocene) there were various types of fossil men, but no finds have been made which would prove, with the finality 
of a theorem in geometry, the presence of Homo sapiens. Thus there is a break, at the beginning of the Upper Paleolithic, with no indisputable men of our own species earlier, and no men of any other species after it. The situation is such that only the captious would deny that Homo sapiens existed before the Cro Magnons, who are his first clear manifestation; but on the other hand it is not such that any anthropologist can ring general agreement from his colleagues as to a particular time, whether relatively late or going back toward the beginning of the Ice Age, when Homo sapiens might be said first to have become a distinct species.

Through the long reaches of the Lower Paleolithic there is sprinkled a corporal's guard of human fossils. The Neanderthal species is well represented by finds, especially in the west, which can be referred to the last 100 millenniums or more of this time. Equally well known (for the cranium at least), thanks to recent discoveries, are the Java and Peking types, obviously related to one another and probably dating from the lower middle part of the Pleistocene. Aside from these, the main species are largely single specimens or scraps; the Heidelberg (an early forerunner of the Neanderthals) and Piltdown men, and the undatable Africansthe Broken Hill skull of Rhodesia, and Africanthropus, from the Lake regions. Of all these and certain others none is assigned to Homo sapiens. This gives a picture of several species of man, some of whom at least must have been contemporaneous, though differing considerably. The question is: Did Homo sapiens also overlap any of them in time, or did he, appearing late, arise from one of them, and if so, from which one?

The possible representatives of our own species during the Lower Paleolithic are not many. (There are reasons, however, for not expecting them to be. For example, Homo sapiens has a thin skull, which is less likely to survire in fossil form.) One is the Galley Hill skeleton of the Thames Valley, whose physical type is fully sapiens but whose geological claims to antiquity are impaired by the confusion and carelessness which attended its discovery in 1888 . There are a few other modern looking skulls with similarly sullied credentials. Otherwise the skeletal evidence of early Homo sapiens rests on two finds. The first is the very important Swanscombe skull, also of the Thames valley, whose parts were found in an absolutely certain connection (a rare thing) with glacial deposits and archeological tools which are believed to belong to the second interglacial, in the first half of the Pleistocene. It is thus very ancient, but its establishment as an actual specimen of Homo sapiens has to rest on the crown and back of the head, all else being gone. This is not entirely satisfactory. Most are inclined to accept its validity, and to believe that it legitimizes Galley Hill at last, but some would regard it with acute suspicion, remembering that the back of the ape-jawed Piltdown skull would seem almost equally modern. The other main find comprises skeletons from two caves at Mount Carmel in Palestine, excavated ten years ago and dating apparently from 
the later part of the Lower Paleolithic. In the Tabun cave was found a Neanderthal-like woman with some sapiens characteristics, while the skull cave contained several skeletons of a practically sapiens type but with Neanderthal-like features. The interpretation of all this is likewise in doubt. The discoverers believe that they have found what is perhaps the actual moment of appearance of Homo sapiens, while others think the skeletons represent a mixture of the two species, in which case Homo sapiens must already have been in existence, and probably for some time.

This is not much with which to reconstruct the trail of Homo sapiens into the past after the visible part of it disappears abruptly with the Cro Magnons, or at best becomes pocketed in the mysterious case of the Mount Carmel skeletons. Even if we provisionally accept the Swanscombe skull as a specimen of Homo sapiens, there remains a large gap in time between it and the Cro Magnons, bridged only by a moral certainty. Consequently there is a flourishing diversity of opinion in the whole matter-notice that even regarding the Mount Carmel skeletons alone there are currently two quite different explanations, logically leading to equally different conclusions as to the age of our species. In general there are two schools of thought. One holds that the development of Homo sapiens was independent of that of other species, all of them being considered as a constellation of different descendants of a common source placed well back in Tertiary time. At the other extreme are those who would graft him onto some one of the known non-sapiens forms of man, at some period well along in the Pleistocene.

Neanderthal Man supplies a case in point. Becoming extinct less than 50 millenniums ago, he seems to have ruled Europe for the preceding 100 millenniums at least. A few students think that during his career he gave rise to, or influenced, Homo sapiens. Others feel that this is not so; that his physical unlikeness, in his low, massive head and huge face, is too great, and that he had developed definite peculiarities of his own which are not to be found in modern man and which would therefore exclude him from our ancestry. In spite of all the racial variety of the latter, and a considerable variety of the Neanderthal species as well, there is no actual overlapping of the two stocks in physical form.

Now if there has not been any important connection between the two species in recent times, then it would appear that Homo sapiens existed somewhere outside of Europe, and that his line goes back, parallel to but not connected with that of the Neanderthals, for many thousand years. Does it go back to the Java and Pekin types, or is the same situation repeated here? Probably it is. The Swanscombe skull shows, if it shows nothing else, that a high, vaulted brain case of the sapiens type, whether actually parental to that of our species or not, had been evolved in the human family long before the known period of the Neanderthals, and almost certainly as early as, or earlier than, the backward Java-Pekin 
family. And the always-mysterious Piltdown skull, in spite of its extremely ape-like jaw, has a very human brain case which indicates the same thing.

It is possible to disregard the limitations of the fossil evidence and to take a fresh view of the problem by considering the living races of Homo sapiens as they have probably been in the past. To-day two billion people are spread thickly upon the earth. They are divided somewhat unequally into the conventional White, Yellow and Black, with infinitely weaker representations of American Indians, Australian blackfellows, South African Bushmen, and so on. They constitute different races but all belong, from a zoological standpoint, to a single species. None of these races alone is the type of the species, which is made up of all of them together. In other words the most advanced is not necessarily the most typical. It would indeed be more proper to represent Homo sapiens as a whole by his most primitive manifestation, the native Australian, or by an imaginary form of this sort, which could have become the parent of all living races, as a sort of greatest common denominator.

The picture of the present suffers from lack of depth, because our collections of skulls of various ethnic origins do not go back far enough to tell much of history on a grand scale, and the older remains give us only the barest of indications as to race. Nevertheless, it is clear that before we even begin to trace races back we must modify this picture because of violent changes which must have taken place in the very recent past, in the time since culture really began to develop.

A mere ten thousand years ago, toward the end of the Paleolithic, man knew only the art of hunting. Since then, with the onset of the Neolithic, he has progressed to agriculture, opening a vast food supply to himself; later on, in the Bronze Age and classical times, he has benefited by town life and artisanship, and still later, in the last few centuries, by the subjugation of natural forces to the purposes of transportation and manufacture. These things have occasioned an almost incredible increase in the population of the world. Throughout his previous existence, man could never rise in numbers above what the stable animal population in any region would feed. It can be estimated, from the little that is known about the recent rate of increase, and the population density of present-day hunting peoples, that there can have been only something like ten million beings in the then-inhabited world, compared to the two billion of today. (For example, the New World, most of whose people were relatively advanced in culture, had a population of roughly eight million at the time of discovery.) Now in this tumultuous upsurge of some two hundred fold, it is plain that those peoples who participated in the progress of culture would increase and monopolize the world, while those who remained hunters would continue to be few in numbers and sparse in distribution, or would even face extinction on encounter with a people more advanced.

Ten millenniums is a very short time, being only one hundredth of the 
"Age of Man," yet it has produced this revolution, this amazing upheaval in numbers and in attainments, which is in vivid contrast with the long previous span of man's existence during which culture had plodded ahead at a barely perceptible pace. Very few Bushmen remain in South Africa, or blackfellows in Australia, and these have probably survived by grace of living in a desert and a remote island respectively; but in those days of the end of the Paleolithic the races we distinguish to-day must have been more equal in numbers. The point of this effort to ignore the present scene, and instead to restore that of 10 millenniums ago, is to give these now negligible races their proper significance. When they and possible others stood on more equal terms with those which dominate to-day, the whole species would have presented an appearance of even greater diversity than at present, and this very diversity is an index of the age of the species itself, because races can not have appeared overnight.

Races seem to have formed almost entirely as the result of random evolution. It is conceivable that the tropical sun was an influence in establishing dark skin in the possessors of that feature, and woolly hair as well. If so, it was certainly a long process, too gradual a one to have affected the Indians of tropical America over many thousand years. But geographic isolation, the simple separation of groups descended from the original Homo sapiens, was probably the most important factor. Such groups changed slightly but continuously, by nature's laws, and being separated geographically, they tended to drift aimlessly apart in physical form as well, becoming racially diverse. Bagehot, the economist, once suggested that when man was new his meager culture allowed natural selection to act powerfully upon him, leading to the rapid development of races. This is a poor hypothesis all around; natural selection would affect the functional development of his legs, etc., but selection would actually tend to prevent racial differentiation. There is no real reason to think that there was irregularity in the speed of racial development, or anything except an even increase in diversification, which reached a maximum about ten thousand years ago.

The process probably took a long time. The only sighting point by which we can judge its pace is the beginning of the Upper Paleolithic. The first unquestioned Homo sapiens, the Cro Magnons, demonstrate; (I) that there has been no progressive racial development, as far as can be seen, in some 30 millenniums, and (2) that the men of that time were hardly more primitive in an evolutionary sense. In Europe, the Cro Magnons and related types were purely "white" in character, showing that this racial stock, at least, was fully developed and by no means in any embryonic stage. And there is some evidence from other skeletons of comparable age that the Negro and Mongoloid stocks were equally well established. Furthermore, the native Australian of to-day is definitely more backward 
in form than were these ancient Caucasians; indeed the fact that the most primitive branch of the species that we know of should be found in a living race rather than an ancient fossil emphasizes again our ignorance of early stages of Homo sapiens development.

Now, if no material change in the degree of racial differentiation can be observed in the time from the present back to that which immediately follows the disappearance of the Neanderthals, then it can hardly be denied that the development of all the races out of a common stem must have taken a period several times as long as this one. Even the time when the now archaic Australian, chinless and small-skulled, and with beetling brows and protruding face, represented the forefront of sapiens, development must be relatively remote. (Galley Hill and the other geological hoboes were more advanced than he.) So from this consideration alone, it would appear that Homo sapiens must go back as a distinct species to the middle of the Pleistocene at least, and probably much further. This being so, it is difficult to believe that the Swanscombe skull can have belonged to some other species. And certainly if for these additional reasons the Galley Hill man, who has about the same putative date, can finally be accepted, then the age of Homo sapiens must be really great indeed.

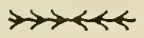

\section{MAN'S LONG STORY *}

\section{LEW IS G. W E S T G A T E}

We live in a time in which human values, built up slowly through centuries with untold sacrifice, are threatened with destruction; when nations at either end of the old world have set out on a career of world conquest with the intention of exploiting and enslaving the conquered peoples, and are pushing that aim with sub-human brutality; when our own country is fighting for its life. It is a time of fear and uncertainty. It is a time of human tragedy, when for millions the future is black indeed. Can science help us to an understanding of what has taken place, or give us a perspective with which to judge the present, or point to any hope for the future?

We need perspective, the perspective of a long past. Swept along in the rapids of present-day happenings, we are in no position to judge them. We need to stand on the bank, watch the river's rush, get some notion of its whence and whither. It were well to turn to the history, American history, European history of the last six millenniums. We have gone far

* Reprinted by permission of the Scientific Monthly, American Association for the Advancement of Science. Copyright 1943. 
since neolithic man started civilization on the flood plains of the Nile and in Mesopotamia. Other times have been worse than this, bad as it is. On the whole there has been advance.

We need a longer perspective even than that of the last six thousand years, a perspective that science alone can give. The master historian is the geologist; he deals with time on a scale which dwarfs ordinary history. To him, as to the Creator, a thousand years are but as yesterday when it is past and as a watch in the night. He speaks of a hundred million years with the same nonchalance that the ordinary historian displays in handling centuries; and if he misses by a million or even ten millions when he is talking big, he sees no need of apologizing.

That the earth is old, very old, has been known for the last two centuries, ever since the birth of geology as a science. But how old in years? Recently the discovery of radioactivity has led to a new and apparently reasonably accurate method of estimating geological time. Uranium by the loss of helium passes into lead. The rate of such loss has been determined in the laboratory. By comparing the amounts of uranium and uranium-derived lead in certain granites we can find the age of the granites, and a minumum age for the sedimentary rocks in which they have been intruded. Thus are obtained the data for the following table, which shows the periods into which the geologist divides the past history of the earth, with their respective lengths:

\begin{tabular}{c|c|c}
\hline \hline Period & Length & $\begin{array}{c}\text { Length of time to beginning } \\
\text { of (in millions of years) }\end{array}$ \\
\hline $\begin{array}{c}\text { Cenozoic (time of re- } \\
\text { cent animal life) }\end{array}$ & 60 & 60 \\
\hline $\begin{array}{l}\text { Mesozoic (time of } \\
\text { medieval animal life) }\end{array}$ & 130 & 190 \\
\hline $\begin{array}{l}\text { Paleozoic (time of } \\
\text { ancient animal life) }\end{array}$ & 300 & 490 \\
\hline Pre-paleozoic. ... & 1300 & 1790 \\
\hline
\end{tabular}

These figures are approximations at best; still, we shall probably not go far wrong in fitting our thinking to this schedule. It gives us some two billion years for the age of the earth as recorded in the rocks. Back of that is an indefinitely long, early planetary period of which the geologist has no record.

Time as mere duration is uninteresting. It is what happens in time that matters. The length of geological time has been emphasized not on its own account, but because probably during the whole of that time there has been life on the earth, slowly, very slowly developing into the variety 
which we see about us to-day. Time is the background for the story of life.

The ancestry of man is a long one. It goes back beyond Neanderthal man; beyond the ape, the early mammal, the fish; beyond whatever invertebrate ancestor the fish had; back to some single-celled form in prePaleozoic seas nearly two billion years ago. A long time for man to be at school. Progress has been slow, for Nature is a severe school mistress. Failure in her school means more than just waiting over a grade; the organism is thrown on the discard. She insists that her lessons be so learned that they become part and parcel of the organism, and she takes all the time necessary to secure that end.

Sonewhere in the pre-Paleozoic sea existed single-celled ancestors of man, possibly like the amoeba. It could eat, assimilate, breathe, move, reproduce, all in very simple ways; but these were the essential functions of life. It was perfectly adapted to its environment; so perfectly that some of its descendants, still amoebae, are with us to-day. It is no newcomer into that early ocean; it had been at school for tens, perhaps hundreds of millions of years, and the lessons of that infantile grade had become a part of its very structure and function. We came along perhaps a thousand million years to the mid-Paleozoic, the Devonian, the age of fishes. Our ancestor is now a fish, admirably adapted to its medium, doing the same things the amoeba had been doing, but in a more elaborate way. And there were those millions of years of schooling between. Some of the Devonian fish, certain ganoids, were ready for a higher grade. In these the swim-bladder opened into the throat, and in extremis could be used for gulping air, that is, breathing. The fins were stout, and again, in extremis could be used for crude walking. Imagine these ganoids, caught season after season in time of drought in muddy pools on the Devonian flats, gulping air and floundering about, half in and half out of water. It was hard schooling, but some graduated; the air bladder developed into a lung, the fins into legs; and these ganoids were the ancestors of all the higher vertebrates. In the monotonous uniformity of the sea, evolution of the higher types of life would have been impossible; that required one variety of the land surface. The coming to land of these Devonian fish has been said to be "the most momentous step in the whole advance from amoeba to man."

Two hundred million years further down the line we are in the midMesozoic. Great reptiles rule the air, the sea and the land. It looks as if their future were secure, that their reign would last forever. It did last for more than a hundred million years. But the future lay not with the reptilian giants, but with certain small primitive mammals, an offshoot of the line of reptiles. They had been waiting their chance for some tens of million years. At the beginning of the Cenozoic, Nature took them in hand for training for the higher grades; sixty million years of schooling it was 
to be. One group, the primates, came in for a special education of body and brain that had a more direct human trend. The early anthropoids, man's line, were tree-dwellers. Toward the middle of the Cenozoic our direct progenitors came down out of the trees, adapted themselves to the ground, spread beyond the forest, and assumed an increasingly erect posture.

The Cenozoic was sixty million years long. Its last division, the Pleistocene or Glacial, was one million. Through this past period, which includes four glacial stages with long intervening interglacial epochs, man was slowly straightening up, increasing in brain capacity and intelligence, developing speech, inventing tools. His prolongation of infancy, far beyond that of other mammals, carried with it increasing teachableness, and the lengthening of the period in which offspring were dependent on their parents led to the beginning of the family with its accompanying intensification of the altruistic sentiments, to the growth of the qualities which we consider most distinctively human.

Early in the Pleistocene, forms recognized as man and not ape are found (Java, Peking and Piltdown man). Neanderthal man (Homo neanderthalensis) made his appearance in the last interglacial epoch; but it was not until the last glacial epoch, perhaps 50,000 years ago, that CroMagnon man appeared in western Europe, the first that is admitted to the present species (Homo sapiens), and whose descendants are doubtless with us to-day. Erect, with prominent chin, high forehead and brain as large as that of modern man, he was skilled in the use of simple tools, and his carvings and drawings and polychrome paintings are the admiration of anthropologists. Cro-Magnon man stands at a pivotal point in the world's history. He is the climax of two billion years of animal evolution. Man's long preliminary education is now completed. The stage is set for a new act in the drama of life; whether comedy or tragedy we do not yet know.

The purpose of this emphasis on the length of life on the earth is to show that the race enters manhood with an immense animal momentum. The Roman Catholic Church is said to hold that if it can have the teaching of its youth for the first seven years, it will guarantee them to the Church for life. Nature is man's teacher, and she has had his early education for a vastly longer time proportionally than the Catholic Church asks for its youth. Man has been in the distinctively human school less than a million years. He was in the primate (not primary) division throughout the Cenozoic, sixty times as long. He began his primary education as some single-celled form in the early pre-Cambrian ocean, possibly two thousand times as far back as the day when he was promoted to the human grade. Nature has insured that he learn his lesson well; that the animal is so inwrought in him that he can never get away from it. His human nature is a recently acquired and uncomfortably-worn garment. 
The first inference to be drawn from man's long animal inheritance is that he is primarily a creature of instinct. His driving forces are hunger, sex, fear, crowd, combativeness. No one who has honestly looked into himself or around at his neighbors can fail to see this. He is not a fallen angel, god-descended, mixed with animal clay. On the contrary he has risen from the animal level. Let us hope he is still rising, and has his eyes at times fixed on the stars. Unless we keep his animal origin and bias in mind, we can neither judge him fairly nor plan wisely for his future.

A second inference, indeed the obverse of the first, is that man is not a creature of reason. The zoologists when they named the human species called it Homo sapiens; man the wise! Whether they did this from egotism or wishful thinking or just for a joke, they were in error; wisdom is not his outstanding characteristic. Reflective thought is a late acquisition and few have it in any large measure. The eighteenth and nineteenth century confidence in reason is now seen not to be justified by the reality. For most people, even for the best of us most of the time, reason is the servant of instinct, finding excuses for what one wants or has already decided to do. It is rationalization, first cousin of wishful thinking, which is not thinking; it is merely wishing. Here again honest introspection will give us the evidence; also observation of neighbors. If one wants proof in public life, he can follow the doings of the United States Senate, the resolutions of Chambers of Commerce, or the propaganda of nations at war. If he looks for it in the rarefied air of abstract thought, he can dip into any book on astrology or even theology.

However, man's being primarily a creature of instinct furnishes a needed conservative and conserving factor. His animal inheritance keeps him on the track, keeps him from going off into all kinds of wild disintegrating experiment. But had this been the only force at work, man would still be on the animal level; progress would be impossible. Sane human history is a balance between the conservative instinct we inherit from our animal ancestors, and the use of reason to guide that instinct.

Again, a clear appreciation of the strength of man's animal inheritance shows us that it serves to qualify both our hopes and our fears. It works against optimist and pessimist alike. The optimist expects that evil can be overcome, and that, speedily; that some sort of golden age or millennium is coming in the not distant future. The pessimist is sure that evil is with us to stay, and that to fight against it is a hopeless adventure. Both to the extreme hopes of the optimist and to the extreme fears of the pessimist the long biological-historical view is a corrective. The momentum of an age-long inheritance is not easily changed. The animal in us, often at odds with our idealism, will carry on indefinitely. But other forces are at work. 
We are told that we can not change human nature. But human nature can change. It has changed. We are what we are because it has. There is no good reason to suppose that it has ceased changing. But the process is extremely slow. Further, whatever may be said of human nature, human behavior can be changed, both in the individual and in the mass, and it is behavior that counts. Recent events in Germany may not be proof of any change in the human nature of the Germans; but they certainly bear witness to a change in German behavior; and it is German behavior that the rest of the world has to deal with. It is equally possible to shape human behavior to good ends.

\section{I $\mathrm{V}$}

Organisms must adapt themselves to their environment as the very condition of survival. If a satisfactory adjustment has been achieved and then the environment changes, a new adjustment must be effected; and that is always difficult. The course of geological history is strewn with the relics of species that, failing in adjustment, perished. The application of this principle to man is this: man's body and mind reached its distinctly human state in one type of environment, and he has lived on into a radically different type, which he has himself created, and he is having tremendous difficulty in making the necessary adjustment.

The environment of early man was that of forest, or forest and plains, suited to hunting; or, if he was near the sea, to hunting and fishing. It was an active life in the open. He needed neither golf course nor gymnasium. He got his food from plants that grew wild, or from animals of the chase; at any odd time, not thrice daily o' the clock. It was one continuous struggle against cold and hunger. Eternal watchfulness was necessary that he get the animal before the animal got him, for both were out for a meal. Strength of limb, keenness of eye and ear, accurate knowledge in a narrow field counted for more than familarity with Plato or the calculus would have done. On them hung the issues of life and death. Dense population was impossible; there was not food enough. If population crowded on food supply, then war, starvation or infanticide kept it down. It was a life close to elemental nature, a life in which every normal adult could and did share somewhat equally, had his chance, and was on the whole equal to the situation.

All that is a matter of far away and long ago. Some thirty thousand years separate us from Cro-Magnon man. Two great environmental changes have taken place. The first, to a settled agriculture, we see already accomplished at the beginning of recorded history, some six or seven thousand years ago. Man at that time possessed domestic animals and cultivated grains; and on this basis he had established permanent agriculture on the rich, level, well-watered flood-plains of the old world. This permitted the accumulation of wealth, the growth of dense population, commerce by 
land and sea, together with arts and industry, and the development of social classes. It permitted war, conquest and slavery. Still, the great mass of the people, the farmers or peasants, lived an out-door life not greatly different from that of the earliest hunters.

The second change, a revolutionary one, the greatest of all in man's environment, began some five hundred years ago. We find ourselves today in the very rush of it. Our age has been called, not wholly accurately, the age of science; the age of technology would be the better term. Technology has been slowly growing, as a process of trial and error, from the very earliest times. The pyranid builders in 3000 в. C. had a high degree of technical skill. Man has not been so stupid that he has not been able through the centuries to improve the old ways, to find both new things to do and new ways of doing them. Invention, quite apart from scientific research, has made great advances in the last two centuries. Mere enumeration is all that is necessary: iron and steel, fuels (coal and oil) for power, transportation, the factory, mass production; all this culminating in crowded peoples and overgrown cities. For a while industry and new-born theoretical science followed separate paths. There was nothing in the early experiments in electricity to suggest the gigantic electrical developments of to-day. Science was largely the experimenting of individuals working alone. Slowly it became clear that science could be of use in human affairs. It was first pity, then endure, then embrace. Governments began to see the advantages of subsidizing geological, agricultural and medical research. To-day most large industrial corporations support their own research staffs. Science and big business have entered into partnership, and technology advances by leaps and bounds. It is reported that $\$ 235,000,000$ were set aside by industry for scientific research in the United States in one depression year. Whether in the end this union of business and science will be for the world's good, it is too early to say. It has made possible mass production and the modern city. Following, as it has, the discovery of new continents, it has led to commercial rivalry, the exploitation of weaker peoples, the demand for new markets and new sources of raw materials, race antagonisms and world wars.

It goes without saying that man himself has produced this new environment. Nature with no help from man shaped the environment in which he acquired his mind and body. But to a large degree he has taken over from Nature the building of his environment, has already tremendously changed it, with what results we are beginning to see. He must now work out his destiny in a world amazingly different from that of any epoch of the past.

This change to a technological environment is inevitably accompanied by maladjustments which reach into every aspect of life. The dwellings in which we live, whether the tenements and shacks of the poor or the air-conditioned apartments of the well-to-do, are a sharp contrast to the open-air life of man's formative period. The specialized and monotonous 
work of the miner or factory hand is slavery compared with that of the early hunter, which, if strenuous at times, lacked neither variety nor interest, and was a real education. The deep-canyon streets of the city, filled with noise, gas, dirt and rush, or the drab surroundings of the factory town, are a sorry alternative to the open country. Two views of lower Manhattan, taken more than three centuries apart, would symbolize the change. One, to-day, would show the wonderful sky-line of high buildings, the other the wooded island Hudson saw when he entered the upper bay in 1609 .

The human element in the environment has changed no less than the material. The pace of modern life and the intellectual level on which it is carried on, make demands beyond any that were made on early men, demands which many can not meet. Modern industry finds many unemployable persons. It requires more from those it takes on, and scraps those it can not use with the same lack of consideration with which it scraps outworn machinery. It imitates Nature in her harsher moods.

The results? Before the war, between five and ten million unemployed in the United States, facing the choice between public support, starvation or crime; worse, unemployables; poverty, economic insecurity and recurrent depressions. Clearly the economic system is not working satisfactorily. Sickness; the medical bill of the United States is some three billion a year, and large numbers get no medical care. Defectives and insane; mental cases in hospitals rose from 63.7 per 100,000 in 1880 to 263.6 in 1934. The total annual cost of crime, direct and indirect, in our country runs into the billions. This tremendous load; unemployment, including the idle rich, crime, sickness, waste, class struggle, and worst insanity of all, war; all this is loaded on the backs of the actual workers on farm, in factory and office. This is the "white man's burden," not his egotistically assumed overlordship of races of another color.

\section{V}

What of the future? Physical conditions alone considered, there is every reason to believe that the earth will be a suitable home for men for a long time to come. There is nothing in the geological past to suggest any speedy wind-up of mundane affairs. If some wandering star approaches our sun and upsets things, or if the sun blows up, as suns (novae) have been known to do, or if in the far distant future our central sun becomes cold, that will end us. But such contingencies are almost infinitely remote, and the scientist, as a student of earth's history, is justified in ignoring them.

Climatic conditions will continue to be favorable. When the extent of the continental glaciers of the northern hemisphere was first appreciated, it seemed as if the earth might be cooling down; that we were about to enter upon a long period of refrigeration, in which human life would be- 
come increasingly difficult, and finally end. We have since learned that glaciers are no new thing in the earth's history. There was extensive glaciation at sea-level in India, South Africa and South America at the end of the Paleozoic, perhaps two hundred million years ago. Another extensive glaciation occurred twice as far back, before the beginning of the Paleozoic. Climatic changes seem to have been rhythmic instead of progressive; swings from warm to cold, and back again; from wet to dry and dry to wet; but at all times of a character to permit human life, had it been in existence. There is no reason to suppose that conditions will not continue much the same in time to come. The weather prediction for the future is "favorable." Today's climate, like all weather everywhere, is "exceptional." We are still in the fag end of a glacial period, with immense ice-sheets in Greenland and Antarctica, and abundant mountain glaciation. There have been four generations in the Pleistocene. It is quite within the realm of the possible that another ice sheet may develop in Canada, push south into the United States, and overwhelm New York, Cleveland and Chicago; the last ice sheet reached that far. The next, if there is a next, may do the same. It will not be a glacial blitzkrieg, however. There will be plenty of notice in advance. And it will be exceptional. Through most of the past the climate has been mild and uniform, and it will probably be so through most of the future.

The environmental aspects just mentioned are exempt from interference on the part of man. Others are not. Man cuts the forest, plows the grasslands, and plants his corn and wheat. He digs or drills the ground for his fuels and his metals. These are his resources for food, for industry. How is it faring with these natural resources?

First, as to the food supply. There will be enough to eat, if . . There have been times in the past when a land animal like man would not have found enough to cat, enough of the right kinds of food. When the lung fish of Devonian times came ashore to become the ancestor of vertebrate land life, he found an abundant vegetation. But it did not contain our present foods. None of the plants which fill the spring seed catalogues were then in existence. Flowering plants did not come until late in the Mesozoic, nor were grasses and grains, man's basic foods, abundant until the Cenozoic. But now they are with us. Nature has done her part. "Behold I have given you every herb yielding seed, which is upon the face of the earth, and every tree, in which is the fruit of a tree, yielding seed; to you it shall be for food." What man is doing at improving this endowment is told in the splendid story of modern scientific agriculture.

But plants require soils; aye, there's the rub! We are waking to the fact that soils are being destroyed in this country at an alarming rate. They are being washed to sea by the rivers and blown away by the winds. Already from one quarter to all of the top soil has been eroded from 59 per cent. of the United States. They are being impoverished by cropping with- 
out any return of the essentizl elements taken. Soil loss is a serious national thrat: soil conservation a great national problem and aeed. The soil is a resource which can be wsed and kept. Soil exhaustion is not necessary. Some solls have cetuined their fertility arter thousands of years of use, but it has been intelligent use.

Resources such as soil and water. if properly handled. can be used and kept. With them you can eat your cake and have it too. It is different with most mineral resources. The fuels-coal, oil and gas-are stored supplies of organic origin which hare come down from the geologic past. If they are forming anywhere coday. it is at a rate which is intinicesimal in comparison with that with which they are being used up. The supplies of coal and oil are limited in amouni, and when they are used up they are gone. There is a certain coal tonnage still in the earth. Is amount is fairly well hnown. How many years it will last depends on so many factors that no accurate forecast can be made. Those already mate speak not of decades, nor millenmiums but of centuries. The story ot erery oil field is one of discovery and exploicrtion, followed by slow decline to exhaustion. There are 3 definite number of oll felds in existence. Some are known. others are yet to be discovert. When the last feld has been discorered and exhausted the scpply of petroleum will be gone forever. Then. unless something is inrented to take its place. we shall be driven to the discillation of oil from oil shale.

Coal and oil are fossil sunlight, the sun's energy stored up by plants of the grological pest. Plant life is temponary storage of the sun's energy. It may be that before these supolies are exhausted our physicists and chemists mit hit on some way of directy catching the suris energy, that future korkwives may can sunlight along with peaches and tomatoes for winter supp'y. Or will the Sunligh Company of America establish a monopoly:

If we cake the long view, there would seem to be but one conclusion that we can draw from the limited scpply of mineral fuels and metals, and that is that there is a fred period set to the age of iron and steel, as we now know it A carsitl use of our mineral resources may prolong its life. perhaps for a iew thousand vears and substitutes for the metals will help. But it looks as though in the end it may be necessary to return to conditions like those which preceded the ninetenth century. Doubtless some would look on sach a chang w with resignation. They are asking whether the Sunday paper, movies and radio, batcleships tanks and planes. and much of the rest of modern production, have really raised our cultural level. Were not many men in Shakespeare's dey living as full lives as any of us now:

To sum up: Nacure has coce her share to insure a faroring home for man for an indefinitely long future. If things do not go well, he has but himself to blame. 


\section{TI}

Will man himself change: in body or mind: And if so. in what direction: These are questions impossible to answer. There seems to hare been no significant change in his body since the beginning of the hiscorical period. But in considering his future we have to do with not thousands but millions of vears; tens, possibly hundreds of millions. There was immense evolution along many mammalian lines during the sirty million years of the Cenozoic; great changes took place in the human stock during the last million, since the first glacial period.

In the past, forms often became narrowly specialized, well fitted to a particular environment; and when that enviromment changed they were unable to adapt themselres to the new conditions, and perished. Man is a generalized form, a sort of jack-ot-all-trades. He can rum bet not lile the deer; climb. but not like the monkey; swim but not like the fish; and he can fiy. But he has what birds. beasts and fishes hare noc, fingers and a superior brain. He can thinl: and by thinking he has, with his unspecialized body and hands and with the tools his hands have made. derised means for beating each of the others at their own specialty. It is probable that man will continue much as he is now. using his intelligence to secure his adjustment and his continced life.

That man has adranced mentally during historic times might seem to be a good bet; but it is one that can not be collected on since there is no way of establishing the facts. Certainly the eminence of the Gret' intellectuals prores nothing. With all their ability the Gresks were unable to weld together the small Greek states and prevent their orerthrow by Macedonia and Rome. And it is a fair inference that Newton Darwin and Einstein. Shakespeare and Goethe. and those who are organizing the complex industrial life of to-day, are at least the equals of the glory that was. for a short time. Greece.

With man a great change has come in the erolutionary process In the past erolving forms have been quite uncoascious of their owa derelopment. For man this is no longer true. He knows the long course he has come. he discovers the factors at worls in his own heredity and environment. he can look into the future; and he is able in a degree to take control of and direct his own evolution. He is alreaty directing the erolution of the animals that are useful to him; the rest he exterminates. What he has doat in producing different breeds of cattle, swine sheep and pouler. a rist to any state fair will show. After sech a visit oae may conclude that it is just as well, in view of his present ignorance, that man has not yet begun to experiment in this way on himself. But the possibity is there. 


\section{I I}

Man's evolution now is primarily social and cultural. It has been going on since earliest man; its description is the burden of history. And in spite of the wails of the pessimists its progress has not been slight. So it will continue to be throughout the immediate future, say for the next ten or hundred millenniums. As in biological evolution, there is variation (by the introduction of new ideas), heredity (in the sense of transmission by tradition), and struggle for survival, both within and between groups. That struggle is everywhere present in current American life, and is now going on on a world scale with furious intensity in the present war. As with biological evolution, cultural evolution has been mainly unconscious and altogether unplanned; but here, too, man has reached a stage when he could in a measure take it in charge.

One important aspect of social evolution is the development of consideration for others, of the idea of right and wrong, of morality. Animal nature is non-moral. The question of right and wrong does not exist when the wolf drags down the deer. Consideration for others began with the early family. The long period of human infancy, close-spaced births over the woman's bearing period of thirty years or so, held the family together. In such soil thought for others had a chance to grow. Man's susceptibility to the favorable or unfavorable opinion of others helped. As a result there has come that slow growth of sympathy for others which has raised the struggle for existence above the animal level. It is these and other distinctly human traits which make life worth while.

\section{1 I I}

What are some of the first steps that should be taken in planning for the future: The foremost need is a clear-cut human ideal, the envisaging of "the highest human values realizable on earth through human effort" (Max Otto). This comes close to the democratic ideal, namely the fullest development of the possibilities of every individual, both on his own account and for the service he can render the world, the state being guardian, not master or slave driver. Each man to have his chance. It means the end of race discrimination. The claim of superiority by Europeans over non-Europeans has done immense harm to both.

In giving content to this aim, science, that is, knowledge, must help. Science, some say, has brought us to the mess we are in. True, technology rests back on science, but science is not responsible for technology, nor is technology responsible for the uses made of it. For that we are all responsible, through our stupidity and selfishness. We need to know vastly more about man, his heredity, the effects of his environment, the way his mind works. Millions are spent for research in technology, for improving glass, rubber, corn and hogs; very little for the study of man 
himself. One sickens at the billions now necessarily given for war, all of which would be unneeded in a decently ordered society; and thinks what tremendous advances the wide use of a fraction of that wealth would bring about if devoted to the problem of man. Just one hundred years ago Longfellow wrote:

Were half the power that fills the world with terror,

Were half the wealth bestowed on camps and courts,

Given to redeem the human mind from error,

There were no need of arsenals or forts.

We must revamp our economic system. We have the resources for a decent life for all. Poverty is no longer a necessity; it is a curable disease, and it is our shame that it is still with us. Our resources must be used for the good of all and not for the profit of the few. We need a new commandment, "Thou shalt not waste!" And we need to put new content into that old one, "Thou shalt not steal." This reconstruction will have to be done on a world basis, for science and technology have so drawn the world together that what is harm to one is now hurt to all.

Education must help, but it must be an education fitted to our present needs, not one that is an inheritance from an alien and aristocratic past. It must be an education that fits for jobs, trains leaders and gires a satisfying philosophy of life. An education that makes it forever impossible for one to forget that all that he has comes to him not through his own efforts, but because of the sacrifices of those who have gone before; and that he is not only a citizen of a national state, but a member of a world society. Above all separate groups is mankind.

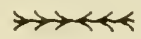

\section{WHAT WE DO NOT KNOW ABOUT RACE * \\ WILTON MIAION KROGMAN}

We are, in this discussion, going to focus upon race and problems of race purely from a biological angle. The approach may be illustrated by an experience the writer had some dozen years ago. In 1930-31 it was his privilege to study in the Galton Laboratory of Applied Eugenics at London University. On the first day, as he ascended the stairs to a second-floor classroom, he saw on the landing-wall in front of him a huge illustration, an enlargement of a cartoon that had appeared in Punch. Two English country gentlemen were standing beside a blue-ribbon bull, and one gentleman said to the other, "We know about breeds in animals, but what about ourselves:" The theme of this discussion is, then: What about breeds in

* Reprinted by permission of the Scientific Monthly, American Association for the Advancement of Science. Copyright 1943 . 
our biological selves? We shall discuss these selves not in individual, but in group terms. In a very real sense what we do not know about human biological groupings may become positive knowledge if it outlines future avenues of research. If we recognize a darkness we also recognize a need for light.

The first "don't" is simply this: we are not sure-at least we do not agree-what actually constitutes a biological race in man. In 187 I Charles Darwin, in "The Descent of Man," expressed the problems of racial classification quite clearly:

"Every naturalist who has had the misfortune to undertake the description of a group of highly varying organisms, has encountered cases . . . precisely like that of Man, and if of a cautious disposition he will end by uniting all the forms which graduate into one another, under a single species; for he will say to hiniself that he has no right to give names to objects which he can not define."

Darwin represents one extreme: there is but one race, the human race. One may study the literature on human racial classification and go to the other extreme, wherein no less than 150 species, each with sub-races, are postulated.

In 1735 Linnaeus, the great Swedish naturalist, gave Man the scientific name he to-day still bears-Homo sapiens (the "wise man"). Let us analyze ourselves biologically; an expanded cerebral cortex that makes of us a reasoning animal; a protracted period of infancy and childhood that enables us to be a learning animal; a facial skeleton reduced in size so that we have a physiognony instead of a snout; a forelimb that is freed from locomotion so that a forepaw has become a hand; a spinal column, viscera, a pelvic girdle, and a hind limb, that are reasonably well adapted to an upright posture and bipedal locomotion. In this general morphological pattern all mankind is truly one; one genus, one species. In all important and major bodily details we are one-in brain, in peripheral nerves, in heart, in blood and blood vessels, in all viscera, in muscles, and in skeletal architecture.

But there do exist differences which are, as it were, superimposed upon this basic ground-plan. There are differences in skin color, in eye color, in hair color and hair texture, in head shape, in nose and lip shape, and even in limb proportions. These differences are obvious, they are external, and we have recognized them for thousands of years. On the basis of skin color, principally, we subdivide Homo sapiens into three major groups: White, Yellow, Black. Scientifically we may designate these as H. s. caucasoideus, H. s. mongloideus, H. s. negroideus, respectively. ${ }^{1}$ Each of these groups-in practice we often call them "stocks"-is a sub-species, and each has certain distinctive morphological features which, taken singly, are not necessarily mutually exclusive, but which, taken in com-

${ }^{1}$ Some anthropologists feel that these merit specific ranking. 
bination or complex, do tend to set the groups apart. Actually, this same general conclusion applies to sub-species in lower forms as well.

So far, so good. Now let us observe one of these stocks-the Caucasoids -in greater detail. Within this sub-species, in Europe, there are groups which, originally on a geographical basis, precipitate out as more or less recognizable entities: Northwest, Central, Southwest, Northeast, Southeast. To these types-and we here use a simplified terminology-have been applied the names Nordic, Alpine, Mediterranean, Baltic and Dinaric, respectively. They fall into place in our scheme as follows:

$\begin{array}{ccc}H . & \text { s. caucasoideus } & \text { nordicus } \\ \text { " } & \text { " } & \text { alpinus } \\ \text { " " } & \text { " } & \text { mediterraneus } \\ \text { " " } & \text { " } & \text { balticus }^{2} \\ \text { " } & \text { " } & \text { Dinaricus }\end{array}$

In this stock break-down we come, finally, to the groups that the anthropologist generally terms race; they are, in taxonomic fact, sub-subspecies, or varieties. Do they exist today? The answer must be a qualified affirmative; that there may be local, isolated, probably highly inbred groups of Alpines, for example, in certain Swiss valleys. Similarly there may be small regional groups of the five Caucasoid varieties we have named. But there are no peoples or nations in Europe who are pure Nordics, pure Alpines, or pure anything else. In substance, there are no pure races: there are only populations in which two or more varieties are intermixed, and that intermixture began before the dawn of European history. Therefore what we term races in Man are poorly defined, because they are not -as in races in lower forms-homogeneous; they are intermixed, hybridized, diffused. That is why one man says "no races," the other "many races." The first is appalled at the difficulty of disentangling intermingled varieties; the second holds that secondary or composite groups warrant racial status.

The problem of mixture above mentioned-of hybridization so that "racial purity" is non-existent-renders it impossible to ascribe genetic homogeneity to the races we have set up. Suppose we took ten persons classed as Nordics (five males, five females), and ten persons classed as Mediterraneans (five males, five females) and bred within each group; we could not guarantee, and we would not expect, that the offspring would be all Nordics and all Mediterraneans, respectively. In the Nordic X Nordic we might get some short, brunet, long-heads; in the Mediterranean $\mathrm{X}$ Mediterranean we might get some tall, blond, long-heads. About all we might reasonably expect is that the Nordic offspring would tend more to tall blondness, and the Mediterranean offspring to brunet shortness. In other words, the groups we call races are genetically heterogeneous; they include

${ }^{2}$ There is reason to believe that these were originally variant combinations of the three preceding, basic types. 
genes that are generalized, and that are also shared more or less equally by one another.

Actually, how have we in practice set up a racial classification? The first method is that of somatological inspection: we look at a group and find that, on the average, they are short, slender, dark-complexioned, longheaded, wavy-haired, and their habitat is circum-Mediterranean; thus H. s. caucasoideus mediterraneus comes into being (Italians, Spanish, southern French, etc.). The second method is by biometric analysis. Here a certain portion of an entire group-a random sample-is measured and described precisely. If mathematical investigation shows that this sample (and hence the group) is statistically homogeneous and significantly different from all other groups, then the group under consideration is termed a race. "A biometrician's concept of race of man is derived primarily from the statistical study of samples. . . . His methods are essentially descriptive and they do not presuppose any particular theory of individual or racial heredity." ${ }^{3}$ The end result of both of these methods is the l'bomme moyen, or type, the hypothetical individual who represents the averages of all the individuals in the group (e. g., John Bull, Alphonse, Hans, Uncle Sam are caricatured types of an Englishman, a Frenchman, a German, an American).

In summary, our first "don't" recognizes that the groups we call human races are, taxonomically, sub-sub-species. As in lower forms the differences which set these races apart-at such a taxonomic level-are not clear-cut and precisely defined. As far as Man is concerned, we focus upon a relatively few apparently stable characters and then accept them as having a definitive and diagnostic value. In doing this, however, we do not diverge radically from accepted zoological principles at sub-sub-specific level for lower animal forms generally. At species level distinctions are quite clear; below that they are dim in the haze of variability.

The second "don't" is found in the fact that we are uncertain how stocks and races arose, i.e., when in human evolution they appeared and the mechanism involved in their emergence. We are pretty well satisfied that Man, as a primitive hominid, probably arose some five million years ago, more or less, as the result of a divergence from a generalized anthropoid form which gave rise to Man and the Anthropoids as we to-day know them. But that accounts for Man as Man-how about the White Man? The Yellow? The Black? Well, we are not really sure. There are suggestive finds, but nothing more. The first White Man may possibly be seen in Galley Hill man, resident in England some 400,000 years ago; the first Yellow Man is suggested by Weidenreich to date to Sinanthropus, the man of Peking, China, of about a million years ago; the first Black Man may date to Rhodesian man in Africa, 100,00o (?) years ago-certainly he was present in southern Europe at Grimaldi, some 25,000 years ago. We

${ }^{3}$ G. M. Morant, in Race and Culture, p. 24, 1934. Royal Anthropol. Inst., London. 
repeat, we are not sure of the import of these finds in terms of the timeappearance of stocks. Two things must be borne in mind: first, the finds are random and inconclusive because we do not have sufficient numbers to know range of variation; second, the characters commonly diagnostic of stock or race are those of soft parts not preserved in the fossil record.

If stocks, or sub-species, be of doubtful origin, how about races, or varieties? Here we are more in the dark than ever. We can answer only that Mediterranean-type crania are found well defined by the opening of the Neolithic, about 10,000-1 5,000 years ago; Nordic-type crania are reported in the Swedish Neolithic. The time element in stock and race emergence is approximate, nothing more.

Now that we have considered when they arose, let us take up how they arose. One of the most intriguing theories is that of Sir Arthur Keith, ${ }^{4}$ who feels that the endocrines may have played a role: "The transformation of man and ape ... is determined by a common growth-controlling mechanism which is residual in a system of small but complex glandular organs." As Keith surveys the role of the pituitary in acromegaly, the thyroid in achondroplasia, the adrenals in pigmentation, the gonads in secondary sex characters, he sees analogies with certain statural, osteologic, cranio-facial, skin conditions in the stocks of mankind; e. g., the big-boned, rugged-skulled Caucasoid shows a possible pituitary dominance; the flatfaced Mongoloid shows a possible thyroid dominance; the dark-skinned Negroid shows a possible adrenal dominance. ${ }^{5}$ Keith offers these endocrine associations more as suggestions than as absolute statements. They undoubtedly exist as factors, but to-day we recognize the endocrines as so complex, so interrelated, that any statement of uniglandular dominance must be taken with tremendous reserve. The exact role of the endocrines in human evolution and in the appearance of stocks and of races is in the realm of conjecture.

In our present knowledge of human evolution we assume that sometime, somewhere, there existed a generalized proto-human or hominid species that had, potentially at least, all of the morphological characters found to-day in all of mankind. This species must have been genetically fairly homogeneous, though probably inherently variable.

From this species there arose through mutation, recombination, selection, migration and isolation, the stocks and races as we now recognize them.

The third "don't" resides in the inadequacy of our knowledge concerning heredity in Man. Specifically, we do not know the precise mechanism whereby traits diagnostic of stock and race are transmitted.

${ }^{4}$ A. Keith, "The Differentiation of Mankind into Racial Types," Ann. Rep. Smith. Inst., pp. 443-53. Washington, D.C., 1921.

${ }^{5}$ About 1775 John Hunter concluded that the original skin color of Man was Black, and in 1921 Keith reaffirmed that statement. 
One of the most obvious methods employed by the physical anthropologist in studying human heredity is to analyze the effects of race mixture. ${ }^{6}$ Here it is assumed that the traits that "show up" or persist in a cross are "dominant." For example, when a long-head is crossed with a broador short-head it is apparently the broadness or shortness that dominates; similarly, nasal breadth thickness over lip thinness, and so on. But all this is not genotypic (genetic constitution) it is phenotypic (physical appearance). We do not know the exact genetic pattern involved; we know, for the most part, only what the end-result "looks like." Moreover, we are observing the operation of only a dozen or so parts of thousands of pairs of genes in Man. It is this dozen or so for hair, eyes, nose, lips, skin, and a few other traits, that we rely upon for stock and racial diagnosis; all the others are presumably constant for all groups.

Strandskov has given us an excellent summary of known gene distribution in Man. ${ }^{7}$ Color blindness is a sex-linked recessive, with gene $(\mathrm{cb})$ on the $\mathrm{X}$-chromosome; color blindness is present when normal color vision $(\mathrm{Cb})$ is absent. Ability to taste the chemical phenyl thiocarbamide is an autosomal recessive with $(\mathrm{T})$ for tasting, $(\mathrm{t})$ for non-tasting. In the A-B blood groups we find inheritance by triple allelomorphs, as follows:

\begin{tabular}{cl}
\hline Blood group & Gene Combination \\
\hline $\mathrm{AB}$ & $\mathrm{I}^{\mathrm{A}} \mathrm{I}^{\mathrm{B}}$ \\
$\mathrm{A}$ & $\mathrm{I}^{\mathrm{A}} \mathrm{I}^{\mathrm{A}}$ or $\mathrm{I}^{\mathrm{A}}$ \\
$\mathrm{B}$ & $\mathrm{I}^{\mathrm{B}} \mathrm{I}^{\mathrm{B}}$ or $\mathrm{I}^{\mathrm{B}}$ \\
$\mathrm{O}$ & ii \\
\hline
\end{tabular}

In the M-N blood groups we find the following:

\begin{tabular}{cc}
\hline Blood group & Gene Combination \\
\hline$M M$ & $\mathrm{~A}^{m} \mathrm{~A}^{m}$ \\
$M N$ & $\mathrm{~A}^{m} \mathrm{~A}^{\mathrm{n}}$ \\
NN & $\mathrm{A}^{\mathrm{n}} \mathrm{A}^{\mathrm{n}}$
\end{tabular}

Biologically the knowledge of these few genetic patterns is important because the mechanism is identical for all human beings; the inherited traits cut straight across stock and race; e. g., all blood groups and their genes are found in Whites, Yellows and Blacks, though in varying percentage combinations. It is possible that these combinations may have some value in racial distinction, just as does skin color, etc., but as far as transfusibility is concerned (allowing for blood groups) all human blood is alike. ${ }^{8}$

${ }^{6}$ T. W. Todd, "Entrenched Negro Physical Features," Human Biology, 1 (1): 5769. 1929; W. M. Krogman, "The Inheritance of Non-Pathological Physical Traits in Man," Eugenical Nerws 21 (6) : 139-146, Nov.-Dec., 1936.

${ }^{7}$ H. H. Strandskov, "The Distribution of Human Genes," Sci. Mon., 52: 203-215, March, 1941; "The Genetics of Human Population," Am. Nat., 76: 156-164, 1942.

8 It is implied in the phrases "blood-relation" or "blood will tell" that somehow blood is a carrier of familial relationship. The blood group is itself inherited, but blood, per se, is not a vehicle of genetic transmission. 
We are certain that physical characters diagnostic of race and stock are hereditary: they arose genetically, via mutations and subsequent isolation; they have been perpetuated genetically in varying combinations. We know, for example, that there is an average of "one mutation for every $5^{0,000}$ individuals per generation" (Strandskov), and that most of these mutations are of indifferent or even negative survival value. The few that are positive are transmitted and over a long period of time have entered into complexes and combinations which differ from stock to stock, and within stocks from sub-type to sub-type, from variety to variety. We are slowly but surely learning the genetics of Mankind in terms of his many physical-type variants.

A fourth "don't" is really a corollary of the third, namely, we realize that discrete traits have a hereditary basis, but we are still not sure which of these traits are relatively stable and which are easily modifiable, so that the first set is useful in classification, the second extremely limited in use.

In studying problems of racial analysis Hooton ${ }^{9}$ has outlined three categories of physical traits in Man: those that are non-adaptive, those that possess an acquired stability, and those that are easily modified. We may summarize these three categories as follows:

There are certain features which appear to act as heritable entities, either as unit characters or with multiple factors. These comprise in general hair-color and eye-color, form of hair, eye-fold, nose, lips, ear, incisor teeth and vertebral border of scapula, head breadth, face length, chin prominence and prognathism, and limb proportions, including intramembral, inter-membral and trunk-limb ratios. These physical characters are non-adaptive, stable, fixed, and may quite reasonably form the basis of the assessment of racial distinctions. Furthermore, certain combinations of these traits, varying within natural boundaries, result in the establishment of subgroups within each major classification.

We come now to several traits which have in the course of time been functionally modified and by selection have become more or less stabilized; at least their variability is of intra-racial rather than inter-racial magnitude. Here we may include skin color, shape, size, and proportion of the molars and the palatal arch, head height and brain volume, and possibly certain calcaneo-gastrocnemic relationships. The list is small and its import uncertain; the farther we go in our study of individual growth patterns and their probable relation to presumed racial criteria the more we nust allow for modifiability. It may be that the stability is spurious, merely a transitory phase in the creation of an ultimate pattern dictated by constitutional vicissitudes.

Finally, there are a number of bodily features so directly susceptible to health, diet and food habits, climatic factors, gait, exercise, occupation

${ }^{9}$ E. A. Hooton, "Methods of Racial Analysis," Science, 53: 75-81, 1926. 
and other miscellaneous influences as to render them useless as racial criteria. Here must be mentioned height, weight, thoracic dimensions and proportions, nasal proportions, facial width, proportions of forearm and hand, relationship of vertebral column and pelvic girdle, and shaft proportions of femur and tibia.

It may be finally emphasized that we must, in problems of racial interpretation, pay general attention to the sum total of all bodily traits, but specific and critical attention to the nonadaptive bodily characters, for these are transmitted regardless of the multifarious and complex extraneous factors of the environment. All things equal, it is not one, nor two, but the majority or all of the traits, in unique combination, which really constitute racial or group differences. But until we know more of the heredity of the several traits, of the effect of the growth-pattern upon these traits, we can not truly assess them in terms of non-adaptivity, acquired stability, or modifiability. ${ }^{10}$

For the last thirty years we have had reason to doubt the stability of certain morphological features, as in the cephalic index studies of Boas and his students, wherein significant generational differences were observed when foreign-born parents and American-born Jews and Sicilians were studied. In recent years Shapiro ${ }^{11}$ has suggested that instability is characteristic of a majority of Man's physical racial traits. He studied three generations: ( I "sedentes," native parents born and still resident in Japan; (2) Japanese-born (of these parents) who migrated to Hawaii in their late 'teens; (3) Hawaiian-born children of these immigrants. The anthropometric battery comprised twenty-eight measurements with twenty-one derived indices and twenty-two observations. When the first two generations were compared it was found that they differed significantly in all traits measured and observed as follows: male, 72.4 per cent.; female, 67.9 per cent. As between the second and third generations the corresponding differences were 55.2 per cent. and 42.9 per cent., respectively. These differences are progressive from sedentes, to immigrants, to Hawaiian-born, but whereas between sedentes and immigrants disproportionate changes occur, between immigrants and Hawaiian-born proportionate changes are the rule. The progression is apparently a real one, relatively unaffected by age-changes or changes in occupational status. The causes of the changes are twofold; the immigrants probably constituted a sub-group of the sedentes population from which they are drawn; the new environment (of Hawaii) provided a stimulus toward change and some inbreeding intensified the variant exemplified by the immigrants. But the changes are of course, limited in extent-the Japanese in Hawaii, as long as they marry within their own group, will always be Japanese; biologically they will

${ }_{10}$ W. M. Krogman, op. cit. pp. $144^{-1} 45$.

${ }^{11}$ H. L. Shapiro (with F. S. Hulse), "Migration and Environment," Oxford University Press, N.Y., 1939. 
not, can not, become Hawaiians, even though there might be some environmental convergence.

We now regard human races as much more plastic than we formerly did. But our concept of plasticity is basically a genetic one. There are a multitude of genes which encompass the entire range of human physical characters. Plasticity resides principally in recombinations of these characters. Recently Mills ${ }^{12}$ has shown that there is another phase to this plasticity, an environment (diatetic) aspect. He found that vitamin B requirements (thiamin, pantothenic acid, and pyroxidene at least) are much higher in the tropic than in a temperate zone and that growth and development are inhibited by inadequate $B$ intake under tropical living conditions. Here is an example where growth-pattern and hence adult configuration (taken as a racial criterion) is modifiable by the food environment. We are just beginning to learn how a temperate-zone White man may possibly adjust to a subtropical or tropical habitat, but for one fact we know there are 100 questions that are still to be answered.

The fifth "don't" is found in the functional aspects of Man: we know little about the physiology of race-types. We have studied racial metabolism, pulse-rate, respiration-rate, and so on, but these analyses are not so much tests of race-groups per se as reflections of conditions under which they live. There is no reason, really, to assume difference in kind, rather only differences in degree. If we relate body-type to body-function then distinct group differences can not be expected, for body-type cuts across stock- and race-lines. ${ }^{13}$

There is another phase of the functional problem which requires classification, viz., so-called "racial susceptibilities." For example, the peoples of North Europe are said to be prone to whooping cough, resistant to goiter and cretinism; the peoples of Central Europe fall prey to goiter and cretinism, but withstand pulmonary diseases; the American Negro succumbs to tuberculosis, diseases of heart, lungs and kidneys, and more successfully combats malaria, yellow fever, measles, scarlet fever and diphtheria. ${ }^{14}$ Are these really racial differences? Probably not. The answer is more likely to be found in problems of relative isolation and exposure, and most certainly in considerations of socio-economic standards. There are, so far as we know, no genetico-racial biological differences in the organs which will conduct to, or inhibit, organic breakdown under the onslaught of disease. The problem, however, is still one to be explored.

The sixth and final "don' $t$ " is that we do not know of any characteristics, either biological or psychological, that in a given race-cross are superior

12 C. A. Mills, "Climatic Effects on Growth and Development, with Particular Reference to the Effects of Tropical Residence," Amer. Antbropol., 44: 1-13. 1942.

${ }^{13} \mathrm{~F}$. Weidenreich, "Rasse und Korperbau," Springer, Berlin, 1927.

${ }^{14} \mathrm{~A}$. Hrdlicka, "Immunity as the Chief Task of Future Medicine," Lit. Digest, Dec. 9, 1933 (see p. 14); see also J. H. Lewis, "The Biology of the Negro," University of Chicago Press, 1942. 
or inferior. On the biological side there may be one exception, viz., the sickle-shaped erythrocyte which is an autosomal dominant trait (Si) found only among Negroes, to the extent of 4 per cent.

Much is being made these days of "race superiority" and "race inferiority." In words of one syllable there is no such thing. ${ }^{15}$ One hears of the woodsman who, on a crowded city street, heard a cricket; he can be matched by the mechanic who in the turmoil of a machine-shop hears a bearing-knock in an engine four rows removed. Again there is the savage whose keen eye sees vast distances or detects a faintly-trodden blade of grass; he can be matched by the scientist who under the microscope sees a new world in a drop of water. The ear and eye are common human possessions as far as morphology is concerned-it is the degree of their training that differs. This type of reasoning can be applied to any phase of Man's activities: how he learns and how much he learns is dependent upon his cerebrum and upon the cultural framework within which he learns; the cerebrum is the constant factor, the cultural framework, the variable. The same holds true for "intelligence," however it may be defined and assessed. We repeat that biological superiority and inferiority in the stocks and races of man do not exist, and that biologically there is no valid bar to stock- and race-mixture. The first generation hybrids are not biologically inferior-it is Society and not Nature that stamps the brand of undesirability.

In recent years German anthropologists have, as we know, advanced preposterous claims of Nordic or "Aryan" superiority (Das Herrenvolk). Such claims have no basis in fact. They have also claimed that widespread race-crossing ("race bastardization") will have a dysgenic effect ("gene chaos"), leading to various bodily abnormalities and asymmetries. This, too, is far more fanciful than real, though Fleming, ${ }^{16}$ an English anthropologist, has found some slight evidence of dento-facial disharmonies in Negro-White hybrids crossed with Negro-Chinese and Chinese-White hybrids. But this evidence is not conclusive, for there is no guarantee that growth inadequacies rather than genes are to blame, i. e., that malnourishment has not modified a genetic pattern. As matters now stand the crossing between sub-species or stocks is socially so unacceptable that only lower social strata are involved. It is precisely here that environmental impact and modification-in terms of insufficient and incorrect foods, improper hygiene, health hazards-are at their maximum. We have no adequate basis, therefore, for a true assessment and interpretation of the solely bi-

15 Otto Klineberg, "Race Differences," Harpers, N.Y., 1935; W. M. Krogman, "Is There a Physical Basis for Race Superiority?" Sci. Mon., 5 I: 428-434, 1940; M. F. Ashley Montagu, "Problems and Methods Relating to the Study of Race," Psycbiatry, 3 (4); 493-506, 1940.

${ }_{16}$ R. M. Fleming, "Physical Heredity in Human Hybrids," Annals Eugen. 9: 55-81, I939. 
ological effects of stock-crossing. As far as we know the genetics of stocks and races, we need not, a priori, expect any biological maladjustment.

This discussion has been -pretty much on the negative side-a sort of "hit parade" of scientific uncertainty with respect to race biology: we are not agreed what a race is, we are not sure when and how races arose; we do not know the precise hereditary mechanism in race; we are not sure which physical traits in race are stable, which modifiable: we do not know physiological and immunological features of race-groups; we can not assess race in terms of superiority and inferiority. In very truth we know little about the bio-genetical aspects of race.

Despite the foregoing avowal of inadequate knowledge we venture to present a definition of race that is sufficiently generalized to include the variables of physical type, heredity, environment and habitat:

A race is a sub-group of peoples possessing a definite combination of physical characters, of genetic origin; this combination serves, in varying degree, to distinguish the sub-group from other sub-groups of mankind, and the combination is transmitted in descent, providing all conditions which originally gave rise to the definite combination remain relatively unaltered; as a rule the sub-group inhabits, or did inhabit, a more or less restricted geographical region.

Certainly the physical anthropologist is not so dogmatic about the clarity of distinction between racial groups as he once was. Indeed, there are those who would deny the existence of human races, and who advocate dropping the term entirely. If the term race is purely genetic, and if we do not know the genetic make-up (the genotype) of a presumed race-group, then it follows that we can not define the group genetically, and therefore it does not exist as a homogeneous genetic entity. This argument, as the present writer sees it, while biological on the face of it, stems more from a cultural misinterpretation of the term ("racism"), wherein race and nationalism are confused, than from considerations of presumedly diagnostic morphological characters.

There do exist certain groups which may be put into categories; i. e., there are groups which tend to precipitate out when defined by a certain physical trait-complex. The trouble resides in the fact that the traitcomplex has been too rigidly defined, with too little allowance made for variability. The physical anthropologist freely admits that his classification has been based on the phenotype-the few external features used in diagnosis. We are prepared to reclassify upon the basis of the genotypethe basic genetic constituency. In both instances we will have groups called races: in the first instance-the present-day method-groups are classified by what they look like physically; in the second instance-the emerging bio-genetic method-groups will be classified by what they are genetically.

The term race as we use it to-day is a recognition that group differences 
do in fact exist. It does not imply, scientifically and biologically, a homogeneity such as demanded by geneticists. When our knowledge of human heredity enables us to classify the peoples of the world genotypically we will gladly accept that classification-we will substitute it for the one we now have. Until then, and with full and complete recognition of all of its many inadequacies, we will use the system at hand. 


\section{XII \\ Ecology}

Cology deals with the action of the environment on plants and animals L and their reaction, in turn, to the environment. These patterns have been built up through thousands of years of evolution and one should realize that not only have plants and animals evolved but so also has the environment.

When one considers parasites such as the tapeworm or the hookworm, it is impossible to believe that they were always parasites. Sometime, in the long dim past they were probably free-living. Organisms however can change in man's memory too. The Colorado potato beetle was not always a potato pest but fed on many western plants which were of no economic importance. Not very many years ago it switched its diet and, using the potato fields as highways, spread far and wide over the United States. When plants and animals move to or are moved to different environments they show startling responses in some cases. The English sparrow was not particularly numerous in the British Isles in the 1800 's but when brought here to this country and released it increased enormously. The same phenomena took place when the daisy, the dandelion, chicory, milfoil, and devil's paint brush were introduced here from Europe. The Mongoose became a pest in Australia and the muskrat became obnoxious in England when introduced there.

In regard to the changes in the environment, it seems to be well known that the sea covered large areas of what is now dry land. Wherever we find marine fossil shells or other remains in rock on dry land we have the right to assume that the immediate area was once ocean bottom. We also know that the climate of many regions now cold was mild if not sub-tropical. In the rocks of Greenland for example one can find fossil leaves of trees now found only in warmer places. We know that the Great Lakes region was once covered with a thick sheet of glacial ice and this certainly made a great difference in the kinds and amounts of organisms there.

One of the chief studies in the science of ecology is the construction of food chains. For example, the combustion of gases in the sun sends waves of heat and light earthward. In the sea one finds tiny one-celled green algae. These minute organisms absorb part of the light rays in their green coloring matter or chlorophyll and with the use of carbon dioxide and water they fix this light energy into the form of a sugar. This sugar 
the algae 'burns' in respiration. Minute fish, however, happen to feed on algae and the stored sugars; also vitamins pass into the systems of the fish where they are utilized. These small fish are eaten, in turn by larger fish and so on until they find their way to the table of man or die in some other way. Other organisms may enter into this chain and change its direction. Animal life is dependent upon the sugars made by green plants and the latter could not exist without light, heat, minerals, gases and water. Thus we see a chain of dependence stretching throughout the realm of the living. This is the chain of life.

\section{INTERDEPENDENCE OF PLANTS AND ANIMALS *}

\section{A. S. PE A R E}

Since life began plants and animals have developed together. A plant and an animal are more or less interdependent. The activities of one result in waste products which are necessary for the syntheses of the other. Photosynthesis, the process which gives rise to nearly all the organic foods which are used by plants and animals, requires carbon dioxide which is, in turn, liberated by the breaking down of the substance of living or dead animals or plants. Decay is commonly brought about by bacteria and other fungi. All living substance forms carbon dioxide as a result of its activities. With a few exceptions, both plants and animals require a continual supply of oxygen, and oxygen is an end product of photosynthesis. Carbon dioxide in large amounts is injurious to living substance, and its presence may make a particular locality unfit for life. On the other hand, the fact that it is necessary for photosynthesis makes it a continual necessity for green plants.

Chlorophyll is the remarkable, life-supporting green substance which, when given a supply of water and carbon-dioxide and energy in the form of light, can manufacture simple starches and sugars. These in turn can be built up by living things into simple protein substances if nitrogen and a few other chemical compounds are available. Although nitrogen makes up a large proportion of the atmosphere it cannot be used by living things in its simple, gaseous state, but must combined with hydrogen, oxygen, and carbon before it can be made a part of living substance. The only

\begin{tabular}{|c|c|c|c|c|}
\hline $\begin{array}{l}\text { Water } \\
\text { contains }\end{array}$ & $\begin{array}{l}2 \text { hydrogen } \\
\text { I oxygen }\end{array}$ & $\begin{array}{l}\text { These in the } \\
\text { presence of }\end{array}$ & $\begin{array}{r}\text { simple } \\
\text { Will form-sugar }\end{array}$ & $\begin{cases}1 & \text { carbon } \\
2 & \text { hydrogen } \\
1 & \text { oxygen }\end{cases}$ \\
\hline $\begin{array}{l}\text { Carbon } \\
\text { dioxide } \\
\text { contains }\end{array}$ & $\begin{array}{ll}1 & \text { carbon } \\
2 & \text { oxygen }\end{array}$ & $\begin{array}{l}\text { chlorophyll } \\
\text { and light }\end{array}$ & $\begin{array}{c}\text { and } \\
\text { Will set free }\end{array}$ & $\{2$ oxyge \\
\hline
\end{tabular}

The Manufacture by Plants of Organic Food from Water and Carbon Dioxide.

* Reprinted from Environment and Life by A. S. Pearse, by permission of Charles C. Thomas, publisher. Copyright 1930. 
living things which are capable of combining gaseous nitrogen with hydrogen and carbon are certain bacteria, especially those often associated with the roots of leguminous plants, such as peas and beans.

Chlorophyll is not generally present in animals, but there are certain of the simplest of living things which can live either as plants or animals. For example, one microscopic organism, Chlamydomonas, when in light manufactures its own food by using the chlorophyll in its own body, but, if the same organism is kept continuously in the dark, it will lose its green color and die if it cannot devour organic food, such as bacteria or other minute things. Chlorophyll is not only essential as the machinery with which organic foods may be manufactured, but it is of great importance to animals in other ways. Some animals, such as certain protozoans, sponges, corals, and flatworms, contain small green plants within their bodies. These serve as little slaves which work to make food for their captors, and in turn receive protection and the essential materials for such synthetic activities. Chlorophyll is also known to be the source of pigments which serve important functions in animals. Even haemoglobin, which in blood is so essential for carrying oxygen to the tissues in man and other animals, is believed to be derived from the chlorophyll which is taken into the bodies of animals as food.

Plants, then, manufacture practically all the organic food in the world and animals must obtain it from them. They are also the chief factors, as bacteria and other fungi, in reconverting the bodies of dead plants and animals into simple substances, such as water, carbon dioxide, and ammonia, which may again be used in the synthesis of foods. Somewhere in their substance plants also contain vitamins, which though they occur in minute quantities, have lately been shown to be of vast importance for the proper nutrition of animals.

The dependence of animals on plants for organic foods brings about certain general relations between the two. Animals that eat plant food usually do not restrict their diet to particular species or parts of plants. However some of them are very specific in their food preferences. For example, the boll weevil eats only cotton and the pronuba moth feeds on certain parts of the yucca flower. Animals that are non-specific in their food habits act more or less as regulators in nature. They tend to keep down the most abundant plants, which might otherwise become pestiferous. Vegetarian animals are of course always much more numerous in any district than the carnivorous species which prey upon them. There is a series of dependencies in regard to food. Plants must be present in sufficient numbers to support vegetarian animals without being seriously depleted; carnivores can never be so abundant as to eat all the herbivores on which they depend for food. In any locality the plants and animals are so adjusted that their rates of growth and reproduction keep conditions fairly stable 
year after year. Without the influence of man there is seldom any overgrazing or famine.

Various animals have attempted to insure a stable food supply by storing food or raising crops. Certain ants, squirrels, beavers and other animals in times of plenty regularly gather appropriate foods which they store away for unfavorable seasons. The ancestors of ants appear to have been generally carnivorous, but certain desert species have gradually developed habits of gathering, husking, drying and storing the seeds of certain grasses. Other desert ants gather honey from flowers and store it away for use during the dry season in certain peculiar individuals of their worker caste. These remain within the nest, become greatly distended, and serve as living bottles for their fellows. Some species of termites make little beds of wood, the dead bodies of their comrades, and excrement. On these they plant and rear the fungi which they use as food. The leaf-cutter ants have progressed to an even more specialized type of agriculture. They go out along beaten paths and bring home bits of leaves. Some of these they use to thatch over their nest, but others are chewed up and arranged in beds on which a peculiar type of fungus is grown. This is not eaten in its natural state, but is first carefully pruned with the mandibles of the ants. In this way peculiar growtls, which were called "kohl-rabi clumps" by Muller, are produced. These growths constitute the sole food of leafcutters. When a young queen is ready to start a new nest she takes a little of the material from an old fungus bed and places it in a little pouch at the back of her mouth. She then makes her nuptial flight, breaks off her wings, digs a burrow, cuts a few leaves and prepares a little bed. Then she takes the fungus from the back of her mouth and plants it. She lays eggs and carefully rears a few young. When these mature, they begin to care for her and she then has nothing to do for the rest of her life but eat and lay eggs. Aside from a few insects, man is the only animal which has practised agriculture systematically. The assurance of a continual and adequate food supply among insects and men has been important in making the development of social life possible.

Plants are important factors in regulating climate and in making conditions in any locality suitable for animals. They cover the bare soil and thus conserve moisture. When there is a growth of plants over an area, winds cannot dry out the soil so readily and deep-growing roots bring water to the surface. Water is continually lost through the leaves of plants and by its presence in the atmosphere tends to make temperatures more equable. During the heat of the day water evaporates and thus cools the air. At night its condensation gives up heat and its presence as vapor serves as a blanket which prevents radiation of heat from the earth. Thus when plants cover the soil they help to furnish water to keep air temperatures more uniform.

Plants continually shed leaves which fall to the surface of the soil below 
and serve as a ground cover. Such accumulations retard evaporation from the soil, prevent rapid changes in soil temperatures, and exert other useful functions. They furnish shelter and food for many animals and fungi. As they decay, they produce heat which may be taken advantage of by many animals. For example, the brush turkeys in Australia depend largely on the decay of plant remains for the incubation of their eggs. These birds scratch together great piles of leaves and twigs and place their eggs within. They watch their rubbish heaps jealously and on warm, sunny days remove some of the material above their eggs, but during cold, wet weather they pile on more. Certain centipedes, salamanders, lizards, and insects take advantage of the heat generated by the decay of fallen logs to keep their eggs and young warm.

The vegetation cover over a tract of country also conserves and holds water in a more general way. The accumulation of living and dead roots, stems and leaves, serves as a great sponge which retains water after rains. In various countries where forests and other vegetation have been thoughtlessly removed, disastrous floods have followed. Of course floods do not always result from denudation, but the removal of vegetation is perhaps the most important factor.

There are many remarkable relations between flowers and animals. Flowers offer various "inducements" to attract visitors. Bright colors and characteristic odors make them easy to find; "rewards" to visitors take the form of nectar, pollen, and other foods. In return for such "favors" animals carry pollen from one flower to another and cross fertilization between different plants is thus insured. Some flowers show a high degree of adaptation for particular visitors. They furnish convenient landing stages, post color signals which indicate the shortest routes to the gifts of food, and have complicated entrances which prevent the stealing of "offerings" by unwelcome visitors. Some flowers depend largely on small birds for pollination and show corresponding adaptations. They are usually red in color and have long trumpet-shaped corollas. Other flowers possess special features which fit them for "fertilization" by bees, wasps, flies, butterflies, moths, beetles, or other animals. Avocado trees have two different types of blossoms on a single tree. The male flowers on a particular tree may open only in the morning, but on a nearby tree they open in the afternoon. On the same trees the female flowers will be open on the first in the afternoon and on the second in the morning. Insect visitors are thus pretty certain to carry pollen from one tree to another, and not between flowers on the same tree. The blooming of many flowers occurs at a particular time of day, and the insects which best carry their pollen are active at such hours but quiet at others. Flowers are of ten protected from creeping marauders, such as ants, by having separate "offerings" of honey exposed below the flowers; by isolation in or above water; by sticky secretions; by slippery, smooth or waxy surfaces; and by other means. 
Flowers have developed with animals. Millions of years ago there were no flowers. The first plants which "crept" from the ocean and freshwater on to land had none. Then plants began to develop pollen and seeds which contained stores of nourishment. The developing land animals soon took advantage of these concentrated and rich foods, especially during dry or cold periods when other foods were scanty. As animals formed habits of visiting particular plants, the latter gradually "responded" and various mutual benefits were derived from such associations. Finally the plants came quite generally to offer food, and advertised the fact; in return, animals carried pollen and distributed seeds. Fruits were developed which furnished luscious food about a hard or inedible seed. Today, a robin which swallows a cherry regurgitates the "stone," and thus these seeds are scattered about where they may find favorable places for growth. Burrs and little beggar-ticks take firm hold on the hairy coats of mammals and are widely distributed.

There are a variety of simple green plants, bacteria, and other fungi which live in the bodies of animals and serve various beneficial functions or cause diseases. Some of these aid in the digestion and assimilation of food. In fishes certain luminescent bacteria live in special cavities and produce light when stimulated by the host in which they reside. There are various fungi and bacteria which live in the skins of animals and cause diseases. In man these are most frequent in dark-skinned races. There are also bacteria which live within the body and cause diseases that are familiar to all: typhoid, typhus, cholera, tuberculosis, leprosy, influenza, etc.

Plants frequently furnish shelter or permanent homes for animals. The fibrous and woody portions of land plants are especially suited for such purposes. The paper-making wasps chew up fibers and shape them into nests which show characteristic forms and considerable architectural complexity. In the tropics bromeliads, which are all more or less like pineapple plants, harbor a great variety of animals, some of which are greatly flattened or otherwise especially adapted to live in the spaces between the leaves. Leaf-rollers, web-worms, and certain ants fasten leaves together to make nests. There are even a few insects that habitually take shelter within pitcher plants, which entrap and devour most types of insects. Natural or artificial cavities in trees are used as homes by bees, beetles, woodpeckers, owls, hornbills, squirrels, and other animals. Wood, on account of its flexibility, strength and durability is an excellent material for the dwelling places of animals. It is also a good insulator and therefore protects animals against the extreme heat of summer and the cold of winter.

Among the most interesting of the relations between plants and animals are those furnished by ant plants. Most of these plants "provide" shelter and food for their guests and in turn the ants protect them from browsing animals and plant-eating insects. In America the ant plants are largely acacias and cecropias. The former usually have hollow thorns at the bases 
of the leaf-stalks. These serve as dwellings, and glands near the tips of the leaves furnish food. The ants which inhabit acacias are very pugnacious and have very potent stings. They drive away leaf-cutter ants and other enemies. The cecropias provide many small chambers for dwellings within their stems. They also supply food along their leaf stalks, but many of their ants procure their food largely from plant lice which are kept in the chambers inside the stems. The ant plants in Asia are usually somewhat spongelike, with intercommunicating spaces within a fleshy body and many small openings on the exterior. In British Guiana, Wheeler studied an ant plant which had about fifty species of animals associated with it. These included twenty-eight species of ants, besides beetles, crustaceans and other things.

The various associations between plants and animals not only show the interdependence between the two, but also add to the evidence concerning the high degree of adaptation that all animals show to the particular environments in which they live. Animals are just as strikingly adapted to the living things which surround them as to the non-living.

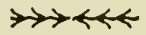

\section{SOME ADAPTATIONS TO THE ENVIRONMENT *}

\section{HORATIO HACKETT NEW MA N}

"The adaptation of every species of animal and plant to its environment," says Jordan and Kellogg, "is a matter of everyday observation. So perfect is this adaptation in its details that its main facts tend to escape our notice. The animal is fitted to the air it breathes, the water it drinks, the food it finds, the climate it endures, the region which it inhabits. All its organs are fitted to its functions: all its functions to its environment. If it were not so fitted, it would not live. But such fitness on the vital side leaves large room for variety in characters not essential to the life of the animal."

So long as the environment remains uniform, a given species will remain unchanged, except for minor fluctuations and occasional mutations; but if the environment changes, sometimes even slightly, the development of the individual responds in such a way as to give a radically different end product.

If the organism fits the environment, no less certainly-must the environment fit the organism. Professor Lawrence J. Henderson points out that the environment, no less than organisms, has had an evolution. There is hardly an element of the effective environment that could be changed without causing the extinction of life or at least the transformation of it so profound that it might not be life at all as we know life. Water, for ex-

* Reprinted from Evolution, Genetics, and Eugenics by Horatio Hackett Newman by permission of the University of Chicago Press. Copyright 1925. 
ample, has a dozen unique properties that condition life. Carbon dioxide could not be replaced by any other substance. In brief, given the environment as it is, life could not be other than it is. The evolution of the environment and the evolution of the organisms have gone hand in hand.

In the case of plants the action of the environment is remarkably direct; for the plant cannot get away from a fixed environment. If the environment undergoes material change, the plant's only response is a structural one. For example, if plants that are accustomed to a relatively humid climate are grown in the desert they develop numerous xerophytic adaptations such as small leaves with greatly diminished transpiration surface, a thick epidermis, hairs, or spines, small stature, deep-root system, and other similar protections against the inimical desert conditions. Similarly, plants accustomed to grow in relatively dry soil, if grown in soil that is covered over with water, will produce aquatic leaves and roots and undergo appropriate changes in epidermis and loss of supporting tissues, for plants that are buoyed up by water need little support.

Animals, on the other hand, are for the most part not so intimately related to a local environment as are plants. They are characteristically mobile creatures with varying capacities for wandering about and selecting the habitat that best suits them. "Animals select their habitats. By this we do not mean that the animal reasons, but that selection results from regulating behavior. The animal usually tries a number of situations as the result of random movements, and stays in the set of conditions in which its physiological processes are least interfered with," according to V. E. Shelford.

Many special adaptations may be explained through habitat choice. Thus animals such as the duckbill platypus, the lung-fishes, and others whose teeth are replaced by bony or chitonous plates that are used for crushing the hard shells of molluscs and crustaceans, may not confidently be said to have developed these crushing appliances in adaptation to a habit of feeding upon hard-shelled prey; but rather it seems more likely that the loss of teeth and the development of crushers occurred through a degenerative process incident to racial senescence and that the possession of the crushing equipment enabled them to avail themselves of a new type of food, formerly unavailable to them.

\section{SOME SPECIAL ADAPTATIONS}

The mammary glands of mammals are skin glands usually with well-defined ducts leading to the surface and terminating in teats. In the lowest mammals, the monotremes or egg-laying mammals, these glands are relatively poorly developed and diffuse; also they are known to be developed through a regional specialization of sweat glands. In the true mammals the glands are modified sebaceous or oil glands and may be seen to develop from the same embryonic rudiments as the latter. 
The marsupial pouch of the kangaroo and its allies is a pocket-like fold of the integument, folded forward or backward over the region of the abdomen in which are located the mammary glands. Hartman has recently described a very striking piece of behavior in connection with the birth of young opossums. The young are born in an exceedingly immature state and looking like tiny pink grubs. They crawl under their own power, by means of a swimming-like motion, through the hairs of the mother's abdomen, till they reach the pouch. This they enter unaided and each tiny "larva" finds for itself a slender tubular teat, which it swallows and holds in place by a specially adapted hold-fast mouth. The young remains attached fixedly to this teat for several weeks, feeding almost constantly on milk. After a long interval the teat is released, the mouth metamorphoses into the adult form and the young feeds only at intervals, as do the young of other mammals. This complex of adaptive structures and instincts is among the most remarkable in the annals of biology.

Nest-making instincts in birds represent, on the behavior side, adaptations of extraordinary perfection. Some nests are built with the greatest care and precision, others represent a relatively crude and slovenly performance. Some nests are made of twigs, fibres, and mud, others of mud alone, still others are hollowed out in clay or sand banks, and some are made in holes in the ground. In any case, the type of nest is highly specific and due to a hereditary instinct; for birds receive no instruction in nest building.

A vast number of animals and plants have given up the active search for food and have taken up the relatively easy habits of parasitism. In adaptation to this life certain structures have developed and many of the characters found in independent, free-roving creatures have disappeared or become reduced to mere vestiges. Thus the more completely dependent or parasitic an animal becomes, the more completely does it lose its organs of locomotion and its sense organs such as eyes, auditory organs, tentacles, etc. Some animals are free-living when young or in the larval condition and only settle down to a parasitic life when near the end of the life cycle; other animals are parasitic only when young or larval and become independent in the adult condition; still others are parasitic throughout the entire life-cycle and pass from host to host without any interval of independent life.

The classic case of extreme parasitic degeneration is that of Sacculina, a crustacean. The young larva swims about and leads a free life for a time, but soon attaches itself by means of its antennae to a hair pit of a crab. The internal tissues of the larva then undergo degenerative processes and are reduced to an almost fluid mass of embryonic cells, which flow through the hair pore of the crab and into the latter's lymph spaces. The small mass of cells then rounds up and is carried about with the circulation of the crab's blood until it comes to a favorable place of lodgment. Here it flattens 
out and sends rootlike branches almost all over the crab's body, like a malignant tumor. The unbranched part of the parasite is little more than a sac of reproductive organs, and these produce eggs and sperms, which unite to form larvae. By this time, the host is killed, and with the decay of its body, the larvae escape into the sea water ready for a period of free life.

Commensalism may be defined as an association in which two organisms exist in close association without any positive detriment to either. In some cases the claim is made that the association is mutually beneficial, but as a rule the relation is relatively one-sided.

Some of the most remarkable cases of commensalism are found in connection with elaborate colonies of ants. In some cases two species of ants live together in the relationship of master and slave. The master species is unable to perform any of the ordinary duties of the colony, such as securing food, taking care of the young, etc. In extreme cases the masters are only soldiers, specialized for fighting and marauding, and cannot even feed themselves unaided. The slave species would be able to carry on to some extent if not captured, but thrives exceptionally well under the protection of the soldier species.

One of the weirdest environments the world affords is the bottom of the sea at great depths. There it is dark and cold and almost devoid of oxygen, while the pressure is almost unbelievably high. Yet in these vast and forbidding abysses there dwell in apparent comfort representatives of most of the animal phyla. We do not at all understand the nature of the adaptive mechanism that enables these animals to withstand with their frail bodies the steel-crushing pressures that prevail at all such depths. We do know, however, how some of the deficiencies of the environment are made good by these denizens of the deep. Thus many abysmal forms produce their own light by means of phosphorescent organs placed at advantageous points of their bodies. Not only fishes of the depths, but some mollusks possess forms of artificial lighting equipment.

Equally highly adaptive to life in a world of darkness are the strange eyes of some of the abysmal fishes. Sometimes these eyes are enormously large, and thus adapted to bring to the perception of the animal the weak light of the depths, or again they may be modified still further in a strikingly peculiar manner, each being drawn out into a cylinder and projecting from the side of the head like a telescope. Such eyes are in fact not telescopes, but are merely adaptations for concentrating the lights of low intensity and making the environment visible.

Other creatures of the darkness live strange lives in caves, such as the Mammoth Cave of Kentucky. Most cave dwellers are blind or nearly so, and usually have a pale and ghostlike appearance because of their lack of pigment. All grades of defective eyes are found, ranging from those that are merely somewhat smaller than normal to those that remain deeply imbedded in the head in a relatively undifferentiated state. It goes with- 
out saying that such animals are better adapted to life in caves than they would be outside. One pressing problem of biology is: How did the cave animals become blind? Did they wander into the caves as normal animals and become blind because their eyes were disused, or did they become blind outside through no fault of their own, as a result of a mutation, and by chance find safety in an underground stream or cave? The first explanation is Lamarckian, the second Darwinian.

Adaptations are characteristic of all living organisms and must be accounted for by any evolutionary theory that is to be acceptable. Any theory that claims to account for new species but does not account for adaptations is at best only a partial explanation.

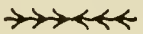

\section{BEES RAISE QUESTIONS *}

\section{H E N R Y S . C O N A R D}

In many ways, the behavior of bees suggests our own ways. Old beekeepers always attribute to their pets the will, the motives, the emotions that they recognize in themselves. Bee-keepers speak of bees in the language of human conduct.

In comparing bees and men certain factors should be borne in mind. From the evolutionary standpoint, we are of course very distantly related to bees, but our common ancestry is not nearer than the segmented worms or perhaps the Cambrian Eurypterids which lived 100 or perhaps 1,000 million years ago. A common origin of our protoplasm explains perhaps the similarities between bees and men in their cruder chemical and physical structure, and even in the muscles, nerves, skin, digestive tracts and body fluids. Both man and bees are made up of proteins, fats and carbohydrates; our active tissues are all protein in nature; we store excess food in our bodies as fat (insects are very oily); we consume carbohydrates and oxidize them for release of energy. We all get our protein and carbohydrate from the plant world, and give it back to the plants during life, as water, carbon dioxide and nitrogenous wastes, and at death our bodies return to dust. There is little reason to think that our common ancestor was capable of experiencing any of the appetites or emotions that we know in ourselves, although Jennings does assert that if the amoeba could be seen and known as we see and know dogs, we should attribute to the lowest animal organism known to science "states of pleasure and pain, of hunger, of desire, and the like, on precisely the same basis as we attribute these things to the dog."

Man and the honey-bee are, however, so profoundly different in most respects that we might almost regard them as inhabitants of different

- Reprinted by permission of the Scientific Montbly, American Association for the Advancement of Science. Copyright 1940. 
planets. Where the two creatures resemble one another, we often seek some other explanation than that of common ancestry. Usually it is due to adjustment on the part of the bee to the same world as that in which we live and to which we are adjusted. For life is adjustment, and any serious lack of adjustment quickly leads to death.

Our common ancestor was without any means for breathing air or for motion on land or for resistance to the desiccating effect of dry air, or for terrestrial hearing or smelling or seeing. It follows therefore that the adjustments of men and bees to terrestrial life have been achieved quite independently of each other.

As to breathing, we "draw air" into our lungs, there load the blood with oxygen and then pump it throughout the body to carry oxygen to the tissues. The insect has a system of fine air tubes whereby the air itself is carried to every part of the body. For motion the bee has six limbs to our four, and surpasses us completely by the possession of four wings. But her limbs so closely resemble ours-made up of two long pieces and a set of small pieces at the foot-that we not only speak of the legs and the feet of the bee, but we call the parts femur, tibia and tarsus. Obviously this resemblance is strictly superficial. It is not due to common ancestry, but to the mechanical nature of the world we inhabit.

The skeleton of the bee consists entirely of her hard outer shell, which serves in place of bones. This shell also serves to prevent desiccation. Our bones are inside us, and consequently we must have a special waterproof skin to keep us from drying up. The powerful muscles of the bee are attached to prongs and bars of the shell, which often project far into the insect's body. That this method is adequate is proven by the legs of the grasshopper and the wonderful flight of many higher insects. Once I saw a worker bee grasp a dead bee by her legs and fly up as high as the house and over a neighbor's lot before dropping her load. The muscles of the bee are "striped" exactly as are the voluntary muscles of the vertebrates. No worms have such muscles.

The eye of the bee is too complex to describe in detail, but it depends upon the lens-shaped bodies of dense refractive material which focus the rays of light. Of course, this is an adjustment to the nature of light-waves in relation to solid bodies. The food of the bee consists of nectar, or honey, and pollen, the latter being the richest bit of protein that plants produce. Why has man never found a way of eating pollen? I have tried it but without success; it didn't taste good. The nectar of flowers is mostly a very thin solution of cane sugar which the bee sucks up and swallows into a special pouch called the crop. The crop connects with the throat of the bee, as our lungs connect with our esophagus. In the crop later, the cane sugar is partly inverted or predigested, becoming dextrose and levulose. This is exactly the effect of human digestion upon cane sugar. 
In the hive, the bee regurgitates the thin solution of sugar which is received and placed in a cell of the honeycomb by a house servant. The water is evaporated by currents of air, set up by fanning by the wings of the bees. During this process the honey is tongued and tested by another class of workers. When a cell is full of sufficiently concentrated honey, it is capped over with wax and sealed. Now this honey, or nectar, serves as the carbohydrate ration for the bee, but pure cane sugar syrup does just as well. Consequently we may take away from the bees all the honey they make and feed them during the winter on a sugar syrup. At this point their digestions are very much like our own, but the inversion of cane sugar in both cases is due primarily to the nature of the sugar molecules, not to the relation between bees and men. Nor should it be assumed that all protoplasms can use the sugars interchangeably. Many bacteria can use but one or a few kinds of sugar and will absolutely starve if given only some other kinds.

Well-finished honey is about 20 per cent. water. A colony of bees will consume from 20 to 40 pounds of honey during the winter months when they can not leave their hives. For each pound of honey consumed, at least three quarters of a pound of water and one half a pound of carbon dioxide will be exhaled by the bees. That is, a hive of bees generates seven to ten quarts of water during the winter, all of which must be expelled from the hive. It is a delicate matter to get enough ventilation to eliminate the moisture, and yet not take in enough cold air to freeze the bees. Sometimes the water does condense on the inside walls and top of the hive. If it drips down and freezes at the entrance to the hive, completely stopping the entrance, the colony will quickly die for lack of air.

The production of carbon dioxide by bees, as by other animals, increases with the temperature and the activity of the animals. When cold and at rest, bees produce but little carbon dioxide and need but little air. One cold evening in early winter, I moved two hives, disturbing the bees and setting them in motion. For some hours afterward it was necessary for them to keep up a vigorous fanning with their wings at the entrance of the hive in order to expel the vitiated air and to draw in enough fresh, cool air. On moving one hundred hives of bees one autumn, we packed the entrances tight with soft snow in order to keep the bees from emerging. But the bees directed a current of warm air against the snow and melted holes through it in from three to five minutes.

In winter, or at any time of rest, the bees cluster together in a solid mass. Those at the center are constantly working out to the surface of the mass, while those at the surface are working in. A neighbor undertaking to kill a small colony by freezing, uncovered the hive, spread the combs apart, and left them overnight. The next morning, with the temperature at $10^{\circ} \mathrm{F}$., all the bees were still alive. By remaining in a compact mass and continually 
exchanging places they were kept warm by their own body heat (combustion of sugars). The healthy cluster maintains a temperature of $57^{\circ}$ or above.

Bees can not void their excrement except when flying; at least it is believed they do not. During the winter their abdomens become greatly distended with waste matter. If their stores are of inferior honey, this condition will be intensified and may prove fatal. If wintered out of doors, bees usually find days in January or February when they can fly out. Hence, wintering out of doors with sufficient protection is better than wintering in a cold cellar, for in the latter case so-called cleansing flights are impossible. Since bees can live all winter with only honey, i. e., water and carbohydrate for food, during these periods they use protein sparingly in their life processes, and they must be in a state of extreme protein starvation when spring comes. There are in honey, usually, a few grains of pollen, and some pollen is commonly stored in the hive in the cells separate from the honey. Perhaps from these sources bees get a sufficient protein ration, but I think they eat only honey in winter.

The personnel of a colony of bees consists of three castes or classes: drones, workers and queen.

Drones are male bees. They are much larger than the workers, and are present in a hive by tens or hundreds. The drones can not gather honey or pollen and can not even feed themselves, but are fed by the workers. They buzz very viciously but have no sting. Their sole contribution to a colony of bees is to mate with the queen, and since a queen mates but once in her life, very few drones ever mate. Drones are reared from June into summer. In September the workers drive them out from the hive and prevent their return. So they starve to death or die of cold.

Drones are the product of unfertilized eggs laid normally in the larger cells of the comb. All drones, therefore, are fatherless, though they have grandfathers and stepfathers, because queens and workers develop from fertilized eggs, and have a male parent. And a drone which mates with a queen will be the male parent of hundreds of workers and a dozen or more queens.

Beekeepers always think of drones as lazy, happy-go-lucky louts, with nothing to do but eat, sleep and buzz about on sunny days, waiting for an occasion for mating. But for the drone, the mating is a serious matter, for the act is fatal. The queen returns to the hive with the end of the abdomen of the male torn off and hanging to her.

There are from 20,000 to 50,000 (some say 80,000 ) workers in a strong colony. The worker is an unsexed female, with only rudimentary ovaries, but in a queenless colony one or more of the workers may acquire the capacity to lay eggs. Probably this condition is brought about by the excessive feeding of selected young bees. Such "laying workers" never leave the hive and never mate. Hence they never lay fertilized eggs; their eggs are 
fatherless and hatch out only drone bees or males. Such a colony soon dies out, since no new workers can be raised and the life of a busy worker in summer is only five or six weeks. Workers hatched late in autumn live over winter, and do a few weeks' work in spring. To get rid of laying workers, one has only to shake all the bees out of the hive in a grassy place, a hundred or more feet from the original position of the hive; the regular workers will easily find their way back to the old stand; the laying workers never having been out of the hive, can not get back and will perish. Then the helpless, eggless colony will accept a new queen, if one is offered to it.

Workers alone have mouths for collecting nectar and the honey-carrying crop. They also have combs on their front legs especially suitable for combing pollen off their bodies. The second pair of legs has a notch through which the first legs can be pulled, to gather up the pollen; and the hindmost legs have each a little basket in which the pollen is placed and carried home. Workers differ greatly in their use of this natural equipment. Some return home all dusty with pollen, and let their sisters clean them up. Others enter as neat as a pin, with huge sacks of pollen on their legs.

Last summer a loaded worker entered an observation hive and presently walked along one side of the comb, then went over to the other side, rambled about over and through and under a cluster of bees, looking into various cells here and there and, finally, after several minutes, settled on a place to unload. She put her hinder legs deep into a cell, and remained for about a minute; then she pulled them out, leaving her two lumps of pollen loose in the cell. Immediately, another worker went in head first and remained for about a minute. When she came out, the pollen was tightly and smoothly packed in the bottom of the cell. The bee which lost the time in deciding on a place for depositing her pollen was typical, for most bees seem always to be just milling around aimlessly over the comb. Do not send the sluggard to the busy little bee to learn a lesson in efficiency.

Observers remark the same characteristic when the bees are building their marvelous comb. They run about without any semblance of order or continuity of work. A bee bites at the comb here, sticks on a bit of wax there, and runs on while others follow. But meanwhile the marvelous comb grows up before our eyes! The wax is secreted in scale-like pieces on the under side of the abdomen of the workers. To produce the wax they eat vast amounts of honey and hang in characteristic clusters over night. The wax appears in a few hours. Bees consume about twelve pounds of honey to make one pound of wax, but one pound of wax will build enough comb to contain sixteen pounds of honey. The cell of the comb is not only hexagonal-a response to the nature of the space in which we live-but its axis slopes upward, so the honey will not drip out. There is, therefore, a very definite right side up for honeycombs.

There are three sizes of honeycomb cells. Most of the cells are almost exactly one fifth inch in diameter. As long as the queen lays eggs in the 
cells as fast as they are ready, this size cell is made. If the workers get ahead of the queen, they build larger cells one fourth inch across. For storage of honey, even larger cells may be made. But all this variety is produced in an apparently disorderly, helter-skelter manner by a host of workers, running about over the comb. We have absolutely no conception of how a precise picce of work can be turned out in this way. Nor can we believe that the method is economical or efficient. Apparently it succeeds merely by dumb persistence-by force of numbers and in defiance of time.

The workers are custodians of the hives; it is they who fly out and sting the intruder. But the different varieties of bees differ greatly in irritability. The gold-banded Italians sting only after rough handling, but a black bee will probably sting you if you simply stand within five feet of her doorway. This reaction is changed by puffing smoke into the hive or upon the bees. Certain it is that smoke induces the bees to rush to the combs and gorge themselves with honey without stopping to sting the intruder. After smoking the bees, one can open the hive, lift out the combs one by one, and inspect them minutely. Sometimes not one bee will attempt to sting; at other times, however, a half dozen will leap on one's hand at once and sting with great energy. Why the calming influence of smoke?

Animals and plants respond to natural stimuli in a manner that has proven, in the last million years of experience, to be useful and profitable. A new and strange stimulus will call forth one or another of the reaction patterns that have been established by age-long experience. Is smoke a new experience, and the reaction fortuitous, or is it a very old stimulus with an adaptive reaction? Since bees have lived for ages in hollow trees, the smell of smoke may indicate to them that their tree is on fire and that the colony should move. So the bees load up with honey and get ready. It is probably possible so to smoke a hive that the workers will leave it, taking their queen along, but usually the queen simply hides among the bees or in some corner of the hive. This hiding of the queen is doubtless a reaction to the stimulus caused by opening the hive. In all the pre-human period bee hives have never been opened up and the combs removed except by predatory animals. And the combs were never put back in as I do it until the invention of the movable frame in 1852 . Under such conditions the preservation of the colony depended upon the queen being hidden among the mass of the bees, or tucked away in some deep crevice. Then when the marauder had gone, she could come out and join the remnant of her family to reestablish a home in the same or another hole in the tree.

So when I smoke my bees, and proceed to tear open their hive, I turn loose two ancient behavior patterns-the behavior suited to a burning tree and that suited to an attacking animal. For the first, the bees fill up with honey and do not sting; for the second, they sting violently and hide their queen. The business of the beekeeper is to keep enough smoke in the 
air to hold the insects to the burnt-tree type of reaction. Even so, why the difference in irritability of the several varieties of bees?

The ability of bees to make long journeys-two to four miles-and return unerringly to their own hive is remarkable. The feat becomes more interesting when we see the bee yard containing 50 to 100 hives, all made as nearly alike as modern machinery and paint can make them, and packed so closely that there is just room for the beekeeper to pass between them. But interest culminates when we learn that this skill is the result of careful training. A young bee first emerging from the hive suns herself on the front porch. Later she flies out a foot or two and buzzes about facing the hive. Then she goes farther and farther, still facing the hive-say to ten or fifteen feet. Finally she makes a real collecting trip.

Last summer I placed a comb of bees in an observation hive, fastened them in, placed them in the cellar to cool off. They settled down at once. Twenty-four hours later I found they were humming in a tone that indicates mild excitation. (One can tell what a bee is likely to do next by the tone of her humming, just about as well as you can predict the next act of a dog or a person by the tone of his voice.) I took my bees out to a new location and opened the little doorway. It was six P. NI., just growing dusk. In a few minutes one bee found the open door. She crawled out, made sure of her freedom, and then stood by the door and buzzed till you couldn't see her wings. Soon another came, and she buzzed too. Then they all made for the door and poured out in a stream, mostly taking wing at once. For several minutes they made quite a swarm within 3 or 4 feet of the little hive, milling about in the air, all facing the hive. Then they spread out farther and farther, to 100 feet or more. I thought they must all be gone. But while I thought it, the crowd gathered again by the door, and all poured in as eagerly as they came out before. In a trice all were in and quiet. Had they been studying the location? Ordinarily, when collecting, they run out of the hive and take wing without a look behind; and returning, swoop out of mid-air directly into the doorway.

When it is necessary to move a colony, one should place a board or net in front of the hive in its new location, so the bees will be compelled to take notice as they come out. The obstruction can be removed after a day or two. There is no doubt that bees can learn to find a certain location, both for their home and for their collecting grounds. A good collecting ground is revisited until its resources are exhausted. Then a new place is sought and similarly worked. Ability to do this is essential to the life of the bee.

I do not see in this any general ability to learn. It is only an adaptation to the peculiar life of bees-gathering nectar from the successive fields of flowers from season to season-and the change of abode when swarming. It does not indicate any ability to learn in any other realm of knowledge.

When bees are much agitated by a disturbance in the hive or by the 
excitement of stealing made-up honey from whatever source ("robbing"), the bees do not usually settle down until nightfall; they have to sleep it off. The length of time for relaxation depends on the intensity of the stinulus. So it is with a person. When he is greatly excited, he gets a large dose of adrenalin poured into his blood from those little glands in his back. And he simply can not settle down until that disturbing hormone is oxidized or eliminated or sent back to its place. Ritter suggests that the human organization is unified by hormones. Does the bee have hormones? Does a puff of smoke let loose in her body fluids some guiding substances from some hidden gland? And when I open the hive, do I stir up some other hormone, which keeps Miss Bee literally on pins and needles until the hormone works itself out?

Speaking of robbing, whenever bees find a chance to gather real honey, ready made, they go for it and carry it away with the utmost haste and energy. They often tear a comb to pieces, a thing they never do in their own hives. They fight one another while gathering the loot. They are unusually irritable and liable to sting. Once about noon I left a lot of combs, wet with honey, exposed in my shed. On getting home at five o'clock, I found the air full of bees buzzing around the shed and the shed crowded with bees. A neighbor down the street called my attention to the great numbers of bees buzzing around his house, my bees stirred up by the experience of robbing. Were I a Maeterlinck, I could describe them as exhibiting all the passions of a madhouse or an army. With nightfall, the bees mostly came home. I put the exposed combs under cover by candle light, and next day all was quiet.

Bees sting in different ways at different times. If one alights quietly on one's face or hand, she means no harm, and soon flies away. If she gets into one's hair by accident, she hurries down and stings. Why? because among the hairs she feels caught; the reaction is to injure and drive away the enemy. If she alights on one's arm and one's sleeve presses down on her, she stings. A drop of ammonia cures it. If her hive is disturbed she comes out with a shrill whistle of the wings, and the intruder is in for it. She alights on his glove, bends down her abdomen and gives a thrust. It misses its goal in the soft fuzz of the gloves. She thrusts again, with a violent contortion,- - she misses. Again she thrusts, with a violence that nearly bends her double, and draws her abdomen into a sphere. One is obliged to think of it as an expression of baffled rage and savage bitterness. She looks and behaves like a veritable little fury.

The queen fulfils the Christian admonition that he who would be greatest must be servant to all. (That is the only Christian virtue about bees.) She has absolutely no freedom of action whatever. She can not feed herself, but is fed by her daughters. When she lays too many eggs, the workers withhold food and she lays fewer. If she lays too few, they feed her up. So do beekeepers. If that doesn't bring results or if she lays only unfertilized 
drone eggs, she is carried out and killed, and a new queen is raised. If she lays eggs in small wax cells, and she is young, she lays fertilized female eggs; if the cell is a large one; she lays unfertilized drone eggs. It seems to be simply a matter of the size of the cell. When the bees are moved to swarm out and leave the hive to start a new colony, the queen goes along with them. If she doesn't go, a guard of workers goes in and gets her. Two summers ago a swarm came out of one of my hives. I caught the queen with difficulty and awkwardness, put her in a cage after much fingering, and gave her and her flock a new hive. Next morning I found her lying dead in front of the hive, with a few bees crawling over her. Authorities tell me I handled her too much; she got a strange smell and the workers killed her.

When a hive is opened on a rainy day and rain falls into the hive, the workers are likely to kill the queen. These are reactions for which it is not easy to see an explanation. Once a colony was left queenless by such madness and without hope of ever getting a queen. Left to themselves they would have died out. But they were given the makings of a new queen, which they accepted, and raised a queen and produced 15 pounds of good honey.

Queens and workers come from exactly the same kind of eggs. Queens are raised in very large cells, as big as the end of one's little finger, and are fed as larvae upon very rich food called royal jelly. If one takes a young worker out of her cell and places her in a big cell with a bit of royal jelly, the bees will go and make a queen of her. Or, if the queen is removed, the bees will make several queens from the recently laid eggs. When, in 16 days, those new queens are hatching there are exciting times.

A queen emerges from ber cell with a number of complete bebavior patterns. One day a worker came by just as a queen emerged. She jumped on the worker and was about to give the death blow with her powerful sting when she suddenly stopped and got off. My informant remarked that "she discovered her mistake." Did she? Soon she met a newly hatched queen. Again she leaped on and this time she plunged her sting into the abdomen of her victim between the plates of armor, and the victim curled up and died.

After killing all her immediate rivals, the young queen lives quietly for a day or so, and then goes out on her mating flight. A few workers go with her. They fly up into the air and are gone a few hours in the middle of the day. She meets the drone in flight and receives into a little sac enough sperm cells to supply her egg-laying for two, three, four or even five years-200,ooo to $\mathrm{I}, 000,000$ male sperms. She returns to the hive with a high degree of certainty. Whether she finds her own way back or is guided by her more experienced attendants we can not say. Having returned, she is groomed by her maids, and in two or three days more begins her career of egglaying. On occasion a vigorous young queen can lay 2,50o eggs a day, more than twice ber own weight! 
For various reasons we often want to give a new queen to a colony-a queen of our own selection, which is quite possible if done correctly. First we must remove the present queen and be sure that no laying worker is at hand. It is well to wait three or four days until the bees have themselves built queen cells and begun to raise new queens. Then destroy all these beginnings, and the colony is hopelessly queenless. There are many ways of introducing new queens. Of course, the situation is absolutely new and strange in the experience of bees. They have no behavior pattern for such a situation. It can only call out some kind of behavior that has been developed for some other circumstances.

Sometimes in adding a new queen to a queenless colony this colony is joined with another. Now there are only two natural situations where a large number of bees enter a colony: First, where a swarm settles in a hole that is already occupied; in this case there is a strange queen as well as strange bees-hence some of the behavior towards strange queens. And, secondly, where the strangers come in to rob and carry off honey. In either case, the rightful owners do all in their power to drive off and kill the invaders. This, then, is the natural reaction when two colonies are united. Last summer I put a small group with a bigger one, and next day the ground in front of the hive was littered with dead bees. Apparently every stranger was killed. To obviate this difficulty, some beekeepers turn in a quart or two of strange bees into the hive and then sprinkle in a quart or so of water. The water changes the type of reaction. One old man tells me: "Oh, no trouble at all. If they get to fighting, just get a spoonful of flour and dust it into the hive all over the bees. Then they get so busy cleaning each other off that they forget all about their quarrel." Why does it work?

I have spoken of the bee as a combination of hereditary structures and behaviors. But it must be remembered that the parents of worker bees are drones and queens, and these parents do not have the characteristic structures nor the industrious or warlike habits of workers. How can workers inherit characteristics which their parents do not possess? Only, as some wag said, by inheriting from their maiden aunts.

While this inheritance has been considered a problem, it is really not so. Or, rather, it is a commonplace problem, and part of all considerations of heredity. Bees are improved by breeding from those queens whose offspring are most productive and least irritable. And nature too has certainly bred from those queens whose offspring best fitted themselves to their surroundings.

It is very easy for me to believe that the bee is a kind of automaton-a complex of physico-chemical reactions bound by and leading to a complex of behavior patterns-and that all is dependent on the nature of the materials and forces of our world and the million-year-old inherited experience of bees. But if that conception of the bee is true, what am I? If 
the bee could observe me as objectively as I observe her, would she not define man in exactly those same terms? Can she do otherwise? Can I do otherwise?

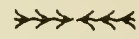

\section{HOW DANGEROUS IS THE JUNGLE? *}

\section{S U Y D A M C U T T I N G}

A good way to improve one's knowledge of natural history is to look into some of the misconceptions that have arisen about the character of wild animals. For misconceptions, like bad pennies, keep cropping up in daily conversations, and our knowledge of animals must stand that test before we can go further. I refer not to wild animals seen along the length of a rifle barrel but wild animals as they exist under natural conditions. Our discussion will be limited to some simple observations, for I have never undertaken an exploring trip for the prime purpose of studying wildlife. But I have always been as much interested in the natural behavior of the wild animals I have hunted in Africa and Asia as in the actual sport.

For all the danger to the lesser animals, the jungle is a more tranquil spot than the romancers make out. The man who enters it for the first time may expect to see a congress of frenzied animals with a symphonic background of roaring lions, barking jackals, hissing snakes. Instead, he is surprised to find a vast silence, broken only by the cries of birds and the stridulations of insects. If he stays long enough, he may, depending on the region, hear a lion roar before starting off on a hunt, a hyena growling as if the sounds came from the depths of his bowels (the hyena's growl, contrary to legend, does not resemble laughter!), or a jackal barking his light, sharp note. Many animals will probably maintain a discreet silence.

The quietest time of all in the jungle is high noon, when the glare of the sun and the heat reach their greatest intensity. Most of the animals are probably sleeping. Even the birds and insects relapse into dead silence. Only the bees are inspired to greater noise and activity by the bright sunlight.

Late in the afternoon life begins to stir. Toward their various water holes, animals of all kinds begin their cautious descent. Whereas the ruminants want only a drink, the meat-eaters are yearning for dinner. The mortality curve rises at this hour.

The lion, tiger, or leopard will probably start his prowling toward the watering hole of lesser animals. The big cats are extremely agile but at the same time they are not in the market for any long distance runs. They first stalk their victims and then make a rush. When they get near enough to strike, it is all over for the victim.

* Reprinted by permission of Natural History Magazine and the author. Copyright 194I. 
Having killed, the big cats do not proceed to eat the entire carcass immediately. They eat a little starting from the rear, and return later. A carcass left for 24 hours in the jungle is likely to become carrion. And carrion is what the big cats like.

Now and then a big cat rushes his prey and misses. In this event he is usually disinclined to give chase. Racing through the jungle or across the open plain is not to his taste. If he bides his time he will find something later with less effort.

Offhand one would think that the habit of leaving game for the morrow's meal would result in thefts and hence lead to fights among the big cats themselves. But the instinct of these animals is usually to eat their own kills and let the property of others alone, and they usually lie up near their kills.

THE VULTURE "GRAPEVINE",

When the beasts have consumed their prey, the vultures take their turn. It has taken a great deal of observation to discover the secret spying methods of these birds. At the moment a beast makes a kill, the human eye is often unable to discover a single vulture either in the sky or in the surrounding trees. Yet within a few minutes, scores, sometimes a hundred birds, come whecling down from the sky, to fall on their game-what is left of the animal.

Their system is simple. Spaced far apart in the sky beyond the range of binoculars, they are able to survey a wide stretch of territory. If one detects something promising, he swoops lower to have a look. One bird sees another swooping down, and curiosity moves him to follow. The signal spreads for miles around. The sky patrol, too high for human vision, operates very efficiently.

With possibly the single exception of the leopard, big cats are not in the habit of killing more than they can eat. This acts as a sort of safeguard for the lesser animals, for all can tell the difference between a hungry cat and a sated one. Once when I was in a machan (a high platform in the trees from which one observes game), I heard a sambar deer get near enough to a tiger to bell at him. The tiger in the neighborhood of his latest kill seemed in no hurry to start feeding. This reassured the deer, who kept up his belling for quite some time and then moved off.

In discussing life in the jungle I have said that the danger for a man is vastly exaggerated. Others have said this before me, and some have gone far enough to say they preferred a jungle, from a safety standpoint, to Fifth Avenue, New York, in the rush hour. I wouldn't go that far.

If there were no other reason to fear most jungles, there would be malaria. There are also scorpions, centipedes, stinging ants, and wild bees.

In Kohima, Assam, a swarm of wild bees once appeared on a tennis court 
while I was in the middle of a game. My partner called across in a peremptory tone, "Stand perfectly still! Don't budge!"

I obeyed, standing breathless for several seconds while the bees whizzed by only a short distance above. The queen was in the center, of course, and any gesture indicating danger to her might have brought the vast cloud closing in around our heads.

We have said a great deal to deflate the common romantic idea of the jungle and the habits of wild beasts. But the fact remains that man-eating animals do exist. When lions, tigers, and leopards acquire a taste for man, they are terrible, relentless enemies. When a big cat shows a tendency to attack man, he is, of course, an abnormal animal, and it is often difficult to say with any degree of finality what caused him to become abnormal.

Many explanations have been given. A big cat, once wounded by a man, may develop an inclination to attack men without further provocation. By example the young may be taught to become enemies of man. Aged or disabled cats that find difficulty in slaying other animals may take to attacking human beings. Cats that have tasted human flesh seem more dangerous than those that have not. Many are the theories and difficult are the proofs. Case histories of wild animals, it stands to reason, are difficult to procure.

A distinction should be made between animals in the jungle and animals that wander afield near human habitations. When one reads that 3000 people lost their lives to wild animals in India during a single year and that 1600 of these were tiger casualties, there seem to be grounds for the notion that the jungle is as dangerous as the romancers make out. Actually the figures prove no such thing. Few of the casualties occurred in the jungle. The miscreant beasts were prowling near villages, many doubtless bent on stealing domestic animals. Their encounters with man certainly altered their natures. It is impossible to say how many of the attacks were unprovoked.

Selous, the most famous of big game hunters, who was killed in the Great War, said, "Any man who invites the charge of a lion is an idiot."

Tigers have a better opportunity than lions for declining further acquaintance with man. Whereas a green hunter, starting off in real lion country with the proper guidance, feels reasonably sure that his chances are good to get a lion, the tiger hunter has no such assurance. He may, as a matter of fact, undertake many shooting trips and never see a single tiger. Bigger and stronger than the lion on the average, the tiger is also more elusive. He is never seen in large numbers. His habitat is dense jungle and high grass. All in all, man and tiger meet less frequently than man and lion.

The density and height of vegetation in the Asiatic tiger country defies a hunter's vision. If he is on foot, views of the tiger are momentary and re- 
quire a quick shot with very little time for a careful aim. Facing a wounded tiger in a jungle is a truly hazardous position. For this reason tigers are shot from the back of an elephant or from a machan which is set 20 feet or more above the ground. Natives of the tiger and lion country erect thornbush palisades to protect their cattle.

What has been said of the tiger applies also to the craftier and more courageous leopard. The same land usually harbors both animals.

Two ruminants who can be very dangerous because of their size are the bison and water buffalo. These animals, if wounded, may charge a man.

I learned something about the water buffalo during a shoot with Theodore Roosevelt, Jr. We were stalking a large herd in a vast, open dry swamp in French Indo-China. Because there were no trees and the grass was too short, we had inadequate cover. The herd sighted us. Instead of moving away or stampeding, they turned and faced us, with their leader out in front. At that time we were shooting with a Frenchman named De Fosse who had lived in Indo-China for a long time and knew the habits of the water buffalo. Instantly he perceived danger. "If the leader makes for us," he said, "the whole herd will charge at us blindly. They have no purpose of their own, a mere blind impulse to follow the leader. All of us must fire at the leader."

We lifted our guns. We fired. Two animals fell. There was a breathless pause while we waited to see if there would be a charge. But the noise of the guns terrified the entire herd. They stampeded away from us.

In South India I had an experience with the bison, or gaur, of that country. Once a solitary bull was wounded and he escaped into the jungle. We had to follow him for more than a day before finishing him off. My companion on this pursuit was Randolph Morris, a coffee planter, with whom we were staying. He knew the habits of the bison, and it was under his direction that we moved forward with infinite care from tree to tree. Twigs, dry leaves, and clumps of earth were daubed with the bloody footprints of the wounded beast. The jungle interfered with our vision. While we could always follow the aninal's path, we could not gauge his proximity. From time to time we threw stones into the dense thicket in order to locate him.

Hour after hour we followed the bloody track. Once we got within 50 yards of the animal. Morris had decided it would be too dangerous to invite the frontal attack of an animal weighing almost 2000 pounds. A way had to be found to divert its attention.

When we found ourselves in a tiny glade not far from the animal, Morris tossed a knife, hoping the enraged bison would charge it and give us an aim. He threw it too far. The knife landed in thick jungle out of our sight. But suddenly we heard a snort, a bellow. The 20oo-pound beast was crashing through the jungle. Our native servants were terrified and clambered up the nearest trees. Just at this minute I looked up. An enormous red and black 
squirrel, four feet long, went springing from tree-top to tree-top with such speed that he seemed to be flying. Then there was silence once more.

This failure meant many-more hours of stalking. It was not until the next morning, as a matter of fact, that the bison was brought down.

These instances prove but one thing, that the bison and water buffalo are disposed to charge, given sufficient provocation. The word "provocation" is important. These two ruminants, along with the big cats, have been taxed with a fundamentally hostile attitude toward man. But often it is man that starts the trouble.

\section{ATTACK WITHOUT PROVOCATION}

I can name two animals, however, that will attack a man without provocation. They are the Asiatic sloth bear and the rhinoceros. Up to the moment no mitigating circumstances have been found for them. The king cobra is also supposed to attack without provocation. But on the whole snakes are much maligned.

We have named three out-and-out aggressors. But this is not such a formidable list when we consider the legends of evil behavior in the animal kingdom.

In American folklore a great deal of mischief has been imputed to the wolf and the eagle. Let us consider the wolf's case. The United States Biological Survey disposes of two legends. American wolves do not hunt in large packs and they do not attack man. The most they achieve in the way of communal organization is the hunting of smaller game in small groups. Man they let alone. On the other side of the wolf ledger there are plenty of cases where Asiatic and European wolves bave attacked men.

The stories about the eagle's exploits usually spring from an exaggerated idea of the bird's strength. It is true they will swoop down and snatch rabbits, hares, and even young lambs. But eagles which seize children belong in mythology. Among the natives of northern Chinese Turkestan, incidentally, the eagle is sometimes used for coursing. The bird is let loose at gazelle. Left to his own choice, he would not ordinarily attack such a big animal since he could never hope to carry it back to his aerie. But he has been well trained. He knows that if he can knock down or impede the animal in his flight, mounted sportsmen will soon ride up to dispatch it.

By this time it has become reasonably clear that in most conflicts between man and beast, man is the aggressor. From earliest times man has hunted-as a means of procuring food and for skins to protect his body against the elements. He has left a legacy of fear with the animals, and the fact that some of them when injured or menaced will fight back is not in the least surprising.

One curious phase of man's relation with the animals is the process of domestication. Although all the domestic animals we know today were originally wild, the transformations all took place in prehistoric times. 
There is no written record of any animal's being domesticated in modern times, except the African elephant. And whether we are to call the African elephant a domestic animal is a moot point.

We have seen that wild animals are inclined to flee from man. Certain animals enjoy special advantages, such as speed and cunning, in avoiding human contacts. Others are well protected because of their isolated habitats.

In my experience the most exhausting kind of hunting is provided by the anoa of Celebes, the panda of Chinese Tibet, and the ibex of northern Ethiopia and of the Tien Shan Mountains of China.

Even to approach the Simen Mountains of Ethiopia or the Tien Shan range requires tremendous effort. Crags and precipices at lofty altitudes are the habitats of the goat. The chances are against the hunter's even seeing game, to say nothing of shooting.

The panda inhabits a mountainous region, dense with dwarf bamboo. Not only is visibility bad but the ground is usually covered with mud so that the hunter must constantly guard against falls. Silent stalking is out of the question: the bamboo cracks and breaks so that the panda is forewarned.

The anoa or dwarf buffalo of Celebes lives in steep, hilly country, protected by dense jungle. Merely to cut one's way through this jungle requires terrific labor. Thorns reach out to scratch the face and tear the clothes. Visibility is usually limited to a green wall a few feet away.

\section{T I G E R H U N T}

I should like to tell of a tiger hunt carried out in Nepal, in the district of Kheri. This hunt, to which I was invited by Kunwar Dillipat Shah, brother of the Maharani of Kheri, was interesting because it showed something of the tiger's characteristics and emphasizes the trait I have stressed -the desire of the big cats to avoid trouble.

The first step was to tether native cattle to trees in the jungle. The forest officer was aware of the approximate number of tigers in the district, having acquired the information from native forest rangers, who seemed to know everything going on in the jungle. When a tiger or leopard had made a kill, the facts were reported to us the next morning by the ranger. Preparations were immediately made for a hunt. The tiger or leopard, after killing a calf, would invariably drag it a short distance away, sample it, and then go away for a while. Until he felt disposed to return and finish his meal, he would in all likelihood remain in the vicinity of the kill.

There were two periods of the day when hunting was feasible. One was the early morning shortly before sunrise, when there was barely light to see one's rifle sight. The other was in the heat of the day, when the animal would be lying in some thick, densely shaded spot and could be driven out by a line of elephants. The middle of the day was the better time be- 
cause it gave us better visibility for shooting. (We hunted both tigers and leopards in exactly the same way.) It was not necessary to hurry, for we knew the tiger would probably be somewhere in the vicinity of his kill all day.

We had twelve elephants in the line, which gave us a beat of considerable breadth. The breadth varied so much depending on the nature of the terrain and the proximity of the tiger, that it was difficult to estimate its mean. Perhaps it was never less than 150 yards or more than 300.

The beat moved through high ratwa and nurtle grass, which sometimes grows as high as the howdah (the commodious railed, canopied seat on the elephant's back). Should a tiger sleeping in the grass be startled by our beat, his natural tendency would be to move on ahead of us. But cases have occurred where a tiger, driven out of his refuge, broke back through the line of elephants. Great precautions had to be taken to keep the elephants close enough together to frustrate any such move; for swinging around to shoot from an elephant's rear is difficult.

As long as we could drive the tigers in front of us we had no fear that they would disappear "into the blue" like deer or antelope. Tigers, like all big cats, will not run far. They have a short temper and no running endurance. It is true one may lose them, but the explanation then would be that they had turned or doubled and were again secreted in a spot where the beat would just miss them.

The tiger as a species was originally a cold weather animal. The Indian tigers of today are supposed to have descended from Korean, Manchurian, and Central Asiatic stocks. The reason for the migration seems to have been the more plentiful game afforded by the hot countries.

The tigers in our area were not fond of heat. As soon as the sun was fairly well up from the horizon, they chose a densely shaded spot wherein to lie down.

With twelve elephants in line, a considerable area could be covered; and since we continued beating as long as the light permitted, our chances for discovering a tiger were excellent. All during the beat the line tried to comb those places where the grass was highest and the jungle thickest.

This difficult and highly technical show was managed by the Kunwar with consummate ease. He used gestures. He spoke in a soft, gentle voice. Occasionally he whistled. Men and elephants were instantly responsive to his signals.

There were no dull moments during the hunt. We never knew when a tiger might appear. But we did know that a bad shot might cause the tiger to charge at an elephant and maul him. An elephant cannot abide the smell of a big cat. Seeing a tiger, he will always trumpet and raise his trunk and curl it over his head, for he knows how vulnerable he is to a tiger's claws. Because a tiger can leap very high, accidents do happen. However, keepers always take great care to dress their elephant's wounds. 
Although we had twelve elephants we did not have a rifle on each. Three or four rifles among the lot was considered a fair number. Each of the elephants carrying a rifle also carried a howdah. The other elephants, merely assisting in the drive, each carried the mabaut (keeper) and one or more other natives.

The mabaut always sat forward of the elephant's shoulders. His knees were curved around the animal's ears, and his feet dangling downward gave the signal for every movement. The other natives sat on a large pad fastened to the elephant's back by ropes. These ropes provided them with a grip when the going was rough.

Shooting from a pad elephant is not uncommon. The hunter, sitting directly behind the mabaut and facing due forward, has two means of traversing his rifle, right and left. For general shooting, however, the howdah is preferable. This is a comfortable perch and is large enough to accommodate an extra kit of guns. For the sake of steadiness one usually stands up to shoot from a howdah. Hunters find it better to lean against the front rail for greater steadiness. Before any shooting is done, the elephant is brought to a halt, but even so there is apt to be some motion for he may suddenly shift weight from one foot to another. Even his breathing may make the bead on the front sight a little wavy.

One morning word was received that two tigers had been spotted. One had made a kill the night before. We started off immediately. After an hour's beat we arrived at a dry swamp covered with nurtle grass. This grass was so high it covered the heads of all our elephants.

The morning was well advanced. It was very hot. The grass gave the tiger an excellent shelter against the sun. Advancing slowly, we roused many wild pig and hog deer from their noonday rest. Everyone was tense. Those with rifles were standing at the rails of the howdahs, staring straight ahead.

In a situation like this the first intimation that a tiger is near comes from the trumpeting of one or more elephants who have winded him. Although tigers and elephants are not natural enemies and usually leave each other alone, elephants, particularly females, are always afraid of tigers and, therefore, quick to sense their presence.

One of our elephants trumpeted. Soon after, we were able to locate our quarries. Their path could be traced by a ripple along the tops of the grass. Shooting was, of course out of the question till the tigers could be driven out of the grass and into the bordering jungle where a proper view could be obtained.

The tigers advanced at first in a short series of slow movements. Then one of them broke to the left and passed safely beyond the elephant at the farther end of the line. No one saw it emerge from the grass. It was never seen again.

We concentrated on the other. Finally we saw him emerge at the end 
of the grass bordering on the jungle. One yellow-striped flash and he was gone. But we were sure he would not run far. If we were persistent in our driving, we would soon see him again.

It was slow work. The jungle vegetation, streaked with light and shade, made it difficult to pick out the tiger. But shortly before the light began to fade, we spotted him. A heavy rifle roared just once, and the tiger lay dead on the ground.

There were several days of the hunt when we received no reports of tiger or leopard. All hands then went out on the elephants to shoot whatever they could. The game on such days included swamp deer, black buck, alligator, chital, hog deer, partridge, pheasant and peacock. We never shot at these when we were out after the big cats, for at such a time the sound of shooting might have frightened them away.

No one could say that comforts and conveniences were lacking on the hunt. We lived in large, firm tents. One pad elephant carrying our lunch always traveled along with us. Out in the open, in the bright sun, it was very hot, but with the jungle always at hand and clumps of trees about, one could easily find shady retreats in which to rest. Our luncheon hour varied greatly, because on the tiger or leopard days we never stopped till we had bagged the quarry or lost it for the day.

All in all our shooting trip netted two tigers, two leopards, and a crocodile, besides the smaller game already mentioned.

One last word about elephants. In our hunt they were so careful of their footwork, so indomitable in pushing through difficult spots of the terrain, that we were able to scour the tiger country quite thoroughly. Their bulk was, an aid rather than a handicap in plunging through the jungle. Their great trunks tossed logs aside, pulled saplings up by the roots, and tore boughs from trees. In dealing with any impediment, their trunks showed almost manual dexterity. A sure and subtle understanding existed between every elephant and its mahaut. As a matter of fact, the mabaut's language is a special dialect incomprehensible to the layman.

In return for their services, the elephants were given particular care by their keepers. They required, for instance, one bath a day in order to keep their skins healthy. The bathing and scrubbing in the stream near the camp was a regular ritual. It was an engaging sight to watch the great beasts lie down docilely and allow the natives to give them a thorough scrubbing. For a brush the natives usually used a good brick which was not too rough for the elephant's thick hide.

This tiger hunt belonged to an elaborate type that takes place at rare intervals. The average man in India does not possess twelve elephants; if he did, he would find more productive uses for them than tiger hunting.

A tiger district, as I have indicated, is not precisely overpopulated with tigers. One does not hunt them in a random way as one might hunt deer. A machan is erected only when tigers are known to be in the immediate 
vicinity. If a tiger leaves a natural kill, the machan is put up nearby. If no natural kill has been discovered, a bait is provided in the form of a live domestic animal. In any case, when hunters climb into a machan they must be prepared for a long and tedious wait.

Machans are designed to provide a maximum of safety for the hunter. Tigers have been known to jump higher than fifteen feet, so the average machan is around 20 feet above the ground. Tigers, in common with other animals, seldom look up. They find nothing of interest in the skies and treetops. If their attention is drawn to the machan by the slightest noise, it is another story.

When man meets tiger, or for that matter any wild animal, it is usually man who takes the initiative.

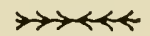




\section{XIIII}

\section{Health and Disease}

To topic is of greater or more immediate concern than that of bodily 1 or mental health. Everyone wants to live to a ripe old age and none wish to be considered as eligible for admission to an institution for the mentally-ill. Death seems to be a certainty for all of us, however and millions in our present population are destined for institutional care. The problem seems to be to avoid or cure serious illnesses and so postpone confinement or death. The articles in this section are all thought-provoking, timely, and helpful.

There are many kinds of diseases and the causes are equally varied. The bacterial diseases such as tuberculosis, pneumonia, diphtheria and scarlet fever are well-known. Poliomyelitis or infantile paralysis, smallpox, mumps, and rabies are the result of infection by tiny particles known as the viruses. Syphilis is due to the action of a spirochaete, a one-celled organism. Amebic dysentery is caused by a tiny, one-celled animal. Diabetes and goitre are due to the malfunction of the pancreatic and thyroid glands respectively. Pellagra, rickets and beri-beri are the result of vitamin deficiencies. Trichinosis is due to the effects of a pork roundworm. Then there are those diseases which are due to none of these but are inherited such as some kinds of feeblemindedness, hemophilia or excessive bleeding, and Huntington's chorea.

The conquest of disease is an inspiring chapter and more honor should be paid to the research workers in all branches of science who discover the causes and cures. Too often these men and women are forgotten and the public is prone to think that university scientists are never engaged upon anything of practical importance.

Penicillin, streptomycin and the sulfa drugs are three of the powerful weapons with which we are combatting disease germs. Although people still die of bacterial diseases, the number has been reduced dramatically. Vitamin therapy is being used successfully in pellagra and rickets, among others. Thyroxin and insulin help those suffering from thyroid troubles and lack of natural insulin. All along the line new drugs are appearing which cut severely into the numbers of deaths from the above causes. However, as these foes have been beaten back to a respectful distance, the degenerative diseases such as arteriosclerosis, and heart troubles are noticed 
more and it is on them and the always-troublesome mental diseases that science has now turned the bulk of its attention.

\section{ENTER LOUIS PASTEUR *}

\section{E. C. L A R G E}

In 186r, Albert, Prince Consort of England, died of typhoid fever. There was then no knowledge of the real nature or cause of typhoid fever, and, a fortiori, no knowledge of the hygienic or prophylactic measures by which his regrettably early decease from this cause might have been prevented. If anyone had suggested that the good Prince died because of the multiplication in his intestinal tract of a microscopic fission-fungus, nourished by the royal juices and brewing virulent poisons in them, that person would have been considered mad. A very great deal more was known about the Potato Blight by 1861 than about typhoid fever. The fungal organism that caused the Potato Blight was known, at least in part; the bacillus of typhoid was not even identified until 1884 .

That typhoid was an infectious disease was apparent to everybody; in epidemics it spread among men almost as fast as the Blight spread in the potato fields, but the agency by which it was communicated from one person to another was a mystery. There might be pernicious "miasmas" or the Disease itself might have "germs"-much as one might speak of the germs of an idea. The "germs" might even have a material existence, for all kinds of notions of germs had been the playthings of the philosophers for about as long as there had been any philosophers in the world. But in 1861 the notions about germs were even more nebulous than those about "atoms" before Dalton. Nobody seriously imagined that the germs of typhoid fever would ever be seen, measured, counted, and cultivated in dishes and testtubes.

One very good reason why knowledge of the bacteria-a few species of which were subsequently found to cause infectious diseases of manlagged so far behind that of the micro-organisms associated with the principal diseases of plants was that the bacteria were of a second o:der of smallness, and of deceptively-insignificant appearance when seen with even the highest powers of the microscopes available. The spore-bearing hyphae of the Potato Blight fungus, the summer and winter fruits of the common Powdery Mildew of the Rose, the germinating spores of the Bunt fungus of the wheat-they all appeared comparatively large when magnified some three hundred and fifty diameters, and they were casy to recognize as organized vegetable growths. But even yeast cells appeared very small at that magnification, and the several forms of bacteria were smaller still, "From The Advance of the Fungi by E. C. Large, Henry Holt and Company, New
York. 
some of them at the extreme limit of visibility. They were mere single cells, quivering and swimming about, or congeries of such simple cells, often colourless, and in the detritus of organic matter amongst which they were commonly found, it was by no means easy to say what they might or might not be.

These "bacteria," or "bacteridia," for they were called by many names, had been known to science since the time of Leeuwenhoek, who in 1683 first described one of the larger species, which he had seen by squinting through his rudimentary microscope-a single tiny lens mounted in a strip of brass-at some remains of food scraped from his own teeth. Innumerable observations had been made upon them since that time, and by 1838 Ehrenberg distinguished what he took to be sixteen distinct species assignable to four genera. After 1844 the study of the bacteria was facilitated to some extent by Dolland's oil-immersion lens for the microscope which enabled a magnification of one thousand diameters to be obtained. But until a way was found-with the Abbe condenser of $1870-$ of concentrating an intense beam of light upon the minute objects under observation, the scene in the microscope was very dim and ways were not then known of picking out the bacteria by means of stains. Later, when the use of differential stains revealed that the bacteria had distinct cell-walls, somewhat resembling those of other plant cells, and that they multiplied by simple fission, the bacteria were claimed by the botanists as Schizomycetes or fission-fungi. A few of the great naturalists, whose comparative studies led them to believe that the law of life would hold down to its lowest manifestations, were convinced, as Spallanzani had been in the eighteenth century, that the swarms of bacteria found in infusions of decaying organic matter had their origin in living spores which drifted in the air. That like all other living things they grew from "seeds" or "eggs." For the rest of the world, however, it seemed very plausible that such minute bodies could well be animated by little sparks of life set at liberty when the stuff of larger organisms died or that the processes of fermentation and putrefaction, then regarded as purely chemical, could originate such trifling living things by the way-and this was "spontaneous generation." By 1861 , resort to the ancient theory of spontaneous generation to account for the appearance of parasitic fungi on the crops had been thoroughly discredited, but for the smaller organisms, the bacteria, such notions still held sway, and the idea, put forward from time to time, that there might be as many distinct species of bacteria as there were flowers of the field was regarded as an extravagant pleasantry or a precious piece of nonsense.

As the microscope was improved, and as botanists paid more and more attention to the smallest things in their weird gardens, the fission-fungi might have been admitted quietly into the vegetable kingdom, in the course of twenty years or so, and most people might have taken their biogenesis for granted, but for one historic circumstance-in 1859 Darwin's Origin of 
Species was published. Darwin's cautious hypothesis, that some species were evolved from others in the course of time, was thoroughly respectable, it was an illuminating idea, by no means new, and it was of profound and special interest to the botanists and zoologists, as it provided them with a better basis for the classification of living things than they had ever had before. It introduced a fourth dimension-Time-into Taxonomy, as into morphology, and it enabled the naturalists to make most interesting museum arrangements illustrative of a hypothetical Tree of Life, out of their bundle of sticks. The break-away from the dogma of original creation had its roots in a long-repressed desire on the part of some people to spit in the eye of the Church. The ultimate clash was between vitalism and materialism; it divided the scientific world into two camps; started as it were, two great and opposing tidal waves of passionate thought which irrigated with violence every province of the biological sciences. The wealth of eagerness and hard-thinking that went into attempts to establish the theory of evolution did much for the advancement of knowledge; but the determination of those of another mind that the theory of evolution should not be pushed to the absurdity of its logical conclusion, led to advances which were perhaps of even greater practical moment.

It could easily be seen why the resurrection of a dwindling belief in the possibility of spontaneous generation was regarded as a philosophical necessity by those who sought to explain away the Creation by wild extrapolations and extensions of Darwin's hypotheses. So long as it was possible to regard the production of living organisms of any kind, no matter how small, as a result of purely chemical and physical processes, it was (just) possible to imagine the evolution or elaboration of life-forms, stage by stage, through successive geological epochs, all the way up from a unicellular organism to a blessed Queen Victoria herself, or even a Thomas Henry Huxley. If the smallest living cell could still be brought into being only through the reproduction of its kind, by the passing on of life from like to like, the farthest-flung train of Evolutionary speculation brought no ultimate balm. There would be no ha'p'orth of reason to suppose that the first amoeba could ever have crawled spontaneously out of the primordial slime. If it was still necessary to imagine some super-natural occurrence or act of Divine intervention to account for the first animalcule, one might just as well believe that God created Adam in his own likeness, and leave it at that. The materialists put Dirt before Life; it pleased them to think of all life as born of the inanimate dirt. The vitalists, on the other hand, men for whom Christianity was a faith essentially humane, along with most of the men of science who studied living things, alive, instinctively put Life before Dirt: a living God before the first dawn on earth, biology before chemistry, and human desires and passions before Gold.

Enthusiasms for the Grand Darwinian Theory was conspicuously lacking in France, and it was by no manner of accident that Louis Pasteur, in 
$186 \mathrm{I}$, was attacking the doctrine of spontaneous generation. He was digging the supposedly fecund Dirt away from the very base of the evolutionists' precious Tree of Life, and leaving that Tree suspended as an eternal mystery in the Divine air. Pasteur's investigations into the disease of silkworms in the south of France were not begun until 1865, he did not turn his attention to anthrax in sheep until 1877 , and it was 1885 before the first child was inoculated against hydrophobia. In 1861 , Louis Pasteur, too good a Catholic, and much too good a chemist, to tolerate materialistic doctrines against the evidences of his senses, was attacking the "philosophic necessity" of spontaneous generation.

As a young man, in 1848 , when he was only twenty-six, Pasteur made his first, brilliant scientific discovery, and happily it received immediate and full recognition by the greatest savants in France. This success fired in him a consuming passion for research, and started him on his course with an unbroken youthful ambition. His maiden discovery meant so much more than an addition to knowledge of the properties of tartaric acid. A minute difference, which he was the first to perceive, among the crystals of the acid, the right and left handedness of certain of the crystal facets, was associated with the power of their solutions to turn polarized light to the right or to the left. What did it mean? It meant that some at least of the molecules of which the whole universe was composed had the power of assembling in two ways, one of which was the mirror image of the other.

While the crystals of tartaric acid were still sparkling for Pasteur, with all the magical brilliance of first discovery, he had not only traveled about Europe collecting specimens of tartar from many sources, poking about in the dregs of the wine vats where the tartar was found, he had also sought for the phenomenon of optical dissymmetry in other substances. Pasteur was happy when his appointment at Lille in 1854 took him into a district where there were many distilleries. He would have to prepare lectures on the chemistry of fermentation for the apprentices and technical workers of the district, but, alongside his teaching work, he would be able to continue his researches, and perliaps find some more dissymmetrical substances. The distillers' vats were good places in which to look for them.

He had not been studying fermentation for very long before he began watching the yeast cells in the fermenting worts and liquors, with a very particular attention. Under the microscope they appeared, normally, as small globules, often with a smaller globule budding out at the side, like a "dolly" on a potato. They multiplied in this way, by budding. In fermentation that went well and gave good brews, the cells were all of this kind: but in those that went wrong, and produced sour wine or inferior beer there were present cells of a different shape, not globular, but elongated or sausage-like. Could that abnormality make all the difference in the brew? 
The numerous groups of simple unicellular fungi associated with various fermentative processes-of which ordinary yeast in alcoholic fermentation was only one-thus began to receive the attention of an exceedingly astute observer. Pasteur's thought, from the very first, was that the yeast globules and smaller, elongated bodies were the cells of living organisms, and as they had life so they would require food. Not only were the cells of yeast and other simple organisms taking their nourishment from the solutions of sugar and other substances in which they lived-they were also, of necessity, transforming it. They were using part of it to build up their own substance and rejecting the rest. Hence the chemical changes that took place in fermentation.

This realization led Pasteur to a number of discoveries of great industrial value. He discovered that the process of making vinegar from wine depended upon the growth of a particular kind of fungus-- "the vinegar plant" -on the beach-wood chippings over which the wine was allowed to flow. Where the wine would not "turn" to vinegar, he put in a little of the living fungus and the vinegar-makers' troubles were at an end. He showed that a souring of wine was due to the growth of an undesirable organism in it after it had been bottled, and he showed the wine-makers how to overcome the trouble, very simply, by heating the wine, to kill the cells of the organism, before it was bottled. An early instance of "Pasteurization," although, indeed, the Romans had been familiar with this dodge for preserving wine. The very idea that fermentation was brought about by any lifeprocess was rank heresy for the chemists at that time and Pasteur was scornfully accused of attempting to put back the clock of up-to-date nineteenth century progress.

Pasteur's researches on "so-called spontaneous generation," which continued from 1859-1865, arose directly out of his work on fermentation. $\mathrm{He}$ had discovered that fermentation and putrefaction were dependent upon the growth of living organisms. Where did those organisms come from? Pasteur knew the answer before he began. The organisms came from the air, in which their imponderable "spores" were always floating about, as the grosser seeds of some of the flowering plants drifted in the wind. But the apparently spontaneous appearance of minute organisms in infusions of fermenting or decaying material was the very "fact" upon which the last belief in spontaneous generation now depended. Pasteur set himself to prove experimentally what he knew beforehand must be true. As the truth would be most unwelcome, and he would be challenged at every step of the way, he had to contrive a series of experiments which would give unambiguous results, and yet be of such simplicity that no one could pretend to misunderstand them.

He did not succeed in routing the materialist's belief in the possibility of spontaneous generation. It was, in truth, impossible to prove that it never occurred in nature. But Pasteur did show that the postulation of spontaneous 
generation was wholly unnecessary to account for anything that happened in his experiments, and as his experiments were expressly designed to cover all the instances in which the phenomenon was supposed to occur, he left his opponents with nothing to put forward but unverified suppositions.

Pasteur made up a number of broths and infusions of organic matter that very quickly fermented or went bad when left exposed to the air. As Spallanzani had done before him, he put the infusions into small glass flasks, heating them to destroy any spores or cells of living organisms and then sealed the flasks. But this time he sealed them positively-by drawing out the narrow necks and fusing the glass with a blowlamp. The infusions kept clear and "good" indefinitely. When he broke the seal, thus permitting a few cubic centimeters of air to rush in, the preparations promptly went bad, and in a few days they were teeming with living organisms, all of which had arisen from the multiplication and growth of the few microscopic cells and spores let in with the air. He repeated the experiments, sterilizing the air before admission by passing it through a red-hot platinum tube. There was then no growth of organisms in the preparations and they kept good.

By 1863 , both Pasteur and Ferdinand Cohn had reached the conclusion that putrefaction of organic matter was a process of the same nature as fermentation, also consequent upon the growth of living organisms. The suppuration of surgical wounds was regarded as an instance of putrefaction, and by 1865 , Dr. Lister in England was excluding air-borne germs from wounds with filter pads of cotton wool; and killing the germs which settled on the skin, on instruments, and on exposed tissues during operations, with carbolic acid as an antiseptic.

The plant doctors were concerned with these new developments no less than the medical profession. When plant tissue was cut or wounded, hosts of smaller organisms, yeasts and bacteria, would get in from the air or the soil and complete the work of decay. They could, for example, rot blighted potatoes in the ground, reducing them to skinfuls of slime. The "vegetable pathologists" would now have to study not only the moulds and mildews, but the yeasts, the myxomycetes and the bacteria.

Assuredly, those early researches of Louis Pasteur left the plant pathologists with much to brood over, and their suggestiveness had not been exhausted by 1947 .

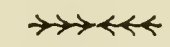




\section{PESTILENCES AND MORALISTS *}

H O W A R D W. H A G G A R D

Most civilizations are willing to accept protection from pestilence when the measures involved require only the eradication of insects, quarantine, the draining of swamps, and similar general measures. But when the concepts of morals are involved in the prevention, fanaticism is aroused even in the highest civilization. There are two pestilences which thus unfortunately involve moral conceptions. They are the plagues of syphilis and gonorrhea. Against them medicine has developed methods of control. They could be eradicated. But as yet civilization has not advanced entirely beyond the ancient belief that disease is imposed by God in vengeance for $\sin$.

Those who today still look on syphilis and gonorrhea as punishment for sin have not progressed beyond the ideas of medieval Europe. There was an excuse for the Emperor Maximilian when he issued his edict in 1495 declaring syphilis to be an affliction from God for the sins of men. Cotton Mather declared syphilis was a punishment "which the Just Judgment of God has reserved for our late Ages. . . ." His ignorance was as great as his religious bigotry which led him to drown helpless old women for witchcraft.

The reason that syphilis and gonorrhea are not viewed as pestilences lies in the fact that they are involved in one of the greatest problems of civilization-the relation of the sexes. The veneral diseases are involved in that great sex problem about which the ideals and ethics of Christian civilization center. A true perspective on sexual matters is lost because the facts are obscured with secrecy and distorted in the imagination.

A continuous epidemic of syphilis has lasted now for at least five centuries. Its origin is a question over which the historians argue. Some maintain that syphilis occurred in Europe at an early date and was known to ancient civilizations. Others maintain that syphilis was a new disease brought into Europe from the island of Haiti by the sailors of Columbus. The preponderance of evidence points to America as the source of the disease; but the evidence is not absolute.

Syphilis often attacks the bones and leaves definite marks by which it can be recognized after death. Skeletons of ancient peoples in China, Egypt, and Europe have been examined with this point in view. Thus far no prehistoric or even pre-Columbian skeleton found in Eurasia shows evidence of syphilis. There are marks on them which have been mistaken for those of syphilis, but these marks are now definitely proved to have

" Reprinted from Devils, Drugs and Doctors by H. W. Haggard with the permission of Harper and Brothers. Copyright 1929, by Harper and Brothers. 
occurred post mortem through the action of insects and fungus growths. Many of the early references to venereal disease, as in the Bible or other ancient writings, have been believed by some observers to indicate syphilis, but they were more probably gonorrhea. There is no question about the antiquity of gonorrhea in Europe and Asia.

If syphilis was brought into Europe by the sailors of Columbus, certainly conditions were ideal for its reception. In 1493 Charles VIII of France claimed the kingdom of Naples as his by hereditary right on the death of Charles, Count of Main. His claim was disputed by the Neapolitans, and Charles VIII gathered an army of mercenaries to take the kingdom by force. In August of 1494 he led his army into Italy and entered Naples in the following February. Toward the end of May King Ferdinand broke a treaty he had made some years before with Charles VIII and sent an army into Naples. In this army there were a number of men who had been to the West Indies the previous year and who were still infected with the disease they had contracted there.

In 1496 the army of Charles VIII fell into factions and was expelled from Naples. Those that remained of the mercenaries ultimately scattered to their own countries. Their various routes were marked by the spread of syphilis. It appeared in France, Germany, Switzerland, Holland and Greece in 1496 , in Scotland in 1497 and in Hungary and Russia in 1499. Vasco da Gama carried it on his ships to India in 1498 , Europeans brought it to China in 1505 , and by 1569 it had been smuggled into Japan. It has been truly said that civilization and syphilization have advanced together.

The age in which syphilis made its appearance in Europe was one of extreme laxity in matters of sexual behavior. The new disease at first involved nothing derogatory to a gentlemen's reputation. It was said at one time that a man who had not had the disease at least once was to be regarded "as boorish and no gentleman." The mother of Francis I of France said that her son was punished where he sinned. According to the story, Francis was infected by the wife of a Parisian tradesman. Francis solicited her favors, but was repulsed. After consulting with the court lawyers he decided to exercise his royal prerogative and notified the lady to that effect. With her husband's assistance she acquired a syphilitic infection and revenged herself on the king. He is said to have died of the disease.

The appearance of syphilis in Europe gave rise to a series of speculations as to the cause of the disease. As the part played by bacteria and other organisns in infectious diseases was not established until the middle of the nineteenth century these early speculations were somewhat far fetched. Both a divine and a cosmic origin were given to syphilis. The conjunction of Saturn and Mars and the rainy weather in Italy were both blamed for the disease. The disease was also attributed to the radical innovation of wearing linen shirts which were coming in at that time to replace woolen or leather 
garments. The physician to Pope Clement attributed the disease to poisoning. The idea that syphilis was a venereal form of leprosy was frequently brought forward.

In 1905 Schaudinn and Hofmann found the organism of syphilis "swimming in the blood." It is known today that the symptoms of syphilis are due to these organisms. The search for the organism of syphilis started when bacteria were discovered by Pasteur to be a cause of disease-a little more than half a century ago. The organisms causing the infectious diseases were discovered in rapid succession, but that of syphilis stayed hidden. Metchnikoff failed to find it but in 1903 he demonstrated that syphilis could be transmitted to the higher apes. This discovery furnished a means for studying the disease experimentally. The higher apes are the only animals which, when inoculated, develop syphilis resembling the disease in man. The fact that calves cannot acquire syphilis is of more than passing interest, for the opponents of vaccination have on occasion talked of "bovine syphilis" which they claim is transmitted by vaccination.

The organism of syphilis could not be made visible under the microscope by means of staining. Most bacteria absorb dyes readily and the color thus imparted to them allows them to be differentiated from the material containing them. The organism of syphilis does not absorb dyes, but remains colorless and transparent and hence invisible under the microscope as it is ordinarily used. Two German investigators, Schaudinn and Hofmann, working at the University of Berlin in 1905, sought for the elusive organism by another method of using the microscope. They used what is known as dark stage illumination. Schaudinn and Hofmann placed a black background under the microscope to cut off all light coming through the material they were examining. They moved their source of illumination to one side and brought its beams horizontally across the field. With the light thus shining in a direction at a right angle to that in which they were looking they could see only such light as was reflected from objects which the rays struck. Under this method of examination the organism of syphilis could be seen. It was a spirochete, that is, an organism spirally shaped. It was, in fact, like a very tiny but a very perfect corkscrew, usually with fourteen turns. The organism was named Spirocbaeta pallida (now called Treponema pallidum).

The Spirocbaeta pallida is a frail organism. It has a relatively short life outside the body; under ordinary circumstances it dies in less than six hours. Moreover soap and water serve to destroy spirochetes that may be deposited on such articles as drinking-glasses. If the spirochete had the resistance of the tubercle bacillus, syphilis would be a vastly more prevalent disease than it is. The spirochete is passed from the syphilitic only during those stages of the disease when there are sores on the skin or mucous membranes, but as such sores, particularly on the mouth and lips, may be 
so small as to escape detection, there is little satisfaction to be gained from this fact. The stage of the disease during which the sores appear lasts from a few weeks to two or three years, depending on whether the disease is properly or improperly treated. After this stage, the disease, although it may persist, can no longer be transmitted in the usual manner.

The spirochetes cannot force their way through the unbroken skin or mucous membrane. They can enter only through a break in the surface. Although theoretically the invasion may occur at any point on the body, it rarely does so outside of the genital organs and lips. About 5-10 per cent. of all cases start from the lips and such cases are usually caused by kissing.

When infection occurs, events follow a characteristic order. The spirochetes at first show none of the aggressive characteristics which mark their later activity. These they develop about a month after infection has occurred. The invading spirochetes are so slow in gaining a foothold that during the first twelve hours they can be eradicated and the disease prevented. This fortunate opportunity for preventing syphilis makes possible an effective prophylaxis. It is an opportunity afforded by very few diseases.

Syphilis is a mild disease, but, paradoxical as it may seem, the mild diseases are often the most persistent. Mild diseases do not elicit an acute reaction on the part of the body. Consequently, they persist, and in persisting they become chronic diseases. There are no acute stages in the progress of syphilis. Its duration is marked by years rather than days. The first symptoms of syphilitic infection is a chancre, a round ulcerated area which appears at the point of infection. The margin of this ulcer is swollen and feels hard under the touch. It is painless, is associated with no feeling of illness, and gives no indication in itself of the serious nature of the infection. It persists for three or four weeks before it shows any tendency to heal.

During the primary stage of syphilis the spirochetes are mostly in the area about the chancre and for the first week the disease cannot be detected by testing the blood with the Wassermann reaction. Nevertheless, an examination of the material from the chancre under the miscroscope with dark field illumination shows the spirochetes in great numbers. Under proper treatment applied early in its primary stage the disease can be stopped so quickly that no manifestation other than the chancre develops. The treatment of syphilis becomes more difficult and the results of the treatment less certain as the disease advances through the secondary and into the tertiary stage.

From their focus in the chancre the spirochetes spread into the blood and are carried throughout the body. The general manifestations of the disease develop and give rise to the secondary stage of the disease about two months after the original infection and at about the same time the chancre is healing. An eruption appears on the skin and the mucous mem- 
brane of the mouth becomes raw in places. Even without treatment the secondary stage of the disease passes away in time; it may last a few months or it may persist for a year or two.

If syphilis produced no effects except its primary and secondary stages it could almost be ignored, for there is little inconvenience or physical suffering. The serious nature of the disease appears years later. Insanity, paralysis, and disease of the heart and blood vessels and other conditions of the so-called tertiary stages develop. The lack of suffering during the early stages of syphilis is one of the most dangerous features of the disease.

The most distressing consequences of syphilis occur when the late destructive action of the spirochetes is centered on the nervous system. The tissue of the brain and spinal cord is destroyed and replaced with scars. It can no longer function normally. If the brain is involved, insanity results; in its most pronounced form this insanity is called paresis.

In locomotor ataxia the syphilitic changes occur in the spinal cord. The feet lose their sensation of position; the gait becomes awkward. The legs become paralyzed. Finally the man is helplessly bedridden but his mind remains clear.

Syphilis is often spoken of as a hereditary disease, but in reality it is not hereditary. Syphilis can be transmitted to the child during pregnancy if the mother has syphilis. That is not hereditary; it is contact infection. To be hereditary the characteristic thus designated must be a part of the germ plasm and be carried in the sperm of the male or the ovum of the female. Children with syphilis are born only of mothers who themselves have the disease.

A child which acquires syphilis from its mother during the early stages of her pregnancy frequently dies before birth. Syphilis is one of the greatest causes of miscarriages and of stillborn children of which there are at least 100,000 annually in the United States. Those children who do not die soon after birth can be treated and frequently cured.

The origin of gonorrhea is lost in antiquity. The germ which causes it is even more frail and delicate than the spirochete of syphilis; under ordinary conditions it cannot exist outside of the body for more than a few minutes. No animal other than man can acquire the disease. Among adult humans it is transmitted by sexual contact. Like syphilis, it strikes at infants -and blinds them.

In the female the symptoms of the infection may be so mild as to escape detection, but the subsequent effects are serious. For women gonorrhea ranks with cancer as a cause for operations and invalidism.

The bacterium which causes gonorrhea belongs to that large group of germs known as cocci because of their round or oval shape. It is shaped like a coffee bean and two germs are usually found together.

Gonorrhea, unlike syphilis, cannot infect the skin, but only mucous membrane. The gonococci burrow into the deeper layers of tissue. An 
acute local infection results in two to five days. Pus streams from the infected surface. In the male the infection occurs in the urethra, the passage leading to the bladder. The raw and inflamed surface gives rise to intense pain during urination. The infection may travel into the generative apparatus or even up to the kidneys.

In women the infection starts in the vagina and from there extends to the uterus. It spreads further and passes into the Fallopian tubes and through them to the peritoneum lining the abdominal cavity. The inflammation of the tubes causes them to be closed by the formation of scars; sterility results.

Gonorrhea, like syphilis, may be transmitted from the mother to the baby. The transmission is effected only during the birth of the child. As the baby passes down through the vagina the infected pus is forced into its eyes. At one time about a quarter of the blindness throughout the world resulted from gonorrheal infection. There is a prophylactic treatment by which gonorrhea of the eyes can be prevented. Most states in this country require by law that this prophylactic treatment shall be given as a routine part of post-natal care. The laws designed to prevent venereal blindness are enacted for economic reasons; the blind are in most cases dependent upon the state for support.

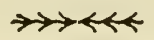

\section{ANIMAL PARASITES TRANSMISSIBLE TO MAN *}

\section{B E N J A I N S C H W A T Z}

\section{N T ROD UCTION}

Practically all vertebrate animals serve as hosts to parasites, and Homo sapiens is not an exception to this general rule. Actually man is an excellent host for various protozoan, helminth and arthropod parasites, the species adapted to live on or in human beings totaling several hundred. There is hardly an organ, tissue or cavity in the human body that is immune to the attacks of one kind of parasite or another. Such vital organs as the liver, spleen, lungs, heart, brain, eyes and others too numerous to mention are susceptible to invasion by parasites that are capable of inflicting serious damage to the parts of the body that are invaded.

Human beings acquire parasites through some form of contamination, usually traceable to soil pollution, through the consumption of raw food of animal origin, and in other ways. In parts of the world where sanitation and hygienic standards are far below the levels that are accepted in most civilized countries, parasites that are acquired through contaminated food

* Reprinted by permission of the Scientific Monthly, American Association for the Advancement of Science. Copyright 1938. 
and water constitute an important health factor; in tropical countries they are usually one of the most important health factors. In countries where the level of sanitation is high and where the standards of hygiene are exacting, parasitism that spreads ordinarily through soil pollution tends to disappear, more particularly in urban communities. In rural sections, however, including those of this country, there is always a greater or lesser residuum of parasitic infection of one kind or another, and urbanites who visit the country for rest and recreation may acquire a few unwelcome guests, such as hookworms, ascarids, whipworms, dysentery-producing amoebae and other parasites, which occur as infective eggs, cysts or larvae in contaminated soil.

By and large, however, human beings living in cities and towns are in most cases adequately protected from acquiring parasitic infestations to which rural inhabitants may be exposed as a result of contact with the soil. The nation-wide campaign against soil pollution, undertaken in this country on a large scale in the beginning of the twentieth century, has done much to reduce the danger of acquiring parasitic infestations, even in rural areas. Several years ago the annual report of the Rockefeller Foundation contained the statement that hookworm disease, for years an important factor in the physical and mental retardation of the population of rural areas in certain parts of the South, had been practically eradicated. While this statement was open to challenge at the time that it was published and was challenged vigorously, the fact remains that the hookworm incidence and intensity in the United States have been greatly reduced, thanks to the activities of such agencies as the U.S. Public Health Service, the Rockefeller Foundation, the state boards of health and local health units in the South.

While progress in the control of human parasitic infestations traceable to soil pollution has been steady and on the whole satisfactory, that relating to the control of parasites of man that are acquired from consuming animal food still leaves much to be desired. Actually, the available evidence shows that one human tapeworm infestation acquired from certain species of fresh-water fish is spreading in the United States, although its distribution is still rather limited. Trichinosis, a serious, painful and sometimes a fatal disease of man, is apparently gaining headway. Whether the increase in the number of cases of human trichinosis is only apparent because of the greater vigilance on the part of physicians in making a correct diagnosis, or whether the increase in the number of such cases is real, is difficult to determine on the basis of available evidence. The extent of beef tapeworm infestation, in so far as this can be determined from the data on the prevalence of the larval stages of these parasites in cattle slaughtered under federal inspection, shows that during the past ten years or so this parasite has been holding its ground, although the data of previous years showed a downward trend.

The parasites mentioned, namely, the fish tapeworm, the beef tapeworm 
and trichina, are the most important parasites of man in the United States that are transmitted through the consumption of animal food. The pork tapeworm, though only of slight importance in this country, must be added to the list. We shall briefly consider each of these parasites and its bearing on human health.

THE FISH TAPE IVOR M

The so-called fish tapeworm, Diphyllobotbrium latum, is really a human tapeworm that spends part of its early life (plerocercoid stage) in certain species of fresh-water fish. According to Wardle the following species of fish in North America are known to be intermediate hosts of the tapeworm under discussion: Pike, Esox estor; pickerel, Stizostedion vitreum; sauger or sand pike, Cynoperca canadense; and perch, Perca flavescens. Prior to getting into fishes this parasite occurs as a larva in fresh-water copepods or so-called water fleas, that constitute a part of the microscopic and near-microscopic aquatic life-plankton-which is an important item in the food of fishes. The life cycle of the tapeworm is rather complicated and is bricfly as follows:

The tapeworm, which may attain a length of about twenty-five feet and, in exceptional cases, a length of sixty feet, in the human intestine, produces eggs which are microscopic in size and which are eliminated from the ripe or gravid tapeworm segments into the lumen of the host's intestine. Occasionally long chains containing as many as one hundred or more segments may be passed with the excreta of infested animals, including dogs, cats and wild carnivores, such as bears and foxes, that also serve as hosts of this tapeworm. The tapeworm eggs passed with excreta and those which become liberated from the passed segments, as a result of the disintegration of the latter, hatch in water following their normal development. The newly hatched larvae, provided with cilia, may be swallowed by copepods which are usually found teeming in fresh-water lakes. When swallowed by suitable intermediate hosts the larvae undergo further development but do not bccome infective to man and other definitive hosts unless they reach the body of a second intermediate host, namely, a suitable species of fish, as already noted, and develop there to the plerocercoid stage that is infective to manmals. Fishes become infested by swallowing the infested copepods, and human beings acquire the fish tapeworm as a result of eating raw, or nearly raw, or cold-smoked or salted fish that harbors the stages of the parasites infective to man.

According to Magath the Finlanders, as well as other northern Europeans in Minnesota, have retained their native fondness for raw fish, and the more nearly raw the fish is the better the Finlanders like it. Magath makes the following statements: "One Finlander remarked that he was in the habit of not carrying a luncheon on a fishing trip, being satisfied with the raw fish he caught. A common dish is fish which has been salted in brine 
for twenty-four hours and cut up with green peppers, cabbage and cucumbers, while some bury the raw fish for a few days to ripen it, then eat it with salt."

At one time there was considerable discussion among parasitologists as to whether the fish tapeworm could complete its life cycle in North America, some investigators taking the position that infested persons in this country must have acquired this parasite abroad. It has been definitely established, however, that the fish tapeworm has become endemic in North America and many cases of infestation of native origin have been traced. Fishes from the Great Lakes region of the United States have been found to be naturally infested, and species of copepods that are capable of serving as the first intermediate host have been shown to be susceptible to experimental infection. Thus, the entire life cycle of this tapeworm can take place in North America, and this parasite, originally introduced into this country by immigrants from northern Europe, is now definitely established in the United States. According to Ward the belt of infection stretches across the Great Lakes, includes the upper Mississippi basin, even reaching out into Iowa, crosses the height of land into Manitoba and embraces lakes almost to the Rockies.

Once having gained a foothold, it is easy to see how this parasite established itself solidly, since untreated sewage from cities and towns is commonly emptied into lakes. Infested immigrants coming to North America from countries along the shores of the Baltic and from other areas where this infestation is common, polluted the lakes in some of our North Central States and other regions.

In parts of Scandinavia, Finland, Russia and Germany, bordering on the Baltic and connecting waters, the local population shows an incidence of infestation up to 50 per cent. or more. Even a few infested immigrants could have greatly polluted our fresh-water lakes, since it has been estimated that an infested person may discharge at least one million tapeworm eggs a day. The fondness of certain people of European origin for raw fish or portions thereof raw, or lightly salted or pickled, has served to propagate this infestation in this country. The susceptibility of the dogs, cats and various wild carnivores to this parasite has added a further complication tending to increase the spread of this tapeworm.

Persons infested with the fish tapeworm may exhibit nervousness, loss of sleep, experience creeping feelings and occasionally show a voracious appetite. The symptoms manifest themselves particularly after a person discovers that he or she is infested, this indicating that the symptoms, at least in part, are probably mental rather than physical. Of special interest in connection with this parasite is the occurrence in a very small percentage of infested persons of an anemia that is indistinguishable from pernicious anemia. However, precise information is still lacking with regard to the 
causal relation of the parasite to the cases of pernicious anemia observed in infested subjects.

The prevention of infestation with the fish tapeworm is simple and absolutely effective. Fresh-water fishes should not be eaten raw, semi-raw, cold-smoked or lightly cured in salt. Thorough cooking of fish is an absolute prevention and can be relied upon as being a one-hundred per cent. prophylactic measure.

THE BEEF TA P W OR M

The beef tapeworm, Taenia saginata, occurs in its adult stage solely in the human intestine where it may attain a length of about thirteen to forty feet. Usually an infested person harbors but a single tapeworm, the occurrence of one worm in the intestine apparently excluding others from developing.

The life cycle of the beef tapeworm is similar to that of the fish tapeworm, except that but one intermediate host, namely, a bovine, is required. Human beings become infested solely as a result of eating raw or rare beef containing the larval stage of the tapeworm infective to man, and cattle become infested with the larval or cystic stage as a result of swallowing the tapeworm eggs with feed or water that has become contaminated in one way or another with the excreta of a tapeworm carrier. The life history of the beef tapeworm involves, therefore, an alternation between two hosts, man and the ox.

Ranson pointed out years ago that a single individual with a tapeworm is a peripatetic center of infection. Each gravid segment of a tapeworm contains several thousand eggs, and several segments may become gravid and expelled every day during a period that may extend over several years. Thus hundreds of cattle might become infested from a single tapeworm carrier, if this person happens to live in a rural district where cattle are raised.

The control of infestation of cattle with the larval stages of this tapeworm will inevitably result in the control of the beef tapeworm infestation in man, and vice versa. Reduced to simple terms, improvement in conditions as regards the disposal of human excreta in rural sections will prevent cattle from becoming infested, and this in turn will tend to reduce and ultimately eliminate the infestation in man.

As an example of the unsanitary conditions that prevail in some rural sections of the United States, particularly as regards the disposal of human excreta, an outbreak of larval tapeworm infestation in cattle, technically known as cysticercosis, was investigated by the Bureau of Animal Industry a number of years ago with the following results:

Following the detection under federal meat inspection procedure of a heavy infestation of cysticercosis in 3 lots of cattle which came from the 
same locality, 105 out of 523 cattle, or 20 per cent. being infested, it was determined that about 1,500 cattle, of which the 523 were a part, had been fed during the winter and spring in the yards of a cottonseed oil mill. These animals were later marketed at various live-stock centers and data were obtained on the 523 animals already referred to. The remaining animals were not traced to the point of slaughter.

The investigation made at the yards of the mill disclosed that the regular water supply for the cattle was taken from a river 75 yards below a sewer outlet. The river was wide and shallow, had a sluggish current, and the banks, which formed a portion of tract of land designed for a public park, were strewn with human feces. The investigation disclosed further that the cottonseed hulls used for feeding the cattle were stored in a building where tramps commonly slept during the feeding season. Evidence was obtained which indicated that the cottonseed hulls had become more or less contaminated with human excreta, the hull house being used evidently by the tramps and mill employees as a place for defecation, especially during very cold weather. An inspection of the 3 outhouse toilets intended for the use of the mill employees showed that the structures were of poor design, the excreta falling directly on the ground or in boxes set on the ground level. As many of the mill employees using these outhouses were transients, it was estimated that about 200 persons used the three poorly constructed and unsanitary outhouses during the cattle feeding season. At the lower end of the feed yards there was a stagnant pool which drained a watershed that included a portion of the town and cottonseed oil mill with its three primitive outhouses. The cattle were occasionally forced to drink from this stagnant pool as a result of frozen pipes which shut off the regular water supply. The 1,500 cattle fed at the yards were therefore exposed to the following sources of infection with tapeworm: (1) The outhouses which drained into the stagnant pool; (2) the regular water supply from the sewage-laden river; (3) the cottonseed hulls, which were more or less subject to contamination, and (4) a portion of the town's waste which drained into the stagnant pool. That fully 20 per cent. of the cattle that were fed under these unsanitary conditions became infected, as shown by the data obtained, is not surprising considering the four possible sources of infection.

Two recent outbreaks of cysticercosis in cattle, investigated by the Bureau of Animal Industry, showed conclusively the important role of a single human tapeworm carrier as a spreader of this parasitic infestation to bovines. The facts in these cases are as follows:

Following the receipt of information that 166 out of 252 cattle carcasses were retained in an officially inspected establishment at Fort Worth, Texas, because of infestation with tapeworm cysts, an investigation was made of the premises where these cattle had been fattened for market. It was determined that the bovines in question were kept in a feed lot to which feed 
was hauled by an individual who later was found to be responsible for the outbreak of cysticercosis. When the owner of the cattle was informed of the retention of a number of beef carcasses, as already noted, from the particular lot of cattle in question, all men on the ranch that were connected in one way or another with the feeding of these animals were examined by a physician, and the individual referred to was found to be infested with a tapeworm. According to the information furnished "about 20 feet of tapeworm" were removed from the person following the administration of a taeniacide. Upon being questioned, the tapeworm carrier admitted that he did not like cooked meat and, therefore, "ate all his meat raw."

The premises to which this and other persons connected with the feeding of the cattle had access had no toilet facilities, and the infested person was seen, on numerous occasions, to defecate in the feed troughs.

In an officially inspected establishment in Oklahoma City, Oklahoma, twelve out of thirty-seven cattle carcasses were retained recently because of infestations with cysticerci. In tracing the origin of these cattle, it was determined that they came from a farm that had no toilet facilities, the barn and chicken house being used as places for defecation by a man and his wife who had charge of the cattle-feeding operations. The only source of water supply for the cattle was a small pond located about a hundred yards from the farm house; all the drainage from the dwelling, barn and chicken house ran directly into this pond. Through the assistance of the State Board of Health, it was determined that the wife of the cattle feeder, who complained of being sick, was infested with Taenia saginata. Considering the primitive conditions under which this couple lived, it is not surprising that one third of the cattle that were fed on this farm became infested with tapeworm cysts.

While the consumption of raw or slightly cured fish will probably strike the readers of this article as a freak habit of certain northern European immigrants, the consumption of raw and rare beef is certainly a well-established American custom. Steaks cooked rare are frequently raw in the middle, and rare roast beef is certainly a common American dish. It is not surprising, therefore, that infestation with the beef tapeworm is quite common in the United States. No adequate statistical information is available on this point, since there is no agency in the United States for collecting this sort of information. Several physicians with whom the writer of this paper has discussed this point stated that cases of human tapeworm infestation are encountered by them, sometimes several times a year in routine practice. That tapeworm infestation in man is not more common in this country is due entirely to the protection that is afforded to the consumer by the vigilant federal meat inspection service and competent state and local meat inspection units.

Beef tapeworm infestation in man occurs in all parts of the world where beef is used for food. In Abyssinia, where beef is regularly eaten raw, prac- 
tically the entire population is infested; in certain parts of Syria, one third of the population is infested. In countries where beef is commonly cooked the extent of the infestation is more limited.

Under federal meat inspection beef carcasses showing an excessive infestation with tapeworm cysts are not passed for human food, thus cutting off the most fertile source of infection. During the past five years, the total number of beef carcasses condemned on account of tapeworm infestation was somewhat under 1,000 out of a total of over 50 million cattle slaughtered under federal inspection. During the same period, however, over 135,000 beef carcasses were retained on account of infestation with tapeworn cysts. Under federal meat inspection the retained carcasses which contain only one dead and degenerated cyst are passed for food following the removal of the cyst and adjacent parts, and a careful inspection to make sure that no other cysts are present; carcasses showing a moderate infestation are not passed until after the removal of all visible cysts and subsequent refrigeration of the carcasses for a period of not less than six days and at a temperature definitely known to be fatal to the vitality of these parasites, or such carcasses are cooked at a temperature that is known to be destructive to the vitality of these tapeworm larvae. Carcasses showing a heavy infestation, or a pathological condition of the muscles indicative of such infestation, are condemned.

It should be borne in mind, however, that only about two thirds of the food animals slaughtered in the United States are subject to federal inspection or under imperfect inspection. Slaughtering done on the farm for home consumption is not, of course, subject to any official inspection. Actually, however, even the best kind of inspection can not guarantee perfect results so far as the detection of tapeworm cysts in beef is concerned, because in most cases the degree of infestation is slight and a large proportion of slightly infested carcasses necessarily escape even the most careful inspection. The actual number of cases of infestation in cattle with larval tapeworms is probably much greater than that shown by the figures cited. From a practical viewpoint, however, it seems scarcely possible to effect a more thorough inspection for tapeworm cysts than is done under existing requirements. The inspection that is made eliminates most of the carcasses that are likely to transmit tapeworm infestation to human beings; the carcasses that are passed without detecting these parasites probably have only slight or almost negligible infestations.

As in the case of the fish tapeworm, the beef tapeworm in many cases may produce no noticeable symptoms. This is particularly true of cases involving robust individuals. Delicate and nervous persons and children may show, at times, rather alarming symptoms, including severe gastrointestinal disturbances, nausea, and vomiting. Nervous persons may show convulsions and even some severe reactions that are suggestive of epilepsy. Sometimes tapeworm infestation gives rise to emaciation and anemia. On 
the whole, tapeworm infestation does not produce serious illness, the severe symptoms mentioned being the exception rather than the rule. Effective treatments for the removal of tapeworms from man have been established, and persons affected should seek the advice of a physician.

Prevention is simple and effective. To avoid tapeworm infestation cook beef until it is well done.

\section{THE POR K TAPE W OR}

Aside from being somewhat shorter, as a rule, the pork tapeworm, Taenia solium, bears a very close resemblance to beef tapeworm. Like the beef tapeworm, the pork tapeworm lodges in the small intestine of human beings, its head being provided with hooks that afford the possibility of a firmer anchorage to the intestinal wall than in the case of the beef tapeworm, which lacks this armature. Ordinarily the pork tapeworm is from about two and one half to five feet long, but it may attain, at times, a length of about twenty-five feet. Its life cycle is essentially similar to that of the beef tapeworm, except, of course, that the hog serves as the intermediate host. Human beings become infested with the pork tapeworm by swallowing infested raw or insufficiently cooked pork, and hogs in turn become infested with the cystic stage by swallowing feed or water that has become contaminated with human excreta passed by infested persons. The life history of the pork tapeworm thus consists in an alternation between two hosts, man and swine. The reduction in the incidence of infestation in swine necessarily leads to a reduction in the incidence of infestation in man, and vice versa.

Actually the pork tapeworm is very rare in man in this country; the rarity of this parasite in human beings is directly correlated with the rarity of the cystic stage in swine. This is a very fortunate situation, because from the view-point of its bearing on human health, the pork tapeworm is far more dangerous than the beef tapeworm. So far as the production of intestinal disturbances and nervous symptoms in infested individuals is concerned, the two species under consideration are on a par. Unfortunately, however, man is also capable of serving as an intermediate host of the pork tapeworm and thus becoming infested with the cystic or bladderworm stage. Since the cysts may lodge in such organs as the heart, the brain and the eye, an infestation in man with the cystic stage of pork tapeworm may lead to serious consequences and often does. Persons harboring the pork tapeworm in the intestine might accidentally contaminate their hands with the tapeworm eggs. It requires but little imagination to see how the hands thus contaminated might transfer the eggs to mouth and thus pave the way for an infection of the muscles and of such vital organs as the heart, brain and eyes. Several years ago a medical officer of the British Army reported the pork tapeworm as a rather common cause of epilepsy in British troops returning from abroad, presumably from places where the cystic 
stage of the pork tapeworm was of rather common occurrence in swine, the epileptiform symptoms being due, of course, to the lodgment of the cysts in the brain and other parts of the central nervous system.

Under federal meat inspection swine carcasses showing a light infestation with tapeworm cysts are passed for sterilization, which means thorough cooking at a temperature more than adequate to destroy life in these parasites; if the infestation is moderate or excessive the carcass is condemned.

For many years it was assumed that the rarity of the pork tapeworm in man and swine in this country was due to the fact that the American people were not in the habit of eating rare or raw pork, a habit which is well established among the people of certain countries of Europe. Unfortunately, in the light of the evidence to be presented in connection with the next and final topic, trichinosis, this assumption does not appear to afford the entire explanation. Federal and other competent meat inspection offer the public the greatest measure of protection against the pork tapeworm. The importance of cooking pork thoroughly will be discussed in connection with trichinosis. Thorough cooking of pork will absolutely preclude the possibility of infestation with a tapeworm that is very dangerous to human health.

\section{T R I CHINOSIS}

Trichinosis is a disease of human beings, swine and other animals. The parasites which produce this disease are small cylindrical worms, known to zoologists as Trichinella spiralis and commonly known as trichinae; these parasites occur in a great variety of carnivorous and omnivorous mammals. So far as human trichinosis in this country is concerned, only swine need be taken into consideration, since practically all the known cases of human trichinosis in the United States that have been definitely traced to their source were shown to have resulted from the consumption of raw or undercooked infested pork or to the consumption of inadequately cooked or cured meat food products containing infested pork muscle tissue. A few cases of trichinosis have been traced in this country to the consumption of jerked bear meat, and in Germany this food was responsible for a serious outbreak of trichinosis several years ago.

Unfortunately, pork that is infested with trichinae does not differ in appearance or in taste from uninfested pork. The trichinae that occur in the flesh of hogs are very small, measuring only about one twenty-fifth of an inch in length and about one eight-hundredth of an inch in width. The individual worms are spirally rolled and enclosed in capsules which are somerwhat less than one fiftieth of an inch in diameter and hence, microscopic in size. The capsules do not stand out in contrast to the meat, except in infestations of long standing. Considering the minute size of encapsuled trichinae, it is impossible, of course, under meat inspection procedure, to detect their presence in pork with the naked eye. Microscopic inspection 
of pork for trichinae is practiced in some European countries. Such inspection, however, is inherently imperfect, many infected carcasses, especially those moderately or lightly infected, being overlooked. Knowledge of the existence of a microscopic inspection of work would tend to create a false sense of security in the minds of persons who are fond of raw pork, and this would tend to promote rather than discourage the unhygienic custom of eating pork in a raw or semi-cooked state. In the United States, microscopic inspection for trichinae of pork intended for home consumption has never been undertaken. Consequently, pork that is passed under federal and other meat inspection as being fit for human food may be infested with trichinae, and for this reason pork should always be cooked. If infested pork is eaten raw or insufficiently cooked, serious consequences are apt to follow and sometimes do.

During the year 1937 three serious outbreaks of trichinosis were reported in the press. Through official correspondence, the Bureau of Animal Industry ascertained the facts in each outbreak from the health officer of the community concerned or from the physician who treated the patients. These three outbreaks illustrate how trichinosis may be contracted and afford information on the seriousness of this disease.

Early in December of last year, a farmer, Mr. X, living in Flathead County, Montana, a Russian by birth, and the father of eighteen children, prepared a lot of smoked sausage which contained venison mixed with pork obtained from hogs slaughtered on his own premises. ${ }^{1}$ These sausages were eaten by $\mathrm{X}$ and his immediate family. Some of these home-made sausages were distributed by the kindly father to his married sons and daughters, and they in turn, partook of these home-made products and, with characteristic western hospitality, distributed the surplus products to their friends and neighbors. The available evidence indicates that the immediate family of $\mathrm{X}$, and some members of the families of his sons and daughters and those of some of their friends ate these products without cooking or only after slight cooking or warming. As a consequence thirtyeight persons became ill, Mr. X and members of his immediate family being the first ones to show symptoms of illness.

The first symptoms shown by the members of the stricken family were a general tired feeling and headache, these being followed by nausea, vomiting and sharp gastro-intestinal pains. These early symptoms were followed later by pains in the eyes and a marked swelling of the lower eyelids; at the same time marked swellings were noted in the muscles of the lower portion of the abdomen and in the flexor muscles of the limbs. The symptoms mentioned, especially the early symptoms, were, in the opinion of the attending physician, suggestive of food poisoning, and it was suspected that the venison which was one of the constituents of the sausage might have

${ }^{1}$ The account of this outbreak is based on information supplied by the attending physician. 
been tainted. As the patients failed to improve, but grew instead increasingly worse and developed fever, the state epidemiologist, who was notified of this outbreak, visited the premises, and obtained samples of water and samples of blood and stools from the infected persons. The samples were submitted to the state health laboratory for bacteriological examination; the results were negative. The youngest member of the family in the meanwhile became severely ill and was placed in a hospital, where the usual laboratory examinations were made, including a microscopic examination of the spinal fluid, a spinal puncture having been resorted to because meningitis was suspected. One microscopic field showed a single trichina larva, and this at once led to a suspicion that the patient, as well as the other members of the family, was suffering from trichinosis. Samples of the pork sausage still available on the farm were sent immediately to the laboratory of the Montana Livestock Sanitary Board, and a telegraphic report from that laboratory to the hospital contained the information that the sausage was heavily infested with trichinae. The hospitalized patient succumbed to the infection about three weeks after eating the infested sausage. In the meanwhile other persons outside of X's immediate family became ill and on the date of the last report $3^{8}$ persons, as already noted, were ill and suffering from trichinosis.

The symptoms shown by the affected persons were due to the progress in the growth, development and migration of the trichinae in the bodies of their victims. The early gastro-intestinal irritation and pain were the result of the growth and development of the worms in the intestine, and the swellings and pain in the muscles were caused by the penetration into this tissue of the new-born trichinae, which wandered from the intestine in the lymph and blood stream until they reached the muscles. The symptoms which were suggestive of meningitis were due, at least in part, to the penetration of the wandering worms into the central nervous system.

One of X's daughters ate some of the sausage well cooked and escaped infection, while several members of her family who ate the sausage only half-cooked became ill. A neighbor of one of the beneficiaries of X's generosity is said to have stolen a number of sausages and his family of five, including himself, became stricken with trichinosis.

A sample of the sausage that brought about this epidemic was forwarded to the Bureau of Animal Industry and was found in our laboratory to contain approximately 2,800 trichina larvae per ounce. A piece of muscle from one of eleven hogs purchased from X by the Montana Livestock Sanitary Board and later slaughtered was examined in our laboratory and found to contain an average of about 168,000 trichinae per ounce.

This outbreak has been described in detail because it illustrates the point that human beings acquire trichinosis from eating raw or slightly cooked pork, shows the principal symptoms of trichinosis, and that this disease may terminate in death. The data given afford conclusive proof that the 
suffering of those stricken as well as the untimely death of the youngest member of the family could have been avoided, if the sausage in question had been cooked, as shown by the experience of one of X's daughters, who apparently did not share her family's fondness for semi-raw pork. The case history of the boy who succumbed to trichinosis illustrates that this disease may be confused with other febrile diseases, such as food poisoning and meningitis. Trichinosis is commonly confused with typhoid fever and occasionally with undulant fever.

Another outbreak which occurred late in October of last year involved forty-four persons in one of the New England states. Fortunately all these cases were moderate or mild. The infection was traced to a meal of undercooked pork loin of which all the persons who later became ill partook. The diagnosis in these cases was established on the basis of clinical symptoms.

Still another outbreak occurred late in the summer in Rochester, New York, and came about as follows: A social organization of that city held a picnic which was attended by about 200 members. The food served was of the customary picnic variety, including pork sausage, which was cooked hurriedly and avidly consumed by the picnickers, following several hours of exercise in the open. The resultant casualties were as follows: Stricken with trichinosis, 85; succumbed to the disease, 1. Aside from the fatal case, only a few individuals developed sufficiently severe symptoms to warrant hospitalization; most of those stricken escaped with rather mild symptoms and were treated in their homes. An article regarding this outbreak, published in the bulletin of the Health Bureau of Rochester, New York, contains the following significant statement: "All this suffering could have been so easily prevented, if only the pork had been thoroughly cooked."

The total number of cases involved in the three outbreaks is 167 , with two deaths. In addition to these cases, there occurred during the year a number of more or less isolated cases in various parts of the country which probably will bring the total number of reported cases of the year up to about 250 .

In the absence of an economically practical method of inspection of pork to detect infected carcasses and in the absence of a practical system of rendering fresh pork and ordinary varieties of cured pork safe for consumption before the meat is released for sale, the consumer should protect himself by cooking all pork thoroughly, unless he has definite assurance that a particular processed pork product intended to be eaten without cooking was prepared with this in mind in a meat-packing establishment operating under federal inspection or competent state or local inspection. Whenever any doubt exists as to whether a particular product may be eaten without cooking, it should be cooked thoroughly.

Under federal meat inspection, all products containing pork muscle tissue that are to be sold as cooked products are heated or cooked under 
the scrutiny of inspectors, according to methods which are known to insure a sufficiently high temperature to destroy in all parts of the meat the vitality of any trichinae that may be present. For all products which are not cooked or heated to a sufficiently high temperature, but which are nevertheless intended to be eaten by the consumer without cooking, various alternative methods of preparation are prescribed, such as prolonged freezing at low temperatures, or curing, smoking and drying in accordance with methods that are known to insure the destruction of life in all trichinae present. As already stated, for fresh pork and ordinary varieties of cured pork, there is no inspection or required treatment for reasons already given.

Some persons, upon discovering that between $I$ and 2 per cent. of hogs in this country contain trichinae, and that these parasites are dangerous to human health, conclude that all pork, no matter how prepared, is dangerous. Such a conclusion is unsound and unwarranted. There is no danger whatsoever of acquiring trichinosis or any other parasitic disease from thoroughly cooked pork. Cooking of pork is a health safeguard and is comparable to the pasteurization of milk, the chlorination of drinking water and similar hygienic measures that have been adopted the world over to protect human health. If one concludes that there is something wrong with pork because it must be cooked to make it safe, to be consistent such a person would also have to conclude that there must be something wrong with milk because it is commonly pasteurized. As is well known to hygienists, cooking is the greatest health safeguard; the facts presented in this paper confirm this generalization.

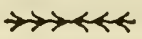

\section{DEGENERATIVE DISEASE *}

\section{K A R L B . M I C K E Y}

It is difficult to realize that less than three generations of human life have passed since Pasteur discovered the bacterial causation of disease. That knowledge so profoundly influences our attitude toward the world we live in, that we tend unconsciously to think of it as having always been a part of the intellectual equipment of civilized peoples.

Of course, the scientific approach to human disease antedated Pasteur. Hippocrates, in Greece in the fifth century before Christ; Galen in Italy in the second century of the Christian era; Harvey, in seventeenth century England-these are but three of the most illustrious of those who, within historical times, attempted by exact observation and reasoning to dispel the demonism and crude ignorance which pervaded the practice of medicine. However, it was not until the young French scientist, from his study

* Reprinted from Health From the Ground $U p$ by Karl B. Mickey with the permission of the International Harvester Company, $194^{6}$. 
of the fermentative diseases of wine and beer, evolved his concept of animal diseases the result of invasion of the tissues by microscopic organisms, that scientific medicine acquired a solid foundation upon which to build.

Upon Pasteur's concept Koch quickly founded the science of bacteriology. Lister, from the same concept, developed antiseptic methods which phenomenally reduced the hazards of surgery and made possible the dramatic progress of that branch of the healing art. Sanitation, public hygiene, immunology, preventive medicine, and the other modern methods which have all but robbed communicable diseases of their terrors followed one upon another, almost without pause. Today's developments of the sulfa drugs and penicillin are milestones on the road originally opened up by Pasteur.

The new ability to cope with infectious diseases, viewed in the light of the cheerful Victorian ideas of progressive evolution and human perfectibility, at first was hailed as presaging a wonderful new world of supermen living in unalloyed happiness and health.

The dream has failed to materialize. True enough, the great plagues of smallpox and typhus no longer decimate the populations of entire countries; the incidence of such infections as diphtheria and scarlet fever is insignificant compared to that of little more than a generation ago; even venereal diseases are under control; ${ }^{1}$ virtually every infectious illness except the common cold is on the decline. Nevertheless, the sum total of human disease has increased and continues to increase.

Another kind of disease-degenerative disease-increasingly exercises a selective effect against civilized men. These are the disorders characterized by deterioration of the body tissues in which disease-producing agents such as bacteria play no part or at most a secondary part-diseases such as dental caries and periodontal diseases, rickets, osteomalacia and other diseases of the skeleton, arthritis, nephritis, arterial sclerosis, heart ailments, etc. And the medical profession, by reason of its success in reducing infant mortality and in keeping the chronically disabled alive and its comparative helplessness in preventing these diseases of degeneration, stands accused by men respected in its own ranks of unwittingly helping to defeat natural selection and hastening evolutionary degeneration.

Evolutionary degeneration! The very words come as a surprise and a shock to modern man. For in no other time has the average man been so pleased with himself as in the present era. Quite a few things have happened in the past 150 years to give him a fine opinion of himself. For one thing, he has achieved a considerable measure of political freedom and is accustomed (in the United States) to hearing himself and his fellows referred to as the "sovereign people"-as kings. By reason of the inventiveness, thrift, and

1 "Dr. Thomas Parran, surgeon general of the United States, said recently in an Office of War Information report that there is every reason to predict that syphilis and gonorrhea will be eliminated as a major public health problem in five years."Chicago Daily News, March 13, 1945. 
daring of the more exceptional of his fellows he has received more for less work than the average man ever received before. During normal times of peace he has been better housed, better clothed, and better fed (quantitatively) than ever before. Moreover, he had been told by the popular philosophers of the nineteenth century that his evolution was a triumphal, oneway procession ever onward and upward toward perfection. This earlier optimism may have been somewhat dampened by periodic economic crises and two world wars, but now to be told that human evolution is a reversible process and that, as an organism, he may be deteriorating instead of improving-well, it comes as a shock!

Dr. Thomas Parran, Jr., surgeon general of the United States Public Health Service, reported a few years ago that one of every 20 gainfully employed persons in this country is prevented by illness from attending to his customary duties each day of the year, and every man, woman, and child, on the average, is incapacitated by illness 10 days of each year. The oldsters average 35 days sick in bed each year.

A two-year study of the nation's health by a United States Senate Subcommittee on Wartime Health and Education has revealed that of more than 14 million men examined for the draft, only two million were up to standard. About one of every six citizens of the United States, the subcommittee reported has a chronic disease or physical impairment. ${ }^{2}$ A later report states that approximately 12 per cent. of all those examined by the armed services were found mentally unfit for military duty. ${ }^{3}$

As to the incidence of the chronic, constitutional type of disease, an analysis by the Selective Service System of reports of physical examination of registrants for military service from 21 selected states is deeply revealing. During the period November, 1940, through September, 1941, approximately 3 million registrants in these states were examined at the local boards. These registrants were, of course, between the age limits within which men presumably are at the physical prime of their lives. And yet, the combined rejection rate at the local boards and the induction stations was 52.8 per cent. The following paragraph from the report sets forth the incidence of defects causing rejection:

Tooth defects were the leading cause of rejection, accounting for 16.5 per cent. of all rejections at local boards and induction stations. Other causes of rejection, and the percentages they constitute of all rejections, are: eye defects, II.7 per cent; mental and nervous defects, 10.4 per cent; cardiovascular defects, I 0.0 per cent; musculoskeletal defects, 8.9 per cent; hernia, 5.9 per cent; venereal diseases, 5.9 per cent; ear, nose and throat defects, 5.5 per cent; tuberculosis and other lung diseases, 3.8 per cent; educational deficiency, 3.8 per cent; defects of the feet, 3.0 per cent; underweight, 2.9 per cent; other causes, 11.7 per cent. ${ }^{4}$

2 Time Magazine, January $15,1945$.

${ }^{3}$ Ibid., October 15, 1945.

${ }^{4}$ Causes of Rejection and Incidence of Defects, Local Board Examinations of Selective Service Registrants in Peacetime, Medical Statistics Bulletin No, 2, Selective Service System, August I, 1943, p. I. 
To those who have studied the phenomenon of physical degeneration it will be no surprise that tooth defects head the list of causes of rejection. Dental caries, together with degeneration of the jaw bone and disease of the periodontal tissues, combine to form the most universal scourge of modern civilization. Examination made in public schools throughout the country reveal that from 85 to 100 per cent. of the children are afflicted with dental decay.

From the evolutionary point of view, dental caries is a comparatively modern disease with an affinity for civilized peoples. Dr. Weston A. Price, whose extensive researches into the causes of this and related diseases have attracted widespread attention, finds it to be practically nonexistent among primitive peoples isolated from civilization. Price reports, further, that even in the first generation after primitive races adopt the foods of white civilization tooth decay appears, together with such evidences of evolutionary degeneration as the narrowing of the face and the dental arches. ${ }^{5}$

Physical anthropologists, and particularly Dr. Earnest Albert Hooton, of Harvard University, regard the condition of the teeth and dental arches as of great evolutionary significance. Diseases of these structures may be used as a measure of the physical degeneration of any race, for they are almost invariably accompanied by deterioration of other tissues. The narrowing of the dental arch, depriving the teeth of normal room, causes malocclusions which may result in gastric disorders. The narrowing of the face may alter the shape and affect the capacity of the brain cavity. These malformations usually are accompanied by a general diminution and deterioration of bony tissues, notably the narrowing of the pelvis which, in women, affects the reproductive function.

But how, the reader may protest, is this talk of evolutionary degeneration to be reconciled with studies which show that Americans are growing taller and heavier each generation? There is impressive evidence on both sides of this case, and much of it cannot be reconciled. It is more a matter of weighing the evidence in order to see on which side the preponderance lies.

Several studies have shown Americans to be taller and heavier than Europeans descended from the same stock. Other studies have shown secondgeneration Japanese in California and off-spring of Europeans in American cities to be larger and better built than their parents. The most recent study of this sort is that of the Metropolitan Life Insurance Company, which shows that the average height of men between the ages of 20 to 29 inclusive, examined at military induction centers in May, 1943, was 68.15 inches, or two-thirds of an inch greater than that of the same age group among the first million men mobilized for war in 1917 ; that the proportion of six-footers among men in their twenties is about one-third greater than it was 25 years ago; and that the native women of the United States, in the

${ }^{5}$ Nutrition and Pbysical Degeneration, p. 18. 
20 years following 1920 , have caught up with and now exceed the birth rate of foreign-born women, with an annual rate of 50.7 children per 1,000 women, as against 49.5 per $1,000{ }^{6}$

Hooton reports the results of a study of Harvard University undergraduates which showed an increase in body size for three generations. ${ }^{7}$ The men in the third generation had increased in height nearly one and one-half inches over their grandfathers and more than Io pounds in weight. Generally speaking, the grandsons' measurements exceeded those of their grandfathers by 2 per cent. The shoulder breadth of the grandsons was greater than that of the grandfathers, but the depth and expansion of their chests were less. While the bony structure of the grandsons was longer than that of their grandfathers, it was more fragile. Though admitting that their impressions had not been scientifically verified, Hooton stated that he and other physical anthropologists believe the grandsons are constitutionally weaker than their more compact grandfathers.

Carrel commented on the magnificent physiques of our college athletes, but remarked that their longevity is no greater than that of their ancestors and their resistance to fatigue and worry seems to be less. He said they have more delicate nervous systems than their ancestors and break down more easily.

It is a matter of common knowledge that average men of primitive races isolated from civilization are capable, as a matter of routine, of sustained physical efforts that seem prodigious to us. The men of the Hunzas, a tribe of northern India, frequently travel 60 miles on foot in one stage, transact business, and make the return trip immediately. The Australian Aborigines, the polar Eskimos, and the many other peoples among whom Price made his comparisons of primitive and modern diets and their effects, all were endowed with a physical and nervous stamina far surpassing that of our most rugged and highly trained athletes.

In weighing the evidence of increase in size, two additional considerations should be kept in mind. One is that the more notable increases reported have been among descendants of foreign-born whose ancestors frequently were undernourished for generations. The other is that anthropological opinion does not hold a mere increase in size alone as indication of biological improvement; the rate of metabolism frequently fails to keep pace with the increase in size, with the result that the larger organism may be less efficient than the smaller organism as a converter of food into energy.

Regardless of differences of opinion as to its evolutionary significance, leaders of the medical profession and allied branches of scholarship regard degenerative disease as civilization's major health problem. Even making the most generous allowance for the advances in the art of diagnosis, which

- Time Magazine, December 25, 1944.

7 Twilight of Man, pp. 272-273. 
reveals many disorders that formerly went undetected, degenerative disease is on the increase. It respects neither economic status nor age. Though its incidence is greater among the old, its destructive effects progress more quickly among the young.

Its burden upon society is incalculable. Medical practice, by lowering infant mortality and by prolonging the lives of the physically inadequate whom pathogenic agents otherwise would weed out, some authorities charge, places an increasing weight on the shoulders of the physically fit. In addition, chronic physical disorder must inevitably be accompanied by chronic mental and moral disorder: where physical stamina is lacking the will lacks power; and the process of digestion, is profoundly influenced by the state of general health. Carrel, Hooton, and Price-to mention only three men already named in these pages-agree in attributing much of the adult insanity and criminality which fills our institutions, and much juvenile delinquency, to the mental and moral consequences of diseases of physical degeneration.

The next question, logically, is- What causes diseases of degeneration? Many answers have been given-most of them tentatively. In the case of some of these diseases-particularly cancer-no honest man would attempt an answer on the basis of the knowledge at hand. In the case of cardiovascular disorders, for example, many answers have been given-the stress and strain of modern life, infections, increased indulgence in smoking, metabolic disturbances, dietary deficiencies. Diseases such as scurvy and pellagra have definitely been traced to vitamin deficiencies. Rickets has been unmistakably traced to calcium deficiency or disorder of the calcium metabolism due to endocrine disturbances or deficiency of vitamin $\mathrm{D}$, or all three. Although clinical medicine has made great advances in recognizing and classifying the symptoms of degenerative diseases, and has achieved some success in alleviating their discomforts and in prolonging the lives of their victims, therapeutic measures necessarily remain empirical - processes of trial and error-because of the almost incredible complexity of the disorders.

Take-for one further example of the difficulties which the subject imposes upon medical science-arthritis, a common malady whose incidence is increasing. Frequently, it has been attributed to infection, and many a tooth has been extracted and many a tonsil removed in efforts to cure it. But why should a focal infection cause arthritis in one man and the same focal infection not cause it in another?

This complexity undoubtedly is due in large part to the fact that the dearth of knowledge obscures many simple relationships. It is the usual experience in scientific inquiry that, as knowledge increases, relationships that at first were baffling in their complexity become progressively more clear and can often be reduced to relatively simple laws. However that may be, medical science stands today, with reference to these chronic, con- 
stitutional diseases, almost where it stood in the days preceding Pasteur with reference to infectious, communicable diseases. There exists an insufficient body of exact, scientific knowledge upon which to base an effective program of preventive medicine.

There are, however, certain important differences between the situation today and that of seventy years ago. Quackery and spiritism will always exist in some quarters, human nature being what it is; some persons will always carry a buckeye as a sovereign cure for "rheumatiz"; but, in general, superstition has been replaced by rationalism. Techniques of investigation and experimentation are vastly improved.

Some investigators think they have found the key to the problem of degenerative disease, and that the key is nutritional deficiency.

The trail has been blazed by such groups as the Medical and Panel Committee of the County of Cheshire in England, and by such men as Dr. Robert McCarrison in India and Dr. Price in the United States. The Committee embodied the results of 25 years of study in a remarkable document entitled "A Medical Testament," which attributed the alarming increase in illness in Cheshire County to "a life-time of wrong nutrition." ${ }^{8} \mathrm{Dr}$. McCarrison fed rats the same diets as eaten by peoples in various parts of India and in each case produced in the animals a state of health corresponding to that of the people. Dr. Price carried on his researches among a large number of primitive people in many parts of the world; he compared those living in isolation with their blood brothers exposed to white civilization, as to tooth decay and skeletal deterioration; analyzed and compared their respective diets in the laboratory.

It will be apparent to the reader that, on the surface, the problem of nutritional deficiency presents a paradox. In the past century and a half the peoples of North America and Western Europe have had more to eat than any peoples in any time or place known to history, and yet it is within that period that the physical degeneration now attributed by some authorities to malnourishment has been on the increase. Prior to the year 1800 , when hunger was the daily companion of the average man, degenerative disease is believed to have been rare.

A number of factors doubtless enter into this. One is that the rigors of life and the ravages of infectious diseases formerly killed off the weaker individuals before they had a chance to acquire degenerative diseases. But a factor most pertinent to this discussion is that quantity does not constitute the only food problem or even the most grave food problem. It is the qualitative, not the quantitative, deficiencies in diet that cause dental caries, rickets, osteomalacia, and other degenerative diseases. A man may be positively satiated with bulk and still be malnourished for lack of those food elements essential to the building and maintenance of the structural integrity of his body and to the development and repair of its tissues.

${ }^{8}$ Quoted from An Agricultural Testament, by Sir Albert Howard. 
In fact, the recent researches of such men as Price and Sir Albert Howard, as well as the studies of some physical anthropologists, tend strongly to the conclusion that man frequently has been least well-nourished where and when his food supply has been most ample. The peoples who live at the lowest economic level-primitive hunters and fishermen-show the fewest evidences of constitutional disease and the physical features of evolutionary degeneration, except when they come into contact with civilization. Pastoral peoples, too, on the next highest level, show relative freedom from dental decay and other degenerative conditions.

Food is so scarce with these primitive hunters and shepherds that they eat all that is available; nothing goes to waste. They cannot afford, like peoples on a higher economic and cultural plane, to eat only the muscles of an animal and scorn the viscera, the internal organs. And as the viscera are especially rich in the minerals and vitamins required by health, the savage is likely to be healthier than men on higher cultural planes.

It is when man moves upward to an artificial existence, when he domesticates plants and practices agriculture, that physical degeneration begins to set in-dental caries, diseases of the gums, skeletal weakness, arthritis, and other kinds of chronic constitutional ailments, frequency of acute infections, and other diseases directly and indirectly referable to dietary deficiency. And when life becomes urban and industrial, then physical degeneration becomes appalling. Civilized man, with a plentiful supply of food, is able to pick and choose. Lacking the instinct of the lower animal, and the intuition and tribal lore of the primitive man, he all too frequently chooses what isn't good for him.

A strict regard for the facts, however, demands the noting of an exception to the generalization developed in the preceding three paragraphs. The health of some primitive peoples within the zone extending about 700 miles on either side of the equator, for example, is far from enviable. It is within this zone that the habitual practice of cannibalism is largely confined today.

In this region high temperatures, accelerating chemical reactions, and torrential rains, exerting both chemical and physical action, carry the calcium and other minerals essential to health down to levels where the plant roots cannot reach them. There is everywhere a definite correlation between minerals and proteins, both because calcium stimulates the nitrifying bacteria and because the nitrates, too, are easily soluble and are leached away with the minerals. The result is grave lack of mineral and proteins in the foods available to the natives of this zone.

Even where cannibalism is practiced as a magical ritual, its basis could be the need of conserving proteins and minerals, for ritual observances usually have their foundations, no matter how obscurely, in practical necessity. Cannibalism in the lower animals is known to be due to mineral hunger. Cannibalism is far from universal among savage peoples, which indicates 
that it must arise from special necessity. Along the Guinea Coast southward into the Congo and for some distance eastward in Africa, the eating of human flesh is today the main part of the diet of some tribes and the market in human flesh is just as commercial and free from ritual as the cattle market in the United States. This market undoubtedly owes its existence to the need of foods containing adequate amounts of minerals and proteins.

The popular vitamin craze in the United States is evidence that the people have awakened to the danger of nutritional deficiencies and are attempting to correct them. The unfortunate fact is, however, most people are not aware that vitamins, essential as they are to health, are merely activators. In the absence of the appropriate minerals, proteins, and other nutrients taken by the plants from the soil, the vitamins have nothing to activate. Moreover, some professional students of nutrition question whether the synthetic vitamins and mineral salts purchased at the drug store are not considerably less beneficial than vitamins and minerals taken in the form of vegetable and animal foods.

According to Dr. Parran, more than $4^{\circ}$ per cent. of the American people did not consume enough milk and milk products, citrus fruits, green vegetables, and meats to maintain good health and vigor; their diets were particularly deficient in calcium and the vitamins A, B complex, and C. ${ }^{9}$ Under wartime food restrictions they ate of necessity more of the energygenerating carbohydrates and less of the protective foods which maintain the organism in good development and repair.

The author has seen no published reports on this subject, but during the war physicians told him orally that the effects of food rationing had appeared in decreased resistance to illness, particularly in the case of growing boys and girls. "They look all right on the outside," said one busy pediatrician of his patients, "but on the inside they haven't got what it takes." This was in America, whose civilians as compared with those of Europe had scarcely been touched by the war.

A tragic glimpse of how war ravaged the civilian populations of Europe with diseases of degeneration was revealed in a report from Paris by A. J. Liebling. ${ }^{10}$ Liebling stated upon the authority of Professor Pasteur ValleryRadot, a physician of the Academie Française, that 54 per cent. of the children born in Paris during the German occupation had rickets. Due to deficiency of calcium and phosphorus in the diet, the bones of adults broke "with sickening ease," and French physicians reported cases of adults who lost as much as four inches in height due to the effect of this deficiency upon their vertebrae. Similar tragic conditions were found in Poland, Yugoslavia, Italy, Greece, and elsewhere.

Despite the fact that the science of genetics holds acquired characteristics

${ }^{9}$ Nutrition and National Health, The Technology Review, June, 1940.

${ }^{10}$ Letter from Paris, The New Yorker, November 4, 1944. 
not to be inheritable (there is some dissent from this tenet) a number of highly competent investigators report much evidence that degenerative characteristics resulting from nutritional deficiency are inheritable in the first generation. This would seem plausible since our inheritance consists of a complex set of chemicals called chromosomes, which we get from our parents. 'Though nature "guards" the germ plasm more jealously than any other tissue, it is difficult to understand why chemical deficiencies in the diet, if sufficiently pronounced, would not cause corresponding deficiencies in the chromosomes and their constituent genes.

Thus we have attempted to outline the situation which has impelled the surgeon general of the United States Public Health Service to declare that, today, knowledge of nutrition opens up to medical progress a field comparable to that opened up less than three generations ago by Pasteur's discovery of the bacterial causation of disease. ${ }^{11}$

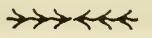

\section{WALTER REED AND YELLOW FEVER *}

\section{GRACE T. HALLOCK A N D C. E. T UR N E R}

The struggle against yellow fever began more than 200 years ago. It approached its close when a master detective unmasked the chief villain that carried the fever from one person to another. The detective was Walter Reed, and he was helped by brave American soldiers who offered their lives in the conquest of this disease.

\section{THE HISTORY OF YELLOW FEVER}

The earliest record of yellow fever says it occurred in Central America in 1596. Then it was heard of in New England among the Indians, in 1618. It appeared in the Island of St. Lucia in 1664, where it killed 1,411 of a population of 1,500 soldiers. In 1665 , in the same place, 200 of 500 sailors died of it. New York was visited by it for the first time in 1668 ; Boston in 1691 , and Philadelphia in 1695. In 208 years there were 95 invasions of our territory by yellow fever. From 1793 on there were not less than 100,00o deaths from it. New Orleans, Philadelphia, Memphis, Charleston, Norfolk, Galveston, New York, Baltimore, and many other cities suffered a tremendous loss of life.

In the terrible epidemic of 1793 in Philadelphia, all the streets and roads leading from the city were crowded with families flying to the country for safety. So many doctors were sick or had died of yellow fever that "at one time there were only three physicians who were able to visit patients,

11 Parran, Nutrition and National Health, The Technology Review, June, 1940.

* Reprinted from Healtb Heroes, Walter Reed by permission of the Metropolitan Life Insurance Company. Copyright 1926. 
and at this time there were probably not less than 6,000 persons ill with the fever." Dr. Rush, then a physician in Philadelphia, relates that a cheerful countenance was scarcely to be seen in the city for six weeks. Once in entering the house of a poor man, he met a child of 2 years who smiled in his face, and he says, "I was strangely affected by this sight. Few persons were met in the streets except those who were in quest of a physician, a nurse, or the men who buried the dead. The hearse alone kept up the remembrance of the noise of carriages or carts in the street."

For more than 200 years, learned men searched for the clues that would tell them how to prevent the crime of yellow fever which was repeated year after year. The strange part of the story is that they found the clues and described them many times, but they didn't have sufficient knowledge to trace the villain. It lived in the community undisturbed and went its criminal way unchecked, until the master detective, using the very same clues that puzzled everyone else, came along and pointed it out.

The first thing Major Reed and his associates decided to do when they reached Cuba was to sift the evidence that seemed to point to an insectcarrier of the disease. Insects, like flies and mosquitoes, had already been convicted of carrying certain other diseases. Walter Reed himself had proved that flies spread typhoid fever; and an English army surgeon, Dr. Ross, had discovered that the parasite of malaria gets into the blood of a human being through the bite of an Anopheles mosquito and in no other way. Another species of mosquito had been suspected of carrying yellow fever. There were many clues that pointed to it as the guilty party.

THE FIRST CLUE

In almost all the old accounts of yellow fever epidemics, mosquitoes were mentioned as being very troublesome. Dr. O'Halloran, describing an outbreak of the disease in Barcelona, Spain, in $182 \mathrm{I}$, wrote: "It is worthy of remark that during the month (July) the flies and mosquitoes were infinitely multiplied." Dr. Drysdale, a Baltimore physician, writing of an epidemic, said: "Locusts were not more numerous in the reign of Pharaoh than mosquitoes through the last few months; yet these insects were very rare only a few years past, when a far greater portion of Baltimore was a marsh." Thus it appears that the suspect was at the scene of the crime.

THE SECON D CL U E

Epidemics always started in the low wet regions or near the docks. All epidemics in Baltimore broke out at Locust Point, a low-lying section almost surrounded by water, or about the docks and wharves.

The report of the epidemic in Mobile, Ala., in 1819 says the first cases were among the people employed on the wharves. "A number of carpenters and sailors employed about the wharf and who were much on board the schooner Sally which was filled with stagnant water, and about the 
steam sawmill, where there was a pond of like offensive water, were taken with violent fevers." Dr. Rush in describing the outbreak of the 1793 epidemic in Philadelphia says: "Upon inquiry, it appears that the first persons who died with this fever ... had been previously exposed to the atmosphere of the wharf." As the mosquito breeds in still water, here was another clue pointing to it as a carrier of yellow fever.

\section{THE THIRD CL U E}

In the high and dry parts of a city the disease was not contagious. In many epidemics people from low-lying sections fled to the higher part of the city or to the country districts. Although many of these people came down with yellow fever after they had left their homes, the disease did not spread to other people in the new neighborhood.

This clue pointed to the thought that yellow fever must be carried in some way other than directly from one person to another. This was the conchusion arrived at by a great many intelligent observers, but the only explaration they could give was that the disease must be present in the air of certain districts and not in others.

\section{THE FOURTH CLUE}

Another clue strengthened the idea that the disease was air-borne. Some people noticed that the fever spread in the direction of the prevailing wind. Whenever the wind blew strongly in a certain direction, yellow fever broke out in its path. When the air was still, the infection was content to pay its calls in the houses of an already infected neighborhood. As the mosquito is a great lover of home, and never travels far unless it gets a free ride on the wind, or on a ship, this clue explains why yellow fever spread so quickly in narrow streets, and broke out at a distance from the wet lowlying districts of a city only when the villain of the drama was carried there by wind.

\section{T H E F I F T H C L U E}

Yellow fever flourished when the weather was hot but was stamped out by frost. Mosquitoes, also, are active in hot weather and disappear after a frost. Here was another important clue, but it didn't mean anything except that "heat was a very common exciting cause of the disorder," until suspicion was thrown on the mosquito. It is easy to explain facts that seem mysterious as soon as the villain of a detective story is uncovered. Then it seems strange that the important clues, which pointed to the guilty person as clearly as a signboard points out a road, could have been misunderstood.

Anyone who has studied the life history of the mosquito can see how the spread of yellow fever tallies with the mosquito's habits. But it is one thing to suspect a villain, and another thing to prove the suspicion to be true. Someone had already suspected that the mosquito carries yellow 
fever, but had been unable to prove it. This person was Dr. Carlos J. Finlay, of Havana, who had advanced the mosquito theory in $188 \mathrm{i}$.

Walter Reed and his associates decided to investigate this theory not only because they had observed that the mosquito's habits tally with the spread of the disease, but also because of one peculiar fact about the infection of houses. This fact was the length of time that it takes to change a noninfected house to an infected.

\section{S I X T H C L U E}

A picture story of what happens when a case of yellow fever breaks out in a house is given on the following page.

In this picture it is shown that A's house was not infected with yellow fever for 15 days after A came down with the fever, because people could go there and not take it. But after the 15 days were up, everyone who went there took the disease in from one to six days.

What were the germs doing, and where were they, before they finally infected the house? Walter Reed suspected they were being entertained in the stomach of a mosquito, and stayed there until they were capable of passing on the disease through the mosquito's bite.

As it was then believed that yellow fever could not be given to animals, the only way of investigating it was to experiment on human beings. This meant a tremendous responsibility for the members of the Board. They agreed they must experiment on themselves as well as on the men who volunteered for inoculation. Think of the high courage of the men who took this great responsibility, and the gallantry of the American soldiers who accepted the risk of suffering, or even death. These men were heroes in the greatest war of all, the war against disease.

\section{THE FIRST EXPERINIENTS}

The first experiments were made in August 1900. Eleven persons were subjected to the bite of mosquitoes of the species Aëdes aegypti (formerly called Stegomyia fasciata) after these mosquitoes had already bitten patients with well-marked cases of yellow fever. Of these in persons, two developed the disease. One of the positive cases was that of Dr. James Carroll, a member of the Board. Both cases recovered. In one of these cases it was proved that the infection could have been received in no other way than by the bite of the mosquito. A third case developed later, accidentally.

On September 13, 1900, Dr. Jesse W. Lazear, while visiting a yellow fever hospital, was bitten. He deliberately allowed the mosquito, which had settled on the back of his hand, to remain until it had satisfied its hunger. Five days after the bite he came down with yellow fever of which he died, a true martyr to science. From these three positive cases Walter Reed and 


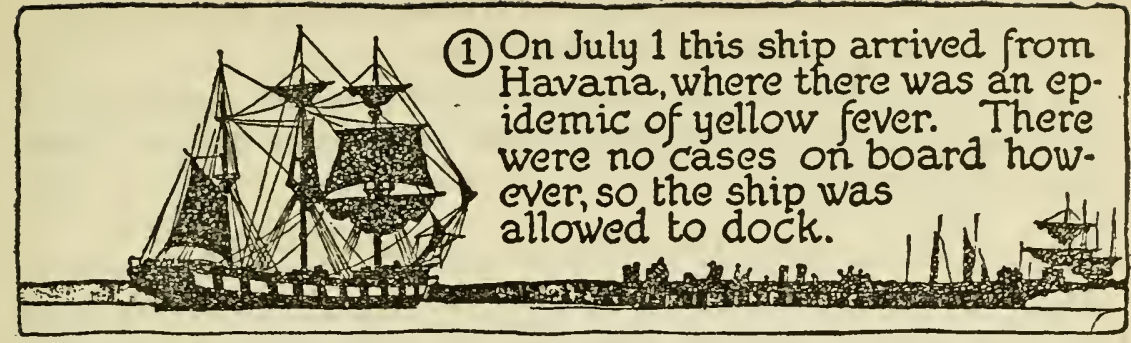

This is Mr.A's house

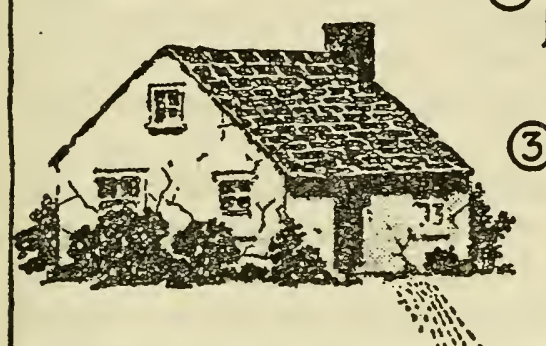

(2) Mr.A helped unload the boat from Havana. In five days he had yellow fever.

(3) This is A's wife. She took care of A for fifteen days without taking the fever but on the fifteenth day she came down with it.

(4) This is Mr.B He went to see A every day for the first week ind and

of As illness and
yet he did not
take the fever take the fever.

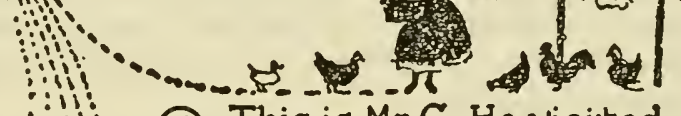

(7) This is Mrs.E. She went to A's house on the first day that Mrs. A had the: yellow fever. In

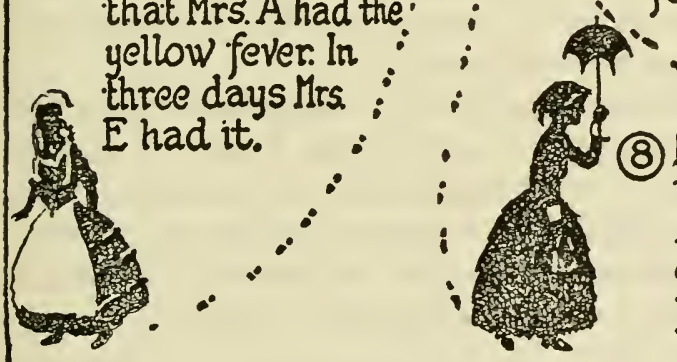

This is MrC. He visited A's house on the second day of the fever and did'nt take it. But he came back on the eighteenth day and in three days had yellow fever.

(6)This is Mr.D. He visited A's house on the twentieth day after $A$ came down with the fever In five days $D$ had it.

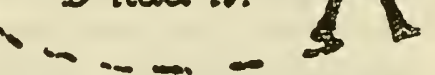

Mrs. F went to A's house twenty-five days after A came down. In two days Mrs. F had yellow fever. 
his associates came to the conclusion that the mosquito serves as the intermediate host for the parasite of yellow fever.

To prove this definitely, it was necessary to carry on experiments in such a way as to make it impossible for the men experimented on to get yellow fever accidentally.

\section{THE EXPERIMENTS AT CAMP LAZEAR}

Major Reed and his associates took a piece of ground about 6 miles from Havana and built a camp there, which they named Camp Lazear after their dead comrade. The camp site was well drained, and freely exposed to sunlight and winds. In this camp were quartered men who had never had yellow fever and who were therefore called nonimmunes. These men were American soldiers who bravely volunteered for the experiment, and Spanish immigrants who gave their services for pay.

If a person is going to have yellow fever, he develops it within six days after exposure. Therefore, if the men were kept in quarantine for two weeks without developing the disease, this fact would show they had not become infected before they entered camp. Things were now so arranged that if a mosquito was allowed to bite a man and the man afterward developed yellow fever the Board would know the disease was due to the bite and to nothing else.

\section{K IS I NGER A N D MORA N}

When it became known in the American troops in Cuba that soldiers were wanted for yellow fever experiments, John R. Kissinger and another young man from Ohio, John J. Moran, volunteered. Major Reed talked the matter over with them, explaining the risk of suffering and even of death. They held to their purpose. Major Reed told them they would be rewarded with a sum of money. They both refused any compensation. Then Reed touched his hat and said, "Gentlemen, I salute you." Kissinger volunteered, to use his own words, "Solely in the interest of humanity and the cause of science." Major Reed's comment on this young man was: "In my opinion this exhibition of moral courage has never been surpassed in the annals of the army of the United States."

Kissinger was bitten on December 5,1900 , by mosquitoes which had bitten yellow fever patients from 15 to 20 days before. Four days later he had a well-marked case of yellow fever, from which he recovered. In all, 13 men at Camp Lazear were infected by means of the bites of contaminated mosquitoes, and the disease developed in 10. Fortunately, they recovered. No one else in the camp of 30 or 40 men became ill.

THE MOSQUITO PROVED GUILTY

As a result of these experiments it was found that yellow fever could be carried from one person to another by the bite of a female Aëdes aegypti 
mosquito that had bitten a yellow fever patient in the first three days of his illness, and had then been kept for at least 12 days before it was allowed to bite a human being who had never had yellow fever. If that plan were followed, the person bitten would generally come down with the disease within six days. It now became clear as to why it took so long for a case of yellow fever to infect a house. Mosquitoes had to bite the patient during the first three days of his illness, then 12 days had to go by before they could pass on the disease by biting another person. But after that interval of 12 days they were a menace to everyone who entered the immediate neighborhood.

\section{A NOTHER SUSPECT}

In a detective story not only must the villain be proved guilty but all other suspects must be proved innocent. Almost everyone at that time thought yellow fever was carried by fomites-that is, by excretions of yellow fever patients in the articles of clothing, bedding, or other materials that had been contaminated by contact with people who had the disease. That belief resulted in the destruction of a great deal of valuable property supposed to be infected, and worked a real hardship on merchants trading in infected ports.

\section{FOMITES PROVED INNOCENT}

Walter Reed and his associates now set to work to prove that fomites do not carry the disease. For this purpose a small frame house consisting of one room 14 by 20 feet in size was erected at Camp Lazear. It was tightly built, and the doors and windows were so placed as to admit as little sunlight and air as possible. A coal-oil stove kept the temperature at 90 degrees during the day, and the atmosphere was provided with moisture. The room was thus kept like the hold of a ship in the tropics-warm, dark, and moist.

The building was now ready for the experiment. Three large boxes filled with sheets, pillow slips, blankets, etc., contaminated by contact with cases of yellow fever, were placed inside; and on November 30, 1900, Dr. R. P. Cooke, acting Assistant Surgeon, United States Army, and two privates of the Hospital Corps, all nonimmune young Americans, entered the building. They unpacked the boxes, giving each article a thorough shaking in order to fill the air with the specific agent of yellow fever if it was contained in these fomites. They then made the beds with the soiled bed clothing and slept in them. Various contaminated articles were hung about the bed in which Dr. Cooke slept. For 20 nights this room was occupied by these nonimmunes. They packed up the soiled articles every morning and unpacked them at night, but not one of the men developed yellow fever.

From December 21, 1900, to January 10, 1901, the room was again occupied by two nonimmune young Americans. These men slept every night in the soiled garments and on the bedding used by yellow fever patients 
throughout their entire attacks. They also remained perfectly well. The experiment was repeated a third time with the same results. This experiment explained why people had been able to wash the bedding and clothing of yellow fever patients without taking the disease. It absolutely cleared the fomites of suspicion.

\section{HOW A HOUSE IS INFECTED WITH YELLOW FEVER}

Since it was proved that a house could not be infected with the yellow fever by fomites, the question now arose: "How does a house become infected?" To answer that question with certainty, a second building was erected similar to the first, except that it was well ventilated. It was screened so that mosquitoes could not get in or out. The room was then divided by a wire netting that extended from top to bottom and allowed the air to pass freely from one side to the other. Therefore, if there were any germs or "miasms" floating in the air that could cause yellow fever they would be found on both sides of the screen. To show that the building was uninfected, four men slept in it for two weeks, two on each side of the netting. They remained perfectly well. "Now," said Major Reed, "I am going to infect one side of this room with yellow fever and not the other side." $\mathrm{He}$ took out the two men from one side and set free there ${ }_{15}$ Aëdes mosquitoes that had previously bitten yellow fever patients. John J. Moran then entered the mosquito-infested space for a short time on three successive days. Four days after his first visit John Moran came down with a well-developed case of yellow fever, from which he recovered. During each of his visits two other nonimmunes remained in the building on the other side of the wire netting, and they slept there for 18 nights. They remained in perfect health. Therefore Reed concluded that as the air on both sides of the wire screen partitions was exactly the same, it must have been the presence of contaminated mosquitoes that infected the side in which Moran contracted yellow fever, and the absence of mosquitoes that made the other side perfectly healthful.

\section{HOW AN INFECTED HOUSE IS DISINFECTED}

Walter Reed then said: "Now that I have shown you a house infected with yellow fever, I will demonstrate how it can be disinfected and rendered safe." He caught the mosquitoes and put them back in their jars. Then he said that the building was disinfected. The two men returned to the side that had been infected and they and the two on the other side continued to live there in perfect health.

PASSING SENTENCE ON THE VILLAIN

The experiments of Camp Lazear proved beyond the shadow of doubt that the Aëdes aegypti mosquito is a carrier of yellow fever. Apparently 
no grounds remained for doubting that one of the greatest detective stories of all times had been brought to a successful close. Sentence was passed on the Aëdes aegypti mosquito in these words of Walter Reed: "The spread of yellow fever can be most effectually controlled by measures directed to the destruction of mosquitoes and the protection of the sick against these insects."

\section{EXECUTING THE SENTENCE IN HAVANA}

W. C. Gorgas, then a Major in the medical corps, United States Army and Chief Sanitary Officer of Havana, set the example for vigorous and energetic measures against the mosquito.

The female mosquito lays her eggs in still water. About 36 hours later these eggs hatch into larvae, also called "wigglers" or "wiggle-tails." The wiggler moves about actively, feeds much of the time, and breathes air which it secures by thrusting its breathing tube up through the surface of the water. After six or seven days it changes into a pupa or "tumbler." In this stage it is an air-breather but it does not feed, and after 36 hours or more it is again changed and comes forth as the perfect winged insect.

When the campaign started in February 1901, all houses and yards in Havana were examined and all tin cans, empty bottles, and similar trash, which were generally found filled with rain water and full of yellow fever mosquito wigglers, were carted off. Openings in cisterns were covered with mosquito netting. The Health Department fitted covers over rainwater barrels, and a wooden spigot was placed in the lower part of the barrel so that water could be drawn off without lifting the cover. As the $A e ̈ d s$ aegypti mosquito lives and breeds almost entirely in or near houses, these measures were very effective.

When a yellow fever case was reported, employees of the Health Department went to the house and screened it so that no mosquitoes could get out or in. Then they fumigated the house to kill the mosquitoes inside.

As a result of this general mosquito hunt yellow fever decreased rapidly, and since September 1901 not a single case has developed in the city. That historic month was the first in which Havana had been free of yellow fever in 150 years. Later, Gorgas repeated this performance in the Canal Zone, with the result that the United States was able to build the Panama Canal. Since then the example of General Gorgas has been followed wherever the $A \ddot{e} d e s$ aegypti had a hiding place.

The mosquitoes that frequent the United States and Canada now probably belong to the harmless tribes of that innumerable race. But it is well to remember that all mosquitoes are a great pest, and that the Anopbeles mosquito is still spreading malaria. For the sake of comfort and of health everyone should make war on them just as General Gorgas did. 


\section{THE DEATH OF IVALTER REED}

The master detective in this story, Major Walter Reed, died of acute appendicitis on November 23, 1902, in Washington. It is good to know that before he died he saw the great city of Havana delivered from her ancient foe, and the way made clear for the saving of his own beloved country from a great plague.

\section{THE SEQUEL TO THE TALE}

The heroism of Walter Reed's little band of scientists and volunteers has run like a golden thread through all the later work done in connection with this disease. The search for the real cause of yellow fever continued even after its chief carrier had been discovered. Fortunately, certain kinds of monkeys were found to be susceptible to yellow fever, so it became unnecessary to use human beings as subjects for experiment. However, the search for the virus proved to be so dangerous that valuable lives were lost until 1931, when a yellow fever vaccine was perfected.

Campaigns against the Aëdes aegypti mosquito were so successful in eliminating yellow fever from the centers where it had once been a major cause of death that the manner of its spread came to be regarded as "one of the best examples of a closed argument" in the entire history of medicine. However, experiments in West Africa have proved that yellow fever can be transmitted by mosquitoes other than Aëdes aegypti, and within the past few years the disease has been discovered in rural and jungle areas in South America where no Aëdes aegypti mosquitoes can be found.

The knowledge that yellow fever is caused by a filterable virus and can be vaccinated against, together with the proof that in certain localities it is spread by carriers other than the $A \ddot{e} d e s$ aegypti, is being used by workers today in their efforts to realize that noble vision which came to Walter Reed just before the clock struck midnight on New Year's Eve in 1900 - the complete conquest of yellow fever in the 2oth century.

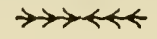

\section{MENTAL DISEASE-A CHALLENGE *}

\section{W I N F R E D OVER H OL S E R}

Mental disorder is a subject which merits the attention of every intelligent citizen, for it constitutes to-day one of the largest and most pressing social problems. It is important from the medical, public health, social and economic points of view. Very nearly one half of the hospital beds of the entire country are devoted to the care of mental diseases. At the beginning

* Reprinted by permission of the Scientific Montbly, American Association for the Advancement of Science. Copyright 1938 . 
of the year 1936 there were, in the United States, 469,100 patients in mental hospitals or on visit to hospitals, and during the year following that date 150,208 others were admitted. Thus, during that year (1936) well over 600,000 people were at some time or other patients in a mental hospitalin other words, one out of about every r 50 adults of the general population!

The investment in mental hospitals in this country is approximately onehalf billion dollars, and the annual cost of the maintenance of these institutions is about one hundred million. The wreckage of human lives, with the accompanying loss in productivity to the conmunity, and the untold heartaches caused to the families of mental patients, can not be fully estimated or expressed in monetary terms. One need only mention, too, the bearing of mental disorder upon dependency and delinquency. There certainly are relationships here which are difficult to evaluate but which are none the less real. To bring the matter somewhat more closely home to the reader, it may be pointed out that it has been estimated from the statistics of the New York mental hospitals that the probabilities are that of all persons in New York, at least fifteen years of age or over, one out of every twenty will at some time during his life be a patient in a mental hospital. ${ }^{1}$

In spite of the vital importance of the topic of mental disorder, there is probably no subject on which more misconceptions of facts are prevalent among the public and even among many educated people. When it is borne in mind that for countless centuries, from the time of Christ or earlier down through the Middle Ages, mental derangement was interpreted as due to demoniac possession, presumably as a punishment for sin, it is perhaps not strange that relics of the medieval attitude still hold over in the form of a disguised fear or hatred or contempt of the mental patient. Many persons even to-day are inclined to look upon the existence of mental disorder in relatives as a "stigma," as something to be kept secret, even though intellectually they may recognize that it is simply another manifestation of disease, and no more cause for shame than the occurrence of, let us say, pneumonia. The lot of the mentally ill person has never been a happy one, but for too long a time in man's history and, indeed, even to-day that lot has been and still is being made more unhappy by man's inhumanity to man.

Institutions for the care of the mentally ill are relatively new things. During the Middle Ages and the early Renaissance these unfortunates were driven out of communities to perish miserably or were executed as witches. The Bethlehem Hospital in London was founded probably in the thirteenth century and has had a continuous history since that time, but for centuries after its opening stood alone as an "asylum" for these unfortunates. Parenthetically, it may be noted that the word "bedlam" is a corruption of Bethlehem, the name of this hospital. One can well imagine the reasons why

1 A convenient synopsis of the statistics and their interpretation is to be found in the recent volume of Landis and Page entitled Modern Society and Mental Disease. 
when it is realized that only the "furiously mad" were confined in institutions, that little or nothing was done for them even in the line of elementary hygiene, and that these places were scenes of the worst types of filth and confusion.

The first public mental hospital in this country, at Williamsburg, Virginia, was founded in 1773 , but it was not until the middle of the nineteenth century that the practice of building public mental hospitals became general, thanks to the activities of Dorothea L. Dix. The purpose of these institutions, which were then known as asylums, was primarily to care for the "furiously mad," as they were denominated. The more quiet patients were often cared for in jails or in almshouses, a situation which is not unknown in some parts of this country even to-day. It may be pointed out and emphasized that mental disorder was early looked upon as being of public interest only in connection with the disturbance of the peace or with "pauperism"; it was a subject to be dealt with by the police or by the poor authorities, not as a medical problem. Historically, these facts are probably connected to some extent with an attitude not entirely unknown, that mental disease impresses some sort of "stigma" upon the person who suffers from it and upon his family. Indeed, even to-day in many parts of the country the mental hospitals are under the control of departments of public welfare; that is, under organizations which are designed primarily to deal with the dependent, rather than raised to the dignity of recognition as medical institutions. The development of the medical attitude toward mental disorder, the attitude that we are dealing with disease and which is amenable to treatment, is relatively recent. It is this evolution which has brought about the change of name from "asylum" to "hospital," with all that that name implies.

In the early days in this country admission to mental hospitals was not especially difficult, although those who were able to pay for care avoided, so far as possible, being sent to the public institution. The "asylum" was designed, as we have said before, primarily for "paupers" and for those who had been considered dangerous to the public peace. In the beginning hospital admission was a simple matter, but in the '50's the "railroading myth" seems to have become established. As a result of the fear that persons would be improperly sent to mental hospitals and there detained for the purpose of permitting others to obtain control of their property, the admission to mental hospitals was in a good many states made decidedly difficult, and some went so far as to require a trial by jury on a charge of lunacy before the patient could be admitted to the hospital. Such a barbaric and antiquated procedure was abolished by statute in the District of Columbia only as recently indeed as 1938 , and is still retained in at least one state. There are many people to-day who believe seriously, in spite of the overcrowding and the constant pressure by hospital administrators to dismiss patients from hospitals, that patients are actually sent to such institu- 
tions improperly. Any one who has had experience in the administration of mental hospitals knows that this is a most untrue accusation, yet laws still exist which make it difficult for patients to enter mental hospitals, although admission to any other kind of hospital is very simple. When admission is made difficult, and particularly when a jury trial (which of ten appears to the patient and to the public both to be in the nature of criminal proceedings) is necessary, admission to a mental hospital is delayed and often the best chance of cure of the patient is lost. The existence of the popular notion of "railroading" has done much to delay the early admission of patients and thereby to deprive the mental hospitals of one of their proper functions. Again it should be pointed out that in some localities it is permitted to use the jail for temporary care of mental patients until such time, sometimes several weeks or months, as the mental hospital finds room for the patient. Such proceeding is, of course, seriously out of line with sound practice and is grossly unfair to the mentally afflicted patient.

Some of the feeling that mental disorder is something apart from general medicine, that it is something which labors under a stigma, is perhaps due to the way in which psychiatry has been presented and in which in the past mental hospitals have been operated. There was a time when the asylum with its forbidding wall made no effort to overcome in the community the attitude of suspicion which was directed toward it by those ignorant of its activities. The "asylum doctors" were looked down upon by the physicians in the locality and an atmosphere of hocus-pocus and of something mysterious tended to keep people away from the institution, both physically and mentally. In medical schools the student was given the impression that mental disorder was something not akin in any way to the rest of medicine; the lectures were the most sketchy and sometimes not even accompanied by a visit to the mental hospital, with the result that physicians have in the past not been in a position to assist in breaking down the public distrust. To-day we find psychiatry integrated with the rest of medicine in medical training. We find medical students spending much of their time in mental hospitals, working at close quarters with the patients and coming to realize that psychiatry is something which touches every other field of medicine. They realize, too, from what they see in the institutions that they are not the places of horror and misery which some even to-day seem to consider them. Further, many general hospitals are establishing psychiatric wards-a decidedly salutary step in bringing psychiatry and general medicine into closer union.

Another misconception has been that once a patient was admitted to a mental hospital all hope was lost, and there are many who think that the inscription described by Dante over the gates of the Inferno is written, even though invisibly, over the entrance of mental hospitals. Such is, of course, far from the case. Mental disorder does not warrant the attitude of hopelessness which the public ascribes to it, even though certain types of mental 
disorder have not so favorable a prognosis as have others, and although in general mental disorders tend to take somewhat longer for their cure than do the disorders which take patients to general hospitals. Most readers will probably be astonished to learn that during the year 1933 for every one hundred patients admitted there were forty-six discharged, of which number thirty-nine were considered recovered or improved. Of those discharged 22 per cent. had been hospitalized for two months or less, 55 per cent. for less than six months, 74 per cent. for less than one year, and 87 per cent. for less than two years. Furthermore, it has been found that at the end of ten years over one half of the patients discharged are living in the community, a small proportion of them, to be sure, having had in the interval one or more readmissions to mental hospitals.

It should be understood that mental disease is not a unitary thing; there are many different types, some of which occur early in life, some in middle age and some in advanced years. The discharge rate and the prospects for these various types are not all alike by any means. This is true likewise of the symptomatology. The average citizen probably thinks of the mentally disordered person in the terms of a "raving maniac," one who is disturbed, noisy, disheveled, annoying others, possibly even making homicidal attacks, and so on. As a matter of fact, patients of this type constitute perhaps not over 5 per cent. of the population of a mental hospital. Some patients are depressed, some are confused, some are apathetic, many show relatively little disorder of conduct. Some of this difficulty is perhaps due to the legalistic notion that a person is either sane or insane, and to the rather fixed definitions most of them entirely out of line with psychiatric thought, which the law gives for that legal term "insanity." Mental disorder represents a failure of the individual to adjust to his environment, but such adjustment depends on many things: it depends upon his heredity and the constitution with which he was born, on his training, on the functioning of his ductless glands, on the situation with which he is confronted, his education, his native endowment and many other factors. In some instances we have degenerative processes due to old age, in others we have brain disease due to infection or intoxication, and it is quite obvious that with so many varying factors the types of reaction and the manner in which adjustnent fails will vary. Mental disorder is not necessarily accompanied by disease of the brain, although brain damage of ten produces mental symptoms. It is rather a failure of adjustment of the entire personality. "Mind" is not a unit, but rather an abstraction which symbolizes the sum total of the reactions of the individual at the social level.

A few words may be in order concerning some of the broader general types of mental disorder which find their way into hospitals. One of the important groups is that due to degenerative processes, that is, hardening of the arteries of the brain (cerebral arteriosclerosis) and senility. By the very nature of the disorder, the outlook is poor. Together these types make 
up about 18 per cent. of the admissions to mental hospitals. As for the future a factor which can not be overlooked is the changing composition of the age groups in the population. Human life is lengthening, the birth rate is falling, immigration has almost ceased. Furthermore the incidence of mental disease increases steadily as age advances; the rates of mental disorder for the respective age groups of the population are somewhat more than four times at age 80 what they were at age 20 . Whereas in 1900 only 4 per cent. of the population was over 65 , at present 6 per cent. is over 65 , and it is estimated that by 1980 somewhere between 14 and 16 per cent. of the population will be over $65 .{ }^{2}$ In other words, there is every reason to believe that the number of patients in mental hospitals suffering from cerepsychoses will probably increase rather materially as time goes on. It is difficult to see how very much can be done about this.

There is another group due to the infections, of which general paresis is a conspicuous example. This disorder is one of the late results of syphilitic infection, and until about twenty years ago was considered to be a rather promptly fatal disorder once it had reached the stage of calling for hospital care. During the world war considerable impetus was given to the campaign against syphilis, and the campaign has been carried on since, having been given more recently a very strong reenforcement through the splendid efforts of Surgeon General Thomas Parran and the symposium organized and presented by the American Association for the Advancement of Science. Already the effects of the twenty-year-old campaigns are being realized in a fall in the admission rate of general paresis; it is confidently to be expected that as time goes on the rate will fall still further. Furthermore, since very striking advances have been made in the treatment of this disease through the fever therapy devised by Wagner-Jauregg, the prospects of this group, which now constitutes about 9 per cent. of first admissions, are good.*

As an example of another group of mental disorders we may mention that due to intoxications; the alcoholic psychoses are a type. Although a drop in admissions for this type of disorder began about 1914, apparently as the result of the campaign against the excessive use of alcohol, and although there was a sudden drop in 1920 when prohibition went into effect, there has been a rather gradual rise since 1920, with the result that we are approaching the pre-war levels in the admissions of alcoholic psychoses, now about 5 per cent. The educational program against alcohol was badly disrupted by prohibition, and it will take a number of years to make this effective again. Ultimately some drop in the rate of alcoholic psychoses is perhaps to be expected. Mental disorders due to other drugs, such as opium, cocaine and marihuana, are relatively negligible. Admissions due

2 "Problems of a Changing Population," National Resources Committee, p. 25. Washington, 1938.

"Drug therapy with penicillin is a promising new approach.-Ed. 
to head injuries are rather infrequent; although mental disorders sometimes ensue following head injury, they are generally not sufficiently disturbing to call for commitment to mental hospitals.

There are some types of mental disorder which have no uniform and clearly demonstrable organic bases. They are, perhaps, constitutional in predisposition and environmental as far as precipitating factors are concerned. With the group of depressions, which account for about 12 per cent. of first admissions, some progress has been made with "shock therapy" in recent months. These depressions are rather inclined to spontaneous recovery and usually do not call for a long hospital residence, except for that relatively small group which occurs during the involutional period and in which the duration is somewhat longer and the prognosis somewhat less favorable. Another large group and very important one is that of dementia praecox, or, as it is frequently termed, schizophrenia. On account of the relatively early age at which this tends to develop and the rather long course which it is inclined to run, nearly one half of the population of any mental hospital is found to be suffering from this disorder, although the first admission rate is only about 20 per cent. Much research work is being carried on in the field of schizophrenia, and a little progress has been made recently through the so-called "shock" treatment. Many baffling problems are still presented, however, and the future is not entirely clear. It is felt by those experienced in this field that much depends upon preventive activities, which will be touched upon later.

The question is often asked whether mental disorder is increasing. The warning should be given that the only reliable statistics are those of hospitalized mental patients. We have very inadequate means of knowing how many cases of mental disorder there are in the community. Consequently, if a state provides inadequate facilities and makes it extremely difficult to enter a hospital, it may boast of a low mental hospital rate. If, on the other, hand, it is progressive, as New York State is, providing ample facilities, a large proportion of those in need of care will receive it. The discrepancy among the several states in the rate (per 100,000 general population) of the patients hospitalized is enormous, the figures for New York and Alabama being respectively 464.5 and 163.5 . It may be said very briefly that there appears to be a slight general rise in the admissions to mental hospitals, and a slight increase, rather steady, in the population of these hospitals. It is questionable whether at the present time, at least, the prospect is alarming. The figures which have been given for the trend in the senile and arteriosclerotic groups, however, certainly seem to indicate heavier future demands for mental hospital facilities.

Much used to be said about the influence of heredity in mental disorder. That there is such a thing as heredity can not be denied, but it is not looked upon to-day as one of those inescapable things to which one may as well surrender without a struggle. The growth of the mental hygiene movement 
has laid stress upon the importance of attempting by proper training, guidance and environment to overcome native handicaps, and much can be done in that line. As for environment, it is quite likely that the constantly increasing pace of life has no particularly beneficial effect upon the mental hygiene of the public; on the other hand, it can not be proved to be the principal factor in any increase in mental disorder. The old myth about farmers' wives, who were generally reputed to be particularly susceptible to mental disorder, has long since been exploded, and it has been found that the rates for hospitalization are in general slightly higher in urban than in rural communities. This, however, may be due in large measure to the fact that peculiarities of conduct are much less well tolerated in closely settled areas than they are in rural districts, with an increasing likelihood of commitment.

The modern mental hospital is as far different from the old asylum as could well be imagined. It is a general hospital thoroughly well equipped, surgically and medically, to deal with any physical disorder which may arise among its patients. It is equipped in addition with occupational therapy, with hydrotherapy and other specialized forms of treatment designed to remedy the disordered mental attitude of the individual. Padded cells have not existed for many years, and seclusion and restraint have long since been virtually abandoned, having been found to have a deleterious effect on patients. As much freedom as possible is given to patients, and the atmosphere of the hospital is one as nearly approaching normal community life as can well be secured in an institution. There are various types of entertainment and social activities, all designed for the purpose of helping the patient to readjust himself to mingling with his fellows in a normal way. Recently considerable attention has been given, partly for economic reasons, to the possibility of caring for the mentally ill in families after the more acute problems have been dealt with in the hospital. The system of family care, which was first introduced into Massachusetts in 1885 , has at last been adopted by several other states.

It should not be thought, however, that all mental hospitals are the ideal places that have been described. Unfortunately some states have been decidedly backward in their care of the mentally ill, have been niggardly in the appropriations voted, and have allowed partisan spoils politics to interfere with efficiency and with the securing of adequately trained and interested personnel. It is to be hoped that the new interest in public health now being fostered by the Federal Government will bring about improvement in those states in which it is needed. Mental hospitals, in addition to their intramural activities, are engaging constantly more and more in community activities, particularly with relation to child guidance and adult mental hygiene clinics. These activities are extremely important from the preventive point of view, being designed in the case of children to overcome habit difficulties, and in the case of adults to prevent mental break- 
downs in those who appear to be showing symptoms of incipient difficulty. Mental hospitals, or at least the more progressive ones, are centers of research and of teaching-a trend which is rapidly developing.

Even the most vigorous opponents of "state medicine" have always admitted that the care of the mentally ill is a proper function of government. As the public becomes more acutely aware of the true importance of mental disease in the community and the needs of hospitals administering to this group, we may look to see the standards raised and greater efficiency brought about in the humane care and treatment of the mentally disordered.

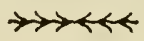

\section{MENTAL DISEASES *}

\section{B E R N AR D J A F F E}

"Everywhere, skin deep below our boasted science, we are brought up short by mystery impalpable, and by adamantine gates of transcendental forces and incomprehensible laws." This was Charles Kingsley's reaction to the panorama of the onward march of science, an advance which seemed only to demolish every obstacle in its path. He was thinking of man's efforts to banish not only all the multitudinous sicknesses of the body but also the countless tortures of the mind. Millions of souls with their minds in ruins-one out of every twenty-two destined for mental hospitals-is the dark picture which still confronts science as its outstanding challenge to redeem mankind from illness.

Throughout the ages four furies pursued those frames from which the mind had gone awry. Superstition, nourished on a demonological conception of insanity, burned, harassed, and beat those frames to exorcise the devils playing havoc with their thoughts and behaviors. Skulls were trepanned to allow egress of demons, bats, snakes, crows, vultures, and other animals housed within the sacred precincts of what would otherwise have been rational men. And when the devil was too firmly intrenched and would not leave, thousands of unfortunates, as late as the beginning of the eighteenth century, were burned amidst heinous cries of "witch."

Brutality, under the cloak of necessity, tortured these "wild beasts" by methods worse than those of the Inquisition, strapped them into choking straightjackets, shackled them to tranquilizing chairs, crucified them on the bed saddle-a steel cross strapped to the bed - and pinned them down in restraining sheets of canvas. To frighten the insane into submission when they became difficult to manage they were placed in wells where the water rose slowly until it reached their mouths, ice-cold water was poured down their sleeves to the aching armpits, or they were whirled on rapidly rotating

* Reprinted from Outposts of Science by permission of Simon and Schuster, Inc. Copyright 1935, by Bernard Jaffe. 
wheels until they lost consciousness. Keepers restrained their wards with threats of death, and of ten beat them into insensibility. The same treatment was meted out to the poor and the rich. Wallowing in their own excrement, they fell victim to every passing epidemic.

Before 1850 most of the insane in the United States were housed in prisons or almhouses. Poormasters boasted of how cheaply they could keep their wards alive. Similar conditions prevailed in Europe. When William A. White, a director of St. Elizabeth's Hospital in Washington, one of the largest and most advanced of such institutions in the world today, visited Europe twenty-five years ago he saw: "One ward occupied by some forty men, every one of them stark naked and strapped to his bed. There was only one bed that was not occupied by a patient, and that was occupied by a giant of an attendant who was asleep. He jumped up as I came in and walked through the ward with me, and I remember those naked men cursing and spitting at us as we went by." To this day some insane asylums, even in civilized countries, reek with primitive ideas and methods. But most of the old lunatic asylums are now things of the past, gone with the rack and other instruments of torture. London's Bedlam, open until 1777 , and the Lunatics' Tower of Vienna, closed in 1853 , where caged insane were exhibited to sightseers who paid for admission, have been banished forever. Lunatic asylums have been changed to hospitals in more than name.

Many things have been listed as causes for insanity. In one form of mental disease, there seemed to be some strong indications of connection with a bacterial infection. Ten per cent. of all new admissions to insane asylums were general paretics. Their Wassermann blood tests were often positive and their spinal fluid was always positive. Their histories showed venereal infection of some ten or more years' standing. Syphilis and paresis seemed linked. Often they had fared well socially for more than twenty years after infection, until suddenly a strange change came over them. Their memory began to fail, they became contrary, irritable, suspicious, and suffered from illusions. Frequently, like Ivan the Terrible of Russia who was undoubtedly a paretic, they were drawn to acts of violence. The deterioration of the mind was progressive. Half of the victims died within a year after reaching the hospital; few survived as long as five years after commitment.

A diagnosis of paresis was a verdict of a sure and ugly death. There were few exceptions and no method of treatment. Syphilis was shown to be the sine qua non of paresis. But no one knew just how the connection existed. Salvarsan, the magical chemical weapon which Ehrlich had forged in his laboratory, brought healing to some syphilitics, but never to paretics. These were doomed. Some talked about sexual excesses, sunstroke, religious excitement, and the stress of life. Emil Kraepelin taught the equation, Syphilis plus Alcohol equals Paresis, but nothing had really been proved. Then 
with the discovery by Schaudinn of the pale spirochete bacterium which showed its spiral form in every syphilitic, began the search for this organism in the brains of paretics. Perhaps it was this microscopic invader which was sending its host to a paretic death. And while thousands of paretics died of emaciation, with bed sores exuding daily pints of pus from the back of their heads to their heels, only one persistent man searched unrelentingly for the spirochete in paretics.

Hideyo Noguchi, who knew more about spirochetes than anyone else alive, had carefully examined one night a lot of two hundred slides of paretic brain material stained for spirochetes. In the early morning he had detected what he thought were spiral organisms in seven slides. $\mathrm{He}$ would not trust his eyes and rushed to the home of Simon Flexner for confirmation. This discovery proved a landmark in the study of paresis. The organism responsible for syphilis sometimes reached the brain and, lodging there, changed its victim into a paretic.

These facts accounted for a phenomenon that a Viennese physician, Julius Wagner-Jauregg, noticed while treating soldiers during the Italian campaign of the first World War. Syphilitics, after getting over an attack of malaria, showed a milder form of the "social disease." Paretics, on recovering from some infectious disease, had long been known occasionally to improve considerably. Wagner-Jauregg reasoned that the spirochete, which could not endure high temperatures, might have been killed off by fever, thus reducing the virulence of the disease. Perhaps this was the explanation of the occasional cure of feverish paretics from whose chest laudable pus had been forced. The infection which produced the pus brought on the fever.

Wagner-Jauregg was almost sixty at the time. He had seen an army of paretics die in asylums. He was going to test out a hunch. Surely there was nothing to lose. Into the veins of two men crazed by the spirochete of syphilis, he injected two cubic centimeters of the blood of a shell-shocked malarial patient. Then he waited for the fever to burn out those bacteria. It was frankly a dangerous experiment. His patients might succumb to malaria. The fever rose and almost burned out their lives. But they recovered from the malarial attack, their memories returned, they became less irritable, and with frequent doses of salvarsan the symptoms of paresis never reappeared. The fever attack on paresis has become a standard practice in mental hospitals.

Research men have been driven into other channels of investigation. The most recent attempt to explain and treat mental disorders from the viewpoint of abnormal physiology is with the data and tools of glandular investigations. As far back as 1881 Kraepelin had fought insanity by introducing extracts of every possible gland of thyroid, testes, ovaries, and so

- on, but unfortunately without effect. When later, however, cretins, hopeless humans disabled in both body and mind, responded miraculously to treat- 
ment with the iodine compound thyroxin produced in the thyroid gland, and this glandular therapy had actually succeeded in salvaging those who for centuries had been considered lost souls, visions of a new day for all the mentally disabled loomed on a blurred horizon.

"The diseases of the mind," said Cicero, "are more numerous than those of the body." The ancients recognized this, yet for convenience divided all mental ailments into two classes. The individual was either melancholic or manic. In mania, said Aurelius, the head was disordered; in melancholia, the stomach. This classification, in more or less modified form, lasted until the nineteenth century. Then many began to make careful studies of the mentally sick, watching their histories, listening to the language of lunacy, and daily recognizing new groups of symptoms. Descriptive psychiatry became the dominant form of investigation in this field, and reached its highest peak about fifty years ago in the work of Emil Kraepelin, a pioneer in experimental psychology of which $W$ undt, his teacher was the father. From a mass of classic case histories he drew a new classification of the insanities, which included as its two most important groups the manicdepressive and the dementia praecox. The latter is now commonly termed schizophrenia.

Manic-depressive insanity is a psychosis of adults. It begins with nervousness, restlessness, and emotional irritability, and ends in such morbid states that incarceration becomes necessary. The afflicted often become suicidal or homicidal. Schizophrenia, the most frequent form of insanity, usually begins at puberty or even earlier. The child becomes queer, shy, dreary, seclusive, different, and a cleavage of the mind develops insidiously. An internal break in the harmony of the personality occurs; the individual becomes, in fact, a split personality. The adult grows even more sensitive and suspicious and less capable of making concessions. The outer world is gradually renounced, and the victim drifts into a realm of fantasy, delusion, and hallucination.

Various forms of schizophrenia have been classified. The catatonic variety finds the victim plunged in a deep despondency followed by sudden irrational excitement. He may refuse to talk (mutism), and to comply with any request (negativism). He may adopt and maintain certain fixed and peculiar positions such as keeping one arm outstretched for hours at a time. These periods of depression and excitation vary both in length and in suddenness of change. The paranoiac is recognized by fixed and systematized delusions. The patient appears perfectly normal except on certain topics. Reason seems preserved but sidetracked, as in this typical case: A childless Russian woman is being tortured every night in her sleep by operations removing children from her body, and she believes that her husband cooperates to get children for scientific experimentation. Otherwise she is apparently quite normal.

Dismissing both the extravagant belief of Watson that "we do not inherit 
our character, temperament, and special abilities; they are forced upon us by our parents," and the pronunciamento of E. A. Wiggam that the environment plays no part, and that we can never escape the effects of heredity, science is drawing closer to the conviction that with the mental diseases as with such physical characteristics as sex and stature, T. H. Morgan's opinion is the most trustworthy. Morgan says: "The gene acts as a differential turning the balance in a given direction affecting certain characters more conspicuously than others. Let us not forget that the environment may also act as a differential, intensifying or diminishing as the case may be the action of the genes."

Neurotics are both born and made, and it is wise not to be alarmed at the implications of genetics. If mental abnormality is due to a single gene, the defective genes of the child inherited from both parents may be so arranged in the chromosome threads that they do not lie side by side, and the child will not inherit this defect. Said Ray Lyman Wilbur, "Human beings do not deal with our defectives, our insane, in the same way as do animals. No doubt foolish dogs are born, but unless they happen to get into the hands of foolish ladies, they soon succumb." Nazi Germany in 1934, in the name of race purity, issued a decree ordering the sterilization of its 200,000 feeble-minded, 60,000 epileptics, 50,000 schizophrenics, 20,000 manic-depressives, and another 47,000 defectives including "hereditary" alcoholics and the hereditary deaf, decisions to be made by Hereditary Hygiene Courts. More than fifty-six thousand sterilization operations were performed there within one year of the issuance of the decree.

Eugenic sterilization laws are on the statute books of twenty-seven states in our own country but they are seldom enforced. New York passed such a law in 1912 , but it was declared unconstitutional. Oklahoma sterilizes the hereditarily insane as well as its three-time convicts. California, home of the over-zealous Human Betterment Foundation which would sterilize fifteen million Americans, accounts for two-thirds of all the eugenic sterilization in the United States. During the last thirty years, more than four thousand insane and two thousand feeble-minded persons were sterilized by this state. It uses the painless technique of tying the ducts from the testes or ovaries without modifying the internal secretions of the gonads or otherwise interfering with the sex life of the individual. Such individuals, however, can no longer become fathers or mothers.

The other camp numbers a large army of men and women who oppose sterilization on the ground that science knows too little about mental diseases. Who can say, they insist, what will be incurable tomorrow? They point to Mozart, Pascal, Mohammed, Schiller, Paganini, as great men who were epileptic. They single out Kepler, both of whose parents were mentally diseased, and they tell us that Francis Bacon's mother was insane. And some are willing to pay the price of mental disease for the world's geniuses. Convinced that the partition between sanity and insanity is indeed a thin 
one, and that very often genius and insanity are not so far apart, they would not sacrifice one single genius for relief from the burden of tens of thousands of mentally diseased persons.

The natural history of the mind is as yet only imperfectly known. The study of the mental diseases has been left far behind in the onward march of science, and today Meyer says, "We are very much in the beginning with the outstanding problems still to be solved in this field." And in such a complicated world Adolf Meyer believed with Voltaire, "It is part of a man to have preferences but no exclusions," especially when this mortal is exploring in the devil's own domain.

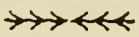

\section{THE SIGNIFICANCE OF PLANT DISEASE IN AGRICULTURE *}

\section{K. ST A R R C H E S T E R}

Waist deep in a sea of ripening wheat stand two men, and they mark a turning point in American Agriculture. The man in overalls dejectedly pulls a few stalks from the soil. The stems are cracked and dried, stained with red and black streaks. He breaks off a head of grain and rubs it between his palms, and as he blows the chaff gently away there remain in his palm a few pitifully shriveiled kernels. Many of the stalks have broken over and fallen beneath the reach of binder or combine. The field that just a few days ago gave promise of forty bushels to the acre, today will hardly yield the expense of harvesting. Perhaps it would be better to cut it for hay, or plow it under to give way to a summer crop of fodder.

This is the grim side of black stem rust, the scourge of wheat farmers in every land. The scene, which took place in 1935 or ' 37 or ' 39 , is a classic scene, which had its prototypes four thousand years ago in the grain fields of the ancient Hebrews.

What will this mean to the man in overalls? Perhaps another postponement of the children's chance for education; perhaps failure to meet the payments on the nearly paid-up farm; perhaps this year will mark the beginning of the long, sad back-trek from combine to binder, from tractor to mules, from a square mile of rich, flat bottom land to a quarter section of eroded hillside,- - on from wheat which takes machinery, to cotton or corn, which you can raise if you have a mule and a family, on to working for the insurance company or the W.P.A.

That's the dark side. But what about the other man beside the man in overalls? He is the county agricultural agent. He's saying something to this effect: "You don't need to put up with this loss another year. The men

* Reprinted from The Nature and Prerention of Plant Diseases by K. Starr Chester, by permission of The Blakiston Company, Philadelphia. Copyright $194^{2}$. 
at the Experiment Stations have been working to breed varieties of wheat that are resistant to the stem-rust fungus. They have been able to combine rust resistance with the other qualities we need in wheat,- -high yields, drought- and cold-resistance, and good milling and baking qualities. Jim Beard, out west of town, has been growing one of these varieties, and it's making thirty-seven bushels to the acre this year. You can get some of that wheat for seeding, and be ready for rust another year."

Because disasters like this occur today and often mean the difference between success and failure in agriculture and because many such disasters can be averted by timely intervention of simple preventive measures, some acquaintance with the science of plant pathology is indispensable to agricultural workers.

You are studying a comparatively new science, that of plant disease. It is only a few decades since plant pathology came into being. Some of the pioneer plant pathologists, founders of the science in America, are still vigorously carrying on their warfare against plant disease, setting a stimulating example to their army of young followers. But plant diseases themselves, and their prevention by empirical or intuitive recipes, are by no means limited to problems of today. Long before the appearance of civilized man, the agents of disease were leaving petrified thumbprints in the fossils that tell us of the leaf spot diseases and other ailments of prehistoric vegetation. Among the earliest written records of man, the unmistakable complaints of blights, mildews, and plagues show us clearly that plant disease has shadowed the agricultural path of man since he first scratched the soil with a pointed stick and planted seed. The Old Testament tells us of plant diseases visited upon man in punishment of his transgressions. Three hundred years before Christ, Theophrastus, the Father of Botany, was well familiar with plant diseases of his time, and in his writings we can recognize many of our plant troubles of today, scorch, rot, scab, and rust. So formidable were the cereal rusts in those early days that the Romans evolved a pair of rust Gods, Rubigus and Rubigo, whom they annually honored as a means of rust prevention.

As ancient times gave way to the intellectual darkness of the Middle Ages, these early sparks of understanding of plant disease were all but extinguished by the superstition and avoidance of reason that overshadowed that period. Plant diseases continued to take their toll from the European peasant and landowner, but we learn little of them save that from time to time great epiphytotics* occurred, attended by disaster, famine, and migrations, and historical documents of the early days tell us of entreaties to The Diety to ward off the evil blights, of tragic suffering and death from the "holy fire" which we now attribute to the eating of ergot-diseased grain, of the suffering and famine in Ireland when disease

\footnotetext{
* The name given to a destructive outbreak of plant disease; comparable to epidemics of human disease or epizootics of animal diseases.
} 
destroyed the potato crop in 1845 and drove many of the Irish people to America, and of the powdery mildew which wiped out the wine industry of Madeira and forced the population of that little island back to their ancient occupations of sugar-cane growing and cochineal gathering.

The story of the Irish potato blight is the story of a microscopic fungus which wrought havoc in Europe equalled by few of Europe's many wars.

It is believed that the potato was first brought to Europe by Sir Francis Drake from the Andean hinterland of South America, where it had long been revered, emblematic of fertility, and even been the inspiration of mutilation and human sacrifice. Thanks to the efforts of Sir Walter Raleigh and many other enthusiasts, the potato soon won its rightful place as a leading source of carbohydrate food throughout all of Europe, from the Mediterranean to northernmost Scandinavia, and in northeastern North America as well. In its migration from South America the potato had left behind its most serious agents of disease; for two hundred years or more it enjoyed comparative freedom from disease. But in the early half of the nineteenth century, disturbing reports of potato failures began to appear. In ever-increasing intensity, a plague of potato fields was laying waste the crops of individual farmers, and of whole communities.

In 1845 the crisis was reached. With unbelievable fury the potato blight devastated millions of acres in Europe, the United States, and Canada. So sudden was the catastrophe and so complete that in only a few days fields with every promise of abundant harvest were transformed into blackened wastes of vegetation overlying foul and putrifying masses of rotten tubers. And this was not a local problem, nor limited to a few fields,--everywhere where potatoes were grown the tragedy was repeated, bringing in its wake privation, then starvation or the fever that inevitably follows malnutrition. In Ireland alone, a quarter of a million people fell victim to the famine, and many others migrated to America and became the basis of the IrishAmerican population of the United States.

Like most tragic experiences of mankind, the potato blight was not without some benefit. In the nineteenth century science was rapidly throwing off its stupor of the Middle Ages: the chains of superstition that so long had bound and suppressed creative thought were rusting away. The intellectual genuises Louis Pasteur and Robert Koch were performing the first crucial experiments that were to open up the vast field of modern research on contagious disease. Charles Darwin was revolutionizing biology and philosophy with his keen deductions on organic evolution. Von Liebig was laying the foundations of modern agricultural chemistry. The stage was set for the first fundamental discoveries on the nature and control of plant disease, and the catastrophe of the potato blight forced the attention of master minds to the solution of this and related problems in plant pathology. Out of the labor pains of Europe, racked by the potato blight, was born modern plant pathology, the science of plant disease. The brilliant young 
German, Anton de Bary, stared at the dying potato leaves through his primitive microscope, saw the green leaf cells in the clutches of the sinuous, pallid fibers of the fungus, and its myriads of wind-driven spores, proved that the fungus was the cause, the sole cause of the blight, and paved the way for Millardet a few years later to give humanity an effective weapon against any future recurrence of the blight, Bordeaux mixture.

The story of Bordeaux mixture itself is worth the telling. According to the tale, a farmer in Medoc, France, had a vineyard that bordered the highway. Passers-by are alike the world over, and to the despair of the farmer, the wayfarers could not resist the luscious bunches of ripening grapes, just over the fence. In a moment of inspiration, the farmer decided to take steps. He went to the barn, and his eye falling on a sack of lime, he made a milky broth to splash on the vines. As the mixture didn't look repulsive enough, he threw in a shovelful of bluestone. This accomplished, he spattered it over the vines, posted a "Poison" sign and awaited results. History does not tell us whether the wayfarers were deterred by the farmer's ingenuity, but it does recall that Dr. Millardet came past the vineyard, noted that the sprayed grapes alone had escaped the destructive mildew disease, learned of the spray so accidentally applied, tested its efficiency against fungus diseases of the vine, and gave us the completely effective protection against future outbreaks of both vine and potato blights which we now know as Bordeaux mixture.

Man has a tendency to learn things the hard way. It took another epiphytotic which has practically exterminated one of our finest forest trees, the American chestnut, to establish the science of plant pathology in America. The chestnut blight fungus was a foreigner that sneaked into America from Asia. Starting its deadly work about 1904, it spread swiftly, destroying every tree in its path. Today there hardly remains a chestnut tree in the great forests of the East which were once dominated by this tree. This disaster taught us what might be expected from unwelcome foreign pests; it was largely responsible for the establishment of the National Plant Quarantine Act in 1912.

Today new and potent enemies of our cultivated plants are coming to the attention of growers and scientists. The Dutch elm disease for a while threatened to exterminate the American elm, as it had done in many parts of Europe. In the royal gardens at Versailles were long avenues of stately elms that were mature trees in the hey-day of the pre-revolution French court. Only a few years after the Dutch elm disease appeared, the avenues were lined with dead and dying trees, nearly all sacrificed to the elm disease fungus. Thanks to our lesson from the chestnut blight and to energetic eradication of diseased elms in America, the elm disease has been brought under control, but any relaxation of these efforts could still release the disease in all its destructiveness.

Few of the main groups of crop plants are free from occasional but 
disastrous attacks of disease. Among the fruits may be mentioned fire bligltt which caused "one of the greatest industries of the San Joaquin valley" to vanish like a dream" when 500,000 pear trees were killed by the disease within a few years. In the rich fruit section of New York State a new virus disease of peaches has broken out in epiphytotic form, promising to be even more destructive than any of the other twelve or more virus diseases of this tree. In the tropics banana plantations cannot be permanent. Invariably they become infested with the "Panama disease" after a few years.

Among vegetables, the ravages of the potato blight are seconded by those of watermelon wilt, at first welcomed as nature's way to maintain price levels by restricting production, but soon wiping out the melon industry in important sections of Florida, Iowa, and California.

And in field crops the story is the same. Flax has always been a pioneer crop, moving on to virgin areas and leaving behind a trail of "flax-sick" soil, infested with the flax wilt fungus, soil upon which susceptible flax cannot again be grown for many years. Texas root rot has rendered great areas of the Southwest unsuitable for culture of cotton, alfalfa, and many other crops. The disease causes a loss in Texas of 300,000 bales of cotton a year, and in addition, attacks more than 2,00o other species of plants, aggregating a total loss from this disease, in the seven states affected, which reached $\$ 150,000$, ooo in 1947 . And finally, no account of epiphytotics in field crops can omit mention of the cereal rusts. Stem rust is always with us, and now and then, when the weather is suitable, it rages northward from the Great Plains to Canada leaving in its wake millions of acres of wasted grain. These epiphytotics are coming more and more frequently. There have been three in the past five years. That of 1935 destroyed a quarter of the national wheat crop, a total of $160,000,000$ bushels, and in North Dakota and Minnesota 60 per cent. of the wheat crop was sacrificed to stem rust.

This is the spectacular side of plant disease, the great epiphytotics that are so often followed by privation, suffering, loss of homes and farms, even famine, migration, or abandonment of farming.

How many farmers realize that a small percentage of loss in the field represents a much larger loss, perhaps all, of the profit. To be specific, take the case of a farmer with a quarter-section in wheat, and assume that under disease-free conditions his average yield is a conservative 25 bushels to the acre, or a total of 4,000 bushels. The harvest return is divided into two elements, part, usually most of it, must be paid out to cover all the costs of production of that crop, the remainder is the farmer's profit, and may be applied to maintaining and improving his standard of living and of farming. Under normal circumstances the 4 , ooo bushels would be used somewhat after this fashion: use of the land, 40 per cent; seed, 3 per cent; labor, 12 per cent; machinery and maintenance, 20 per cent; insurance, 5 per cent; leaving a profit of 20 per cent. based on disease-free conditions. The loss from 
diseases in the American wheat crop for the period 1919 to 1937 averaged slightly more than to per cent. per year. Let us assume that our potential 4,000 bushel wheat crop was subjected to disease to this extent, and that Io per cent. or 400 bushels were lost through disease. All of the costs of production are unchanged; it still cost 3,200 bushels to produce the 3,600 bushel yield. The bills could not be paid with the diseased grain or that which failed to materialize. Ten per cent. disease in the field did not strike the farmer as an unusual or serious loss; yet, the io per cent. field loss cost him one-half of his profit.

We hear much today of the misfortunes of the American farmer as compared with the greater security and prosperity of the American Business man. We blame this difference on many factors, but is not a part of the explanation in the differences in methods between the two? To the business man a loss of one per cent. in his industry through waste is a vital loss, one to be corrected. The story is that Mr. Rockefeller, in an inspection of one of his factories, noticed a machine dripping solder on oil cans. He asked and found that the superintendent had never tested the exact amount of solder needed. Mr. Rockefeller counted and found that the machine was applying 39 drops of solder per can. An experiment was devised on the spot; it was discovered that 38 drops would suffice. In a year's time the concern had been saved $\$ 10,000$ worth of solder and time through this slight economy. No business a fraction as wasteful as the average farm could survive without subsidy in the face of its competition. When the American farmer learns to regard his farming as the business man regards his business, we venture to predict that the need for farm relief and crop subsidy will be materially decreased.

When watermelon wilt first appeared in Florida melon plantings a few growers reported the new disease that was killing the vines, and the Experiment Station undertook to find means of checking the disease. The attitude of some of the growers in the early I920's savors strongly of 1940 agricultural philosophy. They said: "If this disease is eradicated, there will be a surplus of watermelons; the price will be lowered, and our profits will lessen. We do not approve of efforts to prevent wilt." But wilt is not a disease that can be trifled with. A few years after its introduction, affected land became useless for melons; losses of 90 per cent. of the crop were not uncommon. The industry must move on to new land, expensive to clear. The abandoned land went back into scrub-oak, since it was not suitable for other crops.

And now a new thought crystallized in the growers' minds. A profitable industry was seriously threatened. They carried their problem to the Florida Legislature, and in 1929 funds were appropriated for a study of wilt. At the Experiment Station a watermelon wilt project was initiated, and by I936 Dr. Walker of that Station announced that the "Leesburg," a new and desirable wilt-resistant melon, was available to the growers. 
At this point we meet the challenge of modern agricultural philosophy. Is our farm prosperity dependent upon reducing production? And is toleration of disease losses an intelligent way of reducing over-production? As to the first question, opinions may justifiably differ. To those, who like Joseph, look forward to the seven lean years, any interference with production may ultimately work hardship. And the others, the sponsors of reduced production, insist at the same time on uniform production, the "ever-normal granary." So long as plant disease is out of hand, we have no control of production; the ever-normal granary is the shuttlecock of fungus and weather

Cotton diseases are causing a loss of one-fifth of the crop annually. Prevention of these diseases, many of which can be controlled, does not need to mean a 20 per cent. increase in American cotton production. Might it not better mean a 20 per cent. reduction in the labor of planting, chopping, and picking, some release of children and women from this grinding drudgery, a release of 20 per cent. of depleted cotton land for a program of soil restoration. Whichever philosophy we accept the moral is the same; the prevention of waste from plant disease does not mean suffering from overproduction; it means on the contrary an opportunity for improving the lot of the farmer by aiding to buffer him against the shock of sudden and unpredictable crop losses, and by giving him some measure of alleviation of the economic and social burden under which he labors.

This, then, is the challenge of American agriculture to the American scientist: "You can see our problem; we are calling on you to help us," a challenge blended of thousands of pleas to the Federal and State Experiment Stations.

And how are the scientists meeting this challenge? One of the newest branches of science, plant pathology, already has enlisted a thousand or more specialists. In Washington, at the state colleges, in private institutions and plant industries these men are devoting their lives to a crusade against plant disease. Much has been accomplished; against many destructive diseases highly effective chemicals of prevention have been found; sprays for fruit and vegetable crops, simple and inexpensive chemical dust treatments for ridding seeds of the germs of disease, tear gas for sterilizing soil, benzol vapor for protecting tobacco seedlings from mildew, fermentation acids for sterilizing tomato seeds, and a host of others. Better, because they are simpler, are the measures of disease control which depend only upon slight changes in the ways of cultivating plants; changing the date of planting to favor the plant and inhibit its parasites, rotation of crops to starve the parasites out of the soil, farm sanitation to destroy the breeding and hiding places of plant pests, to mention only a few of these. Best of all are the scores of new varieties of plants, joint contribution of the plant breeder and the plant pathologist, varieties that are innately resistant to the attack of parasites and at the same time desirable commercial types. There 
are, for example, the wilt-resistant Bison flax, Marglobe tomatoes, Stoneville and Rowden cottons, Stone Mountain and Hawkesbury watermelons, and Ladak alfalfa. New rust-resistant small grains are coming to the fore and enormous acreages have already been planted to some of these, such as Thatcher wheat and Red Rustproof oats. One of the most outstanding of these recent accomplishments is the development of the Wisconsin Refugee bean which is at once immune from mosaic and rust, tolerant of two bacterial bean diseases, and resistant to two of the three races of the anthracnose fungus.

The story of this winning fight against plant disease is a gripping story of onward marching in the face of many obstacles. There have been failures, and much remains to be accomplished. Many plant diseases still resist efforts at their control. With others, we have methods for prevention but they are costly, difficult, or disagreeable. But as the American farmer moves on into the task implied by the economic stress of today, he will have in the background the hundreds of scientists, quietly working with him, providing him with the knowledge he needs to lighten his own economic load and permit him to produce the raw products that America needs, amply, efficiently, and economically.

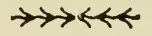

\section{POLLEN AND HAY FEVER *}

\section{A R G T E KIE N A T}

Your allergy is your personal hard luck. If you have one it is because you are abnormally sensitive to food, pollen, hair, or other substances that you inhale or eat. Whatever it may be that causes this kick-back is an allergen. Allergies are various, strange and surprising. Medically the field is broad, requiring volumes for complete discussion. However, the majority of people who are allergic are poisoned by a simple vegetable substance that to most is absolutely harmless. This is pollen. In the summer season hundreds of thousands of people in the United States are following a handkerchief around. They have hay fever. Ninety percent. of our hay fever is caused by ragweed pollen.

Some of the measures you can take in your defense program against this nuisance are medical. If the problem were strictly a medical one, there would be no point in telling about it here. But hay fever is not caused by lack of mineral in the bones, by jumpy nerve endings in your nose, by cruising germs in your bloodstream-or by imagination. A useless weed, in full bloom, broadcasting a simple vegetable substance, is responsible for all this discomfort.

- Reprinted from Nature Magazine with the permission of the American Nature Association. Copyright 1942, 
Ragweed is an unsightly, troublesome plant, good for just one thing-to make an outstanding contribution to the population's stuffy nose. In some eastern sections it is the giant ragweed that is the main offender; in other parts of the country it is the short ragweed.

Its generic name is Ambrosia. Linnaeus chose for it this label of the immortality-giving food of the Gods. John Burroughs regarded the highsounding name in another light. He said: "It must be the food of the Gods, if anything, for as far as I have observed nothing terrestrial eats it-not even billy goats."

It is an easy jump from billy goats to the vacant lots and dumping places of our big cities. Right in these vacant lots, beside apartment houses, behind bill boards, along railways, in factory districts, in detached residential developments, there are large areas of neglected weed-grown land. Dense growths of ragweed, sometimes ten feet high, are found along the banks of canals and rivers.

In a survey made in Chicago, there were pieces of empty land adding up to 20 thousand acres, all supporting a luxuriant growth of ragweed. It was calculated by scientists, who set pollen catchers-plates covered with sticky substances-in outlying residential districts and on top of Chicago's tallest skyscraper, that hundreds of tons of ragweed pollen were liberated each year within the city limits. In mid-city you are as open to attack as if you had gone into the highways and hedges to look for it.

Allergists are a cautious lot. Some maintain that if a whole state were cleared of ragweed plants, not more than seventy-five percent. of the atmospheric pollen would be reduced. Replacements would drift in on the wind from nearby states. But the most pessimistic analyst of the situation will admit that the sufferer is surely better off if the pollen-shedding weeds growing within a few hundred feet of his residence are eliminated.

Cutting down exposure is a gigantic task. It has, at times, claimed the attention of whole cities. Ordinances have been passed, and brigades of interested people have carried out intensive cutting and pulling campaigns. But cities and citizens alike usually have worked at it for a while-then rested on their implements and said "Well, what's the use-the stuff just keeps on coming back!"

Hay fever is new among recognized diseases, but we find mention of discomfort due to contact with plants in medical writing for the past 400 years. We cannot back up our suspicions as to the antiquity of hay fever with museum specimens gleaned from a buried city, an Indian mound or an Aztec temple. People do not die from eczema, hives or hay fever, even today. Hives leave no trace on a mummy. Asthma-the allergic kind-is closely related to hay fever, and Aretaeus, a Roman, first recognized asthma as a disease about A. D. 500.

Thomas Phaer, who died in 1560 , wrote of "Nesying out of Measure." He said: "It is good to stoppe it, to avoyde a further inconvenience." $\mathrm{He}$ 
suggested that the victim should "emplayster the forhead and temples with mylke, oyle of roses, and vynegre a lytle."

Possibly the earliest reference to what we call hay fever was the description by Botallus of Batavia in 1586 . He wrote of people in whom the smell of roses produced sneezing, headache, running at the nose and weeping. Cardinal Caraffa, in the 17 th Century, placed guards at his gates to unburden visitors of any roses. Helmont, in 1607 , described an asthmatic case in which symptoms occurred only in the summer time. This was the first reference to "seasonal occurrence." All these were just personal notes on the fact that odor of roses brought on odd attacks. There were never any suggestions on what to do about it.

In 1819 , John Bostock, an English physician, placed hay fever in the list of clinical diseases by accurately describing his own case. Evidently the disease was quite well known in England by that time and was already popularly called "hay fever." The British developed their hay fever then, as now, from exposure to grasses. Ragweed is not native to England.

Then came Charles Blackley-also an English doctor. He was an honest observer, and besides, he had hay fever. In 1859 Blackley collided with dried grass blossoms that one of his children had placed in a vase in the parlor. He got hay fever-and out of season, too.

Blackley thought: "In most diseases known to medicine something is out of kilter in the makeup of the patient when sickness strikes. Yes, and when it does, something comes in from outside and starts the actual trouble. Now what could there be about that grass that could make hay fever happen to me?" He went back to the dry grass bouquet and examined it. $\mathrm{He}$ had his clue. He got hay fever.

Here was a starting point-a scientific one, dooming Dr. Blackley to years of discomfort, for he doubled as his own guinea pig. He could not go about applying plant and pollen mixtures to the eyes, nose and throat membranes of his patients. They came to be cured, not tormented. $\mathrm{He}$ had to use his own trigger-mechanism to test the pollens. He studied pollens of a hundred or more different plants and grasses. He learned what they did to him. Hay fever symptoms, if left to Nature and the patient, began when pollen of the grain started to increase in the air. They were at their worst when pollen concentration was at its height. He made of himself a human pollen meter. He had figured out a queer little process to test out pollens that were poison to him. He rubbed moistened pollen extract into himself to produce those welts that rose and itched and burned on his arms and legs. He knew which kinds made him "react," but he still needed to learn how many kinds of pollen caused hay fever. Then, too he wanted to know how much of it was floating around. He suspected that there was a whole world of plants busily at work pouring out pollen. Blackley did not want to know why people got hay fever-he just wanted to know how.

To his patients it seemed as if there was no practical use for what he was 
doing. What could you expect of a doctor who spent his time smearing vaseline on glass plates and leaving them around, collecting them and counting pollen grains. He would not try to treat folks. He did not want to cure himself, because then he could not continue his studies. He adnitted he did not expect to cure hay fever. He just told his patients sick with hay fever to go to some place where there was no pollen-if they could find such a place.

There was one famous concentration camp for hay fever "reactionaries" that has gone down in history and literature. By 1860 a few bright people had accidentally discovered places where they were free from hay fever. About 1874 a group of men foregathered in Bethlehem, New Hampshire, and formed the United States Hay Fever Association. The reports, proceedings, and the collected papers of this society read like a cross between Bernarr Macfadden advocating a new breathing exercise and a staff meeting of the New Yorker magazine. Witticisms were set off like fireworks. The circle encompassed Dr. Morrill Wyman, Reverend Henry Ward Beecher, Hon. Daniel Webster and Dr. Elias Marsh. Beecher said one of the meetings was the most interesting he ever attended "for no one had said anything that someone else did not contradict."

The humanitarian objectives of the society reached out into all Eternity. They agreed in writing to "carry on work to relieve all sufferers from hay fever, wherever found, during their natural life, and afterward, if permitted."

In 1886 somebody in the club put up $\$ 100$ as an award for the most outstanding piece of research. A "best essay" contest was held for the pollen pot of gold. Dr. Bishop of Chicago sent in a well-written little item, contending that hay fever was a functional nervous disorder (imagination, to you!). The Association did not subscribe to his theory, but they had to admit he turned in the best-written essay, so he got the research award. This is a clear example of just how far research usually gets when left to groups of jolly laymen.

Hay fever clubs began to form all over the nation. It may be whispered that most of them were closely allied with local chambers of commerce. If you were going to run a health resort what could be better than one for hay fever? Crafty innkeepers, deep in the woods or at the shore, soon found that Mister Average Hay Fever Victim was so glad to be free of his discomfort that he was pleased with everything. But the very ease of the conduct of the business began to defeat commercial resorts. As patients thronged to favored spots, it became necessary to clear more land for kitchen gardens, for tennis courts, for boat houses and canoe clubs, for outhouses and stables. And with clearance of the land up popped the Devil - Ragweed. In a short season or two suspicious sneezes began to vex the guests. Commerce had again overshot its mark.

Of course, as we have intimated, ragweed is not the only source of the 
nose-tickling pollen. But ragweed is the most important. We can pin this statement down with a dollar sign, because commercial drug houses make up their autumn "treatment kits" with ragweed.

The pollen trapping idea of Dr. Blackley was a smart one. Today, pollen catchers furnish advance notice of what is in the air. They measure the amount of trouble on the way and identify the agent causing it. There is a battery of pollen spotters, employed by specialists in allergy-some of them in cooperation with the U.S. Weather Burcau. They learn which weeds are coming into pollen-shedding season. They report that weeds have their preference as to soil, rainfall, and climate, and chart the geographical distribution and trends of the various kinds. Today we have detailed hay fever maps for each type of pollinosis. Spotters reach high up into the air. Even in Blackley's time, he used tandem kites to make exposures of his greased plates. The highest exposure was at 1500 feet. Fifty years later airplanes were used to make pollen concentration studies. Today there is an elaborate network of aids to allergists throughout the United States.

Ragweed is high in the index of our national pollen count, but so are grasses. Grasses are so much a matter of everyday life that most people do not think of them as a possible source of trouble. Trees are possible sources of trouble. Male and female trees may be miles apart. Nature has made it imperative that enormous amounts of pollen be shed to make sure air borne messages may reach the lady.

But it is never the grass, or the tree, or the flower that makes the trouble. It is that ole debbil pollen riding the wind and reaping a whirlwind of sneezes.

Pollen granules are formed in the male organs of plants. Their function is to fertilize the seed. Not a single fertile seed can form in any one of our flowering plants unless a grain of pollen has carried the spark of life to the undeveloped seed.*

It is the drab, uncolored plant, which the allergic person has probably passed by unnoticed, that produces unbelievable amounts of light, dry pollen. The bee snubs it, too. Ragweed has to depend upon the wind to deliver its pollen, and the wind carries it high and scatters it far and wide.

When you consider the hit or miss method of sending pollen grains in the air for fertilizing eggs, the reason for the high rate of overproduction is apparent. Even in an ordinary ragweed patch, enough pollen has to be poured out to hit a mark the size of a needle point twenty blocks away. Nature's office of production management runs her air force on a scale that puts humans to shame. There are no bottlenecks.

A single well-developed short ragweed plant has been watched and found to produce one million million pollen grains. Under observation, a giant ragweed produced about eight billion pollen grains in five hours.

* The pollen grains contain the male sex cells or sperms which fertilize the egg in the young seed.-Ed. 
Pollen grains vary enough in size, shape and general conformation, so that-in a general way-the plants they come from may be identified by inspection of the granules under the microscope of the pollen specialist.

Pollen is a spore and can live for a long time, and under adverse circumstances. A pollen grain is said to be "alive" only so long as it is capable of fertilizing an egg cell. It may live from a few hours to several months. However, alive or dead, botanically, dry hay fever pollens retain their power to produce allergic responses for years. Some have been potent for twenty years.

Some pollens have wings-stationary wings like an air glider. Pine pollen has them and is carried many miles on then. They are microscopic wings and not to be confused with winged seeds. Grass pollens are smoothwalled and spherical and may have indentations on the surface. They look like a golf ball under the microscope, or like a smooth, round ball of clay into which a child has pressed his fingers.

Pollens of the ragweed tribe, Ambrosiaceae in part, include ragweeds, false ragweeds, marsh elder, sunflower, aster, daisy and goldenrod. All have rough and spiny surfaces under the microscope, looking like cockleburs.

Ragweeds shed their pollen best on days when the sun shines. Rainfall washes the pollen out of the air. You have probably noticed that hay fever victims always welcome damp, cloudy days. A heavy wind, of course, stirs more pollen into the air and carries it farther. A wind storm is often followed by an "epidemic" of hay fever.

Weed crops respond to good growing weather just as noticeably as do cultivated crops. The amount of sun and rain during the growing season may determine whether we have an abundant ragweed pollen crop.

Nature, in her distribution plan, adjusts herself to many situations. In the North where the warm season is shorter she hurries to scatter her pollen earlier and continues later in order to pass around enough to reach and satisfy her waiting clients. In the South, where spring comes earlier, one would think the pollen season would be advanced by just that much. But here pollination starts late and lasts but a short time.

Among doctors, allergy has become as much a specialty as is ear, nose and throat work. A large part of the time of the allergist of today is spent in running down the substance that causes that explosive response in his patient. Everything from the pillow you sleep on, the egg in your pancake, to the bears in the zoo, may have to be investigated before your doctor can attempt to protect you from future attacks. The scratch tests he gives you stem from the same idea that Dr. Blackley gave the world through his personal martyrdom.

Ragweed can be ousted by cutting the plant. First, just before the flowers form, and, again, before the flowers develop on the low-growing branches that sprout out again after the first cutting. Watch the weed pile if you cut ragweeds. If you do not whack the tops off before flower buds form, 
pollen will go right ahead and ripen on the severed plant. All cut plants should be burned. Stubble lands should be plowed shallow before the weed forms flowers. If a field is seeded to grass, the autumn growth of ragweed should be cut over with a high-set mowing machine before plants bloom.

Short ragweed may mature and shed pollen at the height of an inch and a half. Do not judge the enemy by the size of the general. Roots are shallow and live only one season, in any case. Spread is through seeds, and they are almost everywhere. As soon as a bit of land is robbed of its forest trees or native grasses, ragweed springs up. Ragweed followed the plow that broke the plains.

Why not get rid of it? It can be cut, pulled, burned and the whole nuisance disposed of within a few short years. Ragweed is one of the most conveniently accessible pests in the world. You do not have to invade a forest, dive under water, or look through a microscope to find it. You just take the walk around the block. It will not hit back at you if you catch it young. The root system is shallow so the whole plant will come up readily to your hand. It exudes no nasty smelling protective juices or oils to stain your clothing; it does not bite or sting or blister.

Can you live with your allergy? If it is caused by ragweed, why should you?

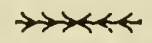




\section{XI]}

\section{Economic Biology}

MHE economic side of biology is important because it deals with figures 1 on the importance of the oyster industry in dollars and cents, with the amount of money spent to control weeds, insects, and coyotes, with the value of the cotton crop and with hundreds of other equally-important topics. Much credit should accrue to those men and women who take time out to make up and show us our biological balance sheet. These cost sheets and inventories show us how we stand with regard to many industries and businesses dealing with zoological and botanical materials. They show the degree of prosperity or decadence and they show, in some instances, whether we are winning or losing our economic battles.

It is difficult, however, to interest most people in dry facts and figures. The layman scarcely shudders when told that insect control and damage costs one billion dollars and that weed control and damage costs us three billion dollars yearly. If a wage earner were handed a bill each year for about thirty dollars for each member of his family for insect and weed control, the basic problem would come closer to home. We pay most of this bill in increased food, clothing, and lumber costs mainly and so naturally the impact is not felt directly.

Economic biology and conservation are tied together. The former may tell us that the forests are being cut three times as fast as they are being replaced. Conservation scientists, who work in both fields of course, will then attempt to insure that an adequate lumber supply will be planted and in time. Other measures such as increased fire control, more careful lumbering, prevention of waste and the development of substitutes will be looked into.

A strong America can remain strong only as long as her natural resources are protected from exploitation. Biologists are vitally interested in the forests, in soil erosion, in good grassland and in any subject which affects plant and animal life. In 1947 prolonged rains prevented early planting in many areas of the country and in addition caused such a rise in the main rivers that the levees broke and hundreds of thousands of acres were flooded. A few days after this happened, the experts were able to predict just what this would mean to our winter food supply and what it would mean in the way of increased food costs. Water, soil and organisms are 
all tied together in a circle of mutual dependence and should one factor get out of balance, someone will have to pay for it.

\section{MAN AND NATURE * \\ R . T. YOU N G}

An ardent French entomologist in Medford, Mass., was one day eagerly inspecting some caterpillars which he had reared from eggs brought by him from Europe, when some of them, growing tired of his society, made their escape and went on their way rejoicing. This was in 1869 . From $1890-1900$ Massachusetts spent about $\$ 1,000,000$ to fight the gypsy moth. At this time the pest being partly under control the efforts were relaxed, with the inevitable increase of the pest, and its further spread over a large part of New England and into Canada.

In 1850 caterpillars were devouring the trees of the eastern United States. But in England there was a merry, if not melodious little sparrow, who was supposed to enjoy nothing so much as a meal of luscious juicy caterpillars, and so what was more natural than to bring sparrows from the old world to enjoy the rich feasts of caterpillars provided by the new? Today he has spread over all of the United States and much of Canada, and is emulating the example of his fellow countrymen by driving before him many of the native inhabitants and inheriting their patrimony.

Inhabiting the wheat fields of the greater part of the United States is a little fly known as the Hessian fly, about an eighth of an inch long, which lays its eggs on the leaves of the wheat, and whose larvae as they hatch crawl down the stem, burrow into it, and kill the plant. This fly is supposed to have come to America as an unintentional ally of King George with his Hessian soldiers; hence its name. Another immigrant which came to us in Revolutionary days was the brown rat.

This rat first crossed the Russian frontier of Asia in 1727 in such numbers that it soon overran Europe, whence it came to America. With the rat came its parasite, the deadly Trichina, while more recently the yet more deadly bacillus of the bubonic plague has become established in California, brought in by rats from oriental ports. What a pity we cannot return to Europe with our compliments all of the undesirables, four-legged, as well as two-legged and winged ones as well!

To kill a hawk is, in the minds of most of us, a laudable act for are not all hawks "hen hawks," the inveterate enemies of the poultry men? So at least thought the farmers in the Humboldt valley in Nevada, which in 1907 was visited by a plague of mice, which ate up everything in sight, gnawing the bark from fruit trees, burrowing in the alfalfa fields and destroying the

"From Biology in America by R. T. Young, copyright 1922 by Chapman and Grimes, Boston. 
potatoes and other crops. At the height of the plague, it was estimated that there were from 8,000 to 12,000 mice per acre, while the total loss to the valley was estimated at $\$ 300,000$. The abundance of mice in the Humboldt valley attracted hawks in large numbers. But failing to recognize in the hawks their best ally in their war against the mice, the ignorant residents seized their guns and proceeded to slay their best friends.

So too thought the legislature of Pennsylvania when they passed the notorious "scalp act," providing for a bounty of fifty cents for every hawk and owl killed within the state, as a result of which half-baked legislation more than 100,000 valuable birds were killed, at an expense of nearly $\$$ ioo, 000 to the state for bounties and notary fees, and an estimated loss of more than $\$ 4,000,000$ from the increase of harmful rodents resulting from the destruction of their enemies, the hawks and owls. And yet all this in the short space of a year and a half.

Hawks and owls have the habit of throwing up the undigested portions of their food in the form of pellets containing the hair, bones, feathers, etc., of their prey. For many years a pair of barn owls were wont to nest in the tower of the Smithsonian Institute in Washington. An examination of two hundred pellets found beneath their nesting site revealed 454 skulls, of which 412 were those of mice, 20 of rats, 20 of shrews, one of a mole, while only one was that of a bird (sparrow).

An examination of 562 stomachs of the red-tailed hawk showed remains of poultry or game birds in 54 , other birds in 51 , mice in 278 , other mammals in $13 \mathrm{I}$, insects in 47 , miscellany in 59 , and nothing in 89 .

The habitue of field and forest, who seeks his favorite haunts after the first snow fall of the winter, is likely to encounter companies of little birds, who, in spite of winter and its snow, are busily engaged in reaping a bountiful harvest of the weeds. Flitting from stem to stem, they pick out the seeds from their shells, while others follow in their wake to pick up the gleanings from the snow. The late Dr. Judd of the Biological Survey, in his studies of the food habits of sparrows, examined a piece of ground eighteen inches square in a patch of smartweeds where several species of sparrows had been feeding. On this patch he counted 1,130 half seeds and only 2 whole seeds. During the ensuing season no smartweed grew where the sparrows had caused this extensive destruction. It has been estimated that in Iowa alone a single species, the tree sparrow, destroys in one year 875 tons of weed seed, and that in the United States as a whole the different species of native sparrows, numbering more than one hundred, save $\$ 35,000$, 000 for the farmers every year.

Many a wild creature is the farmers' inveterate enemy and does untold damage to his cattle or his crops. As an indication of the losses due to predatory animals it may be stated that the chairman of the State Live Stock Board of Utah estimates an annual loss in that region amounting to 500,000 sheep and $4,000,000$ pounds of wool. The president of the New Mexico College 
of Agriculture, as a result of a survey in that state, estimates an annual loss of 34,000 head of cattle and 165,000 sheep. A single wolf killed in southern New Mexico was reported to have killed in the preceding six months 150 head of cattle valued at not less than $\$ 5,000$.

Through the watchful activity of the Biological Survey bureau it is probable that many another catastrophe similar to the introduction of the English sparrow, gypsy moth, and Hessian fly has been averted. Some years ago the mongoose applied for admission and a few individuals did indeed gain an entrance. The mongoose preys on mice and rats, but unfortunately attacks poultry and wild birds as well. It has been introduced into Jamaica where it has proven a nuisance through its depredations. By the passage of a law placing the importation of foreign animals under the Secretary of Agriculture, the bureau has been able to prevent its establishment in the United States.

Monstrous as is the tax which we pay to our four-footed foes, it is small in comparison with the tribute levied by our winged enemies. Estimates of so uncertain a sum as the loss caused by insects are bound to vary, but even accepting the minimum figure of $\$ 1,000,000,000$ annually, the amount is surely ample.

In the eighties the orange and lemon groves of California were threatened with ruin by an innocent-looking but destructive scale insect. Soon the Bureau of Entomology had experts on the ground learning all they could about the vicious stranger. They learned that the scale insects were natives of Australia, whence they had been imported into California on young orange trees in 1868 . Now it occurred to them that in the native home of the scale might perchance be found some natural enemy, which if introduced into California might drive out, or at least hold in check the terrible scale. And so one of them journeyed to Australia and there he found the ladybird beetle which preyed upon the scale. And this he brought back with him to California, where it throve; and making war upon the scale it has ever since held it in check.

In Hawaii the ravages of the sugar-cane weevil, which bores its destructive way into the sugar canes, have been materially reduced by the introduction of a parasitic fly from British New Guinea.

Scab mites, which in years past levied a heavy toll upon the cattle grower, have been nearly exterminated; the foot and mouth disease, which in 1914 was epidemic in twenty-two states, and was seriously threatening the livestock industry of the country, was stamped out after a hard fight; hog cholera, ever a serious drain upon the hog industry, is gradually being brought under control by the use of a serum and other measures, and an active campaign is now under way for the suppression of tuberculosis in hogs and cattle, a disease not alone serious to the animal industry, but, when present in dairy cattle, a very probable menace to human life.

The duties of the members of the Office of Foreign Seed and Plant In- 
troduction of the Bureau of Plant Industry are manifold but one of them is to go into "the uttermost parts of the earth" and bring back to us its treasures. From the Asian steppes to the jungles of the tropics its explorers have gone, and from the fertile isles of Japan to the deserts of Arabia, in their search for the useful and the beautiful, to enrich our fields and adorn our dwellings.

We are accustomed to think of the bamboo in terms of wicker work or fishing rods, but how many of us realize that the young bamboo shoots, which grow at the rate of a foot a day, are succulent and may be eaten like asparagus tips. How often do we think of the bamboo as serving such varied uses as pulp for paper, masts for vessels, pipes for water and timber for buildings? There is no plant in the world which is put to so many uses as the bamboo, and in the regions where it grows it is apparently the most indispensable of all plants. Strange as it may seem, the bamboo is not a tree in the ordinary sense of the word, but a grass. Several species of bamboo have been introduced into California, while in Florida and other southern states are bamboo groves planted by the bureau.

The tung oil tree of the orient, from the seeds of which is obtained one of the best drying oils known, has been introduced into California and the Gulf States, where it appears to be thriving; while the pistache tree is doing nicely in California.

The date palm, that wonderful tree of the oasis in the scorching deserts of Arabia and Africa, is now domesticated in Arizona and Southern California and has taken kindly to its new home. With some trees bearing more than 100 pounds of dates an average profit of $\$ 100$ to $\$ 150$ per acre is a fair estimate.

Many are our natural resources unused as yet, while many another fast disappearing can be restored in part at least to its former abundance, not only by negative measures of conservation, but by the active ones of propagation as well.

In the days of the pioneer the United States was teeming with game. Today the flocks of wild pigeons, the herds of buffalo, elk and antelope are but memories of the past. Of the wild pigeon not one wild bird remains today to bear testimony to their departed glory. To save others from a like fate the Biological Survey in cooperation with our National Park Service and the Audubon Society has established havens of refuge throughout the country, where the remaining herds of large game are safe from the depredations of man, and others where our wild fowl may breed in safety and replenish their fast thinning ranks.

The rapid diminution of our fur-bearing hosts, with the consequent rise in the price of furs, has led to experiments in breeding these animals for market. That enormous profits are possible in successful fox farming is shown by the value of the best animals for breeding, as high as $\$ 25,000$ having been paid for a single pair of silver foxes for this purpose. Not alone 
foxes, but fisher, marten, mink, skunk and other animals have been cultivated for their furs.

The "king" salmon occurs on both coasts of the pacific from California and China north to Bering Straits. During the winter the fish sojourn in the sea, but in early spring they slowly gather in the rivers and begin the long and arduous journey to their breeding grounds, which in the Yukon may be over 2,000 miles from the sea. In the ascent of the rivers they perform prodigious feats, ascending falls $10-15$ feet in height. Arrived on the spawning grounds in autumn the male excavates a little hollow in the gravel of the stream bed, where the female deposits her eggs, upon which the male sheds the "milt" or sperms, after which they cover them with gravel; and then the function of reproduction performed, which is the crowning act in the life of animal or plant, they float downstream to die.

The average number of eggs laid by a female is four thousand. If onehalf of these developed into females and reached maturity in four years, and if their progeny in turn were all to reach maturity, one-half being females, this rate of increase remaining constant from generation to generation, there would result in 32 years $256,000,000,000,000,000,000,000,000$ salmon weighing $2,816,000,000,000,000,000,000,000$ tons or 468 times the mass of the earth. (Such an increase does not occur of course because of the many natural enemies of the salmon including man.)

Sealing privileges have long been a bone of bitter contention between American, Russians, Canadians, and more recently the Japanese. The Pribilof Islands, the principal sealing grounds, originally belonged to Russia. With the sale of Alaska to the United States in 1867 these rights passed to our government. It is an interesting commentary on the foresight of the opponents of the Alaska purchase proposition, that from 1870-1890 our government received in leases, royalties, and duties on furs made up in London, but most of which came originally from Alaska, some $\$ 13,000,000$, or nearly double the price paid for the entire territory.

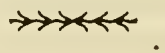

\section{WONDER PLANTS OF COMMERCE AND INDUSTRY *}

\section{A. H YAT T VERRILL}

One of the most wonderful features of plants is the important part they play in our commerce and industries, as well as in our daily lives.

This article, for example, would not be possible were it not for plants. Even if the paper upon which it is printed had been made from old rags it would still be a plant product, for the rags used would have been cotton or linen cloth made from plant fibers. The same plants have supplied the

* From Wonder Plants and Plant Wonders by A. Hyatt Verrill, D. AppletonCentury Co. Copyright 1939. 
thread with which the leaves have been stitched together. The ink used in printing was made of carbon which came from burning wood, and the glue and paste used in making the cardboard covers and attaching the binding to the leaves were probably manufactured from gums or juices of plants, perhaps even from the stalks of maize. And even if the adhesives were wholly or partly animal glue, they would not have been possible without plants which provided food for the features whose hoofs, horns, and hides supplied the glue.

Until one gives serious thought to the matter and looks about at the innumerable things upon which we depend, one does not realize the extent to which we employ plants to supply both the necessities and luxuries of life. It is not even necessary to trace back various substances and materials to their original plant sources, or to argue that by doing so all animal life is dependent upon plants. So let us confine ourselves to materials obtained directly from plants.

Among the most important and valuable plants of commerce and industry are those which supply us with fibers. Moreover, there is a vast number of these fiber-producing plants, some of which are very familiar to every one and serve us everywhere every day. Others are strange to most persons, even though their fibers are commonly used, while others are seldom used except by the natives of the lands where they occur. Yet some of these little known fiber-plants are superior to many of our own and deserve to be much more widely used than they are.

Probably the most familiar of all plant fibers is linen which is made from the leaf and stem fibers of the flax plant, and cotton from the seedcoverings of the cotton plant. Next in importance in our everyday life are hemp, Manilla, jute, and sisal. An entire volume might be written about these alone, and a very romantic and interesting story it would be, for these four fibers come from widely separated parts of the world and are grown and gathered by strange races amid strange surroundings.

Hemp is obtained from the bemp plant which is a native of India and its vicinity. Manila or Manila hemp, which is the source of the best cordage and ropes, especially for use on shipboard, is obtained from a very different plant, a variety of the banana which is a native of the Philippines and the East Indies. Jute is another Oriental fiber derived from an East Indian annual plant with tall stalks and yellow flowers. Although one of the most important and valuable of fibers it is not very strong and hence is not suitable for high-grade cordage. But it is fine, silky, easily woven and serves a multitude of purposes. Great quantities are used in making gunny sacks or burlap bags. Immense amounts in the form of "tow" are employed for caulking the seams of vessels, for making coarse and cheap papers, for fiber carpets, rugs, seat-covers, curtains, draperies, and "art" fabrics, while the finer grades are used in place of hair on wigs for actors.

Sisal comes mainly from Mexico, Central and South America, the West 
Indies, Hawaii, and South Africa. This well-known fiber is obtained from the leaves of the bennequin, a species of agave or "century plant" which is a native of Mexico and Yucatan. Although the hennequin had been cultivated and the sisal fiber had been used by the Indians for countless centuries, yet it was not until comparatively recently that it came into general use by the white races. It is a rather coarse fiber, harsh and somewhat brittle, and much inferior to hemp or Manila for cordage, especially when wet. But some one discovered that it was the best of all fibers for bindertwine used for tying sheaves of grain, and instantly sisal became one of the world's most important and valuable fibers. Where only a few of the stiff-leaved hennequin plants had been cultivated by the native farmers, vast plantations sprang into existence. The crop increased from a few hundred to tens of thousands of tons of sisal yearly. Railways were built to transport the countless bales of fiber from the inland plantations to the seacoast. Tiny towns that had been forgotten by the world became transformed to busy important seaports. Where only an occasional sailing vessel or coasting steamer had been moored beside ramshackle wharves, scores of great wallsided iron freight steamships lay alongside concrete and steel docks. Planters who had found it hard to make both ends meet became millionaires, stupendous sums were invested in planting more and more land with hennequin and in erecting mills and factories for manufacturing sisal twine and other products, and from Yucatan the hennequin industry spread to Hawaii, the West Indies, South America, Egypt and the Orient. Probably no other plant of industry and commerce has had such a meteoric career or has risen so rapidly in importance and value as the hennequin or sisal.

In the Philippines and the East Indies the natives weave beautiful fine silky cloth from the fibers of pineapple leaves, which is also used to some extent in our textile mills, while in other Oriental countries mulberry fiber is an important product. The well-known raffia fiber used in art work and for making baskets and hand-bags, is the fibrous bark of a palm-tree, while another palm-tree supplies the strong, pliable material used in weaving the famous Panama hats.

Even more important in some ways than are the fiber plants used for cordage and textiles, are those which make it possible for us to publish books, print newspapers, or write letters. Without paper we would be sadly handicapped indeed. Imagine what a task it would be to write a novel such as Anthony Adverse on clay tablets or to compile a dictionary by inscribing the letters on stone. And think of the size of the library that would be needed to house thousands upon thousands of clay or stone or even metal volumes. For that matter, try to visualize the occupants of a crowded subway train all carrying morning papers of baked clay or made of metal sheets. And how could our post-offices ever hope to handle millions of letters written on bricks?

No one really knows what race was the first to make that epochal dis- 
covery, for paper of some sort or another was used by several races in widely separated parts of the world in very remote times. The ancient Egyptians used excellent paper made from the papyrus plant and from the lotus. The Chinese, thousands of years ago, used paper made of rice straw, and in the New World the Aztecs and Mayas had been using splendid parchmentlike paper made from the agave or maguey plants for untold centuries before the arrival of the Spaniards.

Today a vast number of plants are employed in making paper. Bamboo, banana leaves, palm fibers, seaweeds, cotton, hemp, jute, Manila, reeds, mulberry, bulrushes, straw and countless other fiber-plants are ground to pulp and passed between massive rollers to come forth as sheets of paper. But by far the greatest quantity of paper is made from forest trees. Spruce, poplar, fir, cedar, and many other woods may be used for paper-making, but the best of all "pulp" trees, especially for the cheap newspaper stock, are the spruces. Whole forests have been leveled to supply our people with their daily papers, and few persons have any conception of the almost incredible quantities of pulp wood that are consumed in this way.

Merely to supply the paper for a single edition of one of the big New York newspapers necessitates the complete annihilation of eighty acres of forest. Multiply that by the number of similar papers of the metropolis, and multiply the result by 365 and we will get some vague idea of the almost inconceivable numbers of trees which are annually felled and converted into paper-pulp. I say "vague" idea, for big as they are, the papers published in New York City are only a very small fraction of the total number of papers published daily throughout our country. More than I 4,000,000 cords of wood are required to supply the paper needs of the United States annually. The United States and Canadian newspapers print annually enough paper to encircle the world with a belt fifty miles wide. If this paper was in the form of the standard roll with a width of 73 inches, it would be $13,000,000$ miles in length. Moreover, vast quantities of trees are used in making cardboard, various composition substitutes for lumber and for crates, boxes, and other purposes, while whole forests are felled to supply the tens of thousands of cords of wood needed to manufacture matchsticks.

Mineral and chemical dyes have taken the place of many plant-dyes, yet there are certain dye-plants which are still in demand, and which have never yet been replaced by artificial substitutes.

Although the use of indigo has decreased until very little of the once important dye-plant is cultivated, yet no one has ever discovered an artificial indigo that can equal that of the plant for color and fadeless quality. Fustic from the big forest trees of South and Central America is still used in enormous quantities, for it is the best and most durable of khaki dyes. When we use butter or eat chili con carne as well as other foods, we swallow a dye made from the seed-coverings of a tropical American tree. 
This is the anotto or acbiote, and as the orange-red dye or pigment is harmless and even contains a certain amount of nutriment, it is perfectly adapted to coloring foods. In its raw state it is a vivid red and is used by the Indians for painting their faces and bodies, but when diluted it imparts a deep yellow color. Its principal use is for coloring butter, hence it has become generally known under the trade name of "butter color."

Formerly our own native trees supplied many world-famous dyes. Butternut-brown was widely used and became famous as the color of the uniforms of the Confederate soldiers during our Civil War. But to-day it has no real conmercial value, and the same is true of our yellow or quercitron oak which furnishes a wonderful yellow dye. At one time hundreds of tons of the chipped oak bark were exported to Europe, but to-day its use as a dye has been almost forgotten.

Even when plants have supplied us with wood for our houses and furniture and fabrics for our garments, our carpets, our draperies and the upholstery on our chairs and couches, and other plants have yielded the stains, dyes, and pigments with which to color them, we still need oils, varnish, and wax with which to finish the woodwork. And when it comes to these important and essential substances we are compelled to rely on plants to supply them. There is no substitute for linseed-oil except other vegetable oils. No one has been able to manufacture a synthetic varnish to compare with those made from copal, couri, or other plant gums and saps. Turpentine and resin from pine trees still hold their own against all competitors made from petroleum or other chemicals, while tung oil is the basis of all our finest quick-drying lacquers, enamels, and varnishes.

It is the same with the various kinds of vegetable wax. Who wouldn't prefer a bayberry wax candle made from the aromatic berries of the seaside bayberry bush to a paraffin or tallow candle? What would scientists do without oil of cloves for use in microscopy and Canada balsam from the fir trees for mounting their slides and cementing the lenses of their instruments? Palm-oil and palm-wax have never given way to synthetic products of the laboratory. And finally there is the oil from the castorbean plant. No doubt many a youngster wishes the broad-leafed tropical plant had never been discovered, but the thick white oil from the plants' mottled seeds has many other uses besides that of medicine and possesses properties unlike those of any other oil. It never thickens, no matter how cold it may be; it never becomes thin even under the terrific heat of highspeed motors when used as a lubricant, in which respect it exceeds all other oils, and it is practically non-inflammable. But it has one important use which few persons suspect, for it is castor oil that makes sticky fly-paper remain sticky and prevents the combination of resin and gum from drying up.

To the ladies there are many plants which are of tremendous importance, 
for they supply the feminine population of the world with scents and perfumes, hair tonics and washes, face powders and toilet soaps, creams and other aids to beauty-even with their lip-sticks and eyebrow pencils, and mascara. Quite aside from the innumerable flowers used in manufacturing perfumery there are many other plants vital to the industry. The leaves of the West Indian bay-tree supply bay-oil from which bay-rum is made.

On one occasion when I was visiting a tribe of primitive Indians in the South American jungles, the women and girls gathered about my camp-fire chatting and sniffing the air as Sam, my black camp-boy, prepared my dinner. Presently, having peeled and sliced an onion, he tossed aside the waste. Instantly there was a wild scramble among the brown-skinned belles followed by squeals of delight as the lucky ones smeared the fragments of odorous bulbs over their faces and naked bodies. That gave me an idea. I was short of trade goods, especially beads and knives, and had been unable to secure many of the ornaments and other ethnologic specimens I desired for my collections. But the women's fondness for onion perfume solved the problem, and for the next thirty minutes or so I did a rushing business doling out sections of onions in exchange for weapons and implements, musical instruments and feather work, bead aprons and jaguar teeth necklaces. But our stock of the bulbs was soon exhausted and there were still many objects I wished to acquire, while many of the Indians were still minus a supply of the perfume they so greatly desired.

"Can't you dig up any more onions, Sam?" I asked while the Indians stood about laden with possessions they wished to trade. "Perhaps some got into the potato bag by accident."

The Negro dumped out the contents of bags and boxes and searched diligently. "No, sir, Chief," he replied at last. "Ah 'spec' they complete finish. But Ah come 'pon little garlic, Chief, an' they sure do smell a-plenty."

The little bulbs certainly did "smell a-plenty" and how those Indians did clamor for them! To them the odor of garlic compared to that of onions was as delightful and desirable as attar of roses compared to the cheapest rose-water would be to any white woman. They were willing and anxious to exchange anything or everything they owned for a mere fragment of garlic, and had I possessed a few pounds of the bulbs I could easily have purchased the entire village with all it contained-including the entire feminine population-had I so desired. Taking all things into consideration, perhaps it was just as well that our supply of garlic was so very limited.

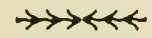




\section{THE VANDALS *}

\section{A N G E L O P A T R I}

It was Sunday evening and the cars were filled with returning holiday makers. Every seat held its quota of weary, sleep-beset children, and from their relaxed hands drooped thousands of dead and dying wild flowers. When the car stopped at their corner their guardians pulled them up and dragged them out and the flowers strewed the passageway.

One sleepy towhead clutched a little tin pail, and as she was dragged along the pail caught somehow and overturned. A foot kicked it along and its contents were scattered about. I looked at them and saw that the child had gathered a score or more of white violet plants. Now they lay smashed beyond recognition on the floor of a dirty trolley car.

I knew the spot where those violets had grown. There is a little dark brown wood pool in which tall trees stand, each rising from a throne of velvet green moss. Out of the moss grow the tiny white violets and the "wind lily of the valley." It is a fairy place, a place that catches one's breath by its exquisite solemn beauty. And the child had tried to gather the beauty and carry it home in the little pail.

Why didn't the grown person with her tell her that she could never do that? Why didn't she tell her that the beauty was a thing of sky and sunshine and color and fragrance and water and wood and could be carried away only in her heart?

Why didn't she tell her that she was carrying death to something that the Creator had instilled with life that it might make glad the spaces of a spirit? Didn't the mother know? I'm afraid she didn't, because she left a bundle of dogwood in the seat behind her!

People with gardens, gardeners who cherish beautiful grounds in great estates, park superintendents who fight to preserve a little of the beauty of the earth that its people may see and know it, cry out against the vandalism of the children.

Better cry out against the vandalism of their elders, who teach them that flowers are to be gathered regardless. The children only follow their parents' example.

There are some people who cannot bear to see anything lovely without longing to possess it. Flowers cannot defend themselves and fall victims to the greed of possession. Women who could not bear to kill a noxious fly will slaughter a bank of wild flowers and go carelessly on their way.

There must be a sad spiritual lack about such people, and the saddest part of it is their passing it along to the children.

Teach the children to look at the beauty of the flowers and keep their hands off. Show them the difference between the beautiful little flower

- Reprinted by special permission of Angelo Patri. 
growing in its mossy bed and the dead and dreary thing they hold in their hands. Teach them to love and preserve the beauty that gladdens their eyes and rests their souls in the fields and woods about them.

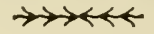

\section{THE CONSERVATION OF WILDLIFE *}

\section{S E T H GOR D O N}

\section{IL DLIFE A ND THE PIONEERS}

When the first white settlers reached our shores, the Indian was the only human inhabitant, and wildlife abounded everywhere. The "balance of nature" still prevailed, because the Indians took only what they needed for food, shelter and clothing. No waste characterized their use of game, and traffic in the creatures of the wild was unknown. The original colonists, coming from lands where the enjoyment of the chase was restricted to the ruling classes, found here a hunter's paradise. Wildlife, like the forest, was considered inexhaustible and free to all for the taking. Furthermore, game was all important as a source of food, and clothing. It soon became an article of commerce, and that was the beginning of the end for many species.

The fur traders were the real trail blazers. The settlers followed in their wake. The early history of both the United States and Canada was influenced more by our wildlife resources, and the battles which were fought over them, than by desire to possess the land. The mistreatment of two young pioneer French fur traders who penetrated the Great Lakes region in 1658 is credited with having been largely responsible for Canada becoming an English instead of a French possession.

With the opening of the west, and the development of agriculture, the extermination of the buffalo became inevitable. Its valuable coat alone did not bring about its destruction. In some regions, the United States Army aided in its extermination in order to more easily whip the roving bands of Indians into submission by removing their main source of food. The advancement of agriculture, and the wasting of our forests, did more to destroy our wildlife than did the firearms of the pioneer settlers or the sportsmen. This is especially true of our waterfowl, today a pitiful remnant of the former millions which swarmed the sky in migration.

\section{THE MARKET HUNTER}

Commercial exploitation of wildlife resources was by no means confined to fur-bearing animals. The last of our former myriads of passenger

* Reprinted from American Conservation in Picture and Story, compiled and edited by Ovid Butler, copyright 1935 by The American Forestry Association. 
pigeons died in the Cincinnati zoo September 1, 1914, a race exterminated by trapping and other methods of the market hunter. Many men living today witnessed the wholesale slaughter and carload shipments of these magnificent birds to satiate the demands of city markets. William B. Mershon in "The Passenger Pigeon" estimates that in the last great nesting in Michigan from three to five million birds were slaughtered. Hunting as a business accounted for millions upon millions of birds and animals annually between 1840 and 1910 . Dr. William T. Hornaday, in one of his books, cites a professional market hunter who admitted having killed more than 1 39,628 game birds and mammals.

The buffalo, passenger pigeon, antelope, elk, deer and many other species were persecuted and destroyed by the carload, not only to fill the demands of city markets, but also to feed the many railroad construction crews and other outposts of the advancing frontier in its sweep westward. Song and non-game birds were killed by the millions for their plumage, demanded by the millinery trade. Market hunting was unquestionably one of the most devastating factors in the decimation of our wildlife. The wonder of it all is that any birds, mammals or other valuable fur-bearers are left today.

\section{G A M E L A W S}

In the beginning there were no game laws. Wildlife was so abundant that restrictions were not deemed necessary. But gradually the need for protective legislation became evident, and the statutes on the subject now fill many volumes. The first game law recorded called for a closed season on deer in Massachusetts in 1694. In 1739, the first game wardens in America were appointed in the Bay state as "deer wardens." Delaware prohibited Sunday hunting in 1750 . By the time of the revolution, most of the colonies had a few game laws.

The first Federal law, passed in 1776 , decreed a closed season on deer in all the colonies except Georgia. Massachusetts in 1818 prohibited the killing of robins in the spring of the year. New York in 1864 was the first state to adopt a hunting license law, and Iowa in 1878 the first state to fix a bag limit on game of any species. About 1885 the American Ornithologist Union, organized in 1883 , became active in promoting the protection of North American non-game birds, preparing a model law for states to adopt. Both New York and Pennsylvania adopted the law within five years and by the close of the century more than a dozen states had written it into their statutes.

These meagre beginnings have been, especially since the opening of the twentieth century, elaborated and extended in an effort to prevent the destruction of game by legislation. Today the game codes of the states are a veritable maze of inhibitions. But recognizing that legislation alone will not bring back the vanished legions of Colonial days, the federal government and many states have in recent years extended their wildlife 
restoration policies to include not only careful regulation of the annual kill but the development of practical management methods on farm lands, the reservation of portions of the hereditary ranges of wildlife for its permanent use, and its definite inclusion in all land utilization plans involving drainage, the impounding of water, or the withdrawal of lands from agriculture.

Advancing civilization, drainage, agriculture, destruction of the forests, pollution of waters, have progressively taken heavy toll of our wildlife. Breeding grounds have been destroyed by promotion schemes which were economically and biologically unsound. Just as the range of the bison was needed for domestic cattle, so the vast prairies of the North Central states were needed for wheat and corn, cows and pigs. Millions of acres of wildlife habitat were needlessly destroyed, with no benefit to agriculture. Approximately $75,000,000$ acres were drained in the United States alone. Added to these encroachments upon wildlife habitats, intensive farming practices, the elimination of the hedgerows and stake and rider fences of yesteryear, removed much desirable breeding and feeding cover for game and other wildlife.

\section{WV I L D L I FE A D M INISTRATIO N}

Wildlife conservation through enforcement of game laws and propagation of game stock is now an established policy in every state; but wildlife management is a comparatively recent conception of public administrative responsibility. It is commonly accepted that wild birds and mammals are under state control, excepting birds of migratory habits and wildlife in the national parks, which by specific acts of Congress have been made wards of the federal government. The great bulk of the nation's wildlife resources are therefore in the custody of the states. The first state game commissions were established in California and New Hampshire in 1878 . State game administration today varies greatly, but the majority of the states now operate under the supervision of non-salaried commissions as the policy-making body, with state organizations charged with enforcing the game laws, propagation and planting of game, administration of state refuges and promotion of wildlife rescarch.

The Biological Survey of the United States Department of Agriculture began in 1885 . As the principal federal agency concerned with wildlife, the survey deals scientifically with the resource in all its aspects. These include the relationship of wildlife to agriculture and forestry, and the interrelationships existing between various forms and species, the study of diseases and food habits and the control of injurious forms.

\section{G R A T OR Y B I R D S}

The ducks and geese of North America have decreased with appalling rapidity. Destruction of nesting and breeding areas by reclamation, drain- 
age, and intensive grazing combined with recent droughts and market and sport hunting have reduced migratory waterfowl to a critical point.

Early conservationists foresaw that protection of migratory waterfowl could not be successfully accomplished by the states. The ducks and geese knew no state lines. The Migratory Bird Treaty Act of 1918 provided special protection for birds migrating between the United States and Canada.

In 1929 Congress supplemented this legislation by passing an act authorizing the purchase of inviolate refuges for migratory waterfowl but each year thereafter it consistently failed to provide the funds authorized. Discouraged, conservationists in 1934 secured the passage by congress of "The Duck Stamp Law" placing a license charge of \$I on all hunters of migratory birds, the revenue to be used in the purchase of breeding grounds.

Continuation of the program contemplates the acquisition and restoration of about 3,000,000 acres of land as sanctuaries for waterfowl and other forms of wildlife. A considerable portion of the total area will be within the region formerly used by the migrants as nesting grounds, but other refuges will be established along the principal flyways to the gulf. The work will have considerable effect in the stabilizing of water levels and the reduction of soil damage by flood and erosion.

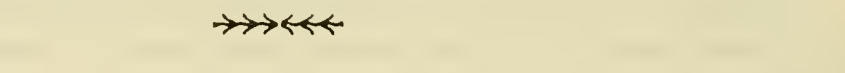

\section{FINISHING THE MAMMALS *}

ROSALIE E D E

K I L L ING WHOLESALE

\section{Man the Destroyer}

Ages ago, the reptile group dominated the animal world-on the earth, in the air, and in the sea. Yet this dominance came to an end; and the great reptiles were eliminated in a way we can never fully understand. They were succeeded as "lords of creation" by the mammals, once almost as widespread and dominant as the reptiles, and now clearly being exterminatedbut in a way we can understand, for it is we ourselves who are causing their extermination.

Scientists state that the fur trade is definitely bringing to a close the Age of Mammals. If the fur trade alone is so powerful a menace, then the end must indeed be near, for the fur trade is only one of several mighty forces that are visibly combining to annihilate mammalkind. Occupation by man of more and more of the environment available for mammals is contribut-

- Reprinted from Finisbing the Mammals by Rosalie Edge with the permission of the Emergency Conservation Committee, 1936. 
ing heavily to their extermination. Hunting has reduced big game species everywhere so greatly that they exist only as wards of government. Bounty payments slay their thousands, and "control" campaigns their millions, while "vermin" destruction has in view the absolute elimination of predators; and, carried on without cessation, in some places its object is almost achieved.

Trappers and hunters should be interested to conduct their activities so as to ensure a continued supply of the animals on which they depend for livelihood, or for "sport"; but ignorance, selfishness and greed among professional trappers and "sportsmen" prevent positive steps toward this end. The false propaganda of "sportsmen" against harmless creatures is instigated largely by the gun and ammunition manufacturers, and is abetted by the state game commissions. Hunters now pursue small animals that men a generation ago would have scorned to call "game"; and are wiping out many of the small creatures of the woods and fields.

"Vermin" control provides no incentive for the perpetuation of species; its proponents would hail with great satisfaction the death of the last predator on earth; and "vermin" control is the most inexcusable of all the inimical factors now pushing our small animals into oblivion.

\section{K I L L I N F OR PROF I T}

\section{The Fur Trade and the Steel-Trap}

The fur business has been pursued so recklessly that the fur-bearers of every civilized country have been almost completely wiped out. The trapper has gone where he could most easily get the greatest money return; until quite recently, he has trapped with little regard to season; and he has relentlessly tracked down the scarce survivors of high-class fur-bearing animals, regardless of sentiment, reason, or law.

Professor H. Fairfield Osborn, late President of the American Museum of Natural History, said: "Nothing in the history of creation has paralleled the ravages of the fur trade." The United States kills more fur-bearing animals than any other country in the world; Russia comes second. Though furs are, or were, one of our richest natural resources, no accurate figures can be given of the number of animals killed annually. Only a few states require reports from trappers; and it must be remembered that licensed trappers are not the only ones who trap; the Biological Survey says that "the large majority of trappers are farm boys and farmers"; trapping in its most cruel forms is a pastime of every rural section.

The Department of Agriculture estimates that sixty million animals are killed yearly in the United States, or two animals every second. This Department values the fur production of the United States at sixty million dollars yearly. And in addition to the animals on which these figures are based, are those other trapped creatures that are killed and discarded be- 
cause their pelts are not prime, or because in the days and nights of torture in the steel-trap they have so torn themselves as to be worthless for the market. Probably for every marketable pelt, two other animals are killed and left to rot.

America was first explored by fur traders; their wilderness trails are now our great highways; their far-flung outposts have grown to be our great cities; the romance of their names is written on the map of almost every state. The profit on furs from Louisiana and New France helped to build Versailles. Beaver skins were currency; and these riches fostered the heartless display of the French Court. But the extravagance of the fur trade of those days, when the wealth of the wilderness was barely tapped, was as nothing to the killing of fur-bearers that goes on today. Stand at the door of any fashionable church any Sunday in winter (or even in summer), and count, if you can, the skins of dead animals that come forth into the sunshine, of ten two hundred or more in one garment, on the backs of the worshippers. When we consider the fur trade, we marvel at the shortsightedness of business men who have so looted their resources. In the United States and Canada few valuable fur-bearers remain. The trade seeks its pelts further and further to the northward; and, unless restrained, its trappers will one day take the last fox that vainly tries to conceal its whiteness against the snow on the polar ice.

Besides being wasteful, steel-trapping is attended by torturing cruelties. It is universally recognized that the steel-trap, chief implement of the fur hunter, causes intense and long-drawn-out suffering to its intended victims, and is besides a menace to small domestic animals. Dogs often get into steeltraps, and lose a foot, or leg; a case is on record of a dog remaining in a trap fifty-five days; in which time hunger, thirst, starvation and torture reduced its weight from sixty-five to fifteen pounds. Put the trapper in a bear trap and leave him there a week, and he will have a greater appreciation of what he is doing. To leave traps uninspected, certainly longer than twentyfour hours, should be an offense subject to severe punishment. The man who will set a trap and leave it unvisited for a long period, or worse, even forget about it entirely, is too irresponsible to be allowed to trap at all. .

The fur trade and its allies, the manufacturers of steel-traps, cannot plead ignorance of the situation. By the trappers' and furriers' own admission, the American fur crop is only about 50 per cent. of what it was some twenty years ago-and everyone knows it had vastly decreased even then. The Department of Agriculture has warned us that even "the remnants of our rich fur resources are fast dwindling," a report of the Bureau of Biological Survey states: "The annual turnover in the retail fur trade has shrunk from $\$ 5,000,000$ in 1929 to $\$ 1,500$,000 the past year.*" Take the muskrat, for instance. It was once so plentiful, and is so prolific that the supply was thought to be inexhaustible. The muskrat is Louisiana's chief fur resource,

* 1935.-Ed. 
and Louisiana has made research to determine how best to foster the muskrat, her most valuable asset; yet the catch of muskrats in Louisiana fell from six million in 1930 to two million in 1935; and the catch for 1936 , is said to be 40 per cent. or 50 per cent. less than that for last year.

The American Trappers' Association has a program embodying certain desirable principles such as the elimination of unnecessary cruelty in trapping. It opposes the use of poison baits, and unfair methods of capture, such as smoking, den-digging and tree-cutting; it advocates protective laws; and urges the protection and improvement of environment. This program is, however, but a single "voice crying in the wilderness"; the trapping of fur animals is carried on by so many individuals scattered in remote districts that propaganda can reach only a limited number; and any form of compulsion reaches only a very few. The tone of the voice, moreover, lacks sincerity, threatening as it does any "fanaticism," such as the prohibition of the steel-trap, which might be detrimental to the interests of the trappers and traders.

Exploitation by the fur trade, together with hunting for "sport" and "vermin control," has either extirpated, or dangerously reduced in numbers, all the more valuable species of mammals indigenous to the eastern United States. The sea-mink and the fisher have been practically exterminated in this territory; the marten has been brought to a state of great rarity; and otters and wildcats of two species persist only in small numbers and very locally.

The beaver, at one time practically exterminated in our eastern states, has responded to a determined effort to protect it, mainly by the reintroduction of colonies; so that there has resulted an encouraging increase of beavers in some states. This shows that the public can be induced to recognize the plight of the fur-bearers, and can be persuaded to do something effective to remedy the situation. Strict regulations should protect such animals as skunks, rabbits, raccoons and opossums; beavers and foxes should be given closed seasons that shall last over a period of years, until the animals show encouraging increase. Mink, marten, wolverines, fishers and otters should be given complete protection ${ }^{1}$ for an indefinite period. The rare fur-bearers can be preserved, if preserved at all, only by absolute protection requiring that, regardless of value, trappers stay their hands, and dealers forego tempting profits.

Propagation of fur animals is a logical and legitimate means of meeting the demand for furs, but unless a system is devised of confining the marketing of rare furs to those actually produced in captivity, and of excluding a boot-legged wild supply, fur farming will not prevent the extermination

1 "The fur of the marten sells for high prices and always commands a good market. The American Marten is close kin to the famous Russian Sable."-H. E. Anthony: Field Book of North American Mammals.

In January, 1936, New York State passed a law closing the season on "otter, fisher, marten (sic) or sable." 
in the wild of any species on which there is a considerable premium. The only real hope for the preservation of the rare fur animals is the end of the practice of wearing their pelts. Giving up the wearing of the feathers of wild birds was all that prevented the extermination of many species by the millinery trade; and giving up the wearing of valuable furs is all that will save the rare animals.

To commercialize any wild creature is the surest way to bring about its extermination.

\section{K I L L IN G FOR FUN "Sport," "Sportsmen," and "Sportsmanship"}

Among the smaller mammals, the chief prey of the hunter includes the squirrel, rabbit, opossum, raccoon and fox. The hunting of each of these animals is characterized by abuses and cruelties that would not be permitted if man were really civilized, or as the dictionary quaintly puts it, "reclaimed from the savage state."

It is customary in some regions to seek the winter nests of squirrels after the leaves are off the trees, (an easy matter requiring no exertion or acumen), and then to blast the nests with the myriad-pellet discharge of a shotgun. The nest is a large target that cannot well be missed, and its occupants are victims that have no chance of escape. Sport? Perhaps so, in the estimation of hopelessly deficient morons. For appraisal, however, contrast this method with that of the old time rifleman. He secured the squirrel needed for an occasional stew with the aid of a muzzle-loading rifie; he never thought of shooting-up a squirrel nest, and he prided himself upon a skill that avoided mutilation of the animal. He stunned or killed it by placing the single bullet on which success depended in the bark close to the squirrel, a practice so widely followed as to call for the addition to the vernacular of the phrase "barking squirrels."

Nor is importation a solution of the problem of game maintenance. Importation is proof that regulation of hunting activities either has failed, or has not even been attempted. Where hunting is not regulated, importation can at best be only a stop-gap. The importation of rabbits is a serious indication of the depletion that must surely be overtaking other species that have a much smaller reproductive capacity. Nor will there always be "sucker states" that will permit their stocks to be commercialized out of existence. Years ago, certain states allowed the wholesale trapping and sale of Bobwhites. Try now to find such a state; there is none, though in 1935 Mexico foolishly permitted us to import 23,358 Bobwhites which were sent to twelve states. Soon, the importation from state to state of rabbits will also have to be abandoned.

The use of dogs in the pursuit of the raccoon (and of the opossum) is 
universal, and the term 'coon dog is everywhere understood. In the crisp autumn nights, 'coon hunting with its lights and flares, its rough and tumble chase, its shouting of men and baying of hounds, takes its devotees for a time to another world. It has a strong appeal for some men, otherwise civilized, and entitled to be ranked among the better classes.

Among those who cannot plead the need of food but who hunt just for the fun of killing, 'coon hunting is attended by grave abuses. Carried on at night, and followed wherever the chase may lead, the permission of landowners is rarely obtained, if a 'coon or 'possum is "holed up," a tree will be cut into; and, if "treed," the tree often is felled. This destruction is an aggravation of trespass, and is something the perpetrators would bitterly resent if done on their own property. Caustic criticism has justly been passed on those who will cut down a tree (not their own) worth ten dollars, or more, in order to get a two-bit 'possum.

From a humane point of view, the practices of 'coon hunting are a sad throw-back to a barbarous age. The treed victim is either shaken out, or dropped by felling of the tree, into a pack of eager, yapping dogs, where it is literally torn to pieces while yet alive. We pretend to regard with scorn the barbarities of the arena as conducted under the Roman Empire, but many of the things we countenance today are just as bad; and this rending of raccoons by dogs, in order to provide amusement is a deplorable example of barbarism.

The finish by rending is characteristic also of fox hunting, where the animal is so mangled by the dogs that only the very hairy tail, or brush, which is of no interest to the bloodthirsty hounds, remains for a trophy. Fox hunting is participated in by both women and men, and is often an important social event.

\section{K ILLING WITHOUT WARRANT}

\section{Propaganda versus Facts}

The gun and ammunition manufacturers and the trades that cater to "sport" have organized a shameless campaign of propaganda against wild creatures. The "sportsmen" have shot the wildfowl and the upland birds so wilfully and so recklessly that game bird shooting is near its end. Years ago the industries realized that new targets must be found, if the sale of sporting goods was to be maintained.

Propaganda was first directed against the birds of prey, the eagles, hawks and owls; in consequence, they too are fast disappearing; and the relentless cruelty of false propaganda is now being directed against the little animals of the fields and woods, hitherto rightfully regarded as the friends of man. Publicity is distributed through the medium of the rod-and-gun columns of every city and county newspaper, and the magazines of the out-of- 
doors which, while purporting to glorify nature, never forget the sources from which come their advertisements. ${ }^{2}$

The Game and Fish Departments of various states also stimulate hatred toward many wild creatures. This is done in order to curry favor with the sportsmen and trappers, for the money paid for licenses supports the game departments. Nature lovers are taunted with the fact that they contribute no state or federal funds for wild life protection; but officials generally turn an ear of stone to any proposal that would admit the general public, and especially the women, to a share in wild life protection.

The shooter of upland birds is the relentless foe of the small animals of field and woodland. Any bird or animal that might under any circumstances take a game bird, or the egg of a game bird, comes under the ban of extermination by "sportsmen." The ignorance betrayed by the propaganda of "sportsmen" and game-officials is profound. Ignorance may be understood, though not excused, in game-officials; they are political appointees, and in many instances have had no training in biology. The honest ignorance of an honest official can be enlightened; and many game-officials are now numbered among the more intelligent conservationists. But what hope is there of enlightening the "sportsmen," often college graduates, who cannot grasp the fact that game and predators lived side by side on this continent in untold abundance until the coming of man; that game has disappeared not because of bird and animal predators, but because of the unbridled predaciousness of men, of "sportsmen"-of themselves.

The emotions of the farmer are played upon with skill. Rodents and insects are the enemies of the farmer-every child knows that; but the farmer is persuaded to kill the very animals that would destroy for him the pests that ${ }_{8} \operatorname{cost}$ him the greatest loss. First the skunk must be killed, and the farmer is told that the skunk habitually steals the eggs of poultry. He may do this-but rarely. There are "rogues" among all creatures; an egg-stealing skunk may easily be caught in a box-trap, and destroyed. Why kill every skunk? A dog may be found killing sheep, but a farmer would not be justified in killing every dog. Skunks eat mice, and the skunk that is seen about the poultry yard may be mousing. Large insects, crickets, beetles and grasshoppers, serious pests of the farm, are the chief food of the skunk. "Sportsmen" accuse the skunk of eating the eggs of game birds. At the season when game birds are nesting, insects are plentiful, and the skunk rarely seeks other food; often game birds are known to nest close to the den of a skunk without being molested. The University of Michigan examined the stomachs of 1700 skunks, and found not a trace of a game bird egg.

${ }^{2}$ One notable exception is Nature Magazine. It does not accept advertisements of merchandise destructive to wild life, and its editorial policy courageously demands the protection of wild creatures. 
Foxes are accused of preying on game birds. The U.S. Biological Survey made a special investigation of the food habits of foxes; it reports that foxes take few game birds. In Michigan on a certain 800 acre game preserve, stocked mainly with pheasants, an investigation was made of the food habits of the fur-bearers occupying the same territory. It was found that the bulk of the food of foxes was meadow mice and rabbits. In only six out of sixty-eight fox droppings were the remains of pheasants found with certainty.

Among the interesting and comparatively harmless mammals that are being shot and poisoned from our forests, the American Porcupine stands out as notable in many respects. It is found only in North America, and mainly in those sections where coniferous trees are common. The wilderness dweller regarded the porcupine as a friend, for it assured food to an unarmed person who by any accident of fate might become lost in the wilderness.

But when, about twenty years ago, the craze for the destruction of predators and rodents broke out, the porcupine could not long rely on what little pity or tolerance could be demanded by an animal so poorly defended, and which was known to carry barbed quills, and to bite trees. It is noteworthy, however, that, although experiments in the control of porcupines by poison were instituted by the Biological Survey in 1922 , the animal did not attain headline importance until three years later, when both the Biological Survey and the Forest Service seemed to awake to the value of the porcupine as material for "control" propaganda. Within the next few years, porcupines were declared to be increasing rapidly; and soon were alleged to be a forest danger, sometimes greater than that caused by fire, and also to be an enemy of several farm crops.

By this time, a salt and strychnine combination had been perfected that, unless its use is curbed, threatens to "control" not only the porcupine, but mammals of many other species so unfortunate as to share the habitat of the porcupine, and to possess a liking for salt. In a certain cooperative project in northern Pennsylvania, it was charged by competent local organizations that squirrels, rabbits and deer were killed by the salt-strychnine baits put out for porcupines.

The Woodchuck, the eastern representative of the Marmot, lives familiarly in the meadows and pastures of the farm. It eats hay, clover and other vegetation, taking a small toll of which no farmer complains. Its habit is to sit motionless at, or nearby, the entrance of its burrow until closely approached. A little boy with a .22 rifle may employ some skill when engaged in a "careful and close stalk." But how degrading it is for a grown man with a high-powered rifle to stand at a distance of 100 to 200 yards, and shoot this harmless, motionless creature. 


\section{KI L L ING FOR GRAFT}

\section{Bounties}

The belief is held that putting a price on the head of any species is a certain way to reduce its numbers-and with rare species it certainly works out that way. Often, however, frauds connected with bounty laws prevent the accomplishment of the purposes of the legislation. Among the more flagrant frauds is the manufacture of "scalps"; where the requirements do not strictly define the part of the animal to be presented for bounty payment, many "scalps" may be made from a single animal. Another common way of "beating" bounty laws is to import "scalps," perhaps from another State; and what is in effect the same thing, is the paying of a bounty on a migratory species. The supposed benefit, were there any, to be derived from the killing of the creature, would accrue to some state other than the one paying the bounty. For instance, it is altogether probable that crows killed for bounty in northern winter roosts are mostly nesting inhabitants of Canada; a state paying a bounty on such crows, would benefit (if there were any benefit) another nation.

Notwithstanding these objections to bounty laws, in 1935 twenty-eight states still retained these archaic and harmful provisions. For common species, the usual result of bounty laws, because of defects in their administration, is the continued payment year after year of about the same number of bounties, showing that the procedure is upon a cropping basis, and no reduction in numbers is being accomplished. Where rare species are concerned, the bounty is higher, the incentive to profit by it is much greater, and the effect of the law is toward elimination of rare animals.

When species already have difficulty in maintaining themselves, bounties are a finishing stroke. States usually deny that their object is the extermination of any creature, but nevertheless bounties are actually exterminating numerous species. So, from the state's point of view, if their denial is sincere, why are bounties paid? Our forefathers trapped an occasional weasel that molested poultry, or shot an occasional fox for the same offense. They did not think of rushing to authorities for aid, or having "control" subsidized by the state. No, these refinements were left for their more politically minded, and truly, even if unconsciously, communistic descendants.

As graft, bounties are nothing to brag about; they are, moreover, ecologically unwise and economically unsound; they are without warrant when they concern animals with pelts of high value, the incentive for the destruction of which is already so great as to threaten the existence of the species.

Bounty payments are entirely indefensible; by their means unique and interesting species are, here and now, being exterminated, being banished forever from the land of the living. 
"VERMIN", CONTROL

Trapping, hunting, bounty-grabbing and "vermin" control are the most important of man's activities that are directly destructive of our small mammal population; and the most destructive of these is "vermin" control. This has not always been so; "vermin" control is a recently imported innovation, and was at first confined to a relatively few hunting estates and game farms. These institutions have now increased in number, and have intensified their destruction of "vermin"; prize contests in "vermin" killing, the result of propaganda, and stimulated by ammunition manufacturers, have increased all over the country. So-called, but one cannot imagine why-"conservation" departments are encouraging state-wide "vermin" campaigns that are destroying small animals and other wild creatures literally by the hundreds of thousands; while the control campaigns of the Biological Survey wipe out animals by the millions.

It must first be said with all possible emphasis that there is no justification for state-wide killing of animals as "vermin." "Vermin" is a gamekeeper's name for the natural enemies of game; game species are a very small minority of the wild life population of any State; and hunters in most places constitute but a minority of the human population. For gunners to assume that suppression of any and all creatures that they imagine inimical to their "sport" (a minority indulgence based on a minor element of wildlife) must be carried on over the state in general, is sheer arrogance that should be sharply curbed. Their payment of nominal fees to state game departments gives them no right to go roughshod over public interests. Game is a product of the land, and aln asset of the landowner; its production is not paid for by license fees going into the state treasury; and its taking without compensation is imposition. If its production were really paid for, gunners would find that their license fees would purchase very little. Not only game, but all that the wild life hunters recklessly slaughter as "vermin" is a product of the soil, and the landowner's interest in it is paramount. It is his right not only to insist that all protective legislation be obeyed, but also, by invoking trespass laws, to prevent any and all killing of wild life on his property.

"Man's inhumanity to man" aroused the inspired scorn of a great poet, but what could he say that would properly castigate man's inhumanity to the small and defenseless creatures of the wild? Every state of the Union has exterminated some of the forms of wild life inhabiting it when white men took possession, and every state right now is pushing other species into the abyss of extinction. Much of the destruction is being accomplished or instigated by minorities of the population, by cliques, seeking only their own advantage, or sadistic pleasure. The immolation of wild life on the altars of fashion, sport, industry, and politics is accomplished by inconceivable cruelty. An intelligent people will not permit the wanton waste 
of their valuable resources; a humane people will not wittingly tolerate such savagery. May the American people rouse before it is too late; may they demonstrate that the public is both intelligent and humane; may they irresistibly assert their interest in our wild life, and end forever the extravagant, the unwarranted, the cruel and unpardonable persecution by hunters and trappers, "sportsmen" and "vermin" killers, of useful, and for the most part harmless wild creatures.

\section{$\rightarrow \rightarrow+4$ \\ THE ITINERANT EEL *}

\section{P A U L B U L L A}

Off the North American continent, southeast of Bermuda and northeast of Puerto Rico, lies a tract of slowly swirling water known to mariners as the Sargasso Sea. Here according to song and story the Gulf Stream is born, and here far below the weed-choked surface is the breeding and spawning grounds of our own fresh-water eel.

Here these strange fish have their rendezvous. In this sea within a sea they are born, and here, after years spent in far places, they return to reproduce themselves and die, for no spent eels have ever been seen, and adult eels have never been known to run upstream.

Of all the fish known to mankind, few have a more remarkable life history, and none have puzzled scientists for so long a time as have these snakelike denizens of the rivers and lakes of Europe and America. Down through the ages they have been a food delicacy in the European and Medirerranean countries, but centuries passed before their migratory habits and method of propagation were explained. Each autumn uncounted numbers of these slimy creatures moved downstream to the sea, where many were caught in the nets of fishermen awaiting their migration. But great numbers avoided this fate and disappeared never to return.

In the spring and summer of each succeeding year, tiny eel-like creatures appeared from somewhere in the vast ocean spaces and swarmed along the coast of Europe and through the Straits of Gibraltar into the Mediterranean. Later they entered the fresh-water streams and rivers that ran down to the sea, penetrating to the interior where they grew to maturity. Confusion further confounded the minds of scientists and simple fisherfolk alike by the fact that eggs of unborn eels were never found in the bodies of adults and males of the species were never seen.

Many strange theories were advanced in explanation of how they were produced, ranging from spontaneous generation to the transformation of horsehairs into little eels. Aristotle, in the fourth century B. c., held that

- Reprinted by permission of Natural History Magazine and the author. Copyright 1942, 
eels were born from earthworms, which were, in turn, produced from mud or damp soil. The early Greeks, failing to find spawn or male reproductive glands within the eels, named Jupiter as the father, as all children of doubtful parentage were ascribed by them to this god.

Pliny the Elder, great Roman naturalist and author, declared with conviction that eels had neither masculine or feminine sex. In accounting for their multiplication he concluded that they rubbed themselves against rocks, and the pieces scraped from their bodies came to life as little eels. He dismissed the subject as a matter for further controversy with the laconic statement that "they have no other mode of procreation." With the acceptance of such beliefs it is small wonder that centuries elapsed before such theories were dispelled and such superstitions overcome.

It was not until 1777 that the ovary of the eel was first recognized by Carlo Mundini, a professor of anatomy at the University of Bologna, thus definitely establishing a female sex. Ninety-five years later Reinhold Hornbaum-Hornschuch announced the discovery of a male individual, and the enigma that had endured for over 2000 years was on its way to being solved.

But while these discoveries partly answered the riddle of their existence, where they came from and how they were produced still remained a mystery. It was left to a German named Johann Jakob Kaup in 1846 , to find in the sea a small ribbon-like fish with a tiny head. Curious as to its species, he took it home and placed it in a bottle of alcohol. After labeling it Leptocephalus brevirostris, a name which exceeded the length of the specimen itself, he left it there to be forgotten.

Half a century passed before the subject emerged from the obscurity into which it had been relegated. On a day in 1896 two Italians, Gracci and Calandrucci, found one of Kaup's little fish in the Mediterranean, but one much larger and more fully developed. This they identified as the leptocephalus or larva of the edible eel that inhabited the streams of the European continent. With that beginning the stage was set for a Danish scientist named Johannes Schmidt.

As Director for the Danish Commission for the Exploration of the Sea, Schmidt sailed in 1906, on the first of many subsequent expeditions, to locate the breeding and spawning grounds of this specter of the deep. For fifteen years he towed nets up and down the Atlantic, taking specimens of leptocephali from the English Channel to Chesapeake Bay, and from Greenland to Puerto Rico. Over this vast area he collected and correlated sizes of eel larvae, carefully noting the latitude and longitude in which they were obtained.

He reasoned that the larvae were growing as they moved from the place in which they were spawned toward the coast and their fresh-water homes. It followed, therefore, that the smaller the larvae found in any part of the ocean, the nearer such specimen must be to the place where it was born. 
After years of tireless effort he was able, through this method, to fix the breeding and spawning grounds of the European eel (Anguilla vulgaris) and the American species (Anguilla rostrata) within the latitudes 20-30 degrees north and longitudes $60-78$ degrees west. He further established the fact that the European beds overlapped those of the American species.

But this discovery uncovered but one phase in the life cycle of the eel. During the period of growth in the waters of their home continent, both males and females are a uniform green to yellowish-brown above, shading to a pale dirty white beneath, and are called "yellow eels." When the migratory instinct asserts itself at the breeding stage, which is in the autumn when they are between the ages of seven and fifteen years, the sides of their bodies take on a metallic sheen and their backs become a deep black. This is their breeding dress, and they are then known as "silver eels."

Upon assuming this dress certain other marked changes take place in the females. Their snouts become sharp, the eyes larger, and the pectoral fins, just back of the gill slits, more pointed than usual. Although they have been voracious eaters all of their lives they cease feeding at this time, and, leaving the lakes and rivers in which they have lived, move downstrean to the sea. But while these visible changes have been taking place, it is not until after they have reached salt water that the ovaries mature. In fact no perfectly ripe female eel and only one ripe male has ever been seen. Upon arriving in the bays and estuaries of their home shores they are joined by the mature males that have been living there, and together they start the journey back to their birthplace over 2500 miles distant.

It is not known how far below the surface they swim, but somewhere beyond the continental shelf they pass from the range of observation. Neither is it known how long it takes them to reach their destination, but it has been estimated that the eel requires about six months to make the crossing, swimming at the rate of one-half mile an hour. As the migration from the European continent begins in early autumn, and spawning starts in early spring at the breeding grounds, this estimate of the period of time seems to be justified.

Upon arrival at the breeding grounds, the European species find that they must share it with their American cousins whose beds overlap their own, but extend westward from it. From Labrador southward to Panama and the West Indies, the "silver eels" from America have journeyed to the rendezvous in from one to two months after reaching salt water. Hundreds of fathoms below the seaweed-clogged surface of this tropical sea the eggs of both species are spawned; the females producing from 5-20 million tiny eggs, transparent and almost colorless.

Spawning begins in late winter or early spring, and a week or so after fertilization the eggs are hatched and larvae of both species begin life with a length of about one-fourth inch. Ribbon-like in shape and so transparent that newsprint can be read through their bodies, they float for a time from 
600 to 900 feet below the surface. Later they rise into the upper layers of water and slowly move northward. Reaching the latitude of Bermuda, a separation occurs. The larvae of the European species move eastward on the long journey back to their native shores, while their tiny American relatives turn toward the coast line of America.

During their first summer of life the European larvae are found in the western Atlantic. By the second summer they have reached the central Atlantic, and by the third they have arrived off the coastal banks of Europe. During their two and one-half years in the ocean, they have attained a length of from two to three and one-half inches, but still retain their flat, leaf-like larval form. They are now faced with a new way of life and must be prepared to meet it. In the course of the autumn and winter a metamorphosis takes place. They cease feeding, lose their larval teeth, shrink in depth and length, and become elvers or little eels. While they are shaped like their parents in miniature, they are still transparent, and so are known as "glass eels."

Our American eel has a shorter larval history. Here again the timing is perfect, for it reaches its home shores and the elver stage of existence in about one year.

After the transformation from larva to elver, the females of both species ascend the fresh-water streams of their native land to live their lives in the interior until the moment when the migratory instinct drives them back to the sea. In these journeys upstream they use pipe lines and sewers and clamber over falls and surmount dams to reach their destination. The males however, remain in the brackish waters of lagoons and estuaries, where they grow to maturity, and await the downstream migration of the females.

As eels have been found in ponds having no outlets or inlets, it is believed they will travel overland to reach these oases, choosing nights when the grass is damp for the journey. As there is no evidence to establish this presumption, their presence in these isolated waters is still something of a mystery. They are also at home in high as well as low altitudes, having been found in Swiss lakes 3000 feet above sea level.

All eels in the headwaters of large streams are found to be females. As a rule they lie buried by day in the muddy bottoms where there is stillwater, and venture to feed abroad at night. Being scavengers and omnivorous, they will eat almost any available food, either living or dead. They have even been known to eat their own kind.

Female eels average from two to three and one-half feet in length, but have been known to reach four feet and weigh as much as sixteen and onehalf pounds. Males average around fourteen to eighteen inches in length, but never grow larger than two feet. The vertebrae of these fish mark the only difference between the American and European species; the former have an average of 107 segments, while the latter averages 114 . 
Differing from their salt-water cousins, the lower jaw of both species projects beyond the upper, while the large mouth gapes back to a point even with or somewhat behind the eyes. On the side of the neck are gill slits with upper corners on a line with the center of the base of the pectoral fins. A single fin, soft and without spines, extends along the back, around the tip of the tail, and forward on the underside of the body. There is no separation into dorsal, caudal or anal parts. After the third or fourth year of life, eels develop small scales that are imbedded in the skin. These are covered with a coating of slimy mucous, which has given rise to the simile, "as slippery as an eel."

Perhaps the most intriguing part of the life cycle of this unusual fish is that neither European nor American elvers have ever been known to appear off the shores of any country but their own. This fact immediately presents two puzzling questions that challenge the imagination.

I. What causes the immature larvae of the European species to move eastward from the spawning grounds, while its American cousin works toward the west side of the Atlantic?

2. How does it happen that the timing is perfect for both species to reach the elver stage within a few months after arriving off the coast of their home continent?

These may be answered in part by the difference in their individual larval histories.

While the European larva requires from two and one-half to three years to reach the elver stage of development after life begins, the larval stage of the American species is terminated in about one year. This time element not only acts to keep the two species distinct, but makes it practically impossible for either to survive in waters other than their own after metamorphosis takes place.

Should the larvae of the European eels move westward they would reach the American coast line still in an undeveloped larval stage; while the American species traveling eastward would reach the elver stage somewhere in the western Atlantic when the time arrived for them to seek fresh-water retreats.

A geographic cause for their distribution is advanced by Doctor Schmidt who points out that the center of production for the American eel lies farther west and south than the center of the European beds. These, together with the movement of the ocean currents as an aid to the journey in the early stages of larval development, must be considered as causes directing the two species to its own side of the ocean.

While much has been learned of the habits of these sluggish, sedentary fish, since the turn of the century, much remains unexplained.

With a singleness of purpose and an unerring instinct that has confused scientists, untold thousands have deserted their home waters each autumn to seek adventure in a tropic sea and to keep their rendezvous with death. 
Weak and immature, their progeny is cast adrift far from its native land and, unguided, these feeble swimmers travel a road over which they have never journeyed, to reach their home continent.

Truly, the eel is one of the greatest of marine mysteries.

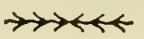




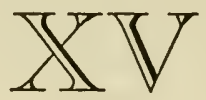

\section{Biological Philosophy}

$\mathrm{T}^{\mathrm{T}}$ has been correctly said- "there is a direct relationship between the 1 content of the human mind and world events." The way in which men think determines largely whether we shall have war or peace, whether we shall have progress or poverty. A course in biological science should do more than teach biological principles; it should teach scientific logic, the habits of suspended judgment and tolerance, and the fallacies of common superstitions. It is becoming clearer, I hope, that there is a fine correlation between the above mentioned qualities and statesmanship. Not that we believe the best statesmen are necessarily the scientists but the qualities of common sense and forbearance and the belief in the oneness of human knowledge that characterize the true scientist are essential for good leadership. How often do we see our chosen leaders preach race hatreds and intolerance, how of ten do they promulgate laws for the good of minorities at the expense of the masses, how often do they twist facts to suit their purpose?

Biological science can and should deal with the philosophical aspects of nature. Is truth static or subject to change? How did man evolve-and where and when? Is man changing now and if so is he improving physically or degenerating? Does science teach moral values and does it attempt to take the place of religion? These are questions which the scientist should be best able to discuss if not answer satisfactorily because they are in the realm of science. A broad background is necessary to see all the implications in these problems. Science has often been accused of assembling the data and then allowing unqualified people to interpret it. They have also been accused of being indifferent to the uses to which their discoveries were put. Both of these accusations have a good deal of merit. It is heartening to see some of the leading scientists of the country raising their voices in an effort to interpret and direct the products of their toil. 


\section{THE LIVING MACHINE *}

\section{R : T. Y O U N}

Is there one law for the living and another for the dead, or is the universe a unit in its workings and all matter governed by universal law? The former is the contention of the "vitalist," the latter of the "mechanist." What is life? Is it some inscrutable process, controlled by a "vital principle" operating outside the realm of physics and of chemistry? Or is it merely a special expression of the forces which control inorganic matter. Our only answer to these questions is that we do not know. Neither the substance nor the energy of life has ever been analyzed, and the only way in which we can identify life is by its manifestations. What are these manifestations, and what light if any do they throw upon the ultimate nature of life itself?

Firstly, what is the stuff of which living things are made? An analysis of living substances or protoplasm is exceedingly difficult if not impossible. In order to analyze it, it must be killed, and the readiness with which the protoplasm breaks down into innumerable simpler substances leads us to suspect that after protoplasm is killed it is protoplasm no longer, so that we are analyzing not protoplasm at all, but something else. Our analyses are sufficient to show us however that protoplasm contains the same elements of which inorganic matter is composed, united into a marvellously complex whole. The manifold varieties of life which we know lead us to believe in as great a variety of protoplasm which determines this variability in living things. In spite of its variability however all protoplasm alike contains protein consisting of carbon, hydrogen, nitrogen, oxygen and sulphur, without which it cannot exist. Protein however is found outside of protoplasm in egg albumin for example and in the various albumins and globulins of the blood. These substances while protoplasmic products are not protoplasm itself; hence we see that in its composition (in some particulars at least) living matter does not differ fundamentally from non-living.

One of the most characteristic features of life is its power of waste and repair and growth. It is folly to attempt, as some have done, to compare these processes in their entirety with any process in the non-living world. There is nothing with which it can be compared. And yet if we analyze them into their component processes, we find that they are composed of a series of chemical and physical reactions, many of which at least can be exactly reproduced in the laboratory.

In the warm spring days when the remnants of last year's crop of potatoes in the cellar start to sprout, and those which are served upon your table have an unpleasant sweetish taste, you are the victim of a ferment (or enzyme) known as diastase, of wide-spread if not universal distribution

"From Biology in America by R. T. Young, copyright 1922 by Chapman and Grimes, Boston. 
among plants, which changes starch, the stored-up food of the plant, into one of the sugars. When the maple sugar sap is flowing in the spring we know that a similar reaction has been taking place within the tree, and all the beauty of the young spring's growth depends upon it. A similar reaction takes place in our own mouth, under the influence of an animal ferment known as ptyalin, and present in the saliva of many mammals. But a similar result can also be obtained in the test tube of the chemist by boiling starch in dilute acid.

In the exchange of materials between the cell and its environment, its (the cells) membrane "determines" what substances shall enter and leave the cell. Thus an uninjured beet may be placed in water without losing any of its color. But cut the beet and its color readily diffuses outward. So in the absorption by roots of substances from the soil and by the walls of the intestine from the digested food stuffs, the cell membrane exercises what is known as "selective absorption," taking some and rejecting others. In the passage of substances between mother and child, through the walls of the placenta, the cells of the latter exercise a selective function, allowing food materials and oxygen to pass from mother to child, and waste materials to pass in the reverse direction. This selective activity of living membranes is strikingly shown by experiments on barley fruits, which are not killed by sulphuric acid because it cannot penetrate them, but are destroyed by bichloride of mercury, which readily enters.

In the burning coal of the furnace and in the forest's decaying logs, one of the final products of combustion or decay is carbon dioxide. So too when we exhale the carbon dioxide from our lungs we are casting off one of the end products in the combustion or oxidation of our foods and our tissues.

Throughout the entire process of metabolism, of growth, repair, decay, of body of animal and plant is a physico-chemical laboratory in which are taking place the processes of the non-living world.

Another characteristic feature of living things is their power of movement. This is not evident at first sight in all organisms, notably plants. In fact, one of the criteria formerly presented as distinguishing plants from animals was the fixity of the former as compared with the motility of the latter. This distinction we now know to be false however, for even in the apparently non-motile plants there is circulation of cell sap, and movements of leaves and roots in response to stimuli; while among animals, the attached forms such as sponges, sea anemones, barnacles, etc., either lack locomotive power or possess it in very slight degree.

All living things then are motile to greater or less degree. But is this quality lacking in the non-living world? Place a diluted drop of ink under the microscope and it becomes a microcosm of violent activity. Wind and water are ever active. The earth is flying through space at the rate of $181 / 2$ miles a second and the universe is a realm of external motion. Light and 
sound are expressions of movement, and the electronic theory of matter postulates that matter itself is a cosmos of ceaseless energy. But the vitalist tells us that living matter possesses "spontaneity," which is lacking in the non-living world. The living thing moves of its own "volition," the nonliving only under the influence of forces external to itself. But what evidence have we of "volition" on the part of an Amoeba or a bacterium, while the energy of the living machine is as truly the result of oxidation of fuel as is that of the steam turbine or the automobile. Any distinction then on the basis of motion alone between the world of the living and the non-living is a fallacy.

Adaptation is one of the characteristic features of life. The bird and bat are adapted for flight, the fish for swimming, the monkey for climbing: one need not enumerate, for one cannot name a single living thing which is not adapted to the conditions of its existence: otherwise it would not exist.

But are living things alone adapted to their environment? Does not the river adapt itself to its channel, the lake to its basin, and the gas to the form and size of its container? Ice exists in winter because it is adapted to the cold and disappears in summer because it is not adapted to the heat. Adaptation indeed is merely an expression of action and reaction, of cause and effect. The fact of adaptation in the inorganic world remains however and when the riddles of life have been solved it is not unlikely that the process of adaptation of living things can be resolved into simple physicomechanical terms, just as surely as can the adjustment of the river to its channel or the snow drift to the wind.

Yet another manifestation of life is its irritability or power of response to stimuli. Examples of this are so common that it is merely trite to repeat them. But is this phenomenon limited to life alone? Does not lifeless matter also respond to stimuli, or changes in its environment? Examples of such changes must occur to the mind of everyone-changes in volume or in state, whether solid, liquid or gaseous, in response to changes in temperature or pressure, are among the most familiar instances of these responses. If a metal is heated, its electrical conductivity is decreased, sound travels faster the higher the temperature, while atmospheric conditions will materially affect the messages of the radio. While the responses of living things and changes in their environment are infinitely more complex and indirect than those of the non-living, yet the same principle holds true for both.

Yet one great characteristic of life remains, namely, reproduction. The development of a human being with his myriad cells, more varied in form than the manifold parts of the most complicated machine, ranging in size from the tiny corpuscles of the blood, less than one four-thousandth of an inch in size, to the motor nerve cells of the spinal cord, which may reach a length of over three feet; and including the intricate structures of the brain by which are performed all the wonderfully complex functions of the 
human body, including the as yet inscrutable processes of thought; all these coming from an apparently simple cell a little more than one-hundredth of an inch in size, is a wonder beside which the magic of an Aladdin or the miracles of holy writ fade into ghostly paleness. The enthusiast in the ranks of the mechanist has attempted to remove even this most distinctive feature of living things, by showing that non-living matter may in a sense reproduce itself, as new crystals form in an evaporating salt solution. However feeble such a comparison may be, it is nevertheless true that all phases of reproduction are all intimately associated with physico-chemical changes taking place in these cells.

What of the mechanism whereby this wonderful machine of life utilizes its fuel? Herein lies one of the fundamental differences between the living and the non-living machine. Whereas the latter uses its fuel solely in the conversion of potential energy into heat and work, the former, in addition to these two functions, also converts some of its fuel into its own substance to take the place of worn-out parts, and to build new parts and enlarge those already formed in development and growth.

Turning from the world of animals to that of plants, we find in the latter a parallel to all of the metabolic processes of the former. The average person is accustomed to think of a plant in terms of the green thing which he finds in garden, field or forest. But when we go a-hunting mushrooms, or poke aside the rotting remains of a fallen tree, we discover other plants which live a different sort of life from that of the tree or shrub or herb. And should we delve yet further into Nature's recesses, and penetrate that hidden world to which the microscope gives entrance, we should discover creatures concerning whom no one can say whether they are plant or animal. Some of these uncertain forms are claimed by both botanist and zoologist as belonging to their own special field of study, for in some respects they are distinctly animal, in others plant in nature.

Perhaps the most fundamental difference between the higher plants and animals is in their metabolism. While the latter are spenders, the former are hoarders of energy, taking raw materials, carbon dioxide from the air and water from the soil, and from these constructing by the energy of the sun, acting through the green chlorophyll of leaf and stem, their own food stuffs; thereby converting the radiant energy of sunlight into the chemical energy of sugar and of starch. From the soil and the air the plant obtains its nitrogen and from the soil the other inorganic substances which are used to build its protoplasm, and combining these with the sugar it builds up its protoplasm. Someday, perchance, the chemist, imitating nature will learn to make our starch and sugar for us, and bid defiance to the "man with the hoe."

But while most plants differ widely in their metabolism, fundamentally their ways of life are alike. Both must have food, from the combustion of which their energy is derived, and from which their wastage is replaced and 
growth material obtained. And this food must be rendered soluble and dialyzable that it may pass through membranes which surround each cell, i. e. must be digested. While in the higher animal there is a place where digestion and absorption occur (the digestive tract) and the digestive enzymes are formed by special glands (liver, pancreas, etc.), in the plant there is no such specialized tract or glands for the function of digestion and absorption. There are however certain specialized tubes of cells in the root, stem and leaf which taken together form "conducting paths" for the water, with its dissolved salts ascending from the soil, and the sugar descending from the leaves to root and stem, there to be stored as starch.

From the leafy surface of humblest herb and mightiest tree, transpiration takes place, or the loss of water absorbed by the roots from the soil. The pressure lifting the water from the soil to the leaf may be as great in some cases as that which would be exerted on the earth's surface by an atmosphere six to eight times the thickness of the present one, a pressure sufficient to support a column of water between two and three hundred feet high.

Various attempts have been made to explain the rise of sap in plants but as yet with no great success. The evaporation from the leaves and absorption of water by cells are not adequate to explain the phenomenon. (Lately the cohesion of water molecules and capillarity occurring in the microscopic stem tubes appear to offer a more reasonable explanation.)

But can physics and chemistry explain the as yet unknown processes of nervous action; the bewildering complexity of the instinct of bee or bird or beast, or the yet more amazing intricacies of human thought? To answer this question, as indeed to solve any of the problems of living matter aright, it is essential that we turn to the lowest rather than to the highest organism, to those which present to us in their simplest terms, all the fundamental processes of the living thing. If the extended processes or pseudopodia of an Amoeba, one of the simplest types of living things, be touched with a finely drawn out thread of glass, the processes are retracted and the direction of movement of the animal is altered thereby. If on the other hand the Amoeba comes in contact with some object, which serves as food, it reacts positively toward it, thrusting out its processes and engulfing the object. Furthermore Amoeba can pursue its food, so that to the observer it seems as if this tiny bit of protoplasm, so small that the largest specimens appear to the naked eye as mere specks of white, were endowed with a sort of primitive intelligence.

Injurious chemicals cause Amoeba to withdraw from them. Similarly, if the water on one side of the Amoeba be warmed, the animal will contract on that side, and thrusting forth its pseudopodia on the other side, move in the opposite direction. If a weak electric current be passed through the water containing Amoeba, its behavior is similar to that under a heat stimulus. The side toward the positive pole contracts, while from the opposite side pseudopodia are extended and the animal moves toward the negative 
pole. When starved, Amoeba becomes more active than usual, while after a heavy meal it becomes sluggish.

One must not however be too sure of the simplicity of an Amoeba. While to the eye of the microscopist it appears as an "almost structurcless mass of jelly," nevertheless the complexity of the molecules composing this jelly is such as to defy analysis by the most skillful chemist. And even were it possible to obtain an exact analysis of the Amoeba molecules, the number of atoms composing the latter is so great as to render possible several million combinations of these atoms, each in a different way and each possibly responsible for every new response which it makes to its surroundings.

The ability of higher plants to respond to stimuli is a matter of common knowledge. We place a plant in our window and soon leaves and stem are bending toward the light. The compass plant is a devoted 'worshiper' of the sun. In the dawn it turns its opening flowers eastward to greet the rising sun, while at eventide they face the west attendant upon its setting. The mold Pilobolus grows upon horse manure. When its spores ripen they are thrown by the plant with considerable force, surrounded by the spore cases, in the direction of the light. If a little fresh horse manure be placed in a box with a small window, the filaments of the mold turn toward the window, and as the spores ripen they are thrown in their cases against the window to which they adhere. A tree is felled by a land-slide or a tornado and some of its roots are left embedded in the ground. Soon the young flexible branches turn and grow upward opposite to the direction of gravity. Roots, on the contrary, when placed in a horizontal position, or inverted so as to point upward, will soon respond to the pull of gravity and grow downward. A seedling is suspended with its rootlets immersed in a stream of water, and soon they bend and grow against the current of the stream. Touch the leaves of the Mimosa or sensitive plant and almost immediately the paired lobes of the leaflets fold together and the leaf itself droops slightly, soon however resuming its original position if undisturbed.

Can these responses of the unicellular animals and plants be explained on a physico-chemical basis? This the leader of the mechanist school in America, Jacques Loeb, endeavors to do with his "forced movement" or "tropism theory." According to this theory every organism is in a state of physiological equilibrium or balance with respect to a median plane of symmetry, until it is subjected on one side or the other to a stimulus, such as heat, light, electricity, etc.; which stimulus induces certain physicochemical changes, differing in degree on either side of the body, this difference forcing the organism to respond unequally on the two sides, and then perform a "forced movement" or a "tropism" (turning). The stem of a plant turns toward the light, or bends upward, because of a difference in the amount of chemical substances* on the two sides, and "this causes

* These are now known as plant auxins, hormone-like substances.-Ed. 
a difference in the velocity of chemical reaction between (the two sides)." The organism has no control over its behavior.

But what proof have we that such chemical changes as Loeb assumes do occur in the organism? If we suspend a stem of a plant in a horizontal position, it soon bends downward, taking the form of a $U$. This bending is not due to sagging of the stem as a rope sags, but rather to unequal growth of the two sides, which can be proven by marking equal distances on upper and lower sides by lines of India ink and later measuring the amount of growth occurring between the marks. If the amount of bending in such a stem with leaves attached be compared with that in a stem lacking leaves, it will be found to be much greater in the former due to the greater amount of growth material available, and similarly there is greater bending in a stem furnished with a complete leaf than in one with a leaf which has been partly cut away. "What has been demonstrated in this case explains probably also why the apex of many plants when put into a horizontal position grow upward, and why certain roots under similar conditions grow downward. It disposes also in all probability of the suggestion that the apex of a positively geotropic root has 'brain functions.' It is chemical mass action and not 'brain functions' which are needed to produce the changes in growth underlying geotropic curvature."

The purely mechanical response of an animal to stimuli is beautifully illustrated by the behavior of the caterpillar of the butterfly (Porthesia clorysorrboea). This butterfly lays its eggs upon a shrub, on which the larvae hatch in the fall and on which they hibernate, as a rule, not far from the ground. They leave the nest in the spring when the first leaves have begun to form on the shrub. After leaving the nest they crawl directly upward on the shrub where they find the leaves on which they feed. If the caterpillars should move down the shrub they would starve. What gives the caterpillar this never-failing certainty which saves its life? It is merely positive heliotropism and the light reflected from the sky guides the animals upward. If we put these caterpillars into closed test tubes which lie with their horizontal axes at right angles to the window they will all migrate to the window end where they will stay and starve, even if we put their favorite leaves into the test tubes close behind them. These larvae are in this condition slaves of the light.

The light which saved its life by making it creep upward where it finds its food would cause it to starve could the animal not free itself from the bondage of positive heliotropism. It can be shown that a caterpillar after having been fed loses its positive heliotropism almost completely and permanently. If we submit fed and unfed caterpillars of the same nest to the same source of light in two different test tubes the unfed will creep to the light and stay there until they die, while those that have eaten will pay little or no attention to the light. It can be shown with a reasonable degree of probability however that even here what we call "instinct" may be 
purely a response to physical and chemical stimuli, modified by certain substances secreted by the body and known as "hormones" from the Greek verb bormáo, to excite. What are these substances, how are they formed and what role do they play in animal physiology?

The recognition of the value of certain organs in curing disease goes back to the days of Hippocrates, the "father of medicine," and since his time many such remedies have been proposed. Thus the liver of the pigeon or the wolf were used in cases of diseases of the liver, the rabbit's brain was given for tremors and the lung of the fox for difficulty in breathing. The testicles of the donkey or stag were recommended by Pliny for the renovation of the debauchee. It is now known that one kind of diabetes, which is marked by the presence of sugar in the urine, is not a kidney disorder, but is due to improper action of the pancreas, as a result of which a specific secretion, passed by the latter into the blood stream and functioning in sugar metabolism, is absent or reduced in amount.

Imperfect development of the thyroid gland leads to the condition known as cretinism. Feeding the extract of the thyroid gland of the sheep, or the gland itself, either raw or cooked, result in great increase in growth and development of both mind and body in such cases. Attached to the lower, central part of the brain is a small gland, the pituitary body, which some enthusiastic theorists have fancied to be the seat of the soul. If this gland is partly removed from a young puppy it ceases to grow except for the accumulation of fat. It keeps its puppy hair and milk teeth, while the development of the genital organs and of the intelligence is much retarded.

One of the most striking examples of the role of hormones or internal secretions is the action of the sex glands in controlling both body form and mental activity. The physical and mental changes occurring in both boys and girls at the time of puberty are too well known to require even passing mention here, while the dependence on the proper functioning of the sex glands of the secondary sexual characters, such as the horns of the deer, the comb and feathering of the cock, the size of the stallion, is equally familiar to everyone. Horses and cattle are castrated to render them docile and serviceable as draft animals, and the cock is castrated in order that he may take on more flesh and become a welcome member of our dinner parties.

Of all the features characteristic of living matter, none is more so than reproduction. Attempts have, it is true, been made to compare the growth of many crystals of salt in a concentrating solution with this miracle of life, but such attempts sound like a mere play upon words. There is nothing in the inorganic world in any way comparable to this wonderful phenomenon. Here then, if anywhere in the world of life, we should find evidence of some force higher than the physical forces, did any such exist. But what do we find? The method of reproduction (bi-sexual or parthenogenetic) can be altered by external means; furthermore in Hydra it can 
similarly be changed from asexual (budding) to sexual. In some plants likewise the kind of reproduction can be determined by external factors. The attraction between the sex cells is in some cases, though apparently not in all, a chemical one. If a capillary glass tube containing a weak solution of malic acid be placed in water containing the sperms of ferns and mosses, the latter are attracted by the acid, and will enter the tube in great numbers. It is a well-known fact that it is very difficult to cross different species of animals, this difference indeed being made the basis for a physiological definition of species, those animals which breed together and produce fertile offspring being grouped as one species; and those which do not interbreed, or do not at least produce fertile offspring being classed as distinct. In lower animals union of egg and sperm of different species may be prevented by physical differences such as size, or chemical differences may prevent the development of an egg into which by chance a foreign sperm has entered. Occasional instances of crossing and the production of fertile offspring are known, in crosses of hares and rabbits, various species of fish, etc. Loeb has succeeded in cross-fertilizing the sea urchin's egg with the sperm of several species of starfish and one of the brittle stars, by simply adding a little sodium hydroxide or carbonate to the water containing the eggs.

Far distant though we be from a solution of the "riddle of life" our only present hope of ultimate success is to proceed from the known to the unknown, working on the hypothesis that nature is a unity and not a duality, and that the same fundamental laws control organic and inorganic worlds alike.

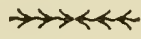 \\ TELEOLOGICAL ARGUMENTS *}

\section{A R C H I E J B A H M}

Arguments for the view that the world has a purpose are many and devious and based often upon curious and dubious premises. In the following, some of the more typical arguments have been selected, stated, and "refuted"-refutations consisting of criticisms typically raised against the arguments. Insofar as the case for the view is refuted, the case against the view is not thereby established. This case must be established on its own account. Arguments for the view that the world has no purpose, and criticisms of these arguments, have not been included here. As to the validity either of the arguments or of the criticisms, the reader will judge for himself.

Design. Familiar to all is the argument that "the world has a pattern and

* Reprinted by permission of the Scientific Montbly, American Association for the Advancement of Science. Copyright 1944 . 
therefore must have a purpose." Different terms are used to express what is meant by "pattern," such as "design," "structure," "order." Usually the argument is stated so as to involve a purposer. For example, beginning with the assumption that the world has a design, the argument deduces that "there can be no design without a designer and that if a designer produced a design he must have done so for a purpose. Thus, if the world has a design, it must have a purpose."

Critics attack the argument in several ways. They say that the assumption that "the world has a design" is unwarranted. For there is also obvious disorder and lack of design which cannot be ignored in claiming that the world as a whole has a purpose, and it is possible that only our part of the world is orderly and the rest of the world which we do not know is chaotic and disorderly, and design may be merely apparent or a product of the processes of perception in human beings who are uniquely purposive and yet persist anthropomorphically in interpreting all other things as purposive.

Secondly, critics contend that the assumption that "there can be no design without a designer" is false. At least some designs are accidental. For example ink drops folded in paper sometimes appear strikingly symmetrical. If some patterns are produced unpurposively, then it is at least possible that such patterns as the world as a whole may have have been produced unpurposively. Also, perhaps teleologists have been deceived by ambiguities of the term "design." Sometimes "design" means "intention" or "purpose," as when one asks, "What did you design to do?" Here of course, "design" involves "purpose." But "design" also means pattern apart from purpose, as exemplified by patterns produced accidentally. Thus deduction of "intended pattern" from mere "pattern" is unwarranted.

Thirdly, critics point out that even if the world has a design and a designer it still would not follow that "if a designer produced a design, he must have done so for a purpose." For he too might have produced the world accidentally, or he might be designing the world as a consequence of some mechanical necessity rather than as a result of purpose. Finally, even though the world was designed for a purpose in the past, there is the possibility that it now no longer has the purpose that it once had, because it may have lost its purpose, or it may have fulfilled its purpose. If so, patterns produced by previous purposiveness may remain without the patterns remaining purposeful.

Such criticisms seem not to down those who would argue from design. When attacked, they reply not so much by refuting these criticisms as by reiterating their argument in a more plausible form. The three following arguments, from analogy, from complexity, and from evolution are really variations of, or extensions of, the argument from design.

Analogy. "Even as a watch requires a watch-maker, a building an architect, an airplane a designer, a vessel a potter, so the world-machine requires 
a master-watchmaker, a master-architect, a master-designer, a masterpotter. The number of obvious cases is so large that surely the argument from this analogy is warranted. Even though it cannot be deduced that the world has a purpose, still it seems highly probable."

Critics usually grant that there is some evidence from the analogy and admit that strictly speaking, the conclusion does have some degree of probability. But the degree is not high. For, while illustrations may be multiplied tiresomely, they nevertheless are selected examples and represent limitations of man's anthropomorphic perspective. Believers tend to see what they look for and the evidence presented represents, even though innocently, a "stacking of the cards." One might if he tried find even more illustrations wherein no analogous purposiveness of parts of the world were overwhelming, still it would not follow that the world as a whole is purposive. The argument from purposiveness of parts of the world to purposiveness of the whole world involves what logicians call the "fallacy of composition." The fallacy in the argument, "This is a bunch of large apples, therefore this is a large bunch of apples," and the fallacy in the argument, "This world is made up of purposive beings, therefore this world is purposively made up," is the same.

Complexity. "Even though some patterns might occur accidentally, man is too complex and intricate to have just happened. Man's chemical, physical, biological, physiological, psychological, economic, political, ethical, aesthetic, and religious interrelations all fit together in multitudes of delicate adjustments. Literary and artistic productions, governments and industries, moral codes and religious hierarchies do not just happen. Such amazing intricateness presupposes purposiveness."

Critics respond in four ways. First complexity is relative. To anything that is relatively complex, something more simple would seem relatively simple. And to anything that is relatively simple, something more complex would seem relatively complex. The world is more complex than the minds which try to comprehend it, so the complexity of the world seems relatively complex to comparatively simple human minds. Relatively simple minds may be easily amazed. Such amazement at complexity is hardly proof of purposiveness in complexity. Secondly, the possibility that the world is one of pure chance, is made up of an infinite number of elements, and has endured or will endure for an infinite time suggests the possibility that the number and complexity of possible combinations is infinite. If, then, infinite complexity may occur from pure chance, complexity hardly presupposes purposiveness. Similarly, if the world is mechanically determined, complexity of result merely presupposes complexity of cause, rather than purposiveness. Critics contend that those who appeal to amazing complexity as proof of purpose merely reveal their ignorance of the complexity of mechanical causation. Finally, if complexity presupposes purpose surely it presupposes complexity of purpose. It seems questionable whether any 
purpose or purposer could be complex enough to take into consideration all of the complexities that actually occur. How could such successive series of so many simultaneous complexities be integrated into a single purpose? One might as easily argue that the world is too complex to have been purposed as to argue that complexity presupposes purpose. Furthermore, if the purpose is at least as complex as its purposed product, what purpose could there be in duplicating the complexity?

Evolution. Although the idea of biological evolution was once ardently opposed by those who believed it inconsistent with the idea of world purposiveness, it is now appealed to as one of the strongest evidences of world purposiveness. "Evolution seems directed toward certain ends. Mere complexity may not presuppose purposiveness, but complexity that is going somewhere does. Evidence of direction is plentiful. Each stage of the reproductive cycle seems to serve the next stage. Each species that developed seems to have served as a basis for the development of later species. The history of biological development toward, and to, purposive man surely must have been for a purpose." Some biologists even appeal to world purposiveness for proof of the previous existence of what some call "missing links." These had to be in order to fulfill the purpose obvious in biological evolution. "Furthermore," some say, "this is a world in which the fit survive, and since evolution has been rather consistently toward those beings which are more purposive surely the superior success in survival of the more purposive beings argues for world purposiveness."

Critics accustomed to defending biological evolution in non-teleological terms may be somewhat taken aback by this appeal of teleologists to evolution. However, upon recovery, they contend that biological evolution has been, and for the most part still is explained without appealing to world purpose. Thus the idea of purpose is not necessarily to evolution. That evolution has direction may be admitted, but that direction always implies purpose may be refuted by pointing out that anything that goes anywhere goes in some direction. The wind blows first in one direction and then in another; but this is no evidence of change in purpose or of purposiveness of any sort. Furthermore, if evolution of species serves a purpose, why have some species developed only to become extinct? Some have developed not merely to lay the foundation for higher species in the line of development of man, but for other lines of development which eventually cease. Do some purposes end? Is it a part of the world purpose that some purposes end? Is such purpose as the world as a whole is supposed to have also endable?

Critics point out further that multitudes of simple species continue to exist to survive, as well as complex and more purposive species. Thus, apparently, development in purposiveness is not essential to survival. Likewise, even if it be granted more purposive beings survive better than less purposive beings, still it would not follow that such superior success in survival is for a purpose. Survival of purpose does not imply survival for a 
purpose. Finally, the argument illustrates human conceitedness rather than objective fact. The purpose of evolution, as thus interpreted, is to develop man, and man is the end, the completion, the perfection of the process. We accept the teleological interpretation of evolution because it glorifies man as a superior product which required so many difficult acons of preparation. Even those who add that the purpose of the evolution of man is to serve God do so in the interest of human conceit by saying, or implying, that man is the chief object of God's attention, and the trouble God went to in planning such a complicated evolution demonstrates the greatness of God's consideration for man. But, if man could discount his own conceit, he would see that the argument for world purposiveness from evolution would have little basis.

Value. "Even though the previous arguments from design, analogy, complexity, and evolution fail to prove that the world has a purpose, one other additional argument does. Value or goodness exists. Many types of value or goodness exist. For example, the value of life, of hope, of love, of companionship, of beauty, of faith, of honor, of loyalty have been mechanically caused. Literature, music, art, drama, painting, pageantry, and poetry, are more than machine-made or circumstantial products. The ecstasy of love, the sublimity of symphonic music, the peace of worship, the exaltation of success, the inspiration of faith in the future-all of these are values which could not just have happened. Life is too worth-while just to have occurred."

Critics may hedge and hesitate to explain value in non-purposive terms, but usually they hold that even though it is not necessary, yet it is possible to do so. Value consists in pleasant feeling and pleasant feeling is produced in bodies by proper stimulation or, according to at least one psychologist, when synaptic resistance to nervous impulses is decreasing. Such reduction of resistance is explainable completely by chemical and physical interpretation. Value exists in the world because those chemical combinations organized into living being that produced pleasure survived better than non-plcasure-producing living beings. Synaptic and glandular conditions may cause objects to appear magnificent, grandiloquent, ecstatic, but such illusions merely happen to have been useful for survival rather than to be true ideas about the real world. Values exist, but exist as illusions, albeit happy and pleasurable illusions. Illusions of value may beget illusions of purposiveness, but unless these illusions also are enjoyable there is no point in being deceived by them.

Critics call attention also to the existence of evil. Values might serve a purpose, but what good is evil? The horror, fear, hatred, anguish, pain, ugliness, nausea, and suffering of life and death are a part of the total picture. There is too much evil in the world for anyone to have planned it that way. The existence of evil is at least as much proof that the world has no purpose as in the existence of good proof that the world has a pur- 
pose. If teleologists assert that evil is mixed with the good to make it all better, critics reply that neither the observable suffering nor the coming promise of eternal punishment warrant such optimism. If one has to choose between believing that the world has no purpose and believing that the world has a predominately evil purpose, surely the former would be more desirable.

Progress. "Progress is possible. And progress means development toward something better or more good, toward some goal or end, toward some purpose. If there were no purpose, there could be no progress. But there is progress, therefore there must be purpose."

Critics may admit that progress is possible. But so is regress. Life can get better, and life can get worse. "The best laid schemes of mice and men gang aft agley and leave us nought but grief and pain for promised joy." Who can tell whether our present optimism about a more glorious future is justified? In the end all values may be destroyed. In the end there may be an end to both good will and evil. Those who continue to be in torment and anguish say, "Let it come quickly." "Ashes to ashes and dust to dust," and between the two a period of pleasure and pain which while we have it we should enjoy and hope happily, but when it is ended ends all for us. Purpose there may be, but progress and regress do not prove it.

Cause. "The world was created. If the world has not been created for a purpose, it would not have been created. For to be created or to be caused means to be caused for some reason. If there were no reason for a thing coming into being, it could not come into being. 'Reason for being' is just another name for 'cause.' But 'reason for being' also means 'purpose.' Therefore, to be caused means to be purposed."

Objection may be raised that the assumption that the world was created is highly dubious. For, it is possible that the world always existed, that it had no beginning, that it has been eternally. Or, if it did not exist eternally then whatever caused it to exist either existed eternally or was caused by something which existed eternally, and so on. Thus, either the premise, "the world was created," is false, and thus the conclusion does not follow, or the difficulties which one seeks to avoid by postulating creation are simply pushed back to that which did the creating. If the latter be granted, that is, that the world was created, then was that which created the world itself created? If not, then it had no creator and thus no reason for being. Thus there would be an uncaused and unpurposed creator of the world. But if so, the creator of the world must, by the same argument, have been created for a purpose; and the creator of this creator either must have been created for a purpose or have existed eternally unpurposed. Thus purpose must have arisen somehow without purpose. And even if there were an endless series of creative purposes, one might still ask, "Was the series as a whole purposed?"

Definition of "cause" as meaning the same as "reason for being" begs a 
question which critics will not admit. Causes are "necessary and sufficient conditions," not "reasons." "Reason for being" is a loose popular expression developed in a background which was saturated with human purposiveness. Neither looseness and ambiguousness of popular usage nor questionbegging presupposition of purposiveness can be admitted as proof of world purposiveness. "To be caused" does not mean "to be purposed."

Autbority. Except for appeal to design, probably the most common argument is appeal to authority. Especially those who have tried to argue, and seem to themselves to fail, appeal to authority, which sometimes seems to be above argument. Authorities of many kinds are appealed to-eminent men, the Bible, the Church, Jesus, God. This type of argument may be illustrated by the appeal to the authority of God. "God, through revelation, has said that the world has a purpose, and what God says is so."

Critics are expected to cringe before this appeal to the authority of God himself, yet in fact they seldom do. They rebut as follows: Is there a God? One first has to prove that God exists before he can claim that God is an authority. One of the commonest arguments for the existence of God is the argument from world purposiveness: "The world has a purpose, therefore the world must have a purposer, namely, God." However, such an argument presupposes that the world has a purpose, whereas the present argument for world purposiveness presupposes the existence of God. Using both of these arguments would be to commit the fallacy of "reasoning in a circle." Thus, unless one can find some other proofs of God's existence or can get his critic to grant it, he will be unable to prove his case. But even granting that God exists, it does not follow that the world has a purpose, because God might have created the world accidentally, or have created the world as a result of mechanical necessity, or have created the world in the past for a purpose which he has now forgotten. Furthermore, still granting that God exists, does it follow that God is an authority? God might exist without being a person, or without being actively interested in the world (as Deists claim), or without being interested in acting authoritatively. However, granting both God's existence and authoritativeness, did God ever say that the world has a purpose? All alleged reports of God's speaking to persons in such a way that one might infer that the world has a purpose are dubious. Someone has questioned every one of them. Furthermore, all those who appeal, not to the writings of historical revelators, but to their own experience in communion with God and of his revelation directly to them that the world does have a purpose have been accused of self-hypnosis and self-deception. Also, evidence may be presented for God's nonauthoritativeness. For example, there are contradictions among contentions of different revelators and most revelators contradict themselves sooner or later. Such contradictions prove that God was not involved, because God is always consistent.

Self-contradiction by mechanists. "Those who claim that nothing has a 
purpose do so for a purpose, and thereby contradict themselves. The very laws of mechanics used as a basis for explaining the behavior of things nonpurposively were formulated by human minds for a purpose. Mechanists would be the first to discard those mechanical laws which were not suited to their purposes."

Mechanists reply that the claimed contradiction is only an apparent one, not a real one. For mechanists explain purpose in nonpurposive, or mechanical, terms. Purpose is a notion in a casually (non-purposively) detcrmined mind. Even if the mechanist seems to those who interpret things purposively to be acting purposively, he claims that such purposes are mechanically caused. Thus he involves no contradiction.

Proof by mechanists. "Since every normal person seems to himself at times to act for a purpose, everyone must admit that there are at least human purposes in the world. If, as mechanists claim, the world is uniform, then if there is purpose in part of it, why not also in all of it? Furthermore, since, for the mechanists, nothing can occur spontaneously but everything must have a cause that is capable of causing it, purposes which do exist must have been caused, and in order for them to have been caused there must have existed in the world other prior purposes capable of causing them. These prior purposes must have been caused by still earlier purposes, either backward infinitely or by some first or ultimate purpose. Thus mechanism really presupposes world purposiveness."

Mechanists may grant that personal purposes constitute a part of the world, but maintain that it does not follow that the whole world is made up of personal purposes nor that the world as a whole has a purpose. "Uniformity of nature" does not mean that everything is alike, but only that when a given set of causal conditions recurs there will result an exactly similar set of effects. Argument from parts to whole are unwarranted, as can be seen from the example of a worm in a partly rotten apple. If he is in the rotten part, it may seem all rotten. If he is in the good part, it may seem all good. If he is on the border between the two, it may seem either a good apple with a rotten part or a rotten apple with a good part. One might just as easily argue for non-purposiveness of the whole world on similar grounds, for everyone will admit also that some experiences seem lacking in purpose.

Unprovability of mechanism. "Since human knowledge is limited and since there is much about the universe that we can never know, mechanists can never prove conclusively that the world has no purpose. For even if it were provable that everything in the known universe is non-purposive, it still would not follow that the rest of the universe which we do not know is non-purposive. So long as complete mechanism is unprovable, it is reasonable to suppose that telcology is true."

Mechanists reply with almost exactly the same argument. "Since human knowledge is limited and there is a part of the world which we shall never 
know, even if it could be demonstrated that everything in the part of the world which we do know is purposive, it still would not follow either that the rest of the world is purposive or that the world as a whole has a purpose."

Universal agreement. "People of all times and places have believed that the world is purposive. Except for a few oddities, everyone believes that the world has a purpose. Can such a great majority be in error?"

Normal rejoinder is that popular agreement is no safe proof of truth of any belief. For thousands of years people agreed falsely that the earth is flat. Likewise all people naturally believe that color exists in things independently of persons who see it; yet scientists tell us that color as experienced is not really out there, even though naturally we must continue to act as if it were. Such illusion is convenient, useful, natural, and universal, but not for those reasons true. Popular consensus is indicative not so much of cosmic teleology as of anthropomorphic teleology. People believe that the world is purposive, not because the world as a whole has a purpose, but because people are purposive and tend to interpret other things as if they were like people. This accounts for universal agreement about world purposiveness at least as adequately as does the theory that the world as a whole has a purpose. Furthermore, who knows what the popular consensus is? No poll of opinion on this question has ever been taken. No one can say with certainty that everyone does believe that the world has a purpose, certainly not with regard to those of the past who can no longer be polled, nor those of the future not yet pollable.

Pragmatism. Many pragmatists define truth thus: "Those beliefs which work successfully, which are useful in adjusting ourselves to our environment or in solving our problems, are true. And those beliefs which work most successfully are most true." Teleologists who accept this pragmatic definition of truth say, "The belief that the world has a purpose works successfully and therefore is true. Furthermore, people who have faith in world purposiveness get along better and are happier than those who do not. Thus, it works more successfully and thus is more true."

"But," say mechanists, "such success of teleologists is due to the fact that they haven't yet tried to use their belief in areas where it won't work so successfully. Everyone has some ideas which work well for a while or in certain areas, but which have to be given up when used in wider areas or over a longer period of time. Teleologists are simply less-experienced than the mechanists." Using exactly the same definition of truth, some mechanists seek to "turn the tables" by saying that the belief in mechanism works better than the belief in teleology. Appeal is made to the comparative adequacies of the teleological and mechanistic hypotheses in promoting scientific progress. Mechanists claim that most science presupposes mechanism and the progress of science stands as testimony of the superior success of the mechanistic hypothesis. The history of scientific progress is a suc- 
cession of stories in which belief in mysterious purposes was given up for belief in the reign of natural law. Relative backwardness of the social and political science is accounted for because they deal with areas in which people are least willing to give up their illusions about cosmic teleology and accept the more useful mechanistic hypothesis. If the pragmatic test proves anything, they claim, it proves that mechanism is more true.,

\section{$\rightarrow \leftrightarrow \leftrightarrow$ \\ TO WHAT EXTENT IS A SCIENCE OF MAN POSSIBLE? *}

F R E DERICK OSBOR N

I

Knowledge of man has been growing slowly over thousands of years. But a science of man is something new under the sun. For though science is knowledge, it is a special kind of knowledge. It is obtained by scientific methods, usually involving a collaboration between theory and experiment. Most science is based on the quantitative analysis of measured phenomena. It differs from other knowledge chiefly in its quality of being demonstrable. An experiment to have scientific value must be one that can be repeated. Scientific phenomena can be measured and recorded over and over again or related by theory to other phenomena that can be repeated. New knowledge of this sort becomes generally accepted when it has been checked over by a sufficient number of people. The older type of knowledge which is derived from personal observations and the conclusions of authorities is harder to check up on, is more subject to personal bias and the mental fashions prevailing at any given time. Scientific knowledge, on the other hand, is cumulative in its effect and has a known predictive value.

In a hundred thousand years, by his use of the old forms of knowledge, man developed an environment suitable for a civilized life. He domesticated animals, produced cereal crops, and through the great religions aspired at least to a noble concept of the dignity and character of life.

Then, in a few brief generations, the new forms of knowledge which we call science brought to men a marvelous control of their environment -railroad, telegraph, telephone, electric light, motor car, submarine, aeroplane, radio, television, reduction of labor needed on the farm, canned and frozen foods, cheap goods by mass production, sanitation, medicine and public health. Almost over night the natural and physical sciences have brought these changes.

* Reprinted by permission of the Scientific Montbly, American Association for the Advancement of Science. Copyright 1939. 
The biological quality and the training of man has not undergone comparable changes. Except for medicine, we know so little about man that it is still fair to ask, "Can we have a science of man?" And the question is, somehow, troubling. Man's new power to control the environment has not made him humble. He seeks new short cuts to happiness. The older knowledge of man, heritage of ages of experience and suffering, he tends to discount, because it is not based on the new scientific method, not capable of scientific proof. He is not likely to go back permanently to the old knowledge. He is too impatient of its restraints, too admiring of the success of the new type of thinking based on the scientific method. Yet without more knowledge of himself, of his needs, his weaknesses and his possibilities, we may wonder whether man can safely handle the extraordinary tools he has recently created. They may inflict irreparable injuries. If we ask, "To what extent is a science of man possible?" perhaps we are really asking to what extent can we achieve a secure and permanent civilization?

It is hardly encouraging to compare the present state of the science of man with the marvelous development of the natural sciences. But the picture is a more hopeful one if we make allowance for the respective ages of these two fields of science. Several generations of men have been trained and taught in the physical sciences. But no one of the age of forty-five or more to-day could have had any serious training at college in the sciences that have to do with man. They were not available for teaching twentyfive years ago, which is a pretty brief span of time, even in this hurried age.

Scientific work in psychology was in its infancy at the turn of the century. Mendelian genetics were rediscovered in 1901. At about the same time anthropologists got out of their armchairs and began collecting ordered data in the field. By 1910 , text-books were beginning to make significant use of new scientific materials in these fields. By 1920, courses in scientific psychology, genetics, human biology and anthropology were available in most of our universities. To-day these subjects are among the most popular of any that are offered. But much that is taught about man and society is not science. Not enough research has been done to supply the basic material needed; and, still more important, there has been too little time for critical analysis, interpretation and organization of the research that has been already carried out. Notwithstanding this present handicap, the sciences of man have already begun to influence our thinking in a way which suggests the effect that they may have in the future when they are more fully developed. A few examples will make this clear.

11

Psychology has made important contributions to present-day points of view. There are some two thousand registered psychologists in the United States to-day, where they were only a few scattered individuals in 1900. 
The sum total of their research fills innumerable volumes. But much of this research has been badly done, as would be expected in so new and difficult a ficld.

There is still controversy among psychologists; part of this may be described as a controversy between older schools of psychologists and those trained during the last decade. Laymen who engage in controversy are often found to be leveling their lances against concepts and methods that have been completely discarded by critical contemporary psychologists. Much of this controversy relates to the roles of heredity and environment in the development of intelligence. Recent work goes far to clarify this difficult field. In the past few years, the so-called fixity of the I.Q. has been disproved. We know now that a stimulating environment in the home, in preschool, in elementary school, in high school, in college and in later life tend to raise the I.Q. of an individual, and to maintain it at a higher level. We know that in a depressed environment intelligence fails of a normal growth. On the other hand, there are important differences between individuals in the extent to which they respond to the stinulus of the same environment. Individual differences do not disappear when the environment is equalized at a high level. In a stinulating environment, able individuals show a capacity for response which takes them further than ever out of the class of those of average ability. Among Newman's i9 pairs of identical twins reared apart, there were I I pairs in which the two members of each pair had had similar amounts of education. In each such case the twins differed in I.Q. only about as much as the same individual would vary when tested at different times, the average of differences being 4.4 points. Among four of the pairs there was considerable difference in schooling between the members of each pair; their I.Q.'s differed on the average by ro points. Among the four remaining pairs, educational differences between the members of each pair were large, and in these four cases the twins differed by 19 points, on the average. In every case the twin with the more education had the higher I.Q. But at the same time where one twin was dull for his poor environment, the other was dull for his good environment, and where one twin responded well to his poor environment, his mate responded well to his good environment.

Twin Eleanore only got as far as the fifth grade, and attained an I.Q. of only 66. Her sister Georgiana went through grade school, high school, four years of music and three years of normal school. After all that education, her I.Q. was only 78 . It is hard to escape the conclusion that this pair of identical twins were not endowed with the genetic factors necessary to ordinary intelligence.

Twin Gladys, with only three years' elementary schooling as the total of her education, had the creditable I.Q. of 92. Her sister Helen, with a college degree, had an I.Q. of i 6 . Evidently the genetic endowment of these girls was sufficient for the development of average intelligence. 
The findings on identical twins reared apart check pretty well with other studies on the relative contributions of heredity and environment to individual differences in intelligence in the general run of our population. Of course, nineteen pairs collected by Newman and one by Muller is a number woefully inadequate for statistical validity, but this inadequacy is typical of the present state of the science of man.

\section{1 I}

In the field of genetics, the marvelous advances of the past forty years have been largely limited to the genetics of plants and animals. For some reason, human genetics has been largely neglected in this country compared to what has been done by Fisher, Haldane and Hogben, in England, and by Verschuer and others in Germany. There is almost no knowledge of genetic factors in normal variations in general qualities, such as intelligence, character or susceptibility to disease. Important work has been done on blood groups. A considerable number of infrequent abnormalities are known to be due to genetic factors, and in some cases the mode of inheritance is known. Research work on genetic factors in feeble-mindedness and in mental disease is almost all in the future. Nevertheless, there are many signs of an aroused interest in the medical profession and a new recognition of their responsibility for preventing the spread of serious hereditary defects.

Ultimately, scientific knowledge in regard to the part played by genetic factors in causing individual differences, and further research on the inheritance of different genetic factors, may make possible measures that would tend to discourage the reproduction of inferior genetic strains and encourage the reproduction of those above the average.

Thus, scientific knowledge of the relative parts played by heredity and by environment in developing individual differences may become a valuable tool for improving human qualities, first on the environmental side through changes in education and ultimately through raising the average hereditary level.

\section{V}

Anthropology has made at least one important contribution to the American point of view by showing the extent to which culture patterns are fixed by the social environment with little regard to the type of people involved. The whole concept of race has undergone a violent transformation in the past fifteen years. It is said that Hitler during the two years he spent in jail before coming to power read widely in what were then supposed to be scientific books dealing with race. They were not scientific in our present definition of the term: they were the German analogies of Madison Grant's "Decline of the Great Race," which was having a vogue in this country at that time. Modern research of a more scientific sort denies 
most of their conclusions. It is interesting to speculate on what would have been Hitler's attitude toward race if he had had access to present scientific knowledge.

These few and tentative conclusions are suggestive for the future, but they do not indicate to what extent the science of man may be possible. It is only very recently that we have really lifted age-long taboos against an honest examination of ourselves. In the past twenty years more of a start has been made than might reasonably have been expected under the circumstances. The prospect for the future seems hopeful. The extent to which we can have a science of man would seem almost unlimited provided three major conditions are met:

The first is plenty of time.

The second is the enrolment in this work of men of high abilities, with adequate support.

The third is freedom of thought, freedom of inquiry and freedom of criticism.

Research problems concerning man are, in many cases, no different in kind from research problems concerning other forms of mammals on which effective work has been done. But the problems of man are infinitely greater in complexity and require more time in proportion as the space between human generation is longer than the space between the generations of the smaller mammals. What Tryon learned about the genetics of maze-running ability in rats might be duplicated in human beings with regard to genetic factors in differences in general intelligence, but it would take 200 years and a quite inconceivable control of human breeding to carry out such an experiment. The difficulties of studying environmental influences are almost as great, but there is no reason to believe they can not be solved by sufficiently persistent effort and by the development and application of new methods.

There remains one important difference between the study of lower animals and the study of man, namely, that in the latter case man is studying himself and thus finds it more difficult to exclude his personal and emotional biases and reactions. It is for this reason, among others, that freedom of criticism is as important as freedom of thought in the development of the science of man. With all these difficulties taken into account, there is still every reason to believe that the development of the science of man will go forward rapidly from its present modest beginning.

V I

It is worth while to consider the different practical applications that may result from the sciences of man. The first has to do with education. Present methods of education are the product of a long evolution under the guid- 
ance of the old type of knowledge. On the whole, education to-day is undoubtedly better than the education available in the past. But we do not know in any precise way what a modern education really does or the different effect it has on different types of people. Psychologists in great number are working on new measures for determining individual capacities along different lines. Other psychologists are trying to determine the effect of different educational environments on people of different capacities. We may be sure that there is no single environment that would be the optimum environment for every one. Each individual will make his maximum development in the environment that will most stimulate the particular responses of which he is capable. The environment that would be optimum for a dull person would be insufficient for the full development of a superior person. In the studies on orphanage and pre-school children being made by Stoddard of the University of Iowa, the brightest children showed the least growth in the deprived environment of the orphanage. The Pennsylvania Inquiry on school and college education by the Carnegie Foundation indicates wide individual differences in ability to respond to a college education. A considerable proportion of those going to college go backwards rather than forward intellectually during their last four years of schooling. It is not too much to hope that work of this sort will develop a science of education such that ultimately we shall be able to measure the specific potentialities of each individual and provide an educational environment which would be the optimum for each of his particular abilities. Such a change in our educational system if universally applied would probably raise the average I.Q. almost 20 points. Few people would remain without some specific capacity which, properly developed, would make them more valuable members of society in their own recognized specialty.

V I I

To date, the most effective applications of a science of man have been in medicine, nutrition and public health. The expectation of life at birth is now double that prevailing a century and a half ago, and has been increased from 49.2 years in $1900-1902$ to 60.3 in 1929-1931. Medicine has a long start on psychology. It is not unreasonable to suppose that in another fifty years we may have a science of man which can prescribe the optimum environment not only for the maximum physical but also for the maximum intellectual and personality development of each individual. The application will not be easy. But when the knowledge is available, some way will be found to apply it.

The science of human genetics will ultimately supply psychologists with additional knowledge necessary for an understanding of different human types. But the major applications of the science of human genetics will be in the field of direct improvement of the genetic qualities of human stocks. That is far in the future. What a few men did in twenty years, working 
in Drosopbila, it may take several hundred men a hundred years or more to do working on man. Given sufficient time, and the development of new tools of research which will surely take place, a fairly complete genetics of man is possible. Whether its practical applications will be important, I leave to you to decide. Does your experience in plant and animal genetics lead you to think that the average man's socially valuable qualities in our changing environment could be improved by creating conditions in which superior strains have the larger families and in which the breeding of inferior strains is effectively discouraged?

\section{I I I}

We have been considering only the sciences relating to individual differences and individual development, and the contributions which these sciences may make to the improvement of human beings. But the study of man can not proceed independently of his environment and his activities, which are the field of the so-called social sciences. Nor can the social sciences proceed successfully without more knowledge of this strange and complicated creature, man. The development of the science of man should therefore have another important effect in the contribution it will make to the sciences which deal with the behavior of men in the mass and their relations to each other.

All branches of sociology are at present handicapped by lack of knowledge of the human material whose activities they are studying. The postulate of the economic man, impervious to all other emotions, does not add to the reality of economics. Perhaps the new field of population study provides the best example of the interdependence of studies of man and studies of man's activities. Here the analysis and forecasting of total population trends has been revolutionized since 1925 by the introduction of procedures for taking changes in age and sex composition accurately into account. It is safe to say that the error in population forecasts for the United States for the next thirty years has been cut in half by the application of these techniques, and equally important information about future age distribution has been added, which was wholly lacking before.

The study of the adjustment of the population to resources in different parts of the nation, which had never been given serious attention before 1930, has been developed to the point where its results already have very practical and far-reaching significance. The study of differential reproduction rates, which prior to 1930 had been based chiefly on such fragmentary and inaccurate data as reports by college students about the numbers of children in their fathers' families, has been extended and refined until it is possible to describe the reproductive tendencies of most population groups in the United States with considerable accuracy, and we are now beginning to get accurate information on how these rates are changing in different groups under different conditions. 
But these so-called group differentials in fertility relate only to occupational groups or to regional groups. We know that farmers have more children than city people, but we do not know what genetic types are surviving in the greatest numbers. It is impossible to say at present on the basis of any scientific evidence whether the human race is improving or whether it is deteriorating. This important question, with all its practical implications, can be answered only when population study can employ measures of innate human qualities, and for these it must wait on the development of the sciences of man.

Thus, the science of man may not only make it possible to improve man himself by supplying the proper environment for his development and, ultimately, even by an improvement in his genetic potentialities, but may give the social sciences sufficient precision to make them truly sciences capable of predicting the end results of current political, social and economic trends.

The sciences of man may in these ways make an invaluable contribution to human welfare. They may also make an even greater contribution in setting up new concepts of human possibilities, new ideals as to the purpose of life.

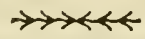

\section{SCIENCE VERSUS LIFE *}

\section{A. J . CAR L S O N}

When the hurricane strikes ships at sea, frail hulls founder, while the crews of sturdier craft experience anxiety, if not panic, and are for a time deflected from their course by the temporary violence of wind and waves. But they ultimately make their goal, thanks to human courage, the compass, and the fixed stars. Such hurricanes, man made, have struck human society, and its institutions, from time to time throughout recorded history. We call them war. There is anxiety and fear, if not panic, on board. When storm clouds cover the heavens men of little understanding question the compass of science, fear that the stars of rectitude will guide no more, and with scant hope drift with the violent wind. The compass of science is not only questioned, but it is charged that this very compass has led us into the hurricane, that science is in conflict with society. So I propose to address myself to these questions: Is our age led or dominated by science? Is science in conflict with the best interest of society? Is it science and the scientific method that lead nations into war? Only last year a British scholar said: "In Europe today it is rather dangerous to ask questions, it is much safer to discuss how a question should be asked." Today this danger is by no means confined to Europe. But as I read the human record

\footnotetext{
* Reprinted by permission of the Sigma Xi Quarterly. Copyright r94r.
} 
in mud, and rocks, and ancient ruins, on tablets of clay, in scratches on stones, papyrus, and paper, I think I discern evidence of the ascent of man, through asking all kinds of questions at all times, and seeking the answers by the best methods of the age. If we do less, we admit that science and civilization is a blind alley in human evolution.

Is outrs the Age of Science? Or rather, in what sense is ours the Age of Science? An eminent physicist said, in this very city (Philadelphia): "In no previous time in human history has life and thinking been so greatly influenced by science as it is today." This is undoubtedly true, but does that alone make ours the Age of Science? I think not. Those who, accusingly or proudly, describe our times as the Age of Science usually cite as evidence the modern aspect of man's inhumanity to man, or the numerous practical applications of the discoveries in physics, chemistry, geology, biology, and medicine during the last hundred years, such as the steam and gas engine, the telegraph, the telephone, the airplane, the radio, modern surgery, fair control of infectious disease, modern sanitation, and many other inventions and measures that contribute to the convenience, the efficiency, the health, the comfort, and the happiness of modern life. It is true that science has, during the last hundred years, increased enormously our understanding of the nature of the world and the nature of man, and with that greater understanding has come greater control of the forces that act in man and in his environment. But fundamental discoveries in science are the achievement of but a few people. The practical inventions based on these discoveries are also the work of a few men, speaking relatively. And the physical and chemical inventions are mostly gadgets that merely modify our tempo and external mode of living. I contend, and I think I wili be able to prove to you, that the great mass of the people of our age, the rank and file of men and women of our day, even in the most enlightened countries, in their thinking and in their motivation are nearly as untouched by the spirit of science and as innocent of the understanding of science as was the "Peking Man" of a million years ago. The modern man adjusts to an environment greatly modified by the scientific efforts of the few. The "Peking Man," we may assume, adjusted himself as best he could to nature in the raw. A span of about a million years separates the two. And yet the two are about equally innocent of science, in the sense of the spirit and the method of science as part of their way of life. For science is more than inventions, more than gadgets, however useful and important they be. Science is even more than the discovery of and correlation of new facts, new laws of nature. The greatest thing in science is the scientific method, controlled and rechecked observations and experiments, objectively recorded with absolute honesty and without fear or favor. Science in this sense has as yet scarcely touched the common man, or his leaders.

The character of human society in any age is determined by man's thinking, motivation, and behavior rather than by external gadgets. The er- 
roneous assumption that ours is the Age of Science, or the very limited sense in which this is true, has led many people to charge to science some of the follies and failures, some of the violence, the brutalities, the suffering, the confusion throughout the world in recent years. Some of these people tell us that "science has failed," that we should declare "a moratorium on science." People who talk thus, who advise thus, cannot understand either the spirit or the method of science. We cannot afford to declare a moratorium on honesty, on integrity, on objectivity, on experimentation, for that would take us straight back to the jungle. The way of science is away from the jungle, away from its violence and fears. If the way of science at times, such as the present, seems obscure and even dangerous that is due to too little, not too much, understanding of the nature of man and our universe, and to the further fact that we do not or are not permitted to follow the light of reason based on facts.

If our age is "The Age of Science," our rulers, our legislators, our businessmen, our educators, our farmers, our factory workers should give evidence of comprehending, using, and following the scientific method. In a recent book the Dean of Canterbury writes: "Our social and economic order is neither scientific nor Christian. When I read, as a headline in the Observer that Poland's good harvest was a severe blow to recovery, I recalled the words of an American professor of agriculture after seeing ten million acres of cotton ploughed under and five million pigs slaughtered: 'If this will bring national prosperity, then I have wasted my life.' The thing is monstrous, an age when science is frustrated." In the broader field of human relations, what do we see on the horizon: Conspicuous, certainly, are: greed, force, faith, and war. These are certainly more conspicuous than the ways of reason based on scientific understanding. In the last analysis, war is murder and stealing on the part of somebody. War is the extension of the practices of the jungle into modern life. The technique of modern warfare is modified by scientific discoveries, but the elements that make for war are certainly not scientific. Hence the persistence of war cannot be laid at the door of science. It is due rather to the failure of science and conscience to as yet essentially modify human conduct. For we must assume that sooner or later reason based on understanding will modify human behavior. Even animals with no cerebrum can be conditioned.

The scientific method demands that we suspend judgment until we know the facts. It demands honesty, integrity and industry in ascertaining the facts. The scientific method and dishonesty are incompatible. But scientists are but human beings, and they frequently make mistakes both in facts and interpretations. Now, is our age conspicuous for honesty and integrity? Is there less lying and deceit locally, nationally, internationally, today than yesterday? The answer is all about us. Modern propaganda, and a good deal in modern advertising, have the earmarks of lying as a fine art, rather than the character of honesty, objectivity, truthfulness, and accuracy of 
science. It is, biologically, evident that we shall have to live with greed for some time to come. But the more serious question is: can buman society survive without individual, social, and national guile? If the answer is "No," we probably have here the most fundamental conflict between the scientific method and society.

Science, in spirit and method, knows no political aspects or national boundaries. Individuals of all races and nations have contributed to our present understanding of the nature of man and of the world. There is no Democratic logic, Republican mathematics, Nazi physics, Fascist chemistry, or Marxian biology. The spirit and the method of science cannot change with capitalism or socialism. This appears to me axiomatic. But fanaticism in society and governments can temporarily retard discovery and further advance in the understanding and control of life and nature. And yet we hear claims from the Germany of today of a special Teutonic or Nazi physics, claims from Russia of something called Marxian genetics, whatever that is. These stupidities characterize our age, but they are not the characteristics of science.

If even our so-called educated fellow citizens were scientific their conduct would be more influenced by proven facts than by wishful thinking. If there is anything that has been proved to the hilt in biology and medicine during the last hundred years, it is the effectiveness of vaccination against smallpox. There are no "ifs and ands" about it. It is one hundred percent. effective and practically one hundred percent. safe. Of course, wherever human hands, human agencies, are involved accidents will happen sometimes. Despite all these facts, men and women in this and other civilized countries neglect and oppose vaccination against smallpox. We have large groups of people organized into "anti-vaccination societies." And these are not all ignorant people. Some are college graduates. If these people walked in the way of science, they would accept and be guided by proven facts.

The exact biologic relations of man to other animals are still, in part, a matter of theory. Animal evolution is probably now going on, but so slowly that we usually fail to discern it. But the essential identity of the structure and function of tissues and organs in man and animals is not a theory. It is a proven fact. The heart, the liver, the stomach, the lungs, the blood, the eyes, the ears, and even the brain are made up of the same stuff and subjected to much the same diseases, wear and tear and ageing in man and animals. It is also true that practically ninety percent. of the understanding gained in the last hundred years of preserving health and controlling disease has been secured through experiments on animals. And yet people, even in civilized countries, oppose experiments on animals as futile and cruel, as of no benefit to man. These people are not all ignorant. But they surely are not scientific. They do not accept, they are not guided by, proven facts. Their thinking and motivation have not been touched by 
the spirit and the method of science. Moreover, the majority of people in some of our states, through their legislatures, pass "anti-evolution" laws, as if the course of events of the past could be altered by legislative dicta of today.

It is still a common practice of man, so-called civilized man, to follow post boc reasoning; that is, because one event may sometimes follow another, the two events are, therefore, necessarily causally related. Mankind as a whole, and even leaders in business, industry, and government, do not yet thoroughly understand or follow the principle of control, the principle of experiment. Post hoc reasoning is one of the commonest sins against the scientific method, and we still see it occasionally in those who have been trained in science; for example, modern physicians. As an example of post hoc reasoning in medicine, I can cite the case of a physician who had practiced medicine honestly, if not intelligently, in a far western state for forty years. A number of years ago he told me in all seriousness that he had discovered a specific remedy for influenza. I was naturally curious, because influenza is one of the maladies which has so far largely defied modern scientific control. On being asked what his remedy was, he replied, "Good whiskey and plenty of it." The doctor was apparently perfectly sincere about it. When I asked him how many influenza patients he had treated without whiskey and how many of these recovered, he looked at me in surprise and said: "You understand, I have treated every one of my influenza patients with whiskey during the last forty years, and I have had a high percentage of recovery." This physician, though stupid, was too honest and venerable to poke fun at. I was tempted to ask him how many recoveries from influenza he thought he would have had if he had ordered his patients to read Mary Baker Eddy's Science and Health at an angle of 45 degrees, practice Coueism, or have their spines or toes twisted according to the chiropractor's cult. Another example is that of another honest physician in a southern state using a remedy whose virtue, if any, was essentially twenty percent. alcohol, a so-called female tonic, a southern counterpart of Lydia Pinkham's well-known vegetable compound. The case was that of a young girl working twelve hours a day in a factory in a southern city at low pay. She lived in a garret room, with poor food, and poor sanitation. She had a high degree of anemia. The doctor wrote: "I took this girl out of the factory, sent her to the country for three months with relatives and gave her this female tonic. After three months she had nearly recovered from her anemia, thanks to this tonic." It is not surprising that even physicians fall into this error of reasoning, because in the not distant past medical education was only partly scientific.

To what extent or in what sense is science in conflict with society? I think there is much confusion, misunderstanding, and unwarranted generalization on this point. Not so many years ago the American Association for the Advancement of Science declared, by resolution: "Science is wholly 
independent of national boundaries, and races, and creeds and can flourish only where there is peace and intellectual freedom." This position is clearly in conflict with the cyclical psychosis exhibited by Homo sapiens, in mass, throughout the ages. But whether there is a conflict of science with the primary interest and ultimate well-being of society is at least an open question. Only last year an outstanding physicist declared: "Science makes man human." I presume our colleague meant that science tends, or should tend, to make man more human. The possible conflict between science and society in this statement obviously depends on our conception of what are the desirable human qualities, or behaviors, today and tomorrow. If deceit, violence, and war are essential for survival and progress there is a conflict between science and society, for deceit, violence, and war are the very antithesis of the scientific method. Two years ago a colleague uttered the following dictum: "Here on this continent where science has achieved its greatest application, science is in conflict with society. Science and technology have gone so far that the present social structure is facing its debacle. Nowhere else in the world today is science in such militant conflict with the social structure under which science survives." The same author also speaks of the "prostitution of science for war." We have here, clearly, a confusion of science and the scientific method with the uses, largely by a non-scientific society, of the understandings and the gadgets developed by the methods and the applications of science, for satisfactions of the ancient use of the hand, the teeth, the rock, the stick, and the club in similar drives by our primitive ancestors.

The services of science to society are, primarily, increased knowledge, understanding, freedom, and power. That such increased knowledge, understanding, and control of the forces of nature are used, not by scientists, but by society, with increasing effectiveness in the continuous and recurrent drives to satisfy greed, lust, hate, and vanity, will, in my judgment, ultimately prove to be due, not to the inherent nature of the scientific method or of knowledge per se, but to the failure of man, so far, to be effectively conditioned by science and the scientific method.

It is sometimes asserted that science is amoral if not immoral. The latter may be true, if it is immoral to challenge and destroy taboos and traditions based on ignorance and misunderstanding. But to call the impartial, industrious, and earnest search for new knowledge amoral or immoral conflicts with my conception of immorality. As I understand it, there is no conflict between the scientific method and our sense of justice, though I admit that the latter stems from a much broader base than science. Individual scientists may at times, in their ivory towers, express distrust of society or the common man, as disclosed by the following recent statement from an eminent surgeon: "Whether the public interest (in medical research) is something deeper than curiosity, and whether it can be relied on as a potent factor for the common good have not been demonstrated. 
Indeed a study of the historical background of surgery invokes in the mind of the medical scientist a distrust of the public." The doctor cites among other examples, the Edict of Tours ( $116_{5}$ ) declaring surgery not respectable. But that Edict was not the work of the common man. It was a product of the leaders of the Church.

On the other hand, the defeatists among us, noting the conspicuous, though superficial, rôle of science in modern life, occasionally see in science and the scientific method the very root of some of our modern ills. Thus the leaders of a little college on our Atlantic seaboard have boldly undertaken to rectify a Harvard University educational failure, by providing "conditions for liberalizing and humanizing science." And this the college hopes to achieve by the "strategy of taking specialists in the sciences and re-educating them in the liberal arts." We are not told what to do for, or do with, the people who were "educated in the liberal arts" before they became specialists in science. Maybe these unfortunates are acephalic satraps of Satan, or just dead and do not know it. I think among the "persons who can produce fine things" are the men of science, and among "the fine things" are new facts about man in health and in disease, new facts about the universe, new facts about the nature of life and matter, new understanding and new powers of control of the forces of nature.

Many world events in recent years have made some assert that worthwhile human society cannot persist or prevail without the perennial supremacy of deceit and greed, violence and war. Others question whether these very antitheses of the scientific method can persist side by side with science and the necessary human qualities that go with the method of science. Deceit, violence, and war have certainly been with us before the dawn of history as a part of the "struggle for existence," while science and the scientific method are of a much more recent vintage. It is also true that the "struggle for existence" in smaller groups such as the family, the tribe, or the nation ultimately curbed, at least in part, both deceit and greed, violence and war. Can such curbing be achieved on a larger scale or is it desirable that such curbing of man's past drives be achieved in the interest of the future welfare and progress of man? So far as I can see there is only one answer to this question, and that answer is given both by history and by the primary interest of society. To refer again to the resolution of the American Association for the Advancement of Science: "Science can flourish only where there is peace and intellectual freedom." Are intellectual freedom and peace the desiderata for man? If this is so, there is no fundamental conflict between science and society, as I view society of the future.

The evident failure of modern science measurably to influence human drives and conduct, individually, nationally, internationally, are probably to be sought in three factors: ( 1 ) the character of our prevailing education. Our prevailing education, starting in the home and in the church, in the grade school and the high school, and extending into the college is 
largely education by dictation. It is indoctrination rather than education by understanding the why and wherefore through experimentation. This applies to countries other than our own. There are those in our own country who insist all along the line on education by more and more dictation and indoctrination. Mcrely the memory of and the ability to repeat a heterogeneous number of facts, or even coordinated facts discovered by science, is not education in the method of science. We can teach a parrot to talk Latin and repeat a syllogism, but that Latin-speaking bird is still a parrot.

(2) Considerable responsibility for the failure of science essentially to modify human conduct must be laid to the scientists themselves. Many of us are scientists only during our working hours, and fall into the common errors of the average man when we step outside our own specific field. Many of us have considerable fog in our brains and clay in our feet, and this is discerned by leaders in other human endeavors, and by the man in the street. Scientists frequently become dogmatic both inside and outside of their own fields, and it may therefore legitimately be asked: if the very high-priests of science thus fail to be influenced by the spirit and method of science, what hope can there be for the rank and file?

(3) The third factor is the tremendous resistance of man to new ways of thinking and new ways of life. During the past million years that man has evolved under the influence of the non-scientific or raw environment, he has developed emotions and habits and drives that are not easily, speedily, or permanently modified by the environments and techniques developed by man himself through science. There is no use crying over this situation. It is one of the recognized scientific facts, and we must accordingly work toward the goal with longer vision and greater tolerance and patience. Science as an educational and social force is but of yesterday. Man has been exposed for ages to the fundamental ethics of the great religions, using the elements of fear, punishment, and perpetual reward as motives, something that science cannot do. And yet the effects of this exposure seem neither significant nor lasting.

From all the evidence now available it seems clear that in the past greed, guile, and violence had survival value for primitive man. Assuming that these drives can be curbed on a national and international scale by the new mores based on understanding, reason, and emerging justice, will the latter have equal survival value in and for the kind of society we hope to build? My answer is yes, with this proviso: I think we must apply new and different measures to reduce the number of the antisocial, the less fit. We have enough information to make a beginning in that direction now, but prevalent mores prevent it. Unless reason based on understanding effectively guides social evolution of tomorrow in the direction of elimination or reduction in the number of the less fit, those who cannot or will not strive for the individual and the common good, I see no escape from the de- 
generation that seems to follow biological parasitism, except the ancient law of tooth and claw.

Now, I shall try to say in one minute what I probably failed to make clear in fifty. As I see it, ours is not an age of science. Man is still driven by greed and confused by guile, rather than guided by reason and justice based on our expanding knowledge. Science has greatly enlarged man's understanding, conquered many of his diseases, lengthened his life, multiplied his joys, decreased his fears, and added much to his physical comforts and powers. But man may use these and other achievements for a greater social injury, instead of for a further social advance. Science is specifically human, in that it stems from the innate curiosity of all men, and the conspicuously plastic brains of the ablest, if not the noblest, of our fellows. If this be so, it follows that the scientific method and its products cannot be, in any fundamental and permanent sense, in conflict with human nature, though our present human society, product of a past dominated by greed, force, and fear, may be, and is in conflict with the scientific method. Whether science and the scientific method, whether understanding, honesty, reason, and justice can contrive survival values equal, if not superior to the blind forces of nature which shaped man's past, is as yet in the laps of the gods. Still, we cannot deny the possibility, and we will nurse the hope, that the hairy ape who somehow lost his tail, grew a brain worth having, built speech and song out of a hiss and a roar, and stepped out of the cave to explore and master the universe, may some day conquer his own irrational and myopic behavior towards his kin.

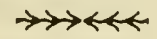

\section{THE BIOLOGIST LOOKS AT MAN *}

\section{J U L I A N . H U X L E Y}

The Western world today is caught in an apparent dilemma between two conflicting modes of thought. The one thinks in terms of absolutesthe absoluteness of truth, beauty, justice, goodness, themselves all deriving from an Absolute of absolutes, which is God. The natural world is complemented by the supernatural, the body by the soul, the temporal by the eternal. This view gives an essentially static world picture; the flux of events is merely change, in which the only progress is a spiritual one, toward the perfection of eternal values. Empiricism and the experimental method are alien to it; the absolute of Revelation and the absolute of pure Reason will between them answer all the questions that can be answered. Man's place in the universe is the place of an eternal soul, created by God, and working out its destiny in terms of eternal values.

* Reprinted from Living In a Revolution by Julian S. Huxley with the permission of Harper and Brothers. Copyright 1942, by Julian S. Huxley. 
The other is the scientific method. It subjects the conclusions of reason to the arbitrament of hard fact to build an increasing body of tested knowlcdge. It refuses to ask questions that cannot be answered, and rejects such answers as cannot be provided except by Revelation. It discovers the relatedness of all things in the universe- of the motion of the moon to the influence of earth and sun, of the nature of the organism to its environment, of human civilization to the conditions under which it is made. The supernatural is in part the region of the natural that has not yet been understood, in part an invention of human fantasy, in part the unknowable. Body and soul are not separate entities, but two aspects of one organization, and Man is that portion of the universal world stuff that has evolved until it is capable of rational and purposeful values. His place in the universe is to continue that evolution and to realize those values.

These two ways of approaching and thinking about the universe are irreconcilable--as irreconcilable as is magic with scientific agriculture, witch doctoring with preventive medicine, or number mysticism with higher mathematics. Because our thinking still contains elements from both, it and we are confused.

To me, this mixing of two totally different kinds of thinking can only lead to confusion. When men assert that the scientific approach is incomplete, it is because they have not been willing to follow it to its final conclusion, or because they are mistaking an early stage in its growth for full development.

Science inevitably began by trying its hand on the simpler phenomena of nature. Its first triumphs were in mechanics, including the spectacular celestial mechanics of Newton. It next proceeded to simple physics, like the gas laws or the decomposition of white light. Chemistry, even elementary chemistry, did not take real shape till a century later. The life sciences developed later than those of lifeless matter, for the sufficing reason that they deal with more complex phenomena. Physiology had to wait on physics and chemistry before it could become scientific. The central fact of biology, evolution, was not established until modern science had been in existence for over two hundred years; the mysteries of heredity did not become clear until well on in the present century. In the same way the science of mind developed later than biological science.

Scientific method today has reached about as far in its understanding of human mind as it had in the understanding of electricity by the time of Galvan and Ampère. The Faradays and Clerk Maxwells of psychology are still to come; new tools of investigation, we can be sure, are still to be discovered before we can penetrate much further, just as the invention of the telescope and calculus were necessary precursors of Newton's great generalizations in mechanics.

However, even with the progress that science has already made, it is possible to give a reasonably coherent world picture based on the scientific 
approach; and this contains elements of the greatest importance to our philosophy and to our practical outlook. One is that the universe is not dualistic but monistic; another is the incorporation of values within the scientific picture, and a reconciliation of their absoluteness in principle with their relativity in practice; a third is the real existence of progress in evolution; a fourth is the complete and sole responsibility of man for achieving any further progress that may be made on this planet, and the falsity of all his attempts to shift any of the burden of his responsibilities onto the shoulders of outside powers; and a fifth is the establishment of the developed human personality as the highest product of the universe (or at least the highest product of which we have any knowledge), with all the implications of this fact for our social and political philosophy.

\section{DAR WIN IS VINDICATED}

Let me take these points one by one, to show their interconnection. The way of advance for truth is in general the same as the way of advance for existing life: of two alternatives, one dies out, not because the other destroys it directly, but because it is less fitted to survive. Even after Copernicus, the doctrine that the sun goes round the earth could still be logically maintained. But it demanded enormous complexity of epicycle upon epicycle. The rival theory that the earth goes round the sun was far simpler and more satisfying; in the climate provided by developing civilization it survived, the other simply died out of human thinking.

The monistic, unitary view of the universe will survive for the same kind of reason. Our scientific knowledge now permits us to assert definitely that there is no break in the continuity of phenomena. All matter, living or lifeless, is composed of the same units-all the millions of different lifeless substances, as well as of living species, are made of different combinations of still more elementary particles (or "Wavicles"). In reproduction, there is no moment at which life enters; there is continuity of life between the offspring and its parent or parents. The offspring is merely a detached portion of the parental living substance. Nowhere in the transformation of microscopic ovum to adult human being is there a break at which one can say "here mind appears," or "there personality enters"; development is continuous.

It is the same with the vast process of organic evolution. Here too gradualness and continuity reign; there is no moment at which we can say that reptile ends or bird begins, no definite demarcation between man and notman, no sharp line at which we must or indeed could postulate the sudden injection of thought or soul into evolving life. The ideas of evolution by brusque mutations of large extent have disappeared: with the new knowledge of the last twenty years the overwhelming consensus of biology has returned to support Darwin's original view of the extreme gradualness of all evolutionary change. 


\section{THE QUICK AND THE DEAD}

What then becomes of the apparent dualism between matter and spirit? Many philosophers persist in affirming that the only alternative is materialism, according to which mind is "a function of the body (matter), and depends upon it completely." This is an easy thesis to demolish; and having demolished it, they can conclude that the dualistic alternative is true. The real alternative to dualism they have conveniently omitted to mention.

The only logical alternative to dualism is monism-that matter and mind are two aspects of one reality, that there exists one world stuff, which reveals material or mental properties according to the point of view. Looked at from the outside, the world stuff has nothing but material properties; its operations appear as mind only to itself, from within.* The first objection to this, that we have experience of the minds of other people, disappears when we remember that this experience is not direct, as is the experience of our own psychic processes, but indirect, deduced from other people's behavior (including expression and verbal behavior), combined with our knowledge of our own minds. The second objection, that a dead man still has the same body as a live one, and therefore differs by the loss of a living soul, is still more easily disposed of. A dead body is not the same as a living body: the chemical conditions in it-for instance the presence of enough oxygen for the functioning of the tissues-are different. If you substitute oil for acid in the battery of your automobile, no current will pass.

But if the world stuff is both matter and mind in one; if there is no break in continuity between the thinking, feeling adult human being and the inert ovum from which he developed; no break in continuity between man and his remote pre-amoebic ancestor; no break in continuity between life and not-life-why then mind or something of the same nature as mind must exist throughout the entire universe. This is, I believe, the truth. We may never be able to prove it, but it is the most economical hypothesis: it fits the facts much more simply than does any dualistic theory, whether a universal dualism or one that assumes that mind is suddenly introduced into existing matter at a certain stage, and very much more simply than one-sided idealism (in the metaphysical sense) or one-sided materialism.

\section{THE SIG NIFICANT ELECTRIC EEL}

The notion that there is something of the same nature as human mind in lifeless matter at first sight appears incredible or ridiculous. Let us, however, illustrate its possibility by considering certain well-established biological facts concerning electricity. Apart from lightning, the only powerful electric phenomena known before the late eighteenth century were the electric shocks produced by the electric eel, the electric ray, and one

* Mind is used here broadly, to denote all psychical activity and experience, conscious or subconscious, sensory, emotional, cognitive and conative.-Ed. 
or two other kinds of fish. The production of electricity by life might justly have appeared as something rare and sporadic. However, as physiology progressed, it was found that electric currents pass when a nerve is stimulated, when a muscle contracts, when a gland secretes; in fact we know that all vital activities, of whatever kind, from conscious thought to the fertilization of the egg, are accompanied by some electrical activity.

In the electric eel, certain muscles have been modified so that though they have lost their original function of contraction, their electric discharges are accumulated as in a galvanic pile, and the total voltage and current are quite respectable. Whereas in the great majority of cases the electrical properties of living matter play no special part in the life of the animal, they have become the specific function of the eel's electric organs: an accident of nature has become biologically significant.

One may suggest that the same sort of thing has happened with mind. All the activities of the world stuff are accompanied by mental as well as by material happenings; in most cases, however, the mental happenings are at such a low level of intensity that we cannot detect them; we may perhaps call them "psychoid" happenings, to emphasize their difference in intensity and quality from our own psychical or mental activities. In those organs that we call brains, however, the psychoid activities are, in some way, made to reinforce each other until, as is clearly the case in higher animals, they reach a high level of intensity; and they are the dominant and specific function of the brain of man.

In evolution, science has not merely revealed the bridge that provides continuity between man and lifeless matter, but has also discovered what is perhaps the most important single biological fact yet known-the fact of evolutionary progress. A great deal of evolution is mere diversification. New species constantly arise, adapted to slightly different conditions, or produced by the biological accidents of isolation or hybridization. Through this frill of diversity, however, there can be perceived a series of longrange trends, whose course runs for millions or tens of millions of years. The great majority of these trends are specializations. They fit the existing type more closely to one mode of life, and in so doing cut it off from success in others. In the evolution of higher mammals, for instance, one line specialized as predators, and became the carnivores; another specialized in chewing and digesting foliage and herbage, and usually in swift running, to become the ungulates; a third in flying - the bats; a fourth in marine life -the whales and porpoises; and so on. It is a universal rule that one-sided specializations eventually come to a dead end. There is a point beyond which natural selection cannot push them. When a specialization has reached its biomechanical limit, it remains unchanged-unless new competition causes it to become extinct. Thus most mammals have not evolved in any impurtant way for ten or twenty million years, birds not for twenty or twenty-five million, ants not for thirty million. 


\section{EVOLUTION OF PERSONALITY}

To assert that man is the highest product of evolution to date is a statement of simple biological fact. There are, however, some other points concerning man's position relative to evolutionary progress that are less obvious. First is the curious fact that the human species is now the sole repository of any possible future progress for life. When multicellular animals first appeared, they all had reached a new level of progress: later, some cut themselves off from further advance by entering on blind alleys, such as the fixed, vegetative existence of the polyps and corals or the headlessness and radial symmetry of the starfish and other echinoderms. The process of restriction has now gone so far that all future progress hangs on human germ plasm. It is a biological impossibility for any other line of life to progress into a new dominant type-not the ant, the rat, nor the ape.

Second, with the evolution of man, the character of progress becomes altered. With human consciousness, values and ideals appeared on earth for the first time. The criteria of further progress must include the degree to which those ideal values are satisfied. The quest for truth and knowledge, virtue, beauty and aesthetic expression, and its satisfaction through the channels of science and philosophy, mysticism and morality, literature and the arts, becomes one of the modes or avenues of evolutionary progress.

It is also important to note that biological progress demands no special agency. In other words, it does not require the intervention of a conscious Divine purpose, nor the operation of some mysterious life force or élan vital: like most other facts of evolution, it is the automatic result of the blind forces of reproduction, variation, and differential survival. Newton's great generalization of gravitational attraction made it possible and indeed necessary to dispense with the idea of God guiding the stars in their courses; Darwin's equally great generalization of natural selection made it possible and necessary to dispense with the idea of God guiding the evolutionary courses of life. Finally the generalizations of modern psychology and comparative religion make it possible, and necessary, to dispense with the idea of God guiding the evolutionary courses of the human species, through inspiration or other form of supernatural direction.

\section{REPRESSION IS NORMAL}

A corollary of the facts of evolutionary progress is that man must not attempt to put off any of his burden of responsibility onto the shoulders of outside powers, whether these be conceived as magic or necessity, as life force or as God. Man stands alone as the agent of his fate and the trustee of progress for life. To accept his responsibility consciously is itself an important step toward more rapid progress. Here is a field where a philosophy based on the scientific outlook is of the utmost practical importance.

But the problem that most perplexes our present age remains the ques- 
tion of moral certitude. As Dean Sperry says, it is the loss of the "ethical universals," with which Christianity has equipped Western civilization, that creates the "grave moral perplexities" of the present. This is where modern psychology enters the picture. For a justification of our moral code we no longer have to have recourse to theological revelation, or to a metaphysical Absolute; Freud in combination with Darwin suffice to give us our philosophic vision. The great contribution of Freud was the discovery of the unconscious mind. What matter if logicians assert that the phrase is a contradiction in terms? It is now firmly established that through the process known as repression, desires and ideas, emotions and purposes, can be forced out of consciousness, or at least out of contact with the main organization of consciousness that we call the self or ego. They are then "in the unconscious," but in the unconscious they continue operating just as if they were ordinary processes of the mind, and they are still able to influence the conscious life of the ego in the most varied ways.

Repression is the banishment from consciousness of desires and ideas that produce otherwise intolerable conflict. It is a special form of what psychologists and neurologists call inhibition. The repressed ideas are so intolerable that consciousness will not even recognize their existence or examine them rationally; yet they are so powerful that they distort consciousness itself.

It has not, I think, been sufficiently recognized that repression is normal in man. Man is the only organism whose mind is so constructed that conflict is inevitable. The young child is subjected to powerful conflicts even before it can talk and reason, and long before it has adequate experience to resolve a conflict rationally. Repression is thus an adaptation to conflict, especially to early conflict; in its absence, the degree of assurance necessary for action and adjustment would be impossible.

Undoubtedly the picture of human psychology given by psychoanalysts and other modern dynamic theories is crude and incomplete, but equally undoubtedly it is a first approximation to the truth.

Its importance for philosophy, and especially for ethics, is enormous, for it enables us to understand how ethical and other values can be absolute in principle while remaining obstinately relative in practice; and in conjunction with our knowledge of evolution, it enables us to reconcile absolutism and relativism by uniting them in the concept of right direction.

THE ETH I CA L C ONFLICT

When, however, we come to practice, we find ourselves plunged back into the confusion of the relative. For instance what will be the right way of treating Germany? The absolute principle of justice makes us feel the demand that crime should be punished. But, applied to the Germans, does this mean punishing Hitler, the Nazi leaders, all those directly guilty of cruelty and injustice, or the whole German people? Furthermore, the ab- 
solute principle of justice conflicts with the equally absolute principles of mercy and love. And finally these absolute emotional principles come in conflict with the frankly utilitarian principles like the greatest good of the greatest number, whose application must be decided rationally and relatively to circumstances. Clearly one course will prove to be more right than another; but in deciding which to adopt, the so-called absolute ethical and moral principles will only take us part way.

The same is true of the individual. As he grows up, he finds that his apparently absolute ethical values constantly need the assistance of relativism, in the shape of rational judgment in the light of experience, if they are to be applicable to particular situations. It is wrong to lie; but we all know circumstances where it is more wrong to tell the truth. It is wrong to take life; but it needs rational judgment to decide whether this applies to war, to certain cases of suicide and abortion, to euthanasia, to birth control.

In fact, one of the chief tasks before each individual is to make a rational and relative adjustment of the apparent absolute of his primitive ethics, derived from infantile repression, to the practical realities of life. To accomplish this, it may even be necessary that the original structure of repressed and repressing forces be destroyed, whether by some violent emotional or religious experience, or by the deliberate "mental operation" of psychoanalysis or other form of psychotherapy.

The task before us, as ethical beings, now begins to take shape. It is to preserve the force of ethical conviction that springs up naturally out of infantile dependence and the need for inhibition and repression in early life, but to see that it is applied, under the correctives of reason and experience, to provide the most efficient and the most desirable moral framework for living. This will undoubtedly mean radical changes in the early upbringing of children, as well as in the methods of education and in accepted religions and codes of ethics. For instance, sociologists are beginning to realize that existing ethico-religious systems often contain a large element of psychological compensation: they compensate for the miseries of this world with the bliss of a world to come, they compensate for ignorance of fact with certitude of feeling, they compensate for actual imperfections of ethical practice by setting up impossible ethical ideals. This is not merely hypocrisy; it is a primitive method of self-defense against a hard and difficult reality.

Again, it is becoming clear that harshness of punishment in early life tends to the development of a morally vindictive superego: other methods are required for the development of character where the aggressive and sadistic impulses are kept subordinate. The most difficult lesson to learn is that irrational and intolerant certitude is undesirable. We have seen how this applies to truth: the lesson is difficult there also, but science has learned it. It will be even more difficult to learn in ethics: but it must be learned if we are to emerge from psychological barbarism. To cling to certitude 
is to prolong an infantile reaction beyond the period when it is necessary. To become truly adult, we must learn to bear the burden of incertitude.

\section{MAN IS THE MEASURE OF PROGRESS}

I would draw some such general and final conclusion as this. A scientifically based philosophy enables us in the first place to cease tormenting ourselves with questions that ought not to be asked because they cannot be answered-such as questions about a First Cause, or Creation, or UItimate Reality. Secondly, it encourages us to think in terms of right direction and optimum speed in place of complete but static solutions. At the present moment, for instance, it is much more essential to know that we are moving with reasonable speed toward certain general types of supernational cooperation than to nail some elaborate blueprint of international organization to our masthead. Thirdly, it is capable of giving man a much truer picture of his nature and his place in the universe than any other philosophic approach. Man is now the dominant biological type, and the developed human individual the highest product of the cosmic process that we know. That is a proud piece of knowledge. It is tempered by the reflection that very few human individuals realize a fraction of their possibilities, and that in a large proportion, passive or active evil predominates. But the knowledge has important practical bearings. Once we realize that the development of individuals is the ultimate yardstick by which to measure human progress, we can see more clearly how to formulate our war aims.

The fact that we, all the human beings now in existence, are the exclusive trustees for carrying any further the progress already achieved by life is a responsibility which, if sobering, is also inspiring; as is the fact that we have no longer either the intellectual or the moral right to shift any of this responsibility from our own shoulders to those of God or any other outside power. Indeed, the problem that appears to be the most perplexing and distressing turns out, in the light of a thoroughgoing scientific approach, to be full of encouragement. I mean the problem of ethical and other values. We have been accustomed to think of these as a scaffolding for our morals, conveniently run up for us by some outside agency. Now that this is no longer possible, we feel bewildered, unable to conceive of any firm moral construction in which we can abide. The truth, however, as shown by the extension of scientific method into individual and social psychology, is that we create our own values. Some we generate consciously; some subconsciously; and some only indirectly, through the structure of the societies in which we live. Through a fuller comprehension of these mechanisms we shall be able to guide and accelerate this process of value creation, which is not only essential for our individual lives but basic to the achieving of true evolutionary progress in the future.

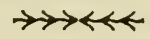




\section{MEET THE AUTHORS}

Below will be found a very short sketch of the interests and accomplishments of the men and women who have contributed to this volume. It is unfortunate that space does not permit a more extended treatment of each author. Most of the people below are cited in Who's Who, American Men of Science and similar books.

AREY, DR. LESLIE B.

Robert Laughlin Rea Professor of Anatomy, Northwestern University. Authority on the sense organs, sensory behavior, mammalian histology, and embryology.

\section{Aristotle}

Called by many "The Founder of Natural History." Aristotle lived from 384 B. C. to 322 B. C. and was Plato's most famous pupil. His writings were voluminous, authoritative for that period and his influence has lasted for many centuries. He did pioneer work on the classification, structure and physiology of organisms and ascertained many important facts of biology, a remarkable achievement considering the general ignorance of such matters in his day.

BAHM, DR. ARCHIE J.

Associate Professor, Department of Philosophy, University of Denver. Wellknown writer of articles on philosophy having written thirty articles, forty book reviews, and several books.

Bulla, paul

Veteran newsman and writer.

ButLer, DR. ELMER G.

Professor and Head of the Zoology Department, Princeton University. Wellknown in the fields of comparative anatomy, embryology, and x-radiation.

Carlson, dr. anton J.

Emeritus Professor of Physiology, University of Chicago. One of the great physiologists and teachers of our times, Dr. Carlson has received honors from many institutions for his work in the nervous, alimentary, circulatory and endocrine systems.

Chester, DR. K. STARR

Professor and Head of the Department of Botany and Plant Pathology, Oklahoma A. and M. College. Dr. Chester is keenly interested in plant immunology, virus diseases, cotton and wheat diseases and research in general.

CONARD, DR. HENRY S.

Retired Head of the Biology Department at Grinnell College, Iowa. Dr. Conard is a biologist of note. His studies in the Bryophytes and water lilies are regarded very highly by his colleagues.

ConkLin, DR. EDIVIN G.

Emeritus Professor of Zoology, Princeton University. Dr. Conklin has received honorary Doctor's degree from many institutions and has held many positions of trust in the scientific world. His interests lie especially in the fields of embryology, cytology, heredity, and evolution. 
Cutting, c. suydam

Member of many expeditions to central Asia, Tibet, Abyssinia and Burula for the American Museum of Natural History and the Chicago Museum of Natural History.

DARWIN, CHARLES

Darwin's name is known to every school child, at least from the secondary school level upwards. He was born in 1809 and died in 1882 . Darwin is renowned for his Theory of Natural Selection by means of which he attempts to explain how evolution operates. It may be safely said that his work did more to stimulate scientific endeavors along modern research lines than any preceding book. In addition to his work on Natural Selection, Charles Darwin did notable works on animals and plants under domestication, the descent of nıan, fertilization in the orchids, and earthworms, to mention the most inportant.

EDGE, ROSALIE

Dynamic leader of the Emergency Conservation Committee.

FENTON, DR. CARROLL LANE

Writer and humanizer of scientific knowledge, Dr. Fenton is also wellregarded for his exact studies of various fossil groups especially the Brachiopods.

Garbedian, H. GORDON

Journalist with the New York Times. Writer on science, Mr. Garbedian has published five books on science and scientists.

GoRDON, SETH

Executive Director, Pennsylvania Game Commission.

GUYER, DR. MICHAEL F.

Professor of Zoology, University of Wisconsin. Dr. Guyer is an authority in many fields such as cytology, experimental evolution, genetics and embryology but lately he has turned his attention to the field of biological philosophy, in which, incidentally, he is unexcelled.

HAGgARD, DR. HOWARD w.

Director of the Laboratory of Applied Physiology, Yale University. Besides having the ability to write lucidly for the public, Dr. Haggard has delved into, with more than the ordinary amount of success, the fields of anesthetics, and resuscitation from carbon monoxide poisoning.

HaLlock, GRACE T.

Director, Health and Welfare Publications Bureau, Metropolitan Life Insurance Company.

HAMNER, DR. KARL C.

Director of the United States Plant, Soil and Nutrition Laboratory, Cornell University.

HipPocrates

The most famous of the early Greek physicians, Hippocrates lived from $460-$ 377 B. C., although there is some uncertainty about these exact dates. Some of our present medical knowledge had its foundation in the work of Hippocrates and his followers. They had a fairly good idea of the bones and muscles of the body, the cavities of the heart and the general structure of the eye and the ear. When one considers that dissections of the human body were not performed after death and that chemistry and chemical experimentation on animals was almost unknown, one must be impressed with the amount of accurate information that the early Greeks were able to acquire. 
Holmes, DR. S. J.

Professor of Zoology, University of California. He has done much research in the molluscs, in embryology, evolution and genetics and is well known for his late work in the new field of eugenics. An eminent scholar.

Howells, Dr. w. w.

Department of Anthropology, University of Wisconsin. Dr. Howells formerly held positions at Hunter College and the American Museum of Natural History. He is working in the fields of racial history, and the anthropology of populations.

HUNT, DR. WILLIS R.

Lafayette College. He has done work on the rust fungi and the bacteria.

Huxley, JuliaN

Grandson of Thomas Henry Huxley, champion of Darwin, and brother of Aldous Huxley. Julian Huxley was Professor of Zoology at King's College, London and Fullerian Professor of Physiology at the Royal Institution. It is not well-known but he also taught at our own Rice Institute for four years. $\mathrm{He}$ is active in the Zoological Society in London, Institute of Animal Behavior, Eugenics Society and is associated with the Encyclopedia Britannica. He has written or co-authored about twenty-eight books.

\section{Huxlex, thomas H.}

Huxley was an English scientist who lived from $1825-1895$. He is renowned chiefly for his staunch support of Charles Darwin and his vigorous and skillful defense of Darwin's views on evolution. However he did a vast amount of original work in morphology and paleontology and therefore can be called a scientist in his own right.

ILTIS, DR. HUGO

Profesor of Biology, Mary Washington College. Dr. Iltis was born in Brünn, Czechoslovakia (sometimes spelled Brno) the place where Mendel did his epochal work. Of course Brno was formerly in Austria. He has devoted his life to a study of Mendel.

JAFFE, BERNARD

Head of the Department of Physical Science, James Madisoll High School, Brooklyn, N.Y. Mr. Jaffe is the author of six textbooks in science and numerous articles. He won the International Francis Bacon Gold Medal for his work in humanizing knowledge. His books have been translated into several languages including Braille.

JoHNSON, DEAN VICTOR E.

Dean of students in Biology and Medicine, University of Chicago. Dr. Johnson holds both the Ph.D. and M.D. degrees and is an authority on the circulatory system.

Kienast, MARGATE

Author, editor, educational advisor, United States Forest Service.

Krogman, DR. WILton MARION

Anthropologist and Anatomist, University of Chicago. He is interested particularly in the comparison of growth in face and skull, racial differences in human anatomy, and in child development.

LARGE, E. C.

Large is an English author and like several of his countrymen has succeeded in bringing a deep subject into focus for the laymen. 
LEEUWENHOEK, ANTONY VAN

A famous student of minute objects. Born in 1632, died 1723 . Held numerous jobs during which he carried on his scientific investigations with the aid of lenses and simple microscopes. which he fashioned himself. Wrote over 400 letters describing his findings. Called the "Father of Protozoology and Bacteriology" because he was the first to see living protozoans and bacteria under a lens. Also the first actually to see blood circulating, noted the stripe in voluntary muscles, structure of the crystalline lens and the morphology of the sperm.

LEIVIS, DR. PAUL A.

Dr. Lewis was associated with the Rockef eller Institute. A martyr to science, he died in Brazil while investigating the cause of yellow fever.

LiNTON, DR. RALPH

Department of Anthropology, Columbia University. The fields of the ethnology (study of races) of Polynesia and Madagascar claim much of his attention.

MATZKE, DR. EDWIN B.

Associate Professor of Botany, Columbia University. Dr. Matzke is working on general problems of cell size and shape and has worked out some interesting techniques here.

MICKEY, KARL B.

Late member of the Public Relations Department, International Harvester Company.

MOHR, DR. OTTO L.

Professor of Medicine, Royal Frederick University, Oslo, Norway.

MoRgan, DR. THOMAS HUNT

Late professor at the California Institute of Technology. Dr. Morgan probably did more to further Mendelism than any other man. He has been honored by at least eight Universities with honorary degrees for his work in experimental embryology, heredity, sex, genes and the genetics of Drosopbila.

Netvman, DR. HORATio H.

Emeritus Professor of Zoology, University of Chicago. Dr. Newman is known chiefly for his textbooks and his work on twins but evolution and animal behavior are also his major studies.

OSBORN, BRIG. GENERAL FREDERICK

Chief of Special Service, War Department and Director of the Eugenics Research Association. He is also Director of the Galton Society, a group interested in the study of eugenics.

Overholser, DR. WINFRED

Superintendent of St. Elizabeth's Hospital, Washington, D.C. He has both the M.D. and the Ph.D. degrees and has been associated with many state hospitals and mental institutes. He is regarded as a leader in the fields of psychiatry, hospital administration and gerontology (the study of old age.)

Patri, angelo

Teacher and principal in New York City public schools since 1898. Associated / with "Children's Activities."

PEARSE, DR. A. $\mathrm{s}$.

Zoology Department, Duke University. Dr. Pearse has been honored in many places for his pioneer work in ecology. 
Peattie, donald culross

Botanist and author, one-time government scientist. Mr. Peattie has authored or co-authored about twenty-five books which deal mostly with botany, zoology, and nature in general.

\section{Pliny}

This is Pliny the Elder who lived in Italy from A. D. 23 to A. D. 79. Prior to his scientific endeavors he was commander of a cavalry squadron, a student of law, Procurator of Spain, and holder of a naval commission. His scientific curiosity caused his death for he approached too close to fuming Vesuvius which was in eruption at the time. Pliny was mostly a collector and relater of scientific information putting down fact and error with equal emphasis.

RÁdL, PROFESSOR EMANUEL

Professor of Natural History, University of Prague.

RIFE, DR. DAVID C.

Associate Professor of Zoology, Ohio State University. Dr. Rife, in addition to writing a popular book on heredity, is doing work on the inheritance of tuberculosis and intelligence in twins.

SCHEINFELD, AMram

Writer, New York City. Mr. Scheinfeld presents one of those rare and happy combinations between fluid writing and accuracy. His two books on heredity are widely read and one, You and Heredity has been translated into many languages and was also a Book of the Month selection.

SCHWARTZ, DR. BENJAMIN

Principal Zoologist and Chief of the Zoological Division, Bureau Animal Industry, U.S. Dept. Agriculture. He was born in Austria-Hungary but has his $\mathrm{Ph} . \mathrm{D}$. from George Washington. He is an authority on parasitic worms and the diseases caused by them.

SNYDER, DR. LAURENCE H.

Chairman of the Zoology Department, Ohio State University. His book on heredity is one of the most popular and his researches on medical genetics, blood groups, taste deficiency, and linkage in man are fundamental.

Theophrastus

Just as Plato's most famous pupil was Aristotle, so the latter's disciple was Theophrastus who lived from 372 to 288 в. c. Theophrastus wrote on many subjects but principally on plants and he has come to be known as "The Father of Botany." Over two hundred and twenty-seven studies of plants came from his pen. He knew over five hundred kinds of plants and was the first to distinguish between flowering and flowerless plants, between angiosperms and gymnosperms, and, among other things, he recognized the true nature of the fruit.

TURNER, DR. C. E.

Professor of Public Health, Massachusetts Institute of Technology.

VAUGHAN, DR. WARREN

Late physician, Richmond, Virginia. Dr. Vaughan's practice leaned toward allergy, immunology and influenza. He served on the editorial board of many medical magazines.

VERRILL, A. HYATT

Ethnologist, Archeologist. Mr. Verrill has traveled widely in his search for ancient remains including the W. Indies, Central America, Bermuda, Dominica Island, Santo Domingo, British Guiana, Panama, Peru, Chili, and Bolivia. 
W ARD, HENSHAW

Author of several popular science books.

WESTGATE, DR. LEWIS G.

Emeritus Professor of Geology, Ohio Wesleyan University. Dr. Westgate has his Ph.D. from Harvard and was once associated with the United States Geological Survey. He has done research on the Devonian flora and fauna of Ohio.

WILDER, DR. RUSSELL M.

Mayo Clinic, Rochester, Minnesota. He has held important positions at Rush Medical College and University of Chicago. His chief medical interests lie in the fields of typhus fever, diabetes, metabolism, and nutrition.

YOUNG, DR. ROBERT T.

Scripps Institution of Oceanography, La Jolla, California. Dr. Young has held numerous important positions in the biological field and is interested chiefly in the development of certain parasitic worms, protective coloration, and the biology of fishes.

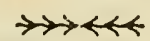




\section{GOOD BROWSING}

\section{Biological Beginnings}

Nordenskiöld, ERic, The History of Biology (New York, Tudor Publishing Co., 1928).

One of the best of the histories of Biology.

Darivin, Charles, The Otigin of Species (London, edition 1, 2, 5. 1859, 1860,1872 ). Originally published in the United States by D. Appleton and Company.

This book outlines Darwin's ideas on the method of evolution. It is quite difficult reading but one should read bits of it from time to time.

Wallace, A. R., Darwinism; an exposition of the theory of Natural Selection with some of its applications (London, Macmillan Co., r 889).

Wallace arrived at much the same conclusions as did Darwin and at the same time.

Galen, On the Natural Faculties (Cambridge, Mass., Harvard University Press, Loeb Classical Library, English translation by Arthur John Brock, 1928 ).

Galen was one of the greatest of the early medical men and he is credited with bringing Greek medicine to its peak.

Snyder, emily Eveleth, Biology in the Making (New York, McGraw-Hill Book Co., Inc., 1940).

This is one of the most interesting and readable accounts of biology.

Locy, william A., The Growtb of Biology (New York, Henry Holt and Co., 1925).

This treats of many of the important phases of biology in an interesting way. The author's death pievented the publication of the second volume.

Life and the Cell

Osterhout, w. J. v., The Nature of Life (New York, Henry Holt and Co. 1924).

A small but good book covering the differences between the living and the non-living.

SchröDinger, ERwin, What ls Life? (Cambridge, The University Press; New York, The Macmillan Co., 1945).

This is a new book dealing with the physical aspects of the living cell but life still remains a riddle.

The Structure and Function of Higher Plants

Ganong, william f., The Living Plant (New York, Henry Holt and Co. 1913).

This is an old book but few write as interestingly about difficult subjects as Dr. Ganong.

Swingle, D. B., Plant Life (New York, D. Van Nostrand Co. Inc., 1942).

A textbook of botany but very easily read.

Wilson, ernest H., The Romance of Our Trees (New York, Doubleday, Page and Co., 1920).

The inside story of trees and man. 
Nutrition

Macy, icie g. and Williams, harold H., Hidden Hunger (Lancaster, Penna., Jacques Cattell Press, 1945).

One of the most readable volumes dealing with food and nutrition.

Circulation

Wilder,-Harris hawthorne, The History of the Human Body, Rev. Ed.,

(New York, Henry Holt and Co., 1923).

This well-known book discusses the development of the circulatory system among other things. Very advanced.

Nervous and Endocrine Control of the Body

RoMer, ALFred SHERwood: Man and the Vertebrates (Chicago, Univ. Chicago Press, 1941).

This has a good account of the nervous system as well as fascinating pictures in other fields.

Dorsey, grorge A., Why We Bebave Like Human Beings (New York, Harper and Brothers, 1925).

This is still one of the popular books in its field. While it covers a tremendously wide field, it deals largely with human behavior.

Reproduction

Brambell, F. w. rogers, The Development of Sex in Vertebrates (New

York, The Macmillan Co., 1930).

Difficult reading for freshmen but full of worthwhile information.

Embryology

Huettner, Alfred F., Fundamentals of Comparative Embryology of the

Vertebrates (New York, Macmillan Co., 1943).

The pictures of human embryos in this volume will be of interest to students.

Heredity

RifE, David c., The Dice of Destiny (Columbus, Ohio, Long's College Book

Co., 1945).

A small but very readable and interesting book. Recommended highly for elementary students.

Holmes, s. J., Human Genetics and its Social Import (New York, McGraw-Hill Book Co., 1936).

This is one of Dr. Holmes' latest and best books and is of special interest to those students of biology who are interested in man.

Eugenics

Holmes, s. J., The Eugenic Predicament (New York, Harcourt, Brace and Co., 1933).

A fine treatise on the well-born and the ill-born.

Hunt, harrison R., Some Biological Aspects of War (New York, Galton Publishing Co., Monograph Series II, 1930).

Too seldom is the effect of war on the caliber of the human race understood. A work for thoughtful students.

Evolution

Clark, austin H., The Nerv Evolution, Zoogenesis (Baltimore, Williams and Wilkins Co., 1930).

Dr. Clark writes better than most scientists about this involved and controversial subject of evolution. 
Mason, Frances, Creation by Evolution (New York, The Macmillan Co., 1928).

This is an interesting collection of essays on evolution by leading biologists.

WaRD, HENSHAW, Evolution for Jobn Doe (Indianapolis, Bobbs-Merrill Co., 1925).

A book for laymen written by a layman. Thoroughly enjoyable and simple enough for students.

Ecology

Pearse, A. s., Animal Ecology (New York, McGraw-Hill Book Co. Inc., 2nd Ed., 1939).

The student will find lots of good browsing material here although it is primarily a textbook.

King, eleanor and Pessels, wellmer, Working with Nature (New York, Harper and Bros., 1939).

Contains discussions about animals and their lives.

Health and Disease

Pearl, Raymond, The Biology of Death (Philadelphia, J. B. Lippincott Co., 1922).

A study of the causes and chances of death written by a great scientist. For advanced readers.

Causey, David, Uninvited Guests (New York, Alfred A. Knopf, 1932).

A short, humorous account of animal parasites.

Diehl, Harold s., Textbook of Healthful Living (New York, McGraw-

Hill Book Co., 1945).

A book hard to lay down once it is started.

De kruif, paul, Men Against Death (New York, Harcourt, Brace and Co., 1933).

A fascinating series of accounts of the conquest of disease, written by a well-known and well-liked author.

Economic Biology

Fernald, m. L. and Kinsey, A. c., Edible Wild Plants of Eastern North America (Cornwall-on-Hudson, New York, Idlewild Press, 1943).

This book tells of the great stores of wild foods which may be safely utilized.

Hill, Albert F., Economic Botany (New York, McGraw-Hill Book Co. Inc., 1937).

A reference book on useful plants.

ReESE, Albert M., Outlines of Economic Zoology (Philadelphia, Blakiston Company, 4th Ed., 1942).

Contains information about the dollar and cent value of animals to man. Interspersed with interesting anecdotes.

Howard, L. o., The Insect Menace (New York, D. Appleton-Century Co. Inc., 1931).

Dr. Howard is not only an authority but a pleasing writer as well. The problem of the danger of insects to man is forcefully told.

Biological Philosophy

Wheeler, william morton, Foibles of Insects and Men (New York, Alfred A. Knopf, 1928).

Most of this book is too involved for beginning students but attention is 
GOOD BROWSING

called to the chapter entitled "The Termitodoxa, or Biology and Society" for a highly hilarious comparison of termite and human society written by the late and incomparable Professor Wheeler under the pen name of "The King of the Termites."

General

Beebe, william, The Book of Naturalists (New York, Alfred A. Knopf, 1944).

A fine anthology of natural history collected by one of our best-known scientists.

Andrews, roy chapman, This Amazing Planet (New York, G. P. Putnam's

Sons, 1940).

A collection of short interesting stories about this earth and the life upon it; very enjoyable.

DitMars, RAYMOND L., Thrills of a Naturalist's Quest (New York, The Macmillan Company, I932).

Students cannot become acquainted too early with Ditmar's fascinating tales of adventure.

KAHN, FRITz, Man in Structure and Function, 2 vols. (New York, Alfred

A. Knopf, 1946).

A great work but a little advanced for freshmen. The pictures, however, are unique and must be looked at.

Olmstead, Charles E., The Story of Living Plants (Chicago, University of Knowledge, Inc., 1938).

This is botany for the laymen and it does a much better job of it than most similar attempts. 





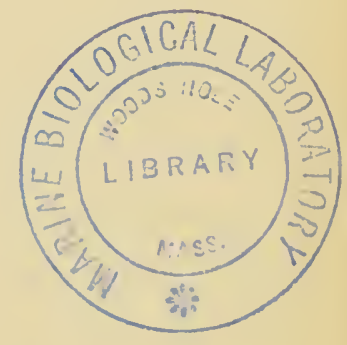


